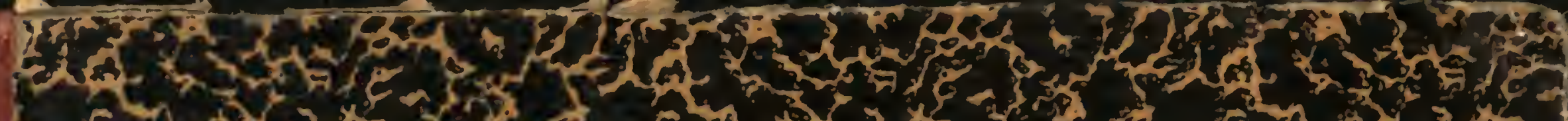

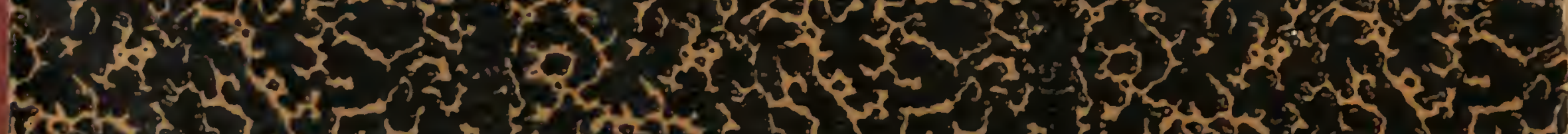

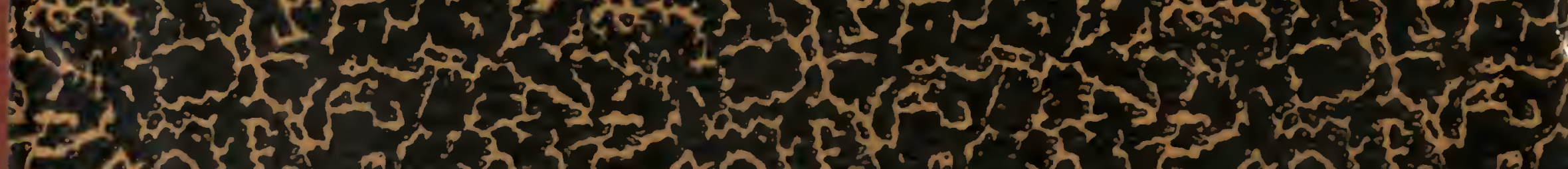

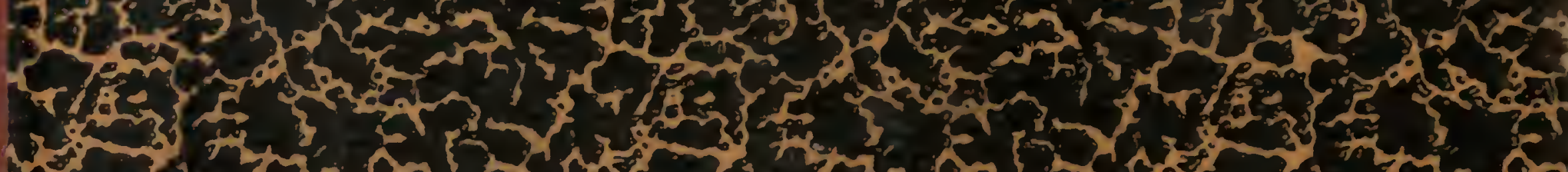

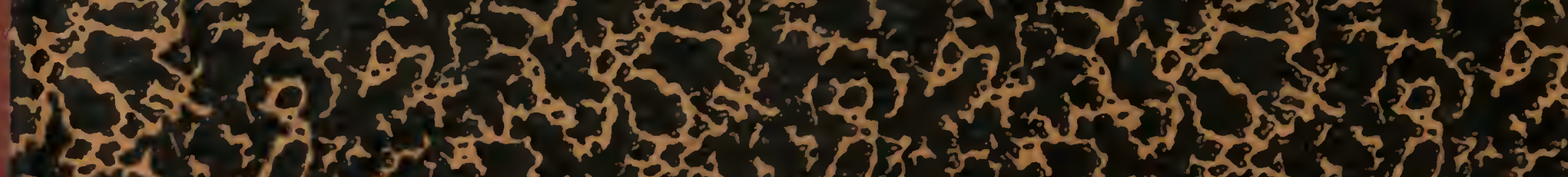

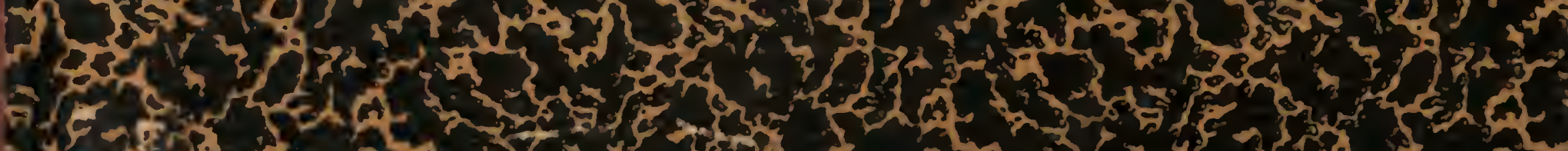

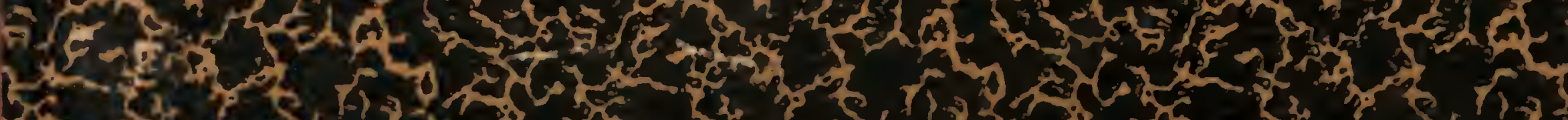

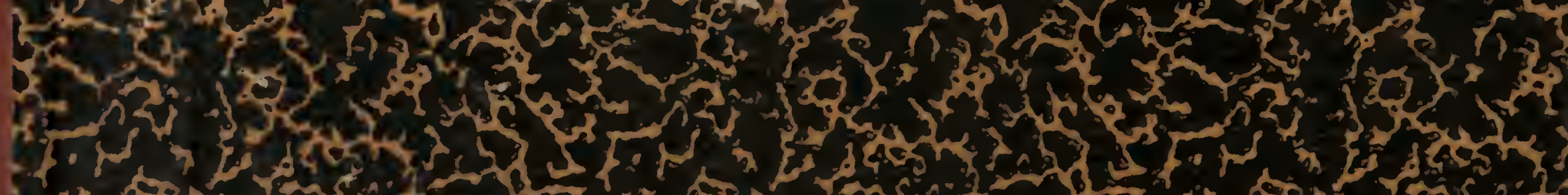

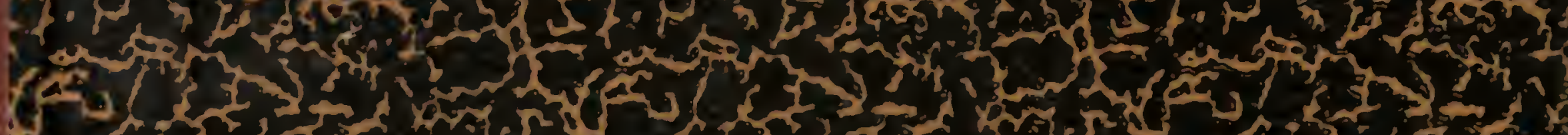

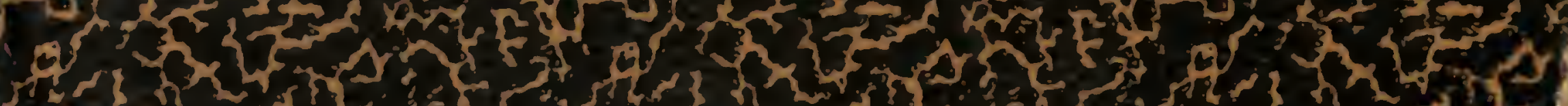

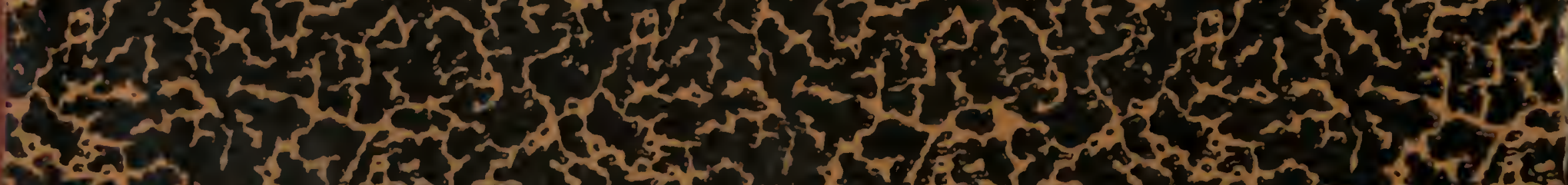
3)

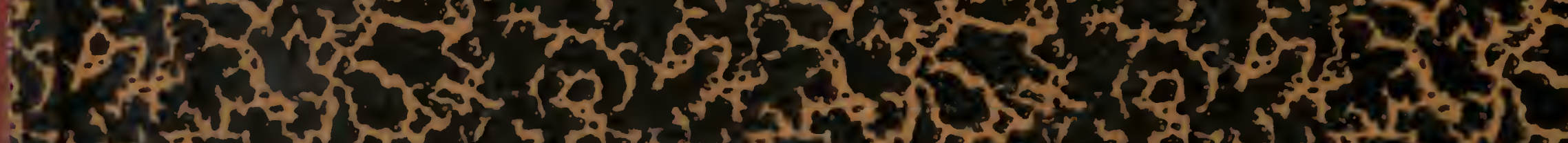

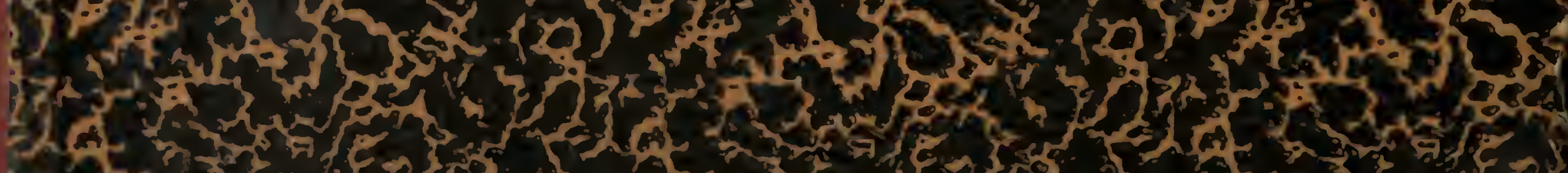

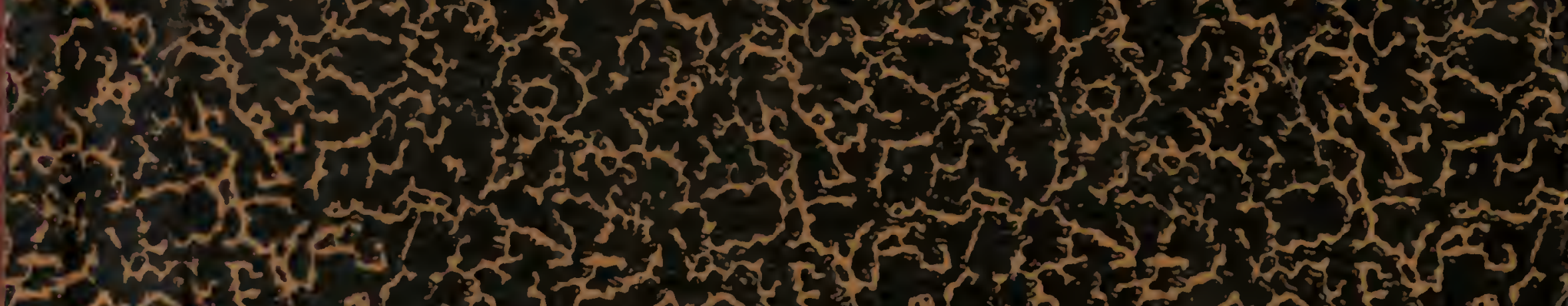
$5\left\{\begin{array}{l}5 \\ 5\end{array}\right.$

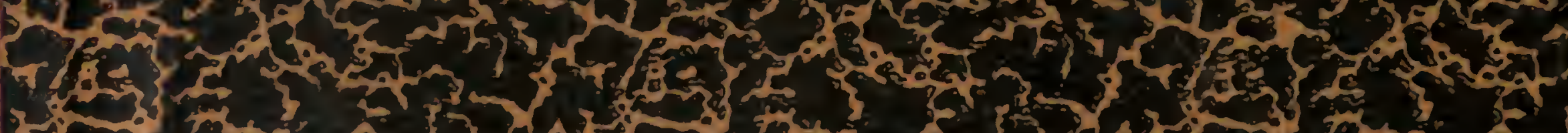

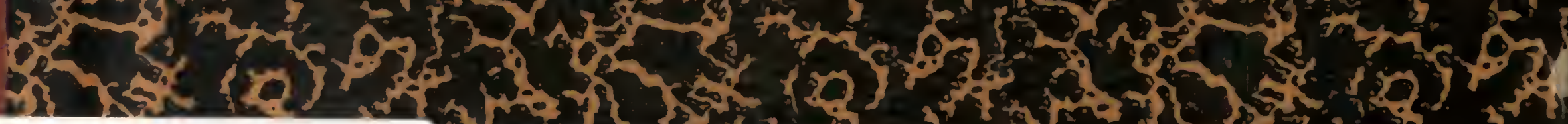

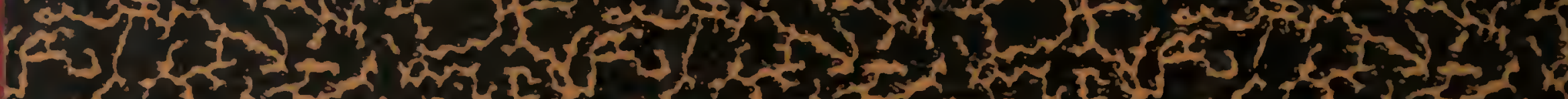
f.

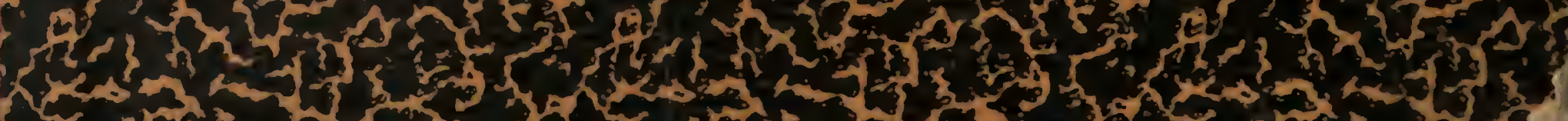

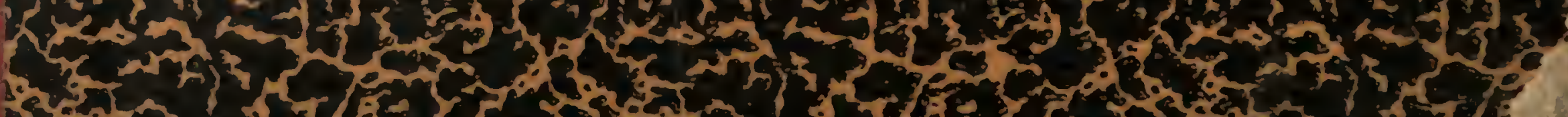

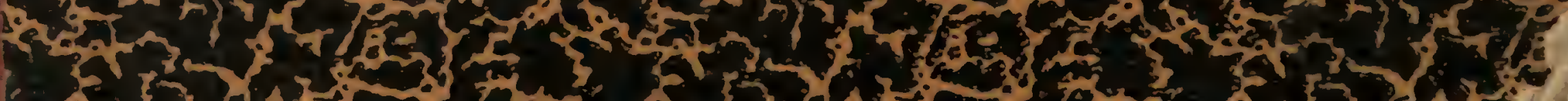

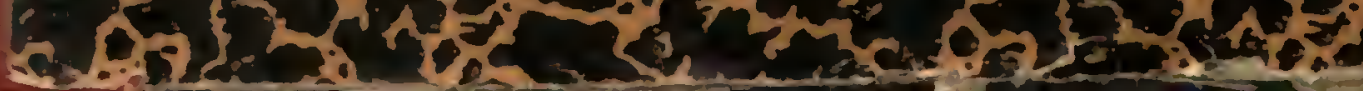




\section{RS402}

R56

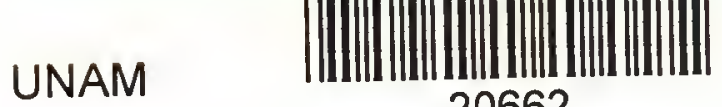

20662

INSTITUTO DE GEOLOGIA - CU

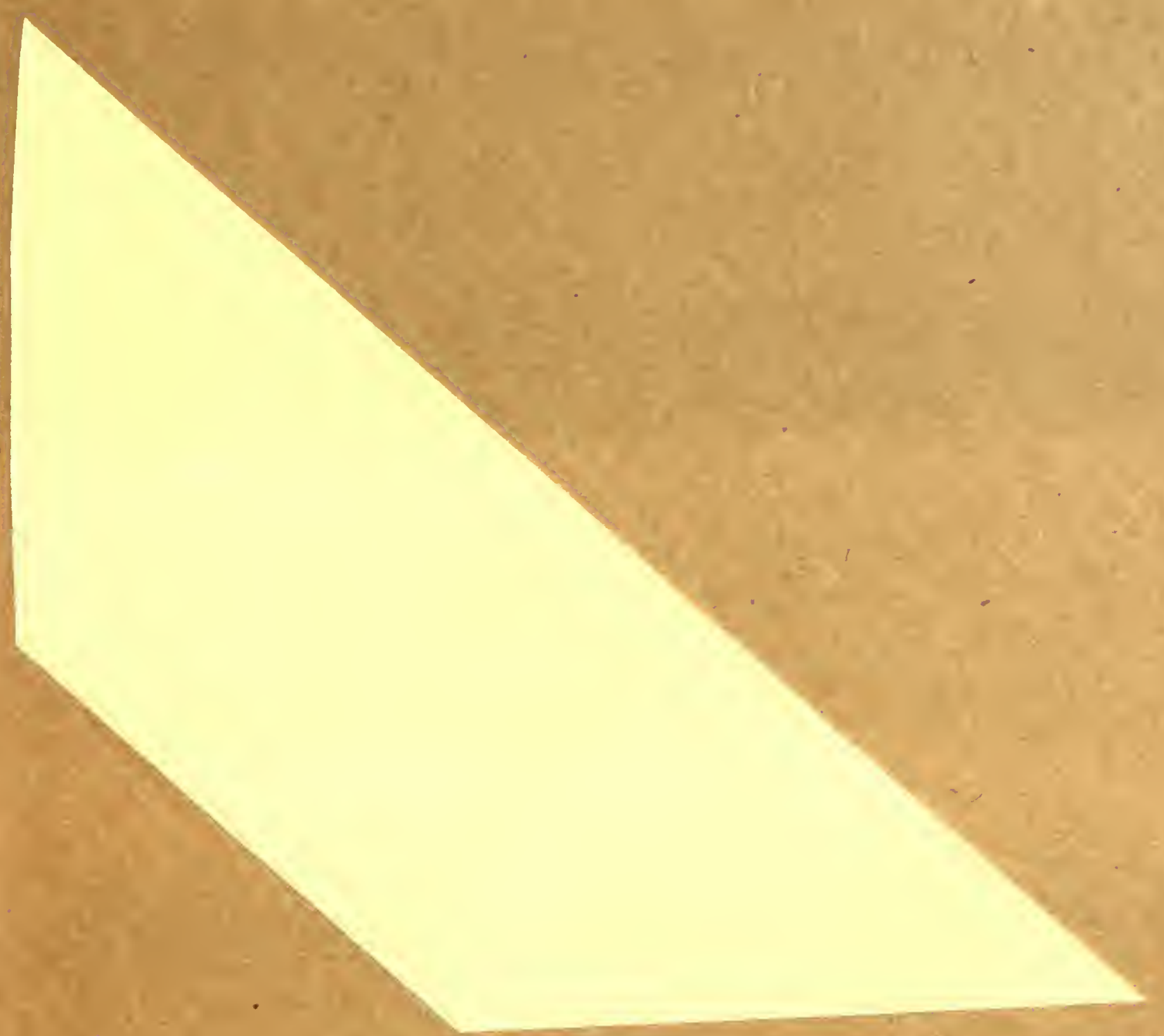




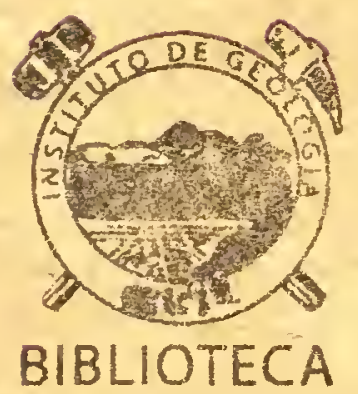





\section{LEOPOLDO RIO DE LA LOZA}
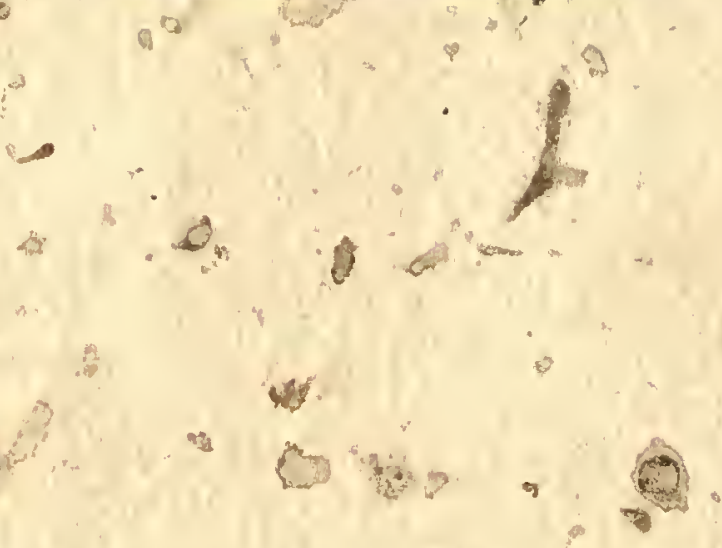

\&
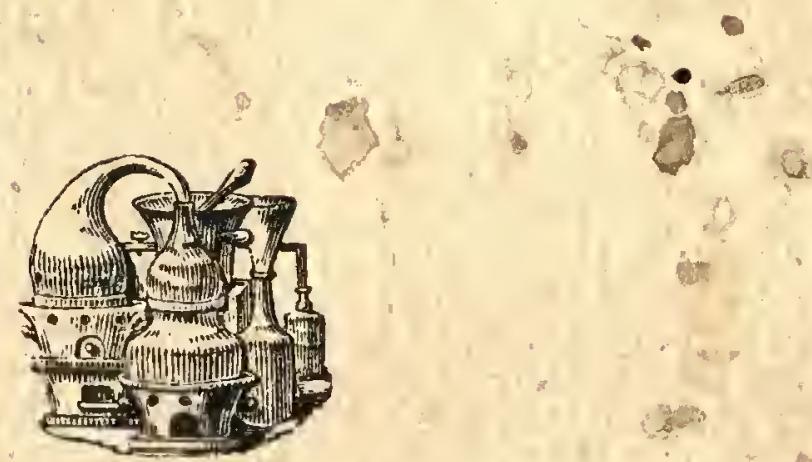

\section{MÉXIOO}

IMPRENTA I. ESCALANTE, S. A.

1.2 Cincuenta y Siete No. 8.

6 


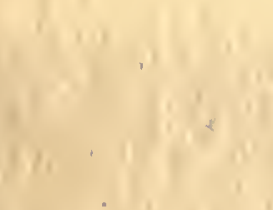

14.

\section{9}

4 


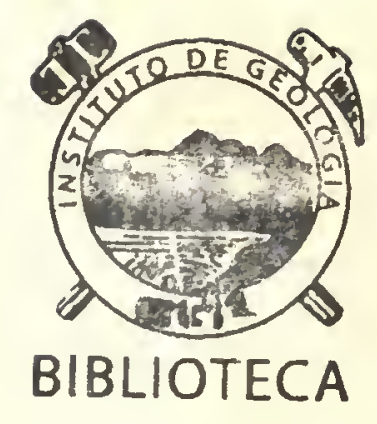

\section{ESCRITOS}

- DE -

\section{LEOPOLDO RIO DE LA LOZA}

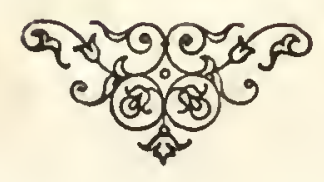


$850(300)$

No8e 



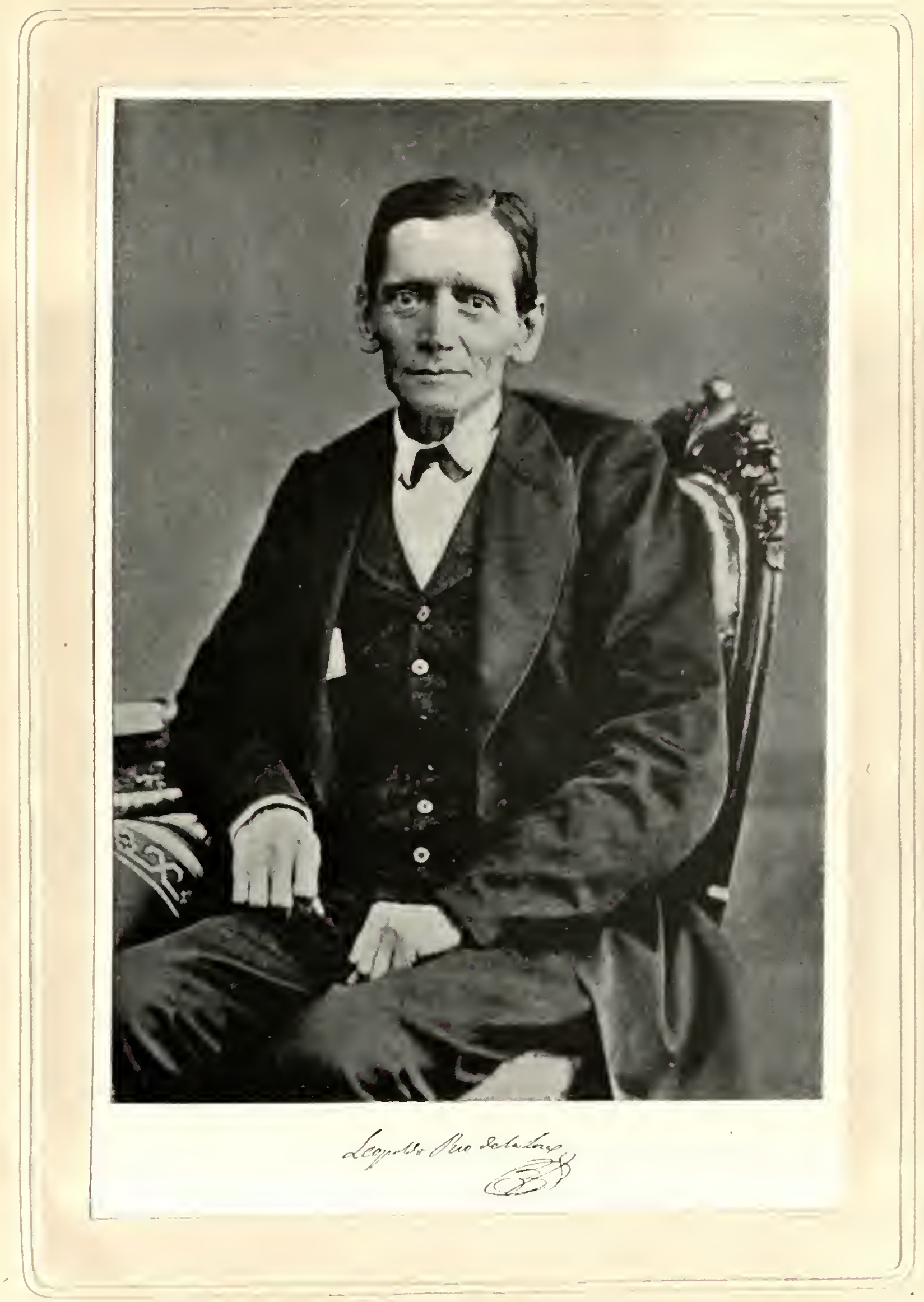




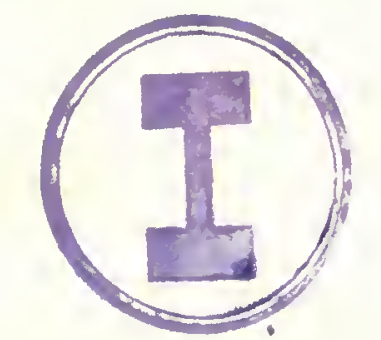

FSORITOS

\section{LEOPOLDO RIO DE LA LOZA,}

COMPILADOS POR EL SEÑOR FARMACÉUTICO

\section{JUAN MANUEL NORIEGA}

Y PUBLICADOS POR LA

SECRETARIA DE INSTRUCCION PUBLICA Y BELLAS ARTES,

EN CONMEMURACIÓN DEL

PRIMER CENTENARIO DEL NACIMIENTO

DE

RIO DE LA LOZA.

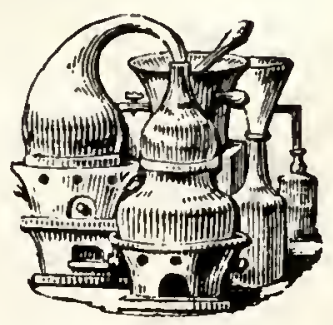

do. (1)

an. edit

\section{MÉXICO}

IMPRENTA DE IGNACIO ESCALANTE

$1 .{ }^{2}$ de Cincuenta Y Siete Núm. 8. 


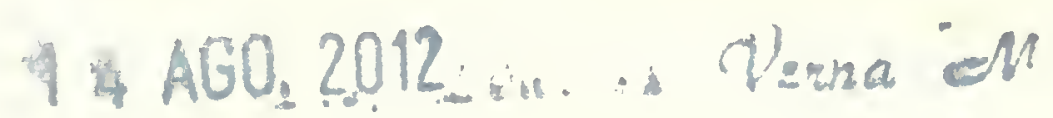

$$
\begin{aligned}
& \text { RS402 } \\
& R 56 \\
& I-20662
\end{aligned}
$$

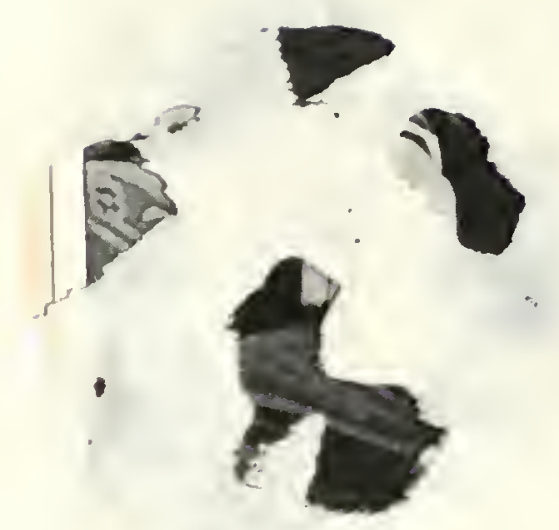


ACUERDO POR EL QUE SE RESOLVIO LA PUBLICACION DE ESTA OBRA.

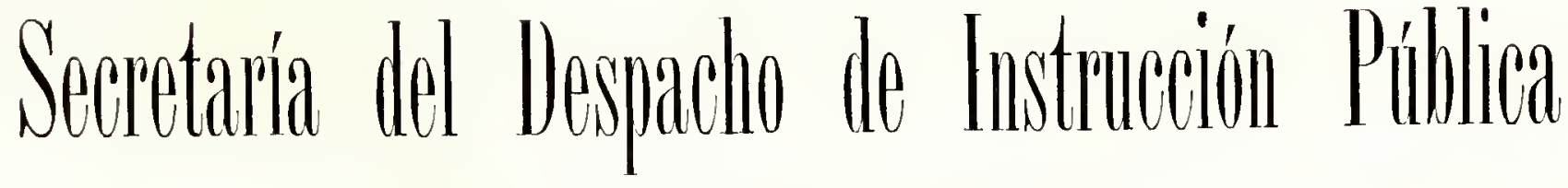 Y BELIAS ARTES.}

SECCión de INSTRUCCIÓN SECUNDARIA, Preparatoria Y Profesional.

México, 19 de julio de 1907.

Comisiónese al C. Profesor Juan Manuel Noriega para que coleccione los estudios escritos por el C. Leopoldo Río de la Tuza y dirija la publicación de dichos estudios, que formarán una obra editada por esta Secretaría con el fin de conmemorar el centenario del nacimiento del repetido C. Río de la Loza.

Iusto Sierra. 



\section{PRÓLOGO}

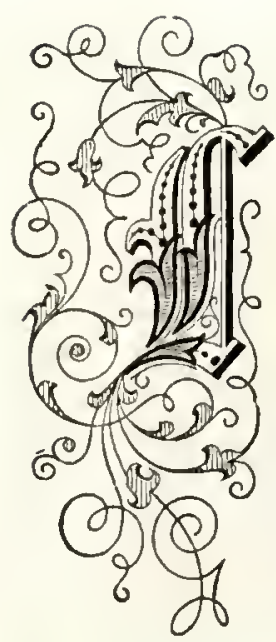

A Secretaría de Instrudcáón Pública y Bellas Artes ha querido honrar la memoria del primer químico mexicano, Dr. Leopoldo Río de la Loza, publicando los escritos del ilustre desaparecido con motivo del primer centenario de su nacimiento, acaecido en esta ciudad el día 15 de noviembre de 1808 , y para el efecto se sirvió encargar al subscrito que los coleccionara.

Al mismo tiempo que honrosa, satisfactoria y grata ha sido para mí esta comisión, y para corresponder por mi parte á esta confianza, en mí depositada, he puesto en juego cuantos medios han estado á mi alcance para coleccionar los escritos de este ilustre sabio, esparcidos en diversas publicaciones de su época, casi agotadas hoy y por lo mismo inuy dificiles de encontrarse; pero tras asiduas pesquisas y constante trabajo puedo presentar al fin una colección de estos escritos en la que sólo faltan dos: uno acerca del cólera y otro de la vacuna, los que á pesar de una busca tenaz y cuidadosa (así como otros trabajos encontrados), en la que he sido hábil y empeñosamente auxiliado por el Sr. Don Leopoldo Carrasco, ha sido imposible hallarlos; por tanto, si la recolección de estos escritos no pudo ser absolntamente completa, sí puede decir'se que tiene una integridad suficiente.

Nada correcto y sí muy iujusto sería tildar á Río de la Loza de poco adelantado en las ciencias que cultivó, tan sólo porque en sus escritos se ve que estaba muy distante su enseñanza de lo que hoy nos presentan las ciencias modernas; pues con tal criterio tendríamos también que tachar de ignorantes á Vidal de Casis, Mierneyer, Luis, Lavoisier y otros sabios que fueron lumbreras en su época, tan 
sólo porque no conocieron los microbios de Pasteur, las leucomainas de Armand Gautier, los fagocitos de Metchnikoff ó las modernas teorías atómicas: para juzgar á un hombre tenemos que retrocedel á la época en que virió; tenemos necesariamente, si nos preciamos de justos, que conocer hasta dónde habían llegado los adelantos de aquella época, y si con este juicioso criterio juzgamos á Río de la Loza, no sólo encontraremos que fué un revdadelo sabio, que conoció cuanto la quínica enseñaba en su tiempo, sino que con su esturdio, su constancia y su claro talento supo adelantarse á la época en que rivió.

Tos escritos del Sr. Río de la Ioza no deben apreciarse tomando como término de comparación los conocimientos químicos que corresponden al estado actual de la ciencia, ni las teorías hoy aceptadas; pues si con ese criterio se juzgaran, resultaría que lejos de honrar su memoria al coleccionar sus trabajos, se tendría que calificarle como lamentablemente atrasado. Tampoco debe exigirse que la pnblicación de ellos renga á serrir, si no es bajo de un punto de rista especial, de auxiliar de la instrucción actual. El fin que la Secretaría de Instrucción Pública ha tenido, es evitar que estos escritos se pierdan y homrar la memoria de este ilustre mexicano, poniendo do uranifiesto lo que este lombre de ggenio fué en su época; cóno se eurpapó en los conocimientos quómicos de entonces; cómo los mejoró y transmitió ý cómo con su ilustración houró á su patria.

Fu sus escritos se ve retratado al hombre de genio; se ve al nexicano amante como el que más, del adelanto de su nación en todo orden de conocimientos; al maestro que protesta contra las lutinas y que se adelanta á su época, que ya entrevé horizontes nueros para la química, su ciencia predilecta, y guía á sus discípulos por caninos nneros, inculcándoles el horrot á los métodos irracionales y l’ntinarios; al consejero de muchos gobiernos, que les indica el mejor camnino para el adelanto de las ciencias, el bien y progreso de la agricultura, el aumento de la riqueza y la defensa de los bosques; al concienzudo químico, que en sus resultados analíticos no puede recibil objeción hasta nuestros días; al inrestigador celoso de los intereses nacionales, que estudia la naturaleza de los productos de su país; al sabio valiente que con sus consejos aparta á la nación del ridículo que hombres de escasos conocimientos ó de ruin eriterio pudieran haber atraído sobre ella; y, en suma, al hombre por todos conceptos houra- 
do, concienzudo, aneno, que no por haber pasado su época deja de procurar instrucción; porque retratándose en sus escritos su genio metódico, observador, profundo, tranquilo y de amplios horizontes, no puede menos de resultar útil y provechosa la lectura de esos escritos, puesto que en ellos el autor comunica su espíritu, sus tendencias, su amor al progreso; ilustra con la claridad de sus apreciaciones y enseña á tener solidez y buen juicio para apreciar las cosas, las ideas científicas y los procedinientos.

Entre los citados escritos, la «Introducción al estudio de la Química» es la que más se resiente de las ideas aceptadas en su época, y si se prescinde de la consideración del tiempo en que fuó escrita, hasta se experimenta alguna contrariedad al leer $y$ al comprender que de los autorizados labios de ese maestro se oyeron teorías hoy inadmisibles de todo punto. Para evitar siniestras interpretaciones, me permití poner al calce de algunos párrafos de esa obra notas que recuerdan al lector que tenga presente la época en que apareció; pero no es culpa de $u n$ hombre ser influenciado por las ideas de su tiempo ni es fácil adelantarse á ellas: para juzgarlo con equidad basta saber que fueron entonces aceptadas, que se tuvieron como la última palabra de la ciencia, y en el caso particular de Río de la Loza, que éste en todo revela no tener como ariterio lo dicho por otro, sino que sólo acepta una cosa en tanto que no sabe algo en contra; y se ve á cada paso que no le dejan del todo satisfecho las teorías mal apoyadas por los hechos; por lo tanto, que sus críticas son hoy dignas de estimación; pero en ese escrito dedicado á los estudiantes, no iniciados siquiera en los conocimientos químicos, era indispensable que condensara y diera como bueno lo que por los sabios de esos días era tenido como tal; y no debe exigílsele en esa obra que entre en discusiones, si se atiende á la naturaleza de su objeto. Es, pues, disculpable por lo que en ella hay de atrasado para esta época, puesto que su labor significa un esfuerzo en favor de la difusión de los conocimientos en química y revela al maestro que prepara á sus alumnos para inculcarles después más sólidos conocimientos. ¿Cuántos escritos de los que hoy se publican serán mañana inaceptables?

En los escritos relativos á investigaciones químicas se revela más claramente su genio y sus alcances. Siempre toma como punto de estudio algún objeto de interés general, lo desarrolla con claridad y con franqueza, tratando en todos los casos de llegar á un resultado práctico. 
y de benéficos resultados para la industria, el comercio, la alimentación ó la medicina; pero es enemigo de asuntos tririales: lo que sienta como revdad lo ha comprobado por la práctica de laboratorio. No es, como se dice en lenguaje familiar, de los que hablan de memoria. Por personas que lo conocieron y por algunos de los muy poeos discípulos que aún quedan de los que asistieron á sus clases, he sabido practicaba reinte veces cada operación, siemple con gran maestría, y la media de los reinte resultados que obtenía era lo que consignaba en sus escritos como resultado fimal. Para ello empleó los nojores métodos, y los resultados en cifias que obturo son hasta loy aceptables.

La falta de elementos de laboratorio, que en su tiempo se hizo sentir grandemente en el país, le impidió lacer muchos más estudios que, por haberlo ó́do de boca de uno de sus discípulos predilectos, me consta que desé́ y que procuró emprender, y que no llerí á cabo por habérselo impedido las referidas dificultades, y esto que finé notoria su habilidad para suplir los útiles que no le era posible obtener en el conercio; pero si esos elementos no le hubieran faltado, le deberíanos ahora, repito, más y muy importantes trabajos, como la ralorización del ázoe, que aquellos señores no pudieron entonces ejecutar y que mucho ha practicado ahora el Sr. Tucio y lasta ha creado métodos propios. Sin embargo, lo que Río de la Loza hizo lo dejó y lo dejará siempre bien acreditado como lrábil manipulador y químico oliginal, exacto y concienzudo.

En sus discursos se ve al hombre reflexivo, sólido, tranquilo hasta en su manera de atacar, cortés en la defensa, enemigo de trivialidades y de ocupar la atención de sus oyentes con simples juegos de palabras.

En sus informes da á conocer cómo tomaba á pechos, como el mayor de sus deberes, el cumplimiento de cualquiera comisión que se le confiaba. Verídico en sumo grado, nunca se le ve ocultar verdades por dolorosas que fueran, y perseguía en todo con sus consejos el bien general y la mejora de cuanto esturo en sus manos. Rerela haber poseído el dón de prudencia, proponiendo siempre al gobierno ó á la sociedad remedios factibles, como conocedor que era de sus tiempos; y constante, con una envidiable constancia, se le ve lnchar años enteros contra toda clase de obstáculos hasta conservar la vida de la Escuela de Agricultura, por lo que ese plantel le es deudor de nua 
estatua en señal de gratitud, y nunca olvidar que debe llanarle su padre.

Para terminar estas líneas, sémme permitido dejar aquí consignados los siguientes breves apuntes biográficos.

Nació Don Tueopoldo Río de la Loza en la ciudad de México el 15 de noviembre de 1807 . Sus padres fueron el muy honrado fabricante de productos químicos Don Mariano Río de la Iuza y la Sra. Doña María Guillén, ambos oriundos de la ciudad de Querétaro. En 1819 perdió al autor de sus días, y, hasta donde esto es posible, fué reemplazado por el segundo esposo de la señora su madre, que fué el Profesor de Farmacia Don José María Bustillos.

Desde sus primeros años vióse obligado á compartir los trabajos de sus padres en la fabricación de productos químicos, y si es posible que fuera ésta la causa de sn afición posterior á los estudios químicos, fué por lo pronto la causa de que perdiera la salud por todo el resto de sn vida.

A los trece años terminó brillantemente la educación primaria y pasó á cursar la secundaria en el Colegio de San Ildefonso, bajo el amparo del distinguido Doctor en Farmacia Don José María Vargas. En 1827 conquistó el título de cirujano, casi al mismo tiempo que perdía á sn madre. Emprendió en seguida los estudios de farmacia, y con dispensa de edad obtenía su título en 1833.

Proporcionóle esta carrera el cargo de rocal del Consejo de Salubridad y de encàrgado de la racuna. Hízose notar su celo en la primera epidemia de cólera, hasta llamar la atención del entonces Presidente de la República, Don Valentín Gómez Farías, no sin haberse conquistado en esos días el título de médico.

Una vez en posesión de esos títulos, se dedicó desde entonces hasta el fin de sus días al estndio de la química, y antes de lanzarse á hacer públicos sus vastos conocimientos, se preparó largamente en lo privado; hizo en su propia casa un onsayo de laboratorio, y con su propia familia un ensayo de profesorado, por lo que ya en 1843 se 
le vió desempeñar con lucimiento las cátedras de quínica en la Escuela de Medicina, en la de Minería, en el Gimnasio Industrial en 1845, en el Colegio de San Gregorio en 1852, en Bellas Artes en 1863, en la Escuela Preparatoria desde $1867 \mathrm{y}, \mathrm{por}^{\circ}$ íltino, la de química analítica en la de Medicina desde 1868.

Dice nuo de sus biógratios, el Sr. Don Gabino Barreda: «Lo que absorbía sienpre y de preferencia su atención era la ciencia de Beltholet y de Laroisier, y mu especialmente las complicadas, minnciosas y precisas operaciones de la análisis, cuyas manipnlaciones ejecutaba con mua delicadeza y ma probidad científica intachables, no perdonando precanción ni medio algmo por insignificante que pareciese, con tal que él pudiese contribuir á ưarantizar la exactitud del resultado. El soplete, por el que tenía particular predilección ! en cuyo manejo proenraba siempre adiestrar á sus disćpulos, era en sus manos una verdadera caja de reactivos. ya oxidando, ya reduciendo. ya rolatilizando las diferentes substancias á roluntad, y preparando siempre mua análisis que los otros reactivos sólo tenían las más reces que confirmar.

«Cuando llegóá adquirir esa profinnda rersación en las manipnlaciones prácticas; cuando se hubo asinilado todo lo que la ciencia había adelantado hasta entonces; cuando en el silencio de su gabinete y en medio de los utensilios y aparatos de su laboratorio, se consideró suficientemente preparado para su importante misión, connenzó con el entusiasmo de un apóstol y la abnegación de un héeoe, aquel trabajo de propaganda científica que constituye su principal título á nuestra gratitud.

«La difusión del gusto por los estudios químicos y sus numerosas aplicaciones se debe, entre nosotros, á Río de la Loza. El fué el primero que comenzó á quitar á ese estudio el carácter misterioso, y por decirlo así, ese tinte alquimista de que habían quedado impregnadas todas sus operaciones y todos sus resultados: él fué el primero que presentó los últimos como consecuencia de leyes inrariables, y las primeras como condiciones lógicas de esas mismas leyes.

«Durante ocho años, en su laboratorio privado, y laciendo casi siempre él misimo los gastos necesarios para sus demostraciones, se dedicó á difundir entre sus discípulos particulares los sólidos conocimientos que había ahnacenado en su bien organizado cerebro. Sus lecciones fueron siempre ma escuela práctica de la más completa 
experimentación: cada resultado ela allí rigurosamente previsto $y$ preparado. Prefería siempre el lenguaje de Wollaston al de Dalton en la doctrina de las proporciones definidas. De las tres partes en que se puede considerar lógicamente dividido el método de las ciencias físicas, la última, ó la comprobación práctica, era la que había cautivado su atención y la que lo tenía embargado del todo.

«Pero su papel principal entre nosotros fué el de un propagador infatigable, el de un Mesías que debía anunciarnos la buena nuera del cultivo efectivo y general de las ciencias que ponen la experiencia y la observación como criterio de toda aserción.

«Como propagador y rulgarizador, nuestro Tueopoldo no tiene entre nosotros riral, y esto le da, en las circunstancias en que le tocó rivir, un valor más aquilatado, ınás precioso que si hubiera hecho dar un paso importante á la ciencia. Ta difusión de los conocimientos experimentales entre nosotros era una imperiosa necesidad, y Río de la Loza la llenó cumplidamente.

«La llenó en su laboratorio particular; la llenó en la clase de la Escuela de Medicina que se instituyó por él; la llenó en la Escuela de Agricultura, cuya cátedra de química aplicada esturo á su cargo.

«La llenó cumplidamente en la Escuela Preparatoria, que turo la feliz honra de tenerlo como profesor desde 1868 hasta 1872, en que las exigencias de una penosa enfermedad le impidieron satisfacer los impulsos de su voluntad de hierro.

«La llenó en la cátedra de análisis química, que desempeñó todavía un año más en. la Escuela de Medicina, á pesar de sus continuos sufrimientos físicos; la llenó, en fin, en todas partes. La cátedra fué, sobre todo, su principal teatro; allí, en su asiento, con el rostro enjuto y marchito, más por los padecimientos que por la edad, con su mirada inteligente y penetrante, que contrastaba con la escualidez de su rostro, con aquellos ojos por los cuales parecía asomarse su alma rigorosa y activa, á lanzar un mentís excepcional al profundo aforismo de los antiguos: Mens sance in corpore sano; con la cabeza completamente inclinada para seguir ma evidente curvatura dorsal; con los muslos fuertemente doblados sobre la pelvis; con las piernas íntimamente ligadas una con otra, retorcida la derecha sobre la izquierda como para reducir en lo posible las dimensiones materiales de su elevada estatura y concentrar en su cerebro toda su actiridad rital; con una voz apacible, pero clara y sonora; con una 
palabra elocuente y siempre precisa, annque con cierta cadencia acompasada é igual, sirviéndose de nu alumno para consignar en el encerado las mutuas reacciones de los cuerpos á que iba aludiendo, y del preparador para ir haciendo las demostraciones prácticas, lograba cantivar á su auditorio por loras enteras, inculcando y grabando sin esfuerzo ni dificultad en sus oyentes los más complicados fenímenos de composición y descomposición de los cuerpos.»

Muchos fueron y muy homrosos los puestos que estuvieron á su cargo, desempeñados todos con gran acierto é integridad: inspector en la Aduana; vocal de la Junta Directiva de listudios; visitador de la Casa de Moneda; presidente de la Comisión Promovedora de Mejoras en los Hospitales; miembro del Consejo de Instrucción Públia; presidente de la Comisión para formar el Atlas de Historia Natural, Geográfico é Histórico del Valle de México; representante de México en la Exposición Industrial de Nueva York; miembro del Consejo de Salubridad, y director primero de la Escuela de Agricultura y luego de la de Modicina. Tales fueron los cargos oficiales en que gastó buena parte de su energía y para cuyo desempeño empléó todo el tiempo que el profesorado y el estudio le dejaron libre. Ya por modestia, ya por exceso de trabajo, rehusó otros muchos cargos y luasta la cartera de Instrucción Pública con que le brindó algún gobierno, desligándola desde luego de la de Justicia.

Ias sociedades científicas se disputaron la honra de contarlo en el número de sus miembros: fué socio de la de Estudios Médicos de la Universidad, corresponsal de la Emmlación. Médica de Guadalajara, socio efectivo del Ateneo Mexicano, de la Sociedad Filoiritrica, presidente de la Promovedora de Mejoras en los Bosques, fundadol de la Sociedad de Beneficencia Médica, doctor de la Universidad, miembro de la Academia Nacional de Ciencias, de la Sociedad Humboldt, de la Asociación Gregoriana, presidente de la Sociedad Médica «Pedro Fscobedo»y de la de Historia Natural, socio de la Academia Médica «El Porvenir;» las sociedades médicas de Gnadalajara, San Luis Potosí, Guanajuato, Pnebla y Toluca lo hicieron su socio correspondiente; fignró como miembro distinguido de la Asociación Médico-Quirúrgica «Lar'ey.» Confraternidad Médica, Academia de Farmacia, Sociedad Farmacéntica Mexicana, y Geografía y Estadística.

Las sociedades científicas extranjeras no le escatimaron sus ho- 
nores: en 1858 recibió diploma de la Sociedad Imperial de Zoología y Aclimatación de París; lo hizo su socio la Academia de Medicina de Madrid; en 1870 le envió su diploma el Museo de Ciencias, Literatura é Industria de Nueva York; en 1875 la Sociedad Universal Protectora de las Artes Industriales le remitió una medalla de primera clase por su descubrimiento del ácido pipitzahoico ó riolózico, cuya originalidad, aun cuando discutida, es, sin embargo, innegable.

Tal es, á grandes rasgos delineado, el hombre cuyos eseritos me ha cabido la honra de colectar.

Agobiado por los sufrimientos físicos, pero lleno de merecimientos, dejó de existir el día 2 de mayo de 1874. Iuo más distinguido de la clase pensadora lloró á porfía su muerte. Casi en cada sociedad científica turo un biógrafo. Entre otros, el Dr. Don Manuel Domínguez, Don Manuel Soriano, Don Gabino Barreda, se ocuparon en escribir la biografía de nuestro distinguido químico. Lus poetas no le escasearon sus cantos, los gobiernos sus recompensas y todo el país su más profundo sentimiento.

Encuentro, pues, muy atinada la honra que ha resuelto tributar á la memoria de este ilustre mexicano la actual Secretaría de Instrucción Pública y Bellas Artes, y ojalá que yo, por mi parte, haya cumplido satisfactoriamente mi comisión. 



\section{INTRODUCCTÓN}

\section{$\mathrm{AL}$

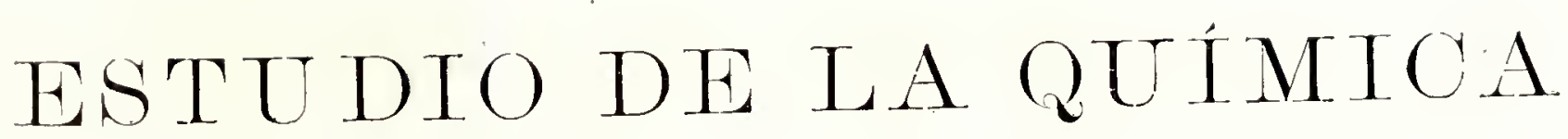

ó CONOCHIIENTOS PRELIMINARES

PARA FACILITAR EL ESTUDIO DE LA CIENCIA.

Á LA JUVENTUd ESTUdiosa DE MÉXICO.

\section{ADVERTENCIA DE LA PRIMERA EDICIÓN.}

A mala organización que se ha dado en la Repúbliea á la enseñanza de las ciencias exactas, hace que se carezca de una cátedra de química elemental que, economizando el tiempo, contribuya á que los alumnos comprendan fácilmente las doctrinas especiales que se enseñan en cada, una de las de aplicación. En rano se ha manifestado la necesidad de establecer, aunque sea una, en esta Capital, en la que se enseñen los principios generales de la ciencia; en rano se ha dado á conocer su influencia en los adelantamientos de las artes fabriles, en los de la agricultura, de la medicina $r$ del comercio; en rano, en fin, se ha demostrado que ese es uno de los ramos de la buena educación en los países civilizados del mundo; esperanzas remotas y promesas no cumplidas: he aquí todo lo que se ha conseguido. Por esto los profesores encargados de las cátedras de química aplicada á la mineralogía y á la inedicina, únicas con que hasta ahora cuenta México, se ven precisados á ocupar una parte del año escolar en la enseñanza oral de aquellos principios: de aquí el embarazo en que se encuentran para la elección 
del antor que les ha de servir de texto, y de aquí tambión el pocon fiuto de sus afanes.

Para remediar en parte tales inconrenientes, me he decidido redactar estos prolegómenos, conrencido por la experiencia de qur en vano se esfuerza el profesor en la exposición de doctrinas que no están en el libro; de que los alumnos deben reverlas y meditarlas; de que no es conveniente y útil obligarlos á que se ocupen en escribirlas, y de que son, por otra parte, indispensables para la inteligencia de las doctrinas químicas.

Nada nuevo se hallará en este trabajo: mi objeto es solamente presentar á los cursantes un cuerpo de doctrina, tan compendiado como es posible; pero en el que encuentre lo más importante, para familiarizarse sin gran pena con el lenguaje de la ciencia: sólo me propongo llenar los racíos que se notan á primera vista en los autores designados, y remediar en parte los que proceden de la mala organización que en general se ha dado á la enseñanza. ¿Cómo poder hablar á los cursantes de química, aun desde las primeras lecciones, de la pulrerización y solución, de la filtración y decantación, sin saber lo que significan estas roces? ¿Cómo tratar después del isomerismo é isomorfismo, y menos de las formas cristalinas, siendo desconocida para ellos la manera de apreciarlas? Aun las reglas de nomenclatura, más perfectas y más extensas cada día, son indispensables para entender las obras modernas y conocer, por sola la indicación de los nombres, la naturaleza de los compuestos, la relación de sus elementos, y aun su analogía con otros, así como las propiedades que los caracterizan.

No podré señalar, desde ahora, el orden y la extensión que me propongo dar á este trabajo, porque son muchos los racíos que liay que llenar, y corto el tiempo de que puedo disponer: mis deseos no tienen límite: quisiera que los cursantes dominaran la ciencia, para que apreciaran su importancia y utiliada; pero sé muy bien que, en las circunstancias actuales, acaso hacen más de lo debido: ciento veinte lecciones que, á lo más, se dan en el año escolar, apenas bastan para estudiar la nomenclatura y los cuerpos simples; así es que hacen mucho si pueden dar lazón de algunas de sus combinaciones y de los principios generales de la química orgánica. No se extrañarí, por lo mismo, que dé la preferencia á las doctrinas más fáciles y compendiadas, y que cuide poco del orden de las materias. Voy á 
escribir .un Opúsculo para el uso de los cursantes de la Cátedra de Química de México, tal como está montada hoy: por lo mismo, sólo debo procurar satisfacer esta necesidad. Feliz si logro el objeto, y más aún, si consigo que este pequeño trabajo sea ńtil, en alguna manera, á los alumnos de la Escuela de Medicina.

\section{ADVERTENCIA PARA LA SEGUNDA EDICIÓN.}

Agotados los ejemplares de la primera, y constantemente solicitados, me reo precisado á hacer la reimpresión de este cuaderno, no obstante que aguardaba para ello la tranquilidad necesaria, y poder disponer de algún tiempo, á fin de dar á estos apuntes la extensión que exige la materia, haciendo en lo ya escrito las correcciones consiguientes al transcurso de trece años que han pasado desde la primera edición. Sin esperanza de lograr lo primero, me decido por la reimpresión, limitándome á hacer algunas correcciones y aumentos que, aunque de poco valor, espero que servirán á los alumnos para recordar las explicaciones que oyen en la cátedra.

Interesado en que se uniforme el idioma científico, y en que se perfeccione cual conviene, desterrando los galicismos, la confusión de unas roces $y$ el doble sentido de otras, no deben extrañarse varios pormenores demasiado sabidos para los inteligentes; pero desconocidos para los alumnos. Por esto he creído igualmente ńtil agregar algunas consideraciones relativas á los principales instrumentos, utensilios, aparatos cuya descripción no es común hallar en las obras que sirven de texto, á la vez que se dificulta á los cursantes el conocimiento de las roces equivalentes. Razones análogas me deciden á dar á conocer más tarde, y en un suplemento, los medios apropiados para el reconocimiento de las sales $y$ de algunas otras substancias de uso commún, pues annque los trabajos analíticos, cualitativos y 
cuaititativos, pertenecen á la cátedra especial, como de đluecho se exige a los alumnos en los exímenes que reconozcan rarias substaicias, me ha parecido indispensable someterme á esa práctica, presẹtúndoles un compendio que podrán estudiar al concluir el curso.

Por último, he creído conveniente adicionar este opúsculo con algunas indicaciones relativas á las propiedades alotrópicas de algunos cuerpos, á la afinidad, y con y sin antagonismo, á la mejor clásificación de los cuerpos simples y, en general, á los puntos que no toca el autor designado, 6 cuyas doctrinas no están conformes con las últimamente adnitidas. Creo que por este medio seguiremos, en cuanto es posible, la marcha de la ciencia, y que los alumnos se encontrarán, al finalizar el año, con los conocimientos indispensables á la carrera que han adoptado.

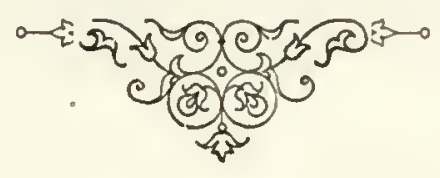




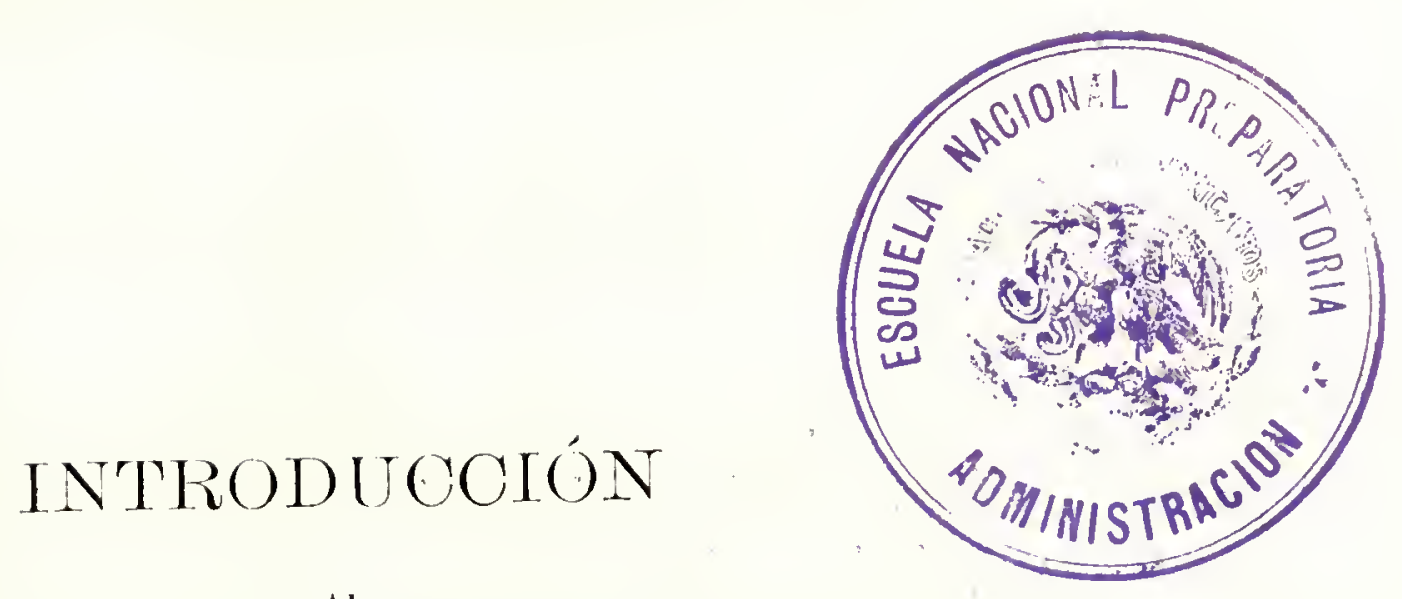

AL

\section{ESTUDIO DE LA QUIMICA}

\section{PARIP PRIMERA.}

DEFINICIÓN DE LA QUIMMICA.-SUS DIVISIONES.-ANÁLISIS Y SINTESIS.

MEDIOS ANALÍTICOS.-NOCIONES PRELIMINARES.

1. Química es la ciencia que enseña á conocer las reacciones nióleculares de los cuerpos, separando y uniendo sus elementos.

La palabra química se deriva, según unos, del griego, y cuya significación equivale en nuestro idioma á la palabra Yo fundo ó liquido: otros la hacen derivar de Cham, por haberse conocido con el nombre de Tierra de Cham, el Egipto, donde primitivamente fué cultivada, así como en la China y en las Indias. Antiguamente se llamó Alchimia, de la palabra Cham, y de la partícula árabe al, superior ó excelente. Más tarde fué conocida con el nombre de Pyrotécnica, ó arte del fuego: ciencia hermética, por atribuirse á Hermes la invención de las ciencias; Argyropea, ó arte de fabricar la plata: Chrysopea, ó arte de fabricar el oro: por último, se le conoció con el nombre de ciencia spagyrica, derivándose ésta de dos voces griegas, separo y reuno, nombre el más significativo y adecuado, atendida la definición y el objeto de la química.

2. Puede ésta dividirse en general y aplicada: la primera conprende: $1 .^{\circ}$ La historia de la ciencia. 2. ${ }^{\circ}$ Las definiciones. $3 .^{\circ}$ La descripción y uso de los instrumentos, utensilios y aparatos. $4 .^{\circ}$ Las nomenclaturas. 5. ${ }^{\circ}$ Tas leyes de las combinaciones. $6 .^{\circ}$ I Ja división de los cuerpos $y$ su clasificación. $7^{\circ}$ La descripción de los simples. 
S. ${ }^{\circ}$ La de las combinaciones que éstos forman. La aplicada se ocupa principalmente de los compuestos especialmente usados en el ramo á que se aplica. De aquí las subdivisiones en orgánica y anorgánica, en analítica, médica, mineralógica, agrícola, industrial, etc.

La química médica es la química general, considerada en sus relaciones con la medicina. Comprende la orgánica y la anorgánicar, y se ocupa especialmente en conocer las reacciones moleculares que se verifican en la economía animal, sea entre sus elementes propios ó entre los de los cuerpos con los cuales están en relación, tales como la atmósfera, los alimentos, las bebidas y las sustancias medicinales.

Ia química agrícola tiene por objeto el estudio especial de los cuerpos simples y compuestos que directa ó indirectamente influyen en la regetación.

'Tanto el médico como el agricultor deben adquiril los conocimientos necesarios de la química analítica, para desempeñar concienzudaunente su profesión.

3. Componer y descomponer son las principales operaciones de la química. Se ha dado el nombre de síntesis á la primera, y de análisis á la segunda. Cuando se han separado los elementos de un cuelpo y nuevamente combinados se obtiene el mismo compuesto, se dice que el análisis es verdadero ó perfecto: por ejemplo, el agua; cuando no se puede recomponer, se llama análisis falso ó impèrfecto: ejemplo, la sangre. Aunque esta división no sea ideológica, porque realmente no hay análisis falsos, está generalmente admitida.

El análisis se divide en cualitativo y cuantitativo: el primero sólo descubre los principios inmediatos, los radicales ó los eleméntos de los cuerpos, y el segundo sus proporciones ó la relación de esos elèmentos.

4. Para analizar los cuerpos, emplea el químico, medios, agentes y reactivos. Las sensaciones y el raciocinio son los medios; la luz, el calórico y la electricidad, los agentes, y un número limitado de sustancias simples ó compuestas, cuyas propiedades y reacciones están determinadas, son los reactivos.

Los medios son, por lo común, indicantes de la marcha que se ha de seguir para descubrir la composición. El estado, brillo, densidad, formas, textura, dureza, quebradura, color, olor y sabor, son los caracteres fisiológicos ú organolépticos: unos obran físicamente y otros químicamente. Por ejemplo, al tocar el mármol, sentimos ma im- 
presión desagradable, fría; pero la mano sólo ha perdido algín calórico: mas al contacto de una solución de sosa cáustica, experimentamos una sensación untuosa, y á veces dolorosa, consecutiva á la acción química. El raciocinio da medios positivos y medios negativos para descubrir los cuerpos: el azoato se distingue desde luego de otros gases por sus propiedades negativas; pero el hidrógeno y el oxígeno por las positivas. *

El calórico y la electricidad obran de un modo especial y diferente con relación á los cuerpos: las propiedades que ofrecen, juntas con los caracteres organolépticos, bastan en algunos casos para descubrir la naturaleza de una sustancia. Así, cuando sometemos un cuerpo á la acción del fuego, vemos que se carboniza ó se incinera, que se funde, se volatiliza, etc., etc., y cada uno de estos resultados nos indica la composición.

Las reacciones particulares que presenta un cuerpo desconocido, cuando se trata por otro de composición determinada, resuelven las dudas á que pueden dar lugar el uso de los medios y de los agentes.

FI examen de un cuerpo puede hacerse empleando vehícnlos ó reactivos líquidos, ó algún agente con ó sin reactivos sólidos: en el primer caso se dice que se ha analizado por vía húmeda, $\mathrm{y}$ en el segun do por vía seca; el análisis al soplete, cuyos resultados son, por lo común, decisivos, y cuando menos indicantes, es un análisis por vía seca, y uno de los medios más preciosos, fáciles y sencillos que frecuentemente emplean los químicos.

Algunos antores sólo admiten agentes como medios analíticos, $y$ los diriden en agentes físicos y agentes químicos. Cuentan entre los primeros, la luz, el magnetismo, el calórico y la electricidad: entre los segundos, los reactivos.

5. Para reconocer los cuerpos, separar unos de otros y preparar ciertos compuestos, la química se sirve de algunas operaciones, á las que se han dado nombres particulares, que debe conocer desde lnego el que se dedica al estudio de esta ciencia. Ias principales son:

6. Drvisióx.-Es la operación que tiene por objeto separar más o menos mecánicamente las partes integrantes de los cuerpos. Se

* No obstante que los autores solamente numeran entre los caracteres oroanolépticos los que estiman por los sentidos del tacto, del olfato y del gusto, parece consecuente no excluir las impresiones que recibe el ojo para juzgar del color, brillo, etc.; por tal motivo, confundinos los caracteres organolépticos y los reputados como físicos. 
practica cortando, limando, raspando, triturando, contundiendo ó pulverizando. Algunas de estas operaciones se subdividen con relación á los instrumentos empleados al practicar la división: se corta con tijeras ó con cuchillo; se lima con escofinas ó con limas comnnes; se raspa y se rae con legras, raedores y rayos; se tritura, se contunde y se pulveriza usando de pilones, rastras ó arrastres, mor'teros, tambores, cilindros y pórfidos con moletas. Cada una de estas operaciones tiene nombres particulares, como contusión, trituración, levigación, porfidización, etc. La dilución y precipitación, que algunos comprenden en la pulverización, no deben confundirse con ésta.

La pulverización se hace con intermedio ó sin él: el fósforo se pulveriza fundiéndolo en agua ó en el alcohol, y agitando el líquide? hasta su enfriamiento: algunas resinas y aceites sólidos, empleando el alcohol ó el éter; ciertas partes vegetales y animales, con el arźcar ó la goma. Se usa también de estas sustancias para reducir á polvo fino algunos metales, como el oro, la plata y otros que son maleables; por último, algunas sales se pulverizan por cristalización inicial.

7. Desicacrox.-Es la operación que tiene por objeto privar á los cuerpos de la humedad que retienen mecánicamente entre sus partículas ó condensada en su superficie.

Esta operación es de la mayor importancia para conocer y señalar los fenómenos en las combinaciones, y para tener buenos resultados analíticos, pues es indudable que las diferencias que se encrentran en las análisis de $u$ mismo compuesto, dependen, en el mayor número de casos, de su estado higroscópico.

El agua se combina con muchos cuerpos: entonces pertenece á su constitución misma, y no debe procurarse quitarla por la desecación, cuando se desea conocer la naturaleza del compnesto. Un equiralente de oxido de potasio se combina con otro de agua, y al compuesto que resulta se le da el nombre de potasa cáustica: si se abandona al aire ó se trata por el agua, tomará uno, dos, cuatro ó más equiralentes, formando una solución de lidarato de protóxido de potasio ó un polihidrato. La evaporación y la fusión ígnea prirarán á este compuesto del agua en exceso, rolviéndolo á la combinación de equivalente por equiralente: diremos entonces que hubo una desecación, ó que el hidrato de potasa se puede secar sin descomponerlo, llerándolo lasta la fusión. No debe confundirse la eraporación con la

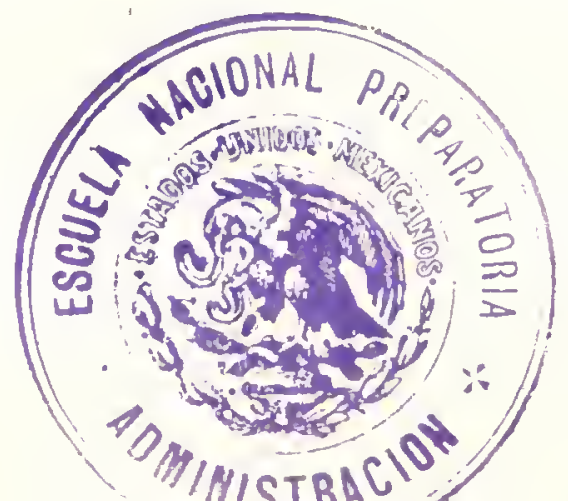


desecación: en el ejemplo pnesto, aquélla lia sido previa y ésta posterior.

Para desecar un cuerpo, es mny importante conocer su naturaleza, ó cuando menos sus propiedades al estado de sequedad: así se llega á elegir, sin peligro y con facilidad, el medio para desecarlo. Los procedimientos de que se sirve la química, son:

A. El simple contacto del aire.

Se usa de este medio con los cuerpos que por su exposición al ambiente quedan opacos ó reducidos al estado de polvo blanco. Ejemplo: El sulfito, el fosfato, el carbonato de sosa, $r$, en general, todas las sales eflorescentes. Fresenius recomienda como medio mejor para desecar estos cuerpos, reducirlos á polvo, colocarlos entre las hojas de papel de estraza, y someterlos á presiones fnertes hasta conseguir el objeto.

B. El contacto de una atmósfera desecada artificialmente.

Si se abandona el sulfato de magnesia al aire húmedo, no sufre alteración; mas si se hace pasar una corriente de aire seco ó caliente, se eflorece con facilidad. Para esto, basta obligar al aire á que se ponga en contacto con algunos cuerpos ávidos de agua, tales conno el ácido sulfúrico, el cloruro de calcio, etc. Las sustancias que se descomponen por su contacto con el aire, se desecan en el racío, bajo la campana de una máquina nenmática, sirviéndose ó 10 de esos cuerpos absorbentes.

$C$. Isa elevación de temperatura por intermedio.

Los cuerpos que no experimentan alteración á la temperatura del rapor de la agua, y am hasta $200^{\circ}$, se desecan colocándolos en estufas, ó empleando el baño de maría, el de vapor de aceite ó de algumas sales. Hay muchos aparatos construidos con este objeto, y que satisfacen todas las indicaciones, como se verá en la parte que trata de los ntensilios.

D. La elevación de temperatura hasta el rojo.

Los cuerpos que no se alteran á esta temperatura, son los que mejor se prestan á la desecación: basta ponerlos en 7 crisol apropiado, evitar el contacto de materias extrañas y esperar el enrojecimiento: en muchos casos sirve de guía la fusión ígnea del cuerpo que se deseca.

Según lo expuesto, pueden reducirse í cuatro los nedios principales de desecación: primero, la compresión; segundo, el vacío; ter- 
cero, las corrientes de aire; y cuarto, la elevación de temperatura. Fstos medios preden ser modificados por la forma de los aparatos, por la acción única ó no del aire, por los medios empleados, y por la acción química. El sulfato de sosa expuesto al aire, se efloroce, del mismo modo que si se coloca bajo la campana de la máquina nemútica, ó al lado de mua vasija que contenga cloruro de calcio. En el primer caso, el aire arrastrará el agua, obrando mecánicamente; en el segundo, el vacío formado farorecerá la erapolación del líquido; y en el tercero, obrará la acción química por la propiedad higroscópica del cloruro. Este es el medio recomendado principalmente para desecar los gases y algunos cuerpos gasificables, obligándolos á pasar por tubos que contengan cloruro de calcio en fragmentos ó potasa, ó amianto empapado con árido sulfín rico, etc.

S. Torrefaccróx-Dis la operación que tiene por objeto descomponer en parte las sustancias orgánicas por la acción del fuego. Aunque algunos cenfuncien la reverberación y la torrefacción, liay diferencias marcadas, no sólo con relación á las sustancias que se exponen al fuego, sino también con el objeto con que se practican, y con la constancia de los resultados: no puede decirse, con propiedad, que se ra á tostur un minerol, porque el tueste da idea inmediatamente de la carbonización: así es que pudiera muy bien definirse la torrefacción, diciendo que es mua carbonización parcial; pero se dará una idea más clara, diciendo que es la descomposición parcial de las materias orgánicas por la acción del fuego, pues en química no se tiene por objeto principal obtener el carbón, sino farorecer las reacciones, combinando en otro orden los elementos de los cuerpos, ó destruyendo en algunos casos las funciones orgánicas.

9. Carbosización.- Essta operación tiene por objeto poner en libertad el carbón de las materias orgánicas, regetales ó animales, separando el carbono de los otros elementos que estaban combinados á él. Annque comúnmente se practica esta operación al fiego y en rasijas cerradas, la química se sirve también de otros medios, tales como el contacto de algunos ácidos concentrados. Se ve, por lo dicho, que la torrefacción y la carbonización presentan una diferencia marcada, y, por lo mismo, no deben confundirse

10. Reterberactós.- Es la operación que se practica sometiendo los cuerpos sólidos á la acción del fnego, en hornos de rererbero, adecuados por su forma á la naturaleza y á la cantidad de las 
sustancias que se quieren reverberar. Se usa con varios objetos: $1 .^{\circ}$ Para privar á los cuerpos fijos de los volátiles que contienen interpuestos. 2. ${ }^{\circ}$ Para separar en su totalidad ó en parte los extraños que están combinados. 3..$^{\circ}$ Para destruir las materias orgánicas. $4 .^{\circ}$ Para modificar la textura de los cuerpos. 5. ${ }^{\circ}$ Para favorecer las combinaciones. En el primer caso, se emplea como un medio activo de desecación, aunque pocas veces, como para desecar las sales en las grandes fábricas. En el segundo, se usa comúnmente para reducir los metales, $\sigma$ para convertir en proto-sulfuros los per-sulfuros metálicos. En el tercero, para favorecer la cristalización de algunas sales, destruyendo las materias orgánicas. En el cuarto, para facilitar la pulverización. Por último, en el quinto, para mantener algunos metales en fusión, favoreciendo su contacto con la corriente de aire: así se obtienen algunos óxidos metálicos, tales como el de plomo.

11. Carcinación.-Esta operación no se distingue esencialmente de la reverberación, sino por los los productos, y en algunos casos por la forma de los hornos en que se practica. Y aunque sólo debería entenderse por calcinación le descomposición á un fuego activo de las sales de cal, se aplica también, siempre que por el mismo medio se obtienen productos análogos á la cal; y aunque los antigụos llamaban cal á todos los compuestos metálicos, más ó menos blancos, obtenidos por la acción del fuego, como cal de antimonio, cal de arsénico, etc., hoy no deben confundirse los compuestos de diversa naturaleza.

12. Incineracióx.-Esta operación es á la calcinación lo que la torreficación á la reverberación. Los compuestos anorgánicos sometidos á un fuego activo y al aire libre, se calcinan, y los orgánicos se incineran. Así, diremos que esta operación tiene por objeto reducir á cenizas los cuerpos orgánicos sometidos á la acción simultánea del fuego y del aire.

13. Fundicióx ó rustóx.-Ls el cambio de estado que se verifica en un cuerpo sólido, pasande al líquido, por la acción del fuego. En química se separan ó se unen por este medio ciertos cuerpos, para formar compuestos, ó para favorecer la acción de los disolventes: también sirre para descubrir las propiedades que los caracterizan, sea en el momento de verificarse la fusión, ó después de su enfriamiento, y por último, para obtenerlos cristalizados.

La fusión se hace con intermedio ó sin éla en el primer cạso se 
llama desagregación. Hay compuestos que se fimden con más facilidad cuando se ponen en contacto con otros más fusibles: también se combinan por este medio en otro orden, haciéndose solubles, como cuando se examinan los sulfatos de base terrosa, los silicatos, etc. Las sustancias empleadas como intermedio, son de preferencia los compuestos conociảos con los nombres de fundente blanco y, fundente nefro: también se hace nso del carbonato, del borato de sosa y del hidrato de barita; pero lo que más se reconienda es mua mezcla, en la relación de sus pesos atónitos, de los carbonatos de potasa y de sosa, 6 sea de trece partes del primero y diez del segundo, uno eflorecido r el otro desecado.

Hay cuerpos que retienen mua cantidad de agua, en la que se cree que se disuelven cuando se ponen al finego, ó cuando menos que farolece su acción disolrente; esto es lo que se conoce con el nombre de fusión acuosu: si el cuerpo no contiene agua ó está en combinación perfecta, ó se funde habióndola perdido, se llama finsión úgner. Muchos compuestos, principalnente las sales, pasan por la fiusión acuosa y despurés por la ígnea.

Cuando se practica la fusión de los metales, toman desprués del enfiriamento formas particulares, según la cantidad que se funde y el medio de que se usa: si resulta un pequeño cuerpo esférico, se llama frono; si discoideo, tejo; y si la cantidad fundida es considerable, se forman artificialmente rieles, barras, etc.

La fusión de algunos cuerpos se liace en ciertos casos en contacto con una mezcla de aroilla y carbón reducido á polvo grueso, de manera que queden cubiertas las paredes del crisol: esta preparación es lo que se llama morere.

También se practica la fusión con el objeto de dividir los metales, enfriándolos rápidamente en el agua ó en otro velículo, después de pasarlos por cribas, si la cantidad lo exige así: esto es lo que se llama reducir á gruncllu, y así se dice granalla de zine, de estaño, de plomo, etc.

El estudio de las propiedades particulares de los cuerpos fusibles, sean simples ó comprestos, da á conocer las precanciones que se lam de tomar al fundirlos.

14. Evaporación.-Es la operación que tiene por objeto separar un líquido de mo ó muchos cuerpos fijos ó menos volátiles que él. 
Is parcialó total: en el primer caso, sólo se separa una parte del rehículo: en el segundo, la totalidad; en cuyo caso se dice: evcuportción hasta la sequedud.

El objeto inmediato de la evaporación es aprovechar los residuos, y en esto se distingue de la destilación, cuyo ebjeto es, por lo común, aprovechar el producto evaporado.

La evaporación puede hacerse al aire libre y á la temperatura ordinaria (evaporación espontánea), por corrientes de aire, por el vacío, por una atmósfera desecada ó por la acción del fuego: en este caso se usa del vapor (evaporación en baño de vapor), del agua (evaporación en baño de maría), de la arena (evaporación en baño de arena), del aceite, del sulfato de sosa, del cloruro de calcio y, en general, de toda sustancia que conserve su estado á una temperatura superior á la del agua hirviendo: por último, en la estufa ó á firego desnndo, según la temperatura conreniente á cada uno de los cuerpos que se someten á la evaporación. Sea cual fuere el medio evaporatorio que se adopte, no debe olvidarse una condición importante, de grande influencia en los resultados, á saber: disminuir cuanto sea posible la presión para favorecer la evaporación.

La práctica lia establecido algunas reglas que sirven de guía para suspender la evaporación en algunos casos. Taas soluciones salinas que han de abandonarse para que cristalicen por el enfriamiento, se eraporan hasta que, á un hervor tranquilo, aparece á la superficie del líquido una costra más ó menos gruesa: esto es lo que se llama evaporación lucesta la pelicula.

La forma, el tamaño y la materia de los vasos evaporatorios, es relativa á la naturaleza de las sustancias que se quieren evaporar: si se hace en rasijas cerradas, toma el nombre de evaporación por destilación.

Se lian inventado muchos aparatos evaporatorios; pero en general, los más útiles y económicos, especialmente para la industria, son aquellos en que se hace uso del vapor de agua á las presiones convenientes; debiendo tenerse presente, que en los trabajos industriales, 10 que más importa es economizar tiempo y combustible; mas cuando se analiza un cuerpo, lo que debe procurarse con más esmero, es evitar las pérdidas, y cuidar de la limpieza y perfección.

Por último, la evaporación y la vaporización deben confundirse en química, porque el químico sólo ve en los dos casos la propiedad 
que tienen algunos euerpos de reducirse á vapores, y porclue siempre debe exaninar el vapor y sus efectos, así como el residuo de la evapo. ración, únicas diferencias en que se han fundado algunos autores para considerarlas como distintas.

15. Destilacióx.- Es la evaporación que se liace al fuego en vasija cerrada, condensando por el enfriamiento los productos rolátiles que se quieren aprovechar.

Según esto, se pueden notar las diferencias que hay entre la raporización, la eraporación y la destilación; diferencias que, si como se ha dicho, son de poca importancia para el químico, no lo son para ol fisico y para el industrial. En la vaporización se aprecian y se utilizan los efectos del rapor: en la evaporación no se tienen estas consideraciones sino secundariamente; siendo el objeto principal aprovechar los residuos en la destilación, se consideran secundariamente los efectos del rapor y algunas reces los residuos; pero se aprorechan de preferencia los productos volátiles, y con ese fin se condensan. Pol esto está generalmente admitida por los químicos la evaporación pol destilación, y es también de la que se nsa generalmente con ventaja para los trabajos analíticos.

Ta destilación puede lacerse por alguno de los mismos medios que se lan indicado al tratar de la desecación y de la eraporación; y así se dice: destilación por el vacío, á fuego desnudo, al vapor, en bano de maría, etc.

También se distingue por la forma de las vasijas en que se plactica, y en algunos casos por el número de destilaciones y la manera de practicarlas: destilación en retorta cerrada, tubulada, etc., ó en alanbiqne común, de baño, etc., de vidrio, de cobre, de porcelana, ete. Se llama rectificución, la redestilación de in líquido; coobrción, la redestilación sobre el residuo de la destilación, y refinación, la redestilación de un sólido. La refinación no se hace únicamente por medio de la destilación: puede hacerse en rasija abierta, tratándose de cuerpos fijos; así se dice: refinación de los metales, del oro, ete.

La sublimución, no es otra cosa que la destilación de los cuerpos sólidos, ó como dice Le Canu, es un modo particular de destilación. Se practica en sublimadores ó en matraces, en ollas, en tubos, etc. La naturaleza de las vasijas es relativa á la de las sustancias que se subliman, á su cantidad ý á la temperatura á que se volatilizan.

Aunque los antiguos distinguían la destilación por ascenso, por 
descenso y por lado (per ascensum, per descensum et per latus), hoy apenas se usan esas voces como un recuerdo histólico.

16. Concentración.-Esta operación no difiere esencialmente de las anteriores, sino por el objeto que se propone el que la practica y por el modo de practicarla. La concentración tiene por objeto separar de los cuerpos líquidos una parte de sus disolventes; ó sea reducirlos á menor volumen, ya por la acción del calórico, por la del hielo, otc.; así es que se concentran los ácidos, las soluciones salinas, las azucaradas, etc., y se usa de la evaporación, de la destilación ó del abatimiento de temperatura, según los casos. Se llama, en general, ácido acético concentrado, tanto al monotrídico que marca $8^{\circ}$, $5^{\circ}$, como al trihídrico, que señala $10^{\circ}, 5^{\circ}$, ya se obtengan á esos grados por la destilación, ó empleando ma mezcla refrigerante. Lo que importa notar es que la rectificación supone que se aprovecha el producto destinado, mientras en la concentración se utiliza éste ó el residuo, como en la de los ácidos sulfúrico, acético y otros.

17. Clantficación. - Esta operación consiste en separar de un líquido las partículas sólidas que tiene en suspensión y lo hacen turbio. Se practica por medio de la depuración ó purificución, de la decrentución, filtrución, despumrción, etc. Ln algunos casos se hace uso de ciertas sustancias ó de agentes, que favorecen la clarificación, sea obrando mecánicamente como el calórico, la sangre, la gelatina y la clara de hnevo; ó bien por la acción química, empleando la sosa, la cal y los ácidos.

18. Lejtriaciós ó mexivacrón.-Esta operación tiene por objeto separar de los cuerpos sólidos las partes solubles, empleando rehículos adecuados á temperaturas convenientes y en diversas porciones, que desalojan á su rez, el líquido que había obrado antes.

El desalojamiento generalmente empleado hoy en química y aun en la industria, y que Robiquet había usado antes en sus inrestigaciones químicas, no es otra cosa que la lejiviación antiguamente conocida.

Se practica de preferencia para lavar algunos cuerpos, siempre que la cantidad de materias solubles sea corta con relación á la masa; cuando se quieren tener líquidos muy concentrados ó hacer la eraporación en el menor tiempo posible. Si la sustancia que se desea obtener es soluble en frío, ó si hay otras pocas solubles á la tempelatura y presión comunes, se prefiere el rehículo en su estado ordinario: de lo contrario, se usa caliente ó hirriendo. 
Tos químicos, los industriales y los farmacéuticos han inventado muchos aparatos de desalojamiento, cuyas ventajas son relativas á la naturaleza de las sustancias que someten á esta operación, á su cantidad y á la mayor ó menor rolatilidad de los líquidos que deben usar; en general, para la mayor parte de las operaciones que se practican en química, bastan el aparato de M. M. Robiquet y Bontron, y el metálico de M. Boullay, modificado por Soubeiran.

19. Precipicacióx.-Es la operación que consiste en separar un cuerpo al estado de polro del líquido en que estaba disuelto.

Se practica: $10^{\circ}$ Determinando un cambio en la naturaleza del disolvente: así, muclıas soluciones acuosas dejan precipitar los cuelpos, tratándolas por el alcolıol, éter, etc. 2. ${ }^{\circ}$ Poniendo en libertad los cuerpos insolubles, en virtud de la ley de sustitución: el amoníaco separa la alúmina de mo solución de alumbre. 3. ${ }^{\circ}$ Formando nuevas combinaciones insolubles, el ácido oxálico se apodera de la cal, separándola de las soluciones. En unuchos casos quedan en solución uno ó más cuerpos, sea que se procure la precipitación por simple afinidad predisponente, ó por la doble, si uno de los compuestos es soluble: mas hay casos en los cuales se precipitan todos los productos, como sucede tratando el sulfato de magnesia por el agua de barita, ó el sulfato de plata por el cloruro de bario; el líquido entonces nala tiene en solución, si las cantidades son proporcionales.

Las sustancias que se emplean para determinar la precipitación, se llaman precipituntes, y el producto insoluble, precipitudo; sea que se deposite en el fondo de la vasija, que quede interpuesto en el líquido ó que ocupe la superficie. Se distinguen los precipitados en cristalinos, pulverulentos, coposos, gelutinosos, caseosos, etc. Si la canltidad de precipitado es corta, está muy diridido y queda en suspensión en el líquido, se dice que éste está turbio ó que el reactiro ha enturbiado su transparencia. Para recoger en estos casos los precipitados, se procura el cambio de naturaleza del disolrente: así, para apreciar las dosis del fosfato amónico-magnesiano, se pone un exceso de amoníaco.

La precipitación, es una de las operaciones más usadas y mų importantes para el análisis cuantitatiro: no sólo se da á los cuerpos disucltos una forma adecuada, con el fin de apreciar su cantidad, también sirve para separar unos de otros. Los resultados analíticos 
obtenidos por este medio, seián tanto más exactos, cuanto que la sustancia precipitada sea menos soluble ó que se ponga en condiciones poco favorables para ser disuelta: así es que se prefiere convertir en sulfato, y no en carbonato, la barita que se pretende separar, para conocer su peso: las soluciones de potasa, de estronciana, etc., se concentran con igual fin, antes de someterlas á la acción de los ácidos tártrico y sulfúrico.

La precipitación puede hacerse á la temperatura ordinaria ó á una temperatura elevada, atendiendo para esto, á la naturaleza y propiedades de los cuerpos, y muy principalmente al uso á que se destinen los precipitados. En general, puede decirse que la densidad y cohesión de éstos está en razón directa de la rapidez con que se obtienen, y es también relativa á la temperatura y á la concentración de las soluciones, pues aunque la precipitación es, como dice Fresenius, una cristalización atropellada, puède favorecerse ó retardarse aquélla, modificando los medios de que se hace uso y las leyes de las combinaciones. La buena práctica enseña en muchos casos á juzgar sobre la existencia de un cuerpo, por el aspecto y manera de precipitarse.

20. Lavación ó roción, Y laAvadura.-Algunos autores distinguen estas dos operaciones: llaman loción, á la que tiene por objeto separar de los precipitados, por medio de un velículo, los principios solubles de que estaba impregnado; y lavadura, la que se practica para separar los cuerpos extraños, simplemente adheridos ó interpuestos á los sólidos, obrando el vehículo por solo su acción mecánica. No es fácil fijar el límite de estas dos operaciones, y por esto parece más conreniente confundirlas con la denominación de lavadura.

Ésta puede hacerse por corriente, por decantación y por filtración; para ello se emplean diversos líquidos, aunqne comúnmente se prefiere el agua pura. La forma de las vasijas y de los aparatos de que se hace uso, también son relativos á la cantidad y al objeto con que se practica la operación. Así es, que se hace uso del plano inclinado para lavar por corrientes de agua, siempre que la cantidad de materia es considerable, y que la densidad de los cuerpos extraños difiere de la de aquel que se quiere aprovechar. Pero si se trata de analizar un cuerpo y de apreciar el peso de un precipitado, lo primero que se ha de procurar es no perder cantidad alguna de ma- 
teria: la lavadura, en este caso, debe hacerse sobre el filtro mismo, prefiriendo la redoma de chorro ó la de gotas.

21. Decantación.- Se usa esta operación para separar, después del reposo, el líquido claro del que contiene un precipitalo, ú otro líquido menos denso. Si la densidad del producto que se ha de aprovechar es mayor que la del líquido, se separa el que sobrenada; otras reces se prefieren como más cómodos los frascos ó embudos con llave, que sustituyen, con mejor éxito, á los antiguos separatorios. En muchos casos, los depósitos se adhieren á las paredes de las vasijas que los contienen, y esto se observa particularmente en las cristalizaciones: las aguas madres son separadas por decantación y sin desprender los cristales: del mismo modo se practica la lavadura. El uso de los sifones y de las pipetas efrece grandes rentajas en la práctica para estas o peraciones.

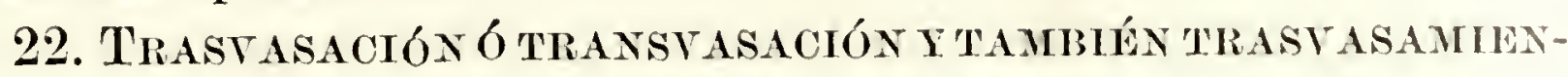
To.-Operación que tiene por objeto pasar un gas de una rasija á otra. También se dice, aunque impropiamnente, trasvasamiento de un liquido, por no estar generalizado el uso del rerbo trasegar, ni de las roces derivadas de él.

23. Fumració x.-Es la operación que tiene por objeto separar, por medio de cuerpos más ó menos porosos, las partículas que contiene en suspensión un líquido.

Los filtros varían por su naturaleza y por su forma: los hay de piedira, de arena, de carbón, de aserrín, de vidrio pulverizado, de lana ó de algodón cardados; de amianto, de fieltro, de papel y de tejidos más ó menos apretados, de lana, algodón, lino ó cáñamo. Fstos son los que más se usan por los industriales; pero los quínicos prefieren el papel sin cola de buena clase, y preparado convenientemente. In cuanto á la forma de filtro, es relativa á la del utensilio que se emplea: los hay planos y cónicos, y éstos pueden ser simples ó plegados; los simples se prefieren cuando se quiere apreciar exactamente el peso de un precipitado, ó recogerlo sin perder nada: los plegados, cuando lo que más importa es recoger el líquido en el menor tiempo posible.

Para que sea bueno el papel de filtro, debe reunir estas cualidades: 1. a Ser bastante fino para que no deje pasar los precipitados, por sutiles que sean. 2. ${ }^{a}$ Dejar pasar con facilidad el agua. 3. ${ }^{a}$ No contener materias solubles, ni aun en los ácidos débiles ni en los ál- 
calis. 4. ${ }^{a}$ Dejar por la incineración la menor cantidad posible de residuo.

Es muy conveniente, al hacer los filtros de papel, no quebrar demasiado las partes dobladas; no poner el líquido que se requiere filtrar, sino cuando haya sido lavado y amoldado el filtro en el embudo; y por último, hacer que el líquido caiga primero sobre una varilla de vidrio, evitando el choque directo sobre el papel.

24. Mezcla y combinación, solución y disolución.-Es muy conveniente fijarse en el significado de estas palabras, ya por el uso frecuente que se hace de ellas, y ya por no estar de acuerdo todos los autores en el que deben tener. En la parte final y bajo el rubro de apéndice, se hallarán los fundamentos que he tenido para preferir las siguientes definiciones.

Mezora.-Se da este nombre á la interposición más ó menos íntima, y en proporciones arbitrarias, de dos ó más cuerpos sólidos, líquidos ó gaseosos; pero conservando cada uno las propiedades que tenían, $\mathrm{y}$ sin que al unirse presenten fenómeno alguno apreciable, aun empleando los medios de observación más delicados.

Combrración.-Es la unión molecular, en proporciones definidas, de dos ó más cuerpos de naturaleza diferente, cuyo producto es homogéneo, aun en la más pequeña partícula. También pudiera decirse que es la afinidad puesta en acción.

Solución y Disoludción.-Hay autores que confunden estas dos voces, dándoles una misma significación; pero otros llaman solución á la desaparición de un cuerpo en un líquido, sin los indicios comunes á las combinaciones. Por el contrario, dicen que hay disolución cuando se nota una reacción ó sea la combinación propiamente ảicha. Veremos en las adiciones los fundamentos que hay para confundir las dos voces, diciendo: que se entiende por solución ó disolución, la unión íntimu de un cuerpo sólido ó gaseoso en un vehículo apropiado, que dé por vesultudo un todo homogéneo. Cuando al verificarse esa unión hay cambio notable en la temperatura, desarrollo de electricidad, $y$ en general, los signos comunes y muy manifiestos de las combinaciones, se llama solución química. Si, por el contrario, esos signos no son manifiestos, se llama solución simple. Ejemplo de lo primero, es la desaparición del mercurio en el ácido azótico; y de lo segudo, la del azúcar en el agua."

El estudio de las propiedades particulares de cada uno de los cuer- 
pos, enseña á conocer su mejor disolvente, así como la temperatura y presión más conveniente. En general, puede decirse que los sólidos son más solubles á una temperatura elevada; los líquidos, á la temperatura y presión comunes, y los gases á ma temperatura menor que la ordinaria y á mayor presión.

En las soluciones simples, se dice que el líquido está suturudo, cuando ha disuelto toda la cantidad de que es capaz; es decir, cuando llega el momento de establecerse el equilibrio entre las tendencias opuestas del disolvente y las del cuerpo que se ha de disolver: así se llama solución saturada de cloro, de ácido sulfhídrico, de sulfato de sosa, etc., á las soluciones acuosas que no admiten mayor cantidad de aquellos gases ó de esta sal. En las soluciones quínicas tannbién se usa de la palabra neutralización, como equivalente de saturación; así se dice: néutralizar el ácido acético con la potasa, la cal, el amoníaco, etc., ó suturar con gas carbónico, la potasa, la sosa, etc.

Algunos distinguen las disoluciones, en directas y por disgregación: para la primera, basta tratar por el rehículo el cuerpo que se quiere disolver: para la segunda, es necesario usar, además, de otro intermedio, como el carbonato de barita, el bisulfato de potasa, etc.

25. Cristarización.- Esta operación tiene por objeto hacer que los cuerpos cristalizables tomen formas regulares, $y$ capaces de sel determinadas geométricamente. La cristalización se verifica en virtud de la atracción molecular de los cuerpos, y el sólido que resulte será tanto más perfecto, cuanto que la cristalización sea más lenta.

Para que los cueípos cristalicen, es necesario disolverlos, fundirlos ó gasificarlos, y hacer después que rarien de estado. Muchos metales, sometidos al fuego, se funden, se liquidan y cristalizan sin volatilizarse: esta es la cristalización ígnea de algunos autores; otras se volatilizan, cristalizando por el enfriamiento; por último, las sales, varios productos orgánicos y otros, se disuelven y cristalizan por la eraporación y el enfriamiento. Por lo común se usa del agua como disolvente, pero en algunos casos se prefiere el alcohol, los aceites volátiles y el.éter. La precipitación lenta es también un buen medio para obtener algunos cuerpos cristalizados; el fósforo, por ejemplo, separa la plata ó el cobre en cristales, abandonando por algún tiempo un cilindro de fósforo en una solución de las sales metálicas respectivas.

No sólo se usa de la cristalización para obtener algunos cuerpos 
cristalizados; sirve también como medio de purificación, separando un cuerpo de otros mezclados á él, haya ó no reacción química.

Además de las operaciones indicadas, hay algunos fenómenos, $o$ más bien puede decirse, que ciertos cuerpos presentan determinadas propiedades, que los químicos enumeran entre aquéllas; pero que de uno ú otro modo es importante conocer, porque son voces de uso común, y cuya significación debe precisarse.

26. Fosforescexcra.-Propiedad que tienen varios cuerpos, puestos en condiciones determinadas, de dar una luz blanca más ó menos débil, sin elevación notable de temperatura. El Océano á prima noche, varios animales, el fósforo en su combustión lenta, diversas sales al momento de cristalizar, algunos minerales cuando se someten á una temperatura elevada, y muchos cuerpos frotados, comprimidos, percutidos ó sometidos á la influencia solar, aparecen fosforescentes en la obscuridad.

27. Decrepitación ó crepitación.-Estas voces, derivadas de la latina crepitus, ruido ó choque violento, indican el peterreo ó chirrio, que es la propiedad que tienen principalmente algunas sales, de ser lanzadas con más ó menos violencia, produciendo un ruido ó trueno particular, y aun en el mayor número de casos, rompiéndose en varias partes, como se observa en la sal común cuando se pone en una vasija ó en una lámina metálica calentada ó enrojecida, y también sọbre una brasa. Aunque se atribuye esta propiedad á la evaporización del agua, se nota que varios cuerpos que no la contienen, decrepitan: dependiendo más bien esta propiedad, en algunos casos, de la dilatación molecular, separándose con regularidad algunas partes del cuerpo, cuando está cristalizado.

2S. Deflagración.-Voz derivada de la latina deflagratio, conflagración; aunque confundida con las de combustión, inflamación é ignición, difiere mucho por la rapidez que la caracteriza, por la actividad con que se verifica $y$ por la flama que produce: la combustión de las pólvoras al aire libre, la de los cloratos, de los azotatos, etc., determina su deflagración; mas no estando al aire libre, son detonantes y aun explosivas.

29. Detonacióx.-Aunque pudiera considerarse como una decrepitación, difiere mucho de ésta por las condiciones en las cuales se verifica el fenómeno, por las causas que lo determinan y por los resultados producidos. La detonación consiste en el ruido ó estruen- 
do más 6 menos sonoro, determinado por el sacudimiento súbito del aire, y producido por la dilatación ó por la contracción instantánea de uno ó muchos gases.

30. Explosión.-No difiere de la detonación sino por las condiciones en que ésta se verifica: es decir, por la resistencia que se opone al efecto de la fuerza detonante: para que haya explosión, es necesario que haya rompimiento, $y$, por lo mismo, un cuerpo detonante puede determinar la explosión, colocándolo en condiciones favorables; la pólvora es una mezcla detonante, que en muchos casos produce una verdadera explosión. 


\section{PARIESEGUNDA.}

DIVISIÓN DE LA MATERIA.

PARTÍCULAS, MOLÉCULAS Y ÁTOMOS.-ESTRUCTURA DE LOS CUERPOS.

ELEMENTOS DE CRISTALOGRAFÍA.

31. Sea cual fuere el estado de un cuerpo, se puede considerar divisible en muchas partes, $y$ cada una de éstas subdivisible más y unás, sin que sea posible fijar un límite, ni señalar la forma, el peso, ni el tamaño de la última partecilla de aquel cuerpo. Sin embargo, nuestros sentidos pueden reconocer su existencia, y muchos fenómenos, ya físicos, químicos y aun orgánicos, nos inducen á buscar en los hechos la explicación de una doctrina que aparece como especulativa.

Las substancias aromáticas, las colorantes, algunos cuerpos simples y muchos compuestos, no dejan duda alguna de la divisibilidad de la materia. Ejemplo: una gota de sulfato de añil, colora una cantidad considerable de agua, y en cada gota de esta solución hay un número indeterminado de partes colorativas, que aun pueden todaría subdividirse por medios análogos. Si se abandona por algunas horas en un aposento, y aun por algunos días, un peso determinado de almizcle, no se conocerá la pérdida, aun empleando la balanza mejor arreglada; sin embargo, el aposento $y$ todos los objetos que hay en él, quedarán impregnados de aquella substancia orgánica. Una pequeñísima cantidad de solnción de azotato de plata descnbre el cloro, precipitándose el metal en combinación con él y en cantidad apreciable, aun á la simple rista: lo mismo se observa al tratal por un sulfato soluble una gota de solución muy dilatada de barita: ol polvo blanco que se precipita, indica la formación del sulfato de barita insoluble, procedente de la reacción entre los dos compuestos. Estos, obrando recíprocamente, substituyendo sus radicales, y aun combinándose con otro, que es el agua, hacen visible el precipitado, 
sin que sea fácil aislar una de esas partecillas para conocer su peso, tamaño, color y forma. I si cada ma es de la misma naturaleza, debe considerarse compuesta de otras pequeñisimas, formadas por los radicales ácido sulfúrico, oxido de bario y agua; siendo estos compuestos formados á su rez de los elementos oxígeno, azufie, bario é hidrógeno, cuyas partículas deben ser aún más pequeñas, é imposible de ser aisladas. Un hecho observado hace algunos años por el Sr. D. José Urbano Fonseca y por mí, contribuirá á dar idea de la divisibilidad de la materia bajo el punto de rista orgánico.

Es sabido que el mesenterio es una membrana demasiado fina, y lo es aún más en la rana, de que me servía un día para observar por medio del microscopio la circulación de la sangre: en el interior de uno de los vasos arteriales de dicha membrana, mucho más delgado que un cabello, se distinguió con toda claridad la presencia de un sér viriente, poco menor que los glóbulos, caminando en direceción opuesta á la corriente, y casi pudiera decirse luchando con ella: pasado algún tiempo, el animal llegó á un punto en el que eỉ vaso quedó cubierto por los tejidos, y aquél se perdió á nuestra vista.

Las consideraciones á que da lugar este hecho, no necesitan explanarse: basta notar cuál es el grueso de la membrana, cuál es el diámetro de la pequeña rama arterial, cuál el tamaño de ese sér viriente, que camina con amplitud en el estrecho canal; y lo que es más, que tiene sus aparatos propios, sus órganos bien formados, sus tejidos y sus fluidos orgánicos, los principios inmediatos de éstos, y por último, los elementos de que están formados. Así es fácil figurarse la extrema dirisión de la materia, y más fácil convenir, en rista de este lıecho y de otros análogos, que sólo un Sér Omnipotente, para quien no hay grande ni pequeño, puede ofrecer al hombre tan admirables fenómenos, dignos de su contemplación.

Algunos, como Baudrimon, confunden las roces partícula, nolécila y átomo, para indicar las partes infinitamente pequeñas en que se pueden dividir los cuerpos: los más consideran las partículas como una reunión de átomos, ó como la parte más pequeña en que se puede diridir un cuerpo por medios mecánicos, reservando la vor átomo y la de molécula para expresar esa división última, tan ideal como la del tiempo y del espacio. El idioma vulgar y el de la ciencia están acordes con la última opinión: pueden confundirse las roces molécula y átomo; pero debe reservarse la de partícula para dar 
iazón solamente de las partes pequeñas, sin đescender á las hipótesis atómicas. En cuanto al substantivo corpúsculo, introducido en el idioma químico, como sinónimo de aquellas roces, vendría á aumentar más la confusión, ya por haberse substituido tanto á las de partícula y molécula, y ya por las diversas teorías corpusculares, como la de Newton y los que más tarde han admitido la división en corpúsculos simples y compuestos, en divisibles, indivisibles, etc.

Según todo lo dicho, la teoría especulativa, admitida más bien para poder apreciar los conceptos, está confirmada por los hechos: en fisica puede apoyarse en las doctrinas sobre porosidad, compresibilidad, dilatabilidad, etc.: en química, con los resultados que se observan en las reacciones: en fin, en medicina, con varios fenómenos, tanto fisiológicos como patológicos. Para dar razón de ellos, es preciso servirse de palabras: es preciso, por lo mismo, convenir en su significado. La voz partícula recordará la división relativa que perinite señalar la forma, $y$ en algunos casos, el tamaño, color, etc.; la roz molécula ó átomo, recordará la última división de un cuerpo, que no permite señalar la forma, el tamaño ni el color: así, una partícula de azufre, de yodo ó de sulfato de mercurio, podrán aislarse y distinguirse por su color y por su forma; pero cada una de estas partículas, formada por la reunión de átomos, será divisible casi hasta lo infinito, sin que sea posible aislar esas pequeñísimas partes, distinguirlas ni apreciar su tamaño, su color ni su forma; no obstante esto, hay un límite señalado á esa divisibilidad, aparentemente infinita. Por último, la palabra corpúsculo debe quedar reservada para dar razón de algunos fenómenos físicos y de algunos síntomas patológicos.

32. El objeto á que se destina este escrito no permite ocuparse extensamente de otras cuestiones relativas á la estructura de los cuerpos, tales como la colocación relativa de las moléculas simples, la que tienen las compuestas, la forma que se supone á unas y otras, la manera de substituirse en las combinaciones, etc., etc. Diremos, sin embargo, que en los cuerpos simples sólo consideramos un orden de moléculas, mientras en los compuestos hay dos, tres y cuatro. Así, en el sulfato de cal hidratado admitimos átomos homogéneos, formado por cuatro elementos;" pero si separamos sus radicales, que son el ácido sulfúrico, el óxido de calcio y el agua, cada molécula, cada átomo será homogéneo con el compuesto binario; y si descompone-

* Tenga presente el lector el año en que esta obra fué escrita.-Nota del recopilador. 
mos estos radicales, tendremos los átomos elementales azufre, oxígeno, calcio é hidrógeno, respectivamente, homogéneos también. Poco importa considerar estos átomos unos dentro de otros, ó unos al lado de los otros, ni suponerlos esferoidales ó angulosos, como están figurados en el número 1 , lámina $1 .^{\mathrm{a}}, \mathrm{A}, \mathrm{B}, \mathrm{C}$; el hecho es que hay átomos simples y átomos comprestos, que pueden condensarse más ó menos, y los segundos ser formados hasta por cuatro elementos, y raras veces seis ó más. Pero en los cuerpos cristalizables, la forma regular que determinan, descubre en muchos casos su naturaleza, y aun cuando esta forma pueda variar, debemos conocerla y apreciarla con todas las modificaciones de que es susceptible.

Dos fenómenos principales y muy uotables presentan algunos cuerpos: $10^{\circ}$ Cambio de propiedades en los compuestos de elementos de una misma naturaléza y en una misma relación atómica (cuerpos isómeros). 2. ${ }^{\circ}$ Una forma comín para los compuestos de dos 6 mís elementos de naturaleza diferente (cuerpos isomorfos).

El cambio de propiedades en los compuestos isómeros no se limita á las físicas; también las químicas varían en muchos casos. Si el compuesto sólo es modificado en su forma, densidad, dureza, propiedades ópticas, etc., se dice que es bimorfo, trimorfo ó polimorfo; si varían también sus propiedades químicas, se llama comúnmente isómero. Fl bimorfismo, trimorfismo y polimorfismo, no son más que una modificación de la isomería; pero ésta se observa en los compuestos, y el bimorfismo, trimorfismo y polimorfismo se presentan también en los simples. Ejemplo: el azufre puede cristalizar en octaedros rectos de base romboidal del cuarto sistema, ó por fusión, en prismas alargados oblicuos, de base romboidal, correspondiente al quinto sistema: es, por lo mismo, un cuerpo bimorfo, y toma, ariemás, la forma utricular. El carbono ofrece tres aspectos diferentes: se dice con más propiedad que es un cuerpo simple, trimorfo. Entre los compuestos, tomaremos el carbonato de cal, por ser el primer compuesto bimorfo que se conoció. La Aragonita cristaliza en prismas rectos de base rectangular, $y$ el Espato de Islandia en romboedros.

El isomorfismo supone necesariamente cambio de elementos y no de forma: es decir, que in elemento ó un radical substituye á otro en su totalidad ó en parte, sin que varíe el tipo del compuesto: $11 n$ equivalente de proto-óxido de fierro se combina con dos de peróxido, 
IAMINTA 1

INTRODUCCION AL ESTUDIO DE LA QUIMICA

Fio
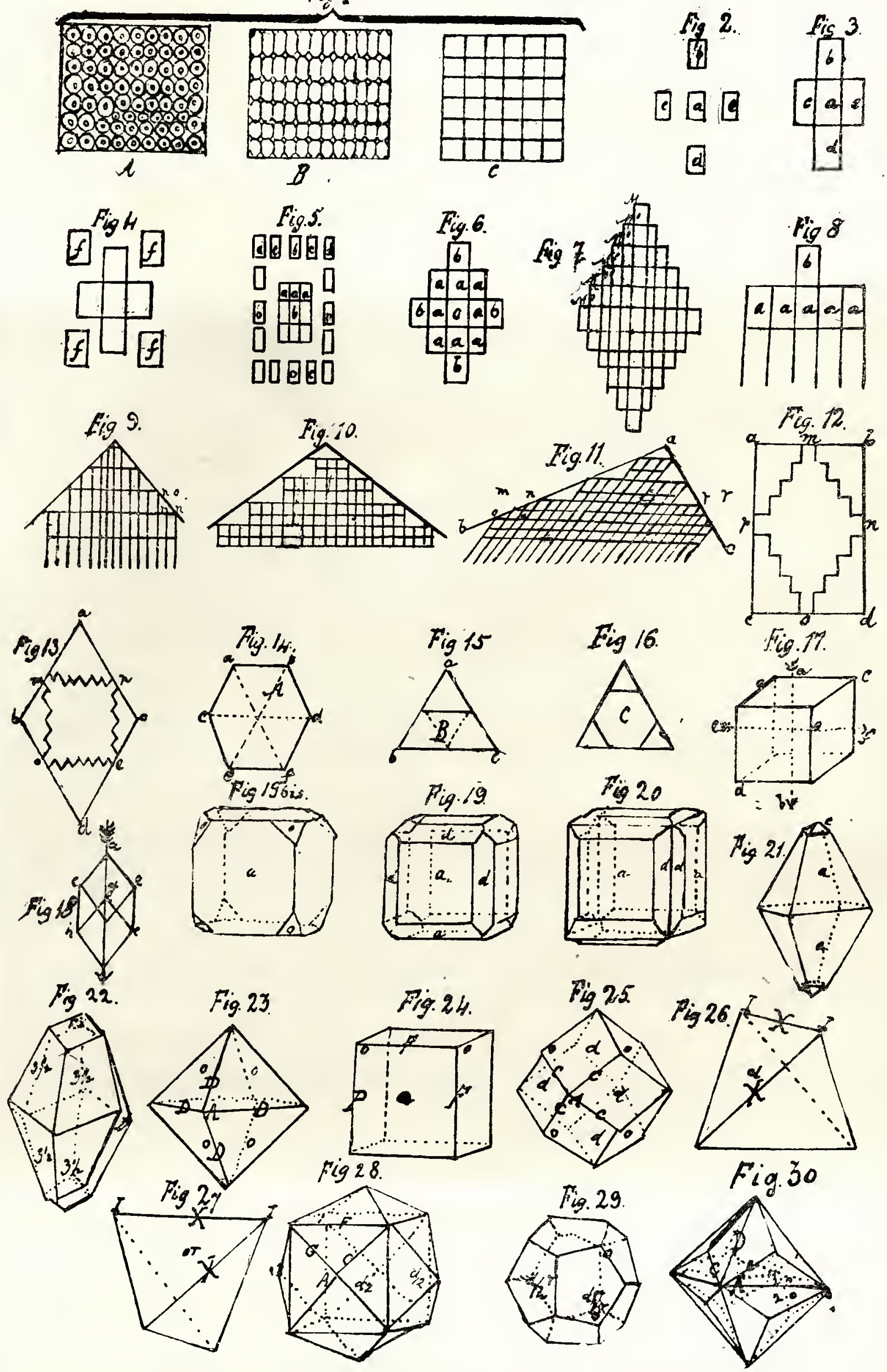
y forma el fierro inagnético: el proto-óxido de manganeso substituye al de fierro, sin determinar cambio en la forma ni en el tipo del compuesto: en este caso el proto-óxido de fierro es isomorfo con el de manganeso.

Algunos usan de la voz polimorfismo como genérica, aplicándola aun á los cuerpos que sólo se presentan bajo dos formas; otros la emplean para indicar las propiedades isomorfas de los cuerpos; pero los más entienden por polimorfismo el cambio de propiedades físicas que presentan los compuestos de elementos de una misma naturaleza. Según esto, hay que considerar en los cuerpos simples y en los compuestos, tres modificaciones principales:

1. ${ }^{a}$ Cambio en las propiedades físicas. Polimorfismo.

2."Cambio en las propiedades químicas. Isomería.

3. ${ }^{a}$ Propiedades comunes en los compuestos de naturaleza diferente. Isomorfismo.

El polimorfismo puede determinarse por la variación de temperatura, por la presión, capilaridad y por la presencia de cuerpos extraños. El azufie cambia de propiedades sólo por la variación de temperatura: el bi-cloruro y el bi-yoduro de mercurio, toman formas incompatibles, haciéndolos cristalizar á temperaturas diferentes. La presencia de una corta cantidad de aceite volátil de romero, de trementina ú otro semejante, destruye la propiedad inflamable que" presenta uno de los fosfuros de hidrógeno, etc., etc.

Resulta de lo dicho: que los cuerpos simples y los compuestos de una misma naturaleza, pueden presentar cambios notables en sus propiedades físicas y químicas, y que estos cambios son relativos á la disposición particular de sus moléculas; disposición que está bien expresada, admitiendo tipos ó grupos moleculares, aun cuando no se conozca à priori su constitución íntima.

Veamos ahora qué se entiende por cristalografía.

33. Se da este nombre á la ciencia que enseña las leyes á que están sometidos los cuerpos cristalizables, así como sus diversas formas y los medios de definirlas. La que trata de la formación de los cristales y de cómo se producen, se llama cristalogenia. La que estudia los fenómenos eléctricos de los cuerpos cristalizados, cristulo-eléctrica. La que comprende estos dos ramos, ha recibido el nombre de cristalología.*

El cristal de roca, el carbonato de cal, el diamante y otros varios productos naturales, habian llamado la atención de los antiguos por la regularidad de sus formas. Lineo fuć 
Se llama cristal, ó más propiamente cristules, á los poliedros regulares que resultan de la solidificación lenta de los cuerpos líquidos ó gaseosos.

Al ocuparse de las formas regulares y apreciables de los cuerpos, debe considerarse en los poliedros las partes de que estín formados, sus divisiones, modificaciones, tamaño, etc.; pero antes es necesario repetir, que siendo los cristales unos sólidos de formas geométricas, con caras, aristas rectas y dispuestas simétricamente al eje, no deben confundirse con los sólidos que presentan caras irregulares, formadas accidentalmente por retracciones ó rompinientos: una rez segruros de esto, dice Beudant, debe buscarse por un estudio detallado los caracteres que distinguen las diversas especies de cristales, y que descubren sus diferencias. El mejor medio consiste en someterlos á una medida rigurosa, sirviéndose de instrumentos convenientes.

34. Para facilitar el estudio de este compendio, será útil conocer algunas hipótesis admitidas por los autores, $y$ formuladas con claridad por M. Laurent.

1. 'Todos los cuerpos sólidos están formados por la reunión de moléculas juxtupuestus.

2. Fistas moléculas son semejantes en un mismo cuerpo, pero diferentes en los demás.

3. ${ }^{a}$ Las formas poliédricas de las moléculas son simples; el tetraedro y el prisma, de tres $y$ de cuatro caras.

$4 .^{a}$ Las formas difieren unas de otras por las dimensiones de sus aristas y por el valor de los ángulos.

5. Todas las moléculas están dotadas de fuerzas atractivas, cuyas resultantes se confunden con los ejes ó líneas que atraviesan simétricamente las moléculas.

6. ${ }^{a}$ La intensidad de esas fueryas varía por la influencia de causas exteriores, tales como el calórico, la electricidad, la presión, la presencia de cuerpos extraños, la naturaleza del disolvente, etc.

Al pasar un cherpo del estado líquido ó del gaseoso al sólido, sea por enfriamiento, por concentración, por reacciones químicas, etc., sus moléculas quedan libres, pudiendo girar sobre sí, conforme

el primero en asegurar que esa regularidad no podia ser un efecto casual, pues era constante: en el hecho, y con su buen juicio, clasificó algunos cuerpos. Los trabajos de Ramé de Lisle, adelantaron los de Lineo, mejorándolos aún con la medida de los ángulos; pero no es sino á Haüy á quien se reputa como el criador de la cristalografía. Más tarde ha llegado la ciencia á un grado de perfección tal, que era preciso dividirla en los ramos indicados. 
á las leyes de su atracción recíproca, yuxtaponiéndose hasta formar un sólido apreciable. Supóngase la molécula $a$ (fig. 2. ${ }^{a}$ ) suspendida en un líquido ó apoyada en un hilo: al precipitarse las moléculas $b$, $c, d$ y $e$, inmediatas á la primera, serán atraídas por ésta, precisamente en el sentido de sus caras homólogas, dando por resultado el sólido representado en la figura $3 .^{a}$, compuesto de siete moléculas, contando con las inmediatas á las caras anterior y posterior.

La precipitación de las cuatro que aparecen con la letra $f$, en la figura 4. a y su adhesión á aquéllas, en virtud de las mismas leyes, dará por resultado el sólido $\mathrm{C}$, que representa la figura 5. ${ }^{\mathrm{a}}$, en cuyo plano aparecen nueve moléculas, más otras tantas anteriores y posteriores; resultando un sólido con veintisiete moléculas: la adhesión de las diez y seis inmediatas, b, $c$, d, dará otro mayor con veinticinco moléculas en un plano, ó sean ciento veinticinco en todo: fácil es conocer, que detenida la cristalización en un momento cualquiera, resultará un cristal con un número de moléculas 1, 27, 125, 343, cuyos números serán los cubos de los impares 1, 3, 5 y 7; la reunión sinétrica de los cristales elementules, formará un cristal semejante á la molécula elemental, al que se da el nombre de primitivo ó forma primitiva.

Si la resultante de la fuerza atractiva de las moléculas $a, a, a$, figura 5. ${ }^{a}$, no es igual y sí mayor con relación á las moléculas $b, b, b, b$, resultará el compuesto que se ve en la figura $6 .^{\mathrm{a}}$ Aplicando el mismo raciocinio, tendremos el rombo que lleva el número 7 , cuyo cristal es una forma secunduria ó derivada, obtenida por la reunión de las moléculas primitivas. Bastará fijar la atención en las figuras 8. $9 .^{a}$ y $10 .^{a}$, para comprender la manera de formarse las retracciones ó descrecimientos.

Cuando las moléculas primitivas son prismas oblicuos, como lo representa la figura 11. ${ }^{a}$, el lado $a, b$, será paralelo á la gran diagonal del cuadrilátero $m, n, o, p, y$ el lado $a, c$, lo será á la pequeña diagonal del mismo cuadrilatero, ó al de $r$, $t$, formado por las tres moléculas que faltan en ancho y dos en altura, en los ángulos entrantes respectivos.

En cuanto á la formación de los cristales derivados, dan los autores una explicación inversa. Supóngase un rectángulo $a, b, c, d$, figura 12. ${ }^{a}$, al que se quitan ó truncan los ángulos paralelamente á sus diagonales, ó lo que es lo mismo, se quita sucesivamente en los: 
ángulos una molécula en el sentido de su altura, y otra en su ancho; es decir, separando diez moléculas de cada uno de los ángulos $a, b$, $c, d$, ó sea cuarenta (en cada plano), resultará el rombo $m, n, o, p$. Por medios análogos, truncando los ángulos del rombo $\iota, b, c, d$, figura 13. ${ }^{\mathrm{a}}$, resultará el rectángulo derivado $m, n, o, p$.

35. Hemos dicho que todos las formas cristalinas pueden ser obtenidas, truncando, sea los ángulos sólidos, ó ya las aristas de los paralelipípedos ó formas tipos. Supóngase la base de un prisma $A$, figura 14." dividido perpendicularmente á esta base, y paralelanente á los lados $a b, a c, b d, \mathrm{y}$, por lo mismo, en dirección á las diagonales $u_{j}$, $b e$, y $c d$, sin coincidir con ellas; es evidente, que con las seis divisiones hehas en las seis caras, se obtendrá un prisnia hexagonal más pesqueño que el primero: cortando el prisma por el centro $A$, en la dirección $a f, c d, b c$, resultarán seis prismas de base triangular equilátera. A su vez, mno de estos prismas dará los cuatro triangulares, representados en la figura 15.", $o$ el prisma hexagonal $C$, con más los tres triangulares representados en la figura $16 .^{\text {a }}$, pudiendo, por lo mismo, ser considerado el prisma hexagonal como triangular y viceversa.

36. En el examen de los cristales hay que considerar los ejes, las caras, las aristas, las esquinas, etc. Se llaman ejes de un cristal, las líneas que se suponen pasan por su centro y terminan en el medio de dos caras, aristas ó esquinas opuestas, como se ve en las figuras 17.9 y 18. Se llama eje principal, al central de la posición vertical, ó al más simétrico ( $a, b$, figuras $17 .^{a}$ y $\left.18 .^{i}\right)$ : los demás se llaman secundarios ó colaterales: $c, d$ y $e, f$, figura 17. '

Las caras de los cristales, son los planos de que están formados: ,$a$, $a$, figuras 19. ${ }^{\mathrm{a}}$ y 20. ${ }^{\text {a }}$; aristas, las líneas que separan las caras: $o$, o, figura 17. '; esquinas, los puntos de interrupción de tres ó más caras: $o$, o, figura 24." Las caras, las aristas y las esquinas, pueden ser lomogéneas ó heterogéneas, es decir, iguales y semejantes ó disímbolas y desiguales, por su posición, tamaño, formas, inclinación, etc. Según la posición del eje principal, y su puesto único, así toman nombres particulares las caras, las aristas $y$ las esquinas: las caras en que termina el eje principal, se llaman básicas ó terminales:,$d$, figur’a 18. ${ }^{\text {; }}$; las caras menores que forman los vértices, se llaman caras de apuntamiento: $c, c$, figura $21 .^{\mathrm{a}} ; \mathrm{y}$ las paralelas al eje principal, laterales ó prismáticas: $a, a$, $a$, figuras $19 .^{a}$ y $20 .^{a}$, así como las aristas; pero las aristas no paralelas al eje principal, se llaman de la base $F$, 
figura 28. ${ }^{a}$, y esquinas de la base á las que son formadas por éstas ó que concurren á su formación: $o$, o, figura 24. ${ }^{a}$; los cristales que sólo tienen un eje principal, se llaman monoaxes, figura $18 .^{a}, y$ los que tienen más, poliaxes, figura 17. a

La substitución de una cará á una arista ó esquina, toma el nombre de truncamiento: $d, d, d$, $d$, figura $19 .^{\mathrm{a}}, \mathrm{y} o, o, o, o$, figura $19 .^{\mathrm{a}}$ bis; la de dos caras homogéneas, biselamiento: $d, d$, figura $20 .^{\mathrm{a}}$; la de tres $o ́$ más, homogéneas también, apuntamiento: figuras 21. $, c, c, y$ 22. $r, r$; las aristas del bisel son siempre paralelas á la arista biselada, figul'a 20.

Con relación á la posición del biselamiento, del truncamiento y apuntamiento, hay que distinguir los de las caras $y^{\prime}$ los de las esquinas; así se dice: biselamiento de las aristas, apuntamiento de las caras, etc.

Las caras laterales de un cristal pueden ser planas ó curvas; si la curratura es hacia dentro, se llaman cóncavas; hacia fuera, convexas; adentro y afuera, convexo-cóncavas; en cuanto á la figura, puede ser cilíndrica, esférica ó cónica.

Aunque los cristales son comúnmente macizos, los hay también huecos y excavados en los extremos.

Los cuerpos cristalizables varían con relación al tamaño de los cristales, y esta variación se nota aun en los de una misma naturaleza; lo cual depende del tiempo en que se rerifica, de la cantidad del vehículo, de la temperatura, etc.; en general, se distinguen los cristales en extremadamente grandes, muy grandes, grandes, medianos, pequeños, muy pequeños y extremadamente pequeños. Si se comparan las dimensiones en cada uno, pueden dividirse en cortos, largos, aplastados, prolongares, tesulares, gruesos, delgados, en agujas, alesnados $y$ capilares. También pueden presentarse separados 6 en grupos: los primeros se llaman solitarios; los segundos, pueden ser agrupados sencillamente (gemelos, triples, cuádruplos), y hallarse perpendiculares, paralelos, etc., ó agrupados complicadamente, formando hacecillos, ramilletes, enrejados, estrellas, botones, crestas, rosas, escalas, tolvas, pirámides, etc. En cuanto á su superficie, puede estar lisa, rayada, áspera, costrosa, granosa ó escabrosa. La rayada puede ser sencilla ó doble, simétrica ó irregular.

Por la textura hay que distinguirla en compacta, estriada, lıojosa, fibrosa y pizarreña. 
Además de estos caracteres, muy importantes para conocer los cuerpos, y aun para señalar en algunos casos su naturaleza, hay que agregar otros que pueden considerarse come relativos ó secundarios, y son el aspecto común y el de separación.

En el aspecto común hay que examinar la trasparencia, la opacidad; la raspadura, su color, riso y lustre; la dureza y flexibilidad, ductilidad y fragilidad; la tiznadura, el sonido y el apeganiento á la lengua. Los caracteres específicos, se toman de los grados en que se presentan los genéricos y también de la falta de éstos, 6 sea de los caracteres negativos: así, la tiznadura comprende á los que tiznan mucho ó poco y á los que nada tiznan: la flexibilidad, á los flexibles y á los inflexibles, etc.

En el aspecto de separación, hay que considerar la figura de las partes separadas, el lustre y las caras de separación, aplicando las doctrinas generales relativas al examen de los cristales. Algunos de estos caracteres sirven también para distinguir los cuerpos amorfos, $y$ aun varios opinan que sólo á éstos se deben referir.

Aunque son muy numerosas las modificaciones que presentan on sus formas los cuerpos cristalizados, el conocimiento de ellas es menos dificil de lo que debiera esperarse, porque hay ciertos principios fundamentales de la cristalografía, que la han simplificado notablemente. En confimación de esto, Beudant establece los hechos siguientes:

1. ${ }^{\circ}$ Que muchas formas, aparentemente diferentes, se entrelazan de una manera natural y no son más que modificaciones más 6 menos rariadas unas de otras.

2. Que todas las formas conocidas y aun por conocer, pueden referirse á sólo seis grupos distintos y que presentan caracteres bien marcados.

3. ${ }^{\circ}$ Que en cada uno de esos seis grupos, todos los poliedros pueden referirse á una forma única, tomada indistintamente entre las que se presentan, resultando de aquí que los estudios cristalográficos se reducen á conocer bien las propiedades físicas y geométricas de un número determinado de formas, tomadas como tipos de todas las otras.

Hemos dicho que los cristales pueden ser más ó menos modificados en sus formas, presentando caras que se colocan de diversa manera sobre sus aristas ó sobre sus ángulos sólidos, extendiéndose en mu- 
chos casos á expensas de las caras primordialés ó liaciéndo que éstas desaparezcan, y den por resultado sólidos muy diferentes. Estas nodificaciones pueden ser parciales $o$ totales, es decir, sobre las aristas, sobre los ángulos, ó en unas y en otros á la vez. La extensión de las caras homogéneas, puede ser desproporcionada y presentarse más ó menos encorvadas, ásperas, estriadas, etc., resultando de estas modificaciones la mayor ó menor imperfección de los cristales, hasta el punto de impedir que se reconozcan fácilmente. Sin embargo, hay leyes cuya aplicación quita todo embarazo, y, por lo mismo, deben tenerse presente en los estudios cristalográficos.

La principal y que está generalmente reconocida, es la ley de simetría, por la cual se establece: que en un cristal, todas las partes dè una misma especie son modificadas à la vez, de la misma manerá ó reciprocamente; que las partes de diferente especie, son modificadas diferentemente. Por esto se observa, que las aristas de una misma especie son todas modificadas á la vez; pero si hay aristas de diferente especie, las modificaciones son también diferentes. Las módificaciones secundarias que pueden presentarse como excepciones de esta ley, son determinadas y aparentes por la formación anormal de los agregados.

El Sr. del Río adınite otras leyes, ó mejor diré, esplana la anterior, así:

1." Paraletismo de lus caras.-Todo eje de caras de un cristal, junta ó reune caras homogéneas.

2." Variación de los ejes.-Los ejes determinados de una figura se alargan $o$ se acortan siempre en las variaciones que ocurren, por coeficientes racionales enteros ó quebrados, y por lo común muy śencillos.

3." Relación de formas.-Dadas dos combinaciones heterogéneas, pueden encontrarse sepạadas, sin que sea preciso que hallándose una dé necesariamente la otra.

$4 .^{a}$ Constancia de los ángulos de inclinación.-Sea cral fuere sir irregularidad que se observe en el crecimiento de las caras y la modificación en las combinaciones, los ángulos de inclinación de las caras de una figura, son constantes é invariables.

Ya se ha dicho que estas leyes pudieran considerarse comprendidas en la de simetría, pero no está por demás tenerlas presentes para la mejor inteligencia de aquélla. 
Se ha dicho igualmente, que los sólidos están formados por la remnión de partículas semejantes para mu mismo cuerpo, pero diferentes de las de otro, pues esas particulas toman las formats poliédricas unás simples, y de su agregación regular resultan los coristales cuyas formas conservan la mimitiva de la particula, que puede considerarse como el núcleo y servir para establecer tantos grupos principales, cuantas son las formas. Esto es lo que constituye los sistemas cristalinos, las formas tipos ó formus simples, y á las que pueden reducirse todas las que se han observado hasta aholar, sea truncamdo los ángulos sólidos ó las aristas de los paralelípedos, correspondientes á las formas simples que vamos á conocer, compendiando el sistema de Regnamlt, con las aclaraciones del Sr. del Río y otros.

Pero antes sería bueno hacer notar, que de los seis sistemas cristalinos, cinco están caracteri\%ados por tres ejes, y sólo nuo tiene cuatro: por lo mismo, éste, que es el tercer sistema, no puedo confundirse con los otros. Lin cuanto á los cinco de tres ejes, el quinto y el sexto están caracterizados por ser oblicuos: de los tres restantes lay que notar que en el priner sistema, los tres ejes son rectandrulares Y semejantes; que en el segundo, annque también los tres son rectangulares, sólo dos son semejantes; por ńltino, en el cuarto, los tres ejes son desiguales y de especie diferente. Teniendo presente costo resumen, es fácil referir las formas cristalinas al sistema colrespondiente.

\section{PRIMER SISTEMA CRISTALINO Ó SISTEMA REGULAR}

37. Las formas de este sistema están caracterizadas por tres pjes rectangulares semejantes (fig. $17^{a}$ ). Taas formas simples correspondientes á este sistema, som:

E7 octuedro regulur.-Formado por ocho triángulos equilíteros; aristas iguales entre sí; ángulos iguales de cuatro caras, y los diedros de $70 \circ, 32^{\prime}$ (fig. 23." $)$.

Hexcuedro ó cubo.- - Seis caras cuadradas iguales: los tres ejes rertaugulares, unen los centros de las caras opuestas; ocho esquinas de tres caras homogéneas; ángulos de las aristas de $90 \circ$ (fig. 2t." ).

Dodecaedro rombal.-Doce rombos cuyos ángulos son $1090,2 S^{\prime}$ ! 700, 32'; reinticuatro aristas homogéneas; seis esquinas de cuatro caras y ocho de tres (fig. 25."). 

IAMINA 2.

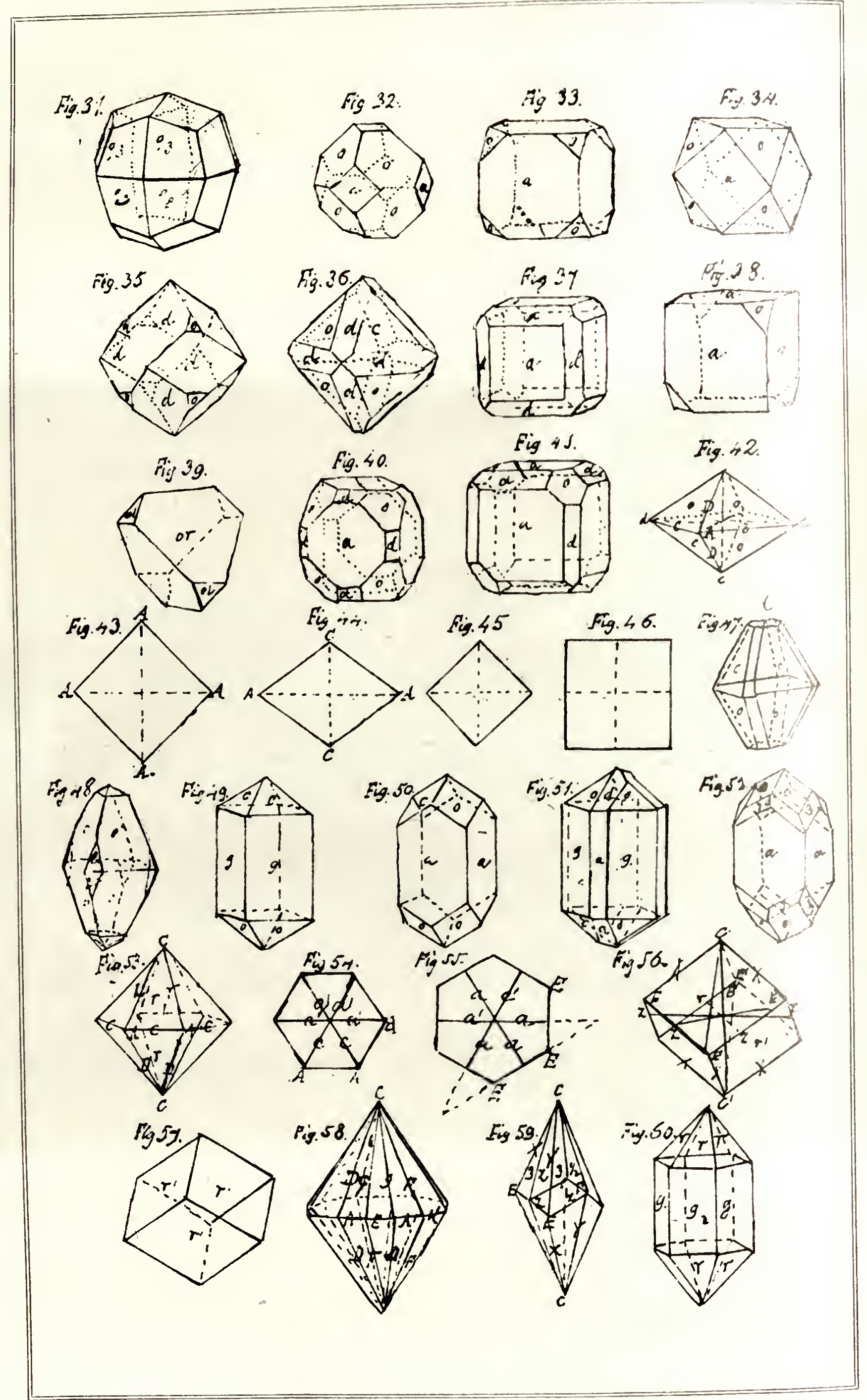


Tetruedro. - Cuatro caras que son triángulos equiláteros: seis aristas y cuatro esquinas homogéneas; ángulo de las aristas de 700, 32'. Este sólido se puede derivar del octaedro regular, suponiendo que las caras alternativas del octaedro se prolongan de manera que hagan desaparecer las caras intermedias, pudiéndose obtener en este caso dos tetraedros perfectamente iguales, pero que se distinguirán por su posición: por esto se llama también á esta forma, hemi-octaedro (figuras $26 .^{\mathrm{a}}$ y $27^{\mathrm{a}}$ ).

Hexaedro piromidal ó tetraquishexaedro (tig. 28. $\left.{ }^{a}\right)$. - Veinticuatro caras, treinta $y$ seis aristas de dos especies. El aspecto general de este sólido es el de un hexaedro, sobre cuyas caras hay colocadas pirámides de cuatro caras, siendo por lo común la altura de las pirámides igual á la mitad del eje del hexaedro, ó pudiendo ser siempre representada por una fiacción racional, muy simple é igual á un tercio, un quinto, dos tercios ó dos quintos. Prolongadas las caras alternativas del hexaedro piramidal, hasta perderse las caras intermedias, resulta el dodeccedro pentugonal (fig. 29."). Los ángulos de las aristas, son: $143 \circ, 7^{\prime}, 48^{\prime \prime} ; 126 \circ, 52^{\prime}, 12^{\prime \prime}$, y 154०, 9', 29'”.

Octaedro piramidal ó triaquisoctuedro (fig. 30." ). - Veinticuatro caras: treinta $\mathrm{y}$ seis aristas de dos especies; catorce esquinas de dos especies. No obstante la analogía con el hexaedro piramidal, se distingue fácilmente por su aspecto general, que es de un octaedro, sobre cuyas caras se encuentran pirámides de tres caras, y la elevación es á longitud de los ejes, como una mitad, un tercio ó dos tercios. Prolongando las caras alternativas de esta forma, se obtiene también una hemiédrica.

Aunque el octaedro piramidal presenta algunas variedades, los ángulos más importantes, son, según el Sr. del Río: 129०, 31', 19"; $162 \circ, 39^{\prime}, 30^{\prime \prime} ; 141 \circ, 3^{\prime}, 27^{\prime \prime}$, y 152॰, 44', $2^{\prime \prime}$.

Irapezoedro biaristado ó icositetraedro (fig. 31." ).-Veinticuatro caras: cuarenta y ocho aristas de dos especies; veintiséis esquinas de tres especies. Se obtiene esta forma, suponiendo que los ángulos sólidos del octaedro regular son reemplazados por pirámides de cuatro caras, $y$ suponiendo también que las caras piramidales hacen desaparecer las deloctaedro. La relación entrè la altura de estas pirámides puede ser diferente, mas la que se ha encontrado hasta ahora es de una mitad ó un tercio. Los ángnlos, son: 131 ${ }^{\circ}, 48^{\prime}, 36^{\prime \prime} ; 146 \circ, 26^{\prime}, 33^{\prime \prime}$; $144 \circ, 54^{\prime}, 11^{\prime \prime}$, у $129 \circ, 31^{\prime}, 16^{\prime \prime}$. 
El Sr. del Río comprende en este sistema lasta trece formas simples, incluyendo algunas que otros antores colocan entre las contpuestas.

Éstas resultan de la combinación de las formas simples de que hemos hablado, y en las que, por lo común, alguna es dominante. Así, se observará la dél cubo y el octaedro, desarrollándose de preferencia el octaedro, como en o, o, o, o (fig. 32." ), ó el hexaedro a (fig. 33. $\left.{ }^{\mathrm{a}}\right)$; pero cuando en el sólido las dos son igualnente dominantes, recibe el nombre de cubo-octaedro (fig. 3t." ).

El dodecaedro se combina con el octaedro y con el hexaedro, dando por resultado cuatro sólidos: dos en los que domina el dodecaedro, en uno el hexaedro y en otro el octaedro (figs. 35. at, 36." y $\left.37 .^{\mathrm{a}}\right)$.

En la combinación del hexaedro con el tetraedro, se presenta una excepción á la regla que hemos dado, pues se advierte, que de los ocho ángulos sólidos del hexaedro, sólo cuatro están truncados, y no tienen, por lo mismo, caras paralelas (fig. 38." ).

Prolongando las caras alternadas de moctaedro, se obtiene la combinación de dos tetraedros (fig. 39." ).

Estas son las formas que resultan de la combinación de sólo dos formas simples del sistema regular; pero hay también otras más complexas que provienen de la combinación de tres ó más formas simples. Se da, por ejemplo, la combinación del hexaedro, con el octaedro y. con el dodecaedro: la del mismo hexaedro, con el dodecaedro y con el tetraedro, etc., ete. (figs. 40." y 41."). In estas formas, la hexaédrica es generalmente la dominante.

\section{Segundo sistema cristalino.}

Tetragonal ó prismático, de base cuadrada.

38. Tres ejes rectangulares, de los cuales dos son semejantes ! el tercero ó úmico es el principal, debiéndose colocar verticalmente. En el primer sistema cristalino regular, las caras son simétricas á los ejes; pero no sucede así en el segundo ó piramidal, porque siendo semejantes los dos ejes secundarios, sólo las caras correspondientes son simétricas.

Las formas simples del segundo sistema, son: 
El octadro de base cuadrada.-Las caras de estos octaedros son triángulos isósceles: ocho aristas terminales que convergen hacia el eje principal y, además, cuatro laterales (fig. 42." ); la sección que pasa por las aristas laterales ó sea por los ejes secundarios, presenta un cuadrado y se llama base del octaedro (fig. 43." ${ }^{\mathrm{a}}$ ); las secciones hechas por las aristas terminales, dan rombos (fig. 44. ${ }^{a}$ ).

Otras de las diferencias que distingue á este sistema del anterior, es: que en el cristalino regular sólo encontramos un octaedro, mientras en el segundo hay muchos de base cuadrada, que difieren entre sí por la inclinación de sus caras, ó por la relación de longitud que presenta el ejo principal con los dos secundarios iguales: el mojor modo de caracterizar el octaedro, es el de conocer esta relación ó el de fijar la inclinación de las caras.

Los ejes secundarios del octaedro, en el segundo sistema de cristales, pueden presentar dos posiciones diferentes: ó juntan ángulos opuestos de la base (fig. $46 .^{a}$ ), ó reunen caras opuestas (fig. $46 .^{\mathrm{a}}$ ), dando por resultado dos octaedros de base cuadrada y con ejes perfectamente iguales: al primero se llama directo ó de primera clase, y al segundo, inverso ó de segunda clase.

Dada ma substancia cristalizable en octaedros de base cuadrada, pueden presentarse algunos cristales diferentes, $\mathrm{y}$, sin embargo, tener entre sí una relación simple, porque la longitud relativa de los ejes principales se hallará en una relación simple.

Las formas compuestas de este sistema, son:

1." La que resulta de la combinación de los dos octaedros prinitivos de primera y de segunda clase, formando ésta truncamientos sobre las aristas de aquél, y presentando al mismo tiempo la cara terminal igual $d$ (fig. 47. ${ }^{\mathrm{a}}$ ) y el octaedro de primera clase $o$.

2." La combinación del octaedro primitivo o, con el octaed ro obtuso de la inisma clase $o$ (fig. 48. ${ }^{a}$ ).

3. ${ }^{a}$ La del octaedro primitivo o, con el prisma recto de la misma clase $g$ (fig. $49 .{ }^{\mathrm{a}}$ ).

4. a La misma forma $o$, con el prisma recto de segunda clase $a$ (fig. $\left.50 .{ }^{a}\right)$.

5." La de dos prismas rectos $g$ y a, con el octaedro primitivo $o$, y con el correspondiente de la segunda clase $d$, dominando en la combinación el prisma recto (fig. 51. ${ }^{a}$ ).

6. ${ }^{a}$ La del octaedro primitivo $o$, con el agudo de la misma clase 
3, y el prisma recto de la segunda a, dominando esta forma en la combinación (fig. 52. ${ }^{\mathrm{a}}$ ).

\section{Tercer sistema cristalino. Hexagonal ó romboédrico.}

39. Las formas simples del tereer sistena cristalino, están caraceterizadas por cuatro ejes, tres semejantes entre sí y que se cortun en ángulos de 600: el cnarto es de diferente especie y perpendiculan á los otros tres; el eje único se considera como principal, y los tres restantes como secundarios; no hay relación constante en la longitud del eje principal con los secundarios.

En este sistema, las caras están dispuestas simétricamente con relación á los tres ejes secmndarios; pero están dispuestas de mua manera diferente con relación al eje principal. Así como en el segundo y en los tres últimos sistemas, hay en el tercero formas indefinida, que no pueden por sí determinar un cristal.

Las principales formas simples que presenta el tercer sistema, soll:

El dodecuedro hexayomal (tig. 53. ${ }^{\mathrm{a}}$ ).-Con doce earas, diey y ocho aristas y ocho esquinas: las caras, son: triángulos isósceles; las aristas, de dos especies, doce terminales, $D$, y scis laterales, $G$; las esquinas, también de dos especies: seis laterales de cuatro caras, A, A, y dos terminales, $C, C$, de seis caras. La base que da la sección por las andistas laterales, es un hexágono regular, con los tres ejes secundarios; las secciones por las aristas paralelas, dan rombos. Se distinguen generalmente dos especies de dodecaedros, el directo y el inverso: en el primero, los ejes remen los ámgulos de la base (fig. 54." ), y en el segundo, los medios de las caras opuestas (fig. 55.").

El romboedro ó semi-dodecuedro (fig. 56." ). Con seis calras, doce aristas y ocho esquinas: las caras son rombos; las aristas, de dos especies: seis terminales, $X$, y seis laterales; las esquinas, también de dos especies: dos regulares de tres caras, $C$, $y$ seis con tres caras ilregltlares, $E$. El eje principal junta los ángulos terminales, $C$; los secundarios remen los medios de las aristas laterales opuestas, $/ 2$.

El romboedro puede considerarse como derivado del dodecaedro hexagonal, suponiendo que las caras alternadas del dodecaedro se desarrollan de manera que hacen desaparecer las internedias, no 

IAMINA 3.

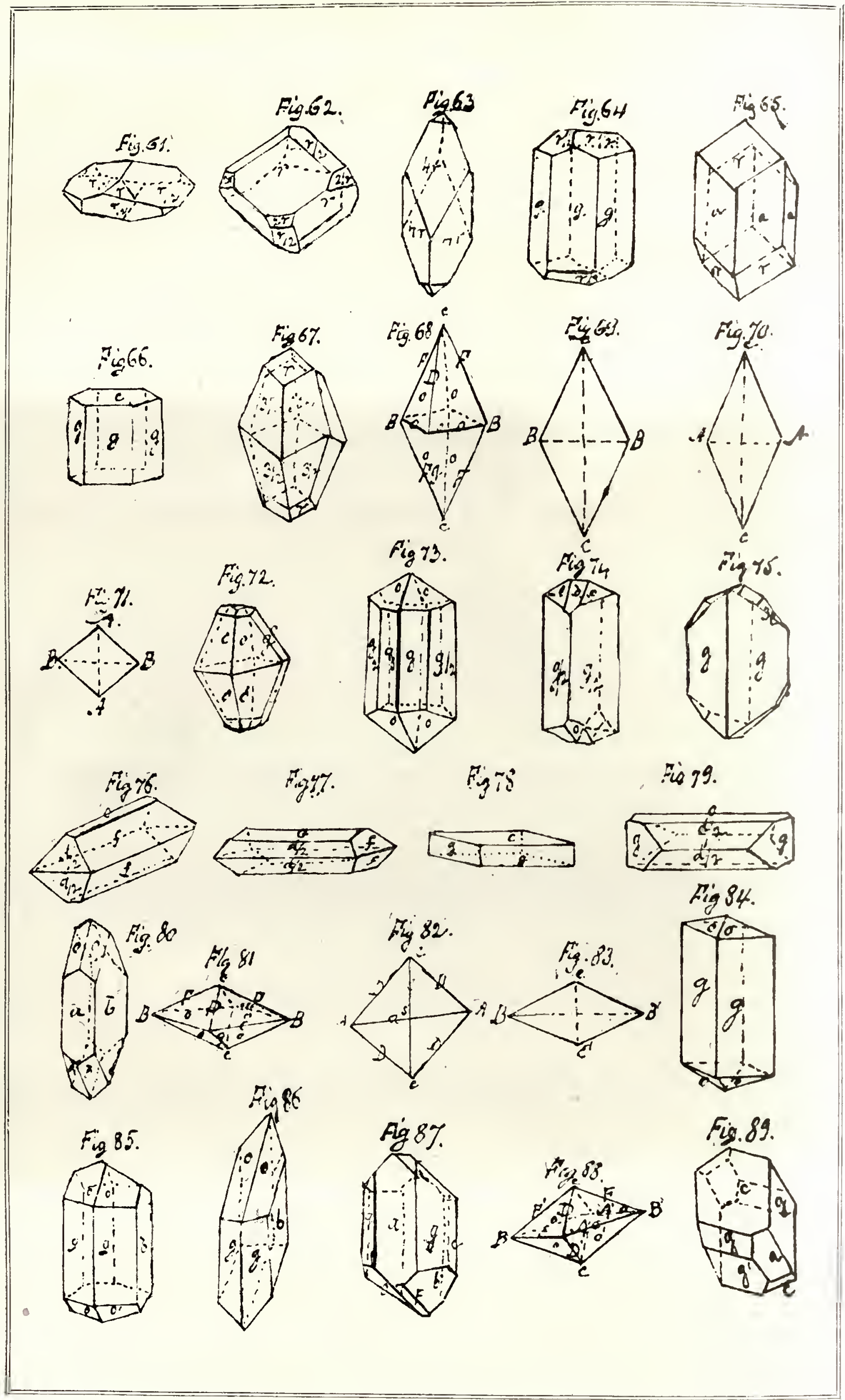


quedando más que las caras del dodecaedro, paralelas dos á dos. Según la elección que se haga de las caras alternadas, así se obtendrán dos romboedros, uno de primera clase ó directo (fig. 56. ${ }^{a}$ ), y otro de segunda ó inverso (fig. 57. ${ }^{\mathrm{a}}$ ).

Los romboedros, así como los octaedros, presentan alguna serie de figuras más obtusas y más agudas: el obtuso tiene las caras inclinadas al eje principal, de la misma manera que las aristas de la forma aguda. Hay en el tercer sistema cristalino, algunas otras formas simples, pero más complexas que las anteriores; por ejemplo, un sólido de veinticuatro caras, que son triángulos escalenos, $y$ al que se da el nombre de didodecuedro (fig. 58..$^{\mathrm{a}}$ ); uno de dos caras y triángugulos escalenos, que se llama hemi-didodecaedro ó escalenoedro (fig. 59. $\left.{ }^{a}\right)$; pero estas formas no son las más comunes.

Las combinaciones del tercer sistema ó formas compuestas, son:

La del dodecaedro primitivo, $r$, con el primer prisma de seis caras, $g$ (fig. $60 .^{a}$ ).

La del romboed ro principal, $r$, con el romboedro obtuso ${ }^{\mathrm{r}} / 2$, dominando éste (fig. $61 .^{\mathrm{a}}$ ).

La del rombeedro principal, $r$, como dominante, con el primer obtuso y el primer agudo (fig. $62 .^{a}$ ).

La del romboedro primitivo, con el segundo romboedro agudo, dominando éste (fig. $63 .^{\mathrm{a}}$ ).

La del prisma de seis caras, ./, con un romboedro de segunda clase, ${ }^{\mathrm{r}} / 2$ (fig. $\left.64 .^{\mathrm{a}}\right)$.

La del romboedro principal, $r$, con el segindo prisma de seis caras, $a$ (fig. $65 .^{\mathrm{a}}$ ).

La del prisma de seis caras, $g$, con la cara terminal $C$ (fig. $66 .^{a}$ ).

Por último, la del escalenoedro. ${ }^{31} / 2$, con el romboedro principal, $v$ (fig. $\left.67 .^{\mathrm{a}}\right)$.

\section{Guarto sistema cristalino. \\ Rómbico ó prismático rectangular recto.}

40. En las formas de este sistema hay tres ejes rectangulares, desiguales y de especies diferentes; por lo mismo, la afección del eje principal es arbitraria, las relaciones de los ejes son también indiferentes. 
Las formas simples de este sistema, son: Pirrimides rombrtes ú octaedros de base rombal (fig. 68. ${ }^{2}$ ). Las caras son triángulos escalenos: aristas de tres especies: cuatro terminales, $D$, que reunen las extremidades del eje principal á las del primer eje secundario; otras cratro tanibién terminales, $F$, que juntan las extremidades del eje principal con las del segundo secundario, y cuatro laterales, $G$, que reunen entre sí las extremidades de los ejes secundarios. Lios ángulos sólidos son de tres especies: dos terminales, $C$, colocados á las extremidades del eje principal; dos laterales, $A$, á las del primer eje secundario, y los otros dos, $B$, á las del segundo eje secundario. Las secciones por las aristas terminales, dan rombos (figs. $\left(99 .^{a}\right.$ y $700^{a}$ ) y la de las aristas laterales dan la base de la fig. 71.". La relación de los ejes en cada ma de las substancias cristalizables en octaedros de base romba, es simple. Tas formas compuestas de este sistema, son numerosas.

1." Combinación del octaedro principal, o, con el obtuso "/3, la cara terminal $c$ y el segundo prisma horizontal f del octaedro principal (fig. 72.a).

2. Del octaedro principal, o, con dos prismas rerticales, if $y^{9} / 3$ (fig. $\left.73 .^{a}\right)$.

$3 .^{a}$ Del mismo, con el prisma horizontal $d y$ el rertical ${ }^{9} / 2\left(\right.$ fig. $\left.74 .{ }^{8}\right)$.

4. Del prisma rertical g, de la forma primitira, con dos horizontales, $f^{\prime} y^{2} / \mathrm{f}\left(\mathrm{fig} .75 .^{\mathrm{a}}\right)$.

5. De dos prismas horizontales, $f \mathrm{y} d / 2$ con la cara terminal o (fig. $\left.76 .^{\mathrm{a}}\right)$.

6. Ta misma combinación, dominando la cara terminal (fig. 77.").

7. ${ }^{\text {a }}$ La del primer prisma vertical de la forma primitiva y, con la cara terminal recta $C$, dominando ésta (fig. 78. ${ }^{a}$ ).

$8 .^{a}$ Del prisma radical \%, de la forma primitiva, con el primer prisma horizontal $/ 2$ y la carta $C$ (fig. 79.a).

9. Ta del octaedro principal, o, con dos caras laterales dominantes, " y l) (fig. $\left.800^{a}\right)$.

\section{Quinto sistema cristalino.}

Prișmático rectangular oblicuo, y también clinorombal ó semiprismático.

41. Caracterizado por tres ejes desemejantes, dos oblicuos, wno sobre otro, y el tercero en ángulo recto sobre los otros dos, no hay relación en el tamaño de los ejes, y es indiferente el principal. 
La figura más sencilla de este sistema representa un octaedro de ejes oblicnos, y las caras, que son triángulos escalenos, son también de dos especies: las aristas de cuatro especies; cuatro terminales, que reunen los ejes y tienen las opuestas iguales entre sí, por la oblicuidad de los ejes; otras cuatro también terminales, que reunen los ejes y son perpendiculares, y cuatro laterales que juntan los ejes perpendiculares y son iguales entre sí (fig. $\left.810^{a}\right)$. La sección hecha en las aristas $D, D^{\prime}$, da un paralelogramo, y se llama sección principal (fig. 82. ${ }^{\mathrm{a}}$ ); la de las aristas laterales da un rombo (fig. 83. ${ }^{\mathrm{a}}$ ).

El octaedro de este sistema no tiene todas las caras semejantes, y, por lo mismo, no es realmente una forma simple. Puede considerarse como una combinación de dos prismas oblicuos, uno formado por las caras $B, A, C ; C, A, B^{\prime} ; B, A^{\prime}, C^{\prime}, \mathrm{y} C^{\prime}, A^{\prime}, B^{\prime} ; \mathrm{y}$ el otro por las caras $B, C, A^{\prime} ; O, A^{\prime}, B^{\prime} ; B, A, C^{\prime}$, y $C, A^{\prime}, B^{\prime}$ (fig. 81." ); uno será el anterior del octaedro y otro el posterior: esta distinción es importante, porque sucede con frecuencia que en las formas compuestas de este sistema, los octaedros siempre presentan uno de sus prismas oblicuos, ó uno es dominante.

Las formas compuestas, son: $1{ }^{a}{ }^{\mathrm{T}} \mathrm{Ta}$ combinación del octaed ro primitivo $o, o^{\prime}$, con el prisma vertical principal $g$ (fig. $\left.84 .{ }^{a}\right)$.

2." La misma $o$, $o$, con el prisma principal $g, y$ las caras terminales b, paralelas á los ejes (fig. 85.").

3. La del prisma oblicuo anterior o, o, del octaedro principal, $y$ el prisma vertical $y, y$ la cara terminal $b$ (fig. $86 .^{a}$ ).

4. ${ }^{a}$ La del prisma oblieuo posterior o, del octaedro principal; el prisma vertical $g$, y tres sistemas de caras terminales (fig. $87^{a}$ ).

\section{Sexto sistema cristalino \\ o prisma oblicuo no simétrico clinoromboidal.}

12. Caracterizado por tres ejes desemejantes oblicnos, sin relaciones constantes en su longitud: la elección del eje principal es indiferente. La desigualdad y oblicuidad de los ejes hace que las formas de este sistema no presenten sus caras simétricas, sino solamente pares de caras que, siendo paralelas, son semejantes.

El octaedro de este sistema, representado en la fig. $88 .^{a}$, es la for- 
ma más sencilla. Presenta cuatro especies de caras: las aristas son de seis especies: la terminal $D$ es diferente de la posterior $D^{\prime}$; la terminal $F$ lo es de $F^{\prime \prime}$, y la lateral $G$ de $G^{\prime}$; los ángulos son de tres especies, formados por aristas desiguales. Las secciones hechas en las aristas terminales y laterales, dan paralelogramos. La fig: 89. . $^{2}$ epresenta la combinación del octaedro principal o y el prisma vertical $g$; la cara terminal , es paralela á los ejes.

Los cristales de este sistema son, por lo común, complicados y muy difíciles de ser definidos de una manera completa, porque los octaedros y los prismas sólo presentan pares de caras. Sin embargo, pueden distinguirse por la falta de simetría, la de truncamientos apuntamientos de caras homogéneas y de caras que se eorten en an gulos rectos. El sexto sistema cristalino contiene unenos sultancins cristalizadas que los cinco primeros, y ear falta de mejor medio para distinguirlo.

En los seis sistemas señalados, apenas se han podido hacer algunas indicaciones muy precisas para llegar á determinar las formas cristalinas. Cada sistema necesita indicarse con algún detenimiento, examinar las fórmulas correspondientes y las combinaciones que pueden presentar; mas como esto corresponde á los tratados de cristalografía, quedará satisfecho el objeto que nos propusimos, terminando esta parte con una indicación de los principales medios nsados para conocer las formas.

43. El examen atento de un cristal y de la simetría en sus modificaciones, basta comúnmente para reconocer el sistema cristalino á que pertenece, si corresponde al regular, y si no se quiere más que indicar las formas simples que entran en su constitución; pero no sucede lo mismo en cuanto á los otros sistemas. No basta indicar entonces las formas simples; es necesario apreciar exactanente los valores de los ángulos que forman entre sí los"ejes, cuando no son rectangulares, y el tamaño correspondiente á cada una de las formas simples que componen el cristal.

Los ángulos de los ejes y las relaciones de tamaño, no pueden medirse sobre el cristal; el único elemento que se presta ál la medida directa es la inclinación de las caras unas sobre otras; pero es evidente que los ángulos de los ejes y su tamaño respectiro, están en relación geométrica inmediata con la inclinación de las caras, ? 
por lo mismo, conociendo esta inclinación, se pueden determinar los ángulos y el tamaño de los ejes, porque no se trata más que de resolver un simple problema de geometría; esto sucede á lo menos en cuanto á los sisteinas rectangulares; pero los cálculos son más complicados tratándose de les sistemas oblicuos; no obstante, los ejemplos numéricos que se encuentran en los tratados de cristalografía, facilitan las operaciones.

Siempre que se quiera definir un cristal, debe medirse el mayor número de sus ángulos; pero hay casos en los cuales basta conocer los valores de sólo algunos, como cuando el cristal pertenece á uno de los sistemas cristalinos simples, ó cuando hay ángulos cuya determinación no es necesaria, por ser conocidas las relaciones geométricas, la dirección de los ejes, etc. Sin embargo, Regnault advierte, que el químico que pretende definir nu cristal con exactitud, debe medir todos los ángulos diedros, con el mayor cuidado, inscribir sus valores y expresar todo de una manera rigntrosa. Con estos datos podrá despnés determinar los elementos del cristal, es decir, la inclinación de los ejes y sus relaciones de longitud.

La operación más importante á este fin, consiste en medir la inclinación de las caras unas sobre otras. Para esto se usa de instrumentos adecuados, que se llaman goniómetros. Dos clases fundamentales son las más nsadas: los goniómetros de aplicación y los de reflexión.

44. Entre los primeros, el más común es el conocido por de Haür'z y que se ve en la figura 90.a: está compnesto de un semicírculo, con dos alidadas, una fija, $a, b, y$ otra movible, $d, f$, la que señala en el limbo el ángulo del cristal. Para medir un ángulo diedro, se aplica una de sus caras sobre la alidada fija, en su prolongación, de manera que la arista del ángulo sea perpendicnlar al plano del limbo: después se hace girar la alidada móvil, hasta que su prolongación descanse sobre la otra cara delángulo: entonces, el ángulo comprendido entre las alidadas mide el que se busca. El mecanismo de las correderas $, \eta, h, h, \mathrm{y} l, m$, permite cortar ó alargar las alidadas. Este goniómetro sólo da valores aproximados, $y$ es de difícil aplicación para los cristales artificiales, que por lo común no tienen resistencia, y se rayan y aun destruyen á la menor presión.

45. Los goniómetros por reftexión dan resultados mucho más exactos: bien que sólo son aplicables á los cristales de algún lustre, 
ó de lo contrario, usando de medios especiales, como las láminas de mica. La construcción de estos instrumentos está sujeta á varias modificaciones, que los hace más ó menos cómodos, más ó menos exactos; pero esas modificaciones no influyen en los fundamentos. Estos consisten en ver por reflexión, en una de las caras del cristal, la imagen de algún objeto, después de haber fijado el círculo convenientemente; en volver el eje junto con el círculo, hasta que aparece la imagen en el lugar correspondiente, y en leer en el círculo y en el nónius el suplemento del ángulo que se busca.

Tres son los goniómetros más generalizados hasta hoy: el de Walloston (fig. 91."), el de Charles (fig. 93.") y el de Babinet (fig. $\left.94 .^{\mathrm{a}}\right)$.

En el primero se ve un círculo vertical graduado en $L, L^{\prime}$, y armado en un eje horizontal $c$, $a$ : el círculo mayor se hace girar por medio del uediano $v$; el nónius $u$ queda constantemente fijo; el eje , $c$, se hace girar noviendo el pequeño círculo $s$; ma pieza articulada $c, g, c^{\prime}, b$, es la que recibe el cristal en $\approx$, la que puede morerse en varios sentidos para dar al cristal la debida colocación respecto á $a, c$, sirviéndose de un pedazo de cera.

Las partes móviles $b, c^{\prime}, \eta, c$, aproximan ó alejan el cristal al limbo, pndiendo darle diversas inclinaciones, hasta colocar la arista en dirección rigurosamente paralela al eje de rotación del limbo.

Colocado después el instrumento sobre mu mesa y al fiente de un edificio que presente líneas horizontales notables, para tomar dos por miras, como la superior del mismo edificio y una cornisa inferior, ventana, etc., se mueven los tornillos $X, X, X$, para dar al instrumento la debida posición por medio de un nivel de burbuja de aire. Hecho esto, se procura que la arista del ángulo que se quiere medir, sea perpendicular al plano del limbo: el ojo debe percibir la línea inferior en la dirección del cristal; girando el eje $\iota, c$, y conservando el otro fijo, debe aparecer la mira superior reflejada sobre una de las caras del cristal y rignrosamente paralela al inferior, vista directamente. Cuando se ha llenado esta condición, el ángulo será perpendicular al plano del limbo, y la arista lo será si la segunda cara satisface la condición de la primera.

Para medir el ángulo, sólo hay que colocar el limbo en el cero del nónius, por medio del círculo v: volver, por medio del botón $s$, el cristal á la posición en la que el ojo percibe la imagen reflejada 
IAMINA 4.

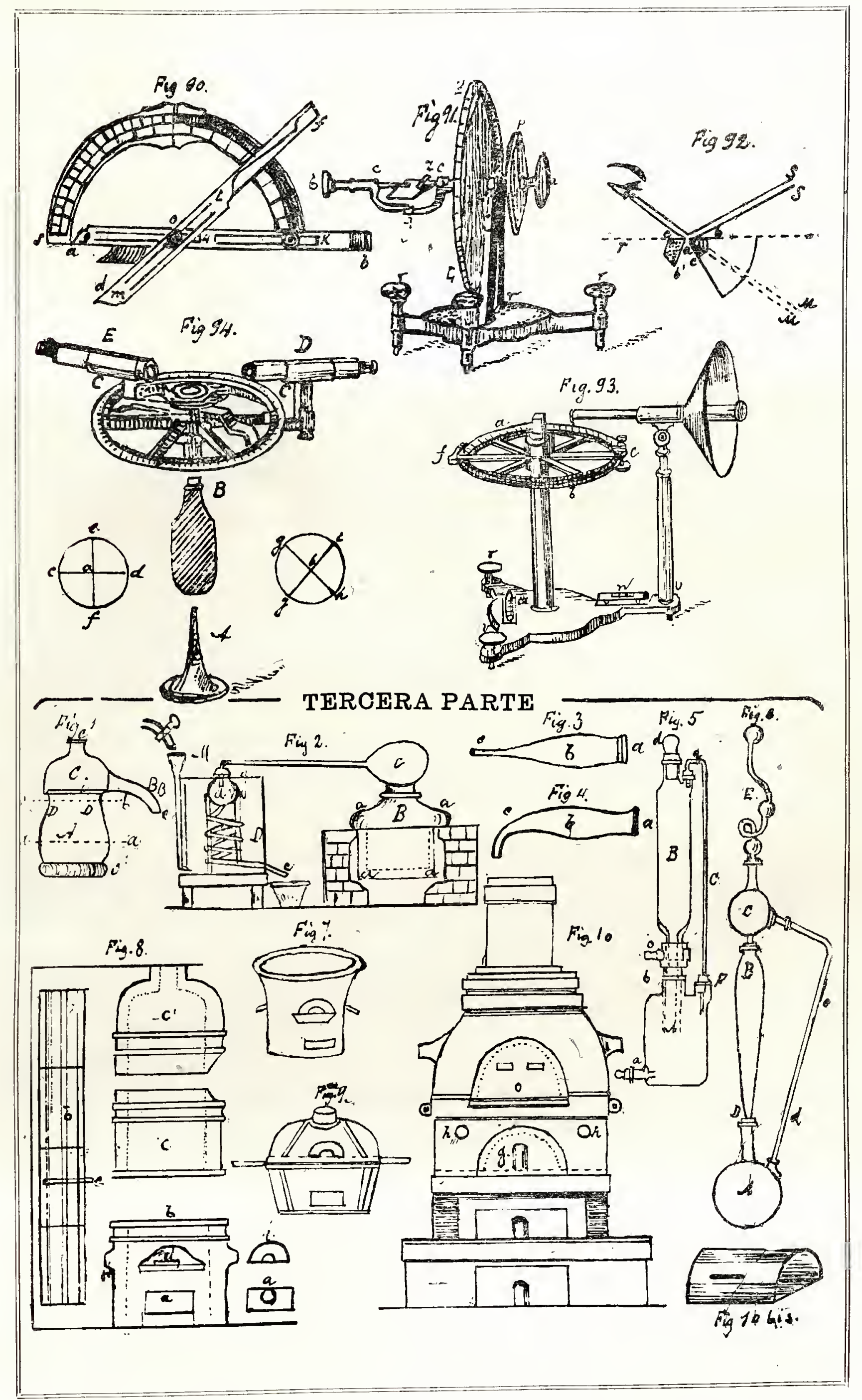



sobre una de las caras del cristal sobrepuesta á la mira directa: después hacer girar, por medio del círculo $v$, el limbo que lleva necesariamente en su movimiento el cristal, hasta que el ojo percibe rigurosamente, en la misma posición, la mira superior reflejada sobre la segunda cara del cristal y en coincidencia con la mira inferior.

El ángulo queda medido por la indicación del nónius, que da el suplemento del ángulo del cristal, como lo demnestra la fig. 92."

46. El goniómetro de Charles se compone de un limbo móvil a, $b$, alderredor de un eje, en un pie y con tornillos $V, V, V$, como aparece en la fig. $93 .{ }^{\text {a }}$; de una alidada $e, f$, igualmente móvil al derredor del mismo eje, en la que hay una cubierta de cera para colocar el cristal; de un anteojo $d$, con un hilo vertical; $y$ de dos niveles, $N$ y $N^{\prime}$.

Arreglado el anteojo debidamente, se hace coincidir el hilo con la esquina de un edificio que sirve de mira: se coloca el cristal con la arista principal y se nota la reflexión sobre una de las caras del ángulo diedro, de manera que la mira quede cubierta por el hilo del anteojo: la misma operación se practica respecto de la segunda cara, y así se consigue, con algunos tanteos, dar la debida posición al cristal. Para obtener el ángulo, se lee el que forma la alidada con el cero, en el momento en que coincide el hilo con el objeto reflejado por una de las caras: se hace girar despnés la alidada sola, hasta hallar la coincidencia en la segunda cara, y el ángulo que resulta formado por el movimiento de la alidada, será el suplemento del ángulo que se busca.

47. El goniómetro de Babinet (fig. 94. ${ }^{\text {}}$ ), se compone de un sustentáculo ó pie de latón $A$, que recibe el mango de madera $B$, en el que está fijo el instrumento, cuyo círculo graduado es $C, C$ : dos anteojos, $D, E$, el primero fijo y el segundo móvil, sirven de miras, por medio de los hilos representados separadamente en $a, b$ : hay, además, el nónins $f$ y la plataforma $F$, como la del goniómetro de Charles.

Para medir un ángulo, se comienza por arreglar los anteojos, haciendo que los hilos se vean claramente, para lo cual se aproxima ó aleja el lente ocular: después se hace lo mismo con el tubo que lleva los hilos, teniendo esto por objeto percibir con toda claridad los cuerpos colocados á distancia: un movimiento de rotación al tubo, basta para dar á los hilos la posición representada en $a$, $l$ : dispuestos así los anteojos, se colocan en su lugar; el punto de cruzamiento de los 
liilos $g, h, i, j$, se encontrará en la intersección a de los hilos $c, d, e$, $f:$ si éstos no se ren con toda claridad, bastará graduar convenientemente el lente ocular del anteojo móvil.

En el caso de no haber superposición de los hilos, se procurará, subiendo ó bajando el tornillo r, cuanto fuere necesario. Hecho esto, se fija el cristal en el platillo $F$; por medio de mna poca de cera, se da al anteojo $E$ un movimiento á la izquierda ýa la derecha, moviendo el portacristal cuanto fuere necesario para percibir los hilos del anteojo fijo $D$, al dirigir la vista por el anteojo $E$ : si el entrecruzanniento $b$ no coincidiere con la línea $c$, $d$, se lerantará ó bajará el cristal lo conveniente para que su cara quede bien colocada: lo mismo se hará para arreglar la segunda cara.

Dispuesto así el goniómetro, se procede á medir el ángulo, para lo cual se coloca el nónius á cero, se hace girar el platillo solo, hasta rer en el cristal coincidir la intersección de los hilos; se mueve entonces el nónius, cuyo movimiento sigue el cristal, y fijándolo, luego que vuelve á aparecer la coincidencia de los hilos, se ve, indicado por el nónius, el suplemento del ángulo que se busca.

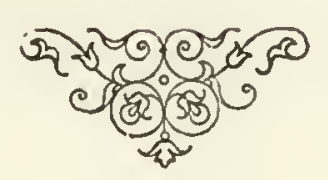


INSTRUMENTOS, UTENSILIOS Y APARATOS.

Comúnmente se confunden estas voces, así como las de herramienta y máquina, y sin embargo, debe darse á cada una su aplicación conveniente Una cápsula, una retorta, una alargadera, una campana, etc., son utensilios y no instrumentos, aparatos ni máquinas; la misma retorta con alargadera y un recipiente, componen un aparato destilatorio y no una máquina, instrumento, herramienta ni utensilio: las limas, perforadores para tapones, tijeras, etc., son instrumentos, aunque también estén comprendidos bajo la denominación genérica de utensilios de laboratorio. Un elemento de Bunsen es un aparato galvánico, y á la reunión de varios elementos se llama igualmente aparato galránico; se da con más propiedad el nombre de máquina galvánica á los aparatos arreglados con algún mecanismo, para facilitar su uso, como sucede con la de Wollaston, máquina eléctrica, pnemmática, etc., y en ningún caso, instrumento, utensilio ni herramienta; pero sí está admitida, annque no con la misma generalidad, la voz aparato; así se dice aparato eléctrico, pneumático, etc. Basta lo dicho para formarse una idea de la aplicación que debe hacerse de cada una de esas voces.

Annque en el curso de las lecciones se verán los utensilios, instruunentos y aparatos de que se hace uso en los laboratorios, es conreniente dar desde ahora la descripción de algunos, á fin de conocer los nombres, $y$ con especialidad las partes de que están formados, ó aquéllas en que se consideran divididos.

Agitadores. (De agitatio ).- - Varillas de vidrio de diferentes gruesos y tamaños, empleadas para mover los líquidos, $y$ facilitar la mezcla ó 
la combinación de los cuerpos. En algunos casos se liace uso de las espátulas.

Alambique.-De la partícula árabe al y la equivalente ál mormita, resultando la frase vasija suprema ó excelente. Es un aparato destilatorio más ó menos complicado, según los usos á que se destina. Los hay de vidrio, de cobre, de loja de lata y de platina. Los primeros conservan la forma defectuosa que tenían los alanbiques antiguos, y, por lo mismo, lau caído en desuso, sustituyendo á éstos las retortas, cuando el líquido que se quiere destilar exige, pol’ su naturaleza, rasijas de vidrio.

El alambique de ridrio consta de dos piezas: la inferior, $c, b$, fig. 1.., llamada cucúrbita, y la superior $C$, copitel, á la que también llamaron los antignos, montera ó culva. Fin la cucírbita se consideran tres partes: el fondo ó cípsula, que comprende hasta la línea $"$, a; el cuerpo, que es la comprendida entre esta linca y la 7$)$, I), que es lo que se llama boca. En el capitel hay, igualmente, otrals tres partes: la bóveda $C$, el concel ó regmere, figurada al interior en $i$, y la nuriz ó prico B. Tos alambiques de vidrio son, por lo común, de mua sola pieza, en cnyo caso tienen una tubuladora en e, por donde se riente el líquido que se quiere destilar. Ta destilación en estos alambiques se hace, comúnmente, en baño de arena.

Los alambiques de hoja de lata son usados rala rez, pol sil poca duración, y los de platina, lo son por su valor subido; pero nuy usados en las fábricas de ácido sulfúrico.

Tos de cobre son los más útiles, y. por lo mismo, los que se entplean generahnente. Varían mucho en el tamaño, forma y en las partes de que se componen; mas para los trabajos de laboratorio, as bastante el que representa la fig. 2." Fstá compuesto de cuatio piezas principales: La cultera $\|$,, ,, ,, ; el baño ó cucúrbita $B$; el carpitel $C, y$ el refrigerante $M$. Cuando se pretende destilar á finego desmudo, se coloca en la caldera el capitel, que commuica con el selpentín, quedando, por lo mismo, sin uso el baño ó cucúrbita $B$; nas cuando la destilación se ha de hacer á baño de muria, éste entra ell ", ",

El refrigerante $M$ se compone de la cuba $D$ y del serpentín ó culebra $E$; éste recibe en su parte superior la extremidad g del capitel, y termina en el tubo $C$, al que se llama nariz, que en algunos casos termina con ma llave. Varios refrigerantes tienen en la parte 
superior del serpentín, la caja $d$, que atendiendo algunos á la forma, la llaman lentejuela, cuyo objeto es facilitar la condensación de los vapores. El embudo de rama larga é, lleva el agua fría al fondo de la cuba, y el líquido derramado por el pico $i$, á proporción que se calienta. Algunos alambiques tienen, además, un tubo que comunica con la caldera y el interior del baño ó cucúrbita, el cual sirve para las destilaciones al vapor. En otros se satisface este objeto por medio de diafragmas perforados, que descansan en el interior del baño y á alguna distancia de su fondo, para colocar en ellos las substancias sobre las cuales ha de llevar su acción, sea el agua ó el vapor.

Alrurgaderus. - Las formas comúnmente usadas, se ren representadas en las figs. 3 y 4; están dispuestas de manera que, recibiendo por una parte la extremidad de una vasija destilatoria, queda la opuesta en comunicación con el recipiente y, por lo mismo, distante éste del fuego. Generalmente son de vidrio, y las hay rectas y curvas.

La parte $a$, se llama boca; la $b$, vientre, y la $c$, pico. Un simple tubo sirve en muchros casos de alargadera y aun á la veź de refirigerante, si es prolongado: en la industria se hace igualmente uso, para el mismo fin, de canales de barro.

Almirez.-Utensilio semejante á los morteros, pero precisamente de metal y no de vidrio, porcelana ó piedra, como los morteros. (Véase esta palabra).

Alzadores.-Discos de madera de diez á quince centímetros de diámetro y de varios gruesos, destinados á sostener las vasijas y piezas de los aparatos á la altura conveniente. También se emplean, con el mismo fin, banquillos y plintos de madera, cuyas formas y tamaños varían mucho, y en fin, los ladrillos comunes y los sustentáculos de aro, de pinzas, etc.

Aparatos de desalojamiento.-Son tan multiplicadas las formas $y$ tamaños de estos aparatos, que sería muy largo describir todos y tantos cuantos nos presenta el comercio: baste decir, que los usados en la economía doméstica para preparar el café por lejivación, son aparatos de desalojamiento.

El más usado en los laboratorios, es el de Robiguet, modificado, y que representa la fig. 5. ${ }^{\text {a }}$ Se compone del frasco $A$, de la garrafa $B$ y del tubo $C$ : el primero tiene una llave en $A$, que sirve para sacar el líquido, sin tener que desmontar el aparato: la boca $b$, recibe la vasija superior, y la $b$, la extremidad recta del tubo $C:$ recurro 
en $e$, para comunicar con la garrafa por la boca lateral; la del centro queda cerrada por el tapón $d$, y tiene, además, la llave c, que se abre ó cierra, según conviene.

El digestor de Mr. Payen, puede considerarse como mat combinación del aparato de desalojamiento r del digestor ó maruntu de Papiro: tiene la ventaja de poder servir á temperaturas superiores á la ordinaria. Se compone (fig. $6 .^{\text {al) }}$ ) de un baño de lliaría, común; de un matraz de dos bocas $A$, y uno de tres, $C$; de mlla gatrafia $B$ ? de un tubo de seguridad $E$ : en el baño de maría se pone, además, un termómetro; en la garrafa se coloca la substancia, sobre la pre lleva su acción el vapor conducido por el tubo $c, d$.

Balón.-Voz usada indebidamente, en lugar de matray y de recipiente. (Véanse estas palabras).

Bainquillos. (Véase alaudores).

Barreños, de la voz brrro.-En Méxiço se usa con más generalidad la palabra cajete. Tos hay de diversas formas y tamaños, según los usos á que se destinan en los laboratorios: lo importante es no confundirlos con los lebrillos, de los cuales se disting'nen pol estan éstos vidriados, ni menos usar de las roces francesas tet ni terrine, hatbiendo las castizas, cajete, barreño y lebrillo.

Braseros.-Generahmente se da este nombre en química, á las loolnillas fijas construidas en el laboratorio con varios hogares, destinados al uso común; nas los braseros manuales que no tienen chincnea, se llaman, con más propiedad, hornillas portátiles; los que las tienen, y están construidos de manera que farorecen la reverberatción, se llaman hornos, distinguiéndosé éstos, según los usos á que se destinan. Las fraguas y las forjas se diferencian de las hornillas y de los hornos, tan to por la forma, como porque unas yotras son alimentadas por el viento de in fuelle: si éste es de tamaño proporcionado para trabajar el fierro, se llaman, con más propiedad, fraguas: si es ménor, ó si se tiene por objeto trabajar el oro ó la plata, se llanman forjas. No obstante esto, son de uso común las fraguas portátiles, algunas de las cuales no son mayores que una forja. Tas lámparas y los sopletes difieren mucho de estos aparatos de combustión.

Fn todo horno hay que considerar cuatro partes; la fig. S." lepresenta un horno de reverbero, en el que se ra el cenicero a, el hogar $b$, el cuerpo del horno $c$, la bóveda $c_{r}^{\prime}$, y la chimenea $d$ : ésta llera algunas ocasiones el registro é, para arreglar el tiro; es decir, para 
IAMINA 5.

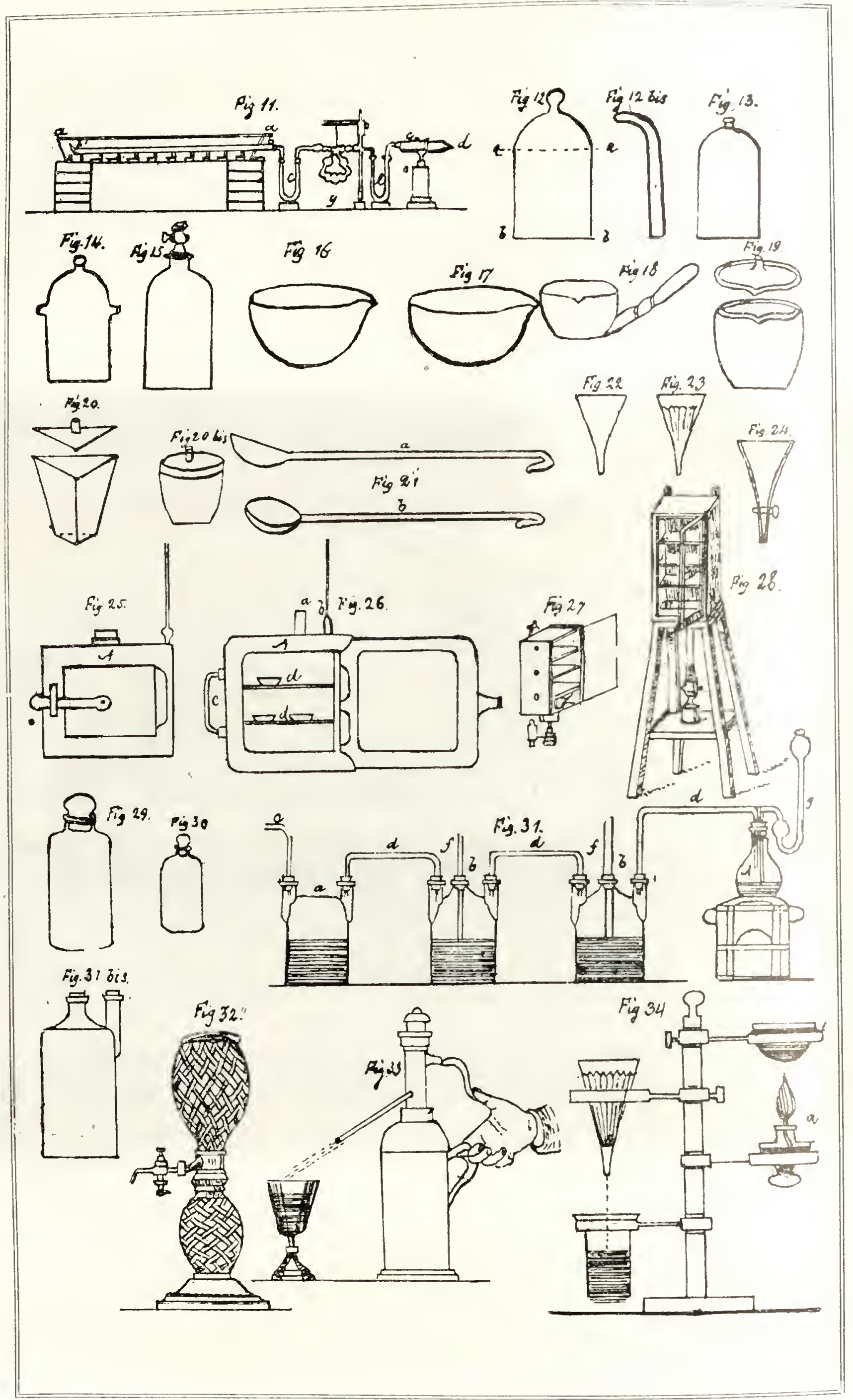


aumentar, disminuir ó proporcionar la combustión: el cenicero está separado del hogar por medio de la parrilla. La parte exterior $a$, que da entrada al aire, se llama boca del cenicero, y la $i$, puerta ó boca del hogar.

En una hornilla común (fig. 7. ${ }^{a}$ ), se consideran las mismas partes, pero funcionando en ellas, como chimenea, las muescas colocadas en la parte superior ó labio de la hornilla, que dan paso á los productos de la combustión. La fig. $9 .^{\mathrm{a}}$ representa un horno de tubos, el cual funciona como los de reverbero.

En el horno de copelación (fig. 9. ${ }^{\mathrm{a}}$ ), hay que considerar, además de las partes correspondientes al lorno de reverbero, los ventiladores $h, h$, la mufla colocada én $g$, figurada con puntos, y la puerta de carga o, que sirve para poner el combustible. La fig. 11. ${ }^{\text {a }}$ representa el horno ú hornilla de Liebig para análisis orgánicas.

Campenas. - Vasijas de forma variada, siendo la más común en los laboratorios, algo semejante á un frasco sin fondo: sirven para recibir los gases, trasvasarlos, medirlos, mezclarlos ó conservarlos. Las campanas se distinguen por su naturaleza ó materia de que están formadas, por su tamaño, figura y número de bocas ó tubuladuras. Con relación á la materia, lo común es que sean de vidrio óde cristal, mas también las hay de fierro, de cobre y de hoja de lata: las de fiẹr'o son muy usadas en las fábricas del gas de alumbrado, y casi todos los gasómetros las tienen de fierro ó de hoja de lata. El tamaño varía mucho con relación á los usos á que se destinan: unas son tan pequeñas como las de los roltámetros; medianas, comolas que sirren para la cuba de Liebig, y tan grandes, que pueden contener dos mil y inás pies cúbicos de gas. En cuanto á la figura, las hay rectas (fig. 12. ${ }^{\mathrm{a}}$ ) y curvas (fig. 12. ${ }^{\mathrm{a}}$ bis): unas $\mathrm{y}_{\mathrm{s}}$ otras se distinguen on commes y graduadas: las comines son de botón (figs: $12 .^{a}$ y $14 .^{a}$ ), abiertas ó tubuladas (fig. 13. ${ }^{\mathrm{a}}$ ), de dos tubuladuras (fig. 14 ${ }^{\mathrm{a}}$ ), y de llave (fig. 15. $\left.{ }^{a}\right)$. En toda campana se coinsideran tres partes: la bóveda $a$, $a$ (fig. 12. ${ }^{a}$ ); el cnerpo, que es la parte comprendida de $a, a \dot{a} b, b$, que es la boca, formada por el labio ó borde de su parte inferior.

Cápsula.-Especie de cazuéla, de dimensiones muy variadas, cuya forma, generalmente se aproxima más ó menos á la de una semiesfera hueca. Las cápsulás más usadas en los laboratorios, son de porcelana ligiocerama; pero las liay de vidrio, de fierro, cobre, plata y platino. Las commes son simplemente segmentos de esfera con 
ó sin pico, sirviendo éste para verter cómodamente los líquidos (fig. 16." ; en unas el fondo es plano (fig. 17.a), en las más es convexo: las hay sin unango y con él (fig. 18.); por último, las más completas tienen tapa.

Cajetes.-Equivalente á la voz francesa tet y test. (Véase barreños).

Copelus. Diminutivo de copa.-Pequeñas vasijas á manera de cápsulas $y$ hechas con polvo de huesos calcinados, pero que difieren de las cápsulas por el mayor grueso de sus paredes, y por ser únicancute destinadas á los ensayes por copelación.

Cornamusa.-Palabra originalmente de la baja latinidad, procedente de las clásicas Cornn y Musu, aplicadá la trompa musical y también á la gaita, á que se asemeja la retorta de los químicos, llamada antiguamente cornamusa. (Véase Rotorta).

Crisoles.-De cruciare, atormentar, y según otros, de que originalmente se pintaba á los crisoles una cruz, antes de servirse de ellos. Vasija cilíndrica, cónica ó triangular, de varias dimensiones, que sirve para someter diversos cuerpos á la acción de un fuego más ó menos activo (figs. 19." y 20."). Comúmmente son de barro refiactario; pero en los laboratorios los hay también de porcelana, de fierro, de plombagina, de cobre, de plata, de oro y de platina (fig. 20. ${ }^{\text {a }}$ bis); tienen ó no pico y tapa, y los hay con fondo plano y convexo; aum los de fondo plano tienen el interior cóncavo.

Cuchares.-De una roz griega que equivale á concha, por servirse primitiramente de las conchas como cucharas. En los laboratorios se hace uso de pequeñas cucharas para colocar los cuerpos en los platillos de las balanzas, para recoger los precipitados de los filtros de lienzo y para los trabajos al soplete; pero las que más se emplean, son las de fierro, que llevan el nombre de cucharas de moyección (fig. 21." (1, b). Están formadas de una cápsula, á la que se une um mango del mismo metal. Las hay de diferentes tamaños y más ó menos cóncavas.

Digestor.-De digerere, digerir, cocer. La construcción de estos aparatos está fundada en los principios que sirvieron de guía á Mr. Papin para construir la marmita, que lleva su nombre. Este digestor y el de Mr. Payen, son los más usados en los laboratorios. (Véase aparatos de desalojamiento).

Embudos.-Vasijas, por lo común de vidrio, cuya forma es la de 
un cono, con el vértice prolongado por un tubo que recibe el nombre de rama del embudo, así como la parte cónica se llama cuerpo. En los laboratorios los hay de varios tamaños $\mathrm{y}$ se distinguen en lisos (fig. 22. ${ }^{a}$ ) y con boceles, á los que vulgarmente se llaman acanalados (fig. 23. ${ }^{\mathrm{a}}$ ); éstos sirven especialmente para las filtraciones; los de rama corta, para trasvasar los gases, y los comunes para pasar líquidos de una rasija á otra. Los hay igualmente de cristal, con llave (fig. 24. ${ }^{a}$ ), y se usan, ya en substitución de los separatorios, de los portafiltros ó de los aparatos de desalojamiento.

Eolípilas. - Voz equivalente á portctviento. Lámparas de construcción especial, que producen un fuego activo por la combustión del vapor alcohólico, comprimido y calentado por sí mismo.

Escusit-mozos.-(Véase portafiltros).

Espátulas.-Dellatín, spattula. Pequeñas palas de naturaleza diferente, que sirven para remover los líquidos, como los agitadores, ó para desprender las materias adheridas á los filtros ó á las vasijas. Las hay de vidrio, de hueso, de cuerno y metálico; éstas tienen, por lo común, un mango de madera, y las de fierro, llamadas elásticas, presentan la forma de un cuchillo sin punta y con doble filo.

Estufa.-Del latín stuffa. Se da este nombre á todo espacio limitado, cuya temperatura es superior á la atmosférica, pudiendo mantenerse más ó menos elevada, por diversos medios caloríficos. Se usan comúnmente para desecar los cnerpos sin alterar sn naturaleza.

La industria se sirve, por lo común, de piezas ó aposentos de más ó menos amplitud; pero en los laboratorios se da la preferencia á la de Gay Loussac, representada en las figuras $25 .^{\mathrm{a}}$ y $26 .^{\mathrm{a}}$ Se compone de una caja doble, $A$, cuya cavidad se llena, sea de agua ó de aceite, por el tubo a: en la tubuladara $b$, se coloca un termómetro, que da á conocer la temperatura interior: el tubo de vidrio $c$, indica el nivel del líquido: en el interior de la caja se ven dos entrepaños metálicos, $d$, $d$, que sirven para colocar las substancias que se pretenden desecar.

M. Liebig hace uso de otros dos aparatos: uno, en el cual queda sometido el cuerpo á la doble influencia del calórico y del aire seco, y otro, á la del mismo agente y del vacío, empleando, para formarlo, la bomba que lleva su nombre.

Hay otras diversas estufas, cuya fuente calórica es un quinqué. La de Mr. D'Arect, es una especie de armario de mucha mayor capa- 
cidad que las anteriores (tig. 27." $)$; mas entre las do este género, ofrece ventajas la representada en la fig. 28."

Resulta de lo dicho, que si se atiene á los medios empleados para calentar las estufas, pueden dividirse en las siguientes: De baño de maría, de aceite, de vapor y de aire caliente.

forjocs.-(Vóase braseros).

Hrogurs.-(Véase braseros).

Hroscos. - Vasijas comúnmente cilindricas, de cristal ó de vidrio y de capacidad variable, muy usadas en los labolatorios para contener o para preparar diversos productos. Los hay comunes y esmerilados: óstos tienen sus tapones de la misma materia, y adoptados pol nedio del esmeril; los primeros no tionen tapón propio; unos y otros se distinguen por el diámetro relativo de las bocas ó tubuladuras: así se dice: frascos de boca ancha (fig. 29." ), frascos de boca estrecha (fig. 30." ); tambión se distinguen por el número de tubuladuras, diciendo: de una (fig. 30."), de dos (figs. 31." " y 31." bis), y de tres bocas b, b (fig. 31." $)$. Por último, los hay perforados en el fondo, oon ó sin llave (fig. 5.").

Algnuros pretenden distinguir con el nombre de pomos, los frascos de boca ancha; mas este uso no se ha generalizado: otros han introducido la roz francesa, bocal, chya significación en español (jarro para vino) dista mucho de la idea que se quiere dar, refiriéndose á los frascos de boca rncha, cuya denominación parece ser la que ofrece menos inconrenientes.

Las materias de que están formados los fiascos, sirven para distinguirlos: así se dice: de vidrio, de cristal, de fierro, de cobre, de porcelana y aun de barro, aunque óstos se llaman, con más propiedad; tarros y porrones, segín el tamaño.

Gusógenos.- Voz que equivale á Generudor de gus. Aparatos de construcción especial, destinados á preparar y conservar los gases, disueltos en un vehículo adecuado, para emplear el líquido según conviene. El más usado es el que representa la fig. 32." Los hay de barro, llamados vasos siphoides, cuya forma se ve en la fig. 33." Los primeros están formados del vaso que funciona como generador, y en el que se ponen las substancias productoras del gas; éste pasa á la rasija que contiene el líquido que se quiere saturar.

Generadores. - Recibe este nombre toda rasija, sea cual fuere su forma, naturaleza y tamaño, que por la reacción de las substancias 
puestas en su interior, produce uno ó varios gases. Así se llama generador de hidrógeno á un simple frasco, matraz, retorta, barril, etc., dispuestos convenientemente para desprender hidrógeno; generador de cloro, de ácido carbónico, etc., á las grandes vasijas de plomo usadas por los industriales, ó á las que se emplean en los laboratorios de química. El matraz $A$, fig. 31. ", funciona como generador.

Hydropyróforos. - Se llaman comúnmente eslabones de gas, pyróforos y lámparas hidro-pneumáticas, á unas vasijas de cristal ó de porcelana, dispuestas de manera que, dejándo escapar por una abertura capilar el hidrógeno producido en su interior, preda éste inflamarse en virtud de la acción que ejerce en contacto con el aire, sobre la esponja de platina: La palabra hydropyróforo está compuesta de tres voces griegas, que equivalen á agua, fuego y llevo, ó sea portafuego del agua, para distinguirlo de los compuestos pyrophóricos, generalmente sólidos.

Hornillas.-(Véase braseros).

Hornos.-(Véase braseros).

Laborrtorios portátiles. - A imitación del inventado por Gay Loussac, y á la lámpara de Griton, se encuentran hoy en el comercio, diversamente modificados. En esencia son unos aparatos metálicos manuales, destinados á los trabajos químicos en pequeña escala, $y$ construidos conforme á los principios que han servido para los snistentáculos. Así es que con un laboratorio portátil se tiene el sustentáculo de aros, con dișlintos diámetros; el de pinzas y el de quijada ó abrazadera. Los hay coñ qụinqué y cọn lámpara común (fig. 34." ).

Lrimparas. - Estos utensilios son de grande utilidad para los trabajos químicos, sirviendo más bien como medios caloríferos que como iluminantes. Es tal la variedad que hay hoy de lámparas, que sería dificil ocuparse de todas las que proporciona el comercio: unas se distinguen con el nombre de sus inventores, como las de Cárcel, de Berzelius, de Guiton, Dary, etc.; otras, por la materia de que están formadas: de vidrio, latón, cobre, hoja de lata, etc.; algunas, por la susbtancia que sirve para la combustión: lámpara de alcohol, lámpara de aceite; otras, en fin, por el sistema de construcción, y según que favorece más ó menos la combustión: lámpara común de alcohol, lámpara de alcoliol, de Argant ó de doble corriente, dosimática ó eolypila, pneumática, etc. Tas más usadas y necesarias en 
un laboratorio, son las comunes de alcohol (fig. 3t." a), las de este líquido y de doble corriente, las de aceite de doble corriente, la eolypila y la lámpara de esmaltador.

Lebrillos.-Utensilios de barro vidriado, de mayor diámetro en la boca que en su fondo, más anchos que altos, parecidos á los cajetes, de los cuales difieren por no ser éstos vidriados. Pueden distinguirse por la clase de barro de que están formados, y por el lugar adonde están construidos. No debe usarse la voz francesa tervine, porque no hay necesidad de castellanizarla, habiendo la palabra lebrillo, y pudiendo decir con propiedad, lebrillo firucés, común, mexicano, etc. (fig. 35. ${ }^{\mathrm{a}}$ ).

Lejiviador ó lexiviador.-(V'éase aparato de desalojamiento).

Matraz.-Vasija de ridrio comínmente de forma esférica, y tannbién semi-esférica y elipsoidal, con una prolongación tubular igualó poco mayor que su diámetro (figs. 36. " y 37."); las vasijas de la wisma forma, cuyo tubo excede del diámetro, reciben el nombre de sublimadores (fig. 35. ${ }^{a}$ ); y el de recipientes, las que sólo tienen un semi-diámetro, poco menos ó poco más (fig. 39." a, a); en los matraces llanados de ensaye, el tubo es prolongado y tienen una forma elipsoidal (fig. 40. ${ }^{\mathrm{a}}$ ). Én los matraces, en los sublimadores y en los recipientes, hay que considerar cuatro partes: el fondo, la bóveda, el cnello y la boca; el primero puede ser plano ó convexo; en este caso el fondo comprende la parte $a, b, c$, fig. $37^{a}$, y se llama cápsula; de la línea $a, e$, á la $d$, e, toma el nombre de bóveda, la que nunca falta, ni amn en los de fondo plano; la parte $d, e, f$, se llama cuello, y la abertura que se halla en la extremidad de éste, recibe el nombre de boca. Ésta puede ser simplemente cortada ó reforyada por medio de nun cinta del mismo vidrio ó rolteada; en este caso recibe el nombre de labio. Algunos recipientes de pequeño tamaño, tienen, además, tubuladura ( $A$, fig. 41. a), sin ó con un tapón ajustado al esmeril; otros llevan dos tubuladuras, resultando en este caso con tres bocas.

Fn la denominación de estas rasijas, es común oil usal de la roz francesa ballon. (Véase la lista).

Morteros.-Del latín mortarium. Utensilios de ridrio, de porcelana, de piedra ó de madera, destinados á quebrantar, triturar, disolver ó mezclar varios enerpos por medio de un pilón. Tarían por su tamaño, por sn figura y por la materia de que están formados. En cuanto al tamaño, los mayores son comúmmente de piedra, más ó 


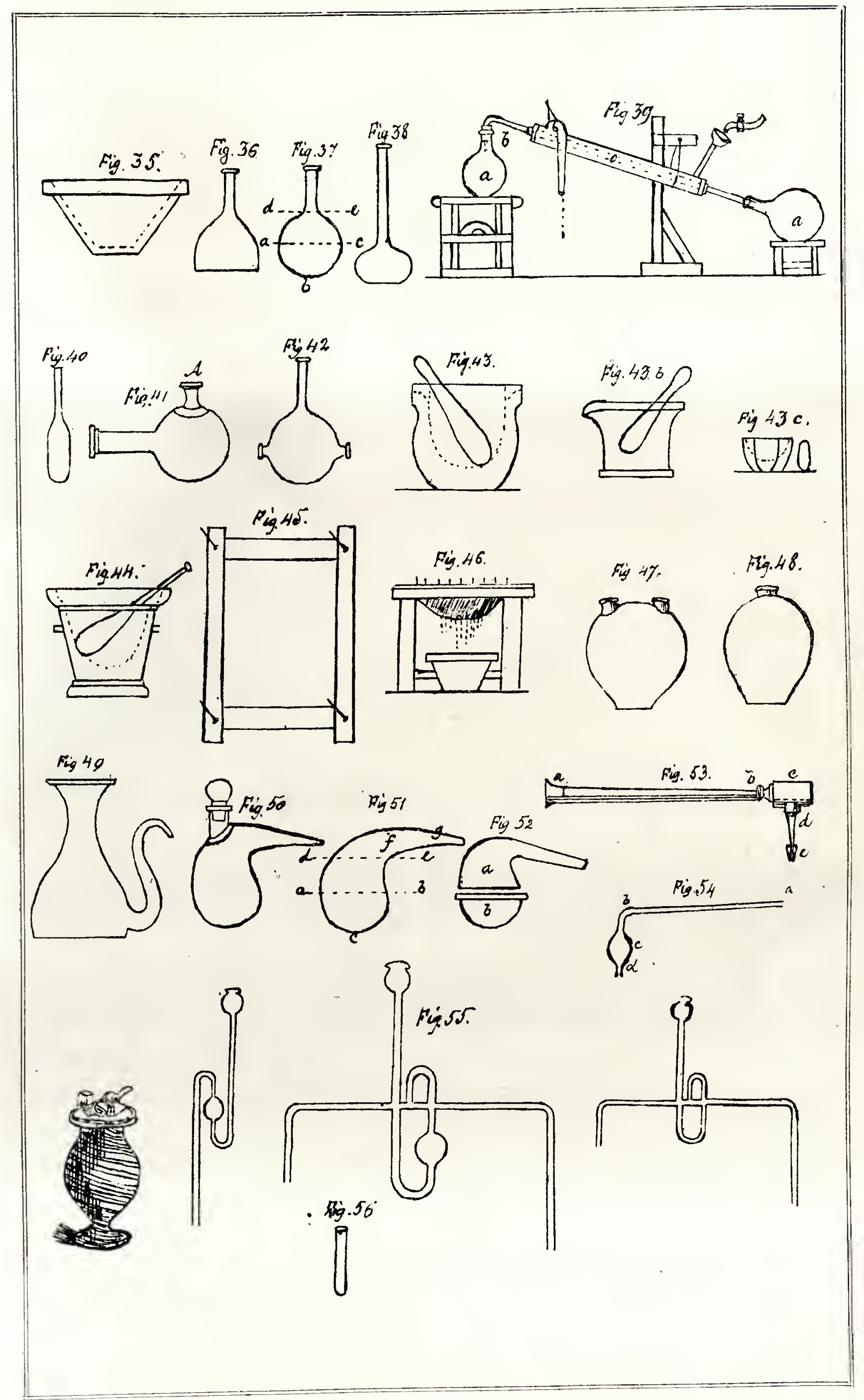



menos dura y con pilones de madera; se llaman de basalto, de pórfido, de mármol (fig. 43." ), de tecali, etc. Los manuales son de porcelana, de bizcocho, de vidrio (fig. $46 .^{\mathrm{a}}$ ), de cristal y de ágata (fig. $43 .^{\mathrm{a}} \mathrm{c}$ ). La forma varía con relación á la profundidad, á la de la curva de su concavidad y á la que hay entre ésta y la convexidad del pilón. Cada una de estas formas es adecuada al uso á que se destinan los morteros; lo mismo sucede con relación á la materia de que están formados, debiendo siempre cuidarse, que la substancia que se ha de pulverizar, sea menos dura que la del mortero, y que 10 ejerza acción química sobre éste (fig. $43 .^{a}$ ).

No obstante que se confunden, como se ha dicho, las voces mortero y almirez, debe reservarse la última para los de metal, como fierro, bronce, etc. (fig. 44. ${ }^{\mathrm{a}}$ ).

Mufla.-Pieza de barro refractario, esencial á los hornos de ensaye y destinada á recibir las copelas (fig. 10. ${ }^{\mathrm{a}} \mathrm{bis}$ ).

Obturadores. - Del verbo obturar, tapar, cerrar. En química se da ese nombre á unos discos de vidrio para transportar, de un lugar á otro, el gas que contienen. Los hay con un reborde, formando especies de platillos, y con pie, como los de una copa grande.

Plintos.-(Véase alzadores).

Pomos.-(Véase frascos).

Portafiltros.-Se da este nombre á unos cuadrados de madera, con cuatro ó más clavos ó puntas, que reciben y sostienen los lienzos empleados como filtros, ó sobre los cuales se pone el papel. Se da el mismo nombre á unos banquillos dispuestos para recibir el lienzo ó uno ó más embudos en los cuales se ponen los filtros. Entre los primeros, los hay sencillos (fig. 45. ${ }^{\text {a }}$ ) y con pies, llamados fijos (fig. 46): éstos también son simples y dobles. Aunque comúnmente se usan los embudos como portafiltros, no por eso reciben este nombre, conservando el propio, por estar destinados á diversos usos.

Porrones. - Grandes tarros ó vasijas de barro, con una, dos y tres bocas, usados en las fábricas como fiascos y como recipientes (figs. $47 .^{a}$ y $\left.48 .^{a}\right)$. No obstante que algunos usan las voces tourillon y bombín, es conveniente desecharlas.

Recipiente.-De recipiens, recibidor. Aunque se da este nombre á toda vasija destinada en las operaciones de laboratorio á recoger algún producto, se aplica especialmente á las esferas de vidrio con cuello corto, usadas comúnmente para recoger los productos destilados. 
Así, un frasco común, un lebrillo, un matraz, etc., sirve en muchos casos de recipiente. Los recipientes de los laboratorios son de poca capacidad; mas en la industria los hay de vidrio hasta de veinte litros, siendo aún mayores los de barro, llamados porrones, y los metálicos. En el artículo matraz se ha dicho que debe desterrarse la palabra ballon del lenguaje químico, usada en lugar del recipiente, y se ha fijado la diferencia entre éstos, los matraces y los sublimadores.

Recipiente florentino ó sepuratorio.-Se da este nombré á una vasija de forma, tamaño y naturaleza variable, destinada á separar un líquido menos denso, de otro que lo es más. Los separatorios connitnes tienen la forma representada en la fig. 49." ; otros son metálicos y semejantes á las cafeteras; otros, en fin, no difieren de los frorescos de llave.

Refrigerantes.-Del latín refirigero. Utensilios de forma y naturaleza variable, destinados á farorecer la condensación de los vapores, por medio de corrientes de agua ó de aire. Hay casos, como en las sublimaciones, en los que no se adopta aparato alguno especial: la bóveda y cuello de un sublimador, de un matraz ó de una retorta, puestos en contacto con el ambiente, sirven de condensadores: los recipientes, tambores y cámaras en la destilación de varios ácidos líquidos, en la sublimación de las flores de benjuí y en la del azufie, sirven, igualmente, de refrigerante. Se ha visto que los alambiques lo tienen especial y de formas variadas; pero hay uno notable por su utilidad y sencillez, conocido con el nombre de refrigerante de Liebig y representado en la fig. 39. ${ }^{\mathrm{a}}$

Retortas.-Del latín retorqueo, sinónimo de cornamusa. Vasijas destilatorias de forma particular con fondo convexo, de diversos tamaños y de diferentes materias. Se distinguen en tubuladas (fig. $50 .{ }^{n}$ ). cerradas ó ciegas (fig. 51. ${ }^{\mathrm{a}}$ ), y en divididas (fig. 52.", $a$ y b). Con relación á su naturaleza, se construyen de vidrio, de cristal, de barro, de porcelana, fierro, plomo y platino: así se dice: retorta de cristal tubulada, retorta de vidrio ciega, retorta de plomo dividida. En toda retorta se consideran cuatro partes: el fondo ó cápsula, que comprende la parte $a, b, c$; el cuerpo ó bóveda, la que hay de ésta á $d, e$; la garganta $f, y$ por último, el cuello $g$; una retorta bien construida debe tener la garganta amplia, de manera que, confundiéndose con la bóreda,no forme ángulo recto. 
Funcionando como vasijas destilatorias los cilind ros de fierro, que se usan para preparar los ácidos clorlhídrico y azótico, el carbón animal, el gas de alumbrado y otros productos, se da á esos cilindros y á los semi-cilindros, el nombre de retortas, distinguiéndolas por sus dimensiones y por el número de tapas: retorta de una boca, de una tapa ó de un fondo, la que sólo tiene un fondo móvil, y de dos, si ambos discos están separados; llevando su respectivas asas y sus tornillos de presión.

Rodetes.-Especies de roscas, tejidos como estera y hechos de paja, de zacate 6 de esparto; se usan para mantener en la posición conveniente, los matraces, retortas, cápsulas, y en general, toda vasija de fondo convexo. Los pequeños, suelen hacerse de orillo ó de lienzo (fig. 1. ${ }^{\mathrm{a}}$ o).

Separatorios.-(Véase recipiente florentino).

Siphoide, botella.-Especie de gasójeno de barro, destinado á contener líquidos gaseosos, principalmente la cerveza y los vinos espumosos (tig. 33. ${ }^{a}$ ).

Sopletes.-Tubos de diez y ocho á veintidós centímetros de longitud, terminados en una extremidad por una abertura capilar, y la opuesta por otra de dos á tres milímetros de diámetro.

Los hay de vidrio, de fierro, de cobre, de latón y de plata, con caja y sin ella, y con ensquillo de platino ó sin él. La forma más cómoda y generalmente usada, es la que representa la figura 53." Está compuesta de cinco partes: Ia boquilla ó embocadura $a$, la rana comprendida de $a$ á $b$, la caja $c$, el pico $d \mathrm{y}$ el casquillo $e$ á éste llaman algunos, aunque impropiamente, boquilla.

También se da el nombre de sopletes á otros varios aparatos, de los cuales forma parte el casquillo de los sopletes comunes. Así, los gasómetros que tienen en la parte superior, una llave, en cuya extremidad recibe el casquillo, funcionan como sopletes; una simple vejiga con llave, un frasco, las bolsas impermeables y otros aparatos, cuyo mecanismo está adecuado para dar salida á los gases comprimidos, se llaman igualmente sopletes $y$ aun se distinguen por la naturaleza de los gases: sopletes de oxígeno y de aire, soplete oxilídrico, aerlí́drico, etc.

Tubos.-Del latín tubus. Caños más ó menos cilíndricos, cuya longitud es mayor que su ancho. En química son muy usados, especialmente los de vidrio, de porcela, de fierro y de goma elástica; va- 
rían mucho en dimensiones y en formas. En todo tubo recto hay que considerar el cuerpo ó rama y las bocas ó extremidades. La longitud, el diámetro y el grueso de la masa, á la que vulgarmente dan el nombre de carne, se indica en fracciones métricas; así se dice: tubo de vidrio de setenta centímetros de largo, quince milímetros de diámetro y dos de grueso ó de carne; con relación á la figura, se llaman rectos (fig. 11. ${ }^{a} b, b^{\prime}$ ); ensanchados, como en c; afilados, $d$ y $b$; en $\mathrm{U}, e, e$; curvos, fig. $31 .^{a} c$; lecurvos, $d, d$, $d$; en tres de bola, $y$; de cinco bolas ó de Liebiğ y también de análisis, ! (fig. 11.a); graduados, etc. Con relación á los usos, se llaman de seguridad, en tres, y en tres de bola, g (fig. 31." ); recto de seguridad, $f, f$; recurvo de seguridad ó de Welther, fig. 55. "; abductor, b (fig. 39. a); refriggerante, $c$; tubo ó probeta de ensaye, fig. $56 .^{\mathrm{a}}$, etc.

Los tubos de porcelana, son, por lo común, rectos, y algunas veces encorvados en una sola de sus extremidados. En cuanto á los de fierro, generalmente se aprovechan los de fusil, dándoles la figura que conviene. Aunque los de hoja de lata son de poca duración, la facilidad con que son construidos y su poco costo, hace que sean muy usados. Los de latón, y, sobre todo, los de cobre, se emplean mucho en los trabajos industriales.

No se ha hecho mérito en este compendio, de otros varios instrumentos, utensilios y aparatos, ya por ser conocidos de los alumnos, todos los que son comunes á las cátedras de física y de química, como los heudiómetros, wooltámetros, aparatos eléctricos, galvánicos, etc., ya porque lo dicho es bastante para llamar su atención, dando á esta parte de la ciencia, la importancia que exige y aplicando las reglas indicadas, tanto á los objetos no mencionados, como á las modificaciones y composiciones de algunos, que sólo forman variedades. Con esto, y con atender á las explicaciones que oyen en la cátedra, les será más fácil comprender las doctrinas del texto que siguieren, teniendo presente en la traducción, la signiente lista, para evitar la impropiedad en el uso de las roces. 


\section{IJISTA}

de algunas de las voces usadas impropiamente, y otras cuya equivalencia es conveniente fijar.

Acetoso.-Voz que ha desaparecido del idioma científico, conforme á las reglas de nomenclatura, debiendo, por lo mismo, substituirla con la de acético.

Análisis.-Aunque es frecuente oir dar á esta palabra el género masculino, lo que acaso decidió á los autores de algunos de los diccionarios á ponerla como común de dos, en el idioma científico debe usarse en el femenino; análisis cuantitativa y no cuantitativo.

Arsénico.—Si hubo una época en la cual se usó este nombre, refiriéndose al ácido arsénioso, debe notarse que aun entonces se agregaba el adjetivo blanco, y hoy con más razón debe limitarse el uso de esta palabra, aplicándola al cuerpo simple. También debe cuidarse de no numerarlo entre los metales, como lo hacen algunos, diciendo arsénico metálico, el metal arsénico, etc., supuesto el acuerdo de los químicos en colocarlo entre los metaloides.

Azóe, ázoe, azoeto y azote.-Aunque usadas indistintamente las tres primeras voces, es preferible la última, tanto para evitar los dos sonidos de aquéllas, según se quiera pronunciar ázoe ó azóe, como porque se presta mejor la palabra azote á la formacion de los derivados: ácido azótico, azoto-sulfúrico, azotatos, azotitos, etc. Con los radicales ázoe y azóe, ó se contravienen las reglas de nomenclatura, supuesto que la sílaba adicional no sería ico sino tico; ó de observarlas, r'esultarían las voces rzoeico ó azoico: con el radical azoeto se tendría el derivado azoético, y los demás, como azoetatos, azoetitos, etc., muy extraños á los nombres usados. Tales motivos hacen más preferible la adopción del radical azote, aun cuando sea voz francesa.

Dos objeciones pudieran presentarse en contra: la primera, no ser conforme exactamente con la etimología; y la segunda, confundirse, en cuanto á la significación, con la acción de azotar, con el azote ó látigo, 
calanidad, etc. En cuanto á lo primero, no es inconveniente, supuesto que hay unuchos casos análogos en los términos científicos, y aun los autores de la nomenclatura nos han dado el ejemplo; y respecto á lo segundo, lo tenemos igualmente en los azotitos, hipo-asotitos, etc., cuyas voces son generalmente usadas.

Balón.-De la voz francesa ballon, por natraz, recipiente, sublimador, globo, etc. Significando aquélla, en español, furdo de mereancícs ó de papel y pelota grande, cuyas significaciones distan mucho de la idea que se quiere dar, creo necesario no usarla on el idioma científico, ni aun ell el vulgar.

Calórieo y calor. - No obstante que tanto científica como generalmente, hay acuerdo en distinguir el agente físico calórico de la sensación que éste deternina, y aun de los efectos que puede producir, se oye con frecuencia confundir las dos voces, lo cual conviene evitar, dando en cada uno de los casos la aplicación relativa.

Capsúles fulminantes.-Debiendo decirse casquillos ó cápulas fulminantes, sin necesidad de usar la voz cúpsul.

Carbón.-En el lenguaje químico debe fijarse la atención en el uso de este nombre y no confindirlo con el carbono, cono es connún hacer por falta de reflexión, aun tratándose del carbón animal y del vegetal.

Cloroforme.-En español debe terminar en o, cloroformo.

Creosote.-Por creosota, voz femenina, y, por lo mismo, es mal dicho, «el creosote.»

Dosar. - Verbo francés no admitido é inadmisible en el idionla castellano: no obstante, lo usan algunos médicos refiriéndose á las dosis de los medicamentos, y otros, en el idioma quínico, á las proporciones ó cantidades de los cuerpos: fijar la dosis, apreciar la cantidad, estimar, valorizar, etc., parece que son frases más apropiadas.

Electroseopo, estetoseopo, etc., en vez de electroscopio, estetoscopio, polariscopio, etc. No es fácil comprender pol' qué se usan aquellas voces, aum por los mismos que dicen, con propiedad, microscopio, telescopio, esteroscopio y otras. Aún es más impropio y no falta quién, suponiendo esdrújulos aquellas palabras, diga electróscopo.

Flux y flujo:-Comúmmente usadas estas roces en lugal de fundente: fundente blanco, fundente negro, y no flux ni flujo blanco, flux y flujo negro, como impropiamente dicen muchos.

Fonte. - Vasija de fonte, tubo de fonte, frasco de fonte, son fiases 
que deben evitarse en la locución científica, diciendo, como debe decirse, vasija de fierro fundido, tubo de lámina ó frasco de fierro colado. Hay algunos casos en los cuales equivale la voz fonte á la de bronce.

Hidriodato.-No debe sustituirse á yoduro, mucho menos tratándose de las combinaciones insolubles. En el mismo caso se hallan los hidrocloratos, hidrobromatos, etc.; aun admitiendo la teoría, que supone la reacción de esos compuestos, cuando son disueltos, debe decirse: yodo-hidrato, cloro-hidrato, etc., ó yodidrato, clorhidrato, etc.

Higrométrico. - Es mny común aplicar esta voz para indicar la propiedad que tienen los cuerpos de tomar agua, en cuyo caso no debe decirse sino higroscópico; pues no obstante que un cuerpo higroscópico puede emplearse como higrométrico, hay diferencia entre las propiedades inherentes á los cuerpos y la aplicación de ellas á un fin particular, como es el de estimar el peso ó el volumen del vapor acioso.

Imantar.-Aunque el diccionario de Salvá admite este verbo, ni está conforme con la voz imán, de que se deriva, ni es la más propia en el idioma científico: hay fundados motivos para creer, que más bien el uso, casi exclusivo de los textos franceses, hace que se tome del verbo aimanter y sus derivados, no usando del más adecuado imanar, al que creo debe darse la preferencia.

Marganesa.-Aunque usada esta palabra por profesores muy respetables, creo que debe abandonarse, tanto por no estar admitida en el idioma, como porque sería oponerse al uso científico general, y porque si, como es de presumir, tomó su origen de Mangala, divinidad mitológica, sería aún más impropia, por tener que sustituir la $n$ del radical con la $r$ del derivado. Pero si se supone derivada de Mar$g a$, sería destruir la idea que se tiene de estos compuestos. También debe cuidarse no confundir los nombres manganesa y manganeso, como suele hacerse involuntariamente, tanto refiriéndose al cuerpo elomental como al compuesto oxigenado.

Mineralógia, climatológin, geológia, etc., en lugar de inineralogía, geología, climatología, para no ser poco consecuentes; siendo un hecho que no se dice, paleontológia, cristalográfia, fisiológia ni anatómia.

Mortero.-Casi todos los que leen, y aun los que publican traducciones del francés, dan la preferencia á esa voz, desechando la más propia, argamasa, conocida con el sinónimo de mezcla. Dos razones 
prineipales hay para no empleai en ese caso la palabra nortero. La primera es: ser voces antienadas las de morter y mortero, y por sólo esto, no tan propias como la de argantasa; y la segunda: tener la $r 0 \%$ mortero diversas significaciones, siendo la menos eonoeida la que se refiere á la argamasa. Parece más conforme decir arganasa hidráulica, de pared, terciada, etc., que morter ó mortero hidráulico.

Niquel ó Nickel, niquelo !n niquelio.-Aunque el diccionario de la lengua admite la primera y la última voz, la preferencia debe fijarse, facultativamente, teniendo presentes las razones de conven iencia eientífica. En ésta como en otras palabras, pndiera resolver la cuestión, el origen de ella; hupfermickel, que equivale á colne te Nicolŕs, parece exigir la adopción del nombre nickel, que, por ot la parte, se presta bien á la formación de los derivados, sin alterar ni aum la ortografia.

Óxido.-Siempre en el idioma español la sido estrújulo y ninguna razón hay para no decir óxido, supuesto que las que dan los que emplean aquélla, son de tan poco valor, que no meren méneionarse.

Platina.-Algunos usan esta palabra refiriéndose al platillo de la máquina nemmática; la que debe preferirse es disco, por ser más significatira.

También se la usado la roz platina eomo femenina, refioiéndose al metal; mas hoy se da la terminación maseulina, para cuyo cantbio, acaso se ha tenido presente que, con exeepeión de la plata, todos los metales son del género masculino: así es que, aunque prinnitivamente se derivara la vo\% platina, de plata, que más tarde recibió el nombre de plata agria, loy está admitida, tanto en Francia como en España, con la terminaeión masenlina, que usaremos en adelante

Quinino.-Así es común deeir, en contravención á la nonnenclatura, pues tiene la terminación en ina, eomo todos los compnestos orgánicos análogos, y es vo\% femenina, como lo son unorfina, estricuina, reratrina, etc., sulfato de quinina, nitrato, solución de quinina, etc.

También es frecuente confundir la base quinina con las satles de que forma parte, y aunque bien puede decirse, sin impropiedad marcada, administro la quinina, no sucede lo mismo, tratando, por ejemplo, de su solubilidad, de la dosis, etc.

Suelo.-Es tan genérica la signifieación de esta palabra, y nuestro idioma tiene tantas muy adecuadas á la aplicación especial que se quiera hacer, que no hay necesidad de emplearla al decir, por ejem- 
plo, snelo volcánico, vegetal, de labor, por ser frases impropias; debe preferirse la voz terreno, en unos casos, y de roca en otros, diciendo: terreno arcilloso, calcáreo, vegetal, etc., así como roca cuarzosa, volcánica, etc.

Tartárico y tartaroso.-En la buena locnción científica, sólo se admite la voz tártrico.

Tierra.-En dos casos se advierte el nso impropio de esta palabra; el primero, refiriéndose á una superficie laborable, y aunque en el idioma vulgar esté admitida tal aplicación, en el científico, parece que debe preferirse la palabra terreno, que indica las dos cosas, á saber: la extensión ó superficie limitada y la naturaleza terrosa.

La segunda impropiedad es aún más notable, diciendo, por ejemplo, crisol de tierra, horno de tierra, etc., en lugar de crisol de barro, horno de barro, pues aunque todo barro es tierra, no toda tierra es barro.

T'ítulo.-Así se dice por algunos, refiriéndose á las ligas metálicas, y aunque la $\mathrm{v} 0 z$ francesa titre, tiene, en muchos casos, esa significación, que está conforme con la latina titulus, de que se deriva, debe tenerse presente que, considerada, aum en el idioma francés, como una parte de la metrología, el equivalente en nuestro idioma es ley; así se dirá: ley de la plata, del oro, de los metales, etc.; pero en ningún caso, título de la plata, del oro, etc.

Trojel.-Si es repugnante esta voz dicha por personas vulgares, lo es más cuando sale de la boca de los peritos, no para referirse al fardo, como, se usó en un tiempo, sino al troquel, tan conocido con el nombre de cuño.

Creo que los ejemplos citados serán suficientes para que los cursantes fijen la atención en el uso de las palabras, evitando los galicismos, tan frecuentes como impropios; especialmente los de aquellas voces que, encontrándose en lus diccionarios con su significación correspondiente, alejan la necesidad de adoptar la de un idioma extraño. Así dicen, por ejemplo, suport por sustencálculo en unos casos; portador ó recibidor en otros: tóle por lámina de fierro, ó fierro laminado; soda por sosa; terrima, por lebrillo; reeflement, por dilatación, ampliación, hinchazón, y así otras, más ó menos inadecuadas que deben abandonar. 
$$
\text { . }
$$ 


\section{APÉNDICE *}

que servirá, concluido que sea el estudio de la química orgánica.

Aunque algunas de las cuestiones que voy á tratar someramente, deberían encontrarse formando parte de los artículos contenidos en lo ya escrito, he creído preferible sacrificar el buen orden á la conveniencia que resultará á los alumnos, consignando aquí los puntos principales de las adiciones y explanaciones orales. Creo que por este medio recordarán fácilmente las doctrinas que faltan en el texto, algunas de las cuales no es fácil á todos comprender desde las primeras lecciones.

Clasificación de los cuerpos simples.-Tres son los sistemas de clasificación ó división que han dado los autores: 1. ${ }^{a}$ Metálicos y metaloideos ó metaloides. 2. ${ }^{a}$ Metálicos y no metálicos. 3. ${ }^{a}$ Electro-negativos y electro-positivos. Fácil es conocer que la primera clasificación es, sin duda, la más impropia, atendiendo á la significación de la voz metaloideo, ó semejante á los metales, y á que todos enumeran entre éstos á los simples, que como el oxígeno y el azoeto, el hidrógeno, el cloro, etc., distan mucho de esa semejanza que debiera caracterizarlos. «Semejante significación, dice un autor distinguido (D. P. Mata), representa ideas falsas, exige suposiciones $\mathbf{y}$ carece de verdaderos caracteres diferenciales.

La segunda, peca, igualmente, por inadecuada: si todos los simples comprendidos bajo la denominación de no metálicos, fueran como aquellos gases ó aun como el fósforo, el bromo y otros, no habría inconveniente en adoptarla; mas numerándose entre ellos el boro y el silicio, el yodo y el carbono, el arsénico, el antimonio, etc., que verdaderamente son semejantes á los metales, no satisface esa clasificación á las exigencias didácticas, ni á la propiedad de las palabras.

* No debe olvidar el lector, la época en que escribió el Sr. Rio de la Loza. N. del R. 
Se objeta á la tercera clasificación, ser relativa y no común la propiedad positiva ó negativa de los elementos en las combinaciones que forman; pero tal objeción no tiene ralor, si se atiende á que ella está reconocida como doctrina en las combinaciones, á que no despierta ideas falsas y á que aleja todo escrúpulo, supuesto que en las combinaciones formadas por los diez y seis simples comprendidos entre los electro-negativos con los metales, éstos funcionan como positivos.

Fundados en tales datos, daremos la preferencia á la división de los cuerpos simples, en dos grandes clases; primera, elcetro-negulivos, subdivididos en no metrílicos y en metaloideos: segunda, electro-positivos ó metúlicos, subdivididos en seis secciones.

Pertenecen á los no metálicos, los siete siguientes: oxígeno, fluoro, cloro, bromo, fósforo, azoeto é hidrógeno: son metaloideos, los nueve que siguen: yodo, azufie, selenio, carbono, silicio, teluro, boro, arsénico y antimonio; éste porque ha pasado últimamente y con larón á formar parte de los electro-negativos.

En cuanto á las seis secciones que clasifican los metales, seguiremos la que se encuentra en el texto, que es la de Thernard, modificada.

Cohesión y afinidad; meacla y combinación.-Para comprendel mejor lo que se entiende por afinidad y lo que indican las voces, con y sin antagonismo, recordaremos: que existen en las moléculas de los cuerpos, dos fuerzas que pueden considerarse opuestas, una atractiva y otra repulsiva: que si la primera se da entre las moléculas homogéneas, se llama cohesión: si entre las heterogéneas, afinidad. Pelonze admite en los cuerpos simples la existencia de nua fuer:an, que llama de cohesión atómica, la que da una una molécula de formu determinuda; y la de cohesión molecular, cuyas moléculas reunidas forman un agregudo. Asimismo admite en los cuerpos compuestos la fuerac de afinidud, en la cual los átomos de diversos cuerpos simples dan una molécula de forma determinuda: y la fuerace de cohesión molecular, en virtud de la cual, muchas moléculas del mismo cuerpo forman un agregudo. Las dos primeras, serán moléculas simples, ! las segundas, compuestas; distinguiéndose éstas en incomplexus, cuan. do son formadas de dos, tres ó cuatro simples; y en complexas, si están formadas de varios grupos distintos de átomos. La mólecula de arúcar anhidra, será incomplexa; la de la misma_azúcar hid̉ratada, complexa. 
Estimada de esta manera la fuera de commidad, pnede considerarse bajo tres aspectos: $10^{\circ}$ En sí, hecha abstracción de toda teoría. $2 .^{\circ}$ Con relación al antagonismo de propiedades, que pueden presentar los cuerpos que obedecen á esa fuerza. $3 .^{\circ}$ Con relación al no untagonismo.

Observando que no hay cuerpo simple que deje de unirse con otro, combinándose, es evidente que la fuerza de áfinidad existe en todos. Pero esa unión es más fácil, cuando los átomos se ponen en contacto en el momento en que se separan, sea por descomposición ó por cambio de su estado sólido: esto es lo que constituye el estado nuciente de los cuerpos, sean elementales ó radicales.

Los compuestos binarios, ternarios y cuaternarios, son los más generales; pero los quintenarios son limitados, y tanto éstos como los cuaternarios y aun los ternarios, deben considerarse como formados, 6 de dos binarios, $o$ de un binario y un simple, $o$, en fin, de un binario y un ternario.

La afinidad en acción se manifiesta por el cambio de temperatura, la emisión de luz, la corriente eléctrica y el cambio de propiedades, si cs que los cuerpos estín dotados de clguna energía. En este caso, únicamente se combinan en un corto número de proporciones; mas si la afinidad recíproca es poco cnérgica, las combinaciones se verifican en proporciones hasta cierto límite indefinidus.

\section{EJEMPIOS.}

A. Comburentes poco enérgicos, ó si son enérgicos que tienen analogía.

B. Compuestos neutros, tales como el agua, el alcohol, etc., con un cuerpo neutro en cualquiera de los tres estados, ó con un cuerpo medianamente ácido ó alcalino.

$C$. Tejidos de lana ó seda con el agua.

D. Los mismos, con líquidos coloridos por substancias orgánicas.

E. Sólidos porosos y gases.

Cuando los cuerpos se unen en las mismas proporciones, pero colocadas sus moléculas de diferente manera, resultan especies y sub-especies, según que las propiedades del compuesto que forman, difieren más 6 menos. El autor considera como sub-especies, el Espato calcá- 
reo y la Aragonita; mas el azúcar, el almidón y la dextrina, como especies, representados estos tres compuestos, al estado antidro, por la fórmula $\mathrm{O},{ }^{9} \mathrm{C},{ }^{12} \mathrm{H},{ }^{18}$.

La propiedad particular que presentan algmnos cuerpos de combinarse con otros en virtud de la afinidad y de ser expulsados por un tercero, y que sirvió á M. Dumas para formular la léy de substitución, es llannada por M. Pelouze, afinidad electiva, en contimatción de lo cual, cita los ejemplos siguientes: El ácido arótico expulsa al carbónico de los carbonatos; el sulfúrico, al azótico de los arotatos; la cal, á la magnesia del azotato; la barita á la cal; y la potasia á la baritil.

Hay otros casos en los cuales, en virtud de la misma afinidad electiva, un enerpo.quita total ó parcialmente algmo de los principios de un compuesto ternario ó cuaternario, a la ve\% que otra porción del mismo cherpo, reemplaza como equivalente al principio expulsado. Fjemplo: En un compuesto formado de oxígeno, carbono y seis de hidrógeno, pueden darse estos casos: 1.", que Cl² desaloje $\mathrm{H}^{2}$, quedaudo $\mathrm{O}+\mathrm{C}+\mathrm{H}^{4}+\mathrm{Cl}^{2} ; 2^{\circ}{ }^{\circ}$, que con el mismo elemento $\mathrm{Cl}$ resulte $\mathrm{O}+\mathrm{C}+\mathrm{H}^{2}+\mathrm{Cl}^{4} ; 3 .^{\circ}$, que desalojando en su totalidad á $\mathrm{H}^{6}$, quede $\mathrm{O}+\mathrm{C}+\mathrm{Cl}^{6}$.

La contidud ó la musu de los cnerpos que reobran, tiene tanta mayor influencia en la afinidad, chanto menos enérgica es ésta; y así como en mecánica se toman en cuenta las masas respectivas, del mismo modo se deben considerar en química, no olvidando que, dada ma cantidad de un cuerpo, el ammento de la masa de ofro, (onn el cual no tiene afinidad, no aumenta el poder de ella. Los ejenpins siguientes darán á este puuto la claridad necesaria.

\section{Una fuerzal comunical 1 de $\mathrm{V}$, il la masa $4 \mathrm{M}$. 2 de $V$, a la masia $2 \mathrm{M}$. 4 de $\mathrm{V}$, il la masa $1 \mathrm{M}$.}

El resultado de la acción ó la cautidad de movimiento, es constaute en los tres casos, é igual á $4 \mathrm{~V}$ ML.: porque

$$
\begin{aligned}
& 1 \mathrm{~V} \times 4 \mathrm{M}=4 \mathrm{VM} . \\
& 2 \mathrm{~V} \times 2 \mathrm{M}=4 \mathrm{VM} . \\
& 4 \mathrm{~V} \times 1 \mathrm{M}=4 \mathrm{VM}
\end{aligned}
$$

Y como en las acciones químicas no anmenta la afinidad indefi- 
nidamente, tendremos, por ejemplo, que el bicarbonato de potasa ${ }_{2}\left(\mathrm{~K} \mathrm{O}_{2} \mathrm{C} \mathrm{O}^{2}\right)$ dará, tratado por el fuego, ${ }_{2} \mathrm{~K} \mathrm{O}, \mathrm{C} \mathrm{O}^{2}+{ }_{2} \mathrm{C} \mathrm{O}^{2}$. Pero si se tratan por el agna hirviendo los mismos dos equivalentes de la sal, se descompondrán en ${ }_{2}(4 \mathrm{O})^{3}\left(\mathrm{C} \mathrm{O}^{2}\right)+\mathrm{C} \mathrm{O}^{2}$. En el primer caso, los dos equivalentes de ácido carbónico, combinados con los de óxido de potasio, tendrán mayor afinidad que los dos equivalentes del mismo ácido que se desprenden. Fn el segundo, los tres equivalentes de éste quedarán unidos más íntimamente á los dos de potasa, y un equivalente de ácido será desprendido. Como este ejemplo se pudieran presentar otros muchos; el ácido sulfúrico trihídrico con relación al mayor poder de afinidad con uno solo de los equivalentes de agua; el azótico, el alcohol, los aceites rolátiles, etc., quedando demostrado lo dicho antes, á saber: «que en química, así como en la mecánica, debe tenerse en cuenta la relación de las mascs.»

Por otra parte, el autor considera el poder de afinidad, con relación al antagonismo de las propiedades que presentan los cuerpos, estimando en los compuestos la fuerza úcida y la fuerza alcalina, y en los simples, la comburente y la combustible. El sabor agrio característico de los ácidos y la propiedad de enrojecer los colores azules regetales, así como el opuesto de los álcalis, sabor urinoso y regeneración del color azul enrojecido, desaparecen en cuanto esos cuerpos se combinan, lo cual indica un antagonismo en las propiedades respectivas, manifestado en alto grado en los compuestos extremos de una misma serie, como lo son los oxácidos y las oxibases, pero sin ser notables, ni presentarse de un inodo marcado aquellos caracteres distintiros y opuestos en los de la serie intermedia, en la que hay neutralización de propiedades. El antagonismo resalta más al observar que en la descomposición de las sales por una corriente eléctrica, el ácido y la base se dirigen á los polos opnestos.

Admitido el antagonismo de los ácidos y de las bases, y observando, por otra parte, que algunos de esos mismos compuestos no manifiestan el sabor ácido ó el alcalino, ni acción alguna con los colores vegetales, como sucede con el ácido silícico, los peróxidos de estaño, de antimonio, etc., cuyos compriestos son salinos, es necesario que estos compuestos estén muy divididos para que dén algún indicio de acción sobre el tornasol; de lo que se infiere, que las propiedades extremas características de acidez y alcalinidad, aun en la misma serie, oxácidos y oxibases, son, en algunos casos, excesiramente 
débiles $\mathrm{y}$ en otros mulas. El agua, aunque neutra á los reactivos coloridos, funciona como base en sus combinaciones con los ácidos, y como ácido en las que forma con las bases; el agua será, por tanto, un compuesto intermedio que, como otros, no neutraliza las combinaciones que forma con un compuesto extruño, de la manera que resulta neutralizada la combinación de dos compuestos extremos.

Examinando lo que pasa con relación á las fueraus comburente y combustible, se nota: que si faltan signos claros para reconocer el antagonismo, como se reconoce en los complexos, por la acidez y la alcalinidad, ha sido implícitamente admitido desde Isavoissier, quien hizo consistir la combustiôn en la mión de un cuerpo comburente, como el oxígeno, con un combustible, como el carbono.

Reconocido el hecho de que en las combinaciones del cloro, jodo, fluoro, etc., con los cuerpos combustibles, éstos se dirigen constantemente al polo denegatiro, mientras aquellos pasan al positiro, cuando los compuestos se someten á la acción de la pila, es preciso convenir en que hay antagonismo entre las dos fuerzas, pudiéndose, en consecuencia, establecer que la fuer:a eomburente y la fuer:a eombustible, no son otra eosa que las propiedudes activas devivarlas de uma afinidar neutra, de las más poderosas y esenciales á los cuerpos simples.

No obstante lo dicho, hay que considerar, según el autor, esa misma fuerza de afinidad con relación al no antugonismo, perfoctanente marcado en muchos de los compuestos definidos. En todos los casos en que se umen dos cuerpos, cuyas propiedades no son decididanente comburentes, ni decididamente combustibles, no debe admitirse el antagonismo, especialmente si, como es común, son necesarios gram número de átomos para constituir mu sola molécula. En este caso se hallan los compuestos de origen orgánico, formados por $\mathrm{H}, \mathrm{O}$ y C, ó por H, O, C y Az, en los cuales deben de considerarse nuidos, un compuesto binario con un elemento 6 dos binarios; pero que ni en uno ni en otro caso habrá antagonismo, ann siendo el 1110 comburente 6 ácido, con relación al otro combustible ó alcalino. Habiendo en estas combinaciones mn número mayor de átonos, y siendo, además, desproporcionados, resultan compuestos que carecen de la estabilidad que tiene el óxido de carbono, el ácido carbónico, el agua y otros. La estabilidad de estos compuestos á todas temperaturas, os fácil de concebir, y lo es también, la que presentan los compuestos orgánicos formados de rarios elementos; pero sólo á temperaturas li- 
mitadas, propias á la vida, é insuficientes para romper el equilibrio molecular, dándose entonces la afinidud incomplexa, en sustitución á la de antagonismo; mas ésta se efectuará en el momento en que un agente rompa su equilibrio, resultando, en consecuencia, dislocados los elementos para dar los radicales amoníaco, oxicarburos, carburhídricos, agua, etc. He aquí por qué parece inconcuso que no es una condición indispensable á la afinidad, la fuerza de antagonismo, ó que, si se quiere, puede considerarse con dos grados principales de intensidad, la que tendrá lugar según las circunstancias relativas.

Veamos ahora qué se entiende por afinidad capilar.

Cuando dos cuerpos sólidos 6 uno sólido y el otro líquido ó gaseoso, puestos en condiciones favorables, dan un compuesto, pero sin cambiar el estado ni aun la forma del cuerpo, hay que considerar dos cosas, en las cuales debe fijarse la atención: sea la primera, que la afinidad se ha puesto en acción, una vez que el sólido resulta combinado con otro cuerpo: segunda, que en esta afinidad ha influido alguna cansa especial é independiente de las anunciadas antes. Estos hechos, reconocidos hace tiempo, pero poco notados ó explicados de varios modos, han dado ocasión á M. Pelonze para estudiarlos bajo el nombre de afinidad capilır, precisándola claramente en los tres casos en quie puede tener lugar, y eomprobándola con los siguientes ejemplos.

1. ${ }^{\circ}$ Afinidad capilar entre dos cuerpos sólidos.-Producción del acero por cementación, y por el mismo método, del arseniuro de platino y del sulfuro de plata.

$2{ }^{\circ}$ Afinidad copilar entre un sólido y un líquido.-Las soluciones salinas, tales como las de alumbre, el sulfato de fierto, de cobre $y$ otros, en su contacto con la seda, algodón y lana, que se unen en virtud de esta afinidad: lo mismo sucede en el curtido de las pieles, $y$ en general, se tienen multiplicados ejemplos en las industrias del tintorero y del curtidor. Pero hay, además, un hecho curioso, descubierto por M. Niepec, y que confirma la existencia de la afinidad capilar, y al mismo tiempo la de la afinidad electiva. Si se pone un grabado en agua yodada, el yodo se fija de preferencia en los negros del grabado y no en el blanco del papel. Pnesta en seguida la estampa yodada sobre un vidrio plano, cubierto previamente con una capa de engrudo, aparece la imagen con el color azul característico del yoduro del almidón; y si se pone una lámina de cobre sobre la ima- 
gen humedecida antes, perderá el color azul, poroue el cobre, com. binándose con el yodo, folmará un yoduro de cobre.

3. Afinidud copilar entre un sólido y un cuevpo geseoso.- Lil carbón regetal se apodera del anoníaco, del ácido sulfluídrico, del vapor acuoso, etc., y otros varios cuerpos porosos quedan impregnados de las substancias aromáticas.

Pasemos á examinar la influencia de las fuevacts fisicus.

Es bien sabido que los agentes físicos son los medios más poderosos para farorecer las combinaciones de los cuerpos, para determinar las descomposiciones y para obrar á la réz en los dos sentidos.

Si el calórico puede cambiar el estado de los cuerpos, haciondo que los sólidos se liquiden, que los líquidos se gasifiquen, y quo éstos disminuyan más y más de densidad, no liạ duda que será un agente repulsivo ó antagonista de la fuerza atractira; pero si á su vezarquel efecto farorece, como sucede en muchos casos, el contacto de las moléculas heterogéneas, resultará el equilibrio molecular, farorablo ́as las combinaciones, por esa especie de libertad en que quedan los átoruos, en los que obrará la fuerza de cohesión, cuyos efectos químicos yneden estimarse en tres casos principales.

1. Descomposición pareial ó total de las combinaciones por el calórico: ejemplo de la primera, los óxidos de mereurio, de plata y de oro; de la segunda, los bioxidos de manganeso y el de lidrógeno.

2. ${ }^{\circ}$ Combinaciones determinadas ó farorecidas por el caĺrico, como la del oxígeno con el lidrógeno, y la del azufre con varoos metales.

3. Descomposición por un elemento y combinación de éste con uno de los del compuesto, ó sea substitución: el cloro, en coractacto con el rapor de agua, se evapora del hidrógeno, desalojando ai oxígeno.

Los mismos tres casos se tienen en cuanto ála luz; pero no hay identidad: así es que, con relación al primer caso, los rayos químicos obran sobre los oxidos de plata y oro, sin ejercer la misma acción sobre el de mercurio. En cuanto al segundo, los rayos químicos determinan la combinación del cloro con el hidrógeno; y en cuanto al tercero, es también, como sucede con el calórico, descompuesta el agna por el cloro, desalojando al oxígeno.

Con relación á la electricidad, hay que considerar la acción rápida ó por conmoción, y la continua ó de corriente. La primera des- 
compone los gases hidrogenados, como el fosforado, el sulfurado, el amoníaco, etc. Combina el oxígeno con el hidrógeno, etc. La de corriente descompone la sal amoníaco y forma una amalgama con el amonio de Beraelius; descompone el agua, y el carbón, que sirve de conductor, arde en el oxígeno, y combinándose éste con el carbono, da el compuesto $\mathrm{CO}^{2}$, etc.

Hay, además, otras fuerzas que desempeñan un papel importante en las combinaciones: una lleva el nombre de fuer:a cataliptica, y otra el de fuerar mecínica, cuyos efectos son indudables, ya se estimen como modificación de las físicas, ó como resultantes, ó como independientes de ellas.

Algunos cuerpos, tanto simples como compuestos, intervienen activamente en las reacciones, sin constituirlas ni sufrir modificación alguna en sus propiedades: la esponja de platino determina la combinación del $\mathrm{O}$ con el H: una lámina del mismo metal produce igual efecto á la temperatura de $200^{\circ}$ á $300^{\circ}$ : el bióxido de manganeso descompone el agua oxigenada: el óxido de cobre, á la temperatura de $+100^{\circ}$, descompone el clorato de potasa, etc.: á esta fuerza se ha dado el nombre de acción de presencia, de contacto, fueræa fisica desconocida, y, por último, fueraa catalíptica, cuyas denominaciones sólo dan á conocer los hechos.

La influencia de la fuerza mecánica se comprenderá fácilmente con algunos ejemplos. Comprimiendo en el eslabón neumático una mezcla de hidrógeno y oxígeno, hay inflamación y formación de agua. El carbonato de cal pierde al aire libre, por la acción del fuego, el ácido carbónico; pero no hay descomposición cuando está comprimido en un tubo y semetido á la influencia del mismo agente: esto sucede á su vez con el ar'sénico y con el ácido arsenioso; sometidos á una presión mayor que la atmosférica, se liquidan, cuya propiedad no tienen cuando están á la presión común. Tales resultados demuestran que la influencia de las fueraces mecúnicas en las combinaciones, no son menos importantes que las físicas, debiéndose, por lo mismo, tener presente en la práctica, así como en el estudio de las combinaciones.

Las doctrinas y los hechos enunciados, confirman lo dicho en la primera parte de este opúsculo, al tratar de la solución y disolución, de la mezcla y de la combinación. No obstante, creo que no estará demás dar á este punto alguna extensión. 
Es incuestionable que la fuerza molecular atractiva sólo tiene lugarr, ó entre los átomos homogéneos 6 entre los heterogéneos, constituyendo, en el segundo caso, lo que se conoce con el nombre de afinidad. Lo es igualmente, que puesta en acción la fuerza de alinidad, resulta la combinación: que cuando dos cuerpos de diferente naturaleza se unen íntimamente, lo verificarán en virtud de alguna finer\%a, y no pudiendo ser la primera de aquéllas, es decir, la de colresión, por no haber homogeneidad, será necesariamente la de atinidad; $y$ si ésta es la que constituye la combinación, parece indudable que todas las reces que haya unión intima de dos ó más cuerpos de distinta naturaleza, labrá combinación. ¿Pero esa unión íntima tiene lugar en los casos de solución simple? Veamos si M. Beloure contesta satisfactoriamente.

Con el rubro de «ncción quimica bajo el punto de rista sintético,» coloca la refinidad de solución, con lo cual admite, sin duda, que en las soluciones lay afinidad, pues aunque al definirla establece como carácter la no alteración en la naturaleza de los productos, y, por otra parte, la descomposición del disolvente (ácido ó agua) en el de las disoluciones, no es fácil concebir cómo en el primer caso puede darse afinidad en acción sin combinación, ni cómo en el segundo no se tiene en crenta la no descomposición de los ácidos ni del agua, siempre que se ponen en contacto las bases propiamente dichas. Así, no puede dudarse que el ácido sulfúrico lidratado y el mereurio daráin sulfato de mercurio hidratado, más ácido sulfuroso: que el mismo ácido sulfúrico y el zinc, darán sulfato de zinc, más hidrógeno; pero ese ácido sulfúrico, con los óxidos de zinc y de mercurio, formatrán las mismas sales, sin desprendimiento de hidrógeno ni formación de ácido sulfuroso, lo cual indica que debe tenerse en cuentar y estimarse separadamente la afinidad de los radicales ácido y base, de la de los elementos rinc y oxígeno, y que, por lo mismo, esos hechos no pueden servir como prueba para asegurar que en las soluciones mo hay combinación.

El mismo autor reconoce, al considerar en sí misma la fuerãt de "finided, que hay combinaciones hasta cierto límite indefinidas, y que precisamente se dan entre cuerpos euya afinidad es mediuna, dice, ó poco enérgica. En fin, casi en toda su mecánica química se encuentran multiplicados datos para admitir la combinación en las soluciones, aun cuando ésta se considere débil, ó ann cuando para 
indicar tal diferencia se distinga con el nombre de solución simple, como han propuesto los químicos que no están conformes con la teolía de Tavoisier.

La cuestión es por su naturaleza tan vasta, que sería impropio darle en este opúsculo inás extensión que la indispensable para que los alumnos formen de ella un juicio claro; así es que me limitaré á repetir lo que había publicado hace trece años, y esto lo hago con la confianza que inspira un juicio tan respetable como el de M. Pelouze, aun cuando aparentemente sea contrario.

Algunos autores, decía en la primera edición, distinguen las voces solución y disolución, diciendo que se da la primera, cuando un cuerpo desaparece en el disolvente ó cuando no hay combinación, y el cuerpo disuelto se puede volver á obtener en su primitivo estado (solución simple). Ejemplo: $\mathrm{Na} \mathrm{O}, \mathrm{C} \mathrm{O},{ }^{2} 10(\mathrm{H} \mathrm{O}$.) $+20 \mathrm{H} \mathrm{O}$; dicen que hay disolución, si el cuerpo se combina con el disolvente, si hay reacción, ó si no se puede obtener por medios fáciles y sencillos el que se había disuelto (solución química): $\mathrm{Na} \mathrm{O}, \mathrm{O} O{ }^{2} 10(\mathrm{H} \mathrm{O})+$ S O ${ }^{2} \mathrm{H}$ O. Pero esta distinción, más bien ingeniosa que positiva, acaso no sería fácil sostener, pues en las que eran consideradas como simples soluciones, se presentan fonómenos marcados que indican claramente que hay combinación. Las sales, dicen, tratadas por el agua, desaparecen, dando por resultado un todo homogéneo: he aquí una solución; muchos metales forman con el ácido sulfúrico compuestos homogéneos, pere que han dado indicios claros de reacción, que se han oxidado á expensas de su disolvente: he aquí una disolución. Mas como en la solución de muchas sales se nota no sólo la elevación ó abatimiento de la temperatura, lo cual es relativo por lo común á su estado de sequedad, sino que se advierten también corrientes eléctricas apreciables por el galvanómetro, estos indicios parecen suficientes para admitir que hay combinación. Además, no puede negarse que el agua, por ejemplo, se combina con muchos cuerpos, funcionando como un radical compuesto, por lo común electro-positivo, y no se debe admitir racionalmente el compuesto de equivalente á equivalente, sin admitir el de dos, tres 6 cuatro del radical positivo. Así, en el ejemplo puesto, basta una nodificación para que varíen los resultados: $\mathrm{Na} \mathrm{O}, \mathrm{O} O{ }^{2} 5(\mathrm{H} \mathrm{O})+20 \mathrm{H} \mathrm{O}$ $=\mathrm{Na} \mathrm{O}, \mathrm{O} \mathrm{O},{ }^{2} 10 \mathrm{H} \mathrm{O}+15 \mathrm{H} \mathrm{O}$. Pero se ha dicho en contra de esto, que si se consideran las soluciones como combinaciones quími- 
cas, será necesario admitir compuestos indefinidos, lo que se opone á las doctrinas establecidas; tal objeción carece de fundamento. Tos óxidos intermedios, los compuestos de arufre, de carbono, de fóstón, de hidrógeno, de yodo, y, en gencral, casi todos los simples electronegativos, se encontrarían en igual caso, supuesto que se puede variar al capricho la relación de sus elementos, sin que por esto se consideren los productos como compuestos indefinidos. La química no tendría voces para indicar, por ejemplo, la relación en que se nuen el azufre, el yodo, etc., con el potasio, el sodio, ete.; también entre los compuestos de segundo y tereer orden se encuentran multiplicados ejemplos: un equivalente de óxido de sodio se combina con uno 6 con dos de ácido sulfúrico, para formar combinaciones perfectas; mas la adición de nuevas cantidades de ácido no puede considerarse que daría lugar á otras tantas combinaciones, ni se consideraría como una combinación perfecta la solución de esta sal en una masa indofinida de agna, no obstante que está admitido el compuesto hidratido de uno ó más equivalentes.

Debe tenerse presente, que muchos compuestos definidos tienen la propiedad de disolver alguno de sus elementos, ó de ser disnoltos por éstos, en cuyo caso deben considerarse como los compuestos hidratados, siempre que no pasen de los límites señalados á las combinaciones. Así, el yodo, combinándose con el aznfie, da compucstos perfectos de primer orden; pero éstos preden obrar también sobre uno ú otro elemento, dando lugar á la formación de un yoduro yodurado ó de un yoduro sulfurado, y á su vez estos compuestos podrían

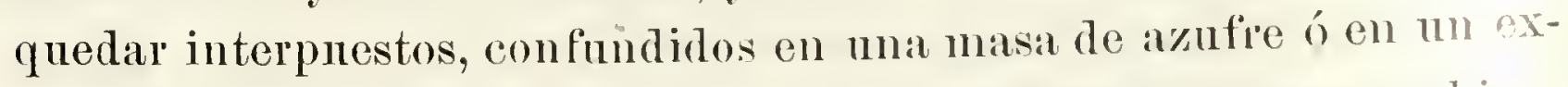
ceso de yodo, sin que los productos sean considerados como combinaciones químicas.

De todo lo dicho es fácil inferir, que son dos las cuestiones que hay que resolver: ma científica, sobre si en las soluciones se las la combinación ó simplemente la mescln; y la otra técnica, relativá las voces que deban preferirse en cada uno de los casos. Como las pruebas enunciadas demuestran, con toda claridad, que las llamadas soluciones no"deben confundirse con las simples mezclas, es preciso colocarlas entre las combinaciones, aun cuando, si se quiere, queden en un orden distinto del que corresponde á las activas ó enćrgicus. I' en cuanto á la elección de las palabras, no hay, creo, inconveniente en adoptar las propuestas por los autores hace algunos años, á saber: 
combinación enérgica ó solución química; combinación débil ó poco enérgica, solución simple.

Modificación alotrópica.-Concluiré los puntos que me propuse tocar en este apéndice, formando un extracto de lo más esencial que hasta ahora se ha escrito con relación á las propicdades alotrópicas de algunos cuerpos.

He indicado antes, que los cuerpos cnya combinación no es fácil determinar en condiciones comunes, se unen sin dificultad cuando se hallan al estado naciente. Se ha dicho igualmente lo que se entiende por fucrac catalíptica, y por último, la necesidad de conocer lo que se ha llamade isomorfismo é isomerismo; pues existe, además, en los cuerpos, otra propiedad no menos interesante, ya se estime como una modificación de algunas de las antedichas, ó como enteramente independiente de ellas. Esta propiedad ha recibido últimamente el nombre de modificación alotrópicá, cuya historia presentaré en un breve resumen, ocupándome á la vez de los medios propuestos para obtener el oxígeno y el hidrógeno alotrópicos, y los reactivos empleados para reconocer su presencia.

El primero de los cuerpos en que se notó por Van Marums, desde 1873; la modificación indicada, fué el oxígeno; mas sus observaciones casi quedaron desapercibidas, hasta que los trabajos de M. Schoenbein vinieron á confirmar los de Van Marums, cincuenta y siete años después. En 1840 fué cuando recibió el oxígeno, procédente de la ảescomposición del agua, el nombre de Ozona (percibo mal). Por algún tiempo se dudó si era un cuerpo nuevo, un compuesto particular ó una simple modificación de éstos, recibiendo los nombres de oxígeno elcctrizado, modificado y naciente, cuyas denominaciones indican con claridad, ya los medios que han sido empleados para extraerlo, 6 bien su verdadera naturaleza. Comenzaré por anunciar la manera de obtener este gas particular.

Anuque se han propuesto varios métodos, tres son los más recomendados.

1. ${ }^{\circ}$ Por el fósforo. En un recipiente ó matraz de veinte á treinta libras de capacidad, se pone la cantidad precisa de agua para que sólo cubra en parte unos cilindros de fósforo; la boca del matraz recibe un tapón de corcho, que da paso á un tubo recto, afilado en su extremidad libre y como de bolas de Liebig, que sirve de lavador y comunica por su rama opuesta con una probeta de pie, en la que se pone 
el reactivo ozonoscópico; por último, la probeta se hace comunicar por medio de otro tubo recurro, con un frasco aspirador. Montado así el aparato, se deja obrar algún tiempo el aipe ó ol oxígeno del matraz con el fósfolo, y después se abre la llave del fiasco para que el escurrimiento del agua obligue al gas á pasar por el tubo lavaror, llegando á determinar su acción sobre el reactivo, del que ne ocuparé adelante.

2. Por la electrolice del agua. Ta descomposición del agua por la pila para obtener el oxígeno alotrópico, puede hacerse por nuedios tan varios como lo son los aparatos gal vánicos usarlos comúnnurente; mas hay que satisfacer dos condiciones principales: la plimera, que los electrodos que están en contacto con el agua pura y acidulada con ácido sulfúrico, sean de platino ó de olo: la segunda, que el gis producido sea lavado cuidadosamente antes de usarlo. 'Todo esto se consigue con el siguiente aparato, al que dan la preferencia los antores. Enlazados dos elementos de Bumsen, se lacen comminian los reóforos con dos hilos ó láminas de platino, las que se sunergen en el agua acidulada contenida en un tubo en V; la lama de éste, con'respondiente al polo positiro, se lace comunicar con tres tubos lavadoles, y el último de éstos con nuo ó más reetos, ó con una plobotat, copa, etc., según el uso que se pretenda dar al gas ozonizado.

3. ${ }^{\circ}$ Por la acción directa de la electricidad sobre el oxígeno. Una serie de tubos cerrados, un endiómetro, frasco, recipiente, etc., que contenga el oxígeno seco, se comnuiea convenientemente, conno es comńn, para hacer pasar una serie de ehispas para obtener el gan ozonizado, que lo será tanto más cuanto más tiempo dure la operación.

Varios reactivos se han propuesto para reconocer el oxígeno alotrópico, y aun para estimar la proporción del principio retivo contenido en un volumen dado de gas. El yoduro de potasio es el que se considera como más sensible, bien por la alcalinidad á que paśa el que era neutro, ó por la coloración azul que produce en su contacto con el almidón: mas habiéndose observado que el cloro, los rapores ácidos, el aceite rolátil de trementina, etc., obran sobre el yoduro, de una manera análoga se han aprovechado las dos propiedades conjountas para evitar la confusión, y am se ha preferido por algunos la timtura de guayacán, que toma un color de piel de rata, en contacto con el oxígeno alotrópico.

El ozonoscopio ú ozonómetro, que parece preferible, es el pro- 
puesto por M. Houzean, que consiste en disolver en diez gramos de agua pura un decigramo de yoduro neutro de potasio, $y$ en empapar con esta solución sólo una parte de las tiras de papel reactivo, muy ligeramente enrojecidas, á fin de poder reconocer, por el mayor enrojecimiento, la presencia de los ácidos, y por la tinta azul, la de los álcalis. Es claro que, si no aparece alteración alguna en la parte que no contiene el yoduro, y sí en la que contiene, puede asegurarse que ésta es debida á la presencia del oxígeno ozonizado.

Haciendo la misma preparación con la tintura de Guayacán, en substitución al yoduro, se tiene un resultado análogo.

Por último, se favorece la reacción, y aun más marcada, agregando una poca de solución de almidón á la de yoduro de potasio.

Las propiedades más notables del oxígeno naciente ó alotrópico, son: tener olor, que es análogo al del fósforo; sabor algo parecido al del camarón; decolorar las substancias orgánicas, y particularmente el tornasol; oxidar varios metales á la temperatura ordinaria, y aun la plata, y sobreoxidar los óxidos y los ácidos, tales como el del fierro entre los primeros, y el sulfuroso entre los segundos; ser absorbjido rápidamente por el mercurio; descomponer el amoníaco, formando ácido azótico, que se combina con la parte de base no descompuesta; la misma propiedad se nota con las otras bases alcalinas; su acción sobre el yoduro de potasio es muy enérgica, transforma la sal neutra en básica, y después separa el yodo; descompone el ácido clorhídrico, desprendiendo el cloro; por último, estable, á $+15^{\circ}$, recobra las propiedades del oxígeno común cuando se eleva la temperatura, según unos, á $+75^{\circ}$, y según otros, á $240^{\circ}$, así como si es agitado con las aguas de cal ó de barita y en contacto con el bióxido de manganeso.

Aunque se han formado varias hipótesis sobre la naturaleza del oxígeno alotrópico, creo que hasta ahora no está resuelta la cuestión: sin embargo, convendrá dar á conocer la opinión de M. Schœubein, quien supone que hay dos especies de oxígenos activos, que siendo de signos contrarios, pueden neutralizarse como las cantidades algebraicas, iguales y de signos contrarios, pasando al estado de oxígeno inactivo, representado por $\mathrm{O}^{\circ}$; así como el activo negativo ú ozona, por $\theta^{\circ}$; y el activo positivo ó antozona, por $\uplus^{\circ}$; en cuyo caso, tomado como ejemplo el bióxido de hidrógeno, $\mathrm{HO}^{2}=\mathrm{HO}+\Theta^{\circ}, \mathrm{y}$ el bióxido de plomo, $\mathrm{PbO}+6^{\circ}$, es claro que puestos en contacto serán catalysados, porque $\Theta^{\circ}$ dẹl uno neutralizará á $\theta^{\circ}$ del otro, reducién- 
dose recíprocamente á O, que no debe quedar con PbO ni con H.O. Del mismo modo puede explicarse la formación del compuesto $\mathrm{P}^{\prime} \mathrm{O}^{2}$, por medio de $\mathrm{PbO}+$ ozona libre $\theta=\mathrm{PbO}^{2}$.

Las propiedades especiales de que me he octupado con rolación al oxígeno, se han observado ignalmente en el hidrógeno, y ann acaso se hayan notado ó se noten más adelante en otros casos. Sea lo que fuere, el hecho es que hoy se conoce el hidrógeno alotrópico, cuyo poder reductor lo distingne del común, como lo comprueba el antor del modo siguiente.

Se condensa el hidrógeno en mu cuerpo poroso que sirva do electrodo negativo, hasta que el desprendimiento del gas anuncio fue el electrodo está saturado: se lava y se pone en una solnción satzuada de sulfato de plata: el metal aparece entonces reducido, lo que no se verificaría empleando el hidrógeno común.

Se pmede, igmalmente, obtener el hidrógeno alotrópico, colorando en mna rasija con agua pura acidnlada, ma campana de bocá á la cual se adapta mu tapón que da paso al hilo negativo ýa nu tubo lécurro, cuyo uso diré adelante. El hilo debe terminar en mua línina de platino, y el electrodo positivo quedarí sumergido en el mismo líquido hacia el exterior de la campana: el tubo recurro sirvo para llevar el hidrógeno á mo solueión de séquix-cloruro de fiero, á la que se ha agregado mua corta cantidad de pervianmo de fieron potasio: el contacto del gas determina la precipitación del cianno fer'roso férrico, lo cual demuestra el poder reductor del hidrógero alotrópico.

No pudiendo retardar por más tiempo la pnblicación de lo escrito, y debiendo servir hasta el fin del curso del compendio analítice que me propuse dar, haré nús adelante la publicación, á fin de que los cursantes tengan nu memoríndum que poder consultar para el reconocimiento de las substancias, que por lo comńn les presentan m los exámenes, cuyo memorándum les servirá igualmente para sus estudios farmacológicos y los toxicológicos. 
Lista alfabética de los cuerpos simples, de los signos que los representan, de sus equivalentes $\mathrm{y}$ de los compuestos que forman con el oxígeno, por el Sr. Dr. D. Leopoldo Río de la Loza. (Publicada en el "Boletín de la Sociedad Mexicana de Geografía y Estadística, 1 a época, tomo X, págs. 281-286).

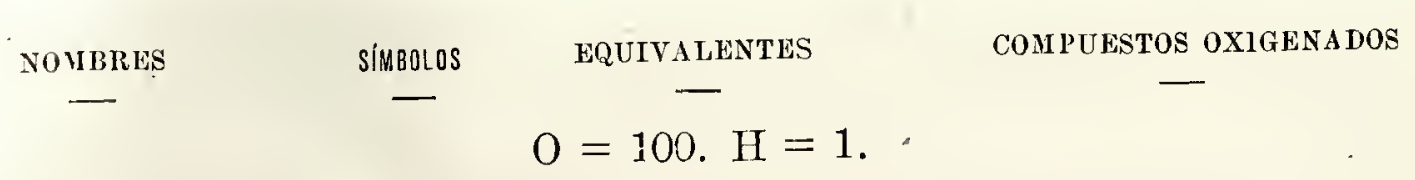

\begin{tabular}{|c|c|c|c|c|}
\hline Aluminium........... & $\mathrm{Al}$ & 170,98 & 13,68 & $\begin{array}{l}\mathrm{Al}^{2} \mathrm{O}^{3} \text {, sexquióxido de alumi- } \\
\text { nio ó alúmina. }\end{array}$ \\
\hline Argentum (a) & $\mathrm{Ag}$ & $1,350,00$ & $108,00\{$ & $\left\{\begin{array}{l}\mathrm{Ag}^{2} \mathrm{O} \text {, subóxido de plata. } \\
\mathrm{AgO}^{\mathrm{g} O} \text {, protóxido de plata. } \\
\mathrm{AgO}^{2} \text {, bióxido de plata. }\end{array}\right.$ \\
\hline Arsenicum & As & 937,50 & $75,00\{$ & $\left\{\begin{array}{l}\mathrm{AsO}^{3}, \text { ácido arsenioso. } \\
\mathrm{AsO}^{5} \text {, ácido ar'sénico. }\end{array}\right.$ \\
\hline Aurum .. .... & $\mathrm{Au}$ & $1,229,16$ & 98,33 & $\left\{\begin{array}{l}\mathrm{AuO}, \text { protóxido de oro. } \\
\mathrm{AuO}^{3}, \text { ácido áurico. }\end{array}\right.$ \\
\hline Azoetum, seu Nitrogenum. & $\mathrm{Az}$ & 175,00 & $14,00\{$ & $\left\{\begin{array}{l}\mathrm{Az}, \text { protóxido de azote. } \\
\mathrm{Az} z^{2}, \text { bióxido de azote. } \\
\mathrm{Az}^{3}, \text { ácido azotoso. } \\
\mathrm{Az}^{4}, \text { ácido hipoazótico. } \\
\mathrm{Az}^{5}, \text { ácido azótico. }\end{array}\right.$ \\
\hline Baryum ... $\ldots \ldots \ldots$ & $\mathrm{Ba}$ & 858,00 & 68,64 & $\begin{array}{l}\left\{\begin{array}{l}\mathrm{BaO}, \text { protóxido de bario ó ba- } \\
\text { rita. } \\
\mathrm{BaO}^{2} \text {, bióxido de bario. }\end{array}\right. \\
\mathrm{Bi}^{2} \mathrm{O}^{3} \text {, sexquióxido de bismu- }\end{array}$ \\
\hline Bismuthum & $B \mathrm{i}$ & $1,330,38$ & $106,43\{$ & $\left\{\begin{array}{l}\text { to. } \\
\mathrm{Bi}^{2} \mathrm{O}^{5}, \text { ácido bismútico. }\end{array}\right.$ \\
\hline Borum. . & $\mathrm{B}$ & 136,15 & 10,89 & $\mathrm{BO}^{3}$, ácido bórico. \\
\hline Bromum & $\mathrm{Br}$ & $1,000,00$ & 80,00 & $\mathrm{BrO}^{5}$, ácido brómico. \\
\hline Cadmium. . . & $\mathrm{Cd}$ & 696,77 & 55,74 & Cdo, protóxido de cadmio. \\
\hline Caesium.... & Cs & ¿1,541,87 & $\dot{1} 123,35$ & CsO, protóxido de cesio. \\
\hline Calcium & $\mathrm{Ca}$ & 250,00 & 20,00 & $\left\{\begin{array}{l}\mathrm{CaO}, \text { protóxido de calcio ó cal. } \\
\mathrm{CaO}^{2} \text {, bióxido de calcio. }\end{array}\right.$ \\
\hline Carbonum & $\mathrm{C}$ & 7500 & 6,00 & $\left\{\begin{array}{l}\mathrm{CO}, \text { óxido de carbono. } \\
\mathrm{C}^{2} \mathrm{O}^{3}, \text { ácido carbonoso ú oxá- } \\
\text { lico. } \\
\mathrm{CO}^{2}, \text { ácido carbónico. }\end{array}\right.$ \\
\hline
\end{tabular}

(a) Aunque algunos químicos de nota dan hoy al protóxido de plata, así como al de potásio y al de sodio, las fórmulas $\mathrm{Ag}^{2} \mathrm{O}, \mathrm{K}^{2} \mathrm{O}$ y $\mathrm{Na}^{2} \mathrm{O}$, se han preferido las que están más generalmente admitidas. 


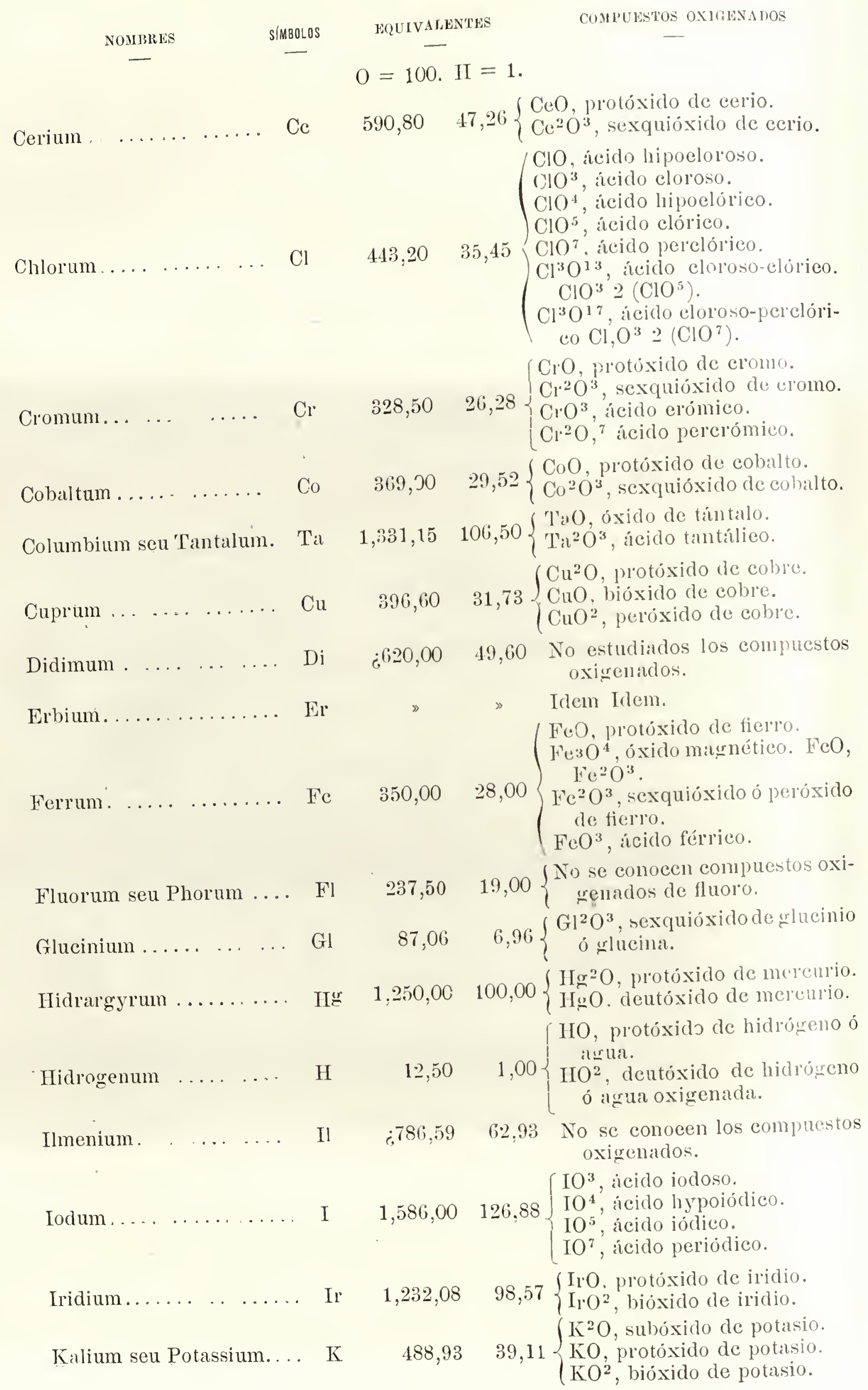




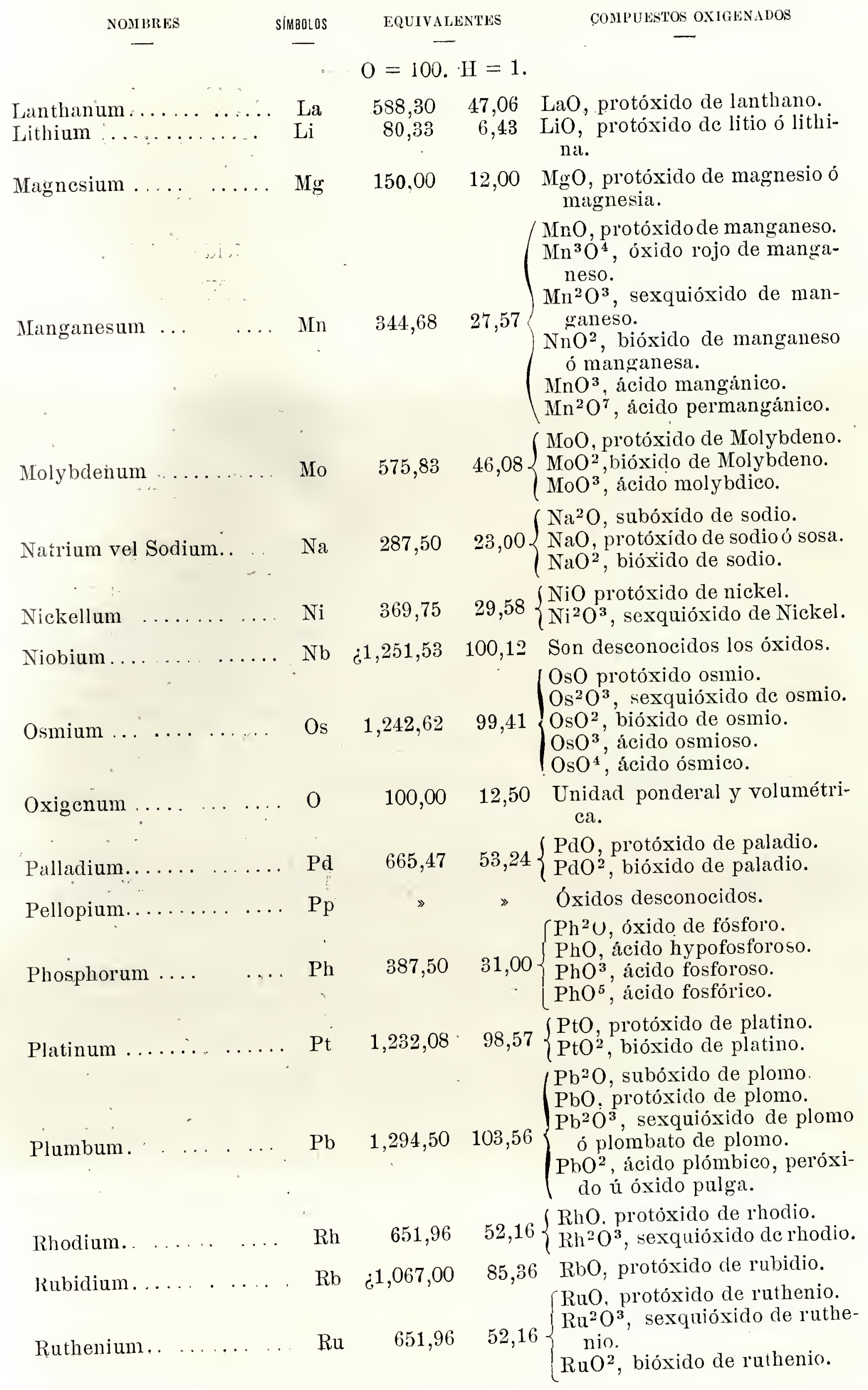




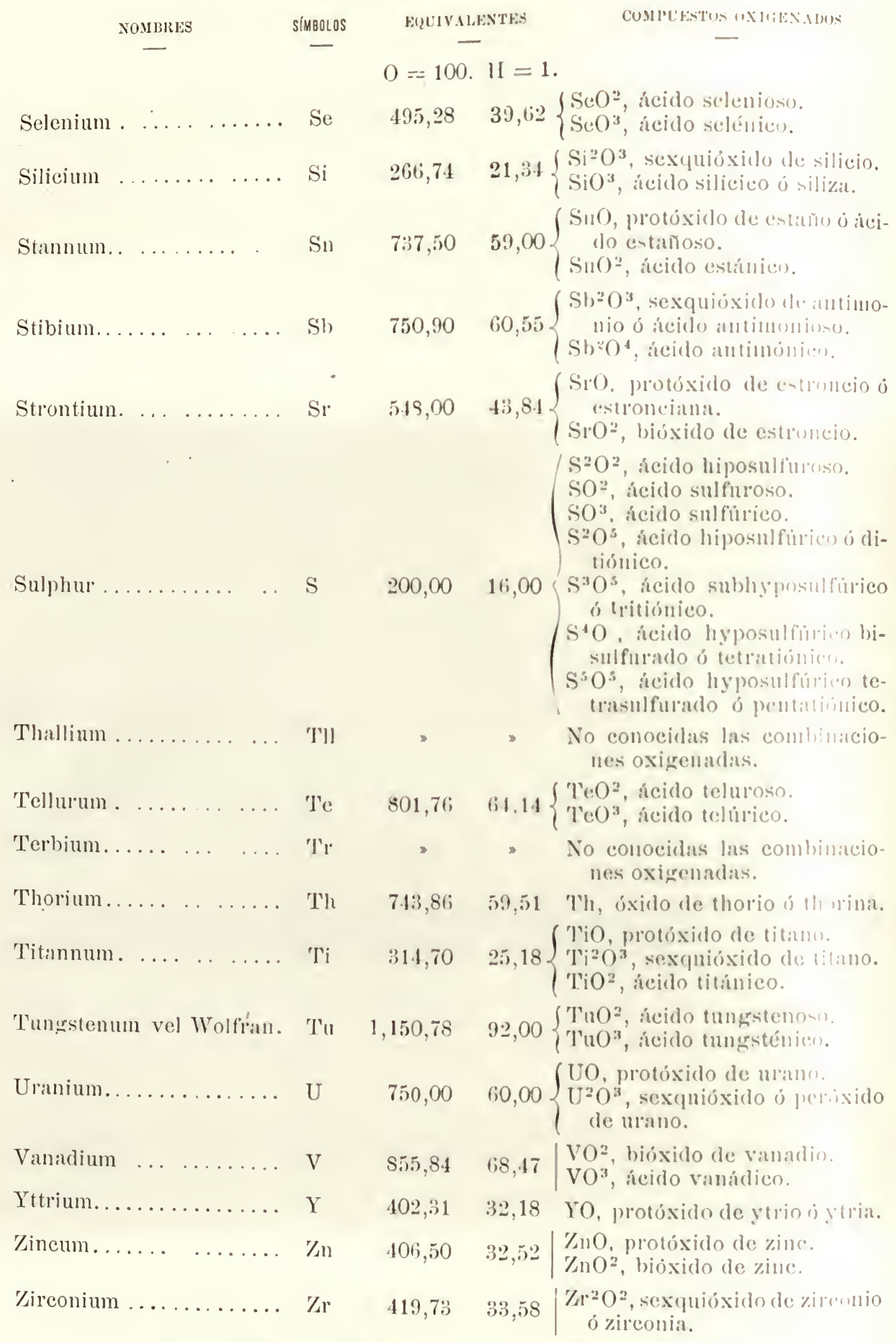


Tabla de signos y equivalentes químicos, por el Sr. Dr. D. Leopoldo Río de la Loza. (Publicada en el "Boletín de la Sociedad Mexi-

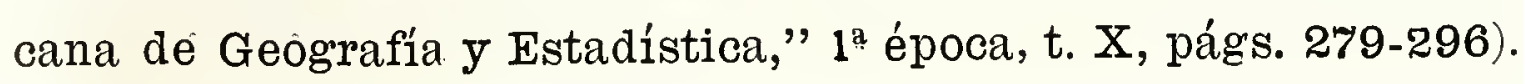

\section{SEÑOREs:}

Háce algunos años que puse en práctica una idea en beneficio de la eñseñanza química, y cuyos resultados han correspondido á mis esperanzas. Cré́ que, fijando en la clase un cuadro perceptible y claro, en el que los alumnos tuvieran á la vista los signos y los equiralentes químicos, serían más conocidos para ellos, y se les fijarían en la memoria con mayor facilidad: así ha sido, en efecto, y por lo mismo, es hoy indispensable el retrocar ese cuadro, puesto que el tiempo transcurrido lia introducido algunas modificaciones, algunas reforinas y aun algunas adiciones. En efecto, en la tabla antigua sólo aparecen sesenta y dos cuerpos simples, mientras hoy se cuentan sesenta y cinco;"el valor relativo de algunos de éstos ha sido mejor estudiado, y por tanto, difiere del que entonces se fijó; otros, que estaban sin cantidad, la tienen ya; por último, deben figurar en la lista el caesio, el rubidio y el thatio, desconocidos hasta aquella fecha. Pues bien, señores; este trabajo, aparentemente sencillo, que casi pudiera presuinirse de un orden mecánico, exige alguna intervención científica, como es fácil demostrar.

No basta tomar un tratado de química y hacer copiar la tabla de equivalentes, por varias razones que indicaré brevemente. Sea la primera, el que los autores no están de acuerdo, ni en el número de los cuerpos, ni en los valores relativos; y supuesta esa diferencia, es preciso decidir, científicamente, la tabla que haya de preferirse, ó en su caso, formar una, tan completa, como es necesario. La segunda, que escritas las más en idiomas extranjeros, hay que adecuar los nombres al Fspañol que se liabla en México. La tercera, que derivados esos nombres, así como los símbolos, de roces latinizadas, deben quedar en armonía con las reglas gramaticales. Pudiera objetarse, diciendo que, por una parte, los españoles ya se han encargado de este 
trabajo, y que, por otra, varios autores, ó los más, han latinizado las voces; por desgracia esto no es exacto. A los españoles la sucedido lo que á nosotros; estudiando y leyendo las obras escritas en idiona extranjero, los galicismos y la impropiedad de las palabras ha llegado á ser familiar, sin cuidarse de la buena correspondencia, de la exactitud, ni menos de la precisión. Pero aun hay más; en el orden científico, el roto ú opinión aislada y, por lo común, sin exanen, de un traductor ó de un profesor, no tienen valor; es necesario que una corporación perita medite, elija y decida; sin esto, jamás se logrará uniformar el idiona científico, principio y base de la ciencia misma.

Hoy que todos sus ramos están representados en las varias connisiones que forman la general científica, es fácil, en mi opinión, prestar ese servicio, encargándose cada una de la parte que le corresponde, y sometiendo cada dictamen á la discusión y resolución de la junta general.

En tal virtud excito á la Sección físico-química:

1. ${ }^{\circ}$ A que exanine, modifique ó corrija la tabla de signos y equivalentes químicos que tengo el honor de presentarle.

2. A que cada uno de sus rocales se encargue de presentalr, en la primera sesión de cada mes, las voces, puntos, teorías ó doctrinas, ya físicas, ya químicas, relacionadas con la propiedad y la uniformidad del idioma científico.

3. ${ }^{\circ}$ A que la Sección físico-quínica excite á la gran Conisión, para que, examinando el punto general, y conviniendo en su utilidad, puedan lis otras secciones cooperar á ese trabajo.

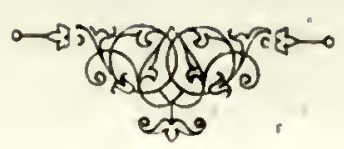




\section{LENGUAJE CIENTÍFICO.}

Propiedad de las palabras equivalentes. (Tomado de "La Unión Médica de México." Publicado por el Sr. Dr.

D. Leopoldo Río de la Loza).

La uniformidad del idioma científico es una necesidad reconocida desde los primeros tiempos, necesidad que aumenta con la marcha de las ciencias $y$ con sus aplicaciones. Si se ha dado la preferencia á los idiomas griego y latino, no sólo ha sido por la facilidad de formar voces compuestaś, sino también porque ha habido una época, y no corta, en que fueron los unás conocidos del mundo litelario. Verdad es que cada nación ha modificado, en armonía con su propio idioma, las palabras derivadas de esas lenguas; mas siempre procurando darles un valor, cadencia y ritmo, no sólo constantes, sino aun consecuentes, y en ningún caso contrarios á los principios científicos.

Amn cuando nada de esto fuera exacto, bastaría la irregularidad consiguiente al desacuerdo, para combatir tan pernicioso abuso, llamando al mismo tiempo, la atención de algunos, que, ó alteran las palabras, pretendiendo fundarse en principios falsos, ó poco reflexiros, las repiten como las han oído, conservando así los abusos que se transmiten de generación en generación, aumentando el número de palabras impropias, y am sancionando en alguna manera el uso de ellas, por la generalidad con que se emplean.

Acaso se diga que hay voces cuya pronunciación es dudosa, así como los equivalentes, y que de esto procede ese desacuerdo que da lugar á que cada cual siga la regla que le parece, ó lo que es más común, que ningura tenga, lo cual no puede menos que ser perni- 
cioso á la enseñanza y amn á las ciencias. Esto demuestra la necesidad de arbitrar un medio que aleje los inconrenientes y latga desaparecer los abusos. Yo no sé qué relación pueda haber entre las palabras: corredero, vare dentadr y cremullere, usadas indistintamente como equivalentes de la francesa crémaillève; el galicisnno, sobre todo, es lo más impropio, como creo sou los signientes:

Balon, palabra que dice tanto, y son tantos los objetos que connprende loy, que nada significa: en español debe referirse únicancente á los fardos de mercería, á los de papol ó á las gorandes pelotas de juego; mas es común oíla aplicada á los acreństatos, matraces, recipientes, sublimadores, $y$, en general, á toda estera huecar, sear cunl fuere la materia de que esté formada y el uso á que se destine; es decir, que se le pretende dar en español la aceptación fiancesa, y esto no sólo sin necesidad, sino introduciendo la confusión y proscoribiendo las palabras significativas de mnestro rico idioma.

Bocal. Esta palabra, nsada, ignalmente, cuando se generalizí el idioma francés, ha recibido nua acepción enterannente contratria á la que tiene, tanto en él comó en español: en éste se refiere al jaron de boca estrechn, que sirve para sacar el vino de las tinajas; y en aquél, al vaso grueso de cuello eorto; pero la mayor parte de los que usan la palabra bocal, se refieren á los pomos ó frascos de boca anchre, contrariando, por lo mismo, la signiticación de aquélla.

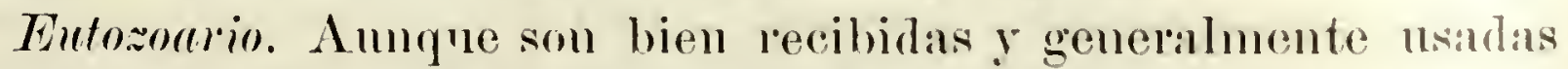
las palabras entomología, entomologista, etr., no veo la necesidad de emplear aquéla, teniendo el equiralente español que falta á éstas.

En cuanto á los góneros y terminaciones, hastaní hacer móritos de las siguientes:

Creosote, cloroforme, quinino, sulfate, nitrate, etc., por creosota, cloroforino, quinina, sulfato, nitrato, etc.

Estetoscopo, lactoscopo y electroscopo, por estetoscopio, lactoscopio y electroscopio.

Azoe, por azoć ó azoeto. Oxído, por óxido. Sílfino, por sulfuro, etc., etc.

Geodesiu, mineralogia, geognosia, ete., no obstante que í la rez se dice topografía, astronomía, fisiología, geometría, ete.

Platina y platino. Aunqué ha sido común usar de la primela de estas palabras, refiriéndose al metal, se encuentra en rarias obras españolas modernas, con terminación masculina: en los más idionas 
es también del mismo género, y varios distinguen, con razón, el metal platino de los objetos que corresponden al femenino, como el menaje ó ajuar, la platina de las armas de fuego, y la contraplatina, la platina ó raspa, usada en las fábricas de papel, la planclua ó lámina de las prensas tipográficas, el platillo de las máquinas neumáticas, etc., etc. Además, con excepción de la plata, todos los metales, ó más bien dicho, todos los cuerpos simples, son masculinos, y aun este género se presta mejor para formar las palabras compuestas y derivadas, razón suficiente, en mi concepto, para no dar grande importancia al origen de la palabra. Sea cual fuere la opinión que se adopte, no hay duda que debe usarse por todos una sola determinación.

Creo suficientes estos datos para demostrar, como se ha indicado, la necesidad de muiformar el idioma científico, muy especialmente en las cátedras que, como se sabe, son las fuentes en que se alimentan las generaciones llamadas á transmitir las palabras, con la propiedad ó impropiedad que las han aprendido. En cuanto á los medios de satisfacer esa necesidad, sin duda que serán varios; pero acaso sea el más pronto y sencillo el establecimiento de una asociación á la que estarían obligados á asistir todos los profesores encargados de las varias cátedras, á discutir éste y otros puntos de interés general, para dar la norma á que todos deberían sujetarse. Esta misina corporación se encargaría de resolver muchas cuestiones de política, ciriles, judiciales y gubernativas; y lo serían de acuerdo con el interés público: la administración, la industria y las ciencias, obtendrían, no hay que dndarlo, incalculables ventajas. Para apreciar más esta exigencia, bastará anunciar lo que son y lo que merecen ser la mayor parte de esos privilegios exclusivos, que no sólo enervan la industria, sino que sirven de rémora á la instrucción científica, sin la cual la nación no puede colocarse en el lugar que le corresponde. 
Opinión del Sr. Dr. D. Leopoldo Río de la Loza, sobre la química elemental de Guerin-Varry. 'Tomado del Periódico de la Academia de Medicina de México).

La dificultad de quo los tratados de química reunan á la concisión la claridad necesaria en las obras didácticas, y el no lanllarse este defecto en la segunda edición del compendio publicado por (tuerin-Varry, lo hacen recomendable, especialnente para los que sílo aspiran á instruirse en los elementos de la ciencia, cuya utilidar se la hecho tan manifiesta, que se cuenta en el múmero de los lamos de educación. Para este fin, es uno de los mejores libros publicatos hasta loy: su antor da en veinte lojas las nociones de física indispensables para la inteligencia de los fenómenos químicos; trata después de los metaloides y sus combinaciones; de los metales y las ligas; de los compuestos de metaloides y metales; de las sales y loyes de composición á que están sujetas; en fin, habla de la fabricarción del vidrio, piedras artificiales y lozas, concluyendo con $n$ pequeño tratado de química orgánica y un apéndice no menos útil. Eun cada artículo hay método y claridad, y la descripeión de los instrumentos y uso de los aparatos, forman un conjunto propio para adquirir los conocimientos precisos, y digno de estudiarse por los que quieran no ser enteramente extraños á la ciencia.

\section{QUÍMICA ORGÁNICA.}

Son conocidos los luminosos escritos de Liebig y Dumas, y la utilidad de sus trabajos puede calcularse por el cambio que han hecho sus doctrinas en las de los ramos que tienen alguna relación con la química. La medicina, sobre todo, encuentra un campo abierto á nuevas investigaciones. Con las teorías de Liebig, se explica hoy mejor la oxigenación de la sangre, la calorificación, la digestión, el modo de obrar de los medicamentos y de los venenos, y aun la produc- 
ción de algunas enfermedades. En la introducción de su obra se encuentran doctinas aplicables á la inteligencia de muchos fenómenos fisiológicos, patológicos y terapéuticos; pero es de temer que pasando esa aplicación de su justo límite, haga retroceder la ciencia á la época, no muy distante, del entusiasmo que produjo el Opúsculo del Mangin.

Su teoría halagó, entonces, como hoy halaga la de Liebig, mas es preciso no olvidar que descansa en hipótesis que disminuyen sn valor. Hn prueba de esto, he aquí lo que dice, en la página décina de su tratado: «Los radicales compuestos nos son desconocidos; de lo contrario, darían medios nás seguros para establecer la constitución de los cuerpos orgánicos.» En otra parte, confiesa que «no hay medios para conocer la manera de unirse ó separarse los diversos grupos definidos de materias orgánicas.» En fin, en la página quinta, advierte que «está obligado á tomar por punto de partida ciertos compnestos hipotéticos, en favor de los cuales hay grandes analogías.» Eista ingenuidad se hace tanto más recomendable, cuanto que por el estilo del autor no se notaría ese vacío á una simple lectura, y sin expresar confesión: por lo demás, la obra merece estudiarse y no juz'gar de ella sin meditar antes en las doctrinas expuestas en la introducción.

También es digno de leerse, el «Ensaye químico de los seres organizados,» publicado recientemente por un mexicano; sin duda es de las mejores lecciones que lıa dado Mr. Dumas; sn claridad y concisión exceden á los escritos conocidos hasta ahora; puede reputarse conso un resumen del Curso de Química Orgánica, en el que se en cuentran pensamientos brillantes $\mathrm{y}$ doctrinas convincentes. 


\begin{abstract}
Discurso pronunciado por el Catedrático de Química Médica de la Éscuela de Medicina, en el acto público del ramo, el día 23 de Noviembre de 1852.
\end{abstract}

Muy útil es pala mejorar la enseñanza, que los establecimiontos de educación dén cuenta al público de su marcha y progresos, por medio de funciones literarias, que acrediten sus adelantos. Taa liscnela de Medicina procura llenar este deber, afirmando así el buen nombre que supiera adquirir con su filantrópica dedicación; y ya que cn el presente año ha tenido el sentimiento de verse atacada con injusta ligere\%a, preeiso es que intente sn defensa, ofreciendo al público y al gobierno, nuevos hechos que contrarien ese equívoco concepto. La cátedra de química, que forma parte de ese útil colegio, debe también tomarla en la defensa; debe demostral que no es indiferente á su fama, y que tanto los almmmos como su catedrático, se han csforzado por llenar sus respectivas obligaciones; sin desviarse del canino que trazara el honor á los que aspiran al título de médicos, anantes del progreso de la ciencia y del renombre del establecimiento. Esto, y no una vana presunción, obligó a los actuntes á admitir réplicas libres, ya que sus catedráticos juzgaron que este medio ela, si no el único, sí el más eficaz para poner un dique á las injustas murmuraciones de sus gratuitos enemigos. Por eso tengo el honol de dirigir la palabra en este sentido á taun respetable concurrencia. Siento que el punto principal de mi alocución no pueda ser ameno y generalmente apreciado; siento también no poderlo tratar con la maestría que sería de desear; y siento, en fin, que los datos y los experimentos se resientan de la imperfección consigniente á la falta de tiempo y al número reducido de observaciones. Pero las personas que me escuchan valorizarán mi buen deseo, apreciando en lo que valgan los trabajos emprendidos y la utilidad que de ellos pueda resultar á la ciencia y al público. 
Pretendo dar á conoeer un nuero principio inmediato, curioso por su aspeeto, precioso por las reacciones que presenta, $y$ útil por la acción que ejerce sobre el organismo. A este principio, que tengo el honor de presentar, con la cristalización que le es propia, he dado el nombre de Ácido Pipitzalhoico, para eonservar el mexicano, que tal rez eambiaré por el de Eupatórieo, sin duda más científieo, si encnentro el áeido en las otras especies del misuo género. Eutretanto, séame permitido que deje eonsignada en este eserito una breve historia que contenga los nombres de las personas que me han proporeionado la bella oportunidad de oeuparme de un adelanto naeional.

Antes de la couquista, era conoeida y muy usada por los indígenas, como purgante, la raíz de 'una planta, á la que dieron el nombre de Pipitzahoae: es decir, planta menuda, y cuyos efectos son repetidos: esta es la opinión del Sr. Galieia, á quien he eonsultado sobre la etimología; pero el doctor Hernández, en su apreeiable obra de Historin plantarum Nove Hispanire, dice lo siguiente: «Herba est radicibus innixa fibrarum, helleborive instar, unde sumsit nomen .... y además, Bilium pituitamque vomitione, aut alvo exeitata detralit semiuneice devoratu pondere tussique et vetustis medetur plagis.» Se ve por esto, que en la época en que escribió el doetor Hernández, no sólo se usaba la raíz para curar los vómitos y las enfermedades conocidas entonees eomo pituitosas, biliosas, etc., sino tainbién, que era empleada como un rulnerario eontra las úleeras iuveteradas. Parece que después ha continuado usándose, probablemente con buen éxito; pero sea lo que fuere, diré eómo tuve conocimiento del vegetal, y del principio inmediato que me ocnpa.

Hará tres años, me fué presentada por los Sres. D. Sereriano Péreza y D. Mariano Ortega, una sustancia particular, que me dijeron ser la resina obtenida de mua planta abundante en Tenango del Valie y que les había dado á eonoeer el Br. D. Paiscual Díaz. Leal. Como aquellos señores deseaban que me ocupara desde luego en el examen de la supuesta resina, $y$ me faltara tiempo para ello, la devolví casi sin examen, siutiendo no poderlos eomplacer. Hace dos años que la dirección de eolonización é industria me consultó, si sería converiente presentar el prineipio á la exposición de Londres: yo hice entonces los experimentos que ereí necesarios para fundar mi parecer, que fué negatiro, proponiéndome aproveehar una oportuni- 
dad para conseguir lá raíz necesaria y dedicarme al reconocimiento de tan curiosa sustancia. Al haberse recibido de aquel curato el antigno profesor de medicina, Br. D. Luis G. Poza, debo el contar con ella y dar cuenta en esta función de los trabajos emprendidos; advirtiendo antes, que hace muy pocos meses presentó el mismo Sr. Ortega, á la Academia de Medicina, las observaciones que tenía recogidas, manifestando el deseo de que continuaran haciéndose, conno en efecto las haan tomado á su cargo los profesores D. Telipe Castillo y I). Tuis Hidalgo, de euyos trabajos haré mérito adelante, ocupándone ahora de la clasificación botánica.

Aunque no me ha sido posible tener á la vista un ejemplar de la planita, en buen estado, para fijar la clasificación con la debidia seguridad, por el que presento, y apoyado en el examen que de fil han hecho los señores D. Pío Bustamante y D. Toaquín Varela, ne decido por la siguiente.

La planta conocida con el nombre de Pipityahoac, es dé las trilumifforns de Mrr. Dec; synunteras de Juss; syngenesin poligumin igunl de Lin.; una de las eupatorices, que abundan en la República, y muy probablemente el Euprotorium sessilifolium, si se atiende á los caracteres que presenta el tallo y las hojas, que, como se re, son sentadas y semi-abrasaderas. La rán, que también está á la rista, ofrece caracteres físicos notables; pero el más particular es, sin tuda, el de contener al estado de libertad, ocho por ciento del principio inmediato que me ocupa: basta dar un corte transrersal para descubrirlo. Como el color, sabor y demás propiedades organolépticas de ella, pueden apreciarse suficientemente, aun por las personas extrañas á esta clase de investigaciones, hablaré de la preprerceción det ricido pipitzahoico.

Son varios los métodos que pueden emplearse; pero me limitaré á indicar los que juzgo más adecuados.

1. Por sublimación.-Reducida la raíz seca á polvo grueso, se inezcla con un volumen de arena igual al suyo: puesto el todo en 111 matraz proporcionado, se coloca en baño de arena, la que se calienta, cuidándo que la temperatura no pase $d e+80^{\circ} \mathrm{C}^{0}$ Para separar el ácido, que cristaliza en la bóveda y cuello del matraz, se quita el fondo de éste, sea usando el diamante, 6 lo que es mejor, de un fier rro enrojecido. En la cápsula queda la arena empleada, complicada én la materia orgánica de la misma raíz y una parte del principio 
alterado por la temperatura, que no puede ser igual en la masa de arena.

Este método no es económico, pero es el mejor para conocer las propiedades del ácido, por obtenerse así más puro.

2. ${ }^{\circ}$ Por precipitación.-Triturada la raíz seca, se deja en maceración, por cuatro ó cinco días, en ocho veces su peso de alcohol á 320 de Chartier, 6 sean 82,5 centesimales: se cuela el líquido con expresión, se filtra y se trata por ocho veces su volumen de agua fría, se recoge el precipitado, se lava con agua destilada y se deja secar b́ le tcmperatura ordinaria: reunidas las aguas de la lavadura, se someten á la destilación para aprovechar el alcohol en otras operaciones, paes no debe destinarse á otros usos.

Este método es el más económico, y el producto que resulta es bastante puro para los.usos medicinales é industriales.

3. Por cvaporación espontánea.-Se sigue la misma marcha indicada en el segundo método para obtener la solución alcohólica, y se abandona el líquido á la evaporcción espontánea para que cristalice: las aguas madres se tratan por el agua común para redisolver después el precipitado resultante y repetir la solución y cristalización. Aunque este método es más costoso y da menor cantidad de producto, ofrece la ventaja de que el principio inmediato es más puro que el obtenido por el segundo método.

4. Por descomposición de las sales.-Se forma un pipitzahoato de plomo, que es soluble en el alcohol, tratando el macerado alcohólico por el acetado de plomo: se descompone la sal que resulta por el ácido sulfúrico y se purifica el principio inmediato, por solución y cristalización. Aunque este cuarto procedimiento parezca más sencillo y económico, creo que no se debe usar y que es preciso asegrirarse de la separación total de la combinación plombosa.

Propicalades del ácido pipitzuhoico.-Es sólido, de color amarillo rojizo, cristaliza en agujas de cuatro caras terminadas en bisel y agrupadas concéntricamente: su olor tiene alguna analogía con el de los productos valeriánicos, sabor acre, persistente, y más sensible en la cámara posterior de la boca.

Sometido á la acción del calor, se ablanda á $+67^{\circ}$ (centigrados), se funde $a ́+70^{\circ}$, se sublima á $+75^{\circ}$, y los vapores son abundantes á $+80^{\circ}$, cristalizando por el enfriamiento y descomponiéndose en parte. 
Es insoluble en el agua fría, casi insoluble en la caliente, y muy poco soluble en los aceites fijos y rolátiles. A $+21^{\circ}$ de temperatura disuelve el alcohol 0,065 y el éter hídrico 0,140 . Las soluciones, y también el producto sublimado, dan reacción ácida.

Los ácidos sulfúrico, clero-hídrico y acético, no forman combinación algmina, annque el primero disnelve parte y lo descompone: el arótico y más fácilmente el cloro-hipoazótico, son descompnestos, sobre todo al calor, pero sin indicar la formación de ácido sulfurico y, por lo mismo, la presencia del azufre en el principio inmediato.

È cloro, el yodo, el bromo y el azufre, se combinan más ó menos fícilmente y dan compuestos con caracteres especiales; siendo el más notable el de conservar, 6 más bien, aumentar su reacción ácida, lo que me hace presumir que haya formación de ácidos compnestos que deberían llamarse cloro-yodo y bromo-pipitzahoicos, como se denominam el cloro-valerísico y cloro-salicílico, etc.

La potasa, sosa y amoníaco, así como los óxidos de plomo, fierro, cobre, zinc y otros, forman sales; algunas cristalizables y cartacterizadas por el color violado, de tinta variable, muy pocas por la amarilla, y todas estas combinaciones pueden considerarse como pipitzahoatos, fácilmente alterables por la acción del fuego. Ta capacidad de saturación de este ácido es débil, pero su sensibilidad con los álealis es ignal, si no mejor, que la del tornasol enrojecido, conor se está riendo en esta solución, que sólo contiene 0,000006 de ácido jipitzahoico; pudiéndose reducir ańm á dos y hasta ma millonésina.

Ios pipitzahoatos coloran los tejidos de lana, seda y algodón, y los colores son fijos, y serán estimados siguiendo las reglas que aronseja la química al tintorero, y estndiando, sobre todo, la cantidat y naturaleza de los mordentes.

Aunque el número de operaciones practicadas lasta ahora, en unión de mi anigo el Sr. Oraveri, no dejan enteranente satisfecha la escrupulosidad indispensable á estos trabajos, no habiendo cosa alguna notable que inspire desconfianza en los resultados, presentamos la composición elemental del ácido pipitzalıoico, protestando rectificarla y fijar los equivalentes cuando se hayan estudiado los pipitzahoatos.

En mil partes de ácido pipitzahoico, hay: 


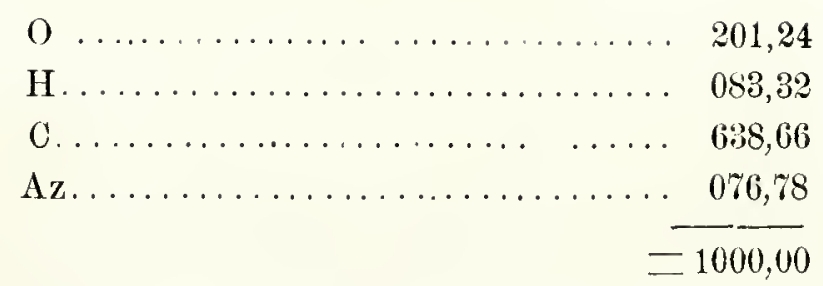

Se ve, por lo expuesto, que el producto de que me he ocnpado es $u$ principio inmediato, volátil, colorante, ácido y azoado, y se ve también, que presenta unuchas reacciones que estudiar, varias propiedades que conocer, y que, an las indicadas, apenas me ha permitido el tiempo tocarlas muy de paso. Concluiré, por lo mismo, esta parte, por no cansar más la atención del auditorio, con el resumen de las propiedades fisiológicas y terapéuticas, tanto de la raíz como del principio que contiene, sirviéndome de los datos recogidos por los profesores Castillo é Hidalgo.

La raíz obra como los purgantes drásticos, á la dosis de dos ó tres dracmas. En mayor cantidad, su acción es más notable, determina cólicos y vómitos biliosos.

Las orinas de las personas que toman la raíz, son coloridas, más ó menos, en amarillo verdoso, y esta coloración se advierte en algunos casos, aun cuando ha pasado el efecto purgante.

Éste se manifiesta, por lo común, dos horas después de la ingestión de la sustancia.

El ácido pipitzahoico es un drástico desde la desis de seis á doce granos, colorando las orinas lo mismo que la raíz.

De todo se infiere que el vegetal debe sus propiedades al ácido pipitzahoico, aunque, si se atiende á la proporción que contiene la raíz del principio inmediato, ésta es mucho menos activa, más entbarazosa y repugnante para su administración, y también para fijar la dosis.

In cuanto á las aplicaciones industriales que puedan hacerse de la nueva materia colorante, será objeto de otros trabajos que exigen experimentos particulares.

Acaso pueda presentarlos al público, y acaso entonces, con más tranquilidad y tiempo, perfeccione los que ahora ofrezco á la Escuela de Medicina.

No debo concluir sin recomendar, cuanto merece, la buena conducta que han observado todos los alumnos que me acompañaron en el año escolar que ha terminado: sólo uno cometió una falta, que re- 
paró arrepentido, separándose después voluntariamente. Los demás han dado pruebas de aplicación, según lo acreditan las honrosas calificaciones que obtuvieron en sus respectivos exámenes: otros las dieron de laboriosidad y desinterés, destinando ma parte de sus ahorros para la compra de las substancias que consumían en sus trabajos de laboratorio, á que se dedicaban todos los días que no eran festivos ó de cátedra. En fin, alguno de los mismos alumnos hizo más; se comprometió á desempeñar, en cuanto lo permitían los conocimientos adquiridos en cuatro meses, la penosa tarea de un preparador que no ha tenido la cátedra por la ansencia inevitable de mi apreciable discípulo D. Florencio Cabrera. Reciban todos esta sincera y tierna manifestación pública, y no olviden que la química es, en nuestro país, una rica mina no explotada aún, y que á ellos toca seguir el camino que dejo trazado al presentar un nuevo principio immediato orgánico, el primero de su género que yo sepa se da á conocer en México.

Nuviembre $2: 3$ de $185 \%$.

I. Río DE La Tora.

(Del periódico de la Academia de Medicina, páginas 1831 й 1:37). 


\section{LA GOMA ARGHIPÍN.}

Treinta y ocho años hace que apareció un pequeño artículo relativo á este producto vegetal, en un opúsculo publicado en Puebla por la Academia Médico-quirúrgica, é intitulado: Ensayo para la materia médica mexicana.

Fin el dilatado período transcurrido, ninguno, que yo sepa, ha desvanecido las dudas á que dió lugar ese artículo; ninguno ha indicado los lugares en que se encuentra; la familia, género y especie del vegetal que le produce; la composición, las propiedades, nsos y aplicaciones de esa goma; no obstante que las indicaré someramente, son más que suficientes para esperar que sea un producto útil en el orden terapéutico é indudablemente en el industrial.

Sea ó no, debe estimarse la goma en vista de datos seguros fundados en los resultados del examen que de ella se haga, ó desecharse por el contrario, pero con la seguridad que exige la consideración demasiado sabida de que «nada hay en la naturaleza que pueda decirse inútil y sin aplicación.» Esta es la que toca al hombre inquiril; y la ciencia le presenta hoy tantos caminos, tantos medios para esa indagación, que bastará un pequeño esfuerzo para lograr el fin.

Increíble parece que los mexicanos, siempre anhelantes por conocer los descubrimientos científicos de todos los países del mundo, veamos con tanto desdén cuanto nos es propio, cuanto corresponde á nuestro país, y aun algo más, que aguardemos á que nos vengan los estudios y datos europeos, referentes á nuestras producciones naturales. El grado de instrucción y laboriosidad de varios de nuestros compatriotas, ya los pone en aptitud de emprender esta clase de estudios, y haciendo á un lado la exagerada modestia que los caracteriza, contribuirán á la independencia científica que exigen la mejo- 
ra de la enseñanza, los progresos industriales y el aprorechamiento de nuestras multiplicadas y ricas producciones.

El cuerpo médico mexicano cuenta con la gloria de ocupar un buen lugar entre los que más fignran en los otros países: ipol qué no procuran la misma distinción en los ramos anexos ál la medicina, puesto que las ciencias físicas y las naturales, han salido do la tutela, ó mejor dicho, del monopolio en que estuvieron hasta hace treinta años?

Grato, muy grato para mí es observar, que á pesar de que el estudio y especial dedicación á las ciencias naturales es casi inproductivo en nuestro país, hoy se generaliza de nna manera provechosa, no sólo entre aquellas personas, cuya profesión exigge esos conocimientos, sino atm entre varias de las que son extraña á las carloras literarias. Por otra parte, las asociaciones científicas que, conno esta Academia, á la que tengo la homra de dirigirme, la Sociedad Hunboldt, la de Geografia y Estadística, las médicas, «Pedro Escobedo» y Filoiátrica, pero muy principalmente, la de Historia Natural, trabajan con entusiasmo y presentan en sus publicaciones, articulos de grande importancia. Aquéllos y éstas concluirán dentro de algún tiempo el importante trabajo que con tan buen éxito han concusado.

Disimulad, señores, el que me haya desviado del camino que al comenzar me propuse seguir; pero es tan vehemente el deseo que me anima por los adelantamientos científicos en uuestro país y por su positiva independenciá, que involuntarianente me encuentro conducido por el camino que menos debiera seguir. Sólo me había propuesto excitar á aquellos de nuestros comprofesores radicados en los lugares en donde se encuentra el archipín, á que se dediquon á la clasificación del vegetal que lo produce, á que tomen nota de los nombres con que se conocen en cada localidad, los usos que hagan de la goma y cuanto más se relacione con ella.

Entretanto, y por mi parte, presento ńmicamente algunos apuntes como resultado de algunos trabajos que hace tiempo conencé, $y$ que últimamente quise rectificar, aprovechando la dedicación de los alumnos de la Escuela de Medieina, Jiménez Don Mannel, Tuncio Don Víctor, Jáuregui y algunos otros á quienes quise dar á conocer prácticamente la marcha que conriene seguir en esta clase de trabajos. El que ahora ofrezco debe verse, por lo mismo, como el principio de los varios que conviene hacer: como un simple anuncio, 
cuyo fin principal es el de llamar la atención de los prácticos á quienes me dirijo.

Ira goma archipín es notoriamente nna producción curiosa, nitil y capaz de diversas aplicaciones, atendidas las propiedades que laasta ahora se conocen. Ha sido considerada como una goma, porque, como se sabe, este es el nombre con que se han confundido todos los productos vegetales análogos al archipín, como las resinas, las gomoresinas, los bálsamos y las verdaderas gomas.

En el «Ensayo para la materia médica» ya citado, y que se publicó en 1832, se anunció, aunquie sin asegurarlo, que era, como es, en efecto, una gomo-resina.

Sus propiedades, aun las simplemente de aspecto, que llamaré fisonómicas, no permiten que se confundan con otros cuerpos, ya aparerca en masa globulosa de varios tamaños, que llegan á ser mayoles que el de una naranja, ya er lágrimas muy semejantesá las que se forman en las velas que han escurrido, y en otras mayores, que son estriactiformes, ó ya, en fin, en trozos irregulares de varios tamaños.

La coloración, aunque muy varia, es tambión característica: se presenta como un blanco de leche, ó amarillenta, como la que toma el marfil, ó de un amarillo rojizo ó moreno más ó menos oscuro: algunas veces se observan manchas verdosas ó de un verde algo azulado.

La goma es compacta, pero quebradiza, y quebradura vidriosa. A reces se notan en la goma incrustaciones foliáceas $y$ aun corticales, engastadas más ó menos en la masa gomosa; también es común hallar en la misma masa ampollas ó cavidades formadas probablemente por la interposición del aire al solidificarse el jugo vegetal.

Fl promedio del peso específico del archipín es, á la temperatura de $\leftarrow 18^{\circ}$ c., de 0,9383. Esta gomo-resina es inodora y de un sabor amargo persistente. Puesta al fuego directo, chisporrotea, decrepita y desprende humos de olor débil algo análogo al del copal. Calentara sobre una lámina, arde, la flama es roja y muy fuliginosa. Al fuogo, en vasija cerrada, desprende humos blancos, vapores acnosos, un aceite amarillo rojizo, que en parte se solidifica, tomando el aspecto de un polvo amarillo; también da algún alquitrán de un moreno oscuro, que el fuego sostenido transforma en brea negra quebradiza: el líquido acuoso, el aceite y el alquitrán, despiden un olor fuerte y picante, análogo al de los productos que resultan de la destilación de las maderas: el residuo que deja la goma, consiste en un 
cârbón ligero. Creo que conviene hacer un estudio especial y en mayor escala de los productos pirogenados, cuya reacción, como debe suponerse, es notablemente ácida.

El archipín forma con el agua un líquido lechoso, ma especie de horchata más ó menos viscosa, según la cantidad de goma empleada: el papel, el cartón, la loza, la madera, etc., quedan bien adheridos por medio de la masa formada con la goma: las chimeneas de los quinqués y las guardabrisas rotas y pegadas con dicha goma, resisten bien la acción del fuego, y cuando ha calentado el peganento, cambia el aspecto lechoso por el moreno transparente.

La solubilidad de la goma en el agua es un tanto variable, mas puede fijarse tomando el promedio en un $34 \%$. El alcohol precipita la goma de la solución acuosa, mas no se obtiene igual cantidad á la disuelta. Abandonando al aire la solución acuosa, se altera, pierde su riscosidad, se acidifica más y aparece la nata criptogínica, tan común á las soluciones gomosas.

El aspecto del archipín, y más aún el de la solución, hacen presumir que contendría alguma cantidad de almidón: no obstante esto, yo no he hallado ni vestigios, aun después de hacer hervir el líquido.

Los reactivos manifiestan la existencia del gumato de cal, y annque no he estimado ponderalmente la proporción, sí puedo decir que es notable la que contiene de esta base, la cual da lugar á sospechar que los terrenos en que regeta la planta que produce la goma, sean
calcáreos.

El alcohol disuelve, por término medio, un cuarenta y cuatro por ciento: el producto de la eraporación conducida debidamente, deja una resina de color amarillo de ámbar transparente, seca, quebradi. za, fusible entre $53^{\circ}$ y $55^{\circ}$ c., que da al fuego el olor balsámico de
lia goma, pero más suare, y no picante ni pirogenado.

El éter obra como el alcohol, disolviendo toda la resina, pres aunque en las operaciones practicadas se han obtenido solamente de treinta y cinco á treinta y ocho por ciento, es probable que esto dependa de las pérdidas y dificultades inherentes á la graude rolatilidad del vehículo, may aumentada, sin duda, con la poca presión de $0^{m} 558$. A tal postra atmó, cuyo término medio, como se sabe, sólo es de $0^{m} 558$. A tal presunción, bien fundada por cierto, hay que agregar, la acción del alcohol, por el éter, es idéntica con la que resulta de la acción del alcohol, sin diferir notablemente en el grado de fusión. 
El sulfuro de carbono disuelve igualmente el archipín, pero en menos proporción que los vehículos antedichos, pues ha sido de diez y nueve por ciento; mas debe tenerse en cuenta, con relación á este líquido, lo que he dicho en cuanto al éter. La resina obtenida con el sulfuro es ignal á las otras dos, en su aspecto y demás propiedades.

También el cloroformo ejerce sobre la gomo-resina efectos análoggos á los del alcohol, el éter y el sulfuro; obra como disolvente de la parte resinosa, $y$ el producto es igual al de los otros vehículos. La proporción ha sido de treinta y uno y cuatro décimos por ciento de resina disuelta.

Es notable la acción que tiene el ácido acético concentrado sobre ol archipín: aun simplemente triturado éste con el ácido, se favorece su desprendimiento, que es como el que se advierte cuando se trata por el ácido sulfúrico un acetato anhidro. I el ácido una masa viscosa algo transparente y sin el aspecto lechoso que presenta cuando es tratada aquélla por el agua: la adición de ósta á la solución acética la determina en el acto. La cantidad dismelta por el ácido corresponde á un treinta y cuatro por ciento, $y$. de las sesenta $y$ seis no distzeltas, lo son por el agua treinta y uno.

El ácido acético no sólo disnelve la resina; á la vez descompone el gumato de cal, combinándose con esta base.

Ei ácido sulfúrico mono-hidratado ofrece también reacciones no. tables. En su primer contacto presenta el archipín una coloración rerde, que desde lnego pasa al rojo, despnés al de guinda claro y al fin obscuro: agregando un poco de alcohol á la solnción sulfúrica, toma un color semejante al del vino carlón. Presumo que estas coloraciones provengan del ácido múcico producido por la acción del sulfúrico, como sucede por el tratamiento de las gomas con el azótico.

Fl agua, sea sola ó conteniendo alguna base soluble, determina la precipitación de la resina en la solución sulfúrica.

El ácido azótico reobra activamente sobre el archipín; desprende vapores r'utilantes: hay notable elevación de temperatura, coloración de un amarillo rojizo y formación de una costra deleznable, que me he asegurado ser formada por la resina. El líquido, tratado debidá mente, da ácido múcico.

El ácido clorhídrico, $y$, en general, los ácidos débiles, así como las 
soluciones alcalinas, disuelven las gomas: ésta es precipitable por el alcohol.

El archipín, sometido á la combustión, deja por residuo un centésimo, por término medio, de una ceniza blanca, porosa, casi insoInble en el agua, pues el producto de la eraporación, apenas da una mancha formada por pequeñísimos cristales, que parecen ser de cal sulfatada. Tratada la parte insoluble de la ceniza por el ácido clorhídrico, es disuelta con efervescencia, casi en su totalidad, y en la solución se descubre la presencia de la cal, y restigios apenas apreciables de magnesia. Ni en las cenizas ni en las soluciones del archipín he laallado otras bases ni sales particulares.

Formando el resumen de lo expuesto, diré:

Primero. Que se ignora hasta hoy cuál sea el regetal que produce la goma archipín y, por lo mismo, la familia á que pertenece: pres . aunque un botánico la presunido que pudiera ser la Burserce grumméfera de L., familia de las Terebinthaceers, todas las probabilidades están en contra, supuesto que el archipín es muy diverso del C'rchibou de las Antillas, llamado también resiua de Gommort ó del gomero blanco.

Segundo. Que el archipín es indudablemente ma gomo-resina, cuya composición sobre cien partes puede fijarse en la sigujente:

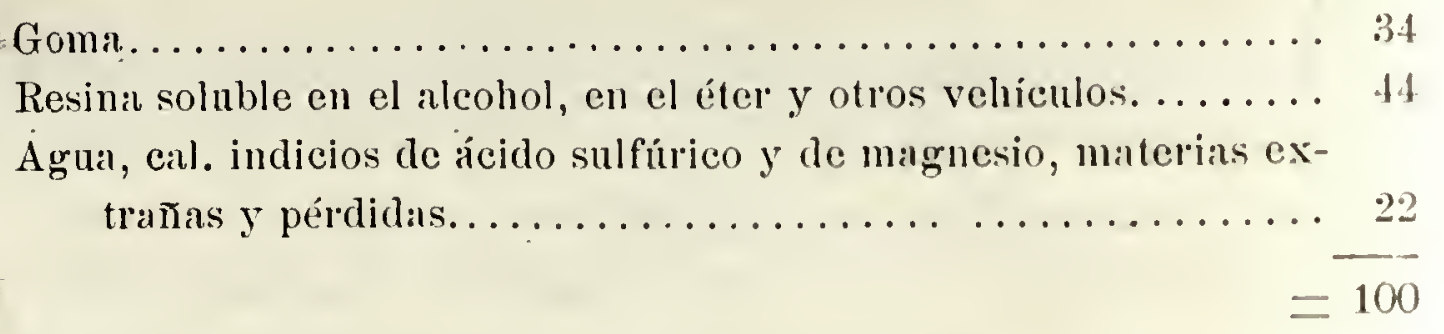

Tercero. Que hasta alora no se tienen las observaciones y datos suficientes para decidir ni en pro ni en contra sobre las propiedades pectorales diuréticas y vulnerarias que se atribuyen al archipín.

Cuarto. Que atendiendo á la naturaleza y propiedades de csta gomo-resina, convendría estudiar su acción fisiológica y terapéntica, así como sus aplicaciones industriales.

Quinto y último. Que sean las que fueran, conviene llenar el racío que se nota relativo á la etimología de la voz, á la clasificación del regetal, á los lugares en donde se encuentra y á los usos del archipín. 


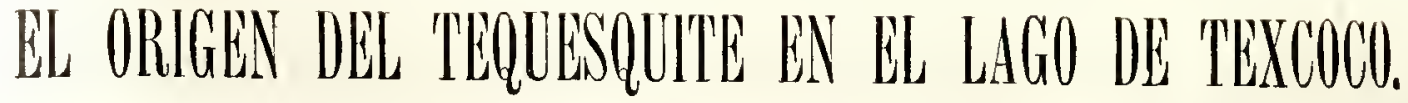

\author{
ARTICULO DEL SR. D. LEOPOLDO RIO DE LA LOZA.
}

Es un hecho, que desde tiempos muy remotos, el lago de Texcoco ha sido una mina inagotable de sales, entre las que figuran, como principales, el carbonato de sosa y el cloruro de sodio ó sal común; ocur'e desde luego preguntar: ¿cómo no se ha agotado esa mina y de dónde vienen tan útiles productos? Oreen unos, que arrastradas por las lluvias algunas rocas feldespáticas y en contacto con los terrenos calcáreos; se despiertan reacciones cuyos productos son las sales que encontramos en las aguas del lago, y que en virtud de la evaporación cristalizan confusamente en los terrenos desecados. Tal aseveración me parece destituida de fundamento, por dos razones principales: es la primera, que no creo fácil la descomposición de los feldespatos, en las condiciones en que se hallarían en la laguna; y la segunda, que no me parece corresponder la proporción de sales contenidas en las aguas, ni aum sólo las explotadas, á la que pudiera suponerse procedente del feldespato; contaremos, además, que no obstante haber hallado en el agua más de tres milésimos de potasa, mayor habría debido ser la cantidad, si todas las otras sales tuvieran su origen en la descomposición de aquellas rocas. De aquí debo inferir, que por mucha parte que se les quiera dar en la producción de las sales, sería muy dudoso que á ellas debieran únicamente su origen.

La segunda opinión, acaso más admisible á la primera vista, deja de serlo después de algunas reflexiones. Se supone que existió en èl lago, ó en comunicación con él, un banco de sal gema sobre la,cual 
obran las aguas continua y regularmente. Yo no creo que exista tal banco; lo primero por considerarse dificil que pasaran siglos sin hatberlo descubierto; lo segundo, porque en ese tiempo, y atendiendo al consumo considerable y continuado, hubiera desaparecido totalmente; y lo tercero y principal, porque no se conoce la cavidad ó profundidad correspondiente á la enorme masa que había sido disuelta.

Si no hay error en las razones de oposición á las dos teorís, es preciso buscar en otras partes el origen de esas sales, de esa fuente de riqueza vista con tan poco aprecio, pero de cuya utilidad no puede dudarse. Yo creo que los habitantes del gran Valle de México, las lluvias, los agentes físicos, los fenómenos meteorológicos, el depísito final de aguas y las reacciones químicas, son otros tantos eslabones de una cadena sin fin, que constantemente produce, modifica y ruelve á reproducir las sales principales de que he hecho mérito, á saber: el carbonato de sosa y el cloruro de sodio. Presentaré los datos en que apoyo esta opinión, y el lector juygará del valor que puedan toner.

Según las análisis más recientes, los excrementos humanos contienen, por término medio, sobre cien partes, 2,367 de sosa y 0,780 de cloro: los de los cuadrúpedos, 2,420 de la primera y 0,193 del segrmdo. Yo quiero suponer, que por las diferencias de edades, las pórdidas, el estado patológico y otros accidentes, sólo sea aprovechado un dos por ciento, y que en atención á estas y otras causas, la calltidad de excrementos humanos correspondiente á cada individuo, en rointicnatro horas sólo sea de doscientos gramos; de lo que resultaría, en consecuencia, cuatro gramos diarios de sosa por individuo. A 111 que la cantidad de excremento es mucho mayor en los animales, quiero, para el fin á que me dirijo, suponerla igual, por ser menor sul número y de más fácil desperdicio, es decir, que sólo supondré otros cuatro "gramos de la misma base de sosa, es claro que, cuando menos, tendríamos ocho gramos diarios de sosa conducidos por las aguas al depósito general, con más, la cantidad proporcional de cloro.

Veámos el segundo dato.

Conforme á la estadística más completa y casi oficial, la población del Distrito es de 269,534, y la del resto del Valle, 196,289. 'Total de habitantes, 465,823 .

Aplicamos á esta suma el cálculo anterior, es decir, suponiendo siempre el mínimo de cuatro gramos de sosa por indiridno, resultarán en cada veinticuatro horas, $1,863^{\mathrm{k}} 292$. 
Mas habiendo supuesto igual cantidad procedente de los cuadrúpedos, hechas todas las compensaciones, $1,863^{\mathrm{k}} 292$, tendremos un total de $3,726^{\mathrm{k}} 584$ diarios, ó sea en cadä año, $1.360,203^{\mathrm{k}} 160$ de sosá. Por enorme que parezca esta cantidad, aun hay algo que agregar. Sólo me limitaré á estimar la sosa proveniente del jábón consumido por los habitantes del Valle, el cnal, siendo arrastrado y descompues: to por las aguas, deja la sosa al estado de carbonato; esta teoría es indudable.

Si fijamos en kilogramos el mínimo que anualmente consume cada habitante en su persona y lavado de ropa, y si tomamos el promedio que contienen los distintos jabones, estimándolo en un ocho por ciento de sosa, es decir, ochenta gramos por individuo, siendo 465,823 los habitantes del Valle, resultan $37,265^{\mathrm{k}} 840$ gramos de sosa, cuya cantidad, agregada á la anterior, procedente de los animales, da un total anual en kilogramos, de 1.397,469.

Para mayor seguridad en cuanto á este cálculo, he tomado informes de buena fuente, á fin de conocer la cantidad de jabón que comúnmente se fabrica cada año en la ciudad, y resultando como míninino 138,500 arrobas, ó sean 1.593,581 kilogramos, he supuesto que sólo una mitad es consumida en el Valle, á saber: $796,790^{\mathrm{k}} 5$, que dividido por èl número de habitantes, resulta corresponder á cada uno, $1^{\mathrm{k}} 710$, es decir, que nada hay exagerado en aquel cálculo.

Debe tenerse presente, que no hago mérito de la sosa ni del cloro procedentes de las orinas de los bípedos ni de los vegetales, de las aguas y de innumerables deshechos, que conteniendo esas substancias, llegan definitivamente al lago, no siendo exagerado estimarlos en una mitad de aquella suma, quiero, al contrario, que ésta se rebaje á la mitad, á un tercio aún, y siempre se tendrá conocido el origen de esas sales y demostrado al mismo tiempo, que hay una admirable circulación salina acompañada de una serie no interrumpida de reacciones tan curiosas y variadas, que la imaginación se pierde al contemplarlas. Sin hacer mérito de los feldespatos, ni de los bancos de sal gema, y sin forzar en nada la imaginación con sólo teorías, se tiene, según creo, explicado satisfactoriamente el hecho de que hayan transcurrido siglos sin haberse agotado esas dos sales tan importantes y útiles, diré mejer, tan necesarias á la mayor parte de las industrias, á las plantas, á los animales, y, sobre todo, á la salud del hombre. 
De todo lo expuesto es fícil inferir: $10^{\circ}$ Que el lago de Texcoco es un depósito de grande importancia para México, ya se considere desde el punto de vista hidraúlico, ya industrial ó ya médico. 2. ${ }^{\circ}$ Que es una fuente inagotable de productos, tanto salinos como alimenticios. $3 .^{\circ}$ Que ejerce una influencia marcada y muy poderosa en la insalubridad del Valle. $4 .^{\circ}$ Que la ciencia tiene medios para evitar ó, cuando menos, para disminuir esa influencia. $5 .^{\circ}$ y último. Que su misma importancia exige que sea atendido convenientemente y no continúe abandonado como lasta aquí. 


\section{AZUFRE Y SALITRE}

(Tomado del Periódico de la "Sociedad Filoiátrica de México." Publicado por el Sr. Dr. D. Leopoldo Río de la Loza).

Parecerá bien extraño ocuparse en un periódico de medicina, de los perjuicios que ocasiona el estanco del salitre y del azufre; mas si se atiende á que tal prohibición sirve de demora á la enseñanża y progreso de una de las ciencias auxiliares de la medicina; á que son indispensables para la preparación de muchos medicamentos de uso común, y, en fin, á que ocupándose hoy el legislador de tan interesante asunto, deben tomar parte todos los que puedan contribuir con sus reflexiones á ilustrar la materia, no se extrañará que los médicos consagren algunas líneas á favor de las ciencias, de las artes, y, lo que es más, á favor de su patria, por cuyos adelantos se afanan.

La medicina quedaría estacionaria, si la química no contribuyera á sus descubrimientos, si no le hiciera conocer las reacciones de los simples, las proporciones de los compuestos, los agentes que modifican su acción, los que la aumentan y los que descubren su naturaleza; si no hiciera palpables las alteraciones á que están sujetos los sólidos y líquidos del cuerpo humano, la dislocación de sus componentes, la falta ó exceso de algunos ó de todos sus principios y el influjo que ejercen sobre los seres de la Naturaleza; esos elementios indispensables á su existencia, y que mezclados en determinadas proporciones, constituyen la atmósfera que los mantiene y vivifica, $o ́$ los que los marchita y destruye en circunstancias especiales. Ia química, que es tan necesaria á la medicina, no sirve menos al agricultor $y$ al fabricante, $y$ aun al legislador $y$ al juez. Esta ciencia no 
puede enseñarse, ni menos aprenderse, si faltan los agentes más útiles, rnás generales y más necesarios para obtener los principios elementales de los cuerpos, para procurarse inuumerables compuestos y para conocer la naturaleza de otros. En vano el discípulo estudiará una teoría en su libro, en vano verá pasar como un telámpago el experimento del catedrático, si no examina por sí los hechos, si no los compara con las teorías y 110 procura fijarlas con sus observaciones y práctica. Nada de esto es compatible con el subido precio de los ácidos, para cuya preparación son indispensables aquellas materias, $\mathrm{y}$ tales compuestos han de valer mucho mientras subsista el estanco peligroso, cuyo único apoyo ha sido el infundado concepto de que farorece al erario.

A éste le es más conveniente atender á la riqueza pública, la que sin duda aumenta con los progresos de las ciencias naturales, y muy particularmente con los de la física y química. Tue es más útil tener buenos médicos, mineralogistas prácticos, fabricantes discretos, agricultores previsores y militares científicos, que aumentar la caja pública con dos ó tres millares de pesos, fruto de ese bárbaro é imprudente moinopolio, que no remedia sus necesidades. Tue es más necesario nivelar la industria del país con la de los más civilizados, favorecer las exportaciones, proporcionar medios honrosos de subsistencia, proteger el comercio interior, y disminuir, cuanto más se pneda, las pasivas relaciones mercantiles con las otras naciones, que el dictar leyes prohibitivas que no han de ser respetadas.

Le es, en fin, más necesario caminar con la época de iltistración, que oponerse al impetuoso torrente de las investigaciones y descubrimientos.

No debe olvidarse que hay semillas que, una vez ariojadas, germinan sin cultivo, sea cual fuere la fertilidad del terreno. México ha despertado de un letargo profundo y duradero, pero reparador $\mathrm{y}$ benéfico; ha conocido las inmensas ventajas que propoiciona el cultivo de las ciencias naturales; no se le ocultan las innumerables $y$ útiles aplicaciones de la química, la amenidad de sus operaciones, la exactitud de sus doctrinas y la necesidad de generalizar su estudio y de que forme parte de la buena educación. Ve que en cada nuera fábrica que se establece, que en cada industria que se proyecta, J en cada establecimiento que se reforma, tiene que ocurrir á la química para resolver mil cuestiones, perfeccionar los procedimientos, eco- 
nomizar gastos, aumentar los productos y aprovechar los muchos que encierra el riquísimo terreno que le pertenece, virgen aún en varios puntos poco conocidos y mal explotado en otros. Ve también que por esa falta de conocimientosno se multiplican los mediosde subsistencia, no se encadenan las artes, y fácilmente se arruinan las más seguras empresas. Ve, por último, y es lo más monstruoso que puede verse, leyes que instalan cátedras de química en los establecimientos de agricultura é industria, en el Colegio Militar, en el de Minería, en el de Medicina, etc., y leyes de la misma época que declaran estancados el azufre y el salitre; decretos que reforman esos establecimientos y otros que se oponen á sus adelantos; disposiciones á favor de los mineros y otras en que se les obliga á pagar á peso de oro las primeras materias indispensables á sus labores. Tal estado no puede existir si de buena fe se quiere proteger la enseñanza secundaria, si se desea aumentar el erario, favorecer la industria, mejorar la agricultura, y atender, en fin, á los ramos más útiles y productivos, íntimamente relacionados con las ciencias exactas, y muy particularmente con la física y la química.

Un vivo deseo de que la actual administración no lleve por más tiempo la fea nota de la anterior, de que se consideren las necesidades del público, de que progresen las ciencias y de que sean atendidas las juiciosas y sólidas reflexiones de la junta de industria, ha dictado estas líneas, que es de esperar no sean infructuosas en la sabia y patriótica consideración del legislador. 


\section{CISTINTA.}

(Tomado del Periódico de la "Sociedad Filoiátrica de México." Publicado por el Sr. Dr. Don Leopoldo Kío de la Loza).

Uno de los servicios más importantes que ha prestado la química á la medicina, es el dar á conocer la composición de los cálenlos urinarios. La facilidad de hacer llegar á este aparato las sulsstancias medicinales; la propiedad que tienen algunas de formar comprestos solubles y aun delicuescentes, y la acción especial de muchas, proporciona un medio fácil y seguro, en ciertos casos, de evitar los dolores de una operación, y los crueles padecimientos á que, por lo común, están sujetos los enfermos por la presencia de esos cálculos en algín punto del aparato urinario.

Sin embargo de las innumerables análisis que han hecho hasta ahora los químicos más distinguidos, no han hallado cálculos cuya composición sea tan variada, que el examen de su naturaleza exija grandes trabajos y profundos conocimientos; por el contrario, hay algunos que muy raras reces se encuentran, y que, por lo mismo, apenas han podido estudiarse, fijando únicamente los caracteres más notables que los distinguen de los demás. A este número pertenece la cistina de Thenard ú óxido cístico de Wollaston, substancia que no se me había proporcionado examinar, hasta estos últimos dáas, que los Sres. Muñoz y Vértiz, casi á un mismo tiempo, la han reco- 
gido de las orinas. Dos particularidades ofrecen, que creo dignas de notarse: la primera, la cristalización perfecta de una de las porciones; la segunda, la solubilidad de ambas en el ácido acético, y, porlo mismo, el no ser precipitada por dicho ácido, de la solución alcalina.

En cuanto á la cristalización, ninguno de los autores que ha llegado á mis manos le da forma; sólo aseguran que es confusa, y la que presento á la Sociedad con el número 1, es tan perfecta, que aun á la luz artificial se distinguen bien los prismas de que hablaré después. Su blancura debe igualmente llamar la atención, pues que la cistina examinada hasta ahora, es amarillenta, como la que se ve marcada con el número 2. Una y otra se disuèlven en los ácidos acético, sulfúrico, clorhídrico y azótico; también se disuelven en la potasa y el amoníaco cáusticos; son insolubles en el agua, el alcohol y el carbonato de amoníaco; las soluciones ácidas dan por la evapolación agujas nacaradas, fáciles de distinguir. En cuanto á los caracteres negativos, sólo diré que no dejan confundir esta substancia con ninguno de los compuestos ó productos de la orina. Y si á las propiedades mencionadas que ofrecen los compuestos de que se trata, se agregan las que presentan al soplete, y que son comunes con el ácido úrico, como lo son los de la cistina, se convendrá en que no es más que la que describen los autores con este nombre, y en que es digno de notarse el que se presente en cristales perfectos.

El examen microscópico de éstos, hace ver claramente que son, enl su mayor parte, prismas cuadrangulares perfectos; que algunos están truncados oblicuamente en un extremo; otros presentan dos caras anchas y dos angostas, biselados en ambos extremos sobre las caras más anchas; hay también tablas cuadrangulares, rectángulas biseladas en todas sus aristas, $y$, por último, prismas cilindroides rectos y curros. Es también de notar, que la cistina marcada con el número 2, presenta algunos prismas cuadrangulares perfectos, $y$ agr'upamientos formados por éstos y más ó menos regulares. Mi amigo, el Sr. Don Domingo Lazo, ha encontrado, al examinar el número 1. cristales de color azul, nueva particularidad que merece estudiarse,

En cuanto á la insolubilidad de la cistina, nada extraño es que, al examinarla, los autores que se han ocupado de ella, le señalarán este carácter particular, no teniéndolo realmente, supuesto que han sido tan pocos los que la han hallado, y supuesto también que no hayan tenido á su disposición la cantidad suficiente para repetir los expe. 
rimentos. Tampoco será extraño, y sí lo más probable, que en efecto presente alguna vez esa propiedad, y que yo no la haya encontrado en las dos que están á la vista, porque varíe el estado molecular, lo que le haga también variar de propiedades, como sucede con otros muchos cuerpos. El tartrato bórico-potasio oficinal, preparado con cuatro partes de bi-tartrato de potasa y una de ácido bórico, no siempre es soluble en dos reces su peso de agua fría, y cuando no lo es, basta disolverlo al calor y eraporarlo convenientennente para que se haga soluble.

Las propiedades químicas y físicas de los cuerpos, pueden variar y varían, en efecto, de los isoméricos, mudando ó no el peso de su átomo, así es que bien puede considerarse como isomérica la cistina examinada, con la que han dado á conocer los antores, fijando como propiedad química especial, el ser soluble en el ácido acético, y como propiedad física, la cristalización prismática de que lıe hablado ya. Esto es, sin duda, más sencillo y natural, que el dar como cuerpo nuevo, el coimpuesto de que me ocupo, sólo porque ofrece los dos caracteres mencionados, y más cuando es idéntica su íntima conposición con la cistina, enyo origen y propiedades son conocidas de todos.

Antes de concluir, debo indicar la utilidad práctica que puede sacarse del examen de las substancias mencionadas y las leflexiones á que da lugar.

Sin duda que ni la inrestigación microscópica, ni la analítica, pueden servir para conocer el asiento y la naturaleza de la enfermedad; mas si se trata solamente de evitar la formación de cálenlos urinarios; si se pretende que desaparezca el precipitado que dejan las orinas de los enfermos, de quienes procede esa cistina, y si no hay otro medio de curación conocido, debe administrarse el ácido clorlídrico en agua azncarada, á fin de llenar tres indicaciones á cual más importantes: primera, regularizar la secreción folicular y glandular del aparato urinario; segunda, cambiar la composición de la orina; y tercera, impedir la precipitación de la cistina. Sin duda que el estado de los enfermos debe arreglar la conducta del médico, y servir de mucho para fijar la dosis del medicamento.

En cuanto á la parte química, creo útil dar á conocer ese nuero estado molecular de la cistina, porque prueba, sin duda, que el ácido úrico no sólo puede hallarse libre ó combinado con las bases, sino también presentar, por la modificación que sufre, los caracteres de 
aquélla, así como la combinación en cristales perfectos, solubles en el ácido acético.

¿ Por qué esa rara coincidencia, de que en una misma época se haya obtenido la cistina de las orinas de dos enfermos, siendo tan rara su presencia en ellas? Cuestión es esta que acaso podrán resolver los profesores que asistan á aquéllos, conformándose, por ahora, en presentar el resultado de mis observaciones. 


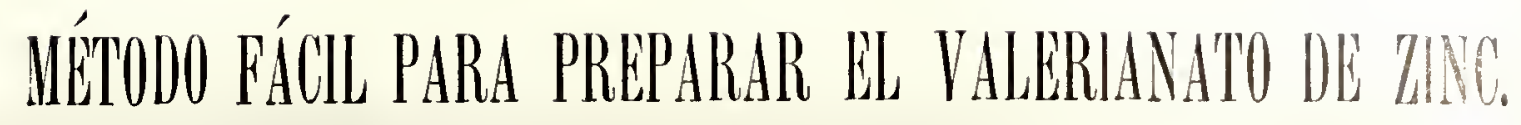

(Tomado del Periódico de la "Sociedad Filoiátrica de México." Publicado por el Sr. Dr. Don Leopoldo Río de la Loza).

El uso que comienza á tener este remedio, obligará á los farmacéuticos á prepararlo, y muchos habrá que, careciendo de los autores que tratan de él, tengan que procurárselo del comercio, que puede estar adulterado, como sucede, por lo común, con los medicamentos de algún valor. Los procedimientos indicados en las obras de química son más ó menos complicados, y algunos hay que no carecen de inconvenientes. El que ahora propongo, es, sin duda, más fácil y sencillo, habiendo tenido ocasión de ensayarlo con buen resultado, aunque nunca dudé ni habrá quien dude del éxito.

Mi método consiste en reducir á polvo grueso la rá́z de valeriana del país; dejarla en macaración por 24 horas, con doble de su peso de agua pura; obtener por destilación la mitad del líquido empleado; saturarlo por el carbonato de cal; filtrar el líquido y descomponer el valerianato por la cantidad precisa de sulfato de zine muy puro; volver á filtrar para separar el sulfato formado; eraporar dos tercios del líquido y repetir la filtración y la evaporación para que cristalice; las aguas madres darán nuevos cristales, que se redisuelven con los primeros para repetir la cristalización, secando después el producto entre hojas de papel de estraza.

No debe hacerse uso de aguas alcalinas para la destilación, porque se pierde una parte del ácido; el sulfato de zinc ferruginoso altera el producto, y aun usando del puro, jamás debe emplearse en mayor cantidad de la muy precisa para descomponer el valerianato, 
debiéndose preferir que haya un poco más de éste que de sulfato, para lo cual basta agregar, después de la precipitación, la cantidad necesaria de valerianato, á fin de descomponer totalmente el sulfato soluble; por último, la segunda filtración, antes de cristalizar la sal, hace que se obtenga enteramente pura, hidratada, soluble, blanca, con el olor característico de la raíz de valeriana, y con el gusto azucarado y estíptico que le es propio, é igual á la que se prepara por -l método directo. De paso recomendaré otra modificación económicar Lecha á éste, que consiste en substituir el carbonato de sosa al de potasa que aconsejan los autores.

Wil poco tiempo de que he podido disponer, no me ha permitido señalar los mejores, reactivos para asegurarse de la pureza de esta sal; pero sí indicaré que el ácido oxálico y los oxalatos dan abundantes precipitados blancos, como los valerianatos de cal y de zinc; que el amoníaco no forma precipitado con ninguno de éstos, y que el cianuro férrico-potásico ó prusiato rojo, apenas enturbia el último. Oreo, por lo dicho, que debe estudiarse con alguna atención, comprestos tan particulares, que acaso serán remedios heroicos, si se administran convenientemente.

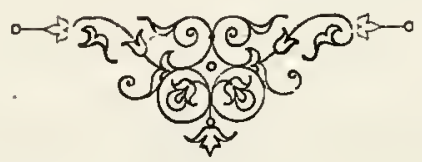




\section{QUÍMTCA.-NUEVO PAPEL REAUTTYO}

(Tomado del Periódico de la "Sociedad Filoiátrica de México." Publicado por el Sr. Dr. D. Leopoldo Río de la Loza).

Aunque tenemos en mestro país muchas materias colopantes regetales, propias para la preparación de papeles reactivos, se ve, con sentimiento, que la mayor parte del que se consume en la República, es traído de Europa. Yo he usado por mucho tiempo los pétalos conocidos en el comercio con el nombre de rosilla (C'metina tuberosa), y en adelante mo propongo dar la preferencia al teñido con el zumo de zal'zamora (Rulms fincticosus), porque creo reune ventajas sobre la rosilla, la violeta del país (Sidu trilobo), ol rábano, ete.

El zumo de zaryamora se fija tan fácilmente en el papel sin cola, que basta sumergir éste en un poco de tiempo en el liquido depurado, para tenerlo de color igual, y con la particularidad de quo puede secarse al sol, sin que por esto se altere. Así preparado, no sólo silve para indicar la presencia de un áleali, sino que puede liacer distinguir unos de otros, porque, según parece, la leacción no os mat con todas. Con el amoníaco, por ejemplo, es mucho más sensible que con la potasa, la sosa y la cal, y am el mati\% valía con cada muo.

No obstante, sobre esto no he hecho todas las experiencias necesarias por falta de tiempo, y porque hasta alora puedo decir que apenas he descubierto la útil aplicación que puede hacerse del zumo de la zalzamola.

También creo que esa materia colorante puede servir para dar color al algodón, al cáñamo y al lino; así es que, con un poco de 
estudio, se hará un importante servicio á la industria manufacturera y á la agricultura.

Al dar á luz estos apuntes, aun antes de poder presentar el resultado de mis observaciones, me propongo llamar la atención de los profesores, esperando que contribuirán con sus trabajos, á los adelantos de nuestra naciente industria.

A este fin he creído conveniente presentar una muestra del papel de zarzamora, que aunque no está preparado más que con el zumo depurado y sin saturar una parte de su ácido, como debe hacerse, es lo bastante para que el que guste pueda ensayarlo, apreciar su utilidad y aun prepararlo mejor.

También debo recomendar el jarabe de zaryamora como uno de los inás gratos al paladar, como reactivo, y como uno de tantos subácidos, que puede ser útil en algunos casos. 


\section{A工MEJAS.}

\section{(Tomado del "Periódico de la Sociedad Filoiátrica de México." Publicado por el Sr. Dr. D. Leopoldo Río de la Loza.)}

Con este nombre se conoce en la República m molúsculo de la clase de los Acéfalos, género primero de la familia de los Ostraseos. No sé que hasta ahora se hayan ocupado los médicos de nuestro país en estudiar estos animales, y conocer sus efectos sobre la cromomía, lo que creo de algún interés, tanto porque son usados como alimento, como porque se les atribuye la propiedad de causar males agudos, que se han considerado por algunos como verdaderos envenemanientos, $y$ aun se ha fijado la época del año en que determina con más fiecuencia esas alteraciones particulares.

Nuestras almejas son testáceos de agua dulce, de pequeño tamaño, compuestas en su mayor parte de albúmina, moco y una pequena cantidad de las sales calizas que forman sus conchas, yon el carbonato y el fosfato de cal. Esta composicion tan simple, daría suficientes garantias para no tener funestos resultados de su empleo, si la experiencia no hubiera demostrado la insuficiencia de las análisis en la inrestigación de las substancias regeto-animales. El hecho es que hay persomas que no digieren las almejas, y que son atacadas de gastro-enteritis grares, que en algmos casos terminan con la muerte.

El pequeño tamaño de estos animales hermafroditas, el no abundar en las inmediaciones de esta capital y, sobre todo, lo desabrido de ellos, hace que más bien se condimenten con otros manjares, como el arroz, que el que formen por sí un platillo especial. Sólo las to- 
man entre nosotros las personas de la clase media y suprema, pues la ínfima, que no en todo tiene depravado el gusto, ve con desprecio un alimento tan poco agradable y proporcionalmente costoso.

Desde luego llama la atención el que las almejas de nuestro país no determinen la urticaria ni los síntomas de narcotisno, que, según se dice, ocasionan los animales del mismo género que se toman en otros países. Yo á lo menos no lre visto ni sabido de algún caso de esta especie, como tampoco he observado si tienen la propiedad de endurecerse en el alcohol, de disolverse en el vinagre y de descomponerse ó cortar la leche, como las de Europa. Para mí, no tienen las alinejas el menor atractivo, ni como manjar, ni como analéptico, ni menos creo que los males que ocasionan sean debidos al veneno que se supone abunda en ellas en la época que media del mes de Mayo á Septiembre.

No es, sin embargo, fuera del caso, liacer estas indicaciones, tanto porque corresponden al plan que me he propuesto seguir, como porque deseo oir las observaciones recogidas por los socios de la confraternidad médica, para decidir fundadanente sobre las ventajas é inconvenientes que resultan de su empleo.

En cuanto á los efectos terapéuticos que se atribuyen á las conclras de las almejas, basta conocer su composición, para inferir que se lian recomendado como otros muchos amuletos, sin que en realidad tengan más propiedades que las comunes á los fosfatos y carbonatos de cal.

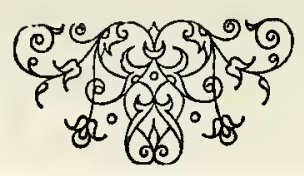




\title{
DROGAS MEDICINALES
}

\author{
(Tomado del Periódico de la "Sociedad Filoiátrica de México." \\ Publicado por el Sr. Dr. D. Leopoldo Río de la Loza.)
}

Es muy interesante al médico saber los firaudes que, por lo comín, se advierten en las drogas medicinales más usadas, y creo, por tanto, que dando á conocer algunos de los que he observado, llamo la atención de los dignos miembros de la Sociedad Filoiátrica á un objeto de utilidad práctica. Es preciso advertir que no todos los medicamentos alterados lo son fraudulentamente; un error de doctrina, el hábito ó la poca reflexión, hacen muchas ocasiones que no se despachen las substancias medicinales, tales como las pide el médico, y como supone que deben ser. Ja costumbre introducida, de algmos años acá, de preparar solamente los emplastos y los ungiientos, los aceites y los jarabes, es, sin duda, lo que más expone al farmacéntico, lo que hace que se confunda el médico y peligre en muchos casos la salud y la rida del enfermo. Para comenzar á desterrar estos abusos, es preciso señalarlos, y aunque sólo haré mención de algunos en este escrito, por tener que sujetarme á determinado tiempo, procuraré ocuparme del mismo asunto en los turnos venideros, limitándome, por ahora, á hacer simples indicaciones, bastantes para prevenir á los profesores que hagan uso de las substancias siguientes:

CoDé́xA.-De tres maneras se ocasionan perjuicios al despacharla. 1.o, por hallarse mezclada con morfina; $2 .^{\circ}$, por substituirla con ésta, y $3 .^{\circ}$, por disminuir la dosis prescrita. Ia mayor parte de 
la codeína que hay en las oficinas, se halla en el primer caso, y aunque no puede decirse que de esto resulte un grave mal, es, sin duda, muy conveniente cuidar que sea enteramente pura. Los profesores médicos harán bien pidiéndola á las oficinas, sola, para evitar en lo posible el engaño, pudiendo así distinguirla de la morfina, y apreciar la cantidad, lo que, sin duda, no es fácil, cuando se manda disolver en las bebidas ó mezclar con otras substancias.

Morfina Y sales de MORFina.-Sigue usándose el acetato impuro, sobre cuyo abuso he escrito ya: mas hay que señalar otro no menos pernicioso. Cnando se prescribe la morfina ó sus sales en pomadas, aceites, etc., se disminuye la dosis para bajar el importe de la receta, á fin de atraer al marchante, seguros los que esto hacen, de la impunidad del fraude. Otro tanto sucede con la veratrina, la estricuina, y en general con los medicannentos valiosos, que también se inezclan torpemente con substancias inactivas, que casija más se reconocen al tomarlas de las droguerías.

LAC'NUCARLo.-Se ha generalizado tanto el nso del extracto de Techuga como sucedáneo del lactucario, que algunos médicos lo han abandonado como inútil, y otros han aumentado considerablemente la dosis: así es que aun cuando el farmacéutico despachara el verdadero lactucario, tendría que modificar la dosis, lo que, por lo común, no es conveniente, ó se expondría á causar un mal realmente sin culpa del médico. Menos activo que el opio, el lactucario es narcótico, y por lo mismo, siempre que se use en buen estado, y se tenga de él entera confianza, debe administrarse en cantidades proporcionadas.

TAyryo.-Parecerá incréble que siendo tan conocidos hoy los procedimientos económicos para obtener en abundancia este ácido orgánico, sean tan repetidos los casos en que se substituye con extractos mal preparados, y cuya acción sobre la economía, no puede compararse con la del tanino: mas el hecho es, que hay boticas en México, en donde no se tiene presente la baja del precio, ni las propiedades particulares del ácido, para despacharlo tal como debe ser.

Ácodo ać́troo.-Si sólo se destinara para uso externo, poco importaría su mayor ó menor concentración, $y$ el que contuviera substancias que alteran su pureza, como sucede con el de comercio; mas el gran consumo que se hace actualnente del acetato de amoníaco, obliga al farmacéutico á desechar el que contiene cobre ó algunas sales que se añaden para hacer que parezca más concentra- 
do de lo que realmente es. Creo, por lo mismo, que para no exponerse, debe purificarse por la destilación, annque se aumente por esto el valor del acetato y demás preparaciones hechas con él.

Acodo Bórico.-La pureza de este ácido es también de alguna importancia terapéutica, porque son bien conocidas las ventajas del crémor soluble que lo contiene. El ácido bórico natural, que es el más abundante en el comercio, necesita ser purificado antes de emplearlo, y la experiencia enseña que es más económico y seguro obtenerlo de la descomposición del sub-borato de sosa, pues trabajando para esto tanto como para purificar el nutural, se obtiene de mejor calidad. De paso adrertiré, que no falta quien substitnya el crémor soluble con el túrtaro soluble, aun cuando esto no se haga de mala fe.

Nitrato de Plata.-Es muy común usar el fundido, an cuando se prescriba el cristalizado, fijando poco la atención en la impureza del primero y en su poca solubilidad. Las substancias medicinales, cuya dosis debe señalarse escrupulosamente, deben también prepararse con cuidado, pues no es de tan poca importancia el mal que pueden cansar aun los remedios del uso externo, pudiendo servir de ejemplo el nitrato de plata.

SULFATO DE sosa.- En el del comercio se encuentra generalmente un exceso de base, que no sólo disminuye Ia propiedad purgante de esta sal, sino que causa muchas reces inflamaciones grares. Además, como el sulfato se florece fácilmente, perdiendo la agua de cristalización, varía la dosis que se pretende dar á los enfermos: estos inconrenientes y su mal sabor, me han decidido á preferir el sulfato de magnesia. El procedimiento operatorio que tanto se ha generalizado hoy, y puse en práctica el primero, que consiste en descomponer el sulfato de cal por el carbonato de sosa, exige repetir la cristalización, ó cuando menos lavar bien los cristales para privarlos del cloruro de calcio que suelen contener, y aunque en pequeña cantidad, hace variar el efecto del medicamento.

Magnesid Calcrnada.--Se ha exagerado tanto la dificultad de conservarla en buen estado, $y$ se han confundido de tal manera las propiedades medicinales de ésta, con las del carbonato, que lo mismo es pedir una ú otra. Afortunadamente han podido apreciar algunos médicos los buenos efectos de la magnesia bien calcinada, siempre que han estado satisfechos de su pureza. En las oficinas de algún despacho se conserva muy bien la magnesia, teniéndola en ponos 
bien tapados y de mediana capacidad; mas si se nota que hace efervescencia con los ácidos débiles, debe repetirse la calcinación ó usarla como carbonato de magnesia.

Éter acḱtco.-Aunque es uno de los más usados, rara vez se encuentra en buen estado, aun para usarlo al exterior. Todavía hay algunas oficinas donde se prepara, destilando agnardiente y vinagre común en proporciones iguales: otras, en las que,se agrega un poco de ácido sulfúrico, y otras, en fin, que descomponen por el mismo ácido el acetato de plomo, mas en tan pequeña cantidad, que apenas se forma una insignificante de éter. Rarísima vez se cuida de que el producto de la destilación no contenga ácidos libres, lo que notablemente perjudica al buen efecto del medicamento. La rectificación es una de las operaciones que puede asegurarse que no se acostumbra hacer en México, porque se supone de poca importancia. Es fácil descubrir, por el gusto, cuándo el éter contiene ácido, y por el olor que es característico, el que está bien preparado de la simple mezcla de alcohol $y$ vinagre.

Aunque es muy frecuente hallar en el éter sulfúrico del comercio, mayor ó menor cantidad de agua y de alcohol, esto no perjudica, sino porque impide fijar la dosis del medicamento; mas no sucede lo mismo con el éter hidroclórico medicinal, pues además de que casi sólo es alcohol, en la mayor parte de las oficinas se substituye con lo que se llama vulgarmente espíritu de nitro dulce, suponiéndose, sin fundamento, que obran de un mismo modo.

Para concluir, señalaré otro frande muy común, aunque parezca insignificante. Ia mayor parte del jarabe de goma que se gasta en México, no la contiene; y aunque es mucilaginoso el que se vende en lugar de aquél, hay un engaño muy fácil de descubrir, y que debe corregirse, tratando por el alcohol común el jarabe que se pretende reconocer; queda diáfano si no contiene la goma, y en caso contrario, la precipita, tomando el líquido un aspecto lechoso.

NOTA DEL COMPILADOR.-Felizmente, los fraudes que el Sr. Río de la Loza señala en su tiempo, se han corregido de un modo radical, y, actualmente, estos productos se encuentran puros en las boticas. 


\section{A J F N J O.}

\section{(Tomado del Periódico de la "Sociedad Filoiátrica de México."} Publicado por el Sr. Dr. D. Leopoldo Río de la Loza.)

Con este nombre se gastan en nuestras boticas las sumidades floridas de una planta vivaz por la raíz, de la familia de las corimbíferas, de la singenesia poligamia superflua, y del género Artemisa ó Artemisia. Annque se encuentran hoy más de cien especies de este género, y muchas de ellas posee nuestra República, silvestres y cultivadas, preferimos como sucedáneo de la A. absinthium, la $A$. $l a$ cinatr, conocida con el nombre vulgar de estafiate. Este se encnentra en las alturas que rodean el valle de México: la feracidad del terreno lo hace crecer tanto, que casi llega á la altura de un hombre; sus flores son tan abundantes, que se coge hasta una vara de tallo cubierta toda de espigas. Septiembre y Octubre son los meses en que más abunda; su olor es fuerte, alcanforado y pesistente, debido al aceite volátil, que contiene en la proporción de 0,008. Este aceite es de un color amarillo claro; su consistencia es como la de los aceites volátiles espesos; se descompone con facilidad, por cuyo motivo debe conservarse en frascos herméticamente cerrados; entra en la composición de algumas preparaciones farmacénticas de uso externo; pero su mayor consumo lo hacen los vinateros, que lo gastan con el nombre de esencia de Palancapatli, para hacer la mixtela de estafiate, conocida con el nombre de mixtela de hambre; no sé si esta roz es corrompida de ámbar ó si le llaman así porque es estomacal y determina la hambre. 
El extracto preparado con este vegetal conserva el aroma de la planta; es de un color pardo negruzco; absorbe la humedad del aire por la potasa, el sulfato y el muriato de potasa que contiene; por esta razón es preferible envolver en un polvo absorbente y no platear las píldoras hechas con él. También está compuesta la planta de una materia azoada muy amarga; de otra resiniforme, que también lo es de clorofila, albúmina, fécula y leñoso. No se deben asociar á esta planta, ni los acetatos de plomo, ni el sulfato de fierro, ni el zinc.

No me detengo en referir las innumerables virtudes que posee este vegetal, por ser las misnias que se atribuyen al verdadero ajenjo ó A. absinthium, á la A. maritima y á la $A$. pontica; basta recordar que entra en la composición del elixir de Stonghton, y de todos los amargos, como el visceral y otros; se preparan con él muchos hidrolados, alcoholados, sacaruros, sacarolados, especies antelmínticas, estomacales, etc.; por último, esta planta puede usarse en lugar de la genciana, la centanra, el colombo y las santoninas, acaso con mejor éxito, por encontrarse en ella en más cantidad los principios á que éstas deben sus virtudes, y tener, además, otros muy actiros y de nna acción decidida sobre la economía.

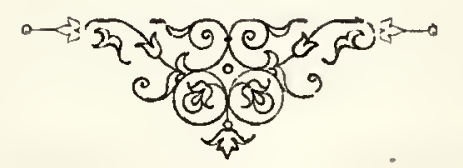




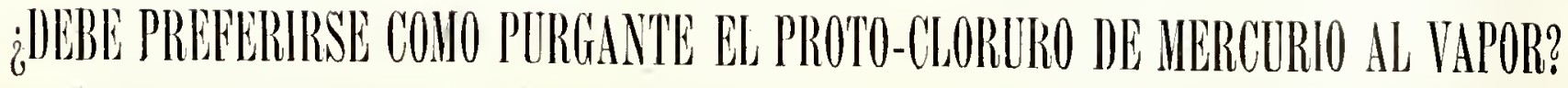

\section{(Tomado del Periódico de la "Sociedad Filoiátrica de México."} Publicado por el Sr. Dr. Don Leopoldo Río de la Loza).

He aquí una cuestión que han resuelto por la afirmativa la mayor parte de los autores de materia médica, y que, sin embargo, no creo decidida. Permítaseme recordar que cuando los métodos de preparación ofrecen ventajas comeiciales, se recomiendan los productos como más eficaces, y muchas veces se encarecen sus virtudes con razones que alucinan, pero que no satisfacen: los médicos, por su parte, prevenidos con las teorías, se deciden á favor de tales drogas; y si hay uno de reputación que asegure el buen efecto del medicamento, repiten muchos su doctrina, y el impetuoso torrente lleva consigo á los más observadores y mejor intencionados.

Esto es lo que creo ha sucedido con-el mercurio al vapor preconizado en el siglo actual, acaso por las muchas aplicaciones que se laan hecho últimamente de su immenso poder, aplicaciones muy útiles, sin duda, pero que no deben pasar de ciertos límites. La manera de obrar el mercurio sobre la economía, no es aún bien conocida, de lo que resulta que los autores no están de acuerdo en sus virtudes y aplicaciones. Los más atribuyen la inconstancia de sus efectos á los diversos métodos preparatorios, olvidando, sin duda, que los conocimientos actuales son más que suficientes para asegurarse de su composición, y olvidando también, que su estało de división es el que más influye en los resultados, y que, por lo mismo, debe estudiarse detenidamente.

Ninguno negará que en la dosis en que se administra el protocloruro de mercurio como purgante, obra irritando la mucosa gastro- 
intestinal; que esta irritación es más favorable y debe procurarse en el intestino grueso; que las sustancias insolubles son absorbidas con más facilidad cuando están más divididas; que la absorción del proto-cloruro disminuye y aun destruye su propiedad purgante; y en fin, que el mercurio al vapor, está mucho más dividido que el levigado, obtenido por sublimación. ¿Cómo, pues, recomendar el primero, cuando se necesita mover el vientre? ¿Cómo olvidar que puede ser absorbido antes de pasar del estómago, y que aun para evitar esto se aconseja asociarlo á la jalapa ó al acíbar, al nitro ó al azufre?

Dos son las razones principales que se han dado para preferir el proto-cloruro al vapor: primera, que está libre de bicloruro y de subnitrato: segunda, que siendo más dividido obra con más energía. El examen de estos dos puntos liará conocer las ventajas que ofrece el mercurio obtenido por sublimación.

Si se supone ignorancia ó mala fe en el despacho ó administración del calomelano, sólo debía recomendarse su pureza y no desconceptuar con tan débil argumento un remedio heroico en muchos casos; mas por si, el contrario, se ha creído quo en todos los otros métodos de preparación que no sea el de vapor, resulta mezclado con bicloruro, con subnitrato ó con los dos, y se ha creído también que estos compuestos no podían separarse del calomelano, se ha cometido un error, y por lo mismo, la doctrina que se funda en él es enteramente falsa.

Yo convengo en que el farmacéutico debe cuidar escrupulosamente que el proto-cloruro no contenga cantidad alguna de bicloruro, y en que el médico, por su parte, debe también estar satisfecho de ello; mas no puedo convenir en que ofrezca la menor dificultad tal reconocimiento, ni menos en que la presencia de una corta cantidad de subnitrato, perjudique ni contraríe la propiedad purgante del medicamento.

También es de notar que se ha cometido otro error al suponer que hay ó puede haber subnitrato en el mercurio sublimado, cuando en los métodos generalmente usados no intervienen los compuestos de azoeto, y que aun cuando se prefiera el azotato de mercurio, no se forma ni puede formarse el subnitrato, que es tan común hallarlo en el proto-cloruro obtenido por precipitación.

En cuanto á la presencia del bicloruro en el mercurio sublimado, es un argumento que prueba mucho, y que, por lo mismo, nada 
prueba. Tanto el mercurio sublimado como el precipitado, y el que se obtiene al vapor, pueden contener y contienen muchas reces solimán; mas por eso debe recomendarse que se lave cuidadosamente hasta disolver todo el cloruro soluble, cosa muy fácil de saber, tratando por un álcali las aguas de las lavaduras.

Queda, pues, demostrado, que la primera razón de preferencia que dan los autores, carece de todo fundamento, lo que debe atribuirse á que no conocen la práctica de los laboratorios, ni los frandes más commnes de los comerciantes de drogás.

La resolución del segundo punto ofrecería algunas dificultades si sólo se fundara en la acción que ejerce el mercurio sobre la economía, y no se atendiera á los hechos observados; afortunadamente, éstos hablan en contra de la doctrina que combato, y aun en cuanto á lo primero, no creo tan difícil, como parece á primera vista, dar una explicación satisfactoria, concediendo, como debe concederse, que cuanto más diridido está el mercurio dulce, obra con mayor energía.

La mayor energía del medicamento es útil, cuando se quiere producir la mercurialización, ó lo que es lo mismo, cuando se necesite un remedio que no limite su acción al canal intestinal; mas cuando se pretende que obre sobre éste, como obran los purgantes, es preciso servirse de todos los medios conocidos para impedir la absorción, y $u n o$ de esos medios es, sin duda, cuidar que su acción sea local, lo que no se consigue cuando está muy dividido, y mucho menos cuando está hidratado.

Hubo un tiempo en que se creyó que el precipitado blanco tenía la misma composición que el mercurio dulce, y no obstante esta opinión, habiendo notado los médicos que variaban los efectos de uno y otro compuesto, hoy no se duda que varían también en su composición, como creo no debe dudarse que varía la del proto-cloruro sublimado y la del vapor, pues éste contiene agua que no hay en aquél, aun cuando sea en menos cantidad que la que se halla en el precipitado.

Bien sé que este argumento supone resuelta otra cuestión química de la mayor importancia, y es: que el agua está en combinación con el mercurio, y no simplemente interpnesta, como aseguran la mayor parte de los autores. Mas el que haya meditado un poco sobre la teoría de la precipitación, ó haya leído las últimas memorias del 
recomendable Berzelius, no dudará que, además de los óxidos hidratados, hay otros compuestos que pueden combinarse con el agua en proporciones definidas.

Si es cierto que los cuerpos simples ó compuestos son rápidos cuando son solubles, y que se hacen solubles cuando están hidratados, aunque no lo sean antes, no hay duda que el cloruro de mercurio hidratado es, en parte, soluble, porque es más rápido que el sublimado, como puede convencerse todo el que tenga educado el sentido del gusto. Ese estado de hidratación y la nueva propiedad que adquiere de disolverse en parte, favorece su acción general, y se opone, por lo mismo, á que obre como purgante.

Según esto, creo fuera de duda, que el proto-cloruro al vapor es el más propio para obrar de una manera general, y que esto es 10 que debe entenderse cuando se dice que es más activo que el sublimado. Creo también, que aunque la dosis del medicamento influye notablemente en sus efectos, no es fácil evitar que sea absorbido total ó parcialmente, aun cuando esa dosis sea bien calculada; y creo, por último, que el segundo argumento que me ha ocupado, lejos de servir para recomendar el prote-cloruro al vapor, es un fuerte dato para prescribirlo en todos los casos en que sea necesario que obre como purgante.

Aunque lo dicho basta para llamar la atención de los prácticos, quiero, antes de concluir, indicar algunas de las ventajas que hacen preferible el proto-cloruro levigado á los que se obtienen por precipitación ó interviniendo el vapor.

De los tres efectos inmediatos comunes á los purgantes: irritación, secreción ó flujo de líquidos en el tubo intestinal, y contracción ó aumento de su movimiento peristáltico, son más necesarios y útiles los dos últimos que el primero.

El mercurio dulce irrita menos cuando sólo obra como purgante, y como el proto-cloruro al vapor y el precipitado se hallan en condiciones más favorables para ser absorbidos, irritan más, no determinan abundante el flujo de líquidos, no activan el movimiento peristáltico, y pierden la ventaja que los hace preferibles á los laxantes, catárticos y drásticos conocidos.

En los casos que el proto-cloruro obra como purgante, y, sin embargo, es absorbido, sus efectos son más lentos y determina otro mal, tanto más grave, cuanta mayor es la cantidad que se adminis- 
tra. $Y$ aunque el proto-cloruro levigado no carece enteramente de estos inconvenientes, pues se ha visto que algunas veces obra como el mercurio al vapor, ni son tan repetidos estos casos, y por lo común sólo sucede cuando se administra con demasiada timidez ó cuando no se asocia á la jalapa ú otra substancia que favorezca su acción. De todos modos, el proto-cloruro levigado es más constante en sus efectos que el proto-cloruro al vapor, y el precipitado, sobre todo si se cuida de proporcionar la dosis y de asociarlos á la jalapa, que de todas las substancias que se han recomendado, es, sin duda, la que favorece el buen efecto del medicamento, sin alterar en nada su composición.

He aquí algunos de los fundamentos que me obligan á no admitir la doctrina de los antores sobre la preferencia que pretende dar al proto-cloruro al vapor, sin exceptuar casos. Pero satisfecho de mis observaciones, deseo que los prácticos publiquen las suyas, que se discnta el punto con la debida imparcialidad, y que, cuando menos, se fije la atención para reunir datos, que no es difícil falten hoy, porque se ha proscrito en muestras oficinas de farmacia el mercurio levigado, substituyéndolo con el preparado al vapor.

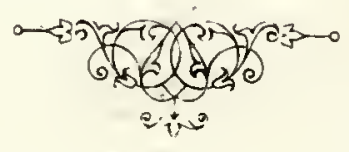




\section{EL PROTO-CLORURO DE MERCURIO.}

(Tomado del Periódico de la "Sociedad Filoiátrica de México." Publicado por el Sr. Dr. D. Leopoldo Río de la Loza).

Ta esperanza de ver publicada la Farmacopea Mexicana, y el deseo de dar á conocer en ella el procedimiento operatorio, inventado y practicado desde el año de 1818 por mi respetable y querida madre, me obligó á no dar antes á luz este artículo, que al fin me he decidido á publicar, en vista de los muchos obstáculos que se oponen á que la Academia de Farmacia realice sus filantrópicos deseos.

Sin duda que el procedimiento que me ocupa, ofrece tanto interés científico como económico. Ninguno de los autores de química que han llegado á mis manos, hace mención de él, y por lo mismo, no se ha establecido la teoría, ni se han explicado los dirersos fenómenos que se presentan en el caso de la operación. Los efectos constantes del producto obtenido por este método, y el estar en armonía con nuestras necesidades y con el estado de la industria en nuestra República, lo hacen recomendable á los prácticos, quienes tienen que luchar á cada paso con la falta de utensilios y con la carestía y mala construcción de los que pueden disponer; inconvenientes que, sin duda, no tiene la fórmula adoptada por la Academia de Farmacia $y$ consignada en su precioso libro. 
El procedimiento mexicano está fundado en la facilidad de combinar el mercurio metálico con el cloro, al estado de gas naciente, y la de fijar las proporciones de los compuestos recomendados en este método.

Si se mezclan partes iguales de colpa ó sulfato de fierro, de sal de la tierra ó cloruro de sodio y de azogue, favoreciendo la reacción entre los dos compuestos por una corta cantidad de agua y por la agitación, se nota que hay elevación de temperatura; que el mercurio se divide, y que la mezcla varía enteramente de aspecto, desprendiéndose una pequeña cantidad de cloro. El que queda, que es precisamente el necesario para formar el mercurio dulce, entra en combinación con el fierro para formar el proto-cloruro, nientras el sodio oxidado por el oxígeno del metal, se une al ácido para formar el sulfato de sosa; y uno y otro compuesto retienen en suspensión los glóbulos del mercurio. Esto es lo que sucede, en mi opinión, en la primera época del procediniento; veamos ahora lo que pasa en la segunda.

Puesta la masa en su sublimador á la acción gradual del fuego, hay evaporación de la mayor parte del agua que contenía aquélla, descomposición de una pequeũa cantidad de la misma agua, separación del clore combinado al fierro, oxidación de éste, unión del cloro con el mercurio, y rolatilización con el nueve cloruro que cristaliza en las paredes del matraz, quedando como productos fijos, sulfato de sosa, ó bien óxido ferroso-férrico, ó peróxido, ó una mezcla de este último y de una corta cantidad de sulfuros de fierro y de sodio, según que la temperatura ha sido más ó menos elevada y más ó menos sostenida.

Pudieran darse otras teorías más satisfactorias á primera vista; pero, en mi opinión, menos probables. En la mezcla del mercurio con las sales $y$ antes de que intervenga el fuego, no hay reacción entre las substancias, ni tiene otro objeto la operación que el de dividir el mercurio, para facilitar después su combinación con el cloro, luego que éste se halla libre, á consecuencia de la descomposición por el calor. Mas en esta hipótesis, ¿cómo explicar la elevación notable de temperatura en el momento de la mezcla? ¿Cómo suponer que el metal queda dividido sólo por la agitación? Además, si se trata por el agua esta mezcla para separar el mercurio, no se obtiene excctamente toda la cantidad que se ha empleado, lo que prueba, sin 
duda, que hay reacción, confirmándose esta doctrina con el examen del producto, en el que se encuentra una pequeña cantidad de protocloruro de mercurio, formado, sin duda, á expensas del gas que se desprende al disolver én el agua una parte de las sales.

También pudiera suponerse que sólo una parte del ácido del sulfato, se combina con la sosa para formar en el primer tiempo de la operación el cloruro de mercurio, ó en otros términos, que no se forma el cloruro de fierro; mas el hecho contraría esta doctrina, no obstante que está en armonía con las teorías químicas generalmente admitidas. Yo me inclino más á la primera, y convengo desde luego en que es preciso repetir las experiencias para decidir fundadamente esta importante cuestión.

Si en lugar de emplear partes iguales de cloruro, de sulfato $y$ azogue, se ponen dos de aquéllas y una de éste, se obtiene el biclo-. ruro por el mismo procedimiento, lo que prueba la exacta correspondencia de la primera doctrina con los resultados prácticos.

Es inútil advertir, que por el método que recomiendo, se obtiene el proto-cloruro al vapor y el sublimado; pues es bien sabido, que sólo se necesita usar de aparatos propios al fin que se proponga el operador; mas no es inútil dar algunas otras reglas que son indispensables al buen éxito de la operación.

No es indiferente emplear el sulfato de fierro, conocido en el comercio con el nombre de colpa, ó el que se usa más comúnmente con el de caparrosa, pues liallándose éste menos descompuesto que el primero, sería necesario rariar las proporciones señaladas, á fin de no obtener las más veces bicloruro, y algunas lo que se llama en los laboratorios mercurio azogado. Tampoco es indiferente el estado de sequedad, ó lo que se llama calcinación, porque haciéndola, como se hace, al fuego, éste descompone más ó menos el sulfato, según que es actiro ó prolongado. Ia sal común debe ser decrepitada y reducida á polvo fino, lo mismo que el sulfato, y al hacer la mezcla con el azogue, se ha de cuidar mucho que la cantidad de agua no sea mayor que la precisa para favorecer la reacción, pues de lo contrario, se unirían las sales sin dividir el mercurio, y los resultados de la operación no serían los que se desean.

En cuanto á las rasijas, es indiferente servirse de las de vidrió de barro, con tal que éstas no estén vidriadas interiormente, ni sean porosas. También hay que notar, que debe mantenerse el fuego por 
más tiempo que el recomendado en los métodos ya conocidos. El aumento de combustible es muy pequeño inconveniente, comparado con las notables ventajas prácticas y con la economía de los ácidos, que en nuestro país es tanto más apreciable, cuanto que por una fatalidad para la industria, tienen un precio subido, y lo tendrán mientras el azufie y el nitro se hallen estancados como están hor.

Creo inútil entrar en otros pormenores, comparando los procedimientos comúnmente usados, con el que ha adoptado la Academia de Farmacia: pocos conocimientos se necesitan para decidir á faror de éste, y aun cuando, por otra parte, no turiera las ventajas que he indicado, es necesario conocerlo y examinarlo, porque contribuye á la mejor inteligencia de la teoría química de los compuestos binarios, teoría que aún no está bastante estudiada, á pesar de lo mucho que se ha escrito sobre la materia, y de los sólidos argumentos de Wilson. 


\section{ALUMBRADO DE GAS.}

(Tomado de la "Unión Médica de México," de 1856. Publicado por el Sr. Dr. D. Leopoldo Río de la Loza).

Comenzaré por dar una idea del asunto que me va á ocupar, supuesto el cambio que sufren las palabras, cuya significación queda muchas reces confiada al capricho de un ingeniero, ó á la poderosa voluntad de un artesano. La voz que tiene hoy en México ma significación tal, que no es ni la científica, ni la falsa de nuestro Diccionario de la lengua, se aplica impropiamente al aceite volátil de trementina, á la mezcla de éstc con el alcohol, ó para corregir el absurdo, se le llama gas líquido. No trataré en este artículo de ninguno de ellos; sí del producto gaseoso complexo, en el que se hallan el hidrógeno proto y bicarbonado, el óxido de carbono, el ácido carbónico, la benzina, etc., etc.; de este producto aeriforme que tanto ha ocupado y ocupa á los químicos y á los médicos.

¿Sería conveniente alumbrar la cindad con este gas? ¿El lugar tomado por los empresarios para establecer los generadores y el depósito, es adecuado? ¿Los aparatos y construcciones dan suficiente seguridad? Ho aquí las cuestiones físico-médicas que desea el cuerpo municipal queden resueltas, y que tocaré someramente, para que otros profesores de instrucción, con mejores datos y más tiempo, las ilustren cual convienen al bien de la población.

Cuando recuerdo que desde que Lebon se propuso aprovechar, en 1786, cl gas de madera, como medio iluminante, que algunos años 
después, Mardoch sustituyó la hulla á la madera, y que más tarde hau empleado otros con el mismo fin las resinas, las grasas, etc., etc., anmentando cada rez los aparatos, dando mayor extensióu á los tubos y multiplicando el número de mecheros, debo presumir, que lejos de ofrecer la práctica inconvenientes graves, por el uso del gas luminoso, ha presentado ventajas, no sólo económicas, sino también ligiénicas.

Francia, que tanto cuida de la salud pública, cuenta en la actualidad con ocho fábricas, en las que hay unos ochocientos generadores de capacidad variable, para alimentar ochenta y cinco mil luces en una extensión de más de cuatrocientos mil metros, es decir, como quinientas mil varas. Sabido es que en Inglaterra, en los Estados Unidos y, en general, en las naciones principales, se halla establecido este sistema de iluminación, sin más accidentes que aquellos comunes á todo lo que está sujeto al descuido ó al abandono. Estos hechos tienen más valor que cuantas teorías pudieran darse. Agregaré, sin embargo, que aun los casos fatales citados por los autores, son, respectivamente, raros, y casi siempre se nota la parte que en ellos ha tenido, sea la ignorancia de los mnos ó el abandono de los otros, resultando de todo, que la primera cuestión debe resolverse por la afirnativa.

El examen médico de la segunda, tampoco ofrece dificultad hasta ahora. La fábrica comienza á lerantarse en uno de los ángulos del terreno de la ciudadela, inmediato al paseo de Bucareli, es decir, á extramuros de la ciudad, en lugar que actualmente es de mny poca población, y opuesto á los vientos dominantes. Verdad es que la mayor parte del año, el paseo es mo de los más frecuentados; que es hoy el tránsito para las poblaciones immediatas, y que se encuentra en la parte más estrecha de la ciudad; pero tal inconveniente lo será sólo para el empresario, y los otros son inherentes á la mejora.

Estos establecimientos pertenecen á los molestos y relativamente peligrosos; debe, por lo mismo, evitarse el que ocupen el centro de la población; pero no pudiendo quedar demasiado distantes, parece que el punto de elección es adecuado.

No se entienda, sin embargo, que yo pretenda quitar á la policía la intervención y la vigilancia que debe tener; está en los intereses de la empresa el que no haya pérdidas de gas, y así se evitará la incomodidad del mal olor y los peligros de las detonaciones y de la as- 
fixia; mas no obstante ese interés, debe también la autoridad sobrevigilar á los empresarios, garantizando así al público. Sería una fatalidad que ésta y la empresa se descuidaran, de manera que la atmósfera inmediata á la fábrica, llegara á contener, en un tiempo dado, tal cantidad de gas, que la hiciera notablemente molesta, pues nunca en esa constante ventilación de la localidad sería peligrosa á los pasajeros.

En cuanto á la tercera cuestión, yo no la juzgo del momento para la municipalidad, aunque sí creo que lo es para la comisión nombrada; ésta debe vigilar los trabajos de construcción y de distribución, marchando los empresarios de acuerdo con ella, y conciliando la economía de los unos con la seguridad del público.

Ya que he tenido que ocuparme de estos puntos, haré una aplicación de esos principios á un aparato establecido hace tiempo: quiero hablar del que está en la Academia de San Carlos. Colocado el gasómetro de plomo en una pieza techada, con poca ventilación, y casi central á un edificio en el que se encuentran objetos irreparables, si fueran destruidos, á el que igualmente concurre cada noche un número considerable de alumnos, tendríamos que lamentar cualquier accidente, no muy remoto si se atiende á las condiciones de organización y construcción. No creo es suficiente garantía el que no haya habido un suceso grave; basta que pueda haberlo para procurar evitarlo, y á ello debo excitar á las personas encargadas de tan útil establecimiento, y á la municipalidad, que manifiesta un noble interés por el bien júblico.

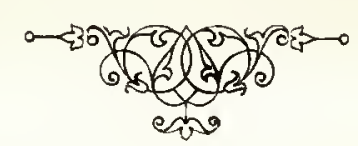




\section{AZOTURO DE HIDRÓGENO.}

(Tomado del Periódico de la Academia de Medicina de México. Publicado por el Sr. Dr. Don Leopoldo Río de la Loza).

Entre los agentes terapénticos que nos proporciona la química, es uno de los más útiles el anoníaco líquido ó álcali volátil. El uso que se hace de él, y la experiencia de muchos años, demuestran las rentajas que se obtienen de su empleo como modificador de los colores, como reactiro ó como medicamento. Ius aparatos para extraerlo se perfeccionan cada día, y los que hoy tenemos presentan bastante comodidad por la cantidad de producto que se puede sacar en cada operación; pero como en las oficinas de farmacia que hay en México no se hace tanto consumo de ese efecto, y como no todos los dueños de ellas pueden gastar ciento ó más pesos que cuestan, me ha parecido útil dar la descripción de los utensilios que componen el aparato económico que acostumbro usar.

Las vasijas de ridrio y de barro que emplean algunos para esta operación, se rompen con facilidad, no permiten sacar cantidades proporcionadas de líquido saturado, y hacen subir el valor del efecto. Las de cobre tienen el inconveniente de que una parte del gas se combina con él y las destruye. Las de fierro son, sin duda, las mejores; pero su precio elerado y las muchas junturas que tienen que taparse, por ser comúnmente retortas ó cilindros de dos piezas, obligan á emplear más tiempo en montar el aparato, y son, por lo mismo, incómodas. El serpentín que tienen algunos de éstos, aumenta los inconvenientes, y no hay necesidad de servirse de él, siempre que 



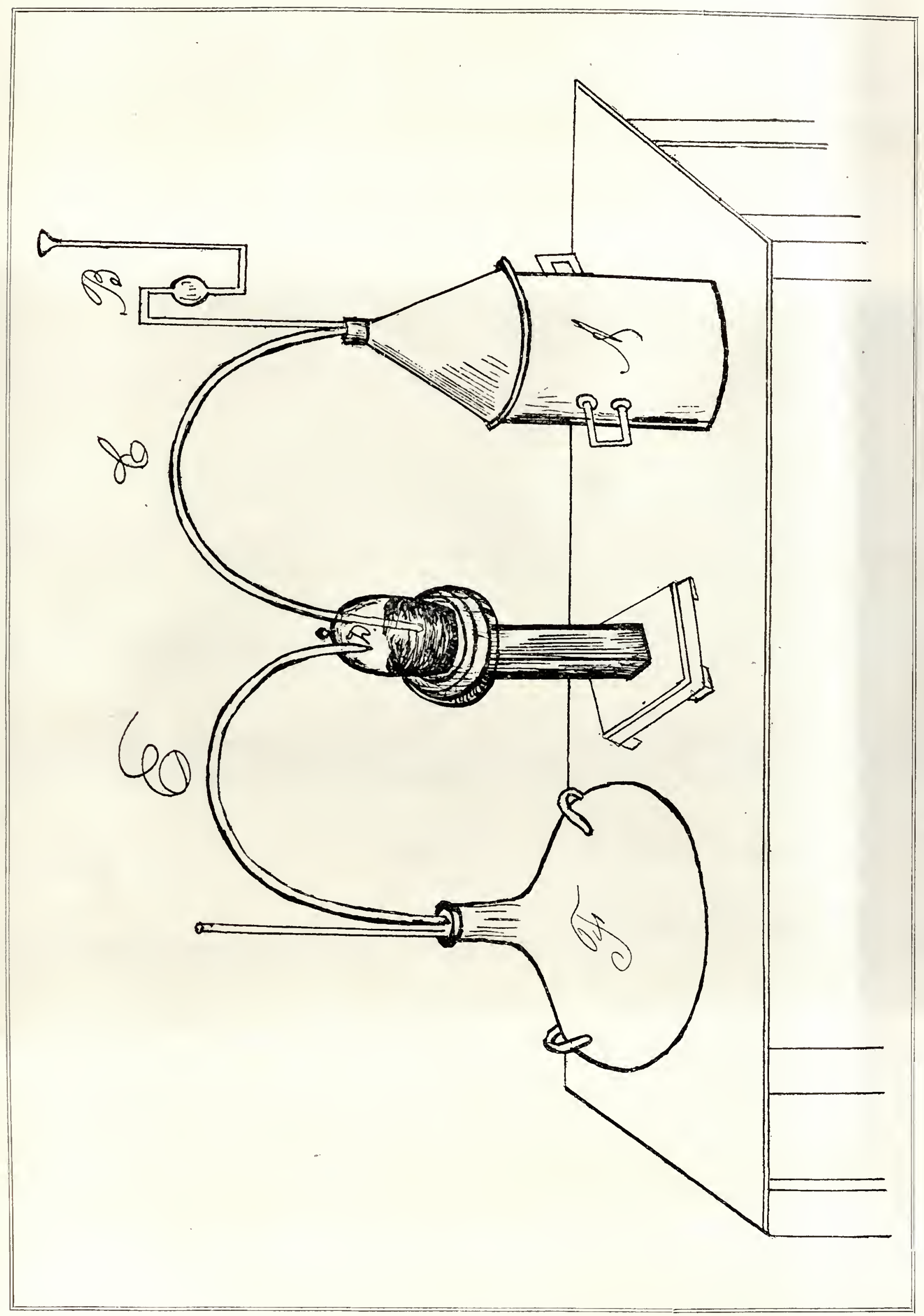


se pongan en cada operación, de diez á doce libras de mezcla, porque basta la corriente de aire para mantener frío el recipiente, $y$ disininuir la tensión del gas.

En una hornilla ordinaria, pongo en baño de arena el bote de hoja de lata A; el tapón está agujereado para dar paso á la extremidad de los tubos B y C: la otra extremidad del segundo queda sumergida en la poca agua que contiene el frasco Woulf D: el tubo E conduce el gas lavado á la damajuana F, en donde encuentra la agua que debe saturar.

Para dar más solidez á la primera vasija, la mando construir de hojas de lata engargoladas, de más de cuarenta y hasta de sesenta libras de capacidad, y pongo en cada operación diez ó quince de mezcla. Algunos antores quieren que se haga con tres partes de cal apagada (hidrato de cal), y dos de sal amoníaco (Hispana Virey); otros pidén dos de la primera y una de la segunda (Chevallier, Richard y Berzelius); pero la experiencia me ha enseñado, que con partes iguales de una y otra, como prescriben Henry, Guibour y Bonchardat, se verifica la descomposición total, y ocupa la masa una tercera parte menos. Tampoco están de acuerdo los autores en la cantidad de agua que se ha de saturar con un tanto dado de hidroclorato de amoníaco; pero en atención á los usos que tiene el álcali como medicamento, y á los grados que marca el del comercio, se tendrá una dènsidad proporcionada, si señala $50^{\circ}$ ó $52^{\circ}$ del alcohómetro de G. L. $=20$ de $\mathrm{C}$. De estos grados salen comúnmente, saturando en este aparato, dos partes de agua con tres de mezcla.

Los cuerpos extraños que se encuentran en el amoníaco líquido, provienen de la sal, de la cal ó del agua que se satura. La cal de comercio contiene algunas veces aceite empireumático, que comunica su olor al producto y lo altera: una parte de la cal pasa con el vapor del agua, queda disuelta, se combina con el gas carbónico, y forma costras que se adhieren á las paredes de las vasijas en que se guarda el álcali: las aguas de México contienen más ó menos cantidad de cuerpos orgánicos que alteran su pureza, y sales que aumentan su gravedad. Para evitar que el amoníaco sea impuro, y para apreciar con alguna exactitud los grados de saturación que señala, se debe emplear únicamente agua destilada, y lavar el gas como tengo dicho.

No se debe echar á la mezcla más que la cantidad de agua muy 
precisa para formal una masa espesa, porque si fuera en exceso, pasaría por el tubo, lo obstruiría ó llenaría el frasco de Woulf. Además, la agua del bote retiene fuertemente una cantidad de gas que se pierde, porque la temperatura no basta á desprenderlo, y como al hacerse la descomposición de la sal se forma agua, ésta impide que se desolde la rasija, y mantiene la masa en consistencia proporcionada.

Puede omitirse en muchos casos el frasco intermedio, siempre que no se quiera tener el gas lavado, y según los usos á que se destine el álcali. Entonces el aparato es más sencillo; pero los grados que marca el líquido no son exactos por la presencia de la cal que pasa con el rapol.

Hay otras consideraciones que no deben olvidarse al preparar el amoníaco, y aunque son reglas generales que se encuentran en los autores que tratan de la extracción de los gases, me parece muy útil dar un extracto traducido del artículo sobre destilación de Soubeiran, procurando aplicar sus doctrinas al aparato que representa la lámina.*

Siempre que se trata de extraer un gas (dice el autor), es necesario tener presentes los principios siguientes:

1. ${ }^{\circ}$ Todos los gases están dotados de cierta elasticidad ó tensión elástica, en razón de la cual obran sobre las paredes de las vasijas en que están encerrados.

2. ${ }^{\circ}$ La tensión de un gas es proporcional á su cantidad, aumenta con la temperatura y disminuye con el enfriamiento.

3. ${ }^{\circ}$ La atmósfera pesa sobre todos los cuerpos: su presión es igual al peso de una columna de agua de treinta $y$ dos pies, ó al de una columna de mercurio de veintiocho pulgadas ó sesenta y seis centíinetros.

$4 .^{0}$ Los líquidos transmiten la presión en todos sentidos.

Haciéndose la emisión del gas en A, pasará sncesivamente del bote al primer frasco, y de éste á los demás. Al principio de la operación, el líquido estará al nirel en todos los tubos; pero bien pronto se acabará este equilibrio. ¿Por qué causa? ¿Cuáles son los fenómenos que resultan? Esto es lo que conviene examinar.

Si se desprende una cantidad de gas de la vasija A, anmenta la

\footnotetext{
* Se supone que bay otro frasco de Woulf entre el frasco D y el bote A; y que uno y otro ticnen un tubo recto es la boca de en medio.
} 
tensión elástica del aire que encierra, y por consiguiente, ejerce una presión más fuerte sobre sus paredes y sobre los líquidos de los tubos B y O, que ceden á esta presión; de manera que el líquido se eleva hasta cierto punto en el brazo más alto del primero, y desciende igual cantidad en el segundo, hasta que la presión de la atmósfera de A sea bastante poderosa para deprimir toda la columna del líquido en C. Entonces el gas atraviesa el líquido, y cuando no se disuelve en él, aumenta la tensión elástica de la atmósfera en D. Aquí se manifiestan fenómenos semejantes á los que acabamos de examinar, á saber: aumento de fuerza elástica, y por consiguiente, presión á la superficie del líquido en $\mathrm{D}$, elevación de este líquido en el tubo recto y depresión de él en el tubo E, igual á la elevación en el tubo recto.

Si hubiera otros frascos intermedios, sucedería lo mismo que con éste; pero en el último, el líquido no sube al tubo recto, porque es. tando abierto el frasco, el gas que recibe se mezcla á la atmósfera, en donde su efecto llega á ser inapreciable, y la presión del aire sobre la superficie del agua es contrabalanceada por la que ésta ejerce igualmente sobre el tubo recto. Así es que este tubo es inútil en el caso que se supone, y sólo se lia puesto para hacer más fácil la exposición de la teoría.

Cuando el gas que se produce en A llega á desprenderse en el último frasco, si se examina el nivel dei líquido en los tubos, se ve que es igual al de la agua en el del último frasco F, que está más elevado en D, que lo estaría aún más si hubiera otro anterior, y en fin, que su elevación en $B$ es igual á la suma de la elevación en los dos frascos. Examinemos la causa de este fenómeno.

El nivel del tubo recto es igual al de la agua; se ha dicho que esto proviene de que la presión del aire se ejerce igualmente y por el interior del tubo sobre la superficie del líquido en el frasco.

El líquido sube cierta cantidad en el segundo tubo recto; esto consiste en que la presión del gas es más fuerte en el frasco que la de la atmósfera que pesa sobre el líquido por el tubo recto, porque era igual antes que la operación comenzara. .... El líquido subilía más si lubiera otro frasco de Woulf entre éste y el bote A: porque la tensión elástica del gas en este frasco aumentaría por la resistencia que opone á su salida el líquido del frasco anterior. En efecto, el gas, en el penúltimo frasco, no tiene que vencer otra resistencia que la del líquido contenido en el tubo y la de la atmósfera, mientras 
que para escaparse del primero, es necesario que su tensión sea tan fuerte, que iguale al peso de toda la agua contenida en el tubo C, aumentada de la presión de la atmósfera del penúltimo frasco, que, como hemos visto, es mayor que la del aire.

En fin, si la depresión es igual en el trbo en tres ó en S á la suma de la de los dos tubos rectos, es porque para salir el gas de la vasija A, debe rencer las presiones que ejercen los frascos siguientes. Por tanto, cuando hay muchos frascos, debe ponerse un tubo en tres muy grande, porque sin esta precaución saldría el gas con más facilidad por' este tubo que por el de los frascos. Pero como los tubos en tres son muy incómodos y se quiebran con más facilidad cuando son grandeà, se llenan de mu líquido más denso que el de los frascos, y entonces se deprimen menos por una presión igual. Para esto se hace uso del ácido sulfúrico, y algunas reces del mercurio.

ILl uso más importante del tubo en tres, es el de impedir la mezcla de los productos. Si no so pusiera este tubo cuando la tensión interior de la atmósfera del bote disminuye por el abatimiento de la temperatura, siendo la presión en el primer frasco la misma, se dirige á la atmósfera de A, obra sobre el líquido del primer frasco y lo hace pasar al bote. Por consiguiente, disminuye la tensión elástica del primer frasco, no contrabalancea la del segundo, el líquido de éste pasa á aquél por el tubo que los comminica, y así en todos, hasta el último, dęl cual pasa por la presión del aire exterior. Pero cuando hay tubos de seguridad, á medida que falta la presión en $\mathrm{A}$, el aire comprime el líquido del tubo en tres, lo obliga á pasar al tubo más corto, $y$ bien pronto cae al aparato y restablece el equilibrio.

El mismo efecto se produce en los otros frascos por los tubos rectos; pero es necesario que entrell muy poco en el líquido, porque si no, sube éste por los tubos recurros antes que el aire obre sobre la columna del líquido que se opone á que entre por el trubo recto.

Cuando se quieren disolver gases, y que se opera en grande, se suprime el tubo en S ó en tres, y para evitar la absorción, se coloca entre el primer frasco y la vasija en que se hace el desprendimiento, un frasco intermedio con una pequeña capa de agua. El tubo que parte de aquella rasija penetra en el frasco sin llegar al líquido. Se sumerje en éste un tubo recto de seguridad. Resulta de esta disposición, que el gas desprendido pasa á los recipientes, y el tubo recto intermedio deja entrar al aire cuando la tensión elástica disminuye. 


\title{
REMEDIOS INCONSTANTES.
}

\author{
(Tomado del Periódico de la Academia de Medicina de México. \\ Publicado por el Sr. Dr. Don Leopoldo Río de la Loza).
}

Son muchas las causas que contribuyen para que los medicamentos sean inciertos: unas dependen de la facilidad con que se alteran; otras del método de prepararlos; algunas del lugar que los produce, y muchas de la codicia de los comerciantes. El descrédito de los agentes farmacéuticos consiste más bien en las modificaciones que reciben, que en su poca acción sobre la economía; al administrar una de estas substancias, es bastaute mal perder el tiempo sin conseguir efecto alguno. México sufre los perjuicios que hace ẹl comercio de la drognería, $y$ los que ocasiona la ignorancia; casi todos los medicamentos enérgicos son valiosos, y los fraudes son, por lo mismo, más frecuentes; el que descansa en la bnena fe del rendedor, se expone á ser engañado y á perjudicar á los enfermos; la desconfianza es esencial al médico y al farmacéntico: éste no debe recibir un cuerpo sin haberlo ensayado por los medios conocidos; no bastan los sentidos para decidir de la pureza de un remedio, ni lo poco que se sabe, acerca de su modo de obrar, antoriza para ver con despre. cio esta parte de farmacología. He señalado en otro artícnlo ma de las cansas que coutriburen para que los medicamentos sean infieles, Y es la falta de una farmacopea que arregle la práctica de la farmacia; ahora me propongo indicar algunos de los remedios inconstantes, á fin de llamar la atención, tanto de los profesores que los pres- 
criben, como de los que están encargados de prepararlos, y evitar, en cuanto se pueda, los males que causan la necesidad, el abuso ó la mala fe.

Ácrdos.-Son pocos los que se usan en estado libre, y.menos los que gozan de propiedades específicas notables, que merezcan conservarse perfectamente puros; pueden reducirse á tres los que se gastan en México, y que exigen cuidados particulares: el nítrico, el hidrociánico y el benzoico.

El ácido nútrico fué en mua época remedio universal, y, por lo mismo, cayó en tal descrédito, que apenas se emplea actualmente; algo han de haber contribuido á esto las alteraciones del medicamento; su mezcla con el ácido sulfúrice, con el cloro, con el gas nitroso, $r$ los grados de concentración, hacen variar su acción sobre la economía: jcómo señalar la que determinan los cuerpos interpuestos? Es muy dificil; pero es fácil conocer que disminuyen la cantidad del que se desea administrar; y aunque todos tienen una propiedad común sobre los tejidos orgánicos, también tienen una especial, que no se advierte en otros. Si los ácidos forman, por su unión con los cuerpos inorgánicos, compuestos particulares, y si su contacto sobre la piel determina fenómenos propios á cada uno, es de presumir que, introducidos en la economía, den lugar á cambios diversos, según el agente empleado. Por tanto, se debe procurar el ácido nítrico, constantemente, de 1042 de densidad, sin mezcla de otro, conservarlo bien tapado y fuera del influjo de la luz.

El hidrociánico, que se ha recomendado en algunas enfermedades pulmonares y de la piel, y como calmante del sistema nerrioso, dista mucho de corresponder á estas virtudes por la facilidad con que se altera: sólo el contacto de la luz lo descompone en una hora, y es raro que dure útil más de quince días; aun el medicinal, que necesita más tiempo para alterarse, llega á quedar inservible. Los buenos resultados que se han conseguido con su empleo, dependen más bien de los remedios asoeiados. Entre los daños ocasionados por la polifitrmacia, es uno de los principales el de no poder apreciar, con la exactitud debida, el efecto de mu medicamento. Si estuviera demostrada la acción de este ácido en las enfermedades del pulmón, sería más seguro usar alguna preparación de almendras amargas, como la agua destilada, con preferencia á la del Laurel ceroso, porque el cianuro de potasio propuesto por Robiquet, como 
succedáneo del ácido hidrociánico, se altera por su contacto con el gas carbónico y el oxígeno de la atmósfera.

El ácido benzoico medicinal, no debe usarse químicamente puro, porque la substancia volátil, de olor de rainilla, es la que obra como expectorante. Los vapores de pez, el creosoto y demás productos empireumáticos empleados en la tisis pulmonar, tienen la mayor analogía con el aceite volátil que impregna el ácido benzoico sublimado, que, en mi opinión, es el que se ha de preferir.

Acetatos.-Se pueden reducir á dos los acetatos inciertos usados en farmacia: el de amoníaco y el de morfina; pues no creo que tenga inconveniente la substitución que hacen algunos del acetato de sosa por el de potasa; antes bien, siendo éste delicrescente, debe preferirse el primero, con particularidad cuando se pide en papeles, teniendo cuidado de aumentar la dosis en la proporción de cuarenta por ciento, atendiendo al agua de cristalización que contiene.

Al principio del siglo XVII, recomendó Minderero una preparación hecha con espíritu de cuerno de ciervo y vinagre fuerte, empleada por los médicos con el nombre de Espiritu de Minderero, que impropiamente conserva el acetato de amoníaco de nuestras boticas. Aquella sal es tan inconstante en sus efectos, como la que se gásta actualmente; el espíritu de cuerno y el vinagre, empleados entonces, no podían contener siempre igual cantidad de ácido y de base, como no la hay en el vinagre destilado y el amoníaco líquido, que la farmacopea española prescribe para hacer esta sal. Por este método sólo marca dos ó tres grados del areómetro, es decir, que en cinco partes no hay realmente más que dos de acetato líquido, sin contar con las substancias extrañas que suele haber en el álcali y el vinagre, que aumentan la densidad. Ya se re á cuántos errores clínicos puede dar lugar este abuso, no sólo por faltarle al líquido concentración, sino porque es más íntima la combinación, siendo mayor la fuerza de los componentes. Por esto creo que el mejor procedimiento para hacer el acetato de amoníaco, consiste en usar el carbonato de amoníaco y el ácido acético concentrado, agregando, cuando se ha rerificado la saturación, una cantidad de agua destilada suficiente para reducir el líquido á 136 de densidad; pero sea cual fuere el método que se siga para prepararlo, sólo debe usarse el que marque cinco grados del areómetro.

No sé por qué se gasta más el acetato que el sulfato de morfi- 
na, teniendo éste algunas rentajas sobre aquél. Las sales cristalizadas son más puras que las evaporadas á la sequedad, y he aquí una de las razones en firvor del sulfato; la otra es, que los que sacan este alcaloide, preparan el acetato con el líquido que no da más cristales de morfina; además, el acetato, en contacto con el agua, forma una sal soluble y otra que no lo es; y como, en general, mientras más dividida está una substancia, es más enérgica, debe preferirse el sulfato á las otras sales de morfina. Por mi parte, tengo más confianza en un grano de extracto de opio bien hecho, que en igual ó mayor dosis de una sal de morfina.

JARABES.-Casi todos los enérgicos varían en sus efectos por algunas 0 por todas las causas señaladas al principio de este artícnlo; hablaré de los más usuales.

El jarabe de maná se gasta hoy inás que todos los jarabes purgantes, y por desgracia no se encuentra en México preparado de igual modo y con las mismas proporciones y substancias. En algunas oficinas le echan tan poco, que no puede tenerse como laxante, aun para los niños de corta edad. Una onza de maná en mna libra de jarabe blanco, no produce efecto alguno; hecho con el cocimiento de sen, resulta un jarabe poliámico, que no está indicado en todos los casos, ó no se puede administrar por circunstancias individuales. Si se hace con cantidades proporcionadas de maná, se tiene un buen purgante para los niños, que remne cuantas ventajas se preden desear, y más si se asociạ con magnesia mexicana, que obra mejor que la inglesa, sin necesidad de agregarle el jabón que nsan algunos, ni de añadirle líquidos que, cuando menos, aumentan las dosis que han de tomar los enfermos. Tas fórmulas que conocemos, piden azúcar para hacerlo; pero me parece más útil la miel de abejas, porque abunda en nuestro país, coadyura á la rirtud del medicamento, no se fermenta ni se cristaliza con la facilidad que el jarabe de azúcar, y no tiene los inconvenientes que se han observado en otros lugares, en donde la toman estos insectos del acónito y otras plantas renenosas, que commican sus propiedades á la miel. Esta es la fórmula que me parece mejor: si se generaliza, tendremos un remedio constante $y$ útil:

Maná en suerte.............. 1 libra.

Miel de abejas.............. 4 libras. 
Clarifíquese con la suficiente cantidad de agua, para que marque $30^{\circ}$ hirviendo, y cuélese, sin dejarla mucho tiempo al fuego. Cada onza de este melito contiene dos dracmas de maná, y con esa cantidad y un dracma de magnesia mexicana, se purga bien á un niño de más de un año.

A pesar de que en la farmacopea española, á que nos debemos sujetar, * se encuentra la fórmula del jarabe de opio, no se prepará en todas partes con arreglo á ella, y es, por lo mismo, un remedio incierto, aunque, por su energía, debía hacerse con escrupulosidad.

La substitución de la tintura tebaica es mala, porque ni obra del mismo modo que el extracto de opio, ni puede regularse, con la exactitud debida, la cantidad que contiene cada onza de jarabe. Es preciso sujetarse á la fórmula de esa farmacopea, para que los profesores de medicina encuentren constantemente la misma dosis de opio, y no pidan cantidades indeterminadas para endulzar las bebidas, como sucede hoy.

El jarabe diacodión debe proscribirse de uuestra materia médica, porque las adormideras con que se prepara, no tienen la virtud que se busca en ellas; es mejor substituir el de extracto de opio, usándolo en menos cantidad.

El jarabe de ipecacuana es otro de los remedios inciertos, pero que serviría de mucho á la terapéutica, si se preparara con exactitud. Su inconstancia no sólo depende de la mala fe, sino también de las diversas fórmulas que se encuentran en los autores; del vehículo empleado para extraer la parte activa del regetal, y de la clase de raíz que se usa. Siempre que varíen los simples, ha de variar la energía del medicamento; para evitar este mal, es preciso que todas las oficinas se sujeten á una fómula, y cuando esto no pnede conseguirse, es indispensable que el médico sepa cómo está preparado el jarabe, para no exponerse á que falte el remedio, ó á producir más efecto del que quería. No me detendré en analizar las diversas recetas que se han publicado para hacer este sacarolado; mi objeto es señalarlo como infiel, y estimular á los profesores á que usen el que recomiendan los Sres. Henry y Guibont en su tratado de farmacia. No sólo es preferible este jarabe, porque se hace con el

* En esa época aún no se publicaba la Farmacopea Mexicana, y debido á su falta, los farmacéuticos de aquella épocia no tenian una regla fija para sus preparaciones.N. del C. 
alcohol á $22^{\circ}$, que extrae toda la parte activa de la ipecacuana, porque cada onza representa diez y seis gramos de ésta, y porque no tiene fécula ni grasa, ni el aceite nauseabundo; sino porque se conserva mejor, y aun puede hacerse extemporáneamente, con tres granos del extracto y una onza de jarabe simple. Los jarabes de ruibarbo, de peonía, de espárrago, de zarza y de liquen, son también inciertos, lo mismo que los melitos de rosas y de cebolla albarrana. El de peonía podía substituirse, con muy buen éxito, por el de contrayerba, preparándolo según esta fórmula:

Contrayerba del Parral.......... 4 onzas.

Agua hirviendo............... 1 libra.

Déjese en infusión por espacio de cuatro horas, y cuélese con expresión. Se tiene dispuesto un jarabe á $37^{\circ}$ hirviendo, hecho con cuatro libras de azúcar blanca, al que se añade el líquido aromático, y se cuela.

Sería necesario llenar algunos números del periódico, para mencionar todos los remedios inconstantes é inútiles que están en uso; una infinidad de plantas secas que no tienen acción sobre el organismo, ó es contrario á la que se les atribuye, como nuestra tila y gordolobo (Gnaphalium), y porción de aguas, aceites, ungüentos, etc., que ocupan lugar, para vergüenza nuestra, debían desecharse por inservibles y aun dañosos en algunos casos. ¿Qué efecto se puede esperar del agua carbónica oficinal, y demás remedios de esta clase? La ciencia ganaría mucho con una reforma radical, y con que los encargados de la policía médica hicieran un esfuerzo en cumplimiento de sus deberes $y$ en bien de sus semejantes.

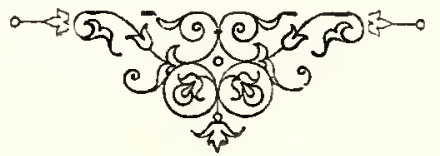




\section{LIPAROLADO DE ESTRAMONIO.}

(Tomado del "Periódico de la Academia de Medicina de México." Publicado por el Sr. Dr. Don Leopoldo Río de la Loza).

Entre los muchos ramos de ciencias naturales que deben ocupar al médico, es uno de los principales el conocimiento de las sustancias medicamentosas que produce el lugar que habita, y el estudio de sus virtudes y modo de obrar en la economía. Este deber, común á todo el que se dedica al arte de curar, es más obligatorio á los hijos de una nación que deben interesarse, no sólo en los adelantos de la ciencia que profesan, sino también en los progresos del país que los vió nacer. Los medicamentos indígenas son preferibles, en igualdad de circunstancias, á los exóticos, por la facilidad que hay en conseguirlos, por tener menos costo, por estar menos expuestos á ser adulterados, y porque, conocida su eficacia, llegan á ser efectos de exportación, dando impulso á la industria y al comercio.

La fertilidad de nuestro suelo, las diversas combinaciones de minerales, y las numerosas familias de animales que se nos presentan por todas partes, son suficientes para reducir la materia médica al círculo de nuestro territorio, sin extrañar, á la cabecera del enfermo, ningún agente que cure sus dolencias. Purgantes drásticos y laxantes, sustancias emolientes, anodinas ó narcóticas, tónicos de toda especie, finalmente, se puede decir que no hay una clase de medicamento que falte en la República. Muchos pueden usarse como succedáneos de otros exóticos, y acaso con mejor éxito; pero las pocas 
observaciones hechas sobre este punto, y el estudio exclusivo de atitores, que no pueden estar al alcance de todos nuestros productos, hace que se prefieran los que se usan en Enropa. A fin de contribuir de algún modo á los adelantos de este r'amo, insertaré, cuando me toque el turno, algunos artículos acerca de las virtudes de los remedios que se usan en México: hablaré de los succedáneos que puedan emplearse, y de los que actualmente se gastan y deben proscribirse por ser dañosos, comenzando por proponer la manteca de estramonio, que puede sustituir á la pomada de belladona, de que tanto se sirven hoy los profesores de medicina.

Desde que Chaussier observó que la belladona era un remedio eficaz para combatir la rigidez espasmódica del cuello del útero, se generalizó tanto el uso de este regetal, que acaso se le supusieron más virtudes de las que realmente tiene; se puede asegurar, que el liparolado de belladona es, de todos, el que más se prescribe para curar muchas enfermedades. No diré que es tam poco eficaz en los casos á que se aplica, como to ha sido el extracto y la tintura de esa planta para preservar de la escarlạtina; pero sí puedo asegurar, que la mezcla del último con la manteca, que es la fórmula más común, tiene el defecto de que, al untarse en la piel, forma grumos, que no pueden ser absorbidos, y lastiman al enfermo. Si se calienta antes de servirse de ella, se precipita el extracto, y sólo queda la grasa sin ninguno de los principios medicinales de la planta. Creo, por tanto, que en caso de emplear esta pomada, sería más ńtil gastar la que se hace cociendo la yerba en la manteca; pero siendo tan abundante en muestros campos el toloache (Datura Stramonium), y no careciendo de las virtudes que se atribuyen á la belladona, debe preferirse á ésta.

Las buenas cualidades de mu medicamento, dependen de que su preparación sea constante, para que lo sean sus efectos: el estramonio contiene la daturina en sus semillas y en las hojas; pero como en aquéllas hay más cantidad de esta base alcalina, no es indiferente hacer la pomada con unas ú otras. Sin embargo, se han conseguido buenos resultados con las hojas aplicadas exteriormente bajo la forma de cataplasmas, en los reumatismos crónicos, en las neuralgias faciales, en algunas enfermedades crónicas del hígado, etc. Se puede decir que tenemos más experiencia de las virtudes de éstas, que de las semillas, sea por el poco uso que se ha hecho de ellas, ó tal rez 
porque se ha creído que el aceite que contienen, entorpece la acción de la base orgánica, cuando se ponen á cocer con la grasa. Se puede preparar la manteca ó liparolado del estramonio, según esta fórmula.

\footnotetext{
Hojas frescas de estramonio, una parte.

Semillas de la misma planta, una parte. Manteca lavada, cuatro partes.
}

Macháquense las hojas y las semillas, y pónganse con la manteca á un fuego suave, hasta que se consuma la mayor parte de la humedad, cuélese con expresión y clarifíquese por el reposo.

Las plantas frescas son mejores que las secas para esta clase de preparaciones: el toloache es de la familia de las solanáceas, su álcali orgánico tiene casi los mismos caracteres físicos y las mismas propiedades medicinales 'que la atropina: la poca diferencia que hay entre ésta y la daturina, hace preferible la última, porque es más soluble en el agua, muy poco menos soluble en el alcohol y más volátil. Dice Dumas que la atropina, la daturina y la hiosciamina, difieren tan poco entre sí, que acaso, estudiando mejor estas bases, se verá que es una sola. También dice, hablando de su acción sobre la economía, que haciendo Ia disolución de una pequeña cantidad de daturina, y tocando con ella el ojo, determina la dilatación de la pupila, en tanto grado y de una manera tan persistente, que puede durar hasta ocho días. Si esta es una de las virtudes más principales de la belladona, si su acción sobre el iris y el cnello del útero, son determinadas por un mismo agente, y si la experiencia ha demostrado la eficacia del estramonio en las enfermedades á que se aplican los narcóticos de la misma familia, debe usarse de preferencia á la belladona, y más para uso externo. Es verdad que interiormente se ha de administrar con más prudencia que la belladona, por ser más enérgica; pero ésta no es razón para proscribirla, ni menos para creer que sus preparaciones son remedios infieles y dañosos, como dice Ewards; él mismo asienta, que la acción del estramonio sobre la economía animal, es semejante á la de la belladona. Merat cita algunos casos de epilepsia, de convulsiones, etc., curados con esta planta. Yo la he visto usar frecuentemente en algunas enfermedades nerviosas, con buen éxito. Por ńltimo, si el estramonio es tan venenoso como dicen algunos, la terapéutica sacará mayores ventajas de su aplicación, 
porque los venenos han sido, por lo común, las medicinas más útiles, sus efectos son palpables, y sólo necesitan de una mano diestra que los administre, y evitar los malos resultados que sólo el abuso puede ocasionar. 


\section{algunas preparaciones farmagéuticas.}

\section{EMULSIÓN DE CERA.}

(Tomado del "Periódico de la Academia de Medicina de México."

Publicado por el Sr. Dr. D. Leopoldo Río de la Loza).

En el último número de este periódico, se ha recomendado la emulsión preparada con cera blanca, y me ha parecido conveniente llamar la atención de los prácticos, sobre la preferencia que debe darse á ésta respecto de la amarilla. Desde luego creo, que siendo muy variables los procedimientos para el blanqueamiento de la cera, hasta el grado de influir algunos en la intensidad de la luz, debe no ser indiferente la acción terapéutica del remedio: fundado en esto, me parece preferible la cera que no ha sufide preparación alguna, teniendo cuidado de desechar la que está mezclada con pez, que es el frande más común que se observa en nuestro pás.

En cuanto al procedimiento de Mr. Geisler, se nota en la práctica no ser el mejor, como ha dicho el Sr. Martínez; la razón es muy sencilla. La cera necesita $68^{\circ}$ para mantenerse en fusión; y no es cómodo ni seguro tener á esa temperatura una redoma, para hacer la mezcla á fuerza de sacudimientos. Tampoco es conveniente servirse de morteros de cobre, porque son atacados por la cera, aun cuando estén bien limpios, y los de porcelana y de composición, necesitan ser calentados por la agua, lo que hace la operación molesta y dilatada. Yo me sirvo, con buen éxito, de una cápsula de porcela- 
na y mano de lo mismo, para liquidar á un calor suave la cera y mezclarse el mucílago, añadiendo después el jarabe y agua. La emulsión así preparada tiene todas las cualidades que se desean, y sin duda que los farmacéuticos de México no encontrarán las dificultades de que se queja Steimbrenner. El Sr. Martínez ha logrado, sin mucho trabajo, hacer la emulsión, sirviéndose de las mismas proporciones que Geisler, pero desechando el procedimiento que éste encarece.

Con respecto al uso de la yema de huevo, soy de la misma opinión que el Sr. Hidalgo: las bebidas hechas con ella, son, por lo cemún, indigestas, y cuando no hay necesidad de usarla, es mejor no aventurarse. Creo que lejos de resultar algún inconveniente de la adición del aceite de almendras ó el sesamino, es útil el asociarlo, pues fundiendo con él la cera, queda más dividida y su acción es más eficaz.

Ácrdo có́rRico.-En estos últimos días he tenido motivo de examinar este ácido, tomado de varias partes, y me ha llamado la atención lo escaso que es en el comercio, y el descaro con que se da el tártrico, que, aun cuando fuera igual en sus propiedades medicinales, no lo es en las físicas y químicas, ni tampoco en su valor; por lo mismo, debe perseguirse el flaude, cuidando escrupulosamente de no recibirlo sin previo análisis. Los farmaccéuticos, fiados en la buena fe de los rendedores, se conforman comúmmente con que la sustancia que compran tenga algunos de los caracteres físicos que le son propios; y más por apatía que por la ignorancia que snponen los droguistas, reciben efectos de mala calidad, y con las mezclas que la codicia del negociante hace alguna vez, con perjuicio del público y de la ciencia.

No me cansaré de repetir que el farmacéutico ha de ser muy desconfiado en estos puntos, para evitar, cuando menos, que le liagan pagar por una libra de ácido tártrico, cinco reces su valor real.

SAL DE SEDLtTz.-Hoy se hace algún consumo de esta sal, y á la verdad que su gusto, menos desagradable que el de otros purgantes, la novedad, los buenos efoctos que produce, y el tener propiedades que no se observan en todos los laxantes, la liacen recomendable á los ojos de los prácticos, del vulgo $y$, sobre todo, de los hipocondríacos, que tanto abundan en las grandes poblaciones. Sin embargo, no carece de inconvenientes, que es útil eritar. Se encuentran en el comercio dos clases de cajas con el nombre de polvos de Sedlitz, 
unas en que entra el sulfato de magnesia, bicarbonato de sosa $y$ ácido tártrico, y otras con estas dos sustancias y el tartrato sódicopotásico, ó sal de Seignette. Esta variedad hace inciertos los efectos del medicamento, y desde luego se nota que la acción purgante de aquéllas, es menor que la de éstas. Las primeras dan por resultado tartrato y sulfato de sosa, sulfato de magnesia y un poco de carbonato de la misma base, porque, comúnmente, hay un exceso de bicarbonato, respecto del ácido. Las segundas sólo dan tartrato sódicopotásico, menos repugnante al gusto y más á proposito para llenar las indicaciones que se desean al administrar el medicamento.

No es mi ánimo ocuparme en la eñumeración de las virtudes que se atribuyen á la sal de Seignette; basta decir, que si una juiciosa observación le niega alguna de esas virtudes, también Je concede muchas de grande utilidad en la práctica. Por tanto, creo necesario proscribir la sal de Sedlitz preparada con sulfato de magnesia, ó á lo menos, no despacharla sino cuando el facultativo la pida exprescmente. También me parece que, para estar seguro de la composición y proporciones en que entran las sales, así como de su buena calidad, es preciso que el farmacéntico disponga por sí las cajas, desechando la preocupación vulgar de dar el mérito que no tienen á las drogas cubiertas de adornos, y cuya única recomendación es la de llevar el. método escrito en idioma que no todos entienden.

Garbanzos supurantes. - Entre las varias fórmulas que recomiendan los antores para preparar este tópico, se da la preferencia á la de Wislin, annque, en mi opinión, hay casos en que se obtienen mayores ventajas de los que se hacen con masas supurantes. Me abstengo de entrar en estos pormenores; porque me lamento, como Frosseau, de la variedad de epispásticos y otros muchos remedios que, sin ventajas positivas, no son más que un lujo de la farmacia. Sólo haré notar, que los garbanzos de Wislin pueden hacerse con los de lirio, y que es mejor usar el alcoholado de torvizco, hecho directamente, que la solución del extracto que piden las farmacopeas.

Respecto de lo primero, tengo dos razones: una, la mayor facilidad con que se empapa el lirio de la tintura; y otra, que á la vez promueve la supuración y dilata la fuente, porque hincha más que las cuentas de naranja.

En cuanto á lo segundo, se advierte que el extracto alcohólico de laureola no se usa entre nosotros, $y$, por lo mismo, tiene que pre- 
pararse únicamente para los garbanzos, que después de ese trabajo, se ha de disolver nuevamente el extracto, y que el alcoholado sobrante, si no es en cantidad regular, se pierde. Todo esto se erita sirviéndose de la siguiente fórmula:

Corteza de torvizco.................. 1 parte

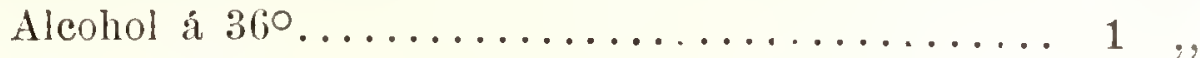

Se divide la corteza por el procedimiento de Coldef, $y$ se deja macerar en el alcohol por ocho días; se recoge el líquido por expresión y se filtra; se separan las cuentas de lirio, hechas á torno, del hilo que las une, se dejan en el líquido durante tres minntos, se hacen secar, cuidando de morerlas, para que el barniz quede igual; se repite esta operación cuatro ocasiones $y$, estando bien secas, se guardan. Es mejor no frotarles para darles lustre, pues esto, lejos de ser ítil, tiene inconvenientes. 'También creo preferible el alcohol a $36^{\circ}$, porque la tintura es más activa que la que se prepara con el de $31^{\circ}$.

Monesta.-Hoy se usa, con el ferror que es común en México, la corteza conocida con ese nombre, y recomendada el año de-1839 en uno de los diarios de química médica, con el pomposo título de nuevo medicamento astringente. Aquí, como en Europa, hay remedios de moda que, desgraciadamente, se prescriben con furor para dejarlos bien pronto. Sin ir muy lejos, pueden citarse como ejemplos, la cainca y el gnaco, el ácido hidrociánico y la codeína, el aceite de croton y otros muchos purgantes drásticos, de fatal recuerdo para no pocas familias.

La nueva corteza tendrá ó no las rirtudes que se le atribnyen; pero es necesario observar sus efectos con especial cuidadn, y desecharla como imútil, siempre que su acción sea igual á la de tantas plantas astringentes que produce nuestro feraz terreno. Recuérdese lo que se dijo en otra época de la cuasia amarga, la simarruba y la ipecacuana; reenérdense también las virtudes que la experiencia concede á estos regetales, y no se olvide el consejo del sabio de Cos: experimentum periculorum.

A los prácticos toca dar á estos apuntes el ralor que merezcan, y á mí oir las reflexiones que quieran hacer, y que no dndo sean el resultado de sus experiencias.

Preparaciones de fierro.-Annque desde tiempo inmemo- 
rial se ha usado este metal como medicamento, no se había hecho tan general como en la época actual, en que la química presta servicios positivos al arte de curar. Muy poco ha que se administra, con seguridad, como antídoto del arsénico; que se combate con 'feliz éxito la clorosis; que se da la debida preferencia á ciertos compuestos medieinales, y que se conocen los cambios que produce en el estado de la sangre. Pero una de las condiciones indispensables es la pureza de los compuestos, sobre lo cual pretendo llamar la atención de los profesores, generalizando al mismo tiempo algunas de las doctrinas publicadas últimamente.

El sulfato de fierro del comercio no debe emplearse en las oficinas, aun cuando se purifique con las limaduras, pues esta operación no da siempre buen producto ni es más económica. La caparrosa abunda en otros sulfatos, tales como el de cobre, y no es raro hallar alguna que contenga arsénico, en cuyos casos es muy expuesto preparar con ella las aguas minerales de uso interno, las píldoras de Bland, las sacarinas de Vallet, los polvos de Meuzer y otros inuchos compuestos. Tampoco es raro encontrar el sulfato descompuesto por falta de precaución para conservarlo, y debe tenerse presente, que no es lo mismo administrar el sesqui, el proto ó el peróxido de fierro, porque no todos estos compuestos son igualmente solubles en los líquidos del estómogo, ni todos determinan iguales efectos. El sulfato ferroso se descompone fácilmente; pero puede conservarse muy bien en alcohol, y debe tomarse esta sencilla precaución para tenerlo bueno.

Carbonatos de FIERro.-La descomposición del sulfato por los carbonatos alcalinos, no siempre presenta las ventajas que se le han señalado; su mayor ó menor acción depende del estado en que se administra y del procedimiento empleado para prepararlo. Con las píldoras de Blard obtienen unos brillantes resultados, mientras otros lamentan la ineficacia del remedio. El sub-carbonato, por doble descomposición, no se conserva en todas circunstancias, y el carbonato de protóxido obra con más energía y prontitud que el peróxido que resulta, lo que se atribuye fundadamente á la solubilidad del primero en los líquidos del estómago.

Si las dos sales que constituyen las píldoras no son puras, ni se pulverizan separadamente; si se trituran juntas mucho tiempo; si para formar la masa se añade gran cantidad de goma; si la potasa 
está húmeda; si es cáustica y si no se envuelven las píldoras en un cuerpo inerte, ni se conservan fuera del influjo atmosférico, no corresponderán los efectos del medicamento. La agua del sulfato es suficiente para hacer la masa, y si la potasa contiene más, hay necesidad de mayor cantidad de goma, y las píldoras adquieren una dureza que las hace de difícil solución. Si el álcali es cánstico, no resulta carbonato, sino óxido ferroso, que por su contacto con el agua y el aire, pasa fácilmente al estado de óxido férrico; mientras que la potasa que no ha entrado en combinación con el ácido sulfúrico, reobrando sobre la pequeña cantidad̉ de sub-carbonato ferroso, lo priva del gas carbónico y se sobre-oxida. He aquí una razón para preferir el bi al sub-carbonato de potasa ó al de sosa.

Mr. Vallet, al explicar los fenómenos que ha observado en el acto de confeccionar estas píldoras, dice: que ya hechrs, continúa la oxidación lenta del metal, de lo que resulta hidrato de peróxido de fierro y bicarbonato de potasa. Esta opinión, adoptada por Mr. Soubeiran y repetida por otros, no satisface al entendimiento. En primer lugar, hay que advertir, que pasado algún tiempo de hechas las píldoras, no está el fierro hidratado; en segundo, y es lo más notable, que no se tiene en cuenta el ácido de la sal de fierro que formó el sulfato de potasa. Acaso por olvido no se mencionó esta sal; de lo contrario, la teoría no es admisible.

La preparación del azafrán de marte exige también estas precauciones. De poco tiempo á acá, se nota que no es igual el de todas las oficinas, lo que proviene de los diversos procedimientos eimpleados para obtenerlo. Son tantos los cambios á que está sujeto el carbonato preparado por doble descomposición, que bastarían para negar al método la preferencia que hoy se le da. Dos cosas se advierten en ese producto: primera, que contiene fierro al estado de peróxido, y segundo, que muchas ocasiones no hay ni restigios de carbonato. Si se tratara de administrar éste luego que se ha precipitalo y lavado, se daría el medicamento que se desea, con la rentaja de ser un polvo impalpable; pero después de secarlo al contacto del aire, no es, por lo común, un hidrato ferroso combinado con el gas carbónico, sino un óxido férrico, que no es raro haya perdido todo el ácido. La mayor parte de los antores, aseguran que se da el carbonato férico, mas no falta quien crea que no hay más que el ferroso, fundando su teoría en que en la supuesta combinación están juntos el carbonato ferroso 
y è óxido férrico, como sucede en el procedimiento de que se ha hecho mérito. No obstante, con algunas precauciones puede conseguirse que el precipitado contenga, ya seco, una parte de carbonato; pero también hay óxido férrico que disminuye los efertos del medicamento.

La preparación del carbonato ferroso por los bicarbonatos alcalinos, da mejor producto que cuando se emplean los carbonatosó subcarbonatos, sobre todo, si se pone menor cantidad de la prescrita; pero no está enteramente libre de los inconvenientes indicados. Si se rocían las limaduras y se abandonan al contacto del aire, se consigue en poco tiempo un medicamento constante en sus efectos, que aunque no está reducido á un polvo tan sutil como el que resulta de la precipitación, es propio para el objeto á que se destina.

Etrope marcial. - Este óxido intermedio no es, entre las preparaciones de fierro, de las más útiles á la medicina; pero tiene todavía algún nso y debe proscribirse el que se halla mezclado con carbón. El procedimiento últimamente recomendado por los autores, que consiste en la descomposición por el fuego, de algún producto orgánico en contacto con el fierro dividido, es, sin duda, el más económico, el más pronto y el que da mejor resultado. Puede servirse indistintamente del azúcar ó el vinagre, y conseguir notables ventajas respecto de los antiguos métodos, por la agua y los aceites fijos; pero la azúcar deja mayor cantidad de carbón que el vinagre, lo que hace á éste preferible. De todos modos, es preciso lavar el producto para tenerlo puro; pues aunque las materias extrañas no influyen en las propiedades del medicamento, disminuyen la cantidad del que se pretende administrar.

En cuanto á los lactatos, acetatos, yoduros, malatos y demás compuestos ferruginosos, recomendados últimamente, no me parecen inejores que los anteriores, sino en los casos en que hay indicación que llenar, aprovechando las propiedades que se atribuyen á los cuerpos negativos, que forman con el fierro una de esas combinaciones. Algunas, como los lactatos, deben ensayarse antes de administrarlas, para evitar el engaño á que dan lugar la ignorancia ó la mala fe.

JaLeas medondmes. - La facilidad con que se alteran las jaleas vegetales y animales, lıa obligado, sin duda, á los médicos á usarlas menos de lo que quisieran, pues hasta ahora no se niega la utilidad de esas preparaciones en el tratamiento de algunas enfermedades. 
También ha cooperado á esto, el abuso, que cada día se extiende más, prefiriendo productos elegantes á los que son más útiles, pero menos vistosos. La cola de pez, que ocupa en las mesas de los gastrónomos uno de los primeros lugares, ha pasado de los talleres al hornillo del repostero, al brasero del último figón y al aparato eraporatorio del farmacéntico, de donde es conducida, despidiendo el aroma del azahar, hasta el lecho del enfermo. ¿Quién piensa hoy en la jalea de cuernos de ciervo? Disparate; es mucho mejor la de Ichtyocolla, más nutritiva, más blanca, menos repugnante y, sobre todo, los químicos han demostrado que es la jaletina pura, la grenetina sin olor ni sabor. Pero debe prescribirse con el nombre de jalea crimul; este es más conforme con el idioma, y nada importa que la jalea sea de ave ó de cuadrúpedo; todas nutren y no hay que ocuparse de los cuernos ni de la cola. A estas y otras conjeturas ha dado lugar el prurito de reforma y la poca observación. Bien sé que no se debe fiar el tratamiento de una enfermedad á sólo el uso de las jaleas; pero no puede negarse la doble ventaja de esta substancia, como alimento y como medicamento. Parece que antiguamente se preferían los cuernos de venados, por carecer de materia grasa; mas como puede aislarse con facilidad de las partes animales, creo indiferente usar de cualquiera, empleando las tendinosas y cartilaginosas de los cuadrúpedos. Para que las jaleas medicinales sean útiles, es preciso cuidar de su preparación $y$, sobre todo, de conservarlas sin que se alteren, lo que es fácil evitar. Se cree generalmente, que tapando bien la rasija que contiene una jalea, se conserva mejor y dura más sin agriarse y aun corromperse; este es un error que me ha hecho conocer la experiencia y del que podría dar razón, si no tuviera que limitarme á llenar sólo una hoja de este periódico; basta referir el hecho, para que haga la prueba quien quiera desengañarse. Dejando de una misma jalea una parte en cápsula ó taza, al aire libre, y otra en bote tapado, se podrá conservar la primera por mucho tiempo, sin descomponerse, mientras la segunda entra fácilmente en fermentación, á no ser que la temperatura se oponga á esta reacción. Otro tanto puedo decir de las jaleas vegetales, y aun de las jaletinas: un hecho que está á la vista de tedos me servirá de prueba. En México es común conservar las jaleas en cajas de madera, que llamamos cajetas, cuyas tapas no ajustan, quedando el dulce al contacto del aire. Sin embargo, antes se azucaran que entrar en fermentación, lo que podrá atribuirse á la 
cantidad de azúcar, que generalmente es mayor de la que se emplea para las jaleas medicinales. Pero como esas mismas jaleas se alteran guardándolas en vasijas bien tapadas, es de creer que aun cuando el azúcar favorezca su conservación, hay también otras condiciones necesarias y aun indispensables. Una poca más de azúcar que la prescrita por los autores, no daña al medicamento, ni destruye sus propiedades, y siempre es preferible la jalea dulce á la fermentada. Lo mismo digo en cuanto á la consistencia: las jaletinas son más suaves y vistosas que las jaleas; pero éstas se conservan mejor, y si alguna vez repugnan al enfermo, es fácil, calentándolas con una poca de agua, darles el punto conveniente. Entre las jaleas vegetales que se usan en farmacia, la de liquen ocupa el primer lugar. Hay quien asegure que no es una jaletina, sino un mucílago espeso, en lo que no estoy de acuerdo, porque, bien preparada, tiene todos los caracteres de la jalea; pero desentendiéndome de esta cuestión de nombre, creo que la adición de la cola del pescado, recomendada por algunos para darle mayor consistencia, facilita su descomposición y da un sabor desagradable, por lo que debe proscribirse, limitándose á concentrar bien el cocimiento de liquen, á darle buena consistencia y á quitar á la gelatina la poca miel que siempre se separa. En conclusión, esta máxima es aplicable á la conservación de los objetos de historia natural, á pesar de que se opone á las que dan los autores, quienes pretenden que se guarden aquéllos en estantes bien ajustados, para impedir el contacto del aire, ó en capelos que sólo encierran una cantidad determinada. He visto muchísimas piezas disecadas $\mathrm{y}$ vegetales destruidos por los insectos, $\mathrm{y}$ aun en perfecta putrefacción, por haberse cuidado de seguir ese consejo, tan contrario á lo que enseña la experiencia.

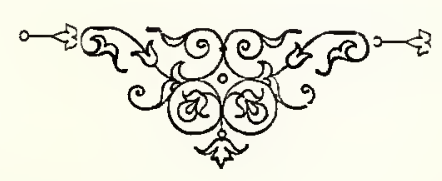




\section{SOBRE VEJIGATORLOS.}

Escrito por el Pfr. de medicina y farmacia, D. Leopoldo Río de la Loza.

(Tomado del "Diario del Gobierno," de 1836).

Sin embargo de que con la palabra vejigatorio se designa en terapéutica toda substancia que, aplicada á la superficie del cuerpo, determina una secreción serosa y forma ampolla, no quiero tratar de todas y cada una de las que se han empleado y emplean con este fin: sólo me limitaré á hablar de aquellas que uás comúmmente se usan entre nosotros, y, con especialidad, del emplasto epispástico ó de cantáridas.

El euforbio, la corteza de drimis, la semilla de mostaza, y algunas timeleas, que casi siempre se emplean como rubefacientes, sirven en muchos casos de vejigatorios, sea por la acción de otros cuerpos con los que se mezclan, ó por el espacio de tiempo que se mantienen en contacto con la piel, ó, en fin, por la mayor disposición de los individuos á quienes se aplican.

El euforbio (euptiorbia officinalis) y el mezereon (daphne mezereum) se usan poco en materia médica; pero se consumen en la veterinaria. El primero tiene el inconveniente de ser peligroso su manejo, en razón de que es más poderoso ptámico ó estornutario. La corteza de drimis (drimis Winter) se gasta bastante en tintura alcohólica, y podría emplearse con muy buen éxito como vejigatorio, haciendo con su polvo y vinagre, una cataplasma que, puesta en contacto con la piel, produciría buen efecto. 
La mostaza (sinapis nigra) es, sin duda, de lo que más uso hácemos como rubefaciente; pero se cree por el vulgo que su acción se aumenta en razón de la fuerza del vinagre; de manera que cuando se quiere que no determine sino una ligera irritación, se manda hacer la cataplasma con vino ó agua, lo que resulta contra la intención que se proponen, pues siendo la agua la que desarrolla más el aceite irritante de la mostaza, produce mayor efecto que la que se hace con vino ó vinagre. La harina de trigo ó de linaza, que se agrega para hacer sinapismos, lejos de aumentar su actividad, la disminuye, supuesta una cantidad; es decir, que la cataplasma hecha con una onza de mostaza y lo que baste de agua, produce sobre una misma piel y en un tiempo dado, mayor irritación que la hecha con media onza de mostaza, media de harina de trigo ó linaza, y el vinagre suficiente, pues es indudable que, en ésta, la cantidad del cuerpo irritante es menor, y el añadido en nada aumenta su energía.

To mismo puede decirse de las otras substancias que se acostumbran agregar á los sinapismos: tales como la pimienta, ruda, ajo y otras, pues disminuyendo la cantidad de mostaza, no compensa la que aquéllas contienen de principio rubefaciente, al que se pierda en ésta:

La contaridina ó principio vejigatorio de las cantáridas, no lra correspondido á los deseos de Mr. Robiquet; pues si es cierto que puede producir los efectos que señala este sabio, también lo es que no son tan violentos como se piensa, y que su uso no carece de inconvenientes. El principio volátil de la cantárida, del que está privada la cantaridina, impide mucho que obre con energía. La solución etérea de esta substancia, no me ha surtido efecto, sino después de muchos y muy repetidos toques, en que se gasta más cantaridina que la que habría producido el polvo de cantáridas necesario para formar ampolla. Aún hay más: la epidermis de muchos enfermos es tan gruesa, tan insénsible á la impresión do los agentes exteriores, que estoy cierto que no alcanzaría un escrúpulo de este principio inmediato para que les hiciera efecto sobre $u$ espacio de dos pulgadas; y aun cuando esta cantidad fuera bastante, no todos podrían gastar en ella.

Ninguna de las substancias mencionadas carece de inconrenientes como epispásticas; por esto preferimos, y con buen éxito, el polvo de cantáridas, mezclado, ó con manteca, cera, etc., ó con la levadura, ó con la pez, trementina y aceite; á estas mezclas se les dan los nombres de pomadas ó unguientos, cataplasma y emplasto epispástico. 
Todas pueden producir rejiga; pero no todas en igual espacio de tiempo, ni de un mismo modo, y por esto usamos más del emplasto que de la cataplasma, y de ésta más que de la pomada. Ésta se emplea para avivar los cánsticos; pero la facilidad con que se liquida al calor del cuerpo, la poca permanencia que tiene sobre una superficie no ulcerada, y el tiempo que tarda en obrar, han obligado á los prácticos á limitar su uso para sólo aquél objeto. Debo advertir de paso, que en los casos que convenga usar la manteca, debe preferirse la colada, que no lleva consigo el polvo de la cantárida, pues éste sé adhieréa las superficies que toca, y produce escoriaciones y ampollas en muchos puntos, que ocasionan dolores, y de los que se desprende con dificultad.

La cataplasma, que vulgarmente se llama cáustico, se usa más que las otras preparaciones, $y$ se hace mezclando el polvo de cantáridas con rinagre y poniendo esta masa sobre leradura. Esta preparación no es de las mejores, pues presenta desventajas en su aplicación, que no tiene el emplasto, por lo que creo que debe preferirse. La levadura y la masa hecha con la cantárida, no pueden ser en tan pequeña cantidad, que no formen una elevación bastante para extenderse á la presión: se extenderá, tanto más, cuanto más prominente, blanda y comprimida esté la cataplasma. El facultativo no puede, en caso alguno, prevenir estos accidentes, ni puede, por consiguien. te, limitar exactamente el tamaño: tampoco puede, en muchos casos, fijar el lugar, pues como este cáustico no es un cuerpo glutinoso, que pueda adherirse á la piel, los movimientos del enfermo, un descuido al ponerlo ú otro motivo, lo desvía y no obra por haberse repartido el tiempo en rarios puntos, ú obra en todos los que toca, si las circunstancias han favorecido; de lo que resulta, 6 una rejiga en el lugar que se desea, pero de mayor extensión, 6 varias rejigas en otros puntos, 6 ningún efecto, cuyos inconvenientes refluyen, de todos modos, en perjuicio del enfermo, y se malogra el tiempo más precioso

Estas desventajas no tiene el emplasto de cantáridas: su consistencia, las substancias que lo componen y el grado de calor del cuerpo, influyen mucho para que determine efectos constantes en el lugar que se quiere y al grado que conviene. Cubierta su superficie en la mayor parte con el polvo de la cantárida, determina una irritación igual: el resto de esta superficie, la ocupa la mezcla que envuelve el polvo, y mantiene el emplasto adherido á la piel, hasta que por 
el aflujo linfático que determina, se desprende, y desprende, al mismo tiempo que la humedad, al emplasto que se había adheridoá ella. Así es que, formada la ampolla, se separa el emplasto sin trabajo, del mismo tamaño y figura que tenía cuando se puso, del mismo lugar y con su propiedad vijigatoria, tan decidida como si no hubiera servido.

Esta última circunstancia recomienda con especialidad su uso, pues proporciona una economía necesaria en algunos casos, especialmente en los hospitales, en donde, los más días, se hace uso de cáusticos: ya sean para un mismo individuo ó ya para otros, pueden servir los que se quiten, con tal que se tenga cuidado de limpiarlos con un lienzo y no calentarlos cuando se pongan. Creo á propósito citar, entre otros, un caso reciente, en apoyo de las ventajas que tiene el emplasto sobre el vejigatorio común.

Un hombre, de más de cincuenta años, que vive en la calle del Parque de la Moneda, número ocho, fué atacado de una hemorragia cerebral y, en su cousecuencia, quedó hemiplégico; le hice aplicar un vejigatorio, hecho con el emplasto, á la parte posterior del cuello, $y$ dispuse que se le curara á las ocho horas: en ese tiempo había formado ampolla; mas deseando asegurar la revulsión con la irritación de una superficie mayor, ordené que se limpiara el mismo parche $y$ so le pusiera entre las dos escápulas, de donde, pasadas cuatro horas, se debía quitar y ponerlo, por igual tiempo, en el dorso, lomos, etc. Como dije á. los asistentes que no había de producir ampolla, cuando quitaron el emplasto y vieron que la había, se propusieron disminuir el tiempo, y lo dejaron la segunda vez sólo dos horas; mas este espacio fué bastante para que se hubiera formado otra, de modo que, en catorce horas, tenía el enfermo toda la columna vertebral cubierta de una vejiga, sin haber hecho uso más que de un cáustico, que aún sirvió para las piernas. Como éste, tengo otros casos, que no me permiten dudar de las ventajas de esta composición, siempre que esté preparada con escrupulosidad, pues en esto consiste el buen resultado y el crédito del medicamento.

Hay varias fórmulas para preparar este emplasto, que no sólo difieren en cantidades, sino también en los ingredientes. Unos quieren que se amase el emplasto simple, ó diapalma, con el polvo de la cantárida; y otros, que se haga sobre un emplasto, por mezcla. El primero no carece de inconvenientes, y el segundo, que es el que más se usa entre nosotros, se prepara con arreglo á la Farmacopea espa- 
ñola, que si es buena en cuanto á los ingredientes, no lo es en cuanto á las cantidades, pues queda tan dure, que no puede adherirse á la piel; circunstancia que es indispensable para que obre bien. Se remedia este mal, substituyendo trementina, en la -misma cantidad, á la pez que pide: de manera que, en lugar de echar para una receta dos onzas de aquélla y dos de ésta, se deben emplear cuatro de la primera, omitiendo la segunda. El mismo objeto se consigue agregando media onza más de aceite del que prescribe la fómula. Así se obtiene un emplasto de buena consistencia, que pega bien á la piel y no se liquida con el calor. No obstante esto, para obtener un buén producto, es necesario otras reglas, que no las observan todos. Se acostumbra por algunos liquidar á fuego fuerte la trementina, la pez y la cera, é immediatamente que se cuela la mezcla, echan el polvo inuy sutil de cantáridas, de lo que resulta que pierde la trementina, por el calor muy fuerte, el aceite volátil que contiene, $y$, por consecuencia, ammenta la consistencia del emplasto. El polro de cantárida también pierde, con este calor, su principio volátil, y estando muy fino, no obra en toda la superficie, como el mediocré.

Otros calientan el emplasto para extenderlo sobre la badana, y algumos, aun cuando lo extiendan en frío, agregan, con la mejor intención, más polvó á la superficie del emplasto, y hacen que se adhieran por medio del calor que comunica una brasa que pasean por encima. Todos estos procedimientos se deben abandonar', para obtener los efectos que se desean.

También es rentajoso el ahor'ro de tiempo, pues para disponer un par de cáusticos, del tamaño común, se necesitan veinte minutos, y pará disponer dos de igual tamaño, no son necesarios más que diez, es decir, que con éstos se alorra una mitad del tiempo, muy preciso en alguuos casos, y que hace preferir éstos á aquéllos.

Resulta de todo, que siempre que el emplasto esté preparado según hemos dicho, y que el enfermo se halle en circunstancias propias para que le obren los rejigatorios, debe preferirse el emplasto epispástico á todos los otros; que la cantridinu, ya sea disnelta en éter, $́$ ya en aceite, no produce su efecto con la violencia que se creyó, y debe, por lo mismo, quedar en el desuso que hoy tiene; que la mostaza obra con mayor actividad mezclada con agua, que con cualquier otro líquido, y que, después de ésta, debe preferirse, como rubefaciente, la corteza de Drimis. 


\section{VARIEDADES.}

\section{FALSIFICACIÓN DEL CHOCOLATE}

\section{(Tomado del "Periódico de la Academia de Medicina de México." Publicado por el Sr. Dr. D. Leopoldo Río de la Loza).}

Il chocolate, de que tanto uso se hace en México, especialmente por la clase media y la ínfima, no está fuera de los tiros de la codicia mercantil. Para economizar la canela, sin que falte el aroma, darle buen color y aumentar el peso, lo adulteran con aceites volátiles y fijos, con achote, fierro y otros cuerpos más ó menos nocivos.

Por fortuna, no se sabe, hasta ahora, que le mezclen substancias tan dañosas, como las que ha descubierto la análisis, en algunos de los fabricados en París. * Aquí se conforman con agregarle tierras ocrosas, para remedar el matiz de los buenos cacaos; pero la proporción del fierro no llega á ser tal que perjudique notablemente á la salud.

En estos últimos días ha sido denunciado el chocolate de ma de las fábricas de la capital; un simple reconocimiento indicó la existencia del fierro, mas quería saberse si sería ó no dañoso, y era preciso, para eso, determinar la cantidad. La análisis cuantitativa demostró, que el chocolate denunciado contenía: 0,01 de fierro, ó sean cinco gramos en cada tablilla, de peco menos de una onza de peso. El reconocimiento comparativo descubrió restigios del mismo metal en otro chocolate, de cuya pureza se tenía satisfacción, lo que hizo

* Diarios de quimica médica, farmacia y toxicologia. 
sospechar su presencia en la semilla; mas son tan pocos y tan limitados los trabajos sobre su composición, que es muy necesario el dedicarse á estas investigaciones, para fijar la de cada especie de cacao. Entretanto, puede asegurarse, con un autor de nota, que la extractiva del cacao, así como la del café, tienen la propiedad de dar un precipitado verde con las sales de fierro, y el tinte azul, con los cianuros dobles.

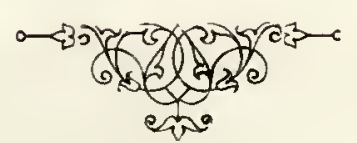




\section{EXAMEN DE UN LĹQULIO ARROJado POR vómito}

Caracteres organolépticos.-Lúquido de color moreno rojizo, visto por reflexión; por refracción, se presenta dividido en tres capas: la superior é inferior, de color moreno, y la media, diáfana, de color amarillo rojizo: algunos cuerpecillos que flotan en él, tienen el aspecto membra-uniforme, y todo abunda en burbujas, iguales á las que ofrecen los esputos. La capa inferior es de consistencia gelatinosa, olor análogo al de la sangre, el que se hace más notable por el calor.

Examen microscópico.—Glóbulos pequeños, redondos, de color rosado, y otros mayores é irregulares, sin color: grandes círculos luminosos, formados por las burbujas: corpúsculos irregulares. La mayor parte de los glóbulos se disuelven en la agua, y los que quedan presentan un cuerpo tembloso.

Caracteres químicos. - La agua disuelve, en parte, la membra-uniforme que contiene el líquido, se enturbia, forma espuma y toma un color rojizo.

El calor hace que pierda el líquido el color, y forma un coágulo moreno.

La potasa le hace tomar este color, visto el líquido por reflexión, y por refracción, el verde amarillento; disuelve la mayor parte del coágulo y deja un líquido glutinoso.

Los ácidos clorhídrico y nítrico, lo decoloran y disuelven en parte el coágulo: el sulfúrico no destruye el color. gulo.

El hidro-sulfúrico hace que tome el verdoso, y disuelve el coá- 
El éter sulfúrico no cambia el color y lleva el coágnlo á la superficie.

En fin, el producto de la incineración, da por el ácido clorhídrico y el hidrocianato ferroso-potásico, un color azulado.

De estos datos puede inferirse que el líquido sometido al reconocimiento, contiene sangre, moco y, acaso también, pus. Una análisis comparativa de las tres, mezclados en diversas proporciones, será de grande utilidad para el diagnóstico de algunas enfermedades.

Reflexiones.-Los caracteres organolépticos son, sin duda, un buen recurso en esta clase de inrestigaciones, cuando se tiene algún hábito para comparar los hechos con utilidad; mas es casi imposible pintar las sensaciones con los coloridos propios. ¿Cómo describir las que dan al olfato la sangre y el pus? ¿Cómo expresar la que distingue á aquéllas, en el acto de la combustión, de este producto anormal? Hay tanta analogía entre la que desarrollan las substancias orgánicas, que es fácil equivocarlas, y más seguro el no atenerse solamente á los datos que ministran los sentidos. En el reconocimiento de que se trata, hay indicios para creer que el líquido no es sólo sangre, y para sospechar de la existencia de algunos de los productos de la expectoración.

Esto mismo confirman las observaciones microscópicas: sin embargo, Kirmer, fundado en la pequeñez de los glóbulos, aseguraría que era sangre arterial; Hewson, que provenía de un animal joven; Dumas, que procedía de otro que no había tomado alimento; Scl-midt, que eran glóbulos sin vida, y no faltaría quien se empeñara en probar que eran de hombre ó de mujer, de buey ó de conejo; todo esto nos parece mna exageración de la utilidad del instrumento.

El que la agua no disuelva todos los glóbulos, y la analogía de los que quedan, con los de la sangre, hacen sospechar la presencia del pus: esta sospecha se aumenta por los caracteres que ofrece el líquido, si se trata por el ácido sulfúrico y por la potasa. La espuma que forua, su solubridad, en parte por el álcali cáustico, el aspecto viscoso que presenta, y, sobre todo, el disolverse en el agua por la presencia de la sangre, revelan la existencia de alguna cantidad de moco.

A éste, ó á la mezcla de los tres líquidos, se debe, tal vez, el que no aumente la consistencia, por su contacto con el ácido hidro-sulfúrico, y á que no cambie de color por el éter, ni tome el tinte verde 
por el clorhídrico. Mas la pérdida de color del líquido por el calor, y la formación del coágulo, el subir éste con el éter hasta la superficie y los matices que presenta con la potasa, son bastantes para asegurar que contiene sangre.

En cuanto á los resultados obtenidos por la incineración, no son satisfactorios.

Otra vez he indicado la propiedad que tiene el hidrocianato ferroso-potásico, de presentar con el ácido sulfúrico débil, el color que da con las sales ferrosas, y con el precipitado azul, si el ácido no es puro; notaré ahora, que igual cosa sucede con el clorlídrico, lo que hace creer que aquel reactivo no merece toda la confianza que se pretende darle, ó, cuando menos, que no se debe fiar sólo en él para las investigaciones médico-legales.

M. Orfila asegura que esos ácidos, así como el acético y otros, no ejercen alguna acción á la temperatura ordinaria, sobre el cianuro amarillo; pero que hay descomposición hreciendo hervir la mezcla. Estas experiencias, repetidas á la temperatura ordinaria, demuestran lo contrario; por tanto, creo muy expuesto juzgar de la existencia del fierro por el tinte azul, cuando no se ensaya el precipitado por los medios convenientes. La pureza de los ácidos, del cianuro, del agua, $y$, más que todo, el empleo de otros reactivos, son indispensables para decidir fundadamente.

En cuanto al líquido analizado, hay que notar, que la persona que lo arroja por vómito, no presenta más que síntomas nerviosos, según me há indicado el profesor D. M. Jiménez, quien está encargado de su asistencia.

Aunque estos apuntes no los creo de mayor interés para los profesores instruidos, acaso servirán, el ralor de los reactivos y la utilidad de esta clase de investigaciones, para el diagnóstico y plan curativo de algunas enfermedades.

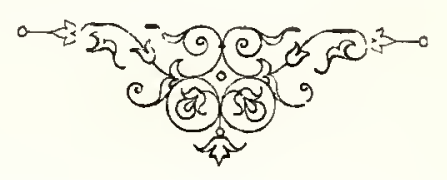




\section{¿DEBEN PROSCRIBIRSE LAS MEDIDAS DE GAPACIDAD EN LAS OFICINAS DE FARUACIA?}

\section{(Tomado del "Periódico de la Academia de Medicina de México," y publicado}

por el Sr. Dr. D. Leopoldo Río de la Loza).

He aquí una cuestión á que ha dado lugar el uso nnevanente introducido en algunas boticas, de servirse de la balanza para el despacho de toda clase de bebidas, fomentaciones, unturas, etc. Aunque nuestras leyes prohiben expresa y terminantemente este abnso, no pretendo sostenerlas ni criticarlas; quiero analizar el punto, invitando á los profesores, que no opinen como yo, á que publiquen las razones en que se apoyan. Creo que la ciencia y el bien de los enfermos, merecen algún sacrificio; por mi parte, estoy resuelto á hacerlo y confesar mi error, si fuere convencido, ó esforzarme en contestar á los argumentos que se hicieren. Mas si quedare sin respnesta este artículo, lo que no es creíble, tendré derecho para asegurar que ha triunfado mi opinión y que la crítica promorida en los corrillos, ha sido injusta y nada decente.

Para iniciar la cuestión, con la clarida y orden debidos, fijaré algunos puntos, que hay que examinar atentamente.

$1 .^{\circ}$ La infidelidad de las balanzas.

$2 .^{\circ}$ La diversa densidad de los líquidos que se despachan en las oficinas.

3. Las muchas substancias que, por lo regular, entran en la composición de esos líquidos. 
$4 .^{\circ}$ El uso de señalar por el volumen la dosis de los medicamentos.

5. ${ }^{\circ}$ La complicación del despacho y lo inútil de la innovación que pretendo combatir.

Es bien sabido que las balanzas de las boticas no son tan exactas como debieran, y que es mucho más difícil construir y conservar una regular balanza, que una buena medida. Comúnmente no se examinan aquéllas, ni se comparan las pesas, y aun ignoran algunos las reglas que se han de observar al reconocer esos instrumentos: mas quiero suponer que la balanza es muy buena y las pesas exactas, en cuyo caso está más expuesta á descomponerse, por mil circunstancias bien conocidas, especialmente por el continuo uso que tiene en las oficinas de regular despacho. Una balanza sensible, puede no serlo por sólo el peso de la tara, por el menor roce del fiel, la oxidación del metal en el punto de apoyo, el cambio del eje de suspensión, etc., etc., de lo que se infiere que las balanzas pueden engañar, no sólo por su mala construcción, sino también por accidentes relativos al uso frecuente que se hace de ellas, al poco cuidado ó al ningún conocimiento de los que las manejan.

La diversa densidad de los líquidos, es otro de los inconvenientes graves del uso de las pesas. Los cocimientos, por ejemplo, que se preparan con substancias compuestas de partes más ó menos solubles, hacen variar el peso específico de los líquidos, de lo que resulta un cambio de volumen. En este caso, el vehículo no debe pesarse antes de hacer el cocimiento, porque la evaporación disminuye su cantidad: tampoco después, porque ni se puede apreciar la que pierden todos los regetales usados en farmacia, ni ésta es una con relación al tiempo, grado de calor y á la proporción entre el vehículo y la substancia. Supóngase que se prescribe una libra de emulsión de almendra en cocimiento de yerbas emolientes, que se pesarán doce onzas de agua para prepararlo y hacer después la emulsión, ó se pesa el cocimiento ó, en fin, la horchata. Los resultados en los tres casos no son idénticos, y de todos modos se anotarán inconvenientes bastantes para asegurar que es mejor atenerse al volumen, que á la densidad de los líquidos usados en terapéutica.

Si todos los que se piden á las boticas fueran cocimientos de plantas poco activas, aguas inertes, nada importaría la mayor ó menor exactitud; pero lo común es que sirvan de vehículo á medicamentos activos, cuya dosis se fija por el volumen. Una libra de agua 
simple con jarabe de ópio, puede ocasionar males, si no se atiende á la proporción de la bebida. En tóas las que entran muchas tinturas, aguas y jarabes en cantidades pequeñas, no pueden pesarse, y aun cuando se procure hacerlo, los resultados serán infieles. Citaré, para notar mejor los inconvenientes, una de las fórmulas que se despachan con frecuencia.

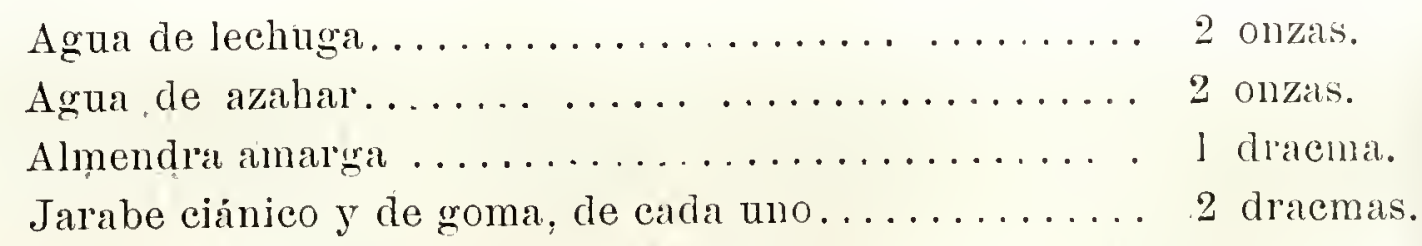

Supongamos que se tara la vasija en que debe ir la bebida; que se pesa uno de los líquidos: la adición de los restantes es tan exacta, que no pasa de la cantidad prescripta. Más de una rez sucederá lo contrario, y no es de creer que se repongan estas faltas, perdiendo el tiempo y el trabajo. Si se pesan separadamente las aguas, los jarabes y demás componentes, hay de menos la parte que queda en la vasija, y falta la escrupulosa exactitind que se recomienda al prescribir las medidas. Otro tanto puedie decirse en cuanto á los líquidos de uso externo, con más que la densidad de los alcoholados, de los aceites $y$ las aguas medicinales es menos proporcionada y más expnesta á errores, que preden y deben evitarse, para que los medicamentos compuestos de muchos líquidos sean fijos en su composición y constantes en sus efectos.

En México, es costumbre ordenar en gotas, dedales, cucharaditas, cucharadas y pozuelos, los líquidos de uso interno, y se ha calculado, por datos aproximativos, el ámbito de cada una de esas medidas, tanto que un médico pocas reces se equivoca al distribuir, en determinado número de tomas, el líquido que receta. Al formar este compuesto, lo que menos tiene presente es el peso, s á la verdad que, por mucha que sea su práctica, no siempre tendrá la seguridad que presta el rolumen, como término fijo é independiente de la densidad.

No es necesario esforzarse para probar que con más facilidad $y$ violencia se mide que se pesa; que la medida simplifica el despacho, y que de esto depende la seguridad del enfermo, la exacta obserración del médico y el menor trabajo y mayor confianza del farmacéntico, que no puede por sí despachar todas las recetas.

Si se examinan con imparcialidad y buena fe las razones que he 
indicado; si se atiende á los descuidos que se observan en la práctica, y se compara el número de autores respetables que aconsejan el uso de las medidas para el despacho de las fórmulas magistrales, se convendrá en que la imnovación que se pretende es inútil y perjudicial, y en que no deben proscribirse las medidas de capacidad en las oficinas de farmacia.

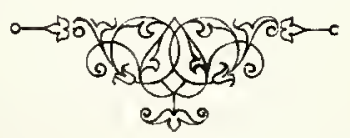




\title{
UN VISTAZO AL LAGO DE TEXCOCO.
}

\author{
Su influencia en la salubridad de México. \\ Sus aguas.-Procedencia de las sales que contiene.-El Ahuautli.
}

(Por el Sr. Dr. D. Leopoldo Río de la Loza).

No sin motivo ha llamado la atención de muchas personas, desde la conquista hasta nuestros días, ese depósito general del Valle de México; pero no obstante esto y los innumerables trabajos emprendidos, las observaciones recogidas y aun los escritos publicados, aún queda bastante por hacer y por decir; cuestiones hay que no se han examinado cnanto deben serlo, tales como las médicas, las químicas, las agrícolas y otras.

Poco, muy poco agregaré, por mi parte, á lo que ya se sabe, y menos aún á lo que está por conocerse; sin embargo, acaso sea en algo útil este pequeño contingente; si no lo fuere, limitado será el tiempo que pierda el lector, pues mi objeto sólo se reduce á presentar unas breves indicaciones sobre la naturaleza de las aguas del lago, su influencia en la salubridad de México, la procedencia de las sales que contienen y algunas otras consideraciones que naturalmente dan de sí estos puntos.

Comenzaré por decir que no he hallado en el lago unos límites tan regularizados y precisos, como es común verlos marcados en los dibujos, con sus términos perfectos y constantes; la multitud de charcos más ó menos extensos, más ó menos superficiales, ya aislados, ya comunicados entre sí, $\sigma$ bien con el gran depósito, por medio de venas, estrechas ó amplias, cortas ó prolongadas; los islotes que apare- 
cen en diversos puntos y los varios canales que allí desaguan, todo contribuye á que no sea fácil fijar, con la debida exactitud, esos límites, más variados aún por las estaciones y por la mayor ó menor abundancia de las lluvias. Así es que, en mi opinión, la forma y dimensiones dadas hasta hoy al lago de Texcoco, únicamente deben estimarse como aproximadas y relativas.

Las aguas que recibe directa y exteriormente, no son de la misma naturaleza en todos los lugares de esa parte, la más baja del Valle; un simple examen basta para persuadirse de esa verdad, conocida aun por los transenntes, quienes distinguen dos: una con el nombre de salada y otra de limpia; aquélla, dicen, ocupa la parte occidental, y ésta la sur y la oriental. Aseguran que las aguas limpias no sólo provienen de las lluvias directas y de las indirectas de los montes de Oriente y Sur, así como de las vertientes de éstos, sino también de varios veneros de agua dulce que se abren en el lago mismo: yo ninguno vi, porque dicen que no son fijos, desapareciendo de unos puntos para derramar en otros. Lo cierto es, que satisfecho de que el líquido no era igualmente salado, debía elegir un lngar determinado, para recoger el agua que pretendía examinar. Yo preferí tomarla como á unas quinientas varas al N. O. de la cruz, ya porque esta senal se reputa como el centro de la laguna, y ya porque debe ser la más concentrada, y al mismo tiempo la más constante en su composición, en una época dada. El agua que me ha servido, está tomada á las once del día siete de Octubre último, con la precaución de suspender por algún tiempo el movimiento de los remos y aun el de la canoa, en cuanto fué posible. Más adelante me ocuparé de la naturaleza del agua recogida, haciendo desde luego algunas indicaciones con relación á la laguna misma.

Lo primero que llamó mi atención, fué su corta profundidad, pues en los pocos reconocimientos que hice en solo la travesía, la mayor que encontré fué de $0^{\mathrm{m}}, \mathbf{5 8 2}$, y como á esa fecha no debían darse por terminadas las lluvias, debo presumir que en los meses de Febrero ó Mařo, habrá menos agua que en otros años por la misma época.

Natural era examinar las lamas tomadas del fondo del lago; las puntas de los remos me sirvieron á este fin, dándome una arcilla muy plástica, tenne, de un gris azulado al salir, y ya seca, de un color moreno cenizo, idéntica en todo á la que aparece en varias capas de los terrenos del Valle, y que ha sido recogida al abrir las fuentes bro- 
tantes. Tal identidad y, además, el aspecto gelatiniforme ocroso que tomó el agua de la laguna, al concentrarla para estimar el residuo, me confirmaron con la idea que he tenido sobre la posibilidad de conocer hoy los límites primitivos del lago. En el opúsculo publica. do en 1854 está anunciada la existencia de esa materia gelatiniforme, ocupando el sexto orden, en el corte del pozo de Santa Catarina, á la profundidad de 8 m, 97 , debiendo notar, que no es el único rumbo en que se ha encontrado: fundado, por una parte, en este hecho y, por otra, en la identidad de las arcillas, creo seguro que los puntos adonde se descubran tales materias, han sido lechos bajos, del lago, cuyo antiguo límite quedará, en consecuencia, indicado por medio de la sonda.

Como en la muy útil memoria que está escribiendo el Sr. D. Manuel Orozco, se dan curiosas noticias relativas á diversos productos usados como alimenticios y procedentes del mosco, que tanto abunda en la laguna, así como de varias aves que aparecen desde que comienza el invierno, procuraré fijar la atención en cuanto se relaciona con esos objetos. Por desgracia, ni la estación, ni los puntos que recorrí, favorecieron mi propósito; algunas agachadizas, conocidas vulgarmente con el nombre de agachonas (scolapax gallinago), fueron las únicas aves que se me presentaron en el tránsito: nada encontré del cuculin ó cuculito, y aun el puxi lo vi en cantidad tan pequeña, que no podría ser explotada. Me he persuadido de que este puxi no es otra cosa que las pieles de la larva del mosco, desecho de su transformación, y que aparece como espuma en la superficie del agua; recogido, seco, y observado con el microscopio, se presenta bajo la forma de un saco transparente, de cinco á siete milímetros de longitnd, de color amarillento, más ó menos rojizo ó moreno, con las impresionies de seis, siete y hasta ocho anillos bien marcados, indicante todo del tamaño y de la forma de la larva. Annque de un olor y sabor repugnantes, para las personas que no han educado su paladar, es un producto bastante azoado, y, por lo mismo, un buen alimento para la clase trabajadora que lo consume. Muy probablemente el puxi ha de abundar en las orillas del lago, opuestas á los vientos dominantes, que son, por lo común, el de N. y sus derivados.

Otro de los productos alimenticios que reconoce el mismo origen, y del cual también se hace mérito en la citada memoria, es el gustoso y curiosísimo ahuautli; yo diría que es el más interesante, bajo 
todos aspectos, entre los productos de ese pequeño insecto, habiendo logrado aun el figurar, tanto en la humilde choza del miserable jornalero, como en las mesas exquisitas de las otras clases sociales.

La industria del ahumutli, es verdaderamente curiosa, y á la verdad que se necesita toda la paciencia, economía y laboriosidad de nuestros pobres indígenas, para sostener y fomentar una empresa, cuyas utilidades distan mucho de la compensación debida á tan molestos trabajos. Los que se ocupan en ellos, tienen que comenzarlos fijando los límites de la parte del lago que pueden ó quieren explotar, lo cual hacen clavando estacas de trecho en trecho, ó simplemente ramas en el fondo del lago: tienen después que formar haces de tule (Cyperus), y que fijarlos también," colocándolos en hileras, con una parte fuera del agua: más tarde, recogen esos haces, los tienden en los islotes para que sequen, los sacuden, á fin de separar los huevecillos adheridos al tule, los limpian de las basuras y demás cuerpos extraños, y tienen, por último, que solicitar la venta de su cosecha, al ínfimo precio de medio real ó á menos el cuartillo. Para juzgar mejor de este trabajo, $y$, sobre todo, para calcular el inmenso número de moscos que hay en la laguna, es conveniente saber que el cuartillo de huerecillos, que equivale á poco menos de dos libras, sólo pesa trescientos setenta y seis gramos, pero contiene muy cerca de siete millones de cascarones, pues no son èn realidad liuevos; yo, á lo menos, no he llegado á encontrar uno solo lleno, no obstante haberlo procurado. Cien partes de ahuautli han dado:

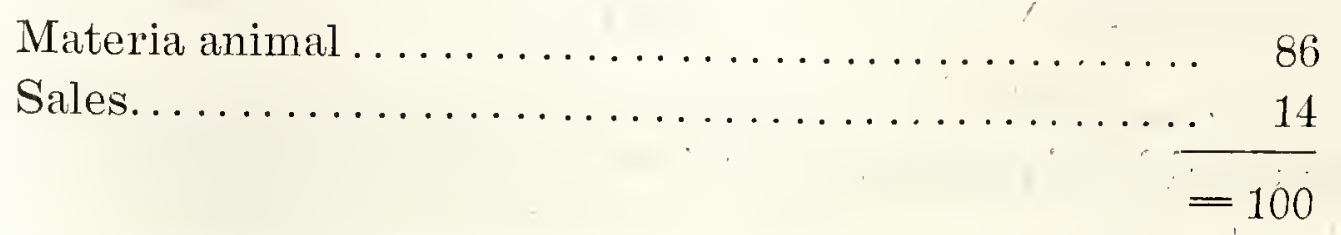

Era de presumir, según lo dicho, que el ahuantli fuera enteramente insípido, mas el hecho es contrario á esta presunción, porque una gran mayoría le encuentra un gusto agradable. Diré, por ńltimo, en confirmación del inmenso número de moscos que hay en el lago y de su extraordinaria fecundidad, que así como no hay exageración al decir que el alıuntli se consume en cargas, tampoco la hay en asegurar que ese pequeño animal se recoge séparadamente en la abundancia, y que sirve de alimento principal á los pájaros domésticos.

Al atravesar la laguna, se percibe un olor pantanoso tan marca- 
do, que naturalmènte ocurren algunas reflexiones. ¿Hasta qué punto influirá ese aire viciado en la insalubridad de México? ¿ Taa constitución médica de la ciudad empeora á proporción que pasan más años? Cuando recuerdo que la parte NE. y SE. ha sufido más por las epidemias que la opnesta de la ciudad; que no pocas, aun han comenzado por algunos de los rumbos comprendidos entre esos vientos; que las enfermedades estacionales, $y$ aun las comunes, son menos frecuentes ó menos graves, en el espacio comprendido de NO. á SO.; que una mayoría de los leprosos ó lazarinos vienen al hospital de las pequeñas y cercanas poblaciones del SE; cuando se comparan, en fin, los datos parroquiales, como complemento de esas observaciones, parece que hay fundamento para creer que el lago de Texcoco, sus canales y vasos de agua ó potreros commicantes, tienen ma parte muy principal en la mayor insalubridad de algunos de los rumbos de la ciudad, y como consecuencia, en la de la población toda, con especialidad por las enfermedades contagiosas que fácilmente se extienden á todo el Valle. Los que conocieron antes de 1813 y 1814 los poblados barrios de San Pablo, ia Palma, y más principalmente los de San Sebastián y Tepito, y comparan lo que son hoy, no pueden desconocer lo dicho antes, á saber: la influencia perniciosa muy probable del lago de Texcoco y de sus partes comunicantes.

Mas sin ir tan atrás, ¿qué sucedió en el cólera morbo en 1833; en las rarias epidemias de escarlatina, enfermedad tan rara antes en México, principalmente bajo las variadas formas malignas; en la viruela confluente, antes reputada como periódica, $y$ en tantas otras epidemias, menos grares, si se quiere, mas no por eso menos molestas y siempre significativas? Creo bastantes los hechos citados para juzgar sobre la primera cuestión; pasaré á la segunda, acaso de más difícil resolución, pero por lo mismo de mayor interés, tanto médico como gubernativo.

Uno de los más útiles servicios que presta la estadística, es el relativo á la salubridad de las localidades: sin buenos datos, los juicios que se formen, no pueden pasar de conjeturales, y como, por desgracia, carecemos de tales datos, la apreciación que paso á hacer, sólo descansa en recuerdos comparativos. La frecuencia y funestos estragos de esa escarlatina maligna que he mencionado, la más sostenida de las fiebres tifoideas, de las catarrales agudas, las eruptivas, etc., hace presumir que la insalubridad de México ha estado y está en ra- 
zón directa del tiempo transcurrido. Pudiera contrariarse esta proposición, señalando como causas el mayor movimiento de la población, el cambio en los usos y costumbres, con particularidad en cuanto al régimen alimenticio, el malestar de los ánimos en tantos años de nuestras punibles locuras, la miseria y otras análogas; no obstante, sin negar á estas causas la parte que pueden tener en algunos casos, es de presumir que influye más lo descampado de la parte correspondiente al lago de Texcoco, su azolvamiento progresivo, la multitud de depósitos superficiales de agua, $y$ en consecuencia, la muy extensa superficie de descomposición y de desecación periódica.

Dado á conocer, aunque muy someramente, el juicio que he formado con relación á las influencias insanas del lago, parece necesario escogitar y proponer algunos medios adecuados y posibles, para quitar, ó á lo menos disminuir, los males que originan esos padrastros de la capital.

Dos son los que estimo realizables: uno consiste en la multiplicación $y$ en el establecimiento de arbolados en la parte descubierta de la ciudad; y el otro, en la regularidad y limitación del lago, pero de manera que fuera disminnida la superficie de descomposición.

Estaría por demás el repetir lo que es tan sabido con respecto á la influencia saludable de los vegetales, así como la que ejercen mecánicamente las arboledas con relación á los vientos; de ahí es que, prescindiendo de tales consideraciones, examinaré los inconvenientes que pudieran suponerse para el logro de esos plantíos. El primero $y$ acaso el principal, se haría consistir en la naturaleza de los terrenos, porque siendo salitrosos, tequezquitosos y en general salinos, son enteramente estériles. Tal dificultad no es, á mi juicio, invencible, habiendo muchos medios para alejarla, aunque con más ó menos costo. Uno sería la elección de los lugares, otro el de los regetales, y en último caso la artificial de la tierra de plantación.

No siendo, como no es, indispensable, que las filas ó hileras de árboles queden en puntos precisos, con relación á las distancias del lago, es claro que pueden elegirse los más adecuados, sean quienes fueren los dueños de los terrenos que se han de plantar; y como de los límites actuales de la laguna, á la parte NE., E. y SE. de la cindad, hay más de una legua, se tiene suficiente espacio para elegir los puntos que más convengan.

Con respecto á las especies de árboles, creo que son bien conocidas 
las buenas condiciones climatológicas del Valle, que tanto farorecen al desarrollo de varios sauces y aun de álamos; aquéllos, con especialidad, remen cuantas ventajas pudieran desearse: su abundancia hace que cuesten muy poco; la facilidad con que se multiplican por estacas, asegura el éxito; la rapidez en su crecimiento, el vivir bien en los lugares húmedos y aun pantanosos, su forma, ya elevada y esbelta como el Salix privamidalis, ó ya copada como el S. Bomplandiu et Babilonica Populos alba et migra, todo contribuye á la pronta realización de un proyecto tan necesario y útil, alejando los inconvenientes que en efecto tendrían otros vegetales extraños á la gran familia de las amentáceas.

Mas supóngase que, no obstante lo dicho, la naturaleza del terreno se opone á la vegetación; ges acaso un obstáculo invencible contra el cual la industria agrícola tenga medios que oponer? $\mathrm{Ni}$ se haga gran mérito del excesivo costo, porque la salubridad de la primera y principal ciudad de México, bien merece aun mayores erogaciones. Por último, el segundo de los medios que paso á indicar, farorece la realización del primero.

Este segundo consiste en la limitación regularizada del perímetro del lago: indicaré los fundamentos que apoyan tal pensamiento.

Habiendo actualmente un espacio muy considerable entre la capital y el lago, cuyo nivel difiere poco de las orillas de éste, estimadas en tiempo de secas así, como de los terrenos intermedios, quedan éstos cubiertos por las aguas en la estación de las lhuvias, ya por la poca profundidad del gran vaso, que es la causa principal, y ya por la confluencia que debe estimarse como general $y$ de tiempo limitado. Por otra parte, varios potreros que sirren como depósitos temporales, no hallando expeditos los canales de desagüe, ni siendo bastante para la corriente su diferencia de nivel, ammentan igualmente la superficie de evaporación y de descomposición, á la de los terrenos inmediatos al lago. Al terminar las lluvias, esa evaporación es general, activa $y$ de una vasta superficie; las aguas siguen los puntos declives, los terrenos ocupados por ellas se desecan, los animales y los regetales mueren y entran en descomposición; con más, las materias orgánicas llevadas de la ciudad á la laguna durante el año y en una cantidad fabulosa. Entonces es cuando más se nota ese olor palustre, cuando más se desarrollan las fiebres catarrales, las intermitentes, etc.; cuando la constitución médica, en fin, cambia notable- 
mente, con perjuicio de los habitantes del Valle. Disminuir cuanto más se pueda la superficie de evaporación, profundizando con regularidad una parte de ella, es el medio que juzgo adecuado para alejar en lo posible los males indicados, favoreciendo al mismo tiempo el plantío con la mayor capacidad del gran depósito y aun acaso llegando á convertir en laborables algunos de los terrenos que actualmente son estériles. Me parece que estas indicaciones no necesitan explanación: podrá el buen juicio médico dudar, conceder ó negar su utilidad; pero aun en este último supuesto, y por mucho que se exagere el gasto, no pudiendo negarse que, cuando menos, es una mejora material, parece lógico asegurar que debe emprenderse la obra, con la fundada esperanza de hallar un medio favorable á la salubridad de México.

Bueno será formar un cálculo, ann cuando sólo se estime como aproximado, de lo que nos importarán los gastos. No siendo fácil, según creo, comenzar y concluir la obra en los cuatro meses útiles del año, es decir, de Enero á Abril, inclusive, quedaría fraccionado el total costo, de manera que tendríamos para 1864 los siguientes resultados, suponiendo que sólo trabajaran mil peones durante cien días, ó sean veinticinco días en cada mes.

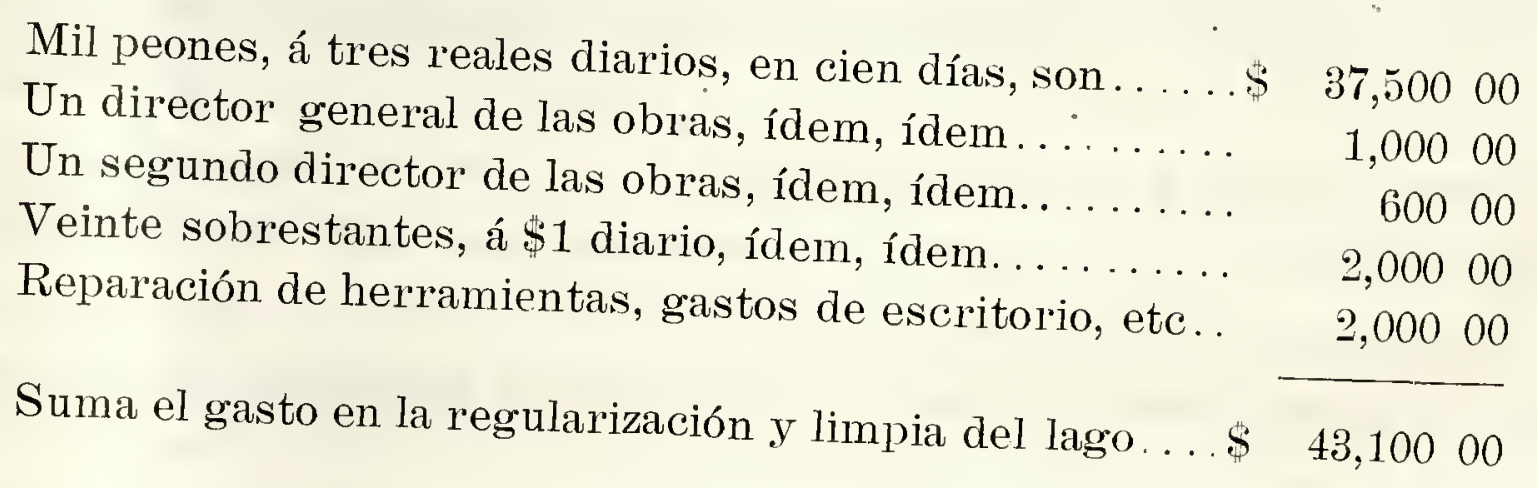

Ouyo gasto daría por resultado:

Mil peones, haciendo sólo dos metros cúbicos por tarea, 6 sean diarios, resultan en 100 días, 200,000 metros cúbicos.

Cuya caja, aumentando la capacidad del lago, dejaría al mismo tiempo un borde proporcionado á las lamas extraídas, y que aun podrían ser extendidas convenientemente, formando una calzada propia para el plantío.

Como éste debería liacerse á la vez, no estará de más calcular también el gasto. 
Cien peones, á tres reales, en cincuenta días.....\$\$ 1,87500

Cuatro sobrestantes, á $\$ 1$, ídem, ídem.......... 20000

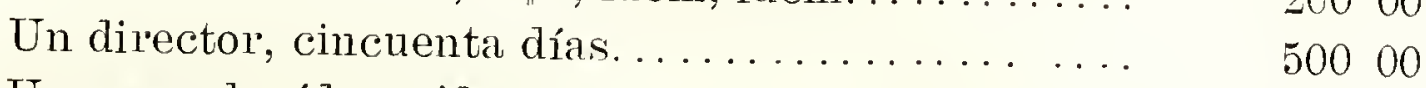

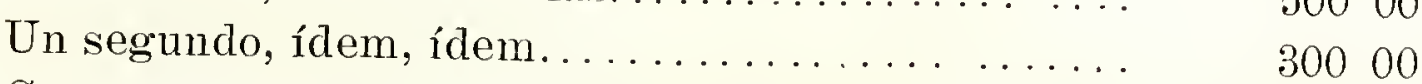

Costo y conducción de 20,000 estacas, á medio real. $\quad 3,75000$

Gastos de conservación, riegos, etc., en cuatro meses, á tres por dos reales diarios (un sobrestante $y$ seis peones)

Suma el gasto por elogar en el plantío..........\$ 7,01500

Suma el de la limpia................. $43,100 \quad 00$

Total costo...........\$ 50,11500

Creo fácil y muy racional el convenir en que, una vez persuadido de la grande utilidad de la obra, por las innumerables ventajas consiguientes á ella, los cincuenta mil pesos del presupuesto quedan suficientemente compensados y aun más, si se atiende á que á los prorechos directos, hay que agregar los indirectos, entre ellos, el de dar trabajo á muchos que hoy viven de la vagancia ó del robo.

Acaso se extrañe que no figure en el presupuesto el gasto de la compra de herramienta; no ha sido olvido: los trabajos emprendidos en las fortificaciones, en los primeros cinco meses de este año, ocupando por algún tiempo á miles de hombres, me hacen creer que habrá un depósito abundante de ella que puede aprovecharse; no obstante, he creído que debía fijar una cantidad para reparaciones.

Por el interés general, desearía que el Gobierno, reuniendo algunas personas competentes y de notorio saber, examinaran detenidamente la cuestión, para que si debía emprenderse la obra, se aprovechara la estación con la oportunidad que conviene. Entretanto, volveré á ocuparme del agua recogida.

Vista ésta en el lago mismo, es turbia, de olor pantanoso, sabor salado y tequezquitoso; su reacción fuertemente alcalina, sin efecto alguno sobre el papel de sal de plomo: la temperatura, á la hora que la recogí, de $20^{\circ} \mathrm{c}$, siendo la atmósfera de $15^{\circ}$ — c. La densidad tomada á $+18^{\circ}$ c., me ha dado:

$$
\begin{aligned}
\text { Agua } \text { sin decantar } & =1,00198 . \\
,, \text { decantada } & =1,00196 .
\end{aligned}
$$

Un litro de agua evaporada convenientemente, ha dejado por residuo, en gramos - 23,536, compuestos de 


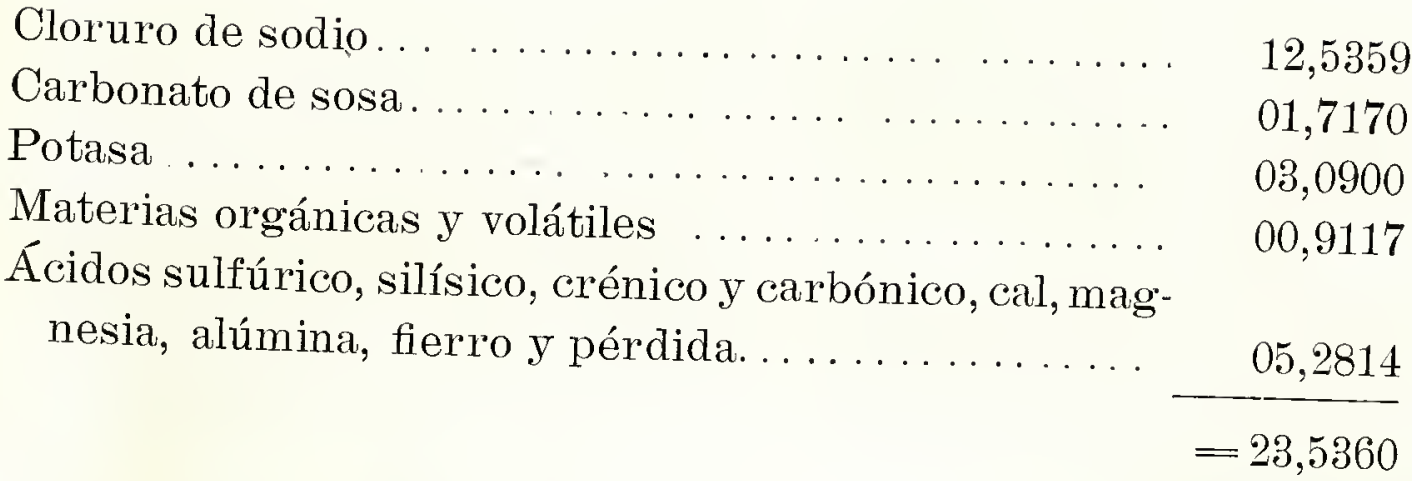

Por falta de tiempo no he estimado cuantitativamente cada uno de estos últimos compuestos, á lo que se agrega, que siendo por hoy mi objeto principal el conocer la cantidad de sal común y la de sosa contenidas en el agua, queda plenamente satisfecho ese propósito con los datos anteriores. Ellos han despertado en mí algunas reflexiones que no estará por demás el indicar.

Sea la primera, la cantidad respectivamente considerable de sales de potasa; la segunda, la muy poca de cal, de alúmina, de siliza y de fierro; acaso la precanción de no agitar el agua al momento de tomarla, hizo que las tres últimas substancias no aparecieran en el residuo, tan abundantes come á la vista era de suponerse. Adrertiré, sin embargo, que esta aseveración no reconoce otro fundamento que el equívoco de la análisis indicativa; así es, que será ó no confirmado al hacer la cuantitativa, y además, el examen cuidadoso del tequezquite y de la lama, como complemento de estos trabajos. Creo que no faltan personas que se hayan dedicado á ellos, y harían un bien si los dieran á luz, así como sería muy útil que las que tienen instrucción, medios y tiempo de que poder disponer, lo dedicaran al examen de las aguas tomadas de diversos puntos del lago.

Conocida la proporción, tanto de la sal común contenida en el agua, como la del carbonato de sosa, paso á tocar una cuestión, que sin ser nueva, no me parece que está resuelta, ni considerada bajo el punto que yo la veo.

Es un hecho, que desde tiempos muy remotos, el lago de Texcoco ha sido una mina inagotable de sales, entre las que figuran como principales, el carbonato de sosa y el cloruro de sodio ó sal común; ocnrre desde luego el preguntar: ¿cómo no se ha agotado esa mina, y de dónde vienen tan útiles productos? Oreen unos, que arrastradas. por las lluvias algunas rocas feldespáticas, $y$ en contacto con los terrenos calcáreos, se despiertan reacciones cuyos productos son las sales que encontramos en las aguas del lago, y que en virtud de la 
evaporación, cristalizan confusamente en los terrenos desecados. Tal aseveración me parece destituida de fundamento, por dos razones principales: es la primera, que no creo fácil la descomposición de los feldespatos en las condiciones en que se hallarían en la laguna; $y$ la segunda, que no me parece corresponder la proporción de sales contenidas en las aguas, ni aun á sólo las explotadas, á la que pudiera suponerse procedente del feldespato. Notaré, además, que no obstante haber hallado en el agua más de tres milésimos de potasa, mayor liabría debido ser la cantidad, si todas las otras sales turieran su origen en la descomposición de aquellas rocas. De aquí debo inferir, que por mucha parte que se les quisiera dar en la producción de las sales, sería muy dudoso que á ellas deberían únicameute su origen.

La segunda opinión, más admisible acaso á primera vista, deja de serlo, después de alguna reflexión. Se supone existir en el lago,ó en comunicición con él, un banco de sal gema, sobre el cual obran las aguas continua y regularmente. Yo no creo que existe tal banco: lo primero, por considerar difícil que pasaran siglos sin haberse descubierto; lo segundo, porque en ese tiempo, y atendido el consumo considerable y continuado, hubiera desaparecido totalmente; y lo tercero y principal, porque no se conoce la cavidad ó profundidad cor'respondiente á la enorme masa que habría sido disuelta.

Si no hay error en las razones de oposición á las dos teorías, es preciso buscar en otras partes el origen de esas sales, de esa fuente de riqueza, vista con tan poco aprecio, pero de cuya utilidad no puede dudarse. Yo creo que los habitantes del gran Valle de México, las lluvias, los agentes físicos, los fenómenos meteorológicos, el depósito final de las aguas y las reacciones químicas, son otros tantos eslabones de una cadena sin fin, que constantemente produce, modifica y vuelve á reproducir las sales principales de que he hecho mérito; á saber: el carbonato de sosa y el cloruro de sodio. Presentaré los datos en que apoyo esta opinión, y el lector juzgará del valor que puedan tener.

Según las análisis más recientes, los excrementos humanos contienen, por término medio sobre cien partes, 2,367 de sosa y 0,780 de cloro; los de los cuadrúpedos, 2,420 de la primera y 0,193 del segundo. Yo quiero suponer, que por la diferencia de edades, las pérdidas, al estado patológico y otros accidentes, sólo sea aprovechando un dos por ciento, y que en atención á éstas y á otras causas, la can- 
tidad de excremento humano correspondiente á cada individuo en veinticuatro horas, sólo sea de descientos gramos, de los que resultarían, en consecuencia, cuatro gramos diarios de sosa por individuo. Aunque la cantidad de excremento es mucho mayor en los animales, quiero, para el fin á que me dirijo, suponerlo igual, por ser menor su número y de más fácil desperdicio, es decir, que sólo supondré otros cuatro gramos de la misma base de sosa, es claro que, cuando menos, tendríamos ocho gramos diarios de sosa, conducidos por las aguas al depósito general, con más la cantidad proporcional de cloro.

Veamos el segundo dato: Conforme á la estadística más completa y casi oficial, la población del

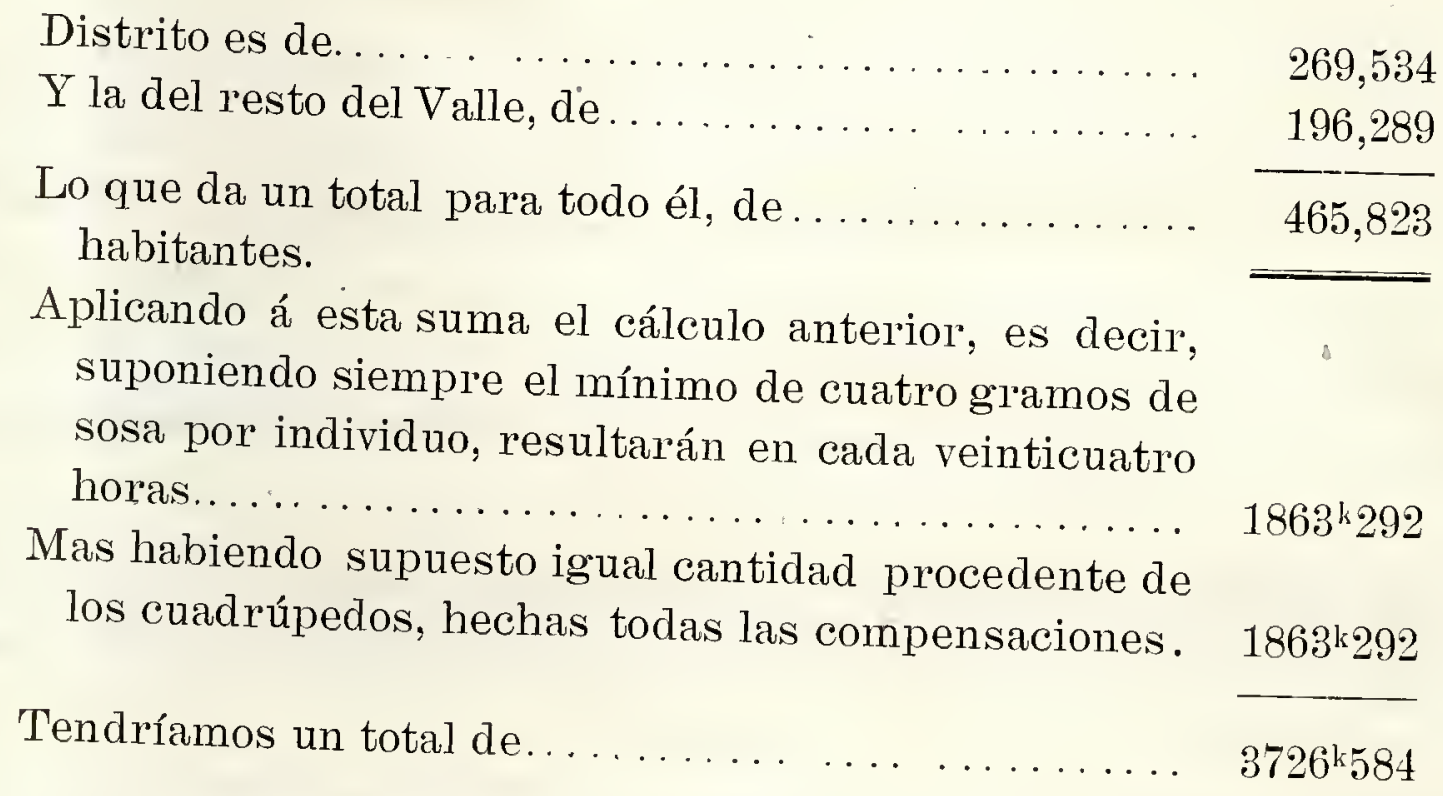

diarios, ó sea en cada año, $1.360,203 k 160$ de sosa. Por enorme que parezca esta cantidad, aun hay algo que agregar. Sólo me limitaré á estimar la sosa proveniente del jabón consumido por los habitantes del Valle, el cual, siendo arrastrado y descompuesto por las aguas, deja la sosa al estado de carbonato: esta teoría es indudable.

Si fijamos en un kilogramo el mínimo que anualmente consume cada habitante en su persona y lavado de ropa, y si tomamos el promedio que contienen los distintos jabones, estimándolo en un ocho por ciento de sosa, es decir, ochenta gramos por individuo, siendo 465,823 los habitantes del Valle, resultan $37,265^{\mathrm{k}} 840$ gramos de sosa, cuya cantidad, agregada á la anterior, procedente de los animales, da un total anual en kilogramos, de 1.397,469.

Para mayor seguridad en cuanto á este cálculo, he tomado informes de buena fuente, á fin de conocer la cantidad de jabón que 
comúnmente se fabrica cada año en la ciudad, $y$ resultando como mínimo 138,500 arrobas, ó sean 1.593,581 kilogramos, he supuesto que sólo una mitad es consumida en el Valle, á saber: 79,6795 kilogramos, que dividido por el número de habitantes, resulta corresponder á cada uno, $1^{\mathrm{k}} 710$, es decir, más que lo supuesto antes: creo, por lo mismo, que nada hay exagerado en aquel cálculo.

Debe tenerse presente, que no hago mérito de la sosa, ni del cloro procedente de las orinas de los bípedos y de los cuadrúpedos, ni de los regetales, de las aguas, y de innumerables desechos, que conteniendo esas substancias, llegan definitivamente al lago; no siendo exagerado estimarlas en una mitad de aquella suma: quiero, al contrario, que ésta se rebaje á la mitad, á un tercio aún, y siempre se tendrá conocido el origen de esas sales y demostrado al mismo tiempo, que hay una admirable circulación salina, acompañada de una serie no interrumpida de reacciones tan curiosas y variadas, que la imaginación se pierde en contemplarlas. Sin hacer méritos de los feldespatos ni de los bancos de sal gema, y sin forzar en nada la imaginación con sólo teorías, se tiene, según creo, explicado satisfactoriamente el hecho de que hayan transcurrido siglos sin haberse ago. tado esas dos sales tan importantes y útiles, diré mejor, tan necesarias á la maỵor parte de las industrias, á las plantas, á los animales, y, sobre todo, á la salud ýa la vida del hombre.

De todo lo expuesto, es fácil inferir:

1. Que el lago de Texcoco es un depósito de grande importancia para México, ya se considere bajo el punto de vista hidráulico, ya industrial, ó ya médico.

2. ${ }^{\circ}$ Que es una fuente inagotable de productos, tanto salinos como alimenticios.

3. ${ }^{\circ}$ Que ejerce una influencia marcada y muy poderosa en la insalubridad del Valle.

$4 .^{\circ}$ Que la ciencia tiene medios para evitar ó, cuando menos, disminuir esa influencia.

$5 .^{\circ}$ y último. Que su misma importancia exige que sea atendido convenientemente, y no continúe abandonado como hasta aquí.

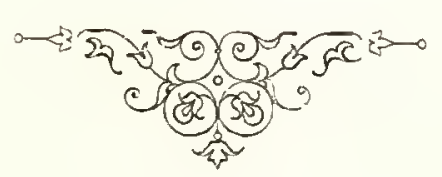




\title{
AGUAS POTABLES DE MÉXICO
}

\author{
Informe presentado por la Comisión \\ de Ciencias auxiliares á la Sociedad Méxicana de Historia Natural.
}

(Por el Sr. Dr. D. Leopoldo Río de la Loza).

La Comisión encargada de los trabajos analíticos promovidos por el Sr. Mendoza, relativos al agua potable, conocida en esta capital con el nombre de agua delgada, tiene el honor de poner en conocimiento de la Sociedad, los resultados de sus investigaciones, los procedimientos que ha preferido, y el juicio que ha formado con referencia á una cuestión de notorio interés, no sólo para los habitantes de la capital, sino también para los de todas las poblaciones que consumen esa agua y la hacen conducir por cañerías de plomo. Y no es este el único servicio que prestará al público y á las autoridades la Sociedad de Historia natural, al ocuparse del asunto, supuesto que la cuestión tiene una importancia general: ella ha sido y es cada día más y más estudiada, pues el uso de las cañerías de plomo, no está limitado al Distrito de México y á la República mexicana: se extiende á innumerables países, en muchos de los cuales se hace uso de aguas potables, cuya composición es más ó menos análoga á la que aquí se consume. El estudio de las cuestiones de este gémero, es, por otra parte, de un interés científico general.

Se observa, además, que no obstante los diversos trabajos emprendidos, de tiempos muy atrás, por muchos de los químicos de más nota, en los diversos páses del globo, los modernos no dan por conchuidos 
los relativos á la acción que puedan tener las aguas potables, ra sean conducidas por cañerías de plomo, ó bien depositadas en vasijas cubiertas en su interior con láminas de este metal. En confirmación de ello, bastará recordar á la Sociedad, que la disposición que tomó para que los comisionados que suscriben se ocuparan del asunto, fué promovido con motivo de que el Sr. Mendoza puso en conocimiento de esta Sociedad, que había leído en la Química analítica de Mnspratt, publicada en 1865, que las aguas rmoniacales, y mincipalmente las que contionen asotato de amonírco, disuetven el plomo, aun curndo aquéllas contengan sulfato y bicarbonato de cul.

Tal observación despertó en dicho señor el deseo de reconocer si en el agua delgada existían algunas sales amoníacales, $\mathrm{r}$ si, en efecto, se liallaba disuelto alguno de los compuestos plumbíferos. La sociedad no sólo comprendió la importancia de la cuestión; juzgó, sin duda, desde luego, que era un obligatorio deber suyo, el llamar la atención de las autoridades y del público, para lo cual necesitaba la plena prueba, que solamente podían ministrar los escrupulosos trabajos analíticos, convenientemente repetidos. He aquí la necesidad de nombrar una comisión que se encargara de ellos, en unión del socio que promovió el asunto. Y como, por otra parte, el que esto escribe había tenido, hace muchos años, que hacer un estudio práctico relativo á las mismas indagaciones, y no creía difícil, por varias razones, que hoy pudiera demostrarse la existencia de algún compuesto de aquel nocivo metal, no obstante el no liaberlo descubierto en aquella época, era preciso repetir los trabajos, supuesto que los notorios adelantamientos de las doctrinas químicas, la mejora de los procedimientos analíticos, el aumento de nuevos reactiros, $y$, sobre todo, la mayol perfección de los instrumentos, utensilios y aparatos, han elerado á esta clase de investigaciones á un grado de perfección tal, que por ella laan sido borrados, en estos últimos años, algunos de los cuerpos que, hace muy poco, figmraban en la lista de los simples; lan sido descubiertos otros y se ha precisado con mayor seguridad la rerdadera naturaleza de diversos compuestos. Nada extraño sería, conio se ha diclo, que hoy fuera apreciada la existencia de un cnerpo que, entonces, no fué posible el descubrir, ni lo será más tarde, si por algúin nuero medio ó procedimiento especial se hiciesen perceptibles, fracciones menores de la que indicará la Comisión. Tan frecuentes son estos casos, que en los mismos trabajos que ahola 
presenta, se tiene mu ejemplo, y es el relativo á la existencia de conpuestos amoníacales, no señalados antes en la agua delgada, y que ahora se han encontrado, aunque no en todos, sí en algunos de los experimentos, lo cual es debido á la mayor exactitud del procedimiento empleado esta vez y recomendado últimamente por prácticos de nota.

La Comisión debía dar, y dió principio al desempeño del encargo que le fué confiado, trazando el plan que convenía seguir en sus investigaciones, fijándose en los métodos más expeditos y seguros, y preparando los medios materiales de que debía servirse. La mayor parte de los trabajos fueron ejecutados en el laboratorio de la Escuela de Medicina, sirviéndose de agua tomada de la misma cañería y no de la fuente: otros experimentos hechos en particular, ó bien repetidos por los individuos de la Comisión, manifiestan la empeñosa solicitud de adquirir cada uno la plena convicción en los resultados: así es que, si en los que pasa á dar á conocer, se hallare alguna inexactitud, ya sea en lo material ó en las deducciones consiguientes al desempeño del encargo que le fué coufiado, podrán hacerse todas las observaciones que ocurrieren, satisfechos los señores socios de que los deseos de la Comisión están reducidos á que la decisión que se diere, sea tan exacta cual conviene á las cuestiones de esta naturaleza, $y$ tan concienzuda cual lo exige la salubridad de las poblaciones y aun la de ellos mismos, entre quienes hay dos enfermos cuyos padecimientos tienen algo de común con los observados en los casos de envenenamiento por la acción lenta de los compuestos de plomo: se comprenderá por esto, que para ellos, la cuestión es á la vez de interés personal.

Otro de los cuidados de la Comisión fué el de alejar todos los accidentes que dieran al agua ó á los residuos de la evaporación alguno de esos compuestos, ú otros que pudieran confundirse con los de plomo; accidentes que, por remotos que parezcan, son más comunes de lo que generalmente se cree. Uno de ellos, y comńnmente general, es el de la impureza del ácido sulfúrico, especialmente cuando se prepara en el acto de usarlo ó en aparatos inadecuados, ya elevando la temperatura más de lo debido, ó ya omitiendo la lavación escrupulosa, lo cual da resultados engañosos de muy perniciosa influencia en las análisís delicadas. En cuanto á la estimación de los reactivos empleados, sólo tuvieron que ser considerados como 
principales, los más sensibles para descubrir el plomo, y el más propio para la apreciación del amoníaco. Respecto á los primeros, la Comisión dío la preferencia al ácido sulfhídrico puro, haciéndolo obrar sobre las soluciones acidificadas, pues además de que,-por regla general, así debía hacerse, se aumenta la sensibilidad del reactivo y se aleja todo motivo de confusión, según lo confirman los siguientes resultados:

El ácido sulthídrico descubrió ${ }^{1} / 160.000$ del plomo contenido en la solución salina, y $\operatorname{con}^{1} / 32.000$ la presencia del sulfuro fué demasiado notable.

Se hizo llegar una corriente de áeido sulfhídrico en siete libras de agua tomada del chorro de la fuente, y ligeramente acidulado el líquido, sin que apareciera reacción alguna; mas bastó /100.000 de hidrato de plomo, para que se notara la coloración característica, pudiéndose afirmar, en consecuencia, que el agua delgada no contiene una cantidad de sal de plomo igual á la indicada esta vez por ese reactivo.

El cromato neutro de potasa hizo sensible la existencia del plomo en la porción de $1 / 160.000$, y el bicromato, cuya sensibilidad aumentó con el ácido acético, permitió descubrir ${ }^{1} / 300.000$ del metal.

El yoduro de potasio no acusó con estas fracciones la presencia del plomo, y, por lo misino, debe concluirse que ia sensibilidad del yoduro es menor que la de los antedichos.

En cuanto á los procedimientos empleados para descubrir el amoníaco, bastará decir que fué adoptado y puesto en ejecución el primero de los recomendados por Mr. Boussingault, y que los resultados obtenidos en la primera experiencia, fueron los siguientes: 93 c. c. de solución ácida normal, que exigían de amoníaco, para ser neutralizados, 20.92 c. c., solamente necesitaron 19.15, de lo cual se deduce que debió producir el agua 1.77 c. c.; mas como este producto fué el de cuatro litros de agua, resultan de amoníaco líquido, para cada litro, 0,4425 c. c.,ó sea, al estado anhidro y en gramos, 0,1266 .

Atendiendo á que los álcalis fijos producen amoníaco en presencia de las materias azotadas alterables, se creyó conveniente repetir el experimento con el agua sola y con la única modificación de sustituir con el ácido clorhídrico, el sulfúrico, nsado antes para la solución normal. El producto de esta operación fué tratado conve- 
nientemente para ensayarlo con el bicloruro de platino; pues éste se creyó ver á la escasa luz crepuscular, el precipitato del cloroplatinato amoníacal, lo cual indicaba que el amoníaco existía en ol agiua al estado de carbonato.

Acto continuo se pasó al segundo tiempo de la operación. Vuelta á poner la probeta en el aparato pneumático, con otra cantidad igual de solneión clorhídrica normal: se agregaron á la misma agua que contenía el matraz, euatro gramos de potasa cáustica, y se hizo marchar como antes la operación. Concluida ésta, y reconocido el líquido de la probeta, resultó una cantidad igual de amoníaco, de cuyos datos puede inferirse que, de los mil doscientos sesenta $y$ seis, diez miligramos de amoníaco anhidro, producidos por un litro de agua, seiscientos treinta $y$ tres corresponden al radical preexistente, y otra cantidad igual al de nueva formación, producida por el efecto de la potasa sobre las materias orgánicas contenidas en el agua, ó por alguna sal amoníacal no volatilizable al hervor del líquido.

Antes se ha indicado que la formación del cloro-platinato amoníacal no fué tan clara que diera la debida seguridad; era preciso, por tanto, repetir la operación, como en efecto se hizo, por tres de los que suscriben (Sres. Hay y Río de la Loza, D. L. y D. M.). Cien centímetros cúbicos de la solución normal clorhídrica empleada esta vez, exigía cuatro y cinco centésimos de amoníaco líquido, para ser saturado. La cantidad de agua, puesta para desprender el amoníaco, fué de cinco litros, y concluida la operación, se encontró que la solución normal necesitó 4,05 c. c. de amoníaco para ser saturada; es decir, que los cinco litros de agna nada produjeron de la base amoníacal; tampoco con la potasa, como se había liecho en la experiencia anterior.

¿Cómo explicar este hecho? ¿Será que, por algunos puntos, en los de unión del aparato, se escaparon los gases desprendidos, sin llegar á la solución normal? No es de creerse esto, supuesto que pudo formarse el vacío, y que se rieron atravesar los gases por el líquido de la probeta.

¿Será que hubo algún error en las medidas ó en el estado de concentración de los líquidos clorhídrico y amoníacal, ó algunos de tantos accidentes análogos, nada raros en estas manipulaciones? Los encargados de ellas, únicamente aseguran que no tuvieron con- 
ciencia de accidente alguno que despertara en su ánimo la duda, pues la marcha de la operación fué regularizada.

¿Será, en fin, que la existencia de los compuestos amoníacales en el agua de que se trata, no sea constante? Cuando se reflexiona que, para llegar el líquido á la Capital, tiene antes que recorrer algunas leguas por atarjeas descubiertas, ya elevadas, ya al nivel de la tierra ó más bajas, de manera que fácilmente se mezclan las aguas superficiales con las materias que arrastran de los lugares inmediatos; cuando se nota que los vecinos y los transeuntes tienen á su disposición el agua, y que, en efecto, se sirven de ella, no sólo en el orden eco-nómico, sino ann en el industrial y como fuerza motriz; cuando se toma en cuenta la ubicación de las vertientes, su eleración, montuosidad y tantos otros accidentes más ó menos favorables para la formación del amoníaco ó para la simple disolución de los compuestos ya formados, así como el de otras muchas substancias de diversa naturaleza, se llega á comprender cuán variada deberá ser en cantidad y calidad la de las materias extrañas contenidas en las aguas, sea en solución ó en suspensión.

Convencido de ello el que esto escribe, no quiso dejar pasar la oportunidad que se presentó de buscar el plomo en el agua, un día después de hecha la limpia en el acueducto inmediato á la Capital. Pudiera ser, acaso, que removidas las lamas de la extensa arquería, arrastraran las primeras aguas algunas materias que en el curso ordinario de ellas no llegaran hasta el lugar de donde se había tomado el agua reconocida. Los resultados de este nuevo examen, practicado conforme á los principios ra mencionados, fueron igualmente negativos; no se descubrió vestigio alguno de plomo.

Mas volviendo á la cuestión relativa al amoníaco, confesará la Comisión, que los trabajos emprendidos no bastan para resolver con plena seguridad si existe ó no en el agua delgada; si su presencia es constante ó temporal; si se forma por sí en el curso del líquido ó le viene de las lluvias, del rocío, de las orinas de los animales, de los estiércoles y demás materias que, como se ha dicho, ensucian más ó menos el líquido en el largo canino que recorre. I si, por otra parte, es un hecho demostrado que ese radical alcalino se forma en un gran número de circunstancias, siendo de las más comunes la coexistencia de los álcalis y las materias azotadas, así como la de los elementos que lo constituyen, especiahmente si aparecen en estado alotrópico, 
se contendrá en la dificultad de dar una resolución concienzuda, sin repetir los experimentos, inquirir varios datos y resolver previamente las interesantes cuestiones generales indicadas.

Pero como lo que ahora ocupa á esta Sociedad, como más apremiante por el interés público, consiste en saber si existe ó no alguno de los compuestos de plomo en el agua potable, y sólo tiene ésta, con la del amoníaco, una relaeión de causa y no de esencia, bien puede encargarse únicamente de la primera, y dejar por resolver la segunda. La Comisión seguirá, por tanto, dando á conocer algunos más de los trabajos practicados, sin omitir aun los que aparentemente pudieran juzgarso contrarios á las conclusiones que presenta.

Como punto general, y para evitar repeticiones, dirá: que todas las reces que necesitó del agua que debía reconocer, fué tomada con las debidas precauciones del chorro de la fuènte, en vasijas bien limpias y sin intervenir la filtración. Que para las varias evaporaciones se sirvió separadamente de una retorta de cristal, de una cápsula de porcelana, de una de plata $y$, por último, de un caso de cobre perfectamente limpio y jamás estañado. Que los reconocimientos del agua ya concentrada, así como de las materias insolubles, los practicó, tanto acidulando el agua muy ligera y previamente, como empleándola en sn estado natural. Que las cantidades de agua prestas á evaporar, lian sido: una de dos litros, otra de cuatro, de siete, y la principal de cincuenta, reducidas á mn octavo, á un décimo y á un cincuentaro del volumen. Que el agua empleada ha dado, á la temperatura y presión del laboratorio, exactamente un peso correspondiente al del volumen; así es que, medido cuidadosamente un litro, pesó un kilogramo, y por último: que siempre que para ello no ha habido alguna contraindicación, ó bien indicación especial para el empleo de un ácido, usó de preferencia del acético puro.

En dos de los reconocimientos practicados por la Comisión, siendo el primero el que hacía con el producto de la reducción á un octavo, sospechó que, en efecto, pudiera contener el líquido sometido al examen algún compuesto plumbífero. Una ligera coloración morena apareció con la solución sulfhídrica, $x$ pasado algún tiempo, se observó una pequeñísima cantidad de precipitado negro, pero cuya naturaleza, con relación á la base, hizo sospechar que fuera fierro. Parecerá extraño este juicio, sabiendo que el ácido sulflú́drico no precipita el fierro; mas cono se suponía en el agua la existencia de 
compuestos amoníacales, en cupo caso podría formarse el precipitado, y como, por otra parte, hay otros varios compuestos que también hacen que se forme, no carecía de fundamento tal sospecha, apoyada, además, con el hecho de que, tratado por el bicromato de potasa otra parte del líquido examimado, no indicó ni ann vestigios del plomo que se buscaba. No obstante, la Comisión debía aspirar á la evidencia, apoyada en hechos tan claros como bien definidos.

Nuevas indagaciones practicadas con el producto de siete litros de agua evaporada y su residuo, bastaron para persuadirla, que la coloración y precipitación eran producidas por el fierro procedente de la arcilla ferruginosa. Esta vez se hizo uso del amoníaco, del sulfhidrato de la misma base, del cromato y bicromato de potasa, del ácido sulfúrico y, por último, del carbonato de sosa para tratar convenientemente el residuo insoluble. Nada de plomo, algún fierro, alúmina y cal, fueron las únicas bases descubiertas.

Veamos lo que pasó con los productos obtenidos de los cincnenta litros del agua evaporada.

Esta fué la concentración hecha en cazo de cobre, sin liga, bien limpio, y previamente reconocido. No obstante estas precanciones, parecerá igualmentete extraño que la Comisión diera la preferencia a la rasija de un metal atacable como es el cobre, y que presenta en sus reacciones varios de los caracteres correspondientes al plomo, por pertenecer ambos al segundo grupo de los metales, es decir, á los precipitables por el hidrógeno sulfurado, é insolubles en los sulfuros alcalinos. Mas si se recuerda la facilidad que hay para separar un netal de otro, y especialmente la propiedad de formar el plomo con determinados ácidos, sales insolubles que, por el contrario, las dan solubles con el cobre, será fácil comprender que, por una parte, la Comisión no halló en esto inconveniente alguno, mientras por la otra quedaba satisfecha la necesidad que tenía de evaporar una gran masa de agua en el menor tiempo posible. Aún hay otra razón que ocurrió al que esto escribe, $y$ fué la de estudiar $y$ satisfacer prácticanente una de las doctrinas bien conocidas de muchos. El amoníaco y rarias de las sales amoníacales, ejercen sobre el cobre y sus compnestos una acción poderosa, bien marcada $\mathrm{y}$ bastante característica, especialmente al contacto del aire: éste había de ejercer su influencia durante el tiempo de la eraporación; y si el agua contuviera compuestos amoníacales, presentaría á la rez el líquido concentrado, los 
caracteres propios de los compuestos amoníaco-cúpricos; mas como éstos no aparecieron, preciso es concluir, que ó no hubo en toda esa grande masa de agua puesta á evaporar, compuesto alguno amoníacal, ó es falsa la doctrina antedicha.

Pero volviendo á ocnparnos de la marcha de la evaporación, hay que notar que se hizo colocando el cazo bajo la campana, aislándolo hasta del hogar, para que en el supuesto de hallarse el plomo, no hubiera que atribuirlo á las influencias exteriores del laboratorio. Los cincuenta litros pnestos primitivamente, fueron reducidos á un litro; y como debe suponerse, quedó un residuo, no sólo por los compuestos de naturaleza insoluble después de la evaporación, sino tam. bién los que, siendo por sí solubles, fueron precipitados por falta de vehículo. Separados esos residuos, bien lavados y tratados convenientemente los insolubles en el agua, así como la solución, fueron á su vez reconocidos por los medios ya indicados, habiéndose obtenido los siguientes resultados. Pero antes dará á conocer la Comisión la cantidad de materias fijas obtenidas de los cincuenta litros de agua:

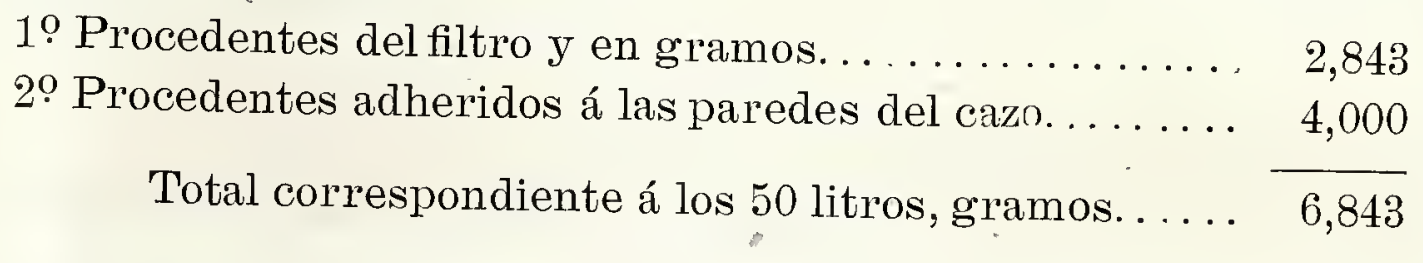

Cuya cantidad corresponde, por litro, á 0,13686 gramos.

Permítase á la Comisión hacer notar que los resultados analíticos obtenidos en 1854 con relación al peso de las substancias fijas, apenas difieren de las que ahora presenta, según se ve por la siguiente comparación:

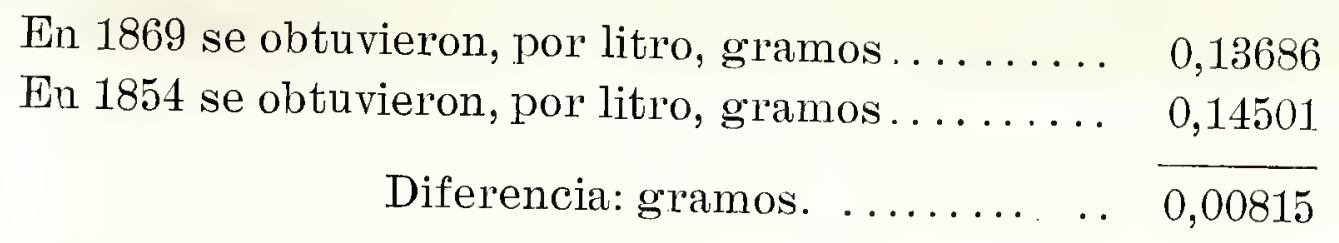

Es claro que una diferencia de ochocientos quince, cien miligramos, en la cantidad de cincuenta litros, más bien pudiera reputarse como confirmatoria de la exactitud de ambos trabajos ejecutados con quince años de diferencia. Pasemos á dar á conocer otros resultados.

Puestos 100 c. c. del producto de la evaporación con la cantidad 
necesaria de ácido acético, y tratado después por el ácido sulfhídrico, no se manifestó reacción alguna, ni la hubo con la adición de un poco de amoníaco.

El residuo insoluble en el agua fué disuelto por el ácido acético, en la proporción sobre mil partes de $0,333, y$ un decigramo de la parte disuelta dió, con el ácido sulfhídrico, en gramos 0,0005 de un sulfuro que, por los medios bien conocidos, quedó demostrado ser de cobre, con más alguna alúmina proveniente de la acción del amoníaco.

Se ha indicado que, además de los trabajos emprendidos por la Comisión, hubo otros ejecutados en particular, siempre en solicitud del pleno convencimiento á que cada uno aspiraba. Entre estos trabajos señalará la Comisión los siguientes:

El Sr. Mendoza quiso asegurarse si en el agua gorda descubría algún compuesto de plomo: á este fin trató convenientemente algunas de las incrustaciones ó depósitos procedentes de la evaporación de dicha agua, $y$ nada encontró.

El Sr. Herrera, por su parte, recogió, con las precauciones debidas, los depósitos arcillosos de las aguas, y en unión del Sr. Río de la Loza, D. Manuel, procedieron al reconocimiento: los resultados fueron claramente negativos; ni vestigio alguno hallaron de compuesto de plomo.

El Sr. Hay estudió cuidadosamente algunos de los tubos condnctores, fundado en el siguiente raciocinio: si existiere en el agua de que se trata, la cantidad de plomo que se ha dicho, ó ann cuando sea en una mucho menor, es claro que dejará en la superficie interna de los tubos, vestigios notables de la acción corrosiva del agua, cuyo efecto será tanto mayor, cuanto mayor haya sido el tiempo que hubiere estado el metal en contacto con el líquido; pues no obstante esto, se vió, con la claridad que toca á la evidencia, como pueden notarlo los señores socios en los tubos que están á la vista, que lejos de perder dichos tubos en espesor, había aumentado éste con el sarro ó toba calcárea arcillosa, la que, barnizando el interior, deja la superficie metálica libre del contacto del líquido. Hay que advertir, que de esos tubos, uno ha estado en servicio durante diez años, y el otro treinta $\mathrm{y}$ seis.

El Sr. Río de la Loza, D. Manuel, se ocupó también de buscar el plomo en el agua gorda, pero nada le indicó la presencia de este metal. 
El que esto escribe, hizo á su vez dos rectificaciones, concentrando por una parte dos litros de agua, y por otra cuatro, reduciéndolos á un décimo de su volumen: en el primero buscó el amoníaco, pero sin hacer uso de base alguna, y sí de ácido sulfúrico para formar una sal más estable; y en el segundo, el compuesto plumbífero: ni vestigios halló de éste, y aunque con aquél obtuvo un precipitado de cloro-platinato, no hubo indicación alguna que revelara el desprendimiento del álcali.

No obstante los datos que ministra el conjunto de los trabajos referidos, pretende la Comisión ejecutar otros en esta sesión, que aunque sencillos, presten materia bastante para que cada uno de los señores socios presentes puedan juzgar de los hechos, previa la sobrevigilante autorización de los señores secretarios, tanto en la procedencia y torna del agua, como en las manipulaciones preparatorias. Si, como lo espera la Comisión, correspondieren los resultados auténticos á los que ha mencionado, quedarán confirmadas las siguientes deducciones referentes á los trabajos ejecutados por los que suscriben.

1. " Que la existencia de sales amoníacales en el agua potable de la Capital de México, no es constante.

2." Que cuando se han hallado dichas sales, se reconoció encontrarse al estado de carbonato y en la proporción de seiscientos treinta $y$ tres, diez miligramos por litro.

3. "Que una proporción igual de amoníaco fué obtenida, después de poner al agua una parte de potasa cáustica. La Comisión carece de dates para resolver si este amoníaco procedió á una sal fija preexistente en el agua, ó de su formación por el efecto de dicha potasa sobre las materias orgánicas contenidas en el líquido.

4. a Que con ninguno de los reactivos empleados ha logrado la Comisión descubrir en el agua ni aun vestigios de compuesto alguno de plomo, ni disuelto ni precipitado.

5. Q Que las incrustaciones calcáreo-arcillosas que tapizan el interior de las cañerías, preservan probablemente al plomo de ser atacado por el agua, aun cuando ésta contenga sales amoníacales.

Será, además, útil el hacer una aplicación en el orden higiénico, fundada en los resultados expuestos. Si es un hecho que los reactivos que han sido empleados por la Comisión, indican la existencia de $/ 160,000$ de plomo, y de ma manera muy clara la de $1 / 32.000$, 
puede asegurarse, sin temor de errar, que las aguas examinadas no contienen esta cantidad, y que, por lo mismo, aun cuando exista alguna menor, no será nociva á la salud. En consecuencia, si más tarde se descubriere álgún otro reactiro más sensible, $\sigma$ si se diere á conocer algún nuevo procedimiento, no por ello resultará falsa esta última proposición.

El relator cumple con un deber de justicia, recomendando á la Asociación la constancia y laboriosidad del Sr. Hay, quien acompañado de D. Manuel Río de la Loza, no omitió trabajo alguno en las dirersas manipulaciones que se juzgaron necesarias para el desempeño de la Comisión que la Sociedad se dignó confiar á los que suscriben, quienes se darán por satisfechos si logra que ella se persuada del interés que han tomado por corresponder á los deseos que lá animan.

México, Mayo 3 de 1869.

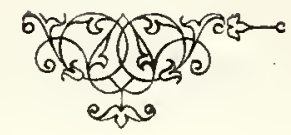




\title{
OPÚSCULO SOBRE LOS POZOS ARTESIANOS
}

\author{
Y LAS AGUAS NATURALES
}

DE MÁS USO EN LA CIUDAD DE MÉXICO, OON ALGUNAS NOTICTAS RELATIVAS AL CORTE GEOLÓGIOO DEL VALLE, Y UNA LISTA DE LAS PLANTAS

QUE VEGETAN EN LAS INMEDIACIONES

DEL DESIERTO VIE.JO.

Publicado por L. Fío de la Loza y E. Craveri.

(Boletín de la Sociedad de Geografía y Estadística. Suplemento al Tomo VI, 1ª Ep., págis. 9 al 19).

Entre los muchos servicios que presta la química á la sociedad, no es de menor importancia el dar á conocer la composición de las aguas, alejando todo escrúpulo al indicar de una manera segura el uso que de ellas puede hacerse. Destinadas unas á satisfacer las necesidades domésticas, otras á las industriales, y no pocas al restablecimiento de la salud del hombre, es preciso descubrir su composición y fijar la naturaleza y proporciones de los cuerpos extraños que contienen. Así pueden separarse las potables, de las que únicamente puedan servir al agricultor, al curtidor $y$ al fabricante, $y$ de aquellas en que el médico encuentre un agente terapéutico que aprovechar, en beneficio del género humano.

Por esto, el reconocimiento de todas las usuales es una verdadera necesidad, que los gobiernos ilustrados procuran satisfacer, ya promoviendo, ó ya premiando suficientemente los trabajos emprendidos con ese objete; mas en los países cuya actividad comercial es 
favorable á las empresas, no es tan necesaria esa protección, porque los negociantes contribuyen, aunque indirectamente, á los muchos é importantes beneficios, que son la consecuencia necesaria de las investigaciones de los químicos. A esto se debe el ver cada día nuevas publicaciones, nuevos tratados especiales, que poder-consultar, sobre la composición de las aguas potables y de las minerales, tanto de las grandes ciudades, como de las pequeñas poblaciones y aun de los lugares desiertos. Sin esas investigaciones, la química no habría hecho, en este orden, algunos descubrimientos útiles, perfeccionando sus procedimientos analíticos, mejorado sus aparatos y dado á la medicina y á la industria nuevos compuestos, explotados con incalculables ventajas. Y si México no ha entrado aún en el pleno goce de ellas, parece llegado el tiempo de que procure apreciarlas, de que destine el gobierno algunas sumas á tan fructuosas indagaciones, $y$ también, de que los establecimientos científicos, y los profesores todos, se interesen en los adelantos del país, en los de la ciencia y en los suyos. Contribuir con una pequeña parte á tan noble fin, es el objeto de este escrito, y será el premio de nuestros trabajos el haber satisfecho un deseo, no menos que la halagiieña, annque remota esperanza, de que sean útiles al público y estimados por los que quieran juzgarlos.

Hace algún tiempo que deseábamos visitar los manantiales que proveen á la ciudad de agua potable, no sólo por curiosidad, sino también para reconocer su posición, distancia relatira, rocas inmediatas, $y$ cuanto pudiera relacionarse con el examen químico de las aguas potables, el que nos proponíamos repetir, sirviéndonos ahora de procedimientos y de reactivos que no se habían empleado antes, y que debían dar á conocer las diferencias consiguientes á su mayor exactitud. Isa ocasión no podía ser más favorable: precisados el año pasado á reunirnos, casi diariamente, en el laboratorio del colegio de medicina; obligados en cierto modo á conocer el agua de que nos servíamos para nuestras operaciones, y provistos de instrumentos, utensilios y aparatos propios, que, con los de la cátedra, formaban una colección más que suficiente, turimos también la fortuna de contar con el empeño de dos de los alummos aplicados, los Sres. Pérez Soto y Diez de Bonilla, quienes desempeñaron satisfactoriamente los trabajos de que estuvieron encargados.

El primero de los que suscriben, confiesa ingenuamente, que sin 
el estímulo, constancia y empeño del segundo, muy difícilmente habría llevado á su término una empresa que exige, además de la práctica, alguna dedicación, y sobre todo, el tiempo preferente de que no estaba á su arbitrio disponer.

Acaso haya quien juzgue excusada la repetición de estos reconocimientos, fundándose en que no han faltado artículos en los periódicos, donde se encuentran relaciones más ó menos extensas, que dan razón de los que han sido hechos en diversas épocas, y dando también por terminado cuanto en el caso pudiera decirse; nuestra opinión, sin embargo, es contraria: algunos de esos artículos han sido escritos por uno de nosotros, y por los dos, el del agua dẹ Peñol; nuestro juicio, por lo mismo, al decidirnos á repetir las experiencias y publicar los resultados, es tan severo como fundado. Hay, además, que advertir, que en cada uno de los reconocimientos practicados antes, se ha tenido un objeto determinado, que no ha sido precisamente el de fijar con escrupnlosa exactitud, y en el orden común, la composición de las aguas sometidas al examen; basta notar que no hay una sola publicación que reuna el análisis, tanto de las potables, como de las minerales de más uso; que todas han sido hechas antes de tener en la ciudad los pozos artesianos; y basta recordar, por último, la perfección á que han llegado los procedimientos analíticos, así como la necesidad de repetir los experimentos, para asegurarse de la exactitud de los anteriores. Nosotros mismos, al encontrar ahora vestigios de yodo en el agua de Guadalupe, hemos creído necesario buscarlo también en la del Peñol, dudando si habíamos hecho esta indagación en aquella época, no obstante haber quedado satisfechos de los trabajos emprendidos entonces.

Mas volviendo á nuestro propósito, diremos: que avivó el deseo de comenzar estos trabajos, la empresa nuevamente establecida por los Sres. Pane y Molteni, á quienes estaba reservada la gloria de hacer conocer prácticamente la utilidad de las fuentes brotantes. EI servicio que han prestado es de triple interés, y cada nno á cual más útil y necesario. No sólo han proporcionado el agua de que carecían muchas localidades: también facilitan el conocimiento geológico de los terrenos, y acaso llegue la ocasión de que la industria minera consiga en la República, rica en metales preciosos, las importantes y positivas ventajas que cada día se obtienen en los países que caminan á la vanguardia de las mejoras. El taladro de los Sres. Pane y 
Molteni, servirá doblemente en la República como sonda exploradora, de cuyas indicaciones se aprorecharán el agricultor y el industrial, sabrá utilizar el geólogo, y ofrecerá nuevas explotaciones al minero. Mas aun cuando así no fuera, nadie puede dudar del hecho bien conocido del público, y es, que los agraciados con el privilegio, han dado á varios puntos de la ciudad, agua brotante y permanente, proporcionando al mismo tiempo el conocimiento de las capas interiores del Valle.

Invitados para examinar las aguas de sus pozos, y comisionados también por la extinguida junta de industria para hacer el debido examen, hemos creído útil el dar á conocer la composición de las que hemos tomado de tres de esos manantiales que actualmente están en uso.

Los propietarios y el público apreciarán, en lo que valen, los datos que presentamos, y que irán, además, acompañados del corte geológico, con la descripción corresponđaiente. Fsta parte del trabajo es, sin duda, desconocida, supuesto que nada hemos visto publicado hasta ahora sobre las rocas del Valle, tomadas á una profundidad de más de sesenta varas.

Acaso estas noticias contribuyan á dar algún interés al escrito, y para hacerlo más completo, nos ha parecido conveniente, no sólo presentar la composición del agua mineral, conocida con el nombre del Pocito de Guadalupe, cuya análisis completa hemos hecho ahora, sino el repetir en la tabla, omitiendo la parte razonada, la que dimos en 1849 sobre la del Peñol de los baños.

Nos es también muy satisfactorio, agregar una lista con los nombres de las plantas que hemos encontrado al visitar los manantiales. Acompañados de nuestro inteligente amigo el Sr. D. Guillermo Schaffner en las expediciones emprendidas con ese objeto, ha bastado una indicación para que se prestara gustoso, of éeciendo un contingente, tanto más apreciable, cuanto que neutralizará de algún modo la aridez propia de los trabajos químicos.

Conocida la parte que cada uno ha tenido en los que publicamos, nos ocuparemos de los manantiales, dando algunos imperfectos pormenores de una de esas expediciones más divertidas, instructivas y útiles, para los que reciben inmediatamente las agradables $y$ variadas impresiones que se disfrutan en esos amenos lugares, en donde tanto resplandecen las obras maravillosas del Criador. 
La idea que en general se tiene de un manantial, nos hacía creer que hallaríamos en el origen de las fuentes del agua, conocida en esta capital con el nombre de agua delgada, vertientes regularizadas $y$ abundantes: creíamos, por los informes recogidos, que la de los Leo. nes estaría á tan corta distancia de la venta de Cuajimalpa, que haríamos á pie, y sin fatiga, desde este punto, la expedición proyectada. Nada de esto fué exacto. Arreglada nuestra marcha con los Sres. D. Guillermo Schaffner y D. José del Pozo, para la mañana del 13 del pasado Diciembre, y preparados con cuanto creíamos necesario para los trabajos emprendidos, juzgamos prudente solicitar personas que, conociendo aquellos lugares, pudieran servirnos de guía. Nos pareció un liallazgo haber encontrado á los aguadores ó guardas, pagados por el Excmo. Ayuntamiento, con sólo el objeto de cuidar de las aguas; mas desgraciadamente salimos pronto de tal error, pues los guardas no conocían las vertientes, ni habían pasado jamás de la presa. Felizmente teníamos en el canal mismo un conductor seguro, pues siguiendo la dirección opuesta á la corriente, debíamos llegar al término propuesto, aunque con alguna más dificultad, como pudimos notarlo á nuestro regreso.

La fuente, ó fuentes de los Leones, no son en su origen una alberca ó depósito de las aguas; éste ha sido construido como á dos leguas antes de llegar á las primeras vertientes, las que, comenzando en dos cañadas, que á pocos pasos terminan en una, presentan inuchas y pequeñas venas diseminadas en todas direcciones.

La extensa y fértil cañada varía de dirección, pero siempre reconociendo al N. y encanalando las aguas; lo que ha economizado al hombre el trabajo de conducirlas de larga distancia, y de recoger la de tantas vertientes que, aunque pequeñas por la cantidad que cada una produce, su número hace que aumente la del agua á medida que más camina. Llegando á esa alberca, conocida con el nombre de presa de los Leones, sigue el arte la obra comenzada por la naturaleza. Allí se ve cambiar el curso natural de las aguas, interrumpido por la mampostería que las recoge, llevándolas á un canal rústico $\mathrm{y}$ nada económico, que se une al que trae el agua del Desierto, antes del depósito conocido con el nombre de reposudera, para seguir con dirección á Santa Fe.

Decimos que el canal no es económico, tanto porque su mala construcción exige frecuentes y, por lo mismo, costosos reparos, como 
por la cantidad de agua que constantemente se pierde, ya absorbida por el lecho terroso del caño, ya derramada por los puntos desbordados y que con frecuencia lo azolvan. Es verdaderamente sensible que no se haya continuado la obra comenzada en la presa, y que habría sido tan ventajosa á la población como á los fondos municipales, evitándose el grave unal de que, en la época de las lluvias, llegue á la ciudad una agua lamosa, que debía ser tan limpia y saludable como en las vertientes.

Al examinar los elevados inontes de ese pintoresco sitio, se descubren marcadas las alturas por la fisonomía particular que da á cada una la vegetación que le es peculiar. El Sr. Schaffner ha creído observar allí el mismo aspecto de los Alpes, confirmando después esta idea, al descubrir, en los Leones, muchas familias vegetales y aun algunas especies que corresponden exactamente á las que, en iguales condiciones, se encuentran en los puntos elerados. Así, la Montia fontana, Luzula Alopecurus, Jungermania tenella, Hypnum tomentosum, y demás que, con la Gentiana y la Alchemilla, la Poa y la Valeviana, la Potentilla, el Gnhnaphalium, Sedum, etc., formando un contraste admirable en esas selras de frondosos pinos, harían creer, al suizo más extraño á la botánica, que se hallaba en terreno de su país natal.

Pero lo que más sorprende al visitar esos lugares en el rigor del invierno, es, sin duda, el encontrar una vegetación lozana y rica, el ver una floresta en contraste con el hielo, que aún permanece á mediodía en los puntos adonde no han penetrado los abrasadores rayos del sol. Nosotros lo hemos tenido á la vista á las tres de la tarde, en un día claro y hermoso, como son comunes en México, y á la verdad, que para extrañar allí los encantos de la primavera, sería preciso haber observado, allí mismo, las bellezas de esa virificadora estación.

Limitado fué, sin duda, el tiempo de que pudimos disponer para un examen, cual correspondía, si nuestra visita hubiera tenido por objeto únicamente la parte botánica: algunos géneros y especies vegetales se ocultarían á la rápida indagación que pudo hacerse en menos de seis horas; sin embargo, se ha podido formar, con los ejemplares recogidos, la lista que pondremos adelante, ocupándonos, desde luego, en dar á conocer el terreno, las observaciones barométricas y los resultados del examen del agua, practicado en la misma fuente. 
Abunda en esos lugares el mantillo terroso más rico que pudiera desearse para el buen cultivo, y así se observa, en efecto, en todos los puntos de donde no ha podido ser arrastrado por las aguas; hay, sin embargo, en otros sitios, alguna cantidad de arcilla ocrosa, irregularmente diseminada, y cuyo aspecto tiene analogía con la materia arcillosa que ensucia el agua delgada en la estación de las lluvias. El pórfido de esos montes presenta dos variedades: una azulada más abundante, que parece ser inferior, y otra rojiza superior, cubiertas las dos de un conglomerado. No hallamos en estas rocas diferencia alguna digna de notarse, aun comparadas con las de otros puntos de la cordillera, cnya identidad se descubre á la simple vista.

Dos observaciones pudimos hacer con el barómetro: una, adelante de la presa de los Leones, á las dos y media de la tarde, y la otra en las fuentes del mismo nombre, es decir, en las primeras vertientes, y una hora después. He aquí los datos recogidos:

\begin{tabular}{|c|c|c|c|c|}
\hline Observaciones. & Barómetro. & Termómetro fijo. & Termómetro libre. & Horas. \\
\hline $\begin{array}{l}\text { Primera..... } \\
\text { Segunda.... }\end{array}$ & $\begin{array}{l}505.10 \\
503.20\end{array}$ & $\begin{array}{l}12 \circ 50 \mathrm{C} . \\
11095\end{array}$ & $10^{\circ} 00 \mathrm{C}$. & $30^{\prime}$ \\
\hline
\end{tabular}

Estas observaciones han servido para conocer que en la primera estación nos hallábamos á cosa de 1,280 metros sobrè el piso del atrio de la Catedral (cuyo punto tomamos siempre por comparación), y en la segunda, á cosa de 1,322: de manera que suponiendo el nivel del atrio á 2,270 metros sobre el del mar, según los datos del Barón de Humboldt, tendríamos una altura para la primera estación, de $3,533,93$ y de $3,560,89$ para la segunda, lo que sólo daría la diferencia de 113 metros 11 centímetros, comparada esta última con la altura dudosa que dió á Ajusco el mismo Humboldt, lo que nos hace presumir que tuvo razón este sabio para dudar de su observación.

El examen de las aguas, tanto de la presa como de las mismas vertientes, indica desde luego mayor pureza, comparada con la que. se toma en la ciudad. La reacción es tan débilmente alcalina, que para apreciarla fué necesario compararla con la destilada. El ácido Pipizahoico dió, sin embargo, un cambio manifiesto, confirmando este hecho el juicio que antes habíamos formado sobre la utilidad de este nuevo reactivo. Para conocer la densidad del agua y estimar su 
residuo, nos pareció mejor recogerla antes de la presa, considerando que la de este punto tendría una composición constante, y al mismo tiempo se habría cargado, en su tránsito, de las sustancias extrañas solubles é insolubles que más importa conocer. Como era de suponerse, hay en esa agua menor proporción de cnerpos extraños que en Ia que llega á México; la densidad no es más que 1,000,028, y el residuo de un litro, ó sean mil purtes, apenas llega á 0,045: también se descubren en el líquido algunos infusorios y muy corta cantidad de tierra vegetal, siendo esto lo único que contiene en la estación en que la hemos recogido, pues no debe olvidarse que varía mucho en la de las lluvias, por las razones indicadas al principio.

Si hubiéramos de dar crédito á los informes recogidos, el agua de los Leones no es permanente; se dice que disminnye $y$ aun falta en la última época de la seca, apareciendo nuevamente cuando han comenzado las lluvias. No obstante esas noticias, hemos encontrado la misma cantidad el día 11 de Marzo. También será conreniente notar, que no llega á la ciudad toda la de los manantiales: á poca distancia de la presa se divide por dos caños, uno que commica con el canal del desierto, $\mathrm{y}$ otro que se nos aseguró ser propiedad de la hacienda de San Borja: en otros puntos hay igualmente algunas tomas, que ignoramos si son permanentes y si pertenecen á particulares ó son de servicio público.

EI segundo manantial, y acaso el más importante de los que surten de agua á la ciudad, porque da, sin duda, mayor cantidad, es el que llaman del Desierto. Situado, como el de los Leones, hacia el sudoeste de la plaza principal de México, da una igual en su aspecto, composición, etc., á la de este manantial, cuyo dato, reunido al de la posición relativa de uno y otro, manifiestan claramente que ambos reconocen un mismo origen, aunque las vertientes se abran en los lados opuestos de las montañas. El desierto y el camino que á él conducen, son fértiles como el de la fuente de los I Leones: el aspecto de las rocas, el de la vegetación y la fisonomía toda, presentan la mayor analogía: y aunque hemos encontrado algunas plantas que no rimos en los Leones, es necesario considerar el tiempo transcurrido de una visita á otra, pnes es bien conocida la influencia de las épocas en la regetación, no obstante que en nuestro país no sean tan marcadas las estaciones, como lo son en otros. Tales motivos nos permiten omitir la descripción de ese lugar, que fué en un tiempo de cris- 
tiana meditación, y actualmente se halla convertido en ruinas y únicamente habitado por el dependiente que cuida los restos de una fábrica de vidrios planos, cuyos trabajos están suspensos, y por las aves nocturnas que anidan en las bóvedas subterráneas, sobre las que descansa hace 248 años el lóbrego edificio que sirvió de alojamiento á los religiosos carmelitas descalzos. Es una pena ver por todas partes los estragos causados por la mano destructora del tiempo, y contemplar cuánto se gastará en edificios que, aunque de tosca construcción, no deberían verse hoy enteramente abandonados. Mas dejando este punto, daremos á conocer las observaciones barométricas hechas en la venta de Cuajimalpa, la que se hizo cerca de la fuente ó estanque frente al convento, y por último, la que corresponde al manantial de Santa Fe.

$\begin{array}{llllll}\text { Hs. } & \text { Baróm. } & \text { Term. tijo. } & \text { Term. lib. } & \text { Altura calculada en metros. } \\ \text { Cuajimalpa } 10 \text { h. } 00^{\prime} & -563 & -14^{\circ} \text { C. } & -130 & - \\ \text { Desierto.. } 11 \text { h. } 20^{\prime} & 543,80 & 14^{\circ} & 130 & 387 . \\ \text { Santa Fe.. 4 h. } 25^{\prime} & 577 & 22^{\circ} & 21^{\circ} & 649 .\end{array}$

Excusado parece recordar que una sola observación no inspira confianza, tratándose de conocer la altura.

Al fin de la lista correspondiente á las plantas recogidas en el manantial de los Leones, pondremos únicamente los géneros que se han encontrado en el Desierto, y que no vimos en aquel lugar; debiendo advertir que todos los de la primera lista, se hallan también en el camino y en las inmediaciones del antiguo convento. Sólo nos resta, para concluir esta parte, hacer unas breves indicaciones sobre los manantiales del agua, llamada en la cindad agua gorda.

Conocidos de muchos, como no lo son los del agua delgada, bastará anunciar que se hallan á la parte Sur del cerro de Chapultepec, situado al OSO. de la catedral. El agua que llega á la ciudad y abastece la parte Sur, procede únicamente de uno de los manantiales: el que distinguen con el nombre de alberca chica. La grande es propiedad particular, y sirve más bien para el riego de los campos. La observación barométrica, única que hicimos en la grande, á las diez de la mañana del día 12, dió 0,590; termómetro fijo, $24^{\circ}$, y libre, $18^{\circ} 75$ : pero no siendo seguro este dato, como hemos dicho, por ser único, no merece confianza el de la altura correspondiente de $2.03{ }^{\mathrm{m}}{ }^{\mathrm{C}} \mathrm{C}$.

Sería largo, fastidioso y en general inútil, entrar en todos y en 
tantos pormenores relativos á los trabajos de laboratorio; por esto nos limitaremos á indicar aquellos que creemos conveniente conocer al lector, comenzando por anunciar que el agua delgada que sirvió para la análisis, la tomamos de la llare del laboratorio de la Escuela de Medicina, en San Hipólito, y la gorda, de la fuente del Salto del Agua.

Hemos tenido, como regla general, filtrar el agua de que se ha hecho uso, sea para estimar la proporción del residno, ó la de alguno de los cuerpos extraños, aproximándonos así al conocimiento de su composición, y separando siempre las materias extrañas insolubles, que no sólo varían según las épocas, sino también por mil accidentes que no es fácil evitar. Mas al recoger los gases, excusado parece decir que esa precaución habría sido perniciosa; por lo mismo, se ha tomado el agua, tal cual se recoge en las fuentes de la ciudad.

Como el estado de hidratación de los residnos solubles varía notablemente, según las temperaturas, se ha preferido la de $120^{\circ} \mathrm{C}$., tanto para la desecación total, como para estimar cada uno de los cuerpos. Verdad es que este método no está enteramente libre de inconvenientes; el más conocido es el de la descomposición del cloruro de magnesia; pero siendo fácil la corrección por el cálculo, y no eritándose la descomposición, ann á menor temperatura, es, sin duda, más seguro llevarla á $120^{\circ}$ que á $80^{\circ}$ y á $100 \circ$, como pudiera hacerse.

También se ha adoptado el sistema de repetir una sola vez las operaciones, siempre que los resultados han confirmado la exactitud de la primera; pero en los casos contrarios, se ha procurado con la repetición de aquéllas. Los datos que ahora se presentan, son, por lo nirismo, el promedio de dos ó mas operaciones.

Como en el agua mineral de Guadalupe se tiene que apreciar el residuo soluble $y$ el insoluble, $y$ el primero no se obtiene privado enteramente del segundo, por la simple filtración en frío, se ha llerado á la concentración en su estado natural, separando después uno de otro. Y ya que nos ocupamos de esta agua, eminentemente medicinal, haremos otra advertencia importante para los que quieran ver por sí los restigios de jodo que contiene. La evaporación no la hemos llevado á la sequedad total, persuadiéndonos que esto exigía gran cuidado, porque el yoduro existente, descomponiéndose con algunos clorturos á una temperatura elevada, hace se pierda fácilmen- 
te la muy pequeña cantidad que contiene del compuesto yodado, el que sólo sería ponderable evaporando una gran masa de líquido: por. esto, no hemos señalado el peso ni la combinación, conformándonos con observar la reacción característica que da con el cloruro de paladio, y la más sensible que se presenta al formarse el yoduro de amidina, tratando colvenientemente el residuo alcohólico, según el recomendable método del profesor Cantú, de Turín.

No dudamos que los trabajos emprendidos con el agua del pocito de Guadalupe, demuestren de un modo palpable lo que dijimos al principio sobre la utilidad de los de este género. Muchos saben que esa agua es carbónica, ferruginosa, y que tiene otras sales que la hacen útil como medio terapéutico, y sin embargo, no se ha hechó de ella el aprecio científico debido, ni se pudiera juzgar de su eficacia, con algún fundamento, sin tener los datos de su composición cuantitativa. Si se compara el agua mineral de Guadalupe con esa multitud de aguas análogas, que tienen en Emropa una celebridad proverbial, será preciso concederle la ventaja, al conocer la naturaleza y proporciones de los agentes medicinales que naturalnente hay en ella. Y si á esta ventaja se agrega la muy apreciable, de encontrarse la fuente á una legua de la capital, no liabrá dificultad en darle la preferencia sobre esa multitud de drogas que, perdiendo $y$ ganando prestigio, según las épocas, la avaricia especulativa y los caprichos de la novedad ó de la moda, no dan más triunfos que los que se obtendrían, en su caso, con el agua del Pocito, verdadera limonada carbónica y compuesto ferruginoso, acaso más eficaz $y$ constante que las famosas píldoras de Blaud ó de Vallet, y hoy el carbonato de E. Merle, reputado conno infalible.

Mas dejando este punto á la consideración de los médicos, haremos otras advertencias.

Raro parecerá á las personas extrañas á las manipulaciones químicas, el ver, por la tabla analítica que presentamos, que no se hubiera apreciado separadamente algunas de las sustancias contenidas en las aguas, como el fierro y la alúmina: más fácil habría sido esto, tratándose de las que contienen mayor cantidad, bastando entonces la del residuo obtenido; mas no consiguiendo esto con todas, preferimos seguir la misma marcha en el examen de las potables, seguros, por otra parte, de que no es de gran valor esa indagación especial; por lo mismo, nos conformamos con presentar el dato recogido. 
Aunque es común suponer que algunos de los compuestos insolubles están disneltos en las aguas, por hallarse al estado de bicarbonatos, como la cal'y otros, sin duda que en las prtables de que nos ocupamos, es inútil tal supuesto, apoyándonos, primero, en la mínima cantidad que contienen (un millonésimo de cal), y segundo, en el hecho de que el hervor no da el precipitado calizo. Aun los depósitos que se forman en las vasijas en que se calienta agua por algún tiempo, y principalmente en las calderas, son más bien compuestos sulfocalcáreos ó silícicos, según que están alimentadas con agua gorda ó con delgada.

El examen atento de la tabla que presentamos, llama la atención por la presencia constante, no menos que la proporción del ácido silícico y sus compuestos, tan poco comunes en las aguas potables de otios países, y tan constantes en todas las de la Ciudad, comprendidas las de los pozos artesianos; pues aunque hay algunos de éstos, $y$ es el de los Migueles, en cuya agua no se encuentra silicato, está, sin duda, compensado, porque, como se ve, tratándose del ácido silícico, lleva la cifra mayor.

En cuanto á la materia orgánica observada en los residuos de cada una de las aguas, creemos de fácil explicación el hecho de haber encontrado más en el de la delgada que en las otras; recorriendo aquélla mayor espacio que ésta, por caños descubiertos y á la disposición de los vecinos de las poblaciones inmediatas, debe estar en contacto por más tiempo y con mayor cantidad de diversas materias orgánicas, disolviendo y arrastrando una parte con la facilidad que no tiene la gorda, ni la de los pozos artesianos: no obstante, insistimos en recomendar la ntilidad y conveniencia de preferir, en general, el agua delgada como más pura, y en aconsejar que se use filtrada, siempre que se pueda.

Es llegada la ocasión de hablar de los pozos artesianos. Creemos haber indicado cuanto pudiera decirse con relación á la parte histórica, al asegurar que los Señores Pane y Molteni, son los primeros que han realizado en la República tal empresa. En efecto, no tenemos noticia que antes de la independencia se hubieran hecho algunas experiencias, y sabemos que las emprendidas después de esa época, no dieron los resultados que se deseaban. La constancia y laboriosidad de esos Señores, vencieron las dificultades, y al fin pasan hoy de veinte los pozos que han abierto y están en uso. Tam- 
bién el Sr. Allan ha emprendido en los últimos meses, el mismo negocio, annque empleando la sonda de vara rígida, y con el proyecto de llevarla á maror profundidad: uno tiene concluido en la Colonia del Paseo de Bucareli, mas carecemos de datos para ocuparnos de estos trabajos.

Las aguas brotantes del Valle de México son tan buenas como las potables, siempre que se toman las precauciones convenientes para evitar la mezcla de las profundas con las salobres superficiales. Esta falta de precanción hizo que la del primer pozo abierto en el Paseo de Bucareli, fuera hedionda, y lo mismo la de San Lázaro: se tiene una prueba de la causa que señalamos, con el hecho de que el segundo de los pozos, abierto en el mismo paseo, y á muy poca distancia del primero, dió desde luego una agua ignal á la de los Migueles, y otras que son, sin duda, potables. Verdad es que generalmente contienen las de los pozos artesianos mayor cantidad de ácido carbónico, que las aguas delgada y gorda; pero, en primer lugar, esto no perjudica á la salud, y aun hay muchos casos en que es útil: $y$ en segundo, basta filtrarlas ó abandonarlas al aire, para que pierdan el exceso de gas ácido; también se nota en alguna de las aguas un olor sui géneris, que el vulgo distingue con el nombre de azufroso: el examen practicado nos da á conocer que proviene de la presencia de una cantidad variable de gases carbonados, que aunque inodoros al estado de pureza, no es así cuando son productos naturales, siendo común también el hallarlos impregnados de ese olor característico de los hidro-carburos bituminosos, lo que en efecto sucede con los gases contenidos en las aguas de algunos pozos artesianos, como es fácil notar en el de la Aduana, calle de Cordobanes y otros.

No siendo tan solubles estos gases combustibles, como lo es el carbónico, basta filtrar el agua, ó aun abandonarla al contacto del aire, para que se volatilicen, disminuyendo $y$ aun desapareciendo del todo el mal olor. En todo lo demás relativo á la descomposición, la tabla da á conocer y sirve para comparar la de los pozos con la de las otras aguas. En cuanto á la cantidad que da cada pezo, hecho con el taladro de que hasta ahora se han servido los empresarios, es de 2,880 barriles en 24 horas, si se toma el nivel del piso, disminuyendo, en proporción á la altura á que se quiere que suba: la mayor á la que la han llevado, es de cinco varas, quedando reducidos 
á 720 barriles en las veinticuatro horas, los 2.880 de que hemos hablado.

No podemos concluir esta parte, sin ocuparnos un momento de las aguas de Sancopinca.

Aún existe al NO. de la Ciudad, y aun á menos de mna legua, el manantial conocido con ese nombre: se cree que surtía antiguamente de agua dulce á mua parte de la Cindad, y á juzgar por los restos de la cañería, debió usarse aun mucho después de la conquista, porque la mampostería está construida al estilo español de aquella época y con los desechos de un caño de barro cocido, que muy probablemente fué el que usaron los indígenas. El manantial de Sancopinca es hoy pernicioso á los propietarios de los terrenos inmediatos, $y$ aun á toda la población, porque su derrame mantiene un extenso pantano insalubre, que favorece, además, en tiempo de lluvias, las inundaciones de todos los otros puntos que tienen sus derrames con dirección á los potreros de Aldana. Se haría, por lo mismo, un doble servicio, y se evitarían estos males, aprovechando el agua que hoy se pierde y perjudica, ó segando la vertiente, si no se considera útil.

Comisionado uno de nosotros en $\mathbf{1 8 4 7}$ para reconocer el agua, y practicado otro examen, nos hemos persuadido de que, aunque no tan buena como la delgada, es mejor que la gorda, pues su densidad es de 1,000201, y sólo contiene sobre mil partes, 0,15011 de sustancias fijas de la misma naturaleza que las del agua gorda, como lo son también los gases. La temperatura en el manantial, es como la de los pozos que hemos examinado, y como la de Guadalupe, y el mayor número de las fuentes del Valle, de $+21^{\circ} 50 \mathrm{C}^{\circ}$, sea cual fuere la atmosférica y sobre cuyo dato llamảnos la atención, por juzgarla de alguna importancia.

Sería útil complotar este trabajo, comprendiendo los relativos á tantas otras fuentes de aguas dulces, que se encuentran más ó menos inmediatas á la Ciudad, tales como las de Coyoacán, Churubusco, Popotla, Guadalupe, etc.; mas sin tiempo para ello, nos limitaremos á decir, que en todas direcciones se hallan vertientes de aguas que tienen mucha analogía, por su composición, con las que hemos examinado, y que son más comunes al $S$. y al O. de la Ciudad que al E. y $\mathrm{N}$.

He aquí la tabla analítica de que hemos hecho mención, ad- 
virtiendo que la indicación correspondiente á la temperatura, señala la que marca cada una de las aguas, en la fuente misma; que 'la densidad está tomada en condiciones iguales, y que la cantidad relativa de los gases, correspondiente á un litro, menos en la del Penol, está apreciada en centímetros cúbicos á $0^{\circ}$ de temperatura y 0,76 de presión: en fin, la proporción de sustancias fijas corresponde también á un litro de agua.

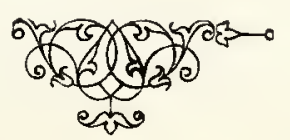


TABIA

DE IAS AGUAS MAS USADAS

Temperatura en las vertientes $\ldots \ldots \ldots \ldots \ldots \ldots \ldots \ldots \ldots$

Densidad

Delgada

ó del Desierto.

\section{PRODUCTOS GASEOSOS}

Aire

Oxígeno

Acido carbónico.

Azoeto.

Vapor de agua

Total c. c. por litro

$+9^{\circ} \mathrm{C}$.

1,000267

\section{PRODUCTOS SOLIDOS}

Sulfato de cal

Carbonato de cal.

de magnesia.

, de sosa...

Clor'uro de potasio.

$$
\text { , de sodio. }
$$

,, de magnesio

Silicato de sosa.

$$
\text { de potasa }
$$

Azotato de potasa

Yoduro de potasio.

Apocrenato de sosa

Siliza

Alúmina y fierro

Fierro

Manganesa

Materia orgánica

, bituminosa.

Pérdida

Total en gramos por litro

Id. de sustancias fijas solubles é insolubles en el agua del pocito

.....

0,00396

* Los gases del agua del Peñol están apreciados tomando cien centímetros cúbicos del que berca grande, reconocida á las diez de la mañana del 12 de Febrero, y á dos metros de profun- 


\section{A NAIÍTIOA}

\section{EN IA OIUDAD DE MÉXICO.}

\begin{tabular}{|c|c|c|c|c|c|c|}
\hline $\begin{array}{c}\text { Gorda } \\
\text { ó de Chapultepee. }\end{array}$ & $\begin{array}{c}\text { Pozo } \\
\text { de los Migueles. }\end{array}$ & $\begin{array}{c}\text { Pozo } \\
\text { de Bucareli. }\end{array}$ & $\begin{array}{l}\text { Pozo de la calle } \\
\text { de Cordobanes. }\end{array}$ & $\begin{array}{c}\text { Peñol } \\
\text { de los Baños. }\end{array}$ & \multicolumn{2}{|c|}{ Pocito de Guadalupe. } \\
\hline $\begin{array}{c}+22,95 \\
1,000280 \\
\end{array}$ & $\begin{array}{c}+21, \circ 5 \\
1,000144 \\
\end{array}$ & $\begin{array}{c}+21,95 \\
1,000230 \\
\end{array}$ & $\begin{array}{c}+21^{\circ} \\
1,000144 \\
\end{array}$ & $\begin{array}{l}+44,05 \\
1,00165 \\
\end{array}$ & \multicolumn{2}{|c|}{$\begin{array}{l}+21,05 \\
1,00134 \\
\end{array}$} \\
\hline $\begin{array}{r}10,390 \\
1,760 \\
0,990 \\
\ldots \ldots . \\
\ldots \ldots \\
\end{array}$ & $\begin{array}{r}15,650 \\
0,060 \\
7,240 \\
\ldots \ldots \\
\ldots \ldots . \\
\end{array}$ & $\begin{array}{c}13,15 \\
1,18 \\
\ldots \ldots \\
\ldots \ldots \\
\end{array}$ & Indeterminados. & $\begin{array}{r}6,2 \\
\ldots \ldots \\
63,3 \\
28,8 \\
1,7 \\
\end{array}$ & : & $\begin{array}{r}8,73 \\
23 \ldots \\
234,90 \\
8,00\end{array}$ \\
\hline 13,140 & 22,950 & 14,33 & & $100,0 *$ & & 251,63 \\
\hline & \multirow[b]{2}{*}{0,00241} & \multirow[b]{2}{*}{0,01130} & \multirow[b]{2}{*}{0,01482} & \multirow{3}{*}{$\begin{array}{l}0,029 \\
0,056 \\
0,256 \\
0,341\end{array}$} & $\begin{array}{l}\text { Sustancias } \\
\text { solubles. } \\
\text { Indicios. }\end{array}$ & $\begin{array}{l}\text { Sustancias } \\
\text { insolubles. }\end{array}$ \\
\hline $\begin{array}{l}0,00652 \\
0,02712\end{array}$ & & & & & $\begin{array}{l}\text { Indicios. } \\
0,00457\end{array}$ & 0,29751 \\
\hline $\begin{array}{l}0,03901 \\
\ldots \ldots\end{array}$ & $\begin{array}{l}\ddot{0}, \ddot{0} \dot{3662} \\
0,03689\end{array}$ & $\ddot{0,06949}$ & 0,07109 & & $\begin{array}{l}\ddot{0}, 19275 \\
\ldots \ldots .\end{array}$ & $\begin{array}{l}0,06035 \\
\ldots \ldots \ldots\end{array}$ \\
\hline$\dddot{0}, \ddot{0} \ddot{5} 845$ & & $\begin{array}{c}0,00086 \\
\ldots \ldots\end{array}$ & $\begin{array}{l}0,00668 \\
\ldots \ldots \ldots\end{array}$ & 0,480 & $\begin{array}{l}0,10790 \\
\cdots \ldots .\end{array}$ & o,o1vöo \\
\hline $\begin{array}{l}\ldots, 02997 \\
\ldots \ldots\end{array}$ & $\begin{array}{l}0,00535 \\
\ldots \ldots \\
\ldots \ldots\end{array}$ & $\begin{array}{r}0,000911 \\
0,08375 \\
0,01040\end{array}$ & $\begin{array}{l}0,00840 \\
0,04271 \\
0.01071\end{array}$ & 0,147 & $\begin{array}{l}0,02825 \\
0,06771 \\
0,03230\end{array}$ & $\begin{array}{l}\ldots \ldots 1321 \\
0,00372\end{array}$ \\
\hline 0,02158 & $\begin{array}{l}\ldots \ldots \\
\cdots \cdots \\
\ldots \ldots\end{array}$ & $\ldots \ldots$ & $\begin{array}{l}\ldots \ldots \\
\ldots \ldots \\
\ldots \ldots\end{array}$ & indicios. & $\begin{array}{l}\text { Indicios. } \\
0,07468\end{array}$ & $\begin{array}{l}\ldots \ldots \\
\ldots \ldots\end{array}$ \\
\hline 0,07745 & 0,06282 & 0,04515 & 0,04082 & & & 0,13809 \\
\hline 0,00686 & $\ddot{0,00162}$ & 0,00276 & $\ddot{0}, 00150$ & $\begin{array}{l}0,016 \\
\ldots \ldots\end{array}$ & $\begin{array}{l}0,06041 \\
\ldots \ldots \ldots\end{array}$ & 0,00364 \\
\hline $\begin{array}{l}\ldots \ldots \\
\text { Indicios. }\end{array}$ & $\begin{array}{c}\ldots \ldots \\
\text { indicios. }\end{array}$ & $\begin{array}{c}\ldots \ldots \\
\ldots \ldots \\
\text { Indicios. } \\
\ldots \ldots\end{array}$ & $\begin{array}{c}\ldots \ldots \\
0,00206 \\
\ldots \ldots\end{array}$ & 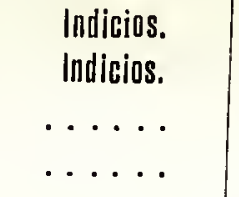 & $\begin{array}{l}\ldots \ldots \\
0,02907 \\
\ldots \ldots\end{array}$ & $\begin{array}{c}0,00102 \\
\text { Indicios. } \\
0,15978 \\
0,01800\end{array}$ \\
\hline 0,00093 & 0,00180 & & $\begin{array}{l}\text { Comprentidia } \\
\text { en la nateriatia } \\
\text { organica. }\end{array}$ & & $\begin{array}{l}\text { Comprendida } \\
\text { enl la materia } \\
\text { organica. }\end{array}$ & $\begin{array}{c}\text { Comprendida } \\
\text { ex la prateria } \\
\text { organtica. }\end{array}$ \\
\hline 0,29004 & 0,14751 & 0,23282 & 0,19879 & 1,3250 & 0,60264 & 0,72618 \\
\hline$\cdots \cdots$ & . . . & $\ldots \ldots$ & $\ldots \ldots$ & & 1,32 & 882 \\
\hline
\end{tabular}




\title{
APUNTES RELATIVOS
}

A LAS

\section{FUENTES BROTANTES O POZOS ARTESIANOS,}

\author{
por el Sr. Dr. D. Leopoldo Rio de la Loza.
}

(Publicado por el "Boletín de la Sociedad de Geografía y Estadística. 1. Ep., t. X, págis. 61-68).

Nombrado, en unión del arquitecto de la ciudad, para l'ecibir los nnevos pozos brotantes abiertos ńltimamente por D. Sebastián Pane en esta capital, lie creído que prestaría un serricio, en el orden científico, no limitándome á dar simplemente mi opinión sobre si las aguas de esas fuentes son ó no potables: esto bastaría, sin duda, para cumplir con el encargo; mas la ciencia ganaría poco, y tal consideración me decidió á reunir los datos que aparecen en la tabla adjunta. Tuve á la vez otra razón, acaso más poderosa para mí, y fué la de dar mayor extensión al trabajo publicado en 1854. El que ahora presento puede reputarse como un apéndice, y creo que la comparación de ambos ofrecerá datos para resolver varias cuestiones de alguna importancia á la física, la química, la geología, la medicina, etc.

Es de sentirse que fulte en este último cuadro una parte del mayor interés, á saber, la continuación del corte geológico. En la publicación de 1854 aparecen treinta y dos órdenes de capas, á la profundidad de cincuenta $y$ dos metros sesenta y un centímetros, profundidad mayor á que había penetrado la sonda hasta esa época; pero hoy ha llegado á poco más de ciento cinco metros, según se ve en la tabla, es decir, á doble profundidad, pero sin que se tenga una idea exacta de los órdenes correspondientes, ni de la naturaleza de las ca- 
pas inferiores. Este vacío, que acaso pueda llenar más tarde, procede de que, nombrado para hacer el reconocimiento, cuando los pozos habían sido abiertos y aun entubados, tuve que limitarme al sinple examen de los materiales existentes en los fondos.

Lo primero que llama la atención es que los pórfidos, arenas y.demás de esos lechos, son de la misma naturaleza que los encontrados en las capas brotantes menos profundas, y todos idénticos á los de algunos cerros del valle, es decir, á los que actualmente son arrastrados por las aguas. ¿Qué tiempo ha transcurrido para llenar, cuando menos, esos ciento cinco metros á que lia penetrado la sonda en el pozo de la Concepción? Hay datos para presumir que aun á mayor profundidad se hallarán materiales de la misma naturaleza; pero de todos modos creo que, con muy poco trabajo, se podrían fijar los años que han pasado, y por lo mismo, la profundidad primitiva del gran lago que forma hoy el extenso Valle de México. Por esto es de sentirse que no lubiera tenido efecto el contrato que se asegura celebró el empresario hace tres años, para continuar sus trabajos con el barreno lrasta tocar el fondo primitivo. Acaso más tarde se realice tal proyecto, tan útil á las ciencias enlazadas con la geología.

Oonviene advertir que la capa de agua de los pozos reconocidos ahora, es la cuarta de las brotantes, contando de arriba para abajo; que es la más duradera; que contiene, con pocas diferencias, las mismas sustancias extrañas, en general la misma densidad, y lo que es más, la misma temperatura, con variaciones insignificantes que no corresponden á las profundidades relativas. Compárese, por ejemplo, el pozo de la calle de Cordobanes, reconocido en 1854, con el de la Plazuela de San Lucas, abierto ahora, y se verá que la temperatura sólo difiere en medio grado; que la cantidad de residuo lo es sólo en setenta y nueve cienmiligramos; y que con relación á los radicales, únicamente hay de diferencia, en la segunda, ácido sulfúrico, que en aquella época no se encontró en la prinera, como no se halló en las de los pozos de los Migueles y de Bucareli: la temperatura de éstos es un grado más elerada que la de San Lucas, no obstante que ésta viene de doble profundidad respecto de aquellos dos, cuyos hechos parecerían contrariar las observaciones recogidas con relación al calórico central. Para más asegurarme de tal resultado, que no debía esperar, me serví de un termómetro bien sensible, rectifiqué el cero, y no sólo repetí la observación en los nuevos pozos, sino que reconocí 
varios de los antiguos, sirviéndome del mismo instrumento; así es que estoy satisfecho de la exactitud en las observaciones.

No puedo decir lo mismo con relación al orden de las combinaciones: es tan firme mi creencia en cuanto á las modificaciones que sufren los compuestos sometidos á la evaporación y desecación, y tan diferentes de las soluciones naturales, que más bien deberían fijarse en éstas, aunque conforme á las doctrinas químicas, que no dan, como se hace, los resultados que de hecho se obtienen al analizar los residuos, pues por sólo serlo, ya han sido alterados ó modificados: un ejemplo me servirá para aclarar este concepto, fundado en datos químicos. Los carbonatos no se hallan en las aguas al estado neutro, ni menos básico, habiendo como hay en las aguas ácido carbónico libre: preciso es, por lo mismo, que las sales, de las cuales forma parte, existan al estado de bicarbonatos, y ann si esto no fuera, algunas no estarían disueltas. Además, es indudable que la elevación de temperatura descompone los bicarbonatos, y este principio bastaría para no estimar como neutros los carbonatos obtenidos en los residuos, ni menos como libre todo el ácido carbónico separado por el hervor de las aguas.

Tales consideraciones, muy importantes para el químico, lo son más para el médico, por la aplicación práctica que tiene que hacer, tanto higiénica como terapéuticamente. id Ia cal, la magnesia y otros compuestos contenidos en las aguas potables, obrarán sobre la economía de la misma manera al estado nentro que al básico ó ácido? ¿La siliza combinada determinará los mismos efectos, ya fisiológicos ó ya patológicos, que la que se encuentra libre? ¿La reunión de diversos compuestos, es decir, esas soluciones complexas, darán los mismos resultados que la solución de uno solo, ó aun de varios, pero empleados separadamente? Para mí no hay duda que la naturaleza de las combinaciones ejerce grande influencia en el orden funcional, $y$ que, por lo mismo, es de considerarse detenidamente. Hagamos una aplicación de esta verdad con un hecho conocido de muchos.

Cuando algunos de los habitantes de la ciudad de México, acostumbrados á tomar el agua llamada delgada, la sustituyen con la gorda, tienen que sufrir por algunos días, más ó menos, en sus digestiones: algunas de las varias aguas potables de la ciudad de Tlalpan . determinan efectos análogos, aun por lo común más rebeldes, y en otros lugares de la República se notan igualmente. Natural es que 
el médico ocurra á la química para estimar la causa de esas alteraciones funcionales: pues bien, siguiendo el ejemplo puesto, comparemos esas aguas. La de Chapultepec ó gorda, tiene de más que la delgada, un poco de ácido carbónico, sulfato y carbonato de cal, carbonato de inagnesia de doble cantidad, carbonato de sosa, cloruro de sodio, azotato de potasa y siliza: hay de menos algún oxígeno, cloruros de potasio y de magnesio, silicato de sosa, alúmina y fierro: en el conjunto ó total resulta tener de menos, en los productos gaseosos, una cantidad que no llega á un centímetro cúbico por litro, mientras las sustancias fijas, en la gorda, aparecen de doble proporción. No obstante, debe creerse que no es el mayor peso del conjunto el que determina sobre la economía el efecto anunciado, sino la presencia de los compuestos calcáreos y unagnesianos en una solución de otras varias sustancias, demostrado como está en la práctica, que las aguas potables que contienen tales bases no son las más saludables, ni lo son las salitrosas, cuando se usan habitualmente, no obstante que unas y otras pueden ser medicinales, según los casos y la manera de emplearlas.

Pudieran, sin embargo, presentarse hechos que, aunque no tan frecuentes, sean en alguna manera contrarios, ó aparezcan como tales. No faltan personas que, habituadas al uso del agua gorda, tienen que sufirir como aquéllas, en los primeros días que emplean la delgada ó la de los pozos artesianos: tal resultado no siempre es debido al simple cambio de una agua por otra: hay que tener en cuenta las habitudes, la variación de rumbo, de habitación y otras. México, como muchas ciudades populosas, tiene sus barrios, sus arrabales, sus rumbos más ó menos ventilados, más ó menos húmedos, más ó menos poblados, abundantes ó no en regetación, talleres, etc., y cada uno de estos accidentes hace variable la importancia higiénica. La práctica médica demuestra diariamente lo que valen esas influencias, á las que debe agregarse la susceptibilidad individual: por tales consideraciones y otras que omito, creo que no hay en el hecho aislado oposición alguna con lo dicho al principio; debiendo inferir que la naturaleza de las aguas potables tiene grande influencia en la salubridad. Y si tales observaciones son de algún peso, si los datos químicos demuestran claramente que las aguas de los nuevos pozos de que me ocupo, son más puras que la gorda, no hay duda que el médico puede, con plena confianza, dar la preferencia á aquéllas, sin más 
que aconsejar que sean expuestas al aire, ó lo que es mejor aún, filtrarlas, para ganar en oxígeno lo que pierden de sus gases naturales.

Muy oportuno me parece el tocar otras cuestiones que, por vulgares que se consideren, cuentan con el apoyo de personas instruidas, ó lo que es peor, de las que tienen reputación de tales. Sea la primera, la de que las aguas de todos los pozos brotantes son muy sulfurosas: otra, la de que son depilatorias, es decir, que favorecen la caída del cabello; generalmente hablando, ambas cosas son falsas, como es fácil demostrar.

Hay algunos pozos que, recientemente abiertos, dan aguas que arrastran más ó menos cantidad de gases pantanosos, es decir, de productos mixtos, en los que, dominando el hidrógeno protocarbonado ó gas de los pantanos, el ácido carbónico, el óxido de carbono y el aire, llevan también hidrógeno libre y una corta cantidad de sulfurado; mas esto no es lo común, y en los nueve á que me refiero, no he podido apreciar cantidad alguna de ácido sulfhídrico, no obstante haber empleado reactivos muy variados y sensibles. Como la existencia del hidrógeno protocarbonado es casi constante, á su presencia y á la mezcla con los otros gases debe atribuirse el olor que se percibe al brotar las aguas, y que se ha confundido con el del hidrógeno sulfurado, llamándole impropiamente sulfuroso. La disolución de esos gases es tan poco estable, que basta la exposición al aire para que desaparezcan enteramente, en cuyo caso esas aguas son más saludables que muchas de las que se usan en varias poblaciones. Aun la delgada, que en tiempo de secas es la mejor de las dos que más consumo tienen en esta ciudad, deja de serlo en el de lluvias. Pero yo quiero suponer que la presencia de esa cortísima cantidad de gas sulflídrico fuera constante; supondré también que no siendo fugaz, queda en las aguas; pues sin embargo, no hay que preocuparse con la aplicación inadecuada de las doctrinas médicas. El hidrógeno sulfurado es un veneno, respirado aún en corta cantidad; ¿pero lo es también ingerido en dosis inapreciable con los alimentos ó las bebidas? La existencia constante de ese gas en el tubo digestivo, no sólo del hombre sino de todos los vertebrados, responde más satisfactoriamente que cualquier otro raciocinio. Esta y otras muchas cuestiones toxicológicas reclaman una critica severa, un examen concienzudo, que haga desaparecer algunos errores. Preciso es, en atención á lo mucho di- 
cho, hacer á un lado la preocupación, por la que se suponen insalubres las aguas de las fuentes brotantes.

Dada á conocer la naturaleza de la mezcla gaseosa, es fácil hallar la explicación de algunos hechos que hace poco tiempo llamaron la atención de varias personas en esta capital, y aun dieron lugar á diversos comentarios, unos comerciales ó especulativos, y otros hijos de la preocupación ó del fanatismo, que con frecuencia dominan á la ignolancia.

Abierto un pozo artesiano en la feligresía de San Sebastián, se halló que los gases desprendidos ardían á la aproximación de una flama: este hecho no se hizo tan público como otro igual, que algún tiempo después causó grande admiración en una de las casas del Puente del Espíritu Santo. Curioso fué y divertido el ver que varias personas se disputaban la preferencia á un privilegio que pretendían, con el objeto de explotar la supuesta mina, ya como luminosa ó bien como calorífica. No se necesitaba mucho para contestar satisfactoriamente á las consultas de los menos ligeros ó más desconfiados: yo lo hice entonces, asegurando á uno de los interesados, que pronto cesaría la abundante salida de los gases, y con ella desaparecería la ilusión dominante de haber hallado una fuente de riqueza.

Mas volviendo á la segunda de las dos preocupaciones anunciadas, que es la propiedad depilatoria á esas aguas, bastará decir que innumerables hechos observados con alguna atención durante diez años, me persuaden que no hay más que una preocupación desfavorable, destituida de razón, pues aunque no faltan quienes pretendan fundarse en datos prácticos, ellos no están juzgados escrupulosamente, y ni cuentan con otro apoyo que el adagio vulgar «Post hoc, ergo propter hoc:» hay, en efecto, coincidencias que pueden simular la realidad, y yo creo que ésta es una de tantas que es necesario destruir. La opinión sobre la supuesta propiedad depilatoria, domina comúnmente en las señoras, más expuestas á preocuparse y más interesadas en conservar su cabello: con sólo esto se tiene explicada tal preocupación, si se reflexiona que ellas son las que más usan esa multitud de cosméticos, entre los cuales no faltan los depilatorios directos é indirectos: ellas, las que con la frecuencia de peinarse y con la manera de hacerlo, favorecen la destrucción del bulbo; ellas, las que tienen que criar á sus hijos, en cuyo período es casi general que pierdan más ó menos el cabello. Para que se juzgue con más 
fundamento de la poderosa influencia de las preocupaciones, mencionaré otra opuesta á la anterior, á saber, la fe que tienen esas mismas personas en varias plantas, atribuyéndoles la virtud de hacer crecer y aun nacer el pelo; sea lo que fuere de todo esto, yo tengo la íntima convicción, fundada en la práctica, de que las aguas de las fuentes brotantes de esta capital no son por sí depilatorias, ni hay doctrina en que fundar tal propiedad.

Excusado sería mencionar las rentajas de esas aguas para el lavado, la tintorería $y$ otras aplicaciones industriales, si no hubiera quienes con su exagerada antipatía, ni aun para ese uso las juzgaran útiles. No hay duda que cuanta menor es la cantidad de sales calcáreas contenidas en las aguas, menor es su acción sobre las materias colorantes, y menor la del jabón descompuesto; y como cuanto menos se descomponen, limpia más y se consume menos, es seguro que las aguas más puras son las mejores para la tintorería y el lavado, tanto por la economía como por el efecto producido. Aplicando estos principios á las aguas de los pozos reconocidos y teniendo en consideración los resultados del examen analítico, queda demostrado que son las más propias, no sólo para esos usos, sino en general para todos los de economía doméstica, y am para muchos de los medicinales y de los químicos.

Me creo obligado á Ilamar la atención sobre un punto, que juzgo de interés social, á saber, el de la legislación relativa á las fuentes brotantes, comprendiéndose la servidumbre de los derrames. Multi- plicándose como se multiplican cada día esos manantiales, muy principalmente en el Valle de México, preciso es evitar las cuestiones, estableciendo reglas que fijen los derechos de los propietarios que pretendan abrir nnevos, $y$ otras que resnelvan las que de hecho se han presentado. A fin de dar á conocer cuán necesario es este paso, me limitaré á citar un caso entre varios que, como perito, me han pasado los juzgados.

Algunos de los recinos de Atzcapotzalco contribuyeron para abrir en la plaza del pueblo ma fuente brotante, con el derecho de poder conducir á sus casas el agua por medio de cañerías subterráneas. Nas como el nirel de la casa de uno de los accionistas era superior al del manantial, se encontró, después de hechos los gastos, con que el agua no llegaba. Entonces resolvió mandar abrir otro pozo en el patio de su casa, 5 como la fuente pública disminuyó en 
cantidad, ó por lo menos se creyó así, el pueblo le puso pleito, y el juzgado me propuso varias cuestiones que debía yo resolver para fundar su sentencia. Fácil fué decidir sobre algunas, tales como la de niveles relativos, distancias, influencia que pudiera tener la nueva fuente con la antigua, etc.; mas no era tan sencilla la más importante para las partes, los derechos del común en oposición con los del vecino. Inútil era buscar un apoyo en nuestras leyes para fundar mi parecer, lo que me obligó en cierto sentido á legislar, procurando una resolución equitativa, y reducida á lo siguiente: «que el vecino estaba en su derecho para abrir en su casa la fuente brotante, pero á condición de tomar una capa distinta de la correspondiente á la ya abierta en la plaza.» Pues bien, como ésta hay otras cuestiones que se han presentado á nuestros juzgados y que reclaman disposiciones legislativas: ellas y las de otros países pueden servir para dar las más adecuadas á las necesidades de México, prestando con ello un buen servicio.

Acaso parecerá superfluo hallar en la tabla algunos datos que bien pudieran omitirse, creyendo que á nada conducen, tales como las horas de observación, la densidad estimada con los gases y sin ellos, y aun las de la correspondencia del metro con la vara y la del litro con el cuartillo; mas yo he tenido para ello razones de observación y razones de necesidad. Estas han sido: que celebrado el contrato con referencia á varas y á jarras, tenía que arreglarme á él, sin omitir por eso la estimación métrica. En cuanto á las de observación, comenzaré por las horas, cuya anotación es, en mi concepto, de más importancia de la que generalmente se cree. Baste decir que no habiendo una regularidad perfecta en la salida de las aguas, ese dato llega á ser necesario. Algo más tengo que agregar con relación á las densidades.

Natural sería suponer que cuanta menor fuera la densidad de una agua dada, menor sería también la de las sustancias extrañas fijas que conturiera; pero tal raciocinio no es siempre exacto, como puede verse examinando los datos que aparecen en la tabla. El agua de Santo Tomás la Palma, tiene una densidad como de cinco diezmiligramos mayor que la de San Lucas, y no obstante esa diferencia, ésta deja casi seis centigramos más de residuo que aquélla. Aún hay otra cosa: la de Santo Tomás, privada de gases, sólo aumenta en densidad once cienmiligramos, mientras la de San Lucas aumenta veinte: 
este hecho, que está en armonía con los datos recogidos de las otras aguas, manifiesta claramente Ia influencia que deben tener en las densidades la presencia de mayor ó menor cantidad de gases, no debiéndose, por lo mismo, inferir por sólo la densidad, la mayor ó inenor cantidad de residuo ó sustancias extrañas fijas que deba contener.

Hace días que habría concluido estos apuntes, si no hubiera tenido el deseo de agregar, en la tabla adjunta, los datos relaticos á la fuerza ascensional, datos que juzgo tan útiles, que acaso sirvan para estimar, con la oportunidad que es de desear, la mayor ó menor estabilidad de las fuentes brotantes.

Confieso, con la franqueza que debo hacerlo, que nada he risto sobre este punto en los autores que han llegado á mis manos, y que, por tanto, no estoy enteramente seguro del resultado práctico; mas éste es mon motivo que me decide á dar á conocer la idea, para que, examinada por personas competentes, sea acogida y reglamentada, ó bien desechada, como acaso pueda merecer.

El primero de los medios que me ocurrió para estimar la fuerza ascensional, fué el de adecuar un flotador, construido bajo los principios fundamentales del aerómetro de Nicholson: pretendía yo y creía fácil estimar con pesas, por medio de mi instrumento, la fuerza ascendente de las aguas brotantes; pero tal idea no correspondió á mis esperanzas, annque sí me sirvió para confirmar las observaciones hechas antes, con relación á la remitencia ó irregularidad en los derrames de esas fuentes. Preciso era ocurrir á otro medio, cuyos principios son conocidos, cual es el de la estimación métrica de esa fuerza ascensional relatica. Entubada una rertiente á una altura dada, sobre el piso, á fin de eritar el escurrimiento, el nirel del líquido en el tubo será tanto más elevado, cuanta mayor es la impulsión ascendente, en cuyo caso, la medida, partiendo del nivel del piso, representará la fuerza relativa, que bastaría para el objeto; mas si se quisiera tener la absoluta, se calcularía el peso de la columna del líquido, partiendo del lecho de la rertiente $y$ tomando en cuenta el de la atmósfera.

Siento, en cuanto á esto, no poder presentar desde ahora los datos correspondientes á los nneve pozos de que he hecho mención; pero motivos independientes de mi voluntad han impedido la aplicación práctica de ese medio sencillo. Concluyo, pues, fijando en términos 
precisos los puntos de que me he ocupado, declarando antes, que sin la cooperación y empeño en los trabajos de laboratorio del profesor D. Sebastián Reyes, preparador en la cátedra de química de la Escuela de Agricultura, acaso no liabría emprendido todos los que se hicieron; así es que creí justo que suscribiera la tabla, como un eficaz colaborador.

1. ${ }^{\circ}$ Las aguas de los nueve pozos abiertos últimamente, tienen, con pocas diferencias, las mismas sustancias extrañas, la misma densidad y las mismas propiedades organolépticas. Casi no difieren de las de los pozos antiguos, cuya profundidad es aproximadamente una mitad menor.

2. ${ }^{\circ}$ La corta diferencia en la temperatura de esas aguas no corresponde á la que debía esperarse, atendiendo á la que se tiene con leelación á la profundidad.

3. ${ }^{\circ}$ Los materiales que se encuentran en las vertientes, aun á ciento cinco metros, son de la misma naturaleza que los que actualmente arrastran las aguas de lluvia.

$4{ }^{\circ}$ Los compuestos contenidos en todas las potables, deben fijarse, médicamente juzgando, más bien conforme á las doctrinas químicas racionales, que á los resultados obtenidos por el simple examen de los residuos.

5. Siendo las aguas de los nueve pozos abiertos últimamente, más puras que la gorda ó de Chapultepec y tanto como la delgada, cuando viene limpia, son de las más saludables y propias para el lavado, la tintorería y en general para todos los usos económicos, industriales y aun químicos comunes.

6. ${ }^{\circ}$ Dichas aguas no son ni sulfurosas ni depilatorias. Su olor fugaz es debido á la presencia de gases carbonados.

7. ${ }^{\circ}$ El desprendimiento abundante de gases combustibles, es sólo recientemente abiertos y de corta duración; por lo mismo, no se prestan á ser aprovechados industrialmente.

8. ${ }^{\circ}$ La legislación relativa á las fuentes brotantes y á sus derrames, es una de las necesidades para México.

9. ${ }^{\circ}$ y último. Hay un medio fácil para estimar la fuerza ascensional de las fuentes brotantes. 


\title{
TABLA ANALÍTICA de las nueve fuentes brotantes el año de 1863, en las plazuelas
}

\author{
Localidades \\ Fechas en que se hicier \\ Horas en que se hicieron los reconocimientos. ........... \\ (La m indica que se hicieron los reconocimientos.
}

DiÁmetro de los tubos exteriores, apreciado en milímetros

Elevación de los tubos sobre el piso de cada lugar estimada en ...

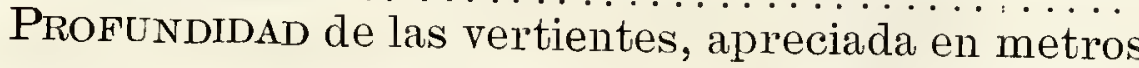

MATERIA " ", ", , varas.............. ment ó menos cantidad, pórfidos en pequeñas matatenas, arena cuarzosa y porfirítica morada, pómez, mica, $y$ en algunas marga tenaz y feldespato.

CANTIDAD DE AGUA por minuto, estimada en litros y á $0 .{ }^{\mathrm{m}} 838$ sobre el piso.............................................

CANTIDAD DE AGUA por minuto, estimada en cuartillos y á 0 m 838 sobre

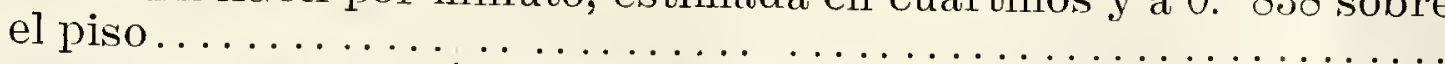

Temperatura ATMOSFÉRICA. Termómetro centigrado rectificado el celo. ..............................

Temperatura del agua. Termómétro centigrado rectificado el cero.

Aspecto DE las aguas. Todas son diáfanas é incoloras, con pequeñas cantidades de areña en suspensión.

OLOR Y SABOR, al salir de los manantiales: ligeramente sulfo-hidro-carbonado, que se pierde prontamente al aire.

REACCión: neutra en todas, y el papel de sal de plomo no presénta alteración alguna.

DENSIDAD, tomada con raras excepciones á $+18^{\circ} \mathrm{C}$. " en las mismas condiciones, pero privadas las aguas de los

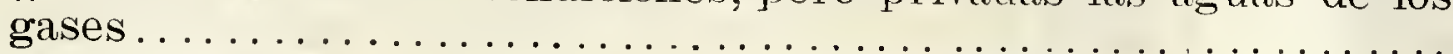

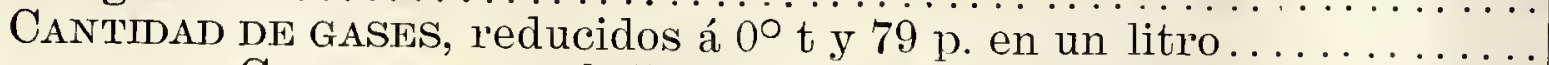
Cuyos gases se hallan en la siguiente proporción:

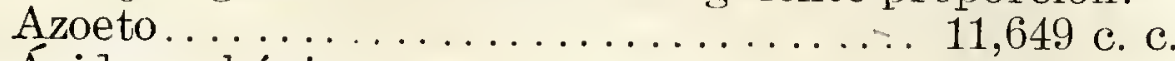

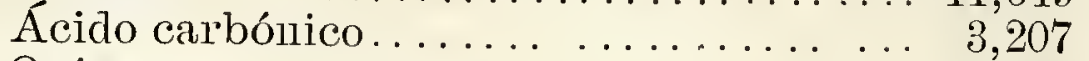

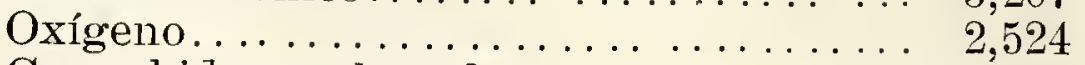

Gases hidro-carbonados ........... 1,030 $=18,41$ *

Sustanclas FiJas ó residuo desecado á $\ddot{+} 120^{\circ}$ por litro y en gramos.

Dichas sustancias son:

Sulfato de cal . . . . . . . . . . . . . . . 0,000547

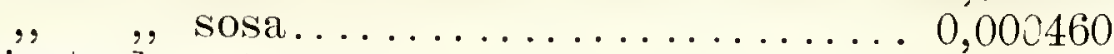

Silicato de potasa. . . . . . . . . . . . . . . . . 0,008916

, $, \quad, \operatorname{sosa} \ldots \ldots \ldots \ldots \ldots \ldots \ldots \ldots \ldots \ldots, \ldots \ldots 22055$

Cloruro ,, sodio.................... 0,010997

Carbonato de sosa.................... . . 0,057143

Silizi.... "magnesia.............. 0,014760

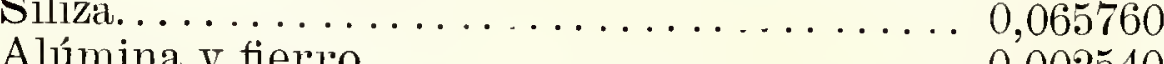

Materias fierro.................. 0,002540

Materias orgánicas ................. 0,010000

Indicios de ácido fosfórico, azótico, apocrénico y pérdida................ 0,004822 


\section{abiertas por D. Sebastián Pane en la Ciudad de México indicadas á continuación.}

\begin{tabular}{|c|c|c|c|c|c|c|c|c|}
\hline $\begin{array}{c}\text { San Lucas. } \\
\text { kbril li. } \\
10 \mathrm{h.} \mathrm{m.} \\
\end{array}$ & $\begin{array}{c}\text { San Juan. } \\
\text { Abril } 15 \\
9 \mathrm{~h}, 40^{\prime} \mathrm{m} . \\
\end{array}$ & $\begin{array}{l}\text { iCandelaria. } \\
\text { Abril } 15 \\
10 \text { h. } 40^{\prime} \mathrm{m} .\end{array}$ & $\begin{array}{l}\text { Los Ángeles. } \\
\text { Abril } 15 \\
5 \text { h. t. } \\
\end{array}$ & $\begin{array}{r}\text { Merced. } \\
\text { Abril } 21 \text { y } 22 . \\
11 \text { h. } \text { G }^{\prime} \text { m. } \\
\end{array}$ & $\begin{array}{l}\text { San Pablo. } \\
\text { Mayo 1. } \\
10 \text { h. m. } \\
\end{array}$ & $\begin{array}{c}\text { Santo Tomás. } \\
\text { Mayo } 1 .{ }^{\circ} \\
11 \mathrm{~h} . \mathrm{m} .\end{array}$ & $\begin{array}{c}\text { Concepción. } \\
\text { Mayo } 9 . \\
5 \text { h. } 25^{\prime} \mathrm{t} . \\
\end{array}$ & $\begin{array}{c}\text { Salto del Aguz } \\
\text { Mayo g. } \\
6 \text { h. 20' t. }\end{array}$ \\
\hline 0,070 & 0,070 & 0,070 & 0,070 & 0,070 & 0,070 & 0,070 & 0,070 & $0,070.3 \mathrm{p}^{\circ}$ \\
\hline $\begin{array}{c}0,838 \\
93,856 \\
112\end{array}$ & $\begin{array}{c}0,838 \\
101,662 \\
120,59\end{array}$ & $\begin{array}{c}0,838 \\
100,162 \\
119,52\end{array}$ & $\begin{array}{c}0,838 \\
95,160 \\
113,55\end{array}$ & $\begin{array}{c}0,838 \\
98,554 \\
117,20\end{array}$ & $\begin{array}{c}0,838 \\
90,562 \\
108,00\end{array}$ & $\begin{array}{c}0,838 \\
96,370 \\
115,00\end{array}$ & $\begin{array}{c}0,838 \\
105,300 \\
125,00\end{array}$ & $\begin{array}{c}0,838-1 v \\
101,400 \\
121,00\end{array}$ \\
\hline 106,76 & 94,447 & 119,998 & 73,478 & 98,554 & 70,264 & 114,522 & 63,184 & 85,00 \\
\hline 234 & 207 & 263 & 161 & 216 & 154 & 251 & 138,46 & 186,20 \\
\hline $\begin{aligned} & +20^{\circ} \\
+ & 20^{\circ}, 5\end{aligned}$ & $\begin{array}{c}18^{\circ} \\
20^{\circ}, 9\end{array}$ & $\begin{array}{c}22,{ }^{\circ} 5 \\
21^{\circ}\end{array}$ & $\begin{array}{l}20^{\circ} \\
21^{\circ}, 5\end{array}$ & $\begin{array}{l}12^{\circ} \\
21^{\circ}\end{array}$ & $\begin{array}{c}22^{\circ} \\
20^{\circ}, 75\end{array}$ & $\begin{array}{r}17^{\circ} \\
21^{\circ}, 5\end{array}$ & $\begin{array}{c}16^{\mathrm{C}} \\
21^{\circ}, 25\end{array}$ & $\begin{array}{l}18^{\circ} \\
20^{\circ}, 5\end{array}$ \\
\hline 1,00038 & 1,00036 & 1,000367 & 1,000366 & 1,000607 & 1,000367 & 1,000812 & 1,000366 & 1,00040 \\
\hline $\begin{array}{r}1,00058 \\
18,41 \text { c.c. }\end{array}$ & 1,000584 & 1,000553 & 1,000659 & 1,000680 & 1,000551 & 1,000923 & 1,000513 & 1,000623 \\
\hline 0,198 & 0,211 & 0,196 & 0,181 & 0,1409 & 0,185 & 0,1398 & 0,248 & 0,191 \\
\hline
\end{tabular}

* No lian sido estimados los gases en las otras aguas, porque con aigunas diferencias en la cantidad, han de ser de la misma naturaleza que las del agua de San Lucas. Por la misma razón no han sido separados los simples y los radicales de las sustancias fijas, una vez que cl análisis indicativo demostró su presencia.

Conclusión: Fácil es inferir de los datos anteriores, que las aguas de dichos pozos son más puras quela gorda de Chapultcpec, y que, suficientemente acreadas, son tan saludables como la delganda limpia.

Merced de las Huertas, Mayo 26 de 1863.
$\mathfrak{L}$. Pio de $\mathfrak{l a}_{\mathfrak{a}} \mathfrak{C} z \mathrm{a}$.
S. Pieyes. 


\title{
QUÍMICA.
}

\section{AGUA POTABLE DE TEOTIHUACÁN}

\author{
(Tomado del Periódico de la "Sociedad Filoiátrica de México." \\ Publicado por el Sr. Dr. D. Leopoldo Río de la Loza).
}

Aunque no presenta mayor interés la análisis de esta agua, por no poder ofrecer un trabajo completo, careciendo de la correspondiente descripción sobre la naturaleza del terreno, situación, temperatura, etc., no creo del todo inútil dar á conocer las sustancias extrañas que contiene dicha agua, tanto porque es una de las más puras que he examinado hasta ahora, como porque este apunte podrá servir para ir formando la historia de las aguas potables y minerales del Departamento, único objeto que me ha impulsado á publicar otros trabajos de este género.

La agua de Teotihuacán, tal como la he recibido de una persona interesada en saber su composición, ofrece los caracteres y propiedades siguientes:

Diáfana, sin color, olor ni sabor: no tiene acción sobre los papeles reactivos; su densidad es sensiblemente igual á la del agua destilada, y no contiene otros productos gaseosos que una corta cantidad de aire. A excepción del azotato de plata, ninguno de los otros reactivos usados comúnmente demuestra la existencia de sustancias extrañas, si se examina el agua en su estado natural; mas reducida por la evaporación á $1 / 10$ de su volumen, forma un precipitado blanco, tratada por las sales solubles de barita, de cal, de plomo y por el bioxa- 
lato de potasa. No precipita con el amoníaco, ni con el bicloruro de platina.

Evaporada convenientemente una libra de agua hasta la sequedad, dió tres granos de residuo de color blanco amarillento, el que, calcinado en un crisol de platina, perdió ${ }^{1} / 6$ de su peso y quedó enteramente blanco.

Los respectivos tratamientos por el alcohol y la agua, los azotatos de plata, de barita y el ácido oxálico, han demostrado que el residuo era compuesto de sulfato y carbonato de cal, de cloruro de sodio y de materia orgánica, en las proporciones siguientes, calculando sobre cien mil partes:

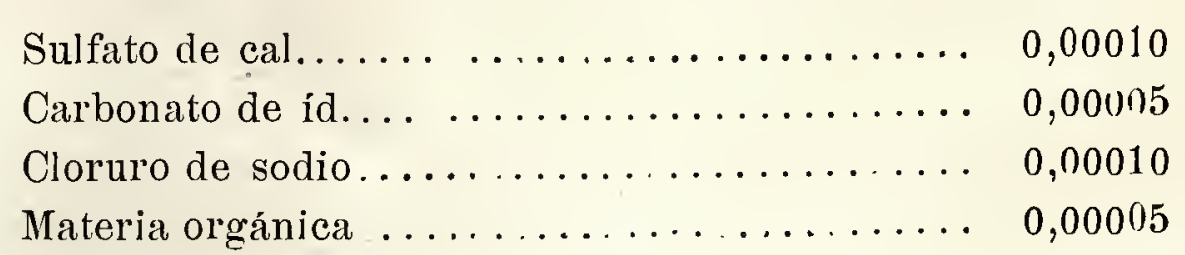

Se re, según estos datos, que ni la agua delgada de esta capital, que es una de las potables más puras, contiene, como la de Teotihuacán, sólo tres diez milésimas de sustancias extrañas. No obstante, me han informado que en el manantial es hedionda, lo que acaso provendrá de la descomposición de algunos cuerpos orgánicos, de la que resultan productos gaseosos muy volátiles, que pueden separarse de la agua agitándola, como lo demuestra el hecho de no haber encontrado esos gases en la que he analizado.

Es de desear que las personas instruidas que visiten la fuente de Teotihuacán, hagan las investigaciones necesarias y publiquen los resultados.

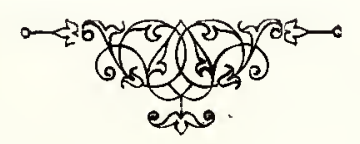


Algunas observaciones sobre la utilidad de las aguas minerales.

Ojeada á las de la República.

Análisis de las termales de Atotonilco.

Entre los diversos objetos que ofrece nuestro país, dignos de la contemplación del naturalista y del médico, sin duda es uno de los principales el examen de las aguas minerales de la República.

No sólo hay que extrañar un tratado especial sobre la composición y uso de las más notables; también hay que lamentar el poco ó ningún conocimiento que tienen de ellas muchos profesores médicos, entre los que no faltan quienes recomienden su empleo. Por' sólo esta consideración, me habría decidido á presentar á la Sociedad Filoiátrica la análisis de las aguas de Atotonilco, que una feliz castralidad me proporcionó examinar; pero he tenido otra más importante, y es el que se ventile la cuestión médica sobre la verdadera utilidad de estos baños como agentes terapéuticos.

La ciega ignorancia, la fatal codicia y la necia superstición, han exagerado hasta tal punto las virtudes y propiedades de las aguas minerales de todos los países, que hombres de alguna instrucción han sido arrastrados al extremo opuesto, como temerosos del maléfico influjo á que conducen involuntariamente las preocupaciones. Este error, más pernicioso que el primero, ha quitado á las ciencias y á las artes un tesoro; á los médicos una arma con que combatir, y á la humanidad un medio de disminuir, en algunos casos, los padecimientos á que está sujeta.

Apenas puede creerse que hombres eminentes, que han enrique- 
cido la ciencia con sus escritos médicos, y cuyos nombres son justamente venerados, mancharan sus obras con artículos burlescos, muy ajenos de sus conocimientos.

Si no es útil ni conveniente ver las aguas minerales al través del prisma de la prevención, como ha dicho Andral, es aún más pernicioso decidir sin observar y juzgar sólo por analogía. En este defecto lan incurrido algunos escritores de materia médica, negando á las aguas minerales una acción especial sobre el organismo, concediendo á las artificiales las mismas propiedades que á las naturales, exagerando los abusos y suponiendo decididas muchas cuestiones geológicas que aún están por resolver.

No me ocuparé en combatir los débiles argumentos en que apoyan sus opiniones, porque sería necesario escribir una memoria extraña al objeto que me he propuesto; pero sí recordaré las muchas curaciones que han logrado con las aguas minerales, innumerables enfermos, atacados de erupciones cutáneas, de parálisis y males nerviosos, en quienes no habían surtido buen efecto compuestos artificiales muy semejantes. También debo recordar que, por exactas que sean las análisis de las aguas con que nos brinda la noturaleza, no dan á conocer todos los principios que entran en su composición, ni sus combinaciones purticulares; que en química, como en medicina, hay frases que halagan sin convencer, pero que marcan el husta aquí de las ciencias; que si se abusa de los baños minerales, lo mismo que de otros muchos agentes terapéuticos, no deben proscribirse como dañosos, porque esto equivaldría á prohibir el uso del fierro, fundado en el necio temor de que puede fabricarse con él el puñal del asesino; y en fin, que hacer olvidar el examen de las aguas minerales, es obligar á los amantes de las ciencias físicas á que no se ocupen más de las interesantes cuestiones sobre la temperatura, acción disolvente, composición, etc., y á no inquirir otros productos tan útiles como el rolo $y$ el bromo, el ácido bórico é innumerables sales.

Satisfecho de estas verdades, me decidí hace tiempo á examinar algunas de nuestras aguas minerales, tanto por saber su composición, como por reunir el suficiente número de observaciones para llenar uno de los racíos que se notan en la terapéutica del país. Y aunque hasta ahora no haya podido realizar este pensamiento, deseo, aprorechando la oportunidad, comenzar por dar á conocer la composición de una de las aguas termales inmediatas á la capital, haciendo 
antes una brere reseña de las minerales en general, con arreglo á los datos que lie podido reunir.

La República Mexicana ofrece, en su vasto territorio, abundantes manantiales de aguas puras como las de las llurias de otoño, cargadas de sustancias extrañas como las medicinales más célebres de Enropa, frías, templadas y tan calientes, que algunas marcan $96^{\circ} \mathrm{C}$. Las hay ácidas y salinas, azufrosas y ferruginosas, pestífelas é inodoras, y tan variables en su naturaleza como en las proporciones de sus principios. Casi todas contienen ácido carbónico, libre y combinado, sulfato y carbonato de cal; en muchas se encuentra el cloruro de sodio, $y$ en corta cantidad el de magnesio. No creo que se han hallado compuestos de yodo ni de bromo, lo que no es raro, si se atiende á que no existen estos metaloides ni en el carbonato de cal, ni en el cloruro de sodio, tan commnes en nuestros terrenos, ni en los vegetales examinados hasta ahora. Hay tanta cantidad de sulfato de magnesia en algunas aguas minerales, que basta evaporarlas al aire libre para obtener la sal cristalizada, casi pura y suficiente para el consumo de la República: pueden citarse, entre otras, las de Chetla, cerca de Izúcar, en el departamento de Puebla, cuya extracción se ha suspendido desde que indebidamente se hace venir la del Norte.

Los azotatos de cal, de potasa y de sosa, que rara vez se mencionan entre los componentes de las aguas minerales de Europa, se liallan, aunque en pequeña cantidad, en algumas de las nuestras, sobre todo en los manantiales de los terrenos calizos. ¿Cómo explicar de una manera satisfactoria los fenómenos de nitrificación, supuesta la regularidad y existencia constante de estas sales? Yo he visto y examinado en las termas de Atotonilco, las agujas capilares del nitro calcáreo de los miueralogistas, y aun he sacado de esas aguas una pequeña cantidad de él.

También debe llamar la atención la presencia del ácido sulflí́drico en las aguas termales, cuyas fuentes se encuentran en esos ter'renos calizos y unu distantes de los piritosos, porque el hecho contraría, á lo menos en parte, la doctrina admitida por los que atribuyen á la descomposición del sulfuro de fierro, tanto la temperatura elerada del agua como la formación del gas ácido; fundándose, entre otras razones, en que sólo se ha encontrado en las aguas de Eughien.

Los comprestos de silicio y de aluminio, en las minerales de México, son más raros de lo que pudiera creerse, si sólo se atendiera á la 
abundancia de sus óxidos en la naturaleza, á que se encuentran en la mayor parte de las de Furopa, y especialmente en las de Toscana, cuyo terreno es análogo al nuestro, y á que no carecemos de sales aluminosas; sin embargo, faltan en muchas de las medicinales de la República que he examinado hasta ahora.

Aunque poco comunes las bituminosas, no se puede decir que carecemos de ellas: es bien sabido que á poca distancia de la capital hay una fuente abundante en petróleo, cuya extracción debe favorecerse, por ser uno de los productos naturales de grande utilidad á la industria, á la química y á la medicina.

En algunas aguas minerales existen igualmente cantidades variables de sustancias orgánicas, pero que no influyen, ni por su naturaleza, ni por la proporción en que se encuentran, en las propiedades medicinales de aquéllas.

Acaso se extrañará que no haya hecho mención de otros gases que suelen hallarse en estas aguas, tales como el azoeto y el hidrógeno, el oxígeno y el aire; mas debo confesar que en este punto carezco de datos propios y que no me son conocidos los ajenos; que los medios de investigación son tan delicados y ocupan tanto tiempo, que no compensa el trabajo á la utilidad; y por último, que no teniendo las más veces á mi disposición más que cortas cantidades de aguas mal recogidas, no he debido ocuparme en aislar esos principios volátiles, de preferencia á los fijos, que, como se sabe, dan á las aguas medicinales propiedades características más permanentes.

Se ve, según esta breve reseña, que las aguas minerales de la República pueden dividirse, siguiendo la clasificación generalmente adoptada, en termales y frías, alcalinas y ácidas, ferruginosas y azufrosas, entre las que se encuentran las gaseosas. En cuanto á sus efectos en las enfermedades, dependen por lo común, ó son debidos á su temperatura y á los compuestos que predominan en cada una, pudiendo asegurar que no obran en general sobre la economía del mismo modo que los medicamentos oficinales de su especie; que las sustancias reputadas como inactivas, entre las cuales se hallan algumas disueltas y que no son solubles en otras circunstancias, obran de alguna manera, probablemente aumentando la acción, disminuyendo ó modificando la que les es propia; que el poderoso influjo de la imaginación, el del régimen y la distracción consiguiente á los viajes, son generalmente provechosos; y en fin, que deben estudiarse los efectos 
de cada una de las aguas minerales de la República y hacerse aplicaciones racionales, sin generalizar su uso ni exagerar sus virtudes. Acaso otra vez tendré el gusto de ocuparme de este importante asunto en la extensión que merece, y también de los diversos efectos terapénticos, entre las aguas minerales facticias y naturales, limitándome por ahora á tratar de las termales de Atotonilco.

La hacienda de este nombre, en cnyo terreno se encuentran los baños, está situada trece leguas al Norte de esta capital, y según las observaciones hechas por el Sr. D. J. G. de la Cortina, á los $19^{\circ} 52^{\prime} 6^{\prime \prime}$ latitud Norte, y á 2,632 varas sobre el nivel del mar. En el terreno inmediato á las termas, dominan la caliza de agua dulce y la creta; á corta distancia y al Sur de los baños, abundan el pedernal y la arcilla endurecida, y al Este formaciones basálticas y capas de pedernal sobre creta.

Aunque la regetación no es muy abundante, hay rarias plantas en las márgenes del Río Saludo, en el que descargan las aguas de las fuentes, encontrándose, tanto en éstas como en sus caños, el tianguispepetla ó illecelrum, la graciola y una gramínea en buena vegetación, y á la temperatura de $350^{\circ}$ á $48^{\circ} \mathrm{C}$. Parece que la naturaleza engrasa los terrenos regados por esas aguas, para el mejor desarrollo y mantenimiento de las plantas.

No hay construidos hasta ahora baños propios para la comodidad de los que hacen uso de ellos y para que sean provechosos como medios terapéuticos; sin embargo, muchas personas ocurren en todas las épocas del año, buscando la salud que han perdido, ó cuando menos el alivio de sus dolencias.

Los manantiales principales ofrecen de particular que, á pesar de su immediación, no señalan una misma temperatura, ni contienen unos mismos principios. El Sr. Cortina hizo sus observaciones en la tarde del 26 de Octubre del año pasado, y notó que marcando el termómetro de Réamur $13^{\circ}$ al aire libre, señaló la agua del manantial más caliente, 4302 . Yo hice las mías á las cinco de la tarde del 20 de Enero de este año: el termómetro marcaba $17^{\circ} \mathrm{C}$. al aire libre; en la terma más caliente, $62 \circ$, y en otras dos, $59 \circ$. En la segunda observación, hecha á las diez de la mañana del 22 del mismo mes, no hubo otra diferencia que dos grados menos en la temperatura del aire. Creo suficientes estos datos para fijar el término medio de la temperatura en $58^{\circ} \mathrm{C}$. 
En cuanto á la variedad que he notado en la composición de estas aguas, consiste en la presencia del ácido sulfhídrico en dos de los manantiales, $y$ la falta de este gas en los otros; pero como en. las proporciones de sustancias fijas son enteramente iguales, las he confundido al tratar de sus caracteres físicos y de su composición.

Sólo he analizado las encostraduras formadas por las aguas del manantial más caliente, porque es inuy probable que en todos se encuentren unos mismos principios y en iguales proporciones. Por último, me ha parecido mejor señalar en granos la cantidad de cada una de las sustancias contenidas en un cuartillo de agua, que equivale á casi una libra, porque es la capacidad de los vasos que comúnmente se usan entre nosotros.

\section{EARACTERES FÍSICOS DE LAS AGUAS DE ATOTONILEO.}

Diáfanas, incoloras, olor notable de ácido sulfhídrico, en las de dos manantiales; sabor ligeramente ácido y después alcalino; temperatura de $54 \circ$ á $58^{\circ}$ C.; frías, marcan $101^{\circ}$ al densímetro, y no se enturbian.

\section{COMPOSICIÓN}

En un cuartillo de dicha agua, hay en granos:

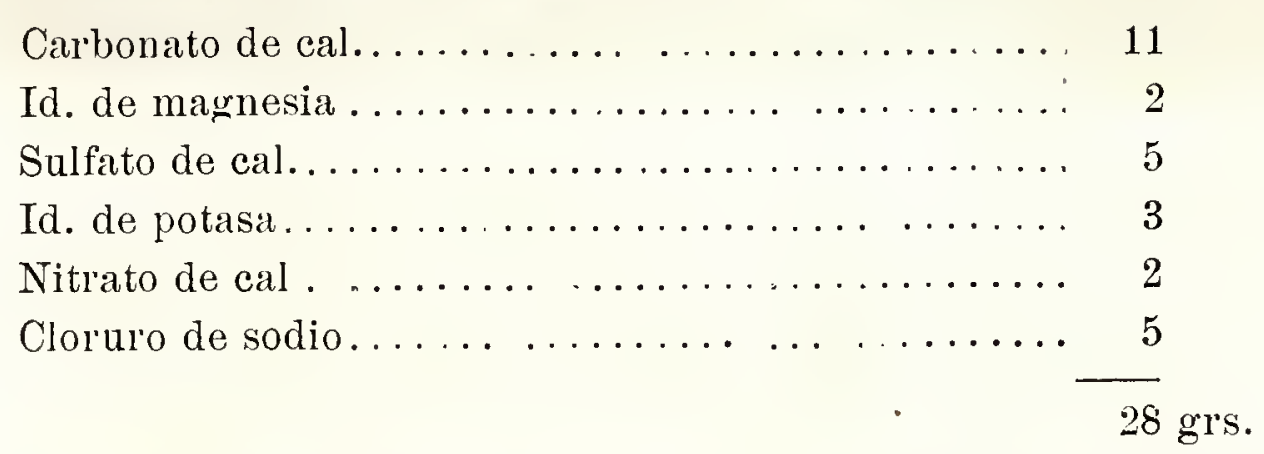

No he determinado exactamente la cantidad de los ácidos carbónico y sulfhídrico libres; pero creo que puede calcularse la de ambos en poco menos del volumen del agua. No contiene la de ninguna de 
las termas, sulfhidratos, ni otro compuesto de azufre, sino el ácido gaseoso; tampoco hay fierro, siliza, alúmina, ni sustancias orgánicas. Debo advertir que, evaporadas convenientemente diez y siete onzas y tres ochavas de agua, me han dado treinta granos de residuo seco, lo que indica una pérdida de 0,0002 en la análisis cuantitativa, cuya proporción es insignificante en las sales mencionadas.

Cien partes de costra del mismo manantial, han dado:

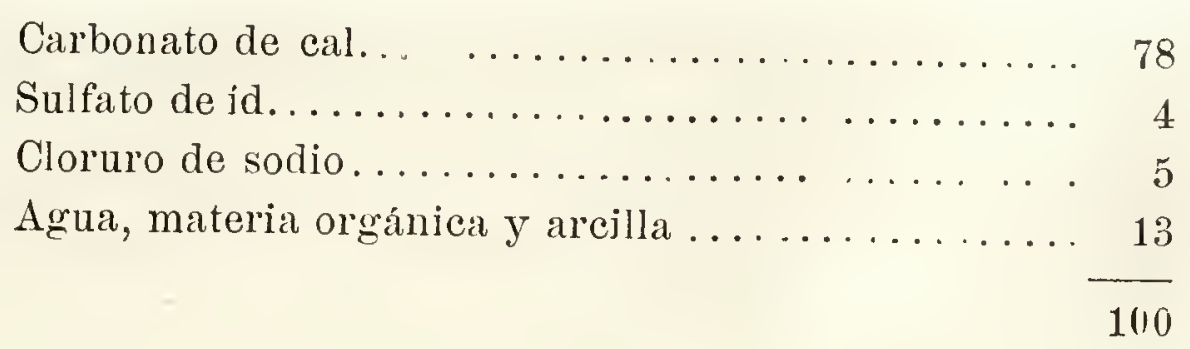

Estas costras tienen en la superficie un color verde claro, debido á una criptógama que vegeta á una temperatura más elerada que la graciola, el illecebrum y demás plantas mencionadas, fenómeno que me ha llamado la atención, por no haberlo notado en otros manantiales, ni tener noticia de que se haya observado en los de la República.

Creo no deber concluir este escrito, sin dar la clasificación médica é indicar brevemente los usos terapéuticos de estas aguas.

Es fácil convenir, en cuanto á lo primero, en la que de todos los manantiales pertenecen á las termales salino-ácidas, y las de dos de éstos están comprendidas entre las azufrosas, hepáticas 6 sulfo-ácidas. Los principios activos de las primeras, son: el ácido carbónico y las sales de cal; y en las segundas, además de esas sustancias, el ácido sulfhídrico: aquéllas pueden usarse interior y exteriormente; éstas sólo en baños y lociones.

No pretendo, fundado en la clasificación, señalar los usos de las aguas de Atotonilco; estoy muy distante de querer explicar sus efectos sólo por los resultados analíticos, ni menos por sólo el concurso de otras circunstancias extrañas á su composición; esto sería incurrir en un defecto justamente criticado. Pero debe tenerse muy presente el influjo de la imaginación, la pureza del aire que se respira en el campo, la agitación del camino, la temperatura de las aguas, los efectos que determinan los baños simples más notables en los minerales, por la propiedad que tienen de favorecer las secreciones, y aun de producir en algunos casos erupciones cutáneas benéficas. 
Entre las sustancias que entran en la composición de las de Atotonilco, se encuentra un metaloide, cuya acción especial en las enfermedades cutáneas ha sido comprobada por la experiencia. Así es que pueden recomendarse contra las enfermedades dartrosas y escrofulosas, herpéticas y reumatismales: también contra la anemia, la clorosis, la amenorrea, los infartos viscerales y otros males crónicos y rebeldes.

Creo que no hay inconveniente en administrar al interior las aguas de los manantiales que no contienen ácido sulfhídrico, en los casos en que están recomendados los absorbentes, los tónicos suaves, y cuando las digestiones son tardías. Es bien sabido que las dosis influyen mucho en estos casos, y que no debe prescribirse el uso interno ni externo de las aguas minerales en el período agudo de las enfermedades. 


\title{
EL LIQUUEN TINTÓREO DE LA BAJA CALIFORNIA,
}

\author{
POR JOS SRES. \\ Leopoldo Río de la Loza, D. Alfonso Herrera y D. Ricardo Ramírez, Socios de número. \\ RELATOR, RÍO DE LA LOZA. \\ (Tomado de "La Naturaleza," año de 1873, tomo 2, pág. 163).
}

Tiempo hace que se había explotado en ese territorio y en otros lugares de nuestras costas, el liquen de que nos ocupamos, sin que hubiera llamado de una manera notable la atención del público, ni menos de las personas competentes para juzgar científicamente. Mas en los primeros meses del año que data, al concluir recibieron, tanto el Gobierno como algunas de las asociaciones científicas, rarios de los redactores de periódicos y particulares, pequeñas muestras de aquel producto comercial, acompañadas de una breve noticia referente á la producción, aplicaciones y demás, respecto de lo cual llamó la atención el Sr. D. A. F. del Pujol, quien la remitió, según tenemos noticia.

La coincidencia de haber sido comisionados por la Escuela de Medicina y por esta Sociedad, los dos que suscriben, primero para clasificar el vegetal é indicar sus usos y propiedades, así como el primero y el último por la de Geografía y Estadística, nos hizo juzgar conveniente el reunir en un solo dictamen, el resultado oportuno de nuestros trabajos y algunas de las observaciones que juzgamos oportuno el consignar en este escrito.

Comenzaremos por decir algo respecto de la sinonimia. La roz «Orchilla» es, entre nosotros, la más usada, y ha sido entre los españoles, especialmente desde que Linneo se ocupó de las Roccellrs cora- 
toides, ceranoides, tinctorum montaqui, etc.; posteriormente, ha sido también introducida la palabra francesa orseille, derivada del radical $o r$, con la que se pretendió indicar la belleza de la tinta púrpura que produce. Tanto la palabra orchilla, como la de orsilla, se suelen aplicar, sin distinción alguna, á todas las especies de los líquenes tintóreos, y la de orseille á la parte ó materia colorante, sin que haya faltado quien le dé, indebidamente, los nombres de orceína y orcina, que están $y$ deben quedar reservados á los principios inmediatos obtenidos del vegetal. Por último, en los lugares de su procedencia, llaman á la orchilla, pasto de ocotillo, con lo cual indican que sirve de alimento para los ganados, y que vegeta en los árboles conocidos en esos lugares con el nombre de ocotillo.

La palabra orseille es, sin duda, la más antiguamente aplicada á la materia colorante ya preparada, supuesto que Plinio se ocupa de ella. Más tarde, á principios del siglo XIV, dice Mr. Dumas, el florentino Fredérigo la introdujo en el comercio, y después, cuando fueron descubiertas las Islas Canarias, se usó también con el mismo nombre, y por último, con los de Persio, de Cutbear, y algunos otros que sustituyeron al de «orseille,» cuyas denominaciones sólo indican la diferencia del liquen empleado para la extracción de la pasta colorante, puesto que las propiedades son las mismas, como lo son, en general, las de la producida por el liquen de que nos ocupamos.

Pasemos ahora á la descripción botánica del tintóreo explotado actualmente en las costas del Océano Pacífico, y por ella reremos que no es la Roccella tinctoren, y sí la Roccella fusiformis, rariedad linearis de Acharius, familia de los Líquenes. Thallus coriciceo, cartilaginoso, blanco cenizo, á reces anarillento, sobre todo en las plantas tiernas, ramoso, laciniado, varias reces dicotomo, con las lacinias planas, lineares, ramosas y adelgazadas en su extremidad; todas soredíferas.

Apothecas formadas en parte por la sustancia del thallus, escuteliformes orbiculares ó globuliformes, blancas, gruesas, sentadas, esparcidas y aglomeradas hacia las márgenes de las lacinias; lámina prolígena, con el disco de distinta naturaleza, plano-con rexo, circundada con un borde de distinto color, formado por el thallus; el parenquima compuesto de dos capas: la superior, delgada y subgelatinosa; la inferior, gruesa, densa $y$ opaca.

Góngilos desnudos, sub-estraídos y colocados en medio de la sus- 
tancia córnea de la lámina prolífica. Por estar las apothecas en partes formadas por la sustancia del thallus, colocamos á este liquen en la falange de los Coenotalamos; por sus conceptáculos escuteliforunes, de naturaleza particular, circundados con una margen de distinto color $y$ formado por el thallus, nos deciden á ponerlo en la división de los Conotalamos Discoedeos. Como el thallues cs ramoso, laciniado, las apothecas sentadas, el parenquima de dos capas distintas; y por último, los góngilos desnudos é inclusos, no cabe duda de que pertenecc al género Roccella; de las especies que encicra este género, la fusiformis se caractcriza por sus lacineas lineares ó lineares lanceoladas, adelgazadas en la extremidad, y las apothecas aglomeradas hacia las márgenes, caracteres que hallamos en la que se nos ha dado á clasificar. Achrorins admite una variedad, llamada linearis, que se distingue por tener simplemente lineares las lacineas, y todas soridíferas, circunstancias que encontramos también en nuestra planta. Por lo tanto, el liquen en cuestión es el conocido en la ciencia con el nombre de Roccella fusiformis, rariedad linearis de Acharius.

No estará de más el adrertir que el liquen á que nos referimos, se encuentra á veces mezclado con otras variedades de la Roccella, como ra han notado varios escritores, que sucede con la de tintoreros, y principalmente con la lineal, y también se hallan comúnmente plantas de varias edades que establecen diferencias en el aspecto $y$ en el valor, porque, si son tiernas, dará menos cantidad de la parte productora de la materia colorante.

Consideremos ahora la planta bajo ei punto de vista industrial.

Ouriosa es, sin duda, la historia relativa al descubrimiento de la propiedad tintórea de la orchilla. El haberse notado que la planta, tirada en los campos, bien por haber caído de los árboles, ó por ser el desperdicio de los ganados alimentados con ella, tomaba color, pasado más ó menos tiempo, y quc la coloración cs más pronta y frecuente en localidades determinadas, no faltó entonces quien se propusiera indagar la causa de ese curioso fenómeno, y bien pronto llegó á encontrarse, cstableciéndose, que tal efecto era debido al contacto de las orinas del ganado vacuno; después se vió que obraban de la misma manera las de los caballos, las humanas y, por ńltimo, que, con más ó menos rapidez, las de todos los animales determinaban el mismo efecto. He aquí el origen del procedimiento más ge- 
neral y antiguamente reconocido para proporcionarse la materia colorante de nuestro pasto de ocotillo y demás congéneres. La ciencia, en aquella época remota, aún no conocía la naturaleza de las orinas; aún ignoraba que existen en ella varios principios inmediatos; que uno de ellos tiene propiedades comunes con los óxidos alcalinos; $y$, por último, que no son necesarios todos aquellos principios para extraer la materia colorante.

Natural era que, cuando la química fué á prestar sus auxilios á la industria, pudiera ésta contar con otros varios agentes que dieran iguales resultados á los obtenidos con el repugnante método primitivo, fundado en el uso de las orinas. Las lejías, preparadas con ceniza, vinieron á figurar entre algunos; á otros pareció que la coloración era más viva, haciendo uso del carbonato de potasa, conocido en el comercio bajo el nombre de sal de tártaro: varios juzgaron ser preferible el empleo de esos mismos agentes, pero asociados á la cal; otros emplearon éste solamente, y todos, más ó menos, consignaron en sus formularios las proporciones de los ingredientes, el tiempo y modo de hacer la preparación y cuanto créan de.interesante para el tintorero, entre lo cual figuraba, como debe suponerse, ya la riqueza de los colores, ó bien la economía industrial que justamente los preocupaba. En efecto, á esto debe atribuirse la preferencia que hasta hoy dan muchos al empleo de las orinas, no obstante los inconvenientes manipulatorios.

Por lo dicho, es fácil notar que, si los adelantamientos científicos han llegado á descubrir los principios inmediatos de las rocellas, como los de otras varias plantas colorantes, á describirlos y á fijar sus propiedades, muy poco han hecho cambiar los procedimientos industriales. Aún creemos poder decir algo más, y es: que bajo el punto de vista químico, queda mucho por estudiar con relación á algunas propiedades commes á las materias colorantes vegetales y animales. Acaso algunos de los que suscriben este dictamen tengan la oportunidad de dar á conocer con más extensión sus opiniones. Entretanto, indicará la Comisión, brevemente, los trabajos emprendidos, los resultados obtenidos y el juicio que ha formado sobre el particular.

El estudio químico industrial que se les confió, no era el de un cuerpo desconocido, bien al contrario; pocos serán los libros de esos ramos que no se ocupan de la materia colorante de los líquenes, como ya dijimos; así es que la Comisión pudo limitarse simplemente 
á la rectificación de lo que lan dicho los antores. Esto, apoyado con la clasificación botánica, bastaría para dar por concluido su trabajo.

Pero como los experimentos practicados le hicieron notar algurias particularidades, ya contrarias á las opiniones de los antores, ó bien no mencionadas por ellos, prefirió retardar el despacho de su encargo, para repetir aquéllos y, á la rez, resolver algunas dudas. Esto supuesto, expondrá con sencillez lo que le parezca más notable.

Materic colorante.-Están de acuerdo los antores en que ella no existe en los líquenes, y basta, en efecto, ver el vegetal para persuacirse de la verdad.

Pero, ¿cómo se forma, y qué cuerpos ó elementos la producen? Desde luego se comprende que debe existir en todos esos líquenes algún principio inmediato que les es común, supuesto que la matelia colorante es producida por todos, siempre que están sometidos á las mismas condiciones. Los experimentos hechos han dado diversos principios inmediatos, que han recibido varios nombres, derivados por lo comńn de la especie de liquen de que proceden.

Así, se enumeran un producto cristalizado, al que se llama ácido licanórico; la orcina que procede de éste, y también de los ácidos erítrico, evérnico, etc.; la oreilla, confundida eon el tornasol; la orcina que, ya colorida, lleva el nombre de orceína, y cuyos productos toman su origen del principio azucarado que se encuentra en los líquenes. Este es el punto en que se nota más acuerdo en los antores; pero no así en las denominaciones, ni aun en las propiedades de varios principios, como es fácil notar, formando un breve resumen con los datos que nos presentan Dumas, Guibourt, Pelouze y otros. Comencemos por señalar uno de tantos métodos aconsejados para obtener el principio inmediato, llamado lecanorina; por otros, ácido lecanórieo, etc.

Puesto el liquen, después de lavado y dividido, en contacto con el alcohol, á mua temperatura poco elevada, se obtiene mia materia blanca, cristalizada, en pequeños prismas de cuatro caras, que es poco soluble en el éter, insoluble en el agua fría é incolorable; parece que esta es la VAriorarina de Robiquet, ó la Lechyorina de

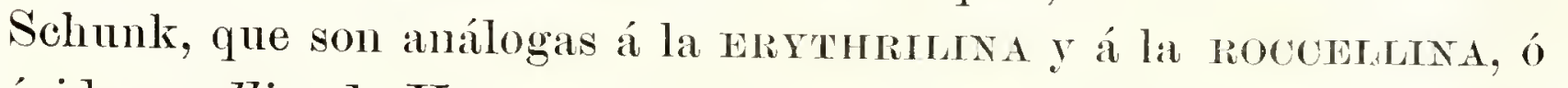
ácido rocellico de Kane, pero diferentes de la erythrinu y de la amarythrina del mismo, supuesto que éstas son materias colorígenas en sí, y aquéllos sólo en condiciones especiales. La muteria aülcurada 
de Robiquet, y la erythrina de Kane, son, á su vez, análogas como colorígenas, pero que difieren en que el principio llamado orceína es azoado, y la orcina no lo es.

Por otra parte, si se comparan los datos que resultan de las análisis de las materias coloridas ya preparadas, ó sean los tres compuestos, llamados por Kane alfo-orceína, beta-orceína y azolitmina, con la orcina de Robiquet, se nota la diferencia en la composición, por faltar á ésta el azoeto.

Si, por otra parte, se trata el toruasol en panes por el agua hirviente, da una materia soluble de color azul, que ha sido llamada spaniolitminu; sometida después la parte insoluble á la acción del ácido clorhídrico, hasta la completa saturación, queda un residuo que, bien lavado y seco, se pone con alcohol hirviente, se filtra, y evaporando la solución, produce un extracto en el cual se encuentran la erythroleinu, que es separable por el éter, en el cual es soluble, $y$ la erythrolitmina, que lo es en alcohol.

Por último, si se trata por el agua amoníacal el residuo que deja el extracto; si se agrega ácido clorhídrico, y al fin el alcohol necesario para separar el exceso de ácido y la sal amoníacal, se obtiene un producto azoado, al cual se ha dado el nombre de azolitmina. Se re, pues, que hay en el tornasol en panes, cuatro principios particulares y diferentes (además de las materias extrañas en que abundi), que han recibido diversos nombres de los producidos directamente por los líquenes.

Sabido es que el tornasol en trapos difiere, en cuanto á su origen, del tornasol en panes; éste procede de rarios líquenes, y aquél del Croton tinctorium ó Chrozofora tinctoria; pero, no obstante esa diferencia, los procedimientos para obtener las materias colorantes, son casi los mismos; mas hay de notable que el color azul del tornasol pasa al rojo por los ácidos, mientras éstos hacen desaparecer el púrpura de los líquenes, obtenido por medio de los álcalis; y á fin de que nada falte para reconocer las multiplicadas dislocaciones, sustituciones y derivaciones de los principios orgánicos, basta tener en cuenta que esos panes azules de tornasol proceden de los mismos líquenes que han dado el púrpura y aun algo más, de esta misma materia colorante sometida por más tiempo á las influencias colorígenas.

Acaso parezca que abusamos al presentar un ejemplo más en 
confirmación de lo dicho, pero to hacemos en solicitud de la mayor claridad. La lecanorina, en condiciones determinadas, produce la materia azucarada; ésta la orcina, que, bajo la influencia del aire, del agna y el ácido carbónico, se convierte en orceína, la que, á su vez, forma orceínatos con los álcalis; compuestos rojos ó púrpuras de materias rariables, pero que, bajo la influencia de los mismos agentes, llega á trasformarse en el azul de tornasol. La presencia ó no del azoeto, la mayor ó menor cantidad de oxígeno y la del ácido carbónico, es lo que establece las diferencias en esos derivados.

Podemos concluir, fundados en todo lo dicho, que examinadas atentamente la composición, las propiedades y las modificaciones de que son susceptibles los principios inmediatos de los líquenes, y á los que se han dado varias denominaciones, llegan á producir uno azucarado, cuyos compuestos salinos son coloridos, ya se llamen lithmatos, orceínatos, lecanoratos, etc., etc.

Dando por concluidas estas indicaciones generales, pasemos á las particulares, referentes á nuestra Roccella fusiformis.

No obstante haber reunido varias muestras del pasto de ocotillo, no logramos contar con una cantidad suficiente para los diversos experimentos que convenía hacer en el orden químico, ni menos, por lo mismo, los correspondientes al industrial. No obstante, creemos poder anunciar algunos datos, que sean acaso rectificados por las personas que se hallan en condiciones favorables para proporcionarse alguna cantidad del regetal. Entretanto, diremos que las reacciones, los principios inmediatos y demás correspondientes á nuestro liquen, difieren poco respecto de lo que indican los autores al tratar de las otras especies de Roccella. Hay, sin embargo, dos cosas que debemos mencionar en este lugar, porque son relativas á las materias colorantes.

Nuestra Roccella contiene, como las otras especies, la materia verde ó clorofila, de que hacen mención los autores; pero encontramos, además, otra amarilla, abundante, muy soluble en el alcohol; para obtenerla, basta tratar por este rehículo los residnos del liquen que ha servido para extraer la roja por el agna; de manera que, si después de lavada y diridida, la planta se somete á la acción del alcohol caliente, éste disuelve la clorofila, así como la lecanorina y demás principios productores de la materia roja. Pero si el liquen sólo ha sido tratado por el agua hirviente, queda disuelto el princi- 
pio colorable, y el residuo se extrae después por el alcohol, la materia colorante de un amarillo claro, la cual presumimos que ha de existir en las otras especies de líquenes, sin que sea rara ni exclusiva de ellos la existencia del amarillo y el rojo, como vemos que existen en nuestro azafranillo (Chartamus tinctorium). Tenemos, por tanto, en el pasto del ocotillo, tres materias colorantes por sí; la verde y amarilla, y una que, aunque no colorida, produce sales de tintas rojas diferentes. No sin objeto omitimes, respecto del ocotillo, el mencionar el azul de tornasol; es porque no hemos logrado obtenerlo por ninguno de los métodos recomendados, lo cual, acaso, haya dependido de la corta cantidad de liquen ó alguna otra cosa que sería necesaria descubrir por repetidos experimentos.

Todos los procedimientos aconsejados hasta ahora, dan definitivamente buenos resultados á la extracción del rojo de ocotillo: las diferencias pueden reducirse á tres principales, yson relativas: $1 .^{\circ}$, al rendimiento; 2. ${ }^{\circ}$, á la fuerza ó brillo del color, y 3. ${ }^{\circ}$, al tiempo necesario para obtener éste. En cuanto á lo primero, hemos notado que no es necesaria la extremada división de la planta, como aconsejan algunos, que la trituración la altera, y que los colores obtenidos son menos limpios, sin que por ello aumente la cantidad del producto: basta cortar la planta en pequeños pedazos, después de haberla lavado, para quitar las materias terrosas $y$ demás extraños que manchan los colores. El método que algunos recomiendan păra obtenerlos limpios, y que consiste en frotar el liquen en una criba, para separar el polvillo, productor de la materia colorante de la fibra vegetal, es el que rinde menos, sin notable diferencia en el tono de la tinta; hemos observado á la vez, que el residuo herbáceo, obtenido por este método, es susceptible de producir materia colorante, amque de inferior calidad. Lo que principalmente influye en el mayor ó menor rendimiento, además de la especie de liquen, su desarrollo, recolección y conservación, es la naturaleza de las bases empleadas, la localidad, la temperatura y el tiempo que dure la operación: un lugar suficientemente rentilado, con buena luz y una temperatura de $+15^{\circ}$ y mejor á $+30^{\circ}$, son las condiciones que más favorecen los resultados. En cuanto á la naturaleza de las bases, tenemos necesidad de hacer algunas observaciones.

En primer lugar, diremosque, tanto las alcalinas, como las alcalino-terrosas, producen la materia colorida; así es quela potasa, sosa, amo- 
níaco, cal y barita, la dan con más 6 menos prontitud de tonos variados y en la misma proporción. Pero hay que notar, que no conviene usar los álcalis cáusticos, pues son muy preferibles los carbonatos. Se dice que la adición de la cal es útil, porque hace que se desprenda el amoníaco, cuando éste ha sido empleado en la preparación del color; mas tal teoría carece de fundamento, como es fácil demostrar. El principio colorígeno, en contacto con el carbonato de amoníaco, determina la combinación de éste y la separación, dislocación ó combinación particular del ácido carbónico; ya sea como radical, 6 bien por sus elementos, favorece las reacciones. Como prineba de esto, citaremos uno de los experimentos hechos con otro fin.

Conrenía observar hasta qué punto era preferible el empleo de los carbonatos, al de los álcalis cáusticos, y por otra parte, la influencia del aire en las reacciones de esas bases, en contacto con el ocoti1lo. Parai ello fué puesta una cantidad de este carbonato de sosa, pero en una atmósfera carbónica, totalmente privada de aire; las reacciones se verificaron como si éste no hubiera faltado, y se obtuvo la materia colorida; en consecuencia, parece claro que la acción del airee, más bien influye por la corta cantidad de ácido carbónico que contiene, que por la acción de los elementos oxígeno y azote.

Esto explica también el hecho observado aun por los industriales, de que el mayor 6 menor tiempo, es favorable á la formación del color producido por̀ el liquen; y como, por otra parte, la sosa cáustica no lo produjo con la facilidad que el carbonato, es seguro que deben ser preferidas estas sales. Pero aún hay más: los químicos han notado que en las reacciones, para obtener algunos de los principios inmediatos, contenidos en los líquenes, hay desprendimiento de ácido carbónico; ¿cómo conciliar esto con el hecho de haber obtenido la materia colorante, en una atmósfera carbónica, y con la práctica tan antigua y común de procurar una fermentación urinosa, productora abundante do ese gas ácido?

Fácil es darse razón de todo, ocurriendo á las doctrinas generales de la ciencia.

Hay que distinguir diversos tiempos en las reacciones que se rerifican para llegar al resultado final, es decir, á obtenerse la materia colorida: uno de los primeros y principales, es el aislar, según unos, ó acidificar, según otros; el de formar con ellos las combinaciones salinas que constituyen la materia colorida: en la primera reacción, la 
presencia del ácido carbónico es favorable como medio, ó radical dislocador, ó bien como sobre saturante: en la segunda, como constituyente de un compuesto que favorece la producción de la sal colorida. ¿Quién no recuerda los buenos efectos debidos á las dobles descomposiciones? Esto es lo que pasa, sin duda, en tales casos.

Ocupémonos ahora de las bases preferibles para obtener la materia colorante roja. Fundados en los experimentos hechos, colocarros, en primer lugar, el carbonato de sosa: su precio cómodo, la facilidad con que se consigue puro, la que tiene para cristalizar el compnesto salino, como se re en la muestra que presentamos, la limpieza del color y la economía en tiempo para obtenerlo, son cualidades que se recomiendan. Ponemos en segundo lugar la potasa, porque también ofrece economías; la lejía de ceniza obtenida por desalojamiento, á la temperatura ordinaria, prodnce buenos resultados; la adición de una poca de lechada, una vez formada la materia colorida, mejora la tinta. En cuanto al carbonato de amoníaco, si se emplea el del comercio, es costoso, y si el de las orinas, es repugnante.

Con respecto á los alcalinos terrosos, sólo habría que considerar la cal; pero ya hemos dicho que son preferibles los carbonatos, pues no sirviendo el de cal, por ser insoluble, y necesitándose más tiempo si se usa la lechada, está claro que no ofrece ventajas, si no es como auxiliar en los casos indicados.

Con lo dicho, quedan establecidas las reglas principales para fac:litar el rendimiento mayor del compuesto colorido, la pureza y brillo de los colores, y los medios para economizar el tiempo. Diremos ahora unas cuantas palabras respecto de la acción del fuego sobre el pasto del ocotillo. Sabido es que existen en varios vegetales, algunos principios inmediatos cristalizables, que pueden ser obtenidos por sublimación; pero nuestra Roccella ninguno ha dado de ese género, sino únicamente los pirogenados comunes; es decir, agna, ácido acético, aceites ligero y pesado, volátiles á diversos grados, gases hidro y oxicarbonados y residuo carbonoso. No contando con la cantidad suficiente del vegetal para reconocer debidamente los productos de la incineración, sólo pudimos observar indicaciones relativas á la existencia de silicatos, sulfatos, cloruros y carbonatos de cal, de magnesia y de sosa; acaso contengan, además, potasa y ácido fosfórico, pero no estamos seguros de ello.

La Comisión ha creído conveniente el poner á la vista de los se- 
ñores socios, tanto el liquen que ya vieron, pero que no había sido clasificado, como algunos de los productos obtenidos, entre los cuales se puede notar la forma cristalina que afectan y que, en general, corresponde al primer sistema regular, así como los agrupamientos casi constantes en plumas ó en estrellas. Entre las sales coloridas, la que cristaliza con más facilidad, no obstante de ser higroscópica, es la obtenida por la sosa; á ésta sigue la amoníacal, y al fin la de potasa.

De todo lo dicho, resulta: que el liquen tintoreal, que vegeta en la Baja California y en otros lugares de la República, llamado orchilla y también pasto de ocotillo, es de la familia de los Líquenes Roccella fusiformis de Acharius, variedad linewris, que suele hallarse mezclada con alguna otra de las especies ó variedades de Roccellr; que en la colectación no se cuida del estado y edad de la planta, de lo cual resulta, que el poder colorante varía, siendo tanto menor, cuanto que las plantas sean más tiernas; que la composición, propiedades y usos del ocotillo; son semejantes á la de la Roccella tintórea; que para obtener las materias colorantes, roja, violeta, etc., pueden usarse los medios y métodos que aconsejan los autores; mas teniendo en cuenta que es preferible el empleo de carbonatos de sosa, y que la temperatura, las aguas carbónicas y una ätmósfera carbonatada, favorecen las reacciones y economizan tiempo; que lejos de ser favorable la extremada división del liquen es más bien perjudicial; que en los residuos del liquen que ha servido para la extracción del rojo, se encuentra $y$ puede obtenerse fácilmente una materia colorante amarilla, $y$ por último, que la cantidad de los principios colorígenos es tanto más abundante, cuanto mayor es el desarrollo de la parásita.

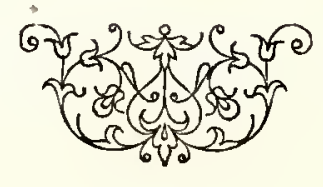




\section{APUNTES}

SOBRE

\section{ALGUNOS PRODUOTOS DEL MAGUEY}

Nuestros apreciables amigos, los Sres. D. Leopoldo Río de la Loza y D. Francisco Pimentel, se han dignado favorecernos con los artículos siguientes:

«Todo el que conozca la historia de esta preciosísima planta, que sepa las innumerables aplicaciones que hacían de ella los antiguos indígenas y que medite en tantas otras de que es susceptible, así como en los medios de mejorar las producciones que actualmente se emplean, no pueden prescindir del interés que conduce á un examen atento, de cuanto se relaciona con tan importante regetal, ó cuando menos al que inspira el conocimiento de los resultados obtenidos por los que de él se han ocupado.

No obstante todo lo que se sabe, es fácil convenir, en que el maguey y sus productos, aún no están suficientemente apreciados ni explotados; que bajo el punto de vista científico, tanto botánico, como médico y químico, tiene mucho que estudiar; que cada especie, cada variedad, presenta diferencias en cuanto á la edad, producciones, naturaleza de éstas y rendimientos; que dada una especie, esas diferencias son también relativas á las influencias meteorológicas y geológicas; que rigorosamente hablando, aún no se conocen suficientemente los productos de los magueyes cultivados; que el fermento propio deljugo azucarado es sui generis; y en fin, que á la abundancia y propiedad acidificante que lo caracteriza, se debe probablemente la fácil alteración del pulque. $\mathrm{Y}$ si á estas alteraciones se agregan las que ponen en práctica los negociantes de mala fe, será fácil conocer la dificultad de fijar á esa bebida fermentada una composición contante. 
Hace algunos años que me limité á dar un promedio, sirviéndome de los pulques de las casillas y de algunos tomados al descargar los arrieros 6 conductores, proponiéndome aprovechar la primera oportunidad para examinar las aguamieles y el licor fermentado, pero recogido en los tinacales ó bodegas de depósito: aunque no he logrado esto último, ni reconocido el aguamiel de Apan, presentaré algunos datos, que serrirán acaso como indicante para que otros emprendan trabajos más completos.

\section{JUGO AZUCARADO O AGUAMIEL.}

La que sirrió en Septiembre de 1858, fué tomada á una legua, poco más al N. N. O. de esta Capital, de magueyes en buena vegetación, cultirados en los bordes de los ríos, cuyo terreno es arcillo-arenoso-calcáreo. Las plantas se hallaban en la época correspondiente á lo que llaman media rospu, y el aguamiel se recogió á las ocho de la mañana, es decir, dos horas después de separada la de la noche, para evitar que esturiera diluida por el agua de las lluvias. Las clases de magueyes fueron tres, conocidas rulgarmente con los siguientes nombres:

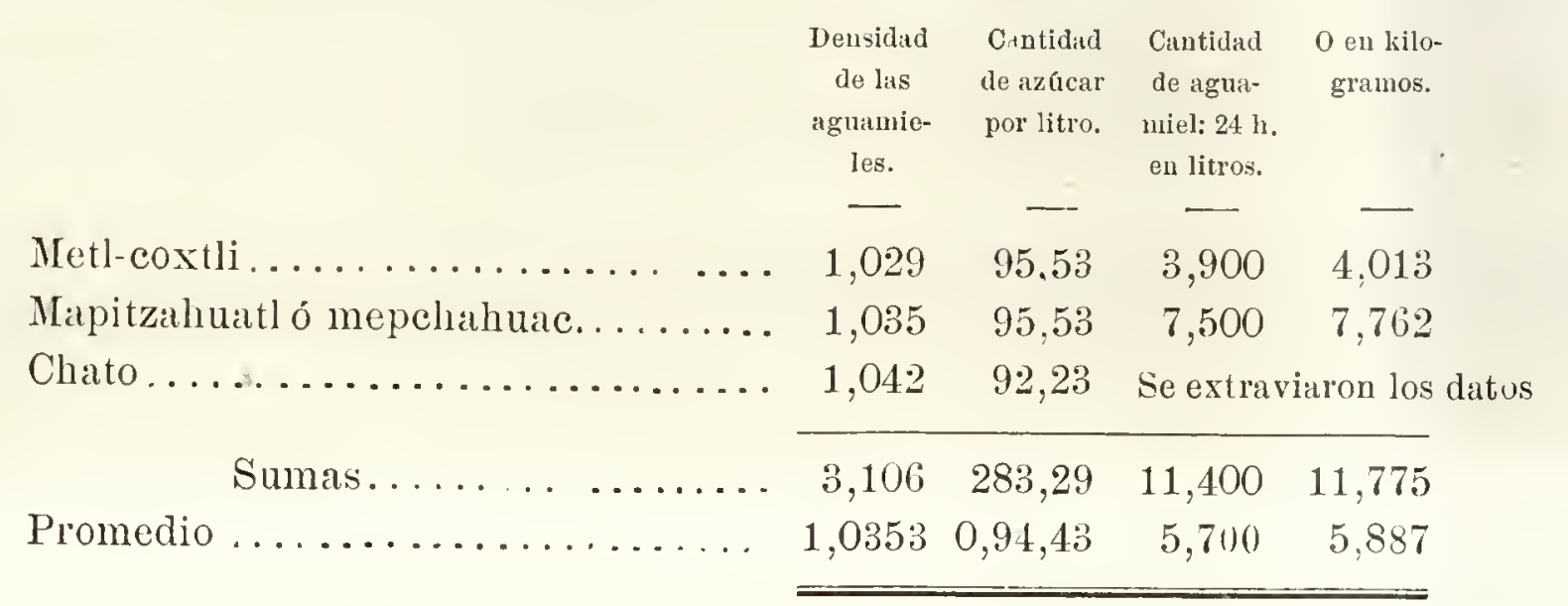

Estos trabajos los emprendí el 17 de Septiembre y siguientes, en la Escuela de Agricultura, de la que era Director, auxiliado por el preparador de la clase de química, profesor Carmona, y en presencii del catedrático de agrieultura, D. F. de León Oollantes, y de los cursantes de su clase, D. A. Herrera, D. N. Aguirre, D. I. Parón y D. T. Zárate. 
En atención á que, tanto al comenzar, como al concluir las raspas, producen los magueyes menor cantidad de aguamiel, ýa las notables diferencias relativas al tiempo que están en fruto, pues hay unos que sólo la dan en un mes, otros, cuatro ó seis, y algunos hasta ocho ó nueve, tomaré como término medio, ciento veinte días y supondré que uno con otro producen cinco litros cada día, formando un total de seiscientos litros, 6 sean en solo entero, seiscientos veintiún kilogramos, como cantidad total del jugo azucarado, equivalente á cincuenta y seis kilogramos de azúcar, conforme á los promedios anteriores. Es de presumir que los rendimientos de los magueyes de A pan, así como los de todas las otras localidades, más adecuadas al cultivo de la planta, sean mayores; pero aun sin esto, las utilidades serán muy superiores á las de cualquier empresa agrícola.

El examen microscópico del agnamiel y el empleo de los agentes y de los reactivos convenientes, ha indicado, además de la presencia del arúcar, la del agua y la de las sustancias albuminoides, cuya reproducción es perceptible, así como la de las reacciones que las caracterizan. Cien partes han dado:

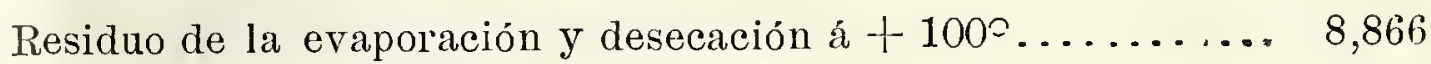

Residuo de la incineración ..................... 0,726

Goma y albúmina, precipitada por el alcohol absoluto .... .. 0,540

Materia resinosa, obtenida por el éter y soluble en el alcohol, cantidad indeterminada.

En las cenizas se encontraron potasa en cantidad notable; sosa, poca cal y magnesia; poca alúmina, cloro, ácidos carbónicos, sulfúrico, fosfórico y silícico.

Pudiera admitirse, juzgando por la cantidad de los precipitados y por las afinidades relativas, que esos radicales existen combinados al estado de sulfato y fosfato de cal, silicatos de potasa y de alúmina, carbonatos de potasa y de alúmina, carbonatos de potasa, de sosa y cloruro de magnesio. Igualmente podría admitirse, en vista de todos los resultados obtenidos al examinar el aguamiel y como término medio, que cien partes de éstas, contienen:

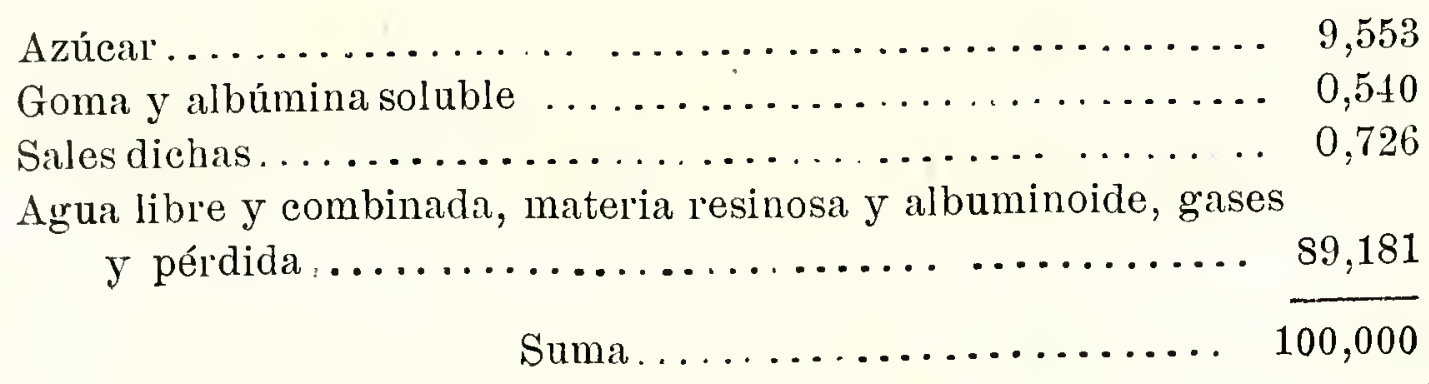


Se ve, por lo dicho, que la cantidad de arúcar contenida en el aguamiel, es igual á la que da químicamente el zumo de las buenas remolachas.

Creo suficientes estos datos para seguir más adelante una marcha sistemada, estimando separadamente, si se quiere, cada una de las sustancias designadas en complexo. Mas por imperfectos que se supongan estos resultados, ellos bastan para sacar las consecuencias necesarias, tanto médicas como industriales.

El médico prede prescribir ó bien proscribir, con fundamento, el uso de la miel de magney y de su derivado, quo es el pulque, sabiendo que en la primera encuentra sustanciłs analépticas, diuréticas, edulcicorantes, etc, y que en el pulque debe èstimar, además, el alcohol, el ácido acético libre y combinado, así como el fermento. A su vez, el industrial hallará los datos precisos y exactos para calcular, según los rendimientos, ya en azúcar ó bien en pulque, si le conviene más fabricar la primera, segnir con el expendio del segundo, 6 bien, según yo creo, aumentar sus plantaciones y abrazar los dos ramos á la vez; pues aunque debe tener en cuenta que, industrialmente, no se obtiene toda la azícar contenida en un jugo dado, sí es de suponer que con el aguamiel conseguirá un ocho por ciento, entre azícar y melaza.

Confirmará igualmente, por los datos que le presento, que uno de los abonos, ó sean mejoradores de los magueyales, son las cenizas vegetales, y que entre éstas debe preferir las de las pencas de las mismas plantas, que en su poda, y más aún en su muerte, las ministran en abundancia.

Debe inferir, por último, que los componentes más apreciables del aguamiel, serán tanto más abundantes y de mejor calidad, cuanto más atendido sea el cultivo, proporcionándose al mismo tiempo una economía de éste en el de su crecimiento y sazón ó raspa. Para mayor seguridad en el juicio, conriene pasar al examen del producto sacarino.

\section{AZÚCAR DE MAGUEY.}

Los antiguos inđágenas, no sólo apreciaron el aguamiel, tanto reciente como fermentada, ó convertida en pulque: también la evaporaban para formar un jarabe espeso, conocido con el nombre de miel 
de maguey, una especie de azúcar morena, que, aun después de la conquista y actualmente, se prepara y consume en las localidades adonde regeta esa preciosísima planta, $y$ finalmente, un rinagre usado como refrigerante, $y$ lo que aún llaman tortillas de maguey.

El Dr. Hernández hace mérito de ello, en la página 253, libro 7. ${ }^{\circ}$ de su obra. Dice, entre otras cosas, hablando dei maguey: "Succus destillatione fit dulcior decoccione vero et dulcior et spission, donec tandem congatur in saccharum ..... E saccharo, quod ex adem succo cogitur parant acetum nempe, resoluto exaqua et noven diebus insolato."

No obstante esto, creo que no se había intentado seriamente la purificación del azúcar de maguey, hasta que los Señores Pontones y Chousal la procuraron, obteniendo después un privilegio exclusivo.

He aquí lo que escribí en Septiembre de 1858, época en que hicieron la solicitud:

«Hay algunas empresas, ideas ó acontecimientos, que aunque por distintos motivos llaman la atención de la sociedad, y aun sin roluntad ni intención se ocupan de ellos á la vez, el entusiasmo se propaga con admirable rapidez, y más ó menos duradero, tiene, como todas las cosas, su declinación y su fin.

La indiferencia es el último término de esa especie de conmoción, que invade, según su importancia, sea á una familia, á una ciudad, á una nación ó al inundo todo.

$Y$ aunque esto ha sido siempre, no podrá negarse que el siglo actual es fecundo en acontecimientos y casi todos de la mayor importancia.

La Nación Mexicana, aunque nueva entre las demás, no ha sido menos, $y$ aun es preciso convenir en que su infancia es toda de actividad y de constancia: guiada por el ejemplo de las que le han precedido, no sólo las sigue en su marcha, sino que aspira á colocarse aI nivel de ellas, teniendo que combatir con los antiguos hábitos de algunos de sus hijos, con la apatía y el egoísmo de otros, y con las exageradas aspiraciones de muchos, cuya única opinión, cuya única mira, es el vivir á costa de la parte productora y laboriosa de la sociedad.

He aquí, por desgracia, el estado normal de este país.

Sin embargo, y aunque aún sufie las fatales consecuencias de las guerras intestinas, las nuevas vías de comunicación, el estudio y co- 
nocimiento del país, el desarrollo de varias industrias y los acontecimientos más notables, son las ocupaciones preferentes de los hombres que conocen mejor los medios más eficaces para destruir el espíritu revolucionario y para elevar al país á la altura á que debe colocarse.

La extracción de la azúcar de maguey, es una de las industrias que, no sin razón, preocupa en este momento á muchos.*

Los propietarios de las haciendas de caña temen á un poderoso rival; los de las de pulques, sienten que un privilegio les prive, por algunos años, de los beneficios que pudieran ellos tener; los comerciantes aguardan una baja del efecto, como consecuencia de la abundancia que suponen ha de haber; los consumidores afirman, aunque sin conocer el producto, que la clase del azúcar no ha de ser buena, por su mal sabor; los médicos piensan proscribirla de sus formularios y colocarla entre los irritantes; unos aseguran que no es producto nuevo, otros que sí; los interesados apuran sus alegatos; los abogados escriben suplementos; el gobierno se encuentra indeciso, ocurre á los peritos, y todos los interesados, ya directa ó ya indirectamente, se hallan á la expectativa de la resolución final, porque, como indiqué al principio, hay empresas que llaman la atención de muchos.

Yo, entretanto, no he debido despreciar la oportunidad, y estudiando el valor sacarimétrico del aguamiel y algunos otros zumos regetales, examiné, también con mi amigo el Sr. D. Luis Varela, las tres muestras de azúcar de maguey, presentadas al gobierno por los Sres. Pontones y Chousal, así como una cuarta de otra superior de caña, resultando de esos trabajos el siguiente promedio:

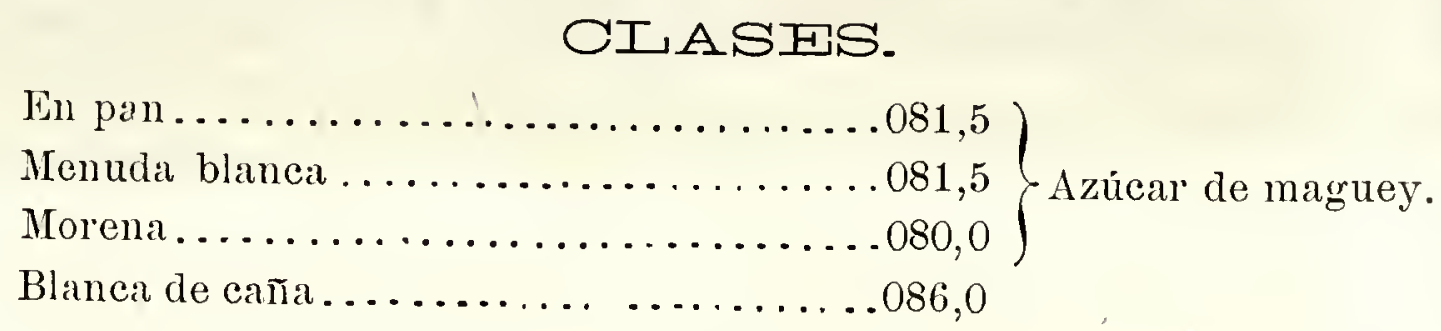

Aunque estos datos bastan para conocer que el maguey da una azúcar tan útil como la de caña, agregaré hoy, que continuando sus trabajos el Sr. Pontones, presentó más tarde, no sólo los derivados más usados del azúcar, como el piloncillo, el aguardiente y el vinagre, sino ann la candi, perfectamente limpia y cristalizada.

* En 1858. 
Decidido, por tanto, que el jugo de nuestros magueyes produce una azúcar que ocupa el segundo lugar entre las del comercio, natural es indagar, como ya indiqué, si su explotación es conveniente, industrialmentejuzgando. Para resolver esta cuestión, hay que considerar, entre otras cosas, dos como principales.

La primera es la comparación entre los rendimientos del aguamiel convertida en pulque, con los del mismo zumo transformado en azúcar. La ségunda, la facilidad ó dificultad para establecer este nuevo ramo productor.

Creo, en cuanto á la primera, que si los magueyales han de permanecer en el estado de abandono en que hoy se hallan; si la práctica racional y los conocimientos agrícolas no han de tener aplicaciones; si los plantíos no se multiplican, y, sobre todo, si los propietarios y los arrendatarios sólo han de contar con los escasos brazos de que hoy pueden disponer, es, sin duda, preferible continuar con la explotación del pulque y no pensar en la del azúcar.

Mas si tales inconvenientes desaparecen, basta un cálculo sencillo para decidirse por lo contrario. Yo lo he formado, agregando á los datos indicados, los del costo de cada maguey, desde su plantación hasta su raspa; el promedio de sus productos en aguamiel y, por lo mismo, en azúcar; los gastos de fabricación, expendio, etc., resultando de todo, que los empresarios pueden contar, por este medio, con el rédito anual de un cincuenta por ciento.

En contra de esta halagüeña idea, hay que oponer las consideraciones relativas á la segunda de las cuestiones propuestas.

En efecto, la falta de población laboriosa, á saber, de brazos secundarios, es un obstáculo de grande importancia para las empresas de este género. Puede asegurarse que todos los ramos de explotación agrícola tropiezan actualmente con esta dificultad, lrasta el punto de tener que limitar sus labores á menos de lo que permite la extensión de sus terrenos.

Pero aún hay más: esos brazos secundarios, á los que acaso puede confiarse una labor, no tienen, en general, la misma disposición para la industria azucarera.

Ésta requiere, además, un capital proporcionado para la buena elaboración de los productos, ó sea el establecimiento para la fabricación; y debe tenerse presente, que pocos han de ser los que cuenten con la posibilidad para ello. 
Por último, antes he indicado que al público repugnaría este efecto, preocupado más de lo debido por sólo su procedencia, cosa que no es nueva en su género, porque así sucedió con la de la remolacha. Presumo, sin embargo, que llegará un día en que el azúcar de maguey, su alcohol y su vinagre, figuren en el comercio como hoy figuran los productos de la caña.*

\section{VINO DE MAGUEY, PULQUE O NEUTLI.}

Si no es fácil hallar en el comercio vinos de ura no adulterados, es más difícil encontrar el de maguey, tal como debía ser, no obstante que su bajo precio sería una garantía que alejara todo temor de fraude. Pero el hecho es, que son tantas y variadas las materias que se encuentran en los pulques del comercio, que se llega á perder la paciencia, con el convencimiento de que no es fácil fijar ni el promedio de su composición, aun con respecto á las partes esenciales, como son el alcohol, agua, azúcar, mucílago, fermento, etc. Parece, en efecto, que cada vendedor al menudeo tiene sus fórmulas particulares ó las materias predilectas de que hace uso, según el estado en que reciben los pulques, el rezago que de ellos tienen y aun la presunción, conforme á su experiencia, de la mayor ó menor salida del efecto.

La cal, el agua, el almidón, harina, la goma, el tequezquite y algunós regetales más ó menos inocentes ó nocivos, son comúnmente de los que más uso hacen para encubrir, ya la mucha fluidez, la acidez y hasta la corrupción de la bebida fermentada: esto sin contar con el abuso de los conductores, que consiste en la adición de diversas aguas más 6 menos impuras, $y$ sin hacer mérito de las modificaciones naturales relativas á las estaciones, como son las lluvias y, sobre todo, la elevación de la temperatura, que tanto violenta la alteración del producto.

No obstante lo dicho, hay en la capital algunas casillas establecidas por propietarios de las haciendas $y$ de los ranchos que prestan mayor garantía, en cuanto á no tener esa bebida sustancias extrañas perjudiciales á la salud, aunque en general no le faltan las de las aguas de que se sirven los conductores.

\footnotetext{
* Esa presunción se ha realizado en parte, puesto que aetualmente se consumen en la plaza algunos barriles de aguardiente de maguey, adcmás del eonoeido tiempo ha eon el nombre de mezcal.
} 
De la misma clase se encuentran en los expendios de algunos de los contratistas, principalmente cuando se procura el pulque á las primeras horas en que reciben la carga; pero en la mayoría de las otras casillas, son tan notables las alteraciones de esa bebida, que llega á percibirse al olfato la presencia del ácido sulfhídrico y de sulfhidratos, y el líquido se ennegrece, dejándolo en vasijas de barro vidriadas, cuyo barniz, como se sabe, es un silicato de plomo.

Si por estos fraudes y aun sin ellos, la sola fermentación que se desarrolla no modificara y alterara el jugo azucarado producido por las plantas, es claro que, conocida la composición del aguamiel, lo estaría igualmente la del pulque. Mas no siendo así, se hace indispensable: primero, el examen del pulque en los tinccales: segundo, el del que se recibe en las garitas ó al llegar á las pulquerías: tercero, el de varias muestras de diversas casillas, tomado principalmente en las tardes, que es cuando, por lo común, se halla más alterado; y cuarto, el de los de Enero, Mayo y Agosto, que son los meses en que principalmente se advierten las alteraciones estacionales.

Entretanto que esto se realiza, presentaré algunos datos tomados de los que en distintas épocas me han dado los trabajos emprendidos, en el concepto de que aún no he logrado examinar el producto recogido en los tinacales ó bodegas destinadas á la fermentación y depósito.

Densidad.-Es tan variable como lo son la cantidad de gases y la del sedimento que contienen los pulques, pues que la modifican notoriamente: he aquí lo que ha dado en las condiciones que se indican:

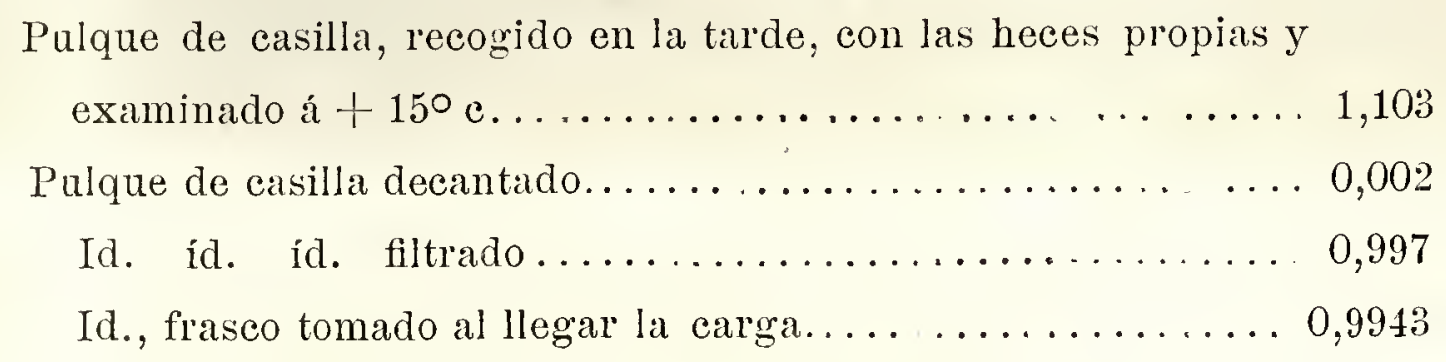

Es de advertir que este último marcó dos grados al aerómetro, lo cual confirma la influencia de los gases en el método de la doble pesada.

Examex miroscóprco.-El pulque fresco, tal como se recibe de los conductores, deja ver las sustancias albuminoides, bajo la forma 
de filamentos ya existentes y de otros que se forman por la unión de pequeños globulillos, que agregándose en un sentido, aparecen como fibras, que á su vez se unen, tomando el aspecto de radículas ó de pequeñas arborizaciones; algunas se agrupan en masas, y entre unos y otros hay glóbulos mayores oscuros, con pequeños núcleos luminosos. El yodo determina débilmente la coloración azul, que es más apreciable si previamente se hierve el líquido.

Examen sacarméterico.-El pulque es más ó menos polarisante, según las condiciones en que se toma; pero debo advertir que este carácter no prueba por sí solo la existencia del azúcar; depende más comúmmente de la presencia de la albúmina. No obstante, privado de las materias extrañas y sirviéndose del licor fresco, suele hallarse alguna cantidad muy varia de azúcar; yo he obtenido una indicación correspondiente á 8,23 por litro; pero lo mejor para asegurarse de la existencia de la azúcar, es el preferir los reactivos químicos, á fin de persuadirse de que no es común hallarla, si es en condiciones determinadas.

ACCIón DeL CALÓ RICO Y DE LOS REACTIVOS.-El pulque se aclara un poco, formando una espuma viscosa, precipitando las materias en suspensión, y desprendiendo los gases con el olor característico y algo alcoholizado del licor. Aunque la cantidad de estos gases es muy varia, puede estimarse, como más común, por litro y reducida á o.t.

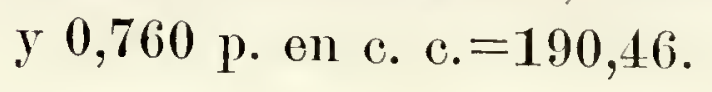

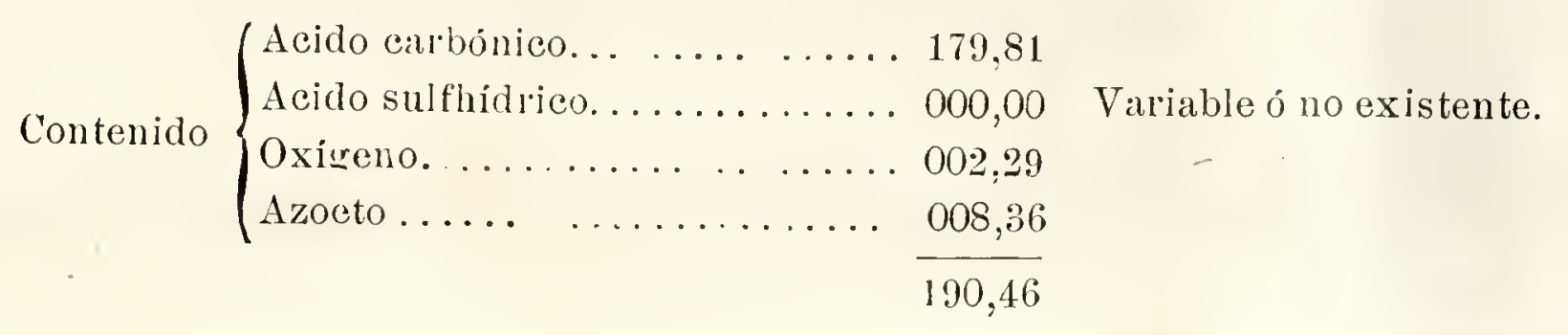

Alconor.-Destilado convenientemente al pulque fresco de casilla, da diversas cantidades de alcohol, según la del agua adicionada y de la mayor acidez; pero en general, puede estimarse como resultado de varias operaciones y en alcohol absoluto, de veinticinco á cuarenta gramos por litro.

Evaporados cien gramos de pulque hasta la desecación á $+100^{\circ}$ C., han dado: 


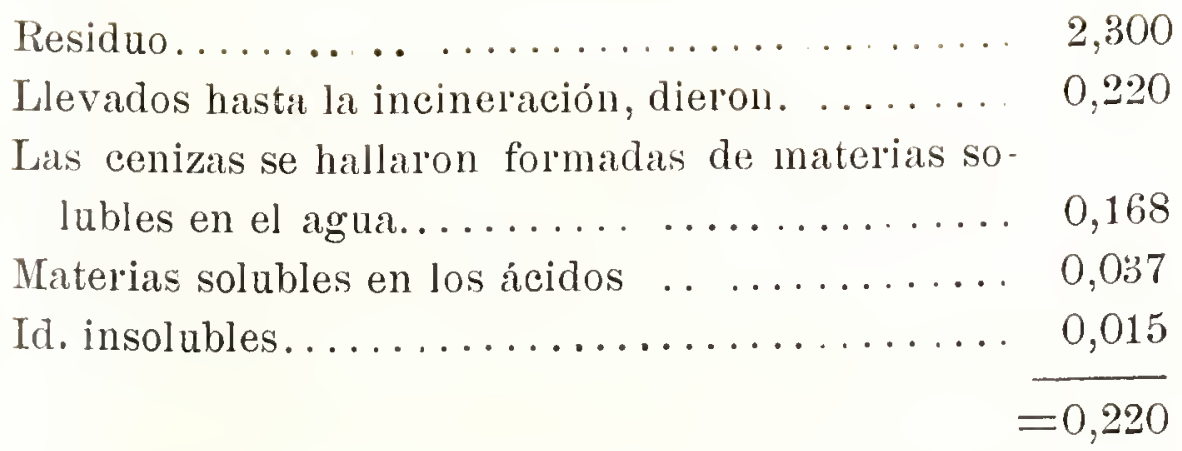

Las substancias que forman las cenizas, sólo difieren, por la cantidad, de las que se hallaron en el aguamiel, pero no por su naturaleza; así es que, como en ella, el carbonato de potasa es el dominante.

Conviene también notar, que filtrados por el papel cien gramos de pulque, dieron dos decigramos de residuo, formado por las substancias albuminoides que aparecen en el microscopio, las cuales producen la proteína y las reacciones correspondientes, á saber: coloración azulada con el ácido clorhídrico, solución en la potasa, precipitación por el ácido acético y formación del ácido xanto-proteico característico. El alcohol absoluto precipita la goma y disuelve la materia resinosa, que á la rez separa el agua: el éter la separa también del mismo modo.

La reacción del pulque sobre los colores regetales es constantemente ácida, y tanto más activa cuanto más tiempo tiene; el herror no destruye esa propiedad. El fermento natural del licor tiene tal disposición á despertar á la vez la fermentación alcohólica y la acética, que al salir del maguey, es decir, cuando apenas está iniciada la fermentación, la reacción ácida es mayor de la que corresponde á sólo la presencia del ácido carbónico: así es que un estudio cuidadoso del fermento, riéndolo bajo todos sus aspectos, así como el del principio aromático, que alguno considera como aceite rolátil acre, y por último, el de la materia resinosa sería muy útil, sin duda.

Pudiera inferirse, en el supresto de que el licol turiera ma composición constante y supuestos también los datos antedichos, que hay en un litro:

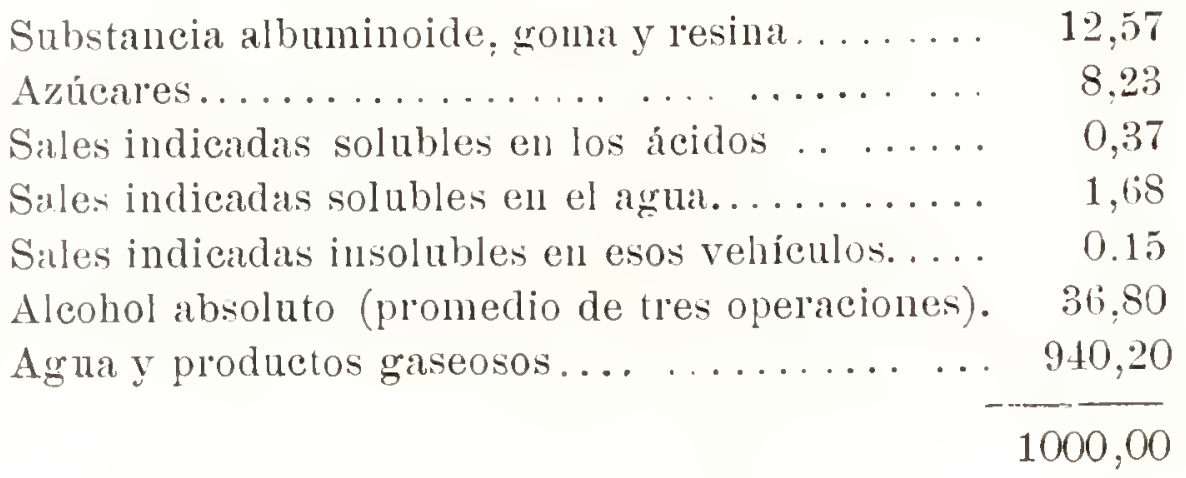


Juzgo oportuno el formar un cuadro comparativo de la composición del aguamiel y del pulque, miendo prudenciahmente, bajo de un rubro, los productos de cada líquido, estimados en mil partes.

\begin{tabular}{|c|c|c|}
\hline & A guamiel. & Pulque. \\
\hline Substancias albuminoides, goma y resina. & 25,40 & 12,57 \\
\hline Azúcares............. & 95,53 & 8,23 \\
\hline Sales................ & 7,26 & 2,20 \\
\hline Alcohol absoluto........... & 0,00 & 36,80 \\
\hline \multirow[t]{2}{*}{ Agua, gáses y pérdida } & 871,81 & $9+0,20$ \\
\hline & 1000,00 & 1000,00 \\
\hline
\end{tabular}

\section{LA GOMA DEL MAGUEY.}

Ėl señor presidente de la comisión científica remitió, con fecha 13 del mes próximo pasado, á la sección físico-química, unos diez ó doce gramos de goma de magney, que el que subscribe se encargó de examinar, en atención al corto núnero de personas con que cuenta la sección, y á que las pocas que concurren á los trabajos ya tienen designados aquellos á que cada mo se ha de ocupar.

Sabido es que la ggoma que producen los magueyes ha sido usada hace muclo tiempo para la preparación de las tintas, ya sola ó ya mezclada con la de los árboles frutales, con la cual tiene semejanza, ó bien, annque laras reces, con la del mezquite ó mezquitl (Inga circinclis), según la malicia ó la riveza de los colectores. Su color obscuro, y aun casi negro, la abundancia de cnerpos extraños adheridos á la goma y el no disolverse con la facilidad que la del mezquite, han hecho que se rea con desprecio por los industriales, quienes la consumen, sin embargo, en las épocas en que escasea la de buena calidad, ó bien estimulados por el ínfimo precio á que la consiguen.

Parece que los antignos indígenas la usaban como medicinal, pues se sabe que hacían dirersas aplicaciones de todos los productos del maguer. Veamos las propiedades de la goma, que dan estos preciosos regetales con que la naturaleza lua enriquecido aun la parte menos fértil de nuestro vasto territorio.

CAracteres Exteriores. - La goma de maguey tiene, por su aspecto, mucha analogía con la de los guindos, de los cirnelos, duraz- 
nos, capulines y demás frutales. Su color es comúnmente obscuro, aunque de tintas variables, desde el amarillo de ámbar liasta el rojo muy obscuro: la forma es en granos de varios tamaños, más ó menos esféricos ú ovales, á veces en lágrimas ó vermiculados, lisos ó rugosos ó más comúnmente mamelonados, con diversos cuerpos extraños leñosos y terrosos, tanto adheridos á la superficie como interpuestos en su masa: la quebradura es vidriosa y más ó menos transparente: el sabor, muy débilmente estíptico; después de algún tiempo se disuelve en la saliva.

DENsIDAD. - Varía según las cantidades de las materias extrañas, principalmente las terrosas; el promedio de tres operaciones ha dado, á $+15^{\circ}$ O., 1,31 .

Higroscopicidad, - No es notable; la que ha estado abandonada al aire húmedo de la estación actual, perdió, sobre cien partes $y$ á $+100 \circ$ C., 007,00 .

SolubILIDAD. - Variable también por las materias extrañas: á la temperatura ordinaria, cien partes dejaron 026,30 de residuo; pero á una temperatura elevada sólo quedaron las materias extrañas, habiendo obtenido 016,00 de residuo.

CARACTERes potariscópicos.-La solución gomosa decolorada por el carbón, es levogira; fué necesario dilnirla, porque concentrada no permite el paso á la luz.

La falta de una cantidad proporcionada de goma no permitió emplear la sal de plomo, porque se haría indispensable descomponer el arabinato insoluble.

Caracteres microscópicos.-1.o Solución. Tíquido gelatiniforme, tembloroso, en parte alguuos glóbulos, y cuyas reacciones corresponden á las que se observan en la copa. 2. ${ }^{\circ}$ Residuo ó parte no disuelta. Materia glutinosa formada por varios cuerpecillos, tanto angulosos como esferoidales, con núcleo luninoso, y otros de forma y tamaño variables, entre los que se descubren fibras leñosas. El yodo, usado convenientemente, produce la tinta azul, aunque débilmente.

ACCión DEL CALórico.-A cien grados aclara el color, pasando al amarillo sucio y aun al amarillo claro, elevando más la temperatura: si ésta se sostiene, hay desprendimientos de liumos espesos, de olor algo sacarino, de reacción notablemente ácida, y que arden con una flama brillante de base azulada: al fin se carboniza la materia sin fundirse, $y$ al contacto del aire se incinera. 
Reacciones.-Tratada la solución hecha en frío, ha dado:

Con el tornasol, reacción casi neutra.

Oxalato de amoníaco, precipitado blanco.

Alcohol íd. íd., notable.

Subacetato de plomo, íd. íd.

Protoazoato de mercurio, enturbiamiento.

El percloruro de fierro sólo determina la coloración del líquido sin dar precipitado alguno.

Tanto el ácido sulfúrico concentrado como el diluido, ofrecen los caracteres correspondientes á la goma arábiga, aunque dando una coloración más subida, probablemente por la abundancia de las materias extrañas orgánicas.

Los caracteres han sido negativos con los siguientes:

Zinc yodado y solución de yodo, agua de cal y de barita.

Acetato neutro de plomo, sulfato de cobre amoníacal, azotato de plata.

Substancias que forman las cenizas:

Cien partes de goma han dado 004,5 de cenizas, es decir, menos que el promedio de la arábiga y algo más que la de frutales. Estas cenizas contienen:

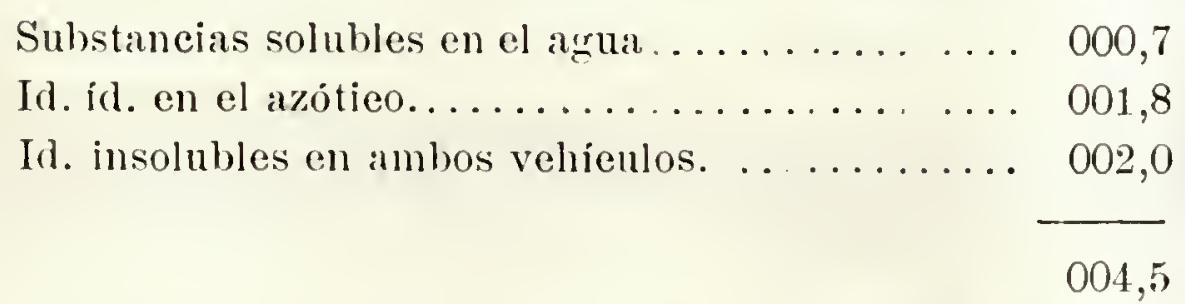

La solución acuosa de las cenizas ha indicado, con los reactivos, las siguientes:

Acido sulfúrico.

Idem carbónico.

Idem clorhídrico.

Cal.

La solución arótica dió:

Acido carbónico.

Idem sulfúrico.

Cal.

El residuo, totalmente insoluble, sólo ha dado siliza y alúmina. La corta cantidad de goma de que pude disponer y el no ser tiempo 
oportuno para colectarla, no ha permitido asegurarse de la presencia del ácido fosfórico, de la sosa, la magnesia, etc.: en cuanto al ácido, se manifestaron indicios con la sal de bismuto.

CONCLUSIONes Y OBSERVACIONEs.-Los caracteres enunciados manifiestan claramente que la goma del magney tiene grande analogía con la que producen los árboles frutales, así como con la variedad colorida de la de las mimosas, comprendida la sección de las ingas, la rariedad roja de la del senegal (Acrcic Adansonii), y en general, con las de color obscuro que rienen mezcladas á las gomas que ofrece el comercio bajo la denominación genérica de goma arábiga y de goma del senegal. La del maguey difiere, sin embargo, de la de los fiutales, por la mayor cantidad de materia disuelta, la facilidad con que se lace soluble la parte que de pronto se reputa como insoluble, el mayor enturbiamiento con el oxalato de amoníaco, acaso proporcional á la mayor cantidad de gona disuelta, por lo mismo, á la notable precipitación con el alcohol, y en fin, por no dar precipitado alguno con el percloruro de fierro, como lo dan, según los autores, tanto la parte soluble de la goma de frutales como la de la arábiga, la del senegal y de tragacanto. No sin motivo lie substitui. do á las roces arabina, basorina, ceracina, kuterina y adragantina, las de materia soluble y materia insoluble, por alejar toda cuestión de tantas como se hallan en los autores sobre este punto. Tal rez no faltaría quien diera el nombre de rgubina á la parte insoluble de la goma examinada.

De todo lo expuesto es fácil inferir: que la goma producida por los magueyes no ofrece grande importancia bajo el punto de rista médico ni el industrial.

Ia goma de las ingas en nuestro país, y en genelal las que llevan en el comercio los nombres de arábiga, del senegal, etc., así como las substancias mucilaginosas, en cuyo número debe contarse hoy la goma arlificicl, que tanto abunda y que tan bien recibida ha sido, acaso porque es muy conocida su procedencia, son preferibles para las aplicaciones terapéuticas. En cuanto á los industriales, sabido es que si algunos han opinado que la goma de los frutales, la goma negra, no es buena ni aun para la tinta de escribir, teniendo la de los magueyes algunas de las propiedades, es conveniente no usarla sino en los casos de necesidad. Además, la dextrina ha facilitado á los fabricantes de tejidos, de papel y demás, un medio económico y en algu- 
nos casos más útil que las gomas, cuya escasez les producía á veces un aumento en sus gastos.

Concluiré por advertir, que juzgando poco fructuosa la análisis elemental, $y$ careciendo de goma para hacerla, he omitido ese trabajo. En confirmación de tal juicio, bastará presentar el siguiente cuadro comparativo, referente sólo á la goma arábiga:

$\begin{array}{lrrrr} & \text { Berzelius. } & \text { Prout. } & \text { Foucroy. } & \text { Ure. } \\ \text { Carbono......... } & 41,906 & 36,3 & 23,08 & 35.13 \\ \text { Hidrógeno . . . . } & 6,788 & 63,7 & 11,51 & 6,08 \\ \text { Oxigreno......... } & 51,306 & 0,0 & 65,38 & 55,79 \\ \text { Azoeto .......... } & 0,000 & 0,0 & 0,00 & 3,00\end{array}$

Estos datos constan en los anales de física y química, y ellos bastan para decidirse á no perder el tiempo en un trabajo infructuoso.

Tengo que dar término á estos apuntes, con el sentimiento, no sólo de no haber formado un trabajo tan completo como lo exige la naturaleza del asunto, sino aun de no haber tocado la parte relativa á los gusanos y á las tortillas de maguey, al algodón, á lo que se usa bajo el nombre de mezcrl de pencr y quiote, y lo que es aún más importante, al examen cuidadoso de los magueyes considerados como plantas textiles. Acaso llegne el día en que, visitando los tinacales y las magueyeras, pueda completar el trabajo, dándome entretanto por satisfecho, si logro que estos apuntes sean el móvil para que otras personas, con más tiempo y mejores elementos, se dediquen al estudio concienzudo de esos regetales, cuyos resultados serán tan importantes á las ciencias como á la industria y al comercio.

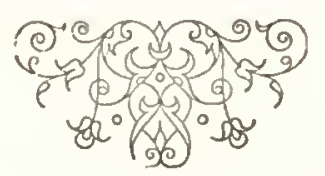




\section{EL ANIMAL PLANTA.}

POR EI SR. DR. D. LEOPOIDO RIO DE IA IOZA.

(Publicado en el "Boletín de la Sociedad Mexicana

de Geografía y Estadística." 1"Epoca, tomo X, págs. 315-318).

En la reseña histórica sobre los trabajos de la Sociedad, que presentó el día 1. ${ }^{0}$ de Enero de este año el señor Secretario Dr. D. José Guadalupe Romero, aseguró que yo me ocupaba en el examen del insecto conocido con el nombre de animal-plantr. Su aseveración me comprometió, de manera que fué preciso el procurar lo necesario para el examen enunciado, teniendo hoy la satisfacción de pagar á la Sociedad esa denda, por extraño que parezca á su institución el asunto de que paso á ocuparme.

Hace más de treinta años que llegó á mis nuanos mojemplar del insecto mencionado; pero la necesidad de adquirir algunos otros, y principalmente la de estar preparando en ese tiempo mi examen general de medicina, me obligaron á aplazar para más tarde el reconocimiento que yo mismo deseaba. La falta de ejemplares y ocupaciones preferentes de otro orden, habían hecho que pasara el tiempo sin realizar ese propósito, hasta que luará dos años conseguí otros tres ejemplares, que me sirvieron para persuadime de lo inexacto de las ideas vulgares que se tenían respecto al origen, naturaleza y propiedades de ese curioso objeto. Hoy, que además del compromiso con la Sociedad, hay otro, para mí muy sagrado que satisfacer, y que he 
tenido la fortuna de que mi apreciable discípulo D. Rafael Barba me remitiera varios ejemplares, paso á exponer el juicio que he formado sobre el particular; pero antes indicaré cuáles son las ideas vulgares más generalizadas.

Se dice que el animal habita en los campos, alimentándose de vegetales, y que á cierta época de su vida cava la tier'a lo necesario para quedar cubierto; pero que esto lo hace eligiendo algunos lugares en donde abunda la semilla de mna planta, la cual, germinando inmediata al animal, deja en él implantadas las ladículas del nuevo ser, y que cuando éste crece, aquél muere.

Aseguran otros que, nutriéndose el animal con esa misteriosa semilla, cuyo nombre ninguno indica, germina en los órganos interiores, el tallo aparece al exterior, el animal se enferma, é instintivamente se inlumma antes de morir, muriendo iguahmente, pero más tarde, el regetal insecticida, de lo que resulta el conjunto que ofrecen los ejemplares que están á la rista. Tales cuentos han dado ocasión á que se afirme, aun por personas no muy rulgares, que el objeto que motira este artículo, es un compuesto de animal y de regetal, ó como suponen algunos, que aquél se convierte en laíz, cuya planta y ramas parten de la cabeza. Preciso es convenir en que, cuando el animal está áún medio cubierto con alguna tierra, el aspecto es efectiramente el de un pequeño vegetal con todas las partes que le son propias; pero visto con atención, se encuentra ser totalmente un animal. ¿A qué fannilia pertenece? ¿Las ramificaciones ó prolongaciones son paltes necesarias, ó son accesorias á él? İn el segundo caso, ¿cómo explicar su formación? He aquí las cuestiones que paso á examinar.

El animal en cuestión y supuesto en el estado natural, es un insecto hemíptero, homóptero, y de la fimilia de las cicadarias: es la cicuda communis, ó sea la C.plebsin, de Lin., que es la Tettigonin foraxini, de Fab.: acaso sea una rapiedad de la común.

Lo que llaman animal-planta es la larra de ese insecto en su transición al estado de ninfa, y probablemente muerto, sin llegar á su total desarrollo, á consecuencia de la alteración orgánica que constiture un estado patológico, cuyos productos son rerdaderamente excrecencias, ó diré mejor vegetaciones dérmicas, que simulan más ó menos el tallo de una planta, en muchos casos, con sus ramos, su inflorescencia y su fructificación. La extremidad libre del tallo aparece 
las más reces como una pequeña coliflor; pero en general, tiene más analogía en su corjunto con el coral, sin que le falte aun la tinta rosada, jropia del coral rojo.

El examen químico apoya aún esta analogía, descubriendo la presencia de las sales calcáreas que se encuentran en ese zoófito; pero aun hay más: en algunos de esos pequeños tallos se observan con el microscopio cristalitos cúbicos de cloruro de sodio, como los hay en el coral bruto, mezclados con alguna arena cuarzosa, todo lo cual aumenta la analogía entre el pólipo marino y el insecto que nos ocupa, y al que el vulgo, sin saberlo, ha dado ó traducido el nombre griego zoófito, llamándole animal-planta.

Aunque yo no he dudado de la naturaleza del supuesto vegetal, ture la necesidad de demostrar químicamente que era animal. En Octubre del año pasado, uno de los médicos del ejército expedicionario, deseaba asegurarse de si las pequeñas ramas eran ó no regetales. La naturaleza de los productos obtenidos por la acción del fuego, la del carbón producido, y por último, la de las cenizas, no dejó duda alguna de que todas esas producciones animales son de naturaleza animal. He aquí los datos recogidos entonces, en presencia del Sr. D. Joaquín Varela.

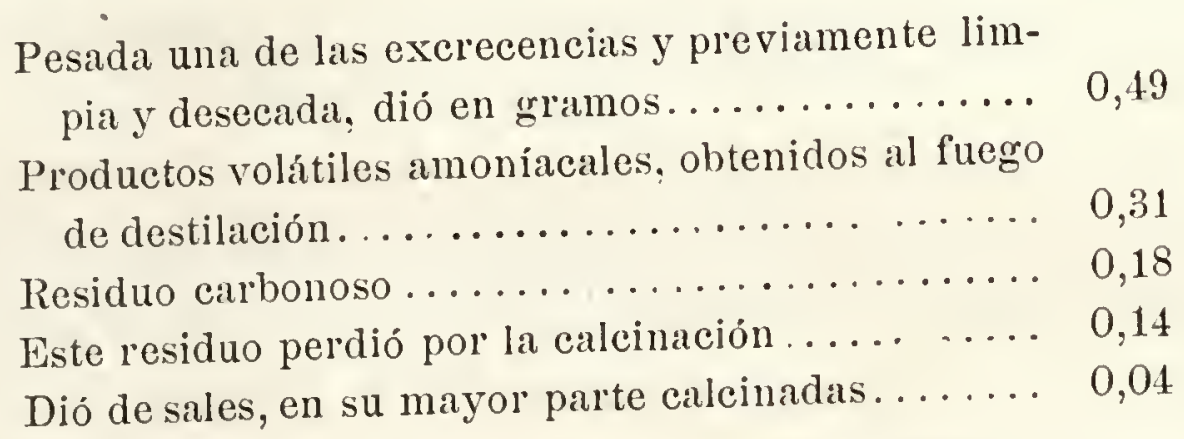

No hay, pues, duda de que la parte que se reputa como regetal, es de naturaleza animal.

La investigación anatómico-patológica era otro de los trabajos que convenía hacer: ella ha venido á demostrar que, conservándose las partes exteriores de la larva, es decir, el esqueleto tegumentario y sus apéndices, todo el interior ha sufrido, por el contrario, una completa transformación. En efecto, dividiéndola por mitad, en el sentido de su longitud, presenta, según se ve, un todo homogéneo, blanco, fofo, y muy semejante al agárico ó á alguno de los hongos comestibles: parece que una modificación análoga á la que se verifica en lo que vulgarmente se llama petrificación, ha solidificado el interior 
de la larva, dándole la uniformidad que se advierte, y por la cual se pueden explicar la alteración orgánica, la enfermedad y la inuerte del insecto al comenzar su transformación. ¿Cuál es la causa determinante de esa alteración orgánica? No es fácil resolverlo, y menos faltando, como me faltan, los datos relativos á la vida de esos seres, en el local en donde se han recogido, y muy particularmente los geológicos, que son, en mi opinión, los que más han de inflnir en el desarrollo de las producciones anormales.

Para que las personas extrañas á la zoología comprendan mejor lo supuesto, creo conveniente advertir que las cigarras pertenecen á los insectos que no sufren, como otios, una completa transformación; es sólo una semi-metamorfosis, cuyas transiciones no están perfectamente marcadas. Desde que nacen tienen la forma que conservan, hasta que mueren, sin más variaciones que las del crecimiento, y la muy notable relativa á la falta ó á la aparición de las alas. En algunos de los insectos en cuestión, apenas se encuentran pequeños mamelones en los puntos correspondientes á las alas; pero en los más, éstas son rudimentarias, es decir, que la alteración orgánica comienza en la larva, y según la constitución individual, el insecto,óllega al estado de ninfa, ó bien muere al comenzar esta metamorfosis. Por esto he creído más propio considerarlo como larra-ninfa, aunque es más común hallarlo en este último estado. Hay más: las cigarras corresponden á los insectos que nacen en los terrenos, y no en las hojas ó en los troncos de los regetales, como hay otros muchos, lo cual explica el hecho de encontrarse enterrada esa larva-ninfa. Por último, las cigarras, aunque pobres en su sistema vascular, tienen un aparato digestivo bien desarrollado, que desaparece en el animal-planta, según se nota en la figura $C$ : en A se tiene un ejemplar, cuyas ramificaciones parten del centro de la cabeza $\mathrm{y}$ terminan en punta; en B, uno en el que salen del tórax y terminan en coliflor, de color rosado; y por último, en $D$, se ve una de las extremidades anteriores, con los dientes de sierra, que sirven al animal para carar la tierra.

Estos ejemplares y los demás que he tenido á la vista, han sido recogidos en Izúcar de Matamoros, distrito del Departamento de Puebla: se me ha dicho que los hay en las Mixtecas y en otras tierras calientes. Es de desear que las personas conocedoras que residan ó que visiten esos lugares, recojan los datos necesarios para formar la historia completa de ese curioso insecto. Entretanto, terminaré estos apun- 
tes, anunciando que las vegetaciones anormales no son especiales á uno solo de los dos sexos, pues tanto se observan en el macho como en la hembra, y que aunque es lo común que sólo tengan una excrecencia, y ésta parta del centro de la cabeza, también las hay múltiples $y$ naciendo de varios puntos del cuerpo.

El adjunto dibujo da una idea del tamaño, forma y vegetación patológica de la cigarra, que hace tiempo ha sido un objeto curioso, pero que no he sabido se hayan ocupado especialmente de él, ni aun he risto en los autores cosa alguna que indique haberlo observado.

Resulta de todo lo dicho, que el animal-planta es la larva-ninfa de un insecto hemíptero, homóptero, perteneciente á la familia de las cicadarias (cicada communis), de la que podrá ser una variedad, y que la parte reputada como planta es una producción anormal, una excrecencia de naturaleza anormal. 


\section{EL ANIMAL PLANTA.}

(Después de dado á luz el trabajo del Señor Don Leopoldo Rio de la Loza, sobre el "animal planta," apareció publicada en el periódico intitulado "La Sociedad," una carta que con fecha 31 de Agosto de ese mismo año (de 1864) dirigio el Señol Don Antonio Castillo á los Señores Redactores de aquel periodico. En dicha carta lacia algunas observaciones al trabajo del Señor Rio de la Loza, basadas todas en estudios y publiereiones de sabios extranjeros y manifestando a la vez quedar en duda sobre el género y especie del "hongo parásito" en cuestion. Diclar carta demandó la siguiente contestación del Señol Rio de la Lozal).

Sres. redactores de «La Sociedad.»-México, Septiembre 7 de 1S64.-Muy Señores míos: En el núm. 441 del periódico de Udes., correspondiente al día 4 del actual, he leído un artículo suscrito por el Sr. D. Antonio del Castillo, referente al que yo presenté en una de las sesiones de la Sociedad de Geografia, bajo el título de «El Animal Planta.» Como el asunto es de interés científico, cuento con el faror de Udes., esperando que tendrán la bondad de publicar las siguientes líneas.

No sin fundamento ha llamado la atención del Sr. Castillo y de otras muchas personas, tanto el animal de que hice mérito, como el escrito mismo. En efecto, cuando una opinión, una doctrina ó una teoría se generalizan, y más aún cuando cuentan con el poderoso apoyo de los sabios distinguidos de diversos países, toda idea presentada en contrario no puede menos que llamar fuertemente la atención y ser combatida fácilmente con las armas poderosas de tan respetables autoridades. He aquí lo que ha pasado y pasará aún con relación á mi primer artículo.

El Sr. Castillo, con mucha caballerosidad que mucho le agradezco, hace algunas reflexiones, muy propias del espíritu observador . 
que más conviene en estos casos, y á lo que yo debo corresponder, no sólo declarando exactas las citas que menciona, sino agregando, que, sin duda, por su genial moderación omitió otras varias que estoy seguro pudo haber hecho, aun cuando se suponga que sólo le son conocidas las obras que cita, á saber: el Diccionario de las ciencias naturales y la Historia de vegetales parásitos, escrita por Mr. Carlos Robin. Con sólo lo que este ilustre profesor refiere al tratar de la Sphcceric, habría sobrado para apoyar este juicio: «que en general los naturalistas más distinguidos se han ocupado de los parásitos en los animales, colocándolos entre las criptógamas.» Añadiré, que los estudiosos profesores D. Alfonso Herrera y D. Gumesindo Mendoza, quienes han examinado con el microscopio la producción anormal de la cigaria, han hallado algunos cuerpecillos que creen ser los esporos de un hongo.

Hecha por mi parte esta aclaración, creo poder indicar, con libertad, algunos de los motivos que, me han obligado á no admitir todas las ideas que se hallan en los autores sobre el asunto que me ocupa; no se podrá, pues, atribuir al capriclıoso espíritu de sostener lo escrito, y sí al solicitar la decisión de algunos puntos que en mi humilde opinión son cuestionables, no obstante la respetable autoridad de la mayoría que los ha dado por resueltos.

Cuando se ve, como puede ver todo el que examine sin prevención alguna, el desacuerdo de los antores, ya sobre el origen, desarrollo, influencia, clasificación, etc., de los parásitos estudiados en los animales: cuando se recuerda la inmensa variedad de sistemas, de doctrinas, de métodos y de principios científicos que en los diversos tiempos han reinado, acogiéndose con entusiasta aclamación, para caer más tarde en el olvido, ó bien para quedar como simples recuerdos históricos, ó ya reducidos á los límites convenientes, sin la abusiva aplicación que se les diera: cuando se comparan las formas, propiedades, naturaleza, etc., de los seres orgánicos vegetales y animales, especialmente en los puntos en que se confunden: cuando á esto se agrega y medita sobre las condiciones y cuidados que requieren las observaciones microscópicas, tanto mayores cuanto mayor sea la fuerza que se prefiera para la observación: cuando se atiende á que las decisiones relativas al estudio de los parásitos en los animales, requiere la concurrencia de varios de los ramos de las ciencias naturales, comprendidas las médicas: cuando, en fin, se ve que profeso- 
res no menos distinguidos que los micrógrafos, niegan alguna 6 algunas de las doctrinas de éstos, ó cuando menos no están en perfecto acuerdo, natmal es que se despierten dudas, que se desconfie de las doctrinas y que se procure investigar la verdad, por nuevas observaciones, ya propias ó bien ajenas; pero sí destituidas de toda preocupación.

No es tan fácil convenir, por ejemplo, como aseguran algunos, en que un pequeñísimo cuerpo flotante en el aire, germen ó simiente de un nuevo ser, fijándose, ya en el interior ó en el exterior de un animal, y sólo obedeciendo á la presión atmosférica, presta ésta el auxilio suficiente para que ese germen penetre los tejidos, dando principio á su desarrollo. Más dificil se hace creer que ese cuerpecillo esté dotado, sea de un instinto electivo, ó de una fuerza atractiva ó cosa equivalente, pero siempre favorable á su reproducción, y eso en puntos determinados y con el requisito de que tengan esos puntos condiciones igualmente determinadas. $Y$ si, por otra parte, se tienen en cuenta las producciones anormales, su aspecto, naturaleza, reproducción y cuanto se relaciona con ellas: si se atiende á la opinión de los micrógrafos, que distinguen la aparición de las criptógamas por semilla ó por absorción, ó sea por contagio, ó como dicen otros, la producción germinal y la espontánea: si no puede dudarse de la existencia de ciertas enfermedades contagiosas, entre cuyas producciones hay algunas que fácilmente se confunden con los parásitos en cuestión, natural es dudar, cuando menos, de las consecuencias, fundadas en tales datos.

Por otra parte, si en alguna de esas excrecencias se examina atentamente la cubierta tegumentaria, fijándose en los puntos de unión del regetal con el animal, se observa una continuidud y una homogeneidud perfectas, incomprensibles, sin duda, si no es admitiendo que tal producción parte del interior, aun cuando más tarde aparezcan ó no las regetaciones. Este es uno de los casos, y no el único, que creo puede presentarse en las cigarras de que me he ocupado.

El mismo Dr. Robsin nos da en la figura 4. ", lám. 13. a de su obra, un dibujo de la Sphacric Robcrtsii, en el que se nota con toda claridad, no sólo la continuidad de la parte tegumentaria del animal, sino también la del micelio, que en cuanto á su origen se halla en igual caso, es decir, que ese, como el de las cigarras, sea más bien en su principio una producción morbosa. 
En la mayor parte de las cigarras que he visto, la parte anormal es única, y sale de un punto determinado de la cabeza, lo cual no es fácil comprender sin admitir la enfermedad del animal, porque, ya se suponga la fijación del esporo, ó bien se admita el contagio, aparecieran indistintamente las ramificaciones, sin que sean aplicables ni convenientes las razones que para explicar hechos análogos da el respetable Dr. Robin. Verdad es, y ya lo he dicho, que también se encuentran las producciones en el dorso y aun en otros puntos del cuerpo de las cigarras; pero además de que esto no es común, generalmente no llegan á su total desarrollo. Puede suceder, sin embargo, que vistos los animales por los colectores, como objetos de simple curiosidad, únicamente se procuren los que tengan ramas cefálicas, reputándolas como más propias para satisfacer esa curiosidad, y desechando, en consecuencia, todos los que á su juicio no ofrezcan interés. Si así fuere, mi raciocinio quedará destruido en cuanto á esto.

Aunque precisado á ser conciso, creo no deber omitir otras indicaciones, para dar término á este artículo, más extenso de lo que me proponía y de lo que por su naturaleza da de sí la materia.

No veo dificultad en admitir, que dado el cadáver de un animal, vegeten en él algunas criptógamas; por consiguiente, si muerto con una producción anormal, ésta presenta mejores condiciones para el desarrollo del vegetal, allí germinará ésta, pudiendo aún suceder que lo mismo tenga lugar durante la vida y laallándose el animal en inacción.

Si todos los hongos tuvieran una misma composición; si la funguina y los fungatos, la materia animal y la grasa, la géna ú otros principios, fueran constantes en esos vegetales, unuchos de los puntos dudosos quedarían resueltos; mas por desgracia, su composición es muy raria, y no hay que contar con ese auxilio.

He dicho que algunos autores de nota difieren en opiniones, sea negando en ciertos casos la presencia de las criptógamas, ó bien al ocuparse de su desarrollo, clasificación, etc., lo cual demuestra claramente que aún no estan resueltas, con la claridad debida, varias cuestiones importantes. Sin ocurrir á otras fuentes, se puede ver que el inismo Mr. Robin ha tenido que ocuparse en su obra, de impugnar á Wallroth, Laboulbene, Grisolle, Linneo, Sulzer, Monneret y tantos otros, que es inútil citar: baste decir, que él mismo reforma 
algunas de sus apreciaciones anteriores, y que termina su obra con un apéndice, en el que constan diferentes especies de cuerpos, que crecen sobre los animales vivos, pero que varios micrógrafos han reputado indebidamente como vegetales, no siéndolo.

En vista de las contradicciones indicadas y de otras muchas que selía largo enumerar, nada extraño es que se dude, que se llegue á ser partidario del escepticismo. Si se quiere, yo lo seré en este punto, mas no puedo obrar contra lo que me dicta la razón. Esperemos á que la Sección de botánica y geología, que según he sabido se ocupa actualmente del insecto, presente sus trabajos. Es probable, que dando una descripción detallada del animal, especialmente bajo el punto de vista anatómico-patológico, así como la de todas y cada una de las partes constitutivas del hongo, en el caso de haberlo, queden resueltas fundadamente las cuestiones anunciadas.

I. RíO DE I $\triangleleft$ A LOza. 


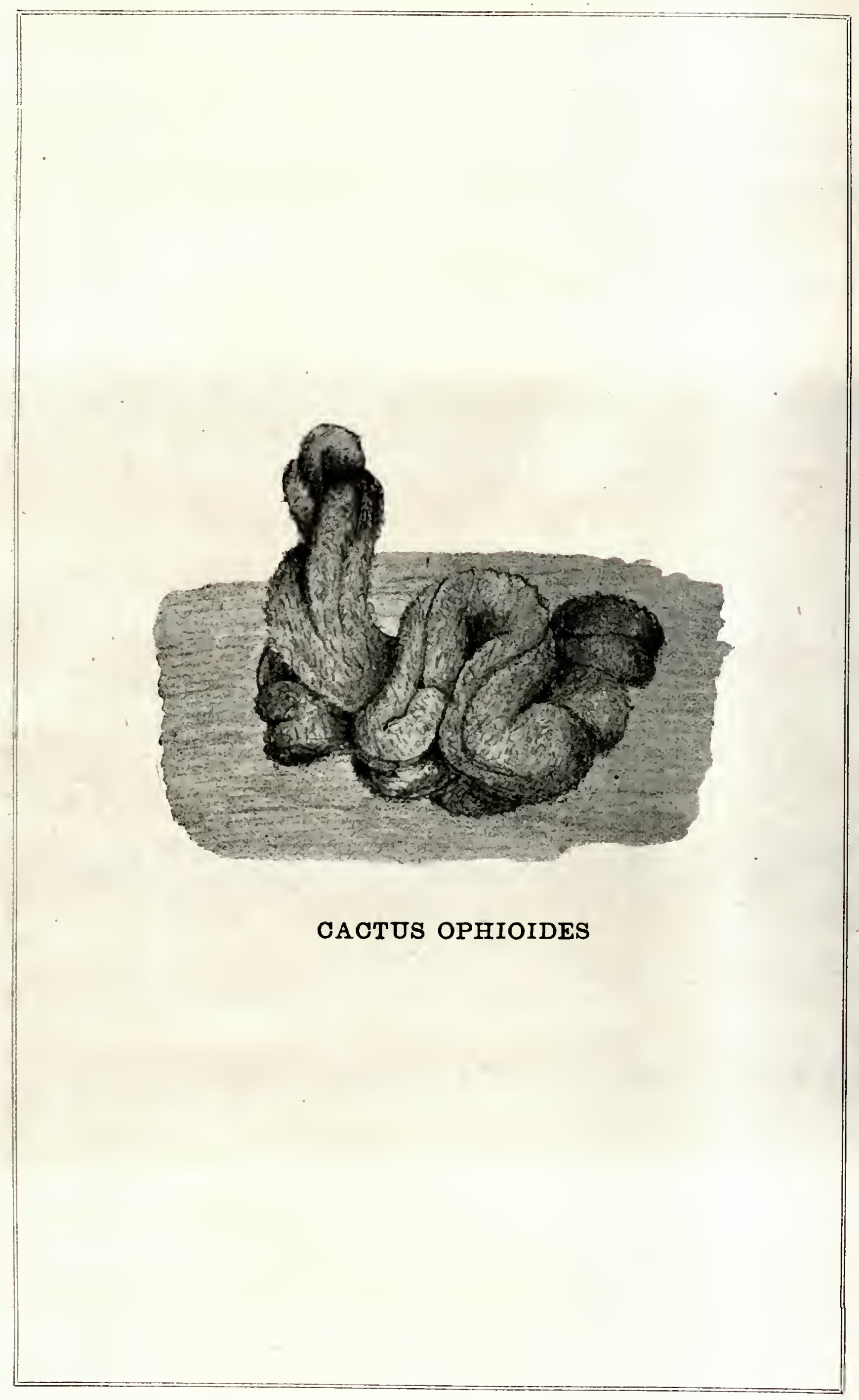




\section{EL CACTUS OPHIOIDES.}

Habiendo encontrado el Señor Conde de la Cortina una nueva especie de cactea en el Hezquital y deseando rectificar ó ratificar sn especie, solicitó la opinión del Señor Doctor Don Leopoldo Rio de la Loza, la cual se la dió en la siguiente carta:

\section{Noviembre $1 .^{\circ}$ de 1845.}

Debo á la fina amistad del Sr. D. J. G. de la Cortina, y á su constante empeño por conocer las producciones de nuestro suelo, el descubrimiento de la nueva especie de cactus que representa la adjunta estampa litográfica.

Reservándome para otra vez el completar su descripción, señalaré ahora los principales caracteres, suficientes por sí para distinguirlo. Su figura, como se re, es la de una serpiente enroscada, aunque los anatómicos la comparan mejor á la que dan las circunroluciones intestinales; por esto, y por estar descritas otras dos especies con los nombres de C. scrpentimus y de C. scrpens, me labía inclinado á llamar á esta nueva, $C$. enteriformis; mas no siendo conocidos de muchos el aspecto que ofrecen los intestinos cuando se levanta la pared anterior del vientre, y queriendo, además, respetar la opinión de algunos amigos, me decidí á llamarle cactus ophiodes, fijando los siguientes caracteres.

«Caulis carnosus cum orbitus tronsversis, sulco longitudinale, tuberculis oblongis et fasciculis, Spinarum sctaccarum coronatis quarum duce quatuorve majores albe cylindrice et decuricato. Nondum florescit escemplariun excmini subjectum.» 
«Tallo carnoso con circunrolnciones que le dan el aspecto de una serpiente; un surco logitudinal, tubérculos mamilares, oblongos y coronados por manojos de espinas cetáceas, con dos 6 cuatro mayores blancos y divergentes. (Aún no florece).»

Me son desconocidos los usos que pueden hacerse de esta planta; pero desde luego me propongo examinar el zumo lechoso que da cuando se le hacen incisiones superficiales; $y$ aunque no ofrezca otro interés que el de su figura, es, sin duda, un regetal sumamente apreciable.

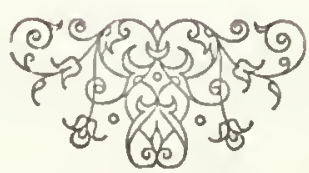




\title{
LA AGRICULTURA Y LA VEIERINARIA.
}

\author{
EN LA NACIÓN MEXICANA,
}

POR EL SR. DR. DON LEOPOLDO RÍO DE LA LOZA.

La historia de la Agricultura nacional debería considerarse en los tres períodos principales: el anterior á la conquista, el de la dominación española, y el de la independencia del país; pero conriniendo por ahora el ocuparse únicamente del último, como más necesario al objeto que motiva este escrito, serán enunciados someramente los hechos que durante él han pasado. A este fin, conviene indicar uno á nuo los proyectos concebidos, las leyes publicadas, y las disposiciones relacionadas con el estableciniento en la enseñanza agrícola.

Conviene, igualmente, comprender la de la Veterinaria, cuya historia data de sólo diez años, en cuyo período ha sido anexa á la primera: conviene después comparar esos proyectos, señalar á cada uno sus rentajas y sus inconvenientes, presentar el plan más adecuado á las exigencias nacionales, en general, á las de las industrias agrícolas en particular, $y$ á las de las carreras de los naturalistas y de los reterinarios, conchuyendo con algunas observaciones, que podrán ser de utilidad en el orden administrativo.

La noticia de los fondos con el que se sosturo el Establecimiento de enseñanza Agrícola que aún existe; la de los profesores que en él han servido durante las cuatro reformas principales por que ha pasado; y por último, el número y clase de alumnos que ha tenido en cada una de ellas, harán igualmente parte de este escrito, como da- 
tos útiles para dejar un juicio fundado. $\mathrm{Y}$ annque el asunto es vasto por su naturaleza, y más que esto, por la serie de sucesos que han tenido lugar, sólo serán indicados aquellos que ofrezcan algún interés.

Durante los primeros doce años, siguientes á la independencia de México, en 1821 la industria agrícola permaneció estacionaria. Muy raro propietario introdujo algunas modificaciones en el cultivo, algunas reformas en los beneficios de sus productos, y esto, luchando, como debe suponerse, con un enemigo poderoso, que lo es siempre, el de las ciegas costumbres y el de las rutineras preocupaciones. Mas al fin, la introducción y la lectura de buenos libros, los viajes á países extraños, emprendidos por algunos de los propietarios y por otros de nuestros compatriotas amantes de la ciencia; los adelantamientos y aclimatación de ciertos ramos auxiliares de la agronomía; el uso de alimentos y de medicamentos, hasta entonces desconocidos; la introducción y cultiro de nuevas plantas de jardinería, y más aún, el entusiasmo patriótico, que alentaba á los promoredores de las mejoras materiales, todo contribuyó á que la industria agrícola no fuera indiferente á varios particulares yá algunas de las administraciones que han gobernado el país.

Veamos cuáles han sido los proyectos á que en consecuencia diel'a lugar ese pensamiento noble, desinteresado y benéfico, pero que no por ello ha dejado de tropezar con obstáculos más ó menos graves.

\section{PRIMER PROYECTO.}

En los últimos meses del año de 1833 apareció un plan general de estudios, por el cual se dispuso, entre otras cosas, que en el Hospicio r lnerta de Santo Tomás se estableciera una cuted"a de botánica, una de agricultura máctica y otra de quimica aplicadu á las artes. No hay duda que, aun cuando tal disposición se hubiera llevado á efecto, lo cual no sucedió, no habrían quedado satisfechas las necesidades de esa enseñanza, ni menos las del país, que aún consideraba en su mayor parte la antigua $y$ defectuosa cultura. El hecho es, que derogada la ley en 1S34, todo volrió á su anterior estado. 


\section{SEGUNDO PROYECTO.}

A mediados del siguiente año de 1835, murió en la ciudad de Lagos, el Sr. Presbítero Don Miguel Guerra, dejando un capital de 90,000 pesos, según el dicho de los albaceas, y de 150,000 según la voz pública, destinados en su mayor parte al establecimiento en dicha ciudad de una Escuela de Agricultura, cuya benéfica disposición no llegó á realizarse, por varios incidentes que sería largo enumerar. La Inobservación de la voluntad del testador, dió ocasión á que la Junta de Industria de México, excitara al Obispado de Guadalajara y á la vez al Gobierno general, para que tal disposición tuviera su cumplimiento; paso que no dió resultado alguno, y por lo mismo, la Nación siguió privada de la enseñanza agrícola, para cuyo establecimiento creyó ver un auxilio en la generosa donación del P. Guerra.

\section{TEKCER PROYECTO.}

Mas en 1843, algunos de los buenos hijos de México, para quienes no era desconocida la importancia de esa ciencia, ni sus progresos en los países cultos, se propusieron con todo empeño el darle una organización adecuada, y uno de ellos, el Señor Lic. Don José Urbano Fonseca, emprendió tan notable tarea, no sólo trabajando personalmente y ocupando á sus amigos para que sirvieran, sin retribución alguna, las cátedras correspondientes, sino también laciendo fuertes erogaciones de su propio peculio, las que por desgracia quedaron igualmente perdidas. Con el modesto nombre de Gimnasio Mexicano se dedicó el Sr. Fonseca á preparar todo lo necesario para montar su Establecimiento en el Olivar del Conde, á legua y media de la Capital, y cuya solemne apertura se verificó dos años después, el $2 S$ de Septiembre de 1845 , bajo la especial atención del Ateneo Mexicano, cuya patriótica y útil asociación concluyó después. 
La falta de cooperación por parte de los gobiernos de los Estados, que la habían ofrecido; los acontecimientos políticos que han sido constantemente la rémora invencible de todas las empresas útiles, $y$ el haber consumido sus fondos propios el patriota desinteresado, que tantos servicios prestara á la enseñanza, todo contribuyó á la clausura del Gimnasio, y México quedó, por tercera rez, sin un establecimiento en el que se dieran los conocimientos agrícolas teóricos-prácticos, cada día más necesarios.

\section{CUARTO PROYECTO.}

Entretanto, un ministro ilustrado y emprendedor, el Sr. D. Manuel Baranda, al formar el plan general de Estudios, publicado en Agosto de 1843, dió á las ciencias naturales un mediano lugar, y con él, una esperanza á los agricultores, esperanza que supusieron convertida en realidad al ser publicada la ley de 2 de Octubre del mismo año, por la cual se establecían una Escuela de Agricultura $y$ una de Artes.

Presidida en esa época la Junta Directiva por una persona igualmente notable, como lo fué el Sr. D. Lucas Alamán, y sometida á esa Corporación la ejecución de la ley, se comenzó desde luego á preparar lo necesario para la erección de ambas escuelas. Mas el desarrollo de este pensamiento, cuyos resultados debieron ser de notoria utilidad; los esfuerzos emprendidos con tan buena fe, $y$ las esperanzas halagieñas que hacían vislumbrar un pacífico porvenir, todo quedó destruido por cuarta vez, dejando en pos de sí una impresión desconsoladora y los fundados temores del desaliento consiguiente á ella.

Sin embargo, en esta ocasión se consiguió algo más que en las anteriores, pues no se abandonó el campo al tropezar con los primeros obstáculos; por el contrario, se luchó con mil y mil contradicciones, se allanaron rarias dificultades, se formaron los reglamentos, fueron nombrados algunos catedráticos, se eligió y tomó un lugar adecuado, como lo es la Hacienda de la Ascensión y, además, el edificio de San Jacinto, y en fin, se dió principio á los trabajos pre- 
vios para la recepción de alumnos $y$ para la apertura de las dos escuelas.

Así pasalon más de tres años sin que se verificara la apertura de las clases, porque disminuidos notablemente los fondos de la Dirección de industria, por el bloqueo y otras varias causas; exhausto el tesoro público y urgido por nocesidades más apremiantes; denegado por la mitra de México el reconocimiento del capital que tenía impuesto en la Hacienda de la Ascensión, y, en consecuencia, anulada la renta de la finca; invadido más tarde el territorio por los Norteamericanos, sin poderse ocupar la Nación toda, más que de la guerra, á que tan injustamente fué provocada, los gastos erogados quedaron perdidos, los trabajos comenzados inútiles, y todos los sacrificios estériles.

\section{QUINTO PROYECTO.}

Demasiado conocida ha sido en México la ilustración y buenos aervicios de uno de nuestros compatriotas, el Sr. D. José Gómez de la Cortina, cuya franqueza y afabilidad acaso excedieron á la que le conrenía; el hecho es, que en toda empresa científica, en todo proyecto útil, en todo lo que era servir al público, el nombre del Conde de la Cortina figuraba en primer término. Apenas había ingresado como Gobermador del Estado de México, en 1S46, cuando dispuso que se arbitrara el medio de proteger la industria agrícola, formando sociedades, que sin gravar los fondos públicos, dejaran satisfecha esa necesidad que le era tan conocida. En efecto, el 24 de Agosto del mismo año, fueron publicados por bando los "Estatutos de la Sociedud de Agricultura del Estudo de México," en los cuales se dejaba á la misma Sociedad el cuidado de organizar la enseñanza agrícola con el establecimiento de Escuelas especiales. Los acontecimientos políticos se opusieron como antes á la realización de este proyecto, aunque obteniéndose la rentaja de que algunos de los propietarios salieran de la apatía que les era general, y aun de que llegaran á formar algunas asociaciones agronómicas. El caso, es que sin embargo, el proyecto fracasó y la buena marcha agronómica siguió exclusivamente confiada á los esfuerzos de particulares. 


\section{SEXTO PROYECTO.}

Ha sido tal la confianza y tal la íntima convicción de la utilidad y necesidad que tiene México de una escuela de Agricultura, que los mismos que habían tropezado con tantas dificultades y aun otros que se resolrieron á tomar parte en esa noble empresa, la proyectaron de nuevo por sexta rez, renorando su fe entusiasta y su esperanza patriótica. Veamos lo que pasó en el segundo semestre de 1849 .

Sabido es que el Colegio de San Gregorio estaba á cargo de una Junta Directiva, servida gratnitamente por personas de muy buena representación social: entre éstas se hallaba el Sr. Fonseca, quien lejos de abandonar el proyecto que tantos sacrificios le había costado, propuso á la Corporación y logró que aprobara un plan de enseñanza agrícola, cuyos fundamentos consistían en aprovechar para la teórica el servicio casi gratuito de algumos profesores, y para la práctica, la propiedad rural que tenía dicho Colegio, á saber, la Hacienda de San José Acolman y sus ranchos anexos, ubicados en el partido de Texcoco.

Tanto el plan, como los programas de cada una de las cátedras que en él se establecían, están publicados, aunque con mnchas erratas, en 1550, bajo el título de Presente á los Agricultores ó noticia de los ramos de enseñanza en el Colegio de San Gregorio y en su Hacienda de San José Acolman.

En el siguiente año, 1851, solicitó la misma Junta Directiva del Colegio de San Gregorio, de la de colonización é industria, que auxiliara una empresa en que la misma Junta esturo interesada: acordó ésta, en efecto, y el Gobierno aprobó, que se dielan quinientos pesos para hacer práctica la enseñanza de la química agrícola, cuya cantidad fué entregada el día diez de Octubre del mismo año.

La administración de 1852, de la que fué uno de sus Ministros el Señor Fonseca, dispuso, primero, que la misma Dirección de industria sosturiera en San Gregorio cuatro alumnos, destinados precisamente á los estudios agronómicos; más tarde pagó, ignalmente, por sólo un año, la colegiatura de un quinto alumno. En todos los jóre- 
nes se notaba, en esa época, la decidida inclinación con que habían adoptado y seguían la nueva carrera, llegando el caso de que aun algumos de los que antes de organizar las cátedras habían comenzado la de Jurisprudencia, la abandonaran por la de la Agricultura, aumentando así el número de los estudiantes de este ramo, no obstante que ni el programa de estudios había circulado lo necesario, ni el estado del país, siempre en revolución, permitía llegaran á rennirse todos los que hubo en el último año escolar.

Preciso es confesar que la enseñanza, tal como estaba montada, no era perfecta, ni debía serlo por dos motiros principales: sea el primero, que las nuevas empresas no son desde luego perfectas; y el segundo, que los escasos fondos con que se contaba no permitían las erogaciones indispensables para la buena instrucción. Sin embargo, los actos públicos de las materias correspondientes á los cuatro años, fueron relativamente lucidos; y además, voremos que este embrión, aunque imperfecto en sus primeros pasos, debía desarrollarse más tarde, conquistando el principio, poco conocido hasta entonces, de la necesidad y conveniencia de la enseñanza agrícola en el extenso terreno que nos concedió la Providencia.

Así quedó la enseñanza como hospedada graciosamente en el Colegio de San Gregorio, y esos buenos resultados fueron el fruto que recogieron por primera rez los hombres constantes que en otras cinco nada liabían conseguido.

Véase ahora lo que resultó de la organización proyectada en 1853.

\section{SÉPTIMO PROYECTO.}

Creado en ese año un nuevo Ministerio, bajo la denominación de fomento, industria y comercio, y Hamadoá él uno de los colaboradores en los proyectos de la enseñanza agrícola, era preciso que le tendiera la mano, como en efecto sucedió.

El Sr. D. Joaquín Velázquez de León, reunido con su sobrino, el Señor D. Miguel, y con dos promoredores de esa mejora importante, se ocuparon desde luego en la formación de la ley: recabó el primero de dichos Señores la sanción del Gobierno, y en 17 de Agosto del mis- 
mo año, fuć publicado un desreto doblenente benéfico, pues por una parte disminúa el considerable número de abogados, con la supresión de uno de los cuatro planteles que entonces había en sólo la Capital, y por la otra mejoraba notoriamente la enseñanza de una profesión, racilante aún y unuy provisionalnente alojada en el Colegio de Sin Gregorio.

No fuó ese el ńnico beneficio que se obturo en esa época. Persuadidos los antores de ese proyecto, de que la Escuela de Agricultura tenía necesidad de terrenos para sus laboles; de que carecía de ellos en el edificio de San Gregorio; á que la Hacienda de Acolncan se lallaba á mayor distancia de la que conviene á la sobre rigilancia. auxilios y conveniencias, tanto didácticas como faniliares; y sabiendo, en fin, que privado el Gobieno de la Hacienda de Ia Ascensión, sólo contaba con el edificio de San Jacinto, y 110 con sus ter'renos, se propuso y logró que comprara éstos el Gobiorno y que finera separado el edificio, adecuándolo á la cnseñanza que debía darse. Desde luego turo que hacerse el arreglo indispensable consiguiente á la extinción del antiguo Colegio de San Gregorio. Porque repuesta á la rez la Compañía de .Jesús, y dispuesto que se volviela á encargar de la Iglesia de Loreto y de la dirección de la juventud, como antes lo esturo, le fueron entregados ambos edificios, y sólo so consiguió dividir, según conrenio, algunos de los muebles, utensilios y libros que pasaron á San Jacinto; que fueran á él los alumnos que quisieran seguir la carlera agrícola, y que pasaran á los Colegios de San Ildefonso y Seminario los que pretendieran continuar la de Jurisprudencia ó de Cánones. Por este medio, se cortaron algunas cuestiones y se alejaron inconvenientes, que acaso, sin la necesaria prudencia, habrían sido nua rémora para la realización del proyecto.

El Sr: Velázque\% juzgó que sería más conveniente el confiar la enseñanza y direcoión agrícolas, á 111 profesor traído de Europa, y consecnente con esta idea, la puso en ejecución; mas como al llegar el profesor, á quien se labía contratado por cinco años, no sólo se vió que desconocía el idioma español, sino también las costumbres, las influencias climatológicas y demás exigencias agronómicas, pasaron dos años sin que los alummos lograran hacer las debidas aplicaciones de los estudios preparatorios que ya tenían, ni menos adquirir los profesionales, de que más necesitaban. Fuera de esta grave dificultad, Ios amantes de la agricultura turieron el gusto de que 
los alumnos tomaran posesión del nuevo plantel el día 22 de Febrero de 1854 .

El Sr. Tic. D. José G. Arriola, quien funcionaba entonces como Rector del Colegio de San Gregorio, siguió en San Jacinto con el mismo encargo; las cátedras comenzaron y, al concluir el año de 1855, se verificaron los exámenes de las clases preparatorias, se dió un acto público de Química agrícola el 14 de Noriembre, y fueron distribuidos los premios respectivos el día 18 del mismo, pudiendo considerarse con estas funciones como terminado el séptimo esfuerzo de los emprendidos con el fin de establecer definitivamente la enseñanza agrícola.

En cuanto á la Veterinaria, nada se hizo, no obstante hallarse organizada la carrera en la citada ler.

\section{OCTAVO PROYEOTO.}

Ias influencias, siempre fatales, á consecuencia de los cambios de administraciones lizo temer mucho por la Escuela de Agricultnrá, al consumarse el plan de Ayutla: mas, por fortuna, fué encargada la cartera de Fomento á una persona cuya ilustración y buenas cualidades son desconocidas para unos y acaso equirocadamente juzgadas por otros. El Sr. D. Manuel Siliceo, lejos de destruir 6 aun de abandonar la obra comenzada, se decidió desde sn ingreso á perfeccionarla, pero con tal empeño, con tal entusiasmo, que logró que tomara una parte activa el Sr. D. Ignacio Comonfort, Presidente entonces de la República. Tanto los hijos de la Escuela, como los promovedores de su organización y sus antiguos empleados, reconocen agradecidos los beneficios de sus decididos protectores.

Algunas de las personas que habían trabajado en las anteriores empresas fueron nombradas desde luego, para modificar ó mejor dicho, mejorar la ley de 1853, y el 4 de Enero de 1856 se publicó la que autorizaron los dos funcionarios mencionados.

No es tiempo de formar el juicio crítico de éstas y de otras leyes $\mathrm{y}$ disposiciones dadas en los diversos períodos; más adelante, cuando estén conocidas todas nos ocuparemos de este penoso trabajo, únicamente por juzgarlo indispensable para que, aprovechándose la expe- 
riencia, pueda escogerse lo más útil y adecuado á la enseñanza del ramo, las conveniencias del país y á las necesidades de las industrias agrícolas.

Previniéndose en la ley de 1856, que los profesores de la Escuela de Agricultura, nuevamente organizada, eligieran de entre ellos mismos al que debía encargarse de la Dirección del Establecimiento, fué uno de los primeros pasos que se dieron, quedando nombrado, el mes de Enero de 1856, el Catedrático de Qúmica que subscribe y á quien entregó el edificio y los terrenos de San Jacinto el Sr. Lic. Arriola, Rector que fué del colegio de San Gregorio, y que, como se ha dicho, había quedado con el mismo carácter en la Escuela de Agricultura.

El nuevo Director se encontró con que faltaba unucho á ésta para lograr el fill á que se debía llegar, y conociendo, además, los proyectos de mejoras discutidas en 1853, solicitó del Gobierno que se dieran los recursos necesarios á fin de emprender algmas obras indispensables. Preciso es, en este punto, hacer justicia á la Administración de esa época, pues no sólo concedió en los días tranquilos lo que le fué pedido, si no que aun en los momentos más críticos, porque pasó después, lejos de escasear los recursos pecuniarios á la atención personal que le diera al principio, se dedicó con el mismo empeño á fomentar la Escuela, como si el Gobierno se hallara en condiciones nor'males, en perfecta paz y abundante en recursos. Acaso esa entusiasta protección y la que el público otorgó al İstablecimiento, influyeron en que se desvirtuara la institución, proyectando darle mayor ensanche del que acaso convenía, conno se dirá adelante. Para que se juzgue de la protección que por su parte concedió el público á la Escuela, bastará comparar los estados que se hallan al fin, en los que aparece el número de alumnos existentes en cada uno de los años correspondientes de 1855 á 1864.

La dificultad de hallar profesores para la enseñanza de la parte agrícola, propiamente dicha, ha sido el obstáculo más poderoso con que se ha tenido que luchar, pues aunque constante y empeñosamente se procuró, por desgracia todos los esfuerzos fracasaron, por motivos que debo callar. La persona que había sido contratada en París bajo el título de Director de Agricultura, no correspondió á las esperanzas y á los deseos, que sin duda, se tendrían al ocuparla: el hecho es que la instrucción quedó limitada durante los ocho meses 
escolares de 1856, á que los alumuos rompieran terrones con el azadón, cuando las llurias lo permitían. Tá Dirección de la Escuela estuve este año y los siguientes en verdadero conflicto, pues por una parte observaba la falta de método en el catedrático nombrado, y por otra reía la confianza que se tuvo eu él, fundada, sin duda, en la estinación que generalmente se ha dado á los extrangeros, como que éste luabía presentado como garantía el título de profesor de agricultula. No obstante esa coufianza, se resolvió la Dirección, en el año siguiente, á informar, reservada y verbalmente, primero á la .Junta protectora y después al Gobierno, de conformidad con el juicio que tenía formado, en vista de los hechos; mas como se creyó que era forzoso respetar el contrato, el mal siguió en 1857, y los alumnos muy poeo ó casi nada aprendieron. Sin embargo, siendo nu deber y adenás un noble interés de la Dilección, el insistir segunda y tercera vez, señalando una falta que continuaba y cuyas fatales consecuencias se tenían á la vista, no vaciló en informar por escrito, logrando al fin que fuera llamado el substituto, a la rez que el propietario concluvera el tiempo de su contrata, en mua comisión independiente á la Escuela. Muy poco se adelautó con el cambio, á pesar de que el nuevo nombrado llevaba, como su anterior, el título de profesor de agricultura, expedido por una de las escuelas europeas; su falta de conocimientos climatológicos, de la aptitud de los trabajadores, de los usos y costumbres en el país, y algunos defectos perniciosos á la buena edncación y extraños al profesorado, nulificaron la enseñanza y obligaron á la Direceión á solicitar que fuera separado. Penetrada la Junta protectora de la conveniencia de esta resolución, la propuso y obturo, annque dejando por necesidad, nu vacío en la parte ulás importante, racío que se proculó llenar de la manela que se dirá después.

Excusado habría sido el ocuparse en estos polmenores, si no fuera preciso el aprorechar para el futuro los resultados del pasado, en un pinto de rital interés.

Mientras esto pasaba (1857), continnaron conno en el año anterior las obras materiales y la apertura de fuentes brotantes; la provisión de máquinas, instrunentos, utensilios y aparatos; la de libros, para la biblioteca y para textos; la de unebles y objetos de iglesia; en fin, siguió la misma protección que se labía dispensado al Establecimiento, hasta el mes de Agosto, en cuyo tiempo, distraídos los fon- 
dos del Gobierno en otros gastos que juzgó preferentes, disminuyeron los auxilios del Ministerio, y la Escuela no pudo realizar las mejoras que labía emprendido y las que tenía proyectadas, considerándolas indispensables.

La falta en la República de profesores de agricultura dotados de las cualidades indispensables, y lo apremiante que era el no suspender las lecciones del ramo principal, obligaron, tanto á la Junta protectora del Establecimiento como á la Dirección, á llamar á un mexicano de quien se habían hecho muy especiales recomendaciones, como práctico, inteligente y conocedor, no sólo de la agricultura del país, sino también de la de Norteamérica, adonde liabía sido educado. Preciso es decir, que los alumnos hicieron indudablemente más que antes, se dió algún orden á los cursos, y auxiliado el profesor con el servicio gratuito de la clase de primer año de agricultura, de la cual se encargó el Director en Fnero de 1860, comenzaron las excursiones agrícolas, y con ellas, á mejorarse la enseñanza, despertando entre los estudiantes ese benéfico estímulo, que tanto influye en les adelantamientos científicos.

Conviene notar que, durante los tres años comprendidos, de fines de 1857 á 1860, la Escuela sufrió, además, frecuentes trastornos, por las conrulsiones políticas, hasta el punto de tenerse que trasladar los alumnos una vez al Colegio de San Ildefonso y dos al de Tetrán, cuyo Rector, que lo era el Sr. Lic. D. José M. " Lacumza, les abrió sus puertas con la mejor voluntad y con la más caballerosa atención. Fácil es conocer, que esos acontecimientos tuvieron grande $y$ muy contraria influencia en los adelantos de la juventud; mas, sin embargo, ni un sólo año dejaron de rerificarse los exámenes finales ni los premios consiguientes á ellos.

Antes se la indicado, que acaso la entusiasta protección que se otorgó á la Escuela en 1556, influyó en su contra, desrirtuando la institución; réase de qué manera:

Resuelto el Sr. Ministro á fomentar los ramos útiles y positivos, y viendo, por otra parte, que en la Escuela de Agricultura y Veterinaria se hallaban establecidas varias de las cátedras, commes con las que corresponden á los estudios de los Ingenieros topógrafos, de los mecánicos y de los ciriles, proyectó agregar las de los ramos que faltaban, y, en consecuencia, acordó que se reformara la ley publicada el 4 de Enero de 1S56. Ta Dirección juzgó inconreniente este 
paso, ya porque en su opinión, y generalmente hablando, el crecido número de alummos perjudica á la buena marcha de la educación y de la enseñanza, ya por las mayores erogaciones que eran consiguientes, y ya, en fin, y como fundamento principal, por el temor de que los jóvenes, prefiriendo la carrera de los Ingenieros, abandonaran la de Agricultura, y con mayor motivo la de Veterinaria, como en efecto sucedió. No obstante estas razones, la Junta protectora creyó más sólidas las del Sr. Ministro, y fué comisionada la misma Dirección para que, en unión de algunos de los profesores, se ocupara, bajo el plan dado, de la reforma de la ley. Así se verificó, publicándose ésta con fecha 31 de Diciembre del mismo año de 1856, en la que fueron organizados los estudios de los Ingenieros.

Bien pronto se vió, como estaba previsto, que varios de los alumnos prefirieron seguir estas carreras, especialmente la de Topógrafos, y que para tener alumnos que se dedicaran á la de Veterinaria fué necesario solicitarlos empeñosamente, lográndose, con no pocas dificultades, que se presentaran siete de la Escuela de Artes, establecida en 1857.

El cambio de administración que tuvo lugar en 1858, dejó á la Escuela en pie y en obserrancia de la ley dada en fines de 1856; pero el Ministerio del cual dependía aquélla, lejos de favorecerla de alguna manera, pensó en disponer y dispuso de los fondos del Establecimiento. En efecto, la Escuela de Agricultura contaba en 1858 con fincas $y$ capitales impuestos al seis por ciento, formando la suma de 859,776 pesos, que desaparecieron del modo siguiente:

En Febrero de 1859, entregados al Gobierno del Gene-

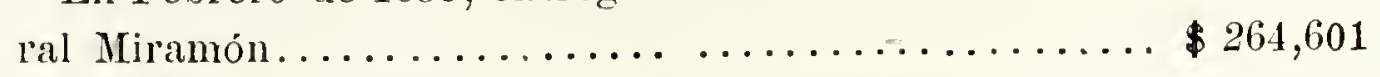

En Mayo de 1860, entregados á la misma Administra-

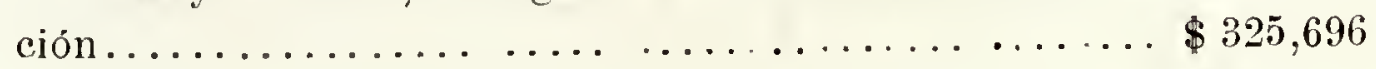

En 1861, á la Administración del Sr. Juárez.......\$269,479

Suma igual ...\$\$ $\$ 59,776$

Es claro que la Escuela tenía disponibles para sus gastos un rédito de 51,586 pesos 56 centaros, de los que únicamente debía deducir 660 pesos por el capital de once mil que reconocía á la Archicofradía del Santísimo, los gastos para el culto en la Iglesia de Loreto, los de los alumnos que contiuuaron en San Ildefonso y Semina- 
rio, y lo correspondiente á contribuciones, reparaciones y recaudación. Espanta verdaderamente el contemplar, cómo ha desaparecido esa suma, en qué tiempo y para qué; preciso es decirlo, porque lay frases que salen de los labios, á la manera que los suspiros se arrancan del pecho. ¿En qué se la empleado esa fortuna por mil títnlos sagrada? En cambiar á los miserables en acaudalados, y lo que es peor, en regar el ex́tenso teritorio mexicano con la sangre de sus hijos. ¡Dios perdone á los autores de tan perniciosos extravíos!

Pero siganos la historia. En el transcurso de 1859 á 1860, en que faltaron los fondos propios, los profesores dejaron de contar con el pago puntual de los sueldos, que aún se les deben, los alumnos no fueron debidamente atendidos en su ropa, calzado y demás necesidades de ese género; las obras materiales quedaron suspensas, las labores mal atendidas, y la aflicción y el desaliento substituyeron á la animación y á las halagiieñas esperanzas que, con fundada razón, se habían concebido.

Con lo dicho debe darse por terminado el segundo período, en cuanto al establecimiento de la Escuela en San Jacinto, 6 sea el retazo de los trabajos emprendidos por los anantes y protectores de la Agricultura.

\section{NOVENO PROYEOTO.}

Ocupada la Capital por las fuerzas liberales, en Diciembre de 1860, y separado, sin causa alguna, el Director de la Escuela de Agricultura y Veterinaria, en los primeros días del mes de Febrero de 1861, comenzó el noveno período que comprende hasta Mayo de 1863. Natural era, que tante el canbio de Gobierno como el del Jefe del Estableciniento, alteraran, en bien ó en mal, la marcha de éste; pero lrabiendo recaído el nombramiento de nuevo Director en una persona demasiado influente en el partido triunfante, se creyó, con fundamento, que la Escuela ganaría, recobrando, cuando menos, sus bienes ú otros equivalentes. Por desgracia no fué así, pues los ingresos apenas bastaron para cubrir los buenos sueldos de algunos de los empleados, sin que se hiciera en toda esa época adquisición alguna de importancia, ni mejora material, 6 se atendiera tal rez al pago puntual de los profesores y á las necesidades de los alumnos. 
Por otra paṛte, la marcha de la enseñanza, en los últimos dos años y medio, fué tan variada como poco atendida. El plan general de estudios, publicado el 15 de Abril de 1861, fijó algunas bases generales que dicen poco; mas como no llegó á observarse, y como las ordenes y disposiciones oficiales eran frecuentes y aun contrarias, debían alterar el orden con perjuicio de la buena instrucción.

Mny pronto quedó como olvidada la Junta protectora, suprimida la cátedra de religión, después destituido el capellán, y, por último, cerrada y abandonada la capilla y en libertad los alumnos para seguir la ereencia que mejor les pareciera. La música, la gimnasia, el manejo de armas, los idiomas, se quitaron igualmente: el Reglamento quedó sin observancia y las disposiciones económicas constantemente expuestas á las consecuencias de los acuerdos eventuales. Lo dicho basta para juzgar de lo que pasaría en cuanto á la educación ciril y moral; rebajado el prineipal resorte que enfrena á la juventud, todo debía seguir esa senda tortuosa que tanto influjo ejerce en la ruina de las sociedades.

Mas volviendo á los primeros meses del año de 1861, diré que la nueva Dirección comisionó á dos de los profesores para que extendieran un proyecto de reforma: este trabajo fué presentado, pero inútil; porque se adoptaron otras modificaciones más 6 menos notables: mencionaremos algunas de las que turieron lugar á principios de 1863, en que fueron aumentados los sueldos de algumos de los profesores de Veterinaria, aumentado, igualmente, el trabajo al de botánica, con notables inconvenientes, encargándole la clase de geología y de minerología; establecida y provista una de zootecnia, reducida á sólo una, las tres de agricultura, y destituidos, por lo mismo, dos de los profesores que las servían, con otras reformas de más ó menos importancia. Fácilmente se conocerán los inconvenientes á que dieron lugar tales disposiciones, yespecialmente la última. Habiendo entonces cursantes de primero, segundo y tercer año de agricultura, y obligados todos á recibir una misma lección, los dos últimos tuvieron que sacrificar el tiempo, oyendo lo que sa habían estudiado, y á quedarse sin que se les enseñara la parte que les faltaba. Desde luego se descubre la fuente de donde partió esa inadecuada reforma. Preocupadas sin duda las personas que interrinieron en ella con el programa de la Escuela de Grignon, y deseando modificar el personal de ella en consecuencia con las ideas de esa 
época, se intentó trasladar á la Escuela de México, un orden de enseñanza que, por inadecuado, debía ser improductivo. Baste anunciar que en Francia están reconocidos y estudiados sus terrenos, sus producciones, sus aguas, climas, influencias meteorológicas, necesidades industriales, aptitud individual, todo,en fin, de cuanto debe tenerse presente al organizar una Escuela de ese género, á la vez que en México, casi todo está por hacer, todo está por crear. Allí abundan los Establecimientos para toda clase de enseñanzas; aquí son limitados: allí bastan las elementales designadas para los grados de bachilleres en letras y en ciencias; aquí es indispensable que á todas, pero muy especialmente á las naturales, las físico-químicas y las matemáticas, se dé mayor extensión: allí serán prorecliosas las lecciones orales; aquí son del todo infructuosas: allí se tiene una juventud en su mayor parte rigorosa y capaz de resistil á las influencias de aquel clima; aquí generalmente éste es fatigante y sus nacionales menos robustos: allí conviene á los cursantes de agricultura trabajar como un gañán; aquí ni su posición social lo permite ni su constitución se presta á ello... mas, para quó seguil: medítese un poco sobre todas y cada una de las condiciones particulares de México, reflexiónese en lo que se ha dicho con relación á los fatales resultados que dieron aquí los profesores cuya carrera habían hecho en Europa, y se convendrá en que no es conveniente adoptar sin examen, en el orden agronómico, todos los métodos, instituciones y iisos de otros países. Esta última proposición es aplicable á otras varias carreras. Pretender trasplantar á México la enseñanza europea tal como allí se da, equivale á retroceder: las ciencias necesitan aclimatarse y la enseñanza relacionarse con las costumbres, con la constitución individual y con las capacidades relativas: sin esto no hay que aguardar buenos frutos. Perdóneme el lector esta digresión, y rolveré al punto del cual me había separado.

Entre los males consiguientes á la marcha de la Escuela durante ese período, fué otro de incalculables consecuencias, el de la admisión tumultuosa á los exámenes de agrimensores, en los que aún funcionaron como sinodales los mismos alumnos, de la manera más extraña: así es, que los títulos se multiplicaron con perjuicio de los estudios agronómicos, y con descrédito del Establecimiento. Sería preciso el dar demasiada extensión á este escrito, si hubieran de indicarse uno á uno, todos los acontecimientos notables de ese corto 
período; basta decir, que en él perdió la Escuela lo que había ganado antes, y más perdió en los sucesos que tuvieron lugar en Mayo de 1863.

Cuando las personas que figuraron en el gobierno de esa época, se decidieron á no defenderse en la capital, de la invasión que se aproximaba, dictaron algunas disposiciones generales relativas á los Establecimientos nacionales de euseñanza y cuyo objeto final parece que fué el de su destrucción completa: esto á lo menos pudiera inferirse observando lo que pasó en la Escuela de Agricultura. Fué arrendada $o ́$ acaso se simuló un arrendamiento de la firica por diez años, á favor de la persona que entonces funcionaba como catedrático de agricultura, pero esto se hizo de tal modo, que desde luego alejó toda idea de realidad: el que se decía arrendatario, no presentó más comprobante del contrato, que un recibo firmado por el Director, representando un valor de siete mil pesos, es decir, que sólo pagaba el tenedor de la finca, á razón de setecientos pesos anuales, ó sean cincuenta y ocho treinta y tres centaros en cada mes. Por otra parte, el ganado vacuno fué vendido, así como los bueyes, bestias de tiro, el coche, alfombras, floreros, objetos de iglesia, otros de la Escuela de Artes y cuanto más se consiguió realizar á vil precio. Varios de los instrumentos y aparatos fueron extraídos del Colegio y conducidos á casas particulares, tal rez para asegurarlos; en fin, tanto se hiro en poco más de un mes, que en realidad admira cómo pudo librarse lo que aún existe actualmente.

\section{DÉCIMO PROYECTO.}

Preciso era que, llegando á noticia del Gobierno tal desorden, procurara poner coto á esos demanes: en efecto, en los primeros días de Julio del mismo año, fué nombrado como depositario el catedrático de física D. Joaquín Varela, á quien se encargó que desde luego entrara en posesión de la finca y de cuanto hasta entonces se había salrado. Conrertido el edificio en cuartel fué inevitable el deterioro, é imposible la continuación de los estudios, para la conclusión del año escolar; así es que durante los últimos siete meses de ese año los trabajos consistieron en procurar recoger algunos de los objetos 
extraviados; en las labores propias de la estación que fueron la cosecha, trilla, desgrane, etcétera, y en disponer lo necesario para que continuaran los estudios en 1864, aun cuando fuera con on plan provisional $\mathrm{y}$ transitorio.

A costa de grandes esfuelzos, y renciendo las muchas dificultades que para ello se presentaban, se logró al fin dar principio á las cátedras el día primero de Febrero de ese año; mas falta de alumnos instruidos en los ramos preparatorios é indispensables para dedicarse á los estudios superiores y profesionales, hizo que únicamente fueran abiertas las siguientes cátedras: de primeras letras, de dibujo, de idioma francés, de idioma inglés, de aritmética, comprendiéndose los principios de contabilidad, y elementos de geografía, de álgebra, geometría y trigonometría plana, de agrimensura, de nociolies de física y de química, de mecánica general y agrícola y la de botánica y zoología.

No es tiempo de juzgar sobre los resultados de esa enseñanza; más tarde podrá hacerse con algún fundamento. Entretanto, y para complemento de esta breve reseña, ha parecido conveniente agregar el estado núm 8 , en el cual constan los nombres de los profesores y de los empleados que estaban sirviendo hasta fines de 1860 , las clases que desempeñaban y sueldos que debían disfiutar. En un estado semejante, marcado con el núm 2, constan los profesores encargados de las cátedras hasta Mayo de 1863 ; por último, bajo el núm. 3, aparecen los que actualmente están sirviendo (1864).

Terminada con esto la historia muy compendiada de los esfuerzos hechos por tantos años para establecer en México la enseñanza agrícola, es tiempo de formar el juicio comparativo que habíamos ofrecido, examinando las ventajas y los inconvenientes de esos proyectos, á fin de señalar el que más conrenga en adelante.

Los autores de la ley publicada en 1833 acaso supusieron, que así como basta un administrador para dirigir una propiedad rural, también bastaría un sólo catedrático para dar con provecho la enseñanza agrícola. No comprendieron, además, que todos los ramos de las ciencias naturales deben popularizarse en México y fomentarse con empeño, no sólo por el enlace que tienen con la Agricultura, sino también con el de las otras industrias y con las ciencias, especialmente las médicas. El plan de 1833 no es, por lo mismo, admisible tal como fué redactado. 
Como en 1835 no llegó á cumplirse con las benéficas disposiciones que dejó en su testamento el Presbítero Guerra, no hubo proyecto alguno; pero debe tenerse presente el hecho, porque aún lıoy la antoridad está en el caso de exigir el cumplimiento de la disposición y acaso poder contar con ese fondo auxiliar.

El tercer proyecto dado en 1843 fué muy útil para la época en que se dió y especialmente para satisfacer el plan que se propuso el Sr. Fonseca, mas no es ya de actualidad. Su mira fué establecer un Gimnasio, á donde se diera la enseñanza agrícola, pero al mismo tiempo la de otros diversos ramos, sin excluir la instrucción social: hoy es preciso que la enseñanza agrícola sea única y sólo conjunta con la Veterinaria por el íntimo enlace que tienen una y otra y por la apremiante necesidad de que ésta continúe sin mucho gravamen para el erario.

El cuarto proyecto, puede considerarse diridido y subdividido en rarios, pues aunque en la ley del Sr. Baranda se trazó un plan, la junta de industria lo modifico primero, lo varió después y lo complicó en fin, uniendo las Escuelas de Agricultura y de Artes que, por las razones antedichas, no es conreniente adoptar. Además, en uno de esos plames, el presentado en 1844 por D. Santiago Merrille, se excluye la instrucción preparatoria, se quiere que los alumnos se ocupen durante tres años en el estudio de la geología, que se les enseñe la construcción de los instrumentos aratorios $y$, en fin, que un solo catedrático sea á la rez Vicedirector y cultivador de riñedos. Tal proyecto es, por lo mismo, inadmisible.

Pero se necesita para conocer los inconvenientes de él, mas no debemos excusarnos de decir dos palabras sobre la conveniencia ó inconveniencia de dividir las escuelas preparatorias de las de los estudios especiales, aun cuando sea un punto que toca más directamente al plan general, supuesto que ese plan debe comprender á la enseñanza agrícola, y que ha habido y am hay diversas opiniones.

Las razones principales que se dan en faror de la división, son: primera, la de haber sido adoptada en muchos de los países civilizados: segunda, la de economizarse por̀ este medio los gastos; tercera, la de no multiplicar las cátedras de mas mismas materias. Véanse ahora algunas de las que son contrarias.

Conviniendo en la utilidad que por lo común resulta de imitar los usos ó las disposiciones de las naciones más experimentadas, no debe seguirse tal sistema de una manera absoluta, y más, cuando es- 
tá bien conocido y plenamente demostrado, que en cuanto al sistema de enseñanza, Mexico es excepcional, en ese y otros rarios puntos, como por ejemplo, la no admisión de internos, la falta de textos, las lecciones orales, etcétera, etcétera: de lo que resulta, que la primera razón no es buena.

En cuanto á la segunda, lo es sin duda menos, ya se considere que todo gasto en faror de la instrucción es indispensable y de ningún modo perdido, y ya que comparando los presupuestos en los dos casos, se advierte desde luego que la diferencia en favor de la economía es tan pequeña, que no merece ser considerada.

Hay que oponer á la tercera las rentajas incuestionables que resultan de que las cátedras preparatorias sean en número proporcional al de los establecimientos de instrucción, ya porque tanto las familias como los alumnos crían simpatías por los establecimientos, y éstas son farorables para los adelantos; ya porque los estudios preparatorios se pueden adecuar á la respectiva profesión, y ya, en fin, porque la enseñanza, es tanto más fructuosa, cuanto menor es el número de los cursantes. 'Tomemos un ejemplo que podrá servir para estimar estas reflexiones en su justo valor. Supóngase organizado en la Capital el Colegio de Estudios preparatorios, para las carreras matemáticas; á él deberían ir todos los que hoy concurren á la Academia de San Carlos, al Seminario de Minería, al Colegio Militar, á la Escuela de Agricultura, á la de Comercio y aun los que asisten á Letrán, San Idelfonso, etcétera. Y bien ¿qué local sería bastante para contener esa multitud de alumnos que en la actualidad cursan el primer año de matemáticas y aun el segundo y las clases de física? Suponiendo que lo hubiera y que estuviese dispuesto de manera que todos los educandos pudieran oir al profesor y ver los experimentos, éste tendría necesidad de limitarse á dar lecciones orales, lo que bastaría para que la enseñanza dejara de ser fructuosa. * De todo lo expuesto resulta que el cuarto proyecto de 1843 y su apéndice ó modificación de 1844 no son conrenientes, para que la enseñanza agrícola en México sea fructuosa.

Como en el quinto plan establecido por el Sr. Cortina en 1864, únicamente se previno la organización de la junta general que laabía de formar el proyecto de snseñanza misma, no es posible formar

* Aun hay más: la experiencia tiene demostrado que en México, no da buenos resultados ese sistema, como no los dió en 1833 y 1853 en cuyas épocas se pretendió establecer. 
juicio de él: pasaremos por tanto á examinar el sexto proyecto correspondiente al año de $\mathbf{1 8 5 9 .}$

El plan que se fijó aparece como el más metódico, de cuantos hasta esa fecha habían sido publicados; comprende la instrucción preparatoria, distribuyendo en cinco años todas las materias, y destinando, además, dos de ellos exclusivamente á la práctica en la Hacienda de Acolman. Sin embargo, se notan en él algunos defectos que lo hacen loy inadoptable: sea el primero, que la enseñanza de los ramos preparatorios y de los auxiliares es demasiado elemental; el segundo, que acaso se atiende más de lo que conviene á la de la agrimensura; y el tercero, que la de la física se divide en dos años, distantes uno del otro, sin que por ello se dé completa. El proyecto tiene la recomendación de estar acompañado del programa que debe seguirse en cada una de las cátedras, pensamiento que conviene adoptar con tanta más razón, cuanto que la experiencia enseña, que los colegios á donde se estudian varios ramos constitutivos de ma carrera, y dados por varios catedráticos, falta esa unidad, ese enlace indispensable que debe formar un todo homogeneo y consecuente, para que el estudio y los resultados finales sean provechosos, con economía de tiempo y de trabajo. Además, por ese medio se instruye al públice de lo que más le importaba rer, y de lo que tiene derecho á exigir del Establecimiento, así como éste de sus profesores. Pasemos á examinar el séptimo proyecto.

Habiendo sido formado por las principales personas que se ocuparon del anterior, es fácil inferir que descansaba en las mismas bases, pero además fué perfeceionado en la parte didáctica y muy mejorado en la adquisición de fondos de que antes carecía.

Aun cuando en la ley de 1853 sólo se viera la organización de las cátedras de Veterinaria, no puede dudarse que fué una mejora de grande importancia para el país. Con tal determinación se crió una nueva carrera, se procuró destruir el charlatanismo y la perniciosa ignorancia de los antiguos albéitares, se proporcionaron al público médicos veterinarios inteligentes y moralizados, á quienes pudiela confiar los animales enfermos, que además de tener un valor real, tienen por lo común el estimatiro que es incalculable; en fin, con el sólo hecho de organizar esa carrera se demostró que los mexicallos no desconocían las exigencias sociales de los países ilustrados, ni la de procurarlas al suyo. 
Con respecto á la Agronomía, se estableció, igualmente, una instrucción sólida, tanto en la parte proporcional como en la de sus ramos auxiliares, con los cuales y los dos años de práctica agrícola, dada debidamente, habrían salido del establecimiento profesores rerdaderamente útiles. Hay que agregar que en esa ley se cuidó de que los alummos no fueran extraños al estudio de la lógica: este es un principio general, pues la experiencia tiene demostrado que el de las mateunáticas precisa las ideas; mas auxiliado por el de la lógica permite, además, comunicarlas con mayor facilidad, claridad y método.

No obstante esas rentajas de la ley, no por eso ha dejado de ser criticada, señalando en ella dos defectos: el primero, que hace la carrera dilatada, y el segundo, que recarga á los alumnos con el estudio de muchas materias; pero si se reflexiona que todas las profesionales consumen tanto y aun más tiempo que la de Agricultura; que ésta es directamente produrtora é indispensable á las necesidades del hombre, y que el conjunto de conocimientos que en ella se adquiere es susceptible de varias aplicaciones, aun independientes de la agrícola en un caso y de la reterinaria en el otro, se convendrá en que son necesarios los siete años que se exigen á los segundos y los diez á los primeros.

Cuando transcurrido algún tiempo se examinan, con los datos de la experiencia, los trabajos de ese género, se ren, por lo común, con perfecta claridad todos los defectos que se ocultaban al formarlos; pero en el que nos ocupa sólo hallamos dos, uno de los cuales acaso se dejó para el reglamento, pero que conviene consignar en la ley; éste es el de no haber establecido las excursiones agrícolas, y el segundo, el de señalar escasas dotaciones á los profesores y empleados.

En cuanto á los fondos de que hemos hecho nención, la ley consignó, en efecto, para las escuelas de Agricultura y de Veterinaria, los siguientes: el sobrante de los bienes de parcialidades, el edificio de San Jacinto y sus terrenos, los bienes del Hospital de naturales, los del Colegio de San Gregorio, los que pertenecían al Juzgado de intestados y sus capellanías laicas; por último, las pensiones de los alumnos: si este conjunto no bastaba para todas las necesidades, las atendía cuanto hasta allí no lo habían sido.

Y si el juicio muy someramente anunciado es exacto, no sería inadecuado el adoptar hoy esa ley en la parte relativa á la enseñanza, aunque con las modificaciones indicadas. 
El octavo proyecto, ó sea la ley de 4 de Enero de 1556, tuvo igualmente los dos anteriores como base fundamental: ella dió además mayor desarrollo al establecimiento, ya disponiendo que hnbiera un cuerpo de profesores agregados, ya aumentando los fondos con los anxilios do los del Ministerio de Fomento, ya extendiendo la enseñanza á la clase de mayordomos, ya abriendo la puerta para que por disposiciones reglamentarias pudieran aumentarse las cátedras convenientes, y ya, en fin, creando una junta protectora que, procurando las mejoras, cuidase del cumplimiento de la ley y de los reglamentos. De aquí pudiera inferirse que el juicio farorable emitido respecto del plan anterior, comprende á éste aun con ventaja, tanto mayor cuanto que reilujo el tiempo á cinco años; mas no es así, por encontrarse los siguientes defectos.

El de sacrificar demasiado á la economía del tiempo, en la duración de los estndios, la extensión y aun algunas materias necesarias al agricultor, como son la lógica, la geología y la mineralogía. Otro es el de no organizar las excursiones agrícolas, el de prevenir que el director fuera temporal, que sólo lubiera un prefecto y, por últino, el conservar las limitadas dotaciones del plan de 1853. De esto resulta que excogitando lo útil de los dos planes, se mejoraría notablemente el que hoy pretenda darse. Hay que mencionar un decreto accidental que tocó en parte á la Escuela de Agricultura, y acaso con más notables resultados de los que pudieran esperarse: éste fué el de $1 .^{\circ}$ de Julio de 1856 , por el que se reglamentó la carrera y los exámenes de los agrimensores. Comprendiéndose en él á la Escuela de Agricultura y autorizándola para expedir títulos profesionales, varios de los alumnos que entonces existían tomaron la resolución de abandonar los estudios agronómicos, por seguir una carrera más corta, más fácil y que equivocadamente supusieron que les sería más productiva.

Los resultados han venido á demostrar, con liechos irrecusables, cuán perniciosa fué esa disposición, con particularidad en los años de 1861,1862 y 1863 , pues no era lo mismo antorizar á los agricultores como agrimensores, supuesto que se les exigían los estudios necesarios, que el permitirles, después de haberlos sostenido cuatro ó más años, que cortaran la carrera, recibiendo el título de simples agrimensores. Es, por lo mismo, de desearse que al formar la nuera ley se tengan en cuenta las razones indicadas. 
Pasemos al examen de la ley de 31 de Diciembre de 1856, que corresponde al noreno de los planes de que se ha hecho mención. Dos clases de modificaciones especiales contiene esa ley: una relatirá á las carreras de agricultura y de veterinaria, ya establecidas, $y$ otra á las de ingenieros, creadas nuevamente. Se ha dicho en cuanto a éstas que deben ser enteramente extrañas al establecimiento, siempre que se quieran fomentar cual conviene las dos primeras: así es que no hay necesidad de agregar nueros fundamentos para apoyar la idea de su separación. En cuanto á las modificaciones en la parte agrícola, juzgamos útil la de diridir la enseñanza en la que corresponde á los mayordomos, á los agricultores teórico-prácticos y á los profesores de agricultura. La de la enseñanza reterinaria, igualmente diridida en la que se ha de dar á los mariscales ó albéitares y la de los profesores ó médicos veterinarios, es una mejora que también debe adoptarse. Fn cuanto á las dotaciones, aunque aumentadas, no son ni equitativas ni suficientes. Por último, la subsistencia de la Junta protectora es indudablemente útil, y sobre no ser, como no es grarosa, debe reorganizarse.

Se ha indicado que el último proyecto, ó mejor dicho, los rarios que siguieron en el período comprendido de Enero de 1861 á Mayo de 1863 , fueron los que dieron los peores resultados; que la ley de 15 de Abril de 1861 sólo dió bases muy generales y no llegó á ponerse en práctica; en fin, que de cuanto entonces hubo nada se encuentra que conrenga adoptar. Pero como aun hoy no faltan quienes opinen á faror de dos modificaciones, que en parte son alucinadoras, una por económica y otra por novedosa, se hace indispensable el volrerse á ocupar de ellas.

Es la primera, la de que un solo catedrático quede encargado á la rez de la administración de las labores y de la enseñanza de los tres años de agricultura. Tal disposición es notoriamente perniciosa: todo el que ha tenido ocasión de seguir un curso completo de las materias que forman todo el curso, y considere igualmente que éste se ha de diridir en los tres años correspondientes á los estudios de los alumnos, se persuadirá que es de todo punto imposible el atender á cuatro cosas á un tiempo, sin sacrificio de la enseñanza y aun del orden en la administración de las labores. Además, como el buen método exige que cada uno de los profesores termine su curso con las excursiones agrícolas, esto no tendría lugar si se adoptara esa ense- 
ñanza unitaria. En conclusión, no debe olvidarse que la adquisición de los buenos conocimientos agrícolas, es la base y el objeto primordial del establecimiento; que á ello deben encaminarse todas las disposiciones, y que entre los medios para lograrlo, ocupa el primer lugar la necesidad de que haya un profesor para cada uno de los tres años que ordenadamente han de cursar los alumnos, terminando con las excursiones, de cuyos provechos nadie deberá dudar.

La segunda modificación, que 110 sin motivo hemos calificado de novedosa, consiste en la creación de la cátedra de Zootecnia. F́sta no es en realidad sino una parte de la Zoología, y es precisamente de la que de preferencia tiene que ocuparse el catedrático de este ramo con más detenimiento; dados á conocer los principios generales de Zoología, debe fijar la atención en el estudio de los animales útiles, ó lo que es lo mismo, de la Zootecnia: no hay, pues, razones fundadas para crear una plaza más, ni para complicar los estudios, demasiado extensos aun sin esta reforma. El alumno que ha concluido con aprovechamiento su carrera escolar, hará más tarde lo que todos y en todas las profesiones es común hacer: perfeccionar sus estudios pasando del de las obras elementales al de las clásicas, y aumentando el de los ramos enlazados con aquellos que tienen conocidos.

El que esto escribe no ignora que en la Escuela de Grignon ha estado confiada á M. Allibert la enseñanza de Ia Zootecnia; mas también sabe que en los estudios seguidos para el bachillerato, se exige como previo el de historia natural, que comprende, como es sabido, el de la Zoología. Mientras en Grignon no son admitidos los alumnos sin tener aquéllos, y además diecisiete años de edad, aquí no se fija ni se debe fijar ésta, y el estudio de los ramos preparatorios y auxiliares es conjunto con el de los profesionales, sistemándolos en un modo gradual, con el laudable fin de economizar el tiempo. No hay, por lo mismo, razón furdada para imitar esa práctica.

Ha llegado el caso de poner término á esta parte del escrito, porque habiéndose indicado que hoy no existe realmente plan alguno en el orden agrícola, tanto por falta de alumnos que turieran los estudios preparatorios, como por el carácter prorisional y transitorio que se ha adoptado, es más conveniente el aplicar las doctrinas establecidas y las observaciones anunciadas, á la redacción del projecto que más convenga preferir, aprovechando para ello la experiencia de treinta años de empeñosos esfuerzos, lo que en general y en ina- 
yor tiempo se ha tenido con relación á los métodos de enseñanza adecuados á la nación mexicana y, sobre todo, el conociniento de sus dirersos climas, usos y costumbres, tanto individuales como agrícolas.

Pero antes diremos dos palabras referentes á una idea desatendida en todos los planes mencionados, idea que acaso á primera vista se juzgue de menos importancia de la que realunente tiene, á saber: la necesidad de que los que aspiren al título de profesores de agricultura, sean por ese mismo hecho agricultores ó naturalistas, á la rez que unos y otros hagan preriamente los estudios de latinidad y de griego.

Aunque estos idiomas se consideran como muertos, no hay dudaque el latino es el que se ha usado y usa actualmente, no sólo en las obras clásicas, sino ann en las más sencillas descripciones botánicas, los nombres de los regetales y de los animales son también latinos; y puede agregarse que para adquirir ma sólida instrucción en los dirersos ramos que corresponden á las ciencias naturales, se hace indispensable el conocimiento de ese idioma. En cuanto al griego, bastará decir que, derivados de él los términos científicos, su estudio facilita y fija mejor el de los ramos principales y, por tanto, es inexcusable el conocer, cuando menos, la parte granatical apropiada á las aplicaciones que se han de hacer.

Aunque el objeto que me obligó á escribir esta reseña, exigía agregar un proyecto de estudios $y$ otros varios datos que convenía tener á la vista, me resuelro á omitirlos, así como los estados de que hice mención, á fin de evitar al lector el cansancio y aun el fastidio de los artículos demasiado extensos; creo que lo dicho basta para seguir la historia de la enseñanza agrícola en México. jOjalá que la nueva ley anunciada últimamente satisfaga á todas las necesidades y no adolezca de los muy grares defectos que acompañan á las que están formadas con el débil apoyo de las teorías alucinadoras, y á las que se oponen nuestros climas, nuestras costumbres y la constitución física de los habitantes de este desgraciado país!

He aquí el proyecto de ley que pudiera adoptarse para la enseñanza agrícola y la veterinaria, sea formando parte del plan general de estudios que se piensa dar, en cuyo caso se antepondría el capítulo ó título correspondiente, ó bien publicándolo como un decreto aislado, en el cual al preámbulo de uso común seguirían estos artículos: 
Art. 19. La enseñanza para las carreras de Agricultura y de Veterinaria, continuará definitivamente, conforme á esta ley, en el edificio de San Jacinto, con los terrenos que le pertenecen y los más que se procurará agregar.

Art. 29 La Escuela Imperial de Agricultura y Veterinaria será sostenida por los fondos públicos, dependerá del Ministerio de Instrucción Pública y se darán en ella, además de la enseñanza prinaria para exterinos, la de los ranos preparatorios y los superiores necesarios á las dos carreras.

Art. 39. La carrera agrícola comprende:

19. Ia instrucción común propia para formar mayordomos inteligentes.

2o La que corresponde á los agricultores teórico-prácticos ó administradores de fincas rústicas.

39 La que deben tener los profesores de Agricultura.

Art. 4\% Ia carrera Veterinaria comprende:

1) La instrucción común necesaria para formar mariscales.

29 La correspondiente á los módicos-veteriuarios ó profesores de Veterinaria.

Art. 5? Todos los que solicitaren ser admitidos como alumnos en la Escuela Imperial de Agricultura, acreditarán que tienen los conocimientos correspondientes á la iustrucción primarias á los que pretendieren seguir la carrera de profesores de Agricultura, se les exigirán, además, los de latinidad y de los dos primeros años de filosofía.

Art. 69 Tos que aspiraren á recibir la instrucción agrícola común ó para mayordomos, recibirán la materia correspondiente á la grande y pequeña cultura, así como la necesaria para perfeccionar su educación, todo couforme con las disposiciones que detallará el reglamento. Permanecerán tres años en el establecimiento, y durante ellos trabajarán en calidad de peones, por el tiempo y de la manera que se les señale.

Art. $7^{\circ}$ Los agricultores teórico-prácticos laarán su carrera en cinco años, conforme al orden siguiente:

Primer año. Aritmética completa; conocimiento de pesas y unedidas, así como de sus correspondencias; álgebra y geometría elemental; idioma francés; dibujo natural. Ejercicios gimnásticos, comprendiéndose los de natación. 
Segundo año. Física y química agrícolas teórico-prácticas. Idioma fiancés. Dibnjo de paisaje. Equitación.

Tercer año. Botánica y zoología agrícolas. Agronomía, comprendiendo el conocimiento y uso de los instrumentos, utensilios y máquinas agrícolas. Ejercicios prácticos de jardinería, dirigidos por el profesor del ramo. Dibujo de máquinas. Manejo de armas.

Cuarto año. Agricultura teórico-práctica. Veterinaria elemental, comprendiendo la pequeña cirugía y la práctica de herrajes. Dibujo anatómico.

Quinto año. Oría, engorda y mejora de ganados. Contabilidad agrícola y elementos de construcciones rurales. Excursiones agrícolas dirigidas por el profesor, para la práctica y perfección de los estudios hechios en los cursos.

Art. 8? Los alumnos que fueren aprobados en el examen de quinto año, podrán presentarse al profesional, y aprobados en él, recibirán el título que los antoriza para la administración de las fincas rústicas y para la valuación de las labores, de los sembrados, de los llenos y de las producciones agrícolas.

Art. 9? Los alumnos que aspiraren al título de profesores de Agricultura, estudiarán, en siete años, los ramos siguientes:

Primer año. Análisis geométrica, geometría descriptiva y principios de cálculo diferencial é integral. Idioma inglés. Dibujo de máquinas. Ejercicios gimnásticos, comprendiendo los de natación.

Segundo año. Agrimensura y nivelación, levantamiento de planos, y aplicaciones de la geometría á los planos acotados. Medida y distribución de las aguas. Idioma inglés. Dibujo topográfico. Manejo de armas.

Tercer año. Botánica, Física agrícola teórico-práctica, Geografía elemental, Gramática griega, Dibujo anatómico, Equitación.

Cuarto año. Zoología, Química agrícola teórico-práctica. Anatomía y fisiología hipiátricas. Dibujo anatómico. Ejercicios prácticos de jardinería, bajo lạ dirección del profesor del ramo.

Quinto año. Agricultura teórico-práctica, Geología y Mineralogía. Patología hipiátrica general, y la interna y externa. Práctica de herrajes.

Sexto año. Agricultura teórico-práctica, comprendiendo la cría, mejora y engorda de ganado. Clínica interna y externa. Materia médica é higiene hipiátricas. 
Séptimo año. Agricultura teórico-práctica, comprendiendo las construcciones rurales, la contabilidad agrícola y los avalúos. Excursiones ordenadas bajo la Dirección del profesor para la práctica y perfección de los estudios hechos en los cursos anteriores, y para la de las industrias de mayor interés al agricultor y naturalista.

A rt. $10{ }^{\circ}$ Concluido el séptimo año podrán presentarse los alumnos al examen profesional, y los que fueren aprobados, recibirán el título que los autoriza, para ejercer las profesiones de agricultor, naturalista, de módico-reterinario y de agrimensor.

A rt. 11. ${ }^{\circ}$ Pasados ocho años de organizada esa carrera, no podrán obtener cátedra alguna en los ramos designados para los cursos, ni desempeñar las comisiones científicas correspondientes, los que carecieren del título respectivo. Los avalúos de las fincas rústicas, de las labores, de los sembrados y de las producciones rurales, así como los reconocimientos y juicios de peritos, únicamente tendrán ralor legal, cuando fueren autorizados por dichos profesores, ó en su caso, por los naturalistas, por los agricultores teórico-prácticos, los médicos reterinarios, los ingenieros ó los agrimensores titulados.

Art. 12. ${ }^{\circ}$ Los que aspirasen al título de Mariscales, estudiarán en tres años los ramos siguientes:

Anatomía generaly descriptiva. Fisiología é higiene. Exterior de los animales domésticos, sns bellezas y sus defectos. Patología general y la interna y externa. Operaciones y herrajes.

Art. 13. ${ }^{\circ}$ Tos médicos-reterinarios estudiarán en seis años los ramos siguintes:

Primer año. Aritmética completa. Lógica. Idioma fiancés. Dibujo natural. Ejercicios gimnásticos, comprendiendo los de natación.

Segundo año. Física y química elementales, teórico-prácticas. Botánica. Idioma francés. Dibujo anatómico. Equitación.

Tercer año. Principios generales de Zoología y estudio completo de los animales domésticos. Anatomía y fisiología hipiátricas. Dibrijo anatómico. Equitación.

Cuarto año. Patología general y la interna y externa. Pequeña cirugía y práctica de herrajes. Manejo de armas.

Quinto año. Clínica interna y externa. Operaciones y herrajes.

Sexto año. Clínica interna y externa, operaciones y herrajes. Higiene veterinaria. Vicios redhibitorios. 
Art. $14 .^{\circ}$ Los alumnos que concluyeren el sexto año, podrán presentarse al examen general: en el caso de ser aprobados, recibirán el título que los autoriza para ejercer la profesión, sin cuyo documento no se permitirá tener enfermería hipiática ni banco de herrador. Los Mariscales titulados podrán tener banco, pero sólo funcionarán como peritos legales dentro de los límites de su ejercicio.

Art. 15. En cada una de las carreras que establece esta ley se harán presisamente los cursos completos, y los alumnos no pasarán de un curso al otro, sin el examen y aprobación en todas las materias asignadas al anterior.

Art. 16. ${ }^{\circ}$ El Establecimiento dará la enseñanza y toda clase de asistencias á diez y seis alumnos pobres, diez destinados á la agricultura $y$ seís á la Veterinaria: estarán dotados de talento claro, moralidad y buena conducta, suficientemente acreditadas: la manel’a de nombrar á dichos alumnos y demás condiciones necesarias, quedarán consignados en el reglamento, sirviendo de base, que en ningún caso serán adnitidos, más de diez y seis alummos de gracia.

Art. 17. ${ }^{\circ}$ Los individuos que habiendo comenzado los estudios en otros Establecinientos pretendieran continuarlos en la Escuela dè Agricultura, serán admitidos en ella presentando el correspondiente certificado, á satisfacción del Director, ó sustentando un examen en los ramos que se creyeren instruidos. Tos que presentaren título profesional, adquirido en el estranjero, acreditarán la legalidad del documento, identificarán la persona y sólo sustentarán el examen general,

Art. 18. ${ }^{\circ}$ El Gobierno nombrará una Junta Protectora del Estublecimiento, compuesta de cinco vocales y otros tantos suplentes, cuyas atribuciones designará el reglamento que ella forme y apruebe el Gobierno; siendo las principales; sobrevigilar y antorizar los gastos, acordar los económicos, cuidar del exacto cumplimiento de esta ley y de los reglamentos y proponer las mejoras y adelantos de que fuere susceptible el Establecimiento.

Art. 19. ${ }^{\circ}$ El cargo de vocal de la Junta es gratuito, honorífico y de confianza, y no será renunciable sino por cansas que el Gobierno califique de justas.

Art. 20. ${ }^{\circ}$ El Director es el jefe del Establecimiento y el inmediato responsable de su buena marcha, en el orden cientifico, moral y económico, así como del exacto cumplimiento de esta ley, del regla- 
mento y de las disposiciones supremas: es el conducto preciso de comunicación con el Ministerio, para todos los asuntos que lo exijan, y cuidará, con especial atención, que los profesores hagan las aplicacaciones correspondientes á los ramos de que están encargados, á fin de que los alumnos adquieran una instrucción sólida y positivamente práctica.

Art. 21․ El Director presentará á la Junta protectora, dentro de un mes, el reglamento que designe sus atribuciones y obligaciones, así como las del Rector, profesores y empleados; las condiciones que han de tener los alumnos para ser admițidos; la manera con que se han de hacer los exámenes anuales y generales; la expedición de títulos profesionales, provisión de cátedras, distribnción de tiempo en cada uno de los años, y cuanto más corresponde al reglamento interior.

Art. 220 La Escuela I. de Agricultura y Veterinaria tendrá un cuerpo de profesores agregados, que serán sustitutos, habiendo nno para cada cátedra; disfrutarán, cuando estuvieran en ejercicio, la mitad del sueldo asignado al propietario, el que cubrirá el fondo, si la falta fuere por enfermedad; en todos los otros casos percibirá el sueldo íntegro, correspondiente al propietario. Los profesores adjuntos serán nombrados por el Gobierno, á propuesta de la Junta protectora, oyendo al Director; mas pasados seis años de publicada esta ley, la provisión de las vacantes se lará por oposición.

Art. 23o La planta de profesores y empleados y los gastos anuales en la Escuela Imperial de Agricultura y Veterinaria, es la siguiente:

Un Director, que scrá catedrá-

tico, con el sobresueldo de. $\$ 1,800.00$

Un Rector y Capellán encargado de la educación religriosa y moral.............

Dos prefectos, á 600 pesos cada

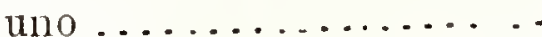

Dos preparadores para las clases experimentales, quienes selán tambiénsubprefectos, á 600 pesos cada uno..... $\quad 1,200.00$ Un prosector de anatomía y Al frente .......\$4,800.00

600.00
Del frentc

$\$ 4,800.00$ preparador de la cátedra de historia natural. ......... Un Ecónomo, tenedor de libros y encargado do la Secretaria.............. 800.00

1,200.00 Un profesor y sustituto de la clase de enscñanza prima-

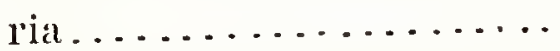

Ull maestro de ejercicios gimnásticos, comprendiendo los de natación.......... 400.00 A la vuelta..... \$7,200.00
600.00 $\frac{00.00}{00.00}$ 
De la vuelta. .... \$ $7,200.00$

Uno de equitación ........

Uno de manejo de armas....

Uno de música...........

Uno de dibujo natural, anatómico y de paisaje.

Uno de enseñanza plimaria.

Uno de idioma francés... ..

Uno de idioma inglés.......

Uno de gramática griega....

Un profesor para la clase preparatoria............

Uno para matemáticas y mecánica elemental..........

Uno de delineacion, geometria descriptiva y sus aplicaciones ................

Uno de topografía y construcciones rurales...........

Uno de botánica y zoolog̣ia..

Uno de fisica.............

Uno de quimica..........

Uno de geologia y mineralogria

Unode horticultura y jardincria teórico-prácticas.......

'Tres de agricultura teóricoprácticas, à 1,200 pesos . ...

Sobresueldo del profesor de agricul tura encargado de la hacienda
400.00

400.00

400.00

600.00

600.00

600.00

600.00

600.00

$1,000.00$

$1,000.00$

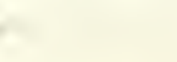

$1,000.00$

$1,000.00$

$1,200.00$

$1,200.00$

$1,200.00$

$1,200.00$

$1,200.00$

$3,600.00$

600.00

$\$ 25,600.00$
Al frente.

$. \$ 25,600.00$

Cuatroprofesores de veterinaria, ¿ 1,200 pesos. . . . . . . . $\quad 4,800.00$

Asistencia de diez y seis alumnos de gracia, á 300 pesos cada uno...............

$4,800.00$

Alimento de los empleados residentes en el Establecimiento ............ 1,600.00

$2,000.00$

Para reposición de utensilios

400.00

800.00

Para gastos de enfermeria...

Parael servicioen las cátedras experimentales ........ $1,000.00$

Para el culto en la Capilla del Establecimiento, comprendidas las funciones de San Isidro y Viernes de Dolores

Gastos anuales en carruajes y animales de tiro y silla...

$1,500.00$

400.00

300.00

300.00

Idem en premios.......... brica.............. 600.00

Del frente....... $\$ 25,600.00$
Idem en rayas y labores, comprendiendo los del jardin y huerta............. $6,000.00$

Idem imprevistos......... 200.00

Suma $\underline{\$ 50,700.00}$

Art. 24: Los gastos en instrumentos, utensilios y aparatos, así como los de las contribuciones rurales, adquisición de terrenos, ganados y semillas; los de libros y periódicos para la biblioteca, excursiones agrícolas $y$, en general, todos los extraordinarios, serán presupuestados gradual y oportunamente á fin de que nada falte para que la enseñanza sea completa y fructuosa.

Art. 25: Quedan derogadas las leyes, reglamentos y órdenes, contrarias á ésta, comprendiéndose la de $1 .^{\circ}$ de Julio de 1856 , en las partes relativas á la Escuela de Agricultura, que desde la fecha no hará exámenes de los agrimensores, ni expedirá los títulos que únicamente autorizan para el ejercicio de esta profesión. 
Por extraño que se considere el que figuren entre las partidas mil y seiscientos pesos correspondientes á los maestros de ejercicios gimnásticos y equitación, de manejo de armas, y de música, es una necesidad que conviene satisfacer en los establecimientos de educación, pero con especialidad en el de Agricultura. In primer lugar, ocupa á los alumnos una parte del tiempo destinado al descanso, que siendo el más peligroso conviene reglamentar, alejando por ese medio todas las ocasiones, á veces, contrarias á la buena moral. En segundo, que cada uno de esos ejercicios tiene ventajas reconocidas: los gimmásticos vigorizan; el manejo de armas educa, es útil al cazador y contribuye á que el hombre estime su dignidad; la música es un entretenimiento recreativo, que suaviza el carácter y sirve de compañía en las soledades del campo; en fin, la equitación es una positiva necesidad para el agricultor.

Acaso á primera vista aparezcan igualmente exagerados los cincuerta mil setecientos pesos anuales que deben invertirse en el sostenimiento de la Escuela; mas si se reflexiona que hay que deducir de esa suma, en la que figuran seis mil pesos para rayas, la de los productos de las labores, con los cuales quedan comprendidos; que casi siete mil pesos se consumen en las asistencias completas de los alumnos de gracia y en la de los superiores, residentes en el Establecimiento; que éste tiene organizado y que sostiene la enseñanza para seis carreras y, por lo mismo, el número de profesores es mayor del que sería para sólo una ó dos; que siendo experimentales la mayor parte de las lecciones, son por lo mismo consumidoras; que la necesidad de sostener dos carruajes con sus animales de tiro, aumenta los gastos; y en fin, que también hay un aumento en ellos por sólo la distancia á que es preciso que esté la Escuela, se convendrá en que realmente los gastos son demasiado económicos.

Por conclusión: si, como es de esperarse, ella corresponde con sus trabajos escolares y con el aprovechamiento de los alumnos al desaríollo de la industria agrícola en todos los ramos á que es llamada, no hay duda que los fondos públicos acrecerán en una proporción incalculable, retribuyendo con usura esa pequeña erogación. En fin, no hay que olvidar, que la protección á la Agricultura y á la Minería, son en todos los países, pero con especialidad en México, las fuentes inagotables de su riqueza, paz y prosperidad. 
Al trazar la listoria compendiada de la Agricultura en México, nos hemos fijado de preferencia en lo que ha sido su enseñanza en los últimos cuarenta y tres años, y muy particularmente la que se la seguido en la Escuela de San Jacinto, que hasta hoy subsiste: pero hemos tocado varios puntos de los que emanan cuestiones que es tanto más conveniente examinar cuanto que están íntimamente enlazadas, bien con el sistema general de enseñanza que haya de preferirse para toda la nación, bien con el que se ha adoptado para continuar ó no la que se da en San Jacinto.

Comenzando por este segundo punto, forzoso es decir que las disposiciones que se tomen deben reconocer como base fundamental la de que lo que allí existe, dista mucho de todo lo que es indispensable á un establecimiento agronómico de enseñanza en armonía con los progresos de la ciencia: fácil es demostrar esto por la simple enumeración de lo único con que puede contarse.

\section{EDIFICIO.}

Aunque irregular por su construcción antigua y por el destino que turo durante tantos años, hay la capacidad suficiente para colegio de internos y alojamiento de algumos de sus empleados y sirvientes. Se cuentan en buen estado la sala de estudios, las cátedras, la capilla y la enfermería; falta, sin embargo, que adecuar algunas de sus partes á los objetos á que deben ser destinadas. A este número pertenece la enfermería veterinaria, indispensable para las clínicas; la sala para disecciones; cuartos para completar los pocos que hoy tienen los sirvientes; cochera, virienda para el director; y por últiino, que hacer algunas reparaciones en los techos, paredes, tapias, ètc. En cuanto á edificio, puede decirse que se tiene lo más y filta lo menos. 


\section{SERVICIO DE CÁTEDRAS.}

Las de botánica y zoología, de geología y mineralogía, de física, de química, de agrimensura, de dibujo y de primeras letras, si no tienen todo lo que requiere una buena enseñanza, no les falta lo más, como sucede respecto de las de reterinaria y de agricultura; las necesidades de éstas siendo mayores y más importantes, son, por lo mismo, más urgentes.

\section{BIBLIOTECA.}

Aunque provista de más de cuatro mil volúmenes, muchos de ellos son extraños á las materias propias del establecimiento; lay otras que faltan enteramente, y varias, con especialidad las periódicas, están truncas. Es conveniente, además, el suscribirse á las publicaciones periódicas extranjeras para estar al nivel de los adelantos.

\section{JAKDIN Y HUERTA.}

He aquí una de las partes que requieren mayor cuidado; hoy no es un jardín de recreación, ni es una huerta, cuyo cultivo y productos corresponden al nombre que lleva; menos es un jardín de plantas, un jardín botánico, en el que el orden y la clasificación de los regetales facilite á los alumnos el conocimiento de la ciencia, al profesor la sólida enseñanza y á los establecimientos todos adonde debe darse ese ramo, un recurso del cual siempre han estado privados.

En el año de 1858 promovió empeñosamente el director de la Escuela de Agricultura, el establecimiento de un jardín botánico que sirviera igualmente á los alumnos médicos: designado el lugar y trazado el plano, se comenzó por preparar el terreno y levantar el cercado. Lus gastos debieron ser cubiertos por ambas escuelas, á saber, la de Medicina y la de Agricultura. El Sr. Muñoz Ledo, Ministro 
entonces de Fomento, acogió la idea con tal agrado, que personalmente lleró cien pesos para que desde luego principiara la obra. ¡Contraste notable! ¿Quién había de suponer que esa miserable suma costaría al establecimiento el perder, mediante dos acuerdos dados por la misma administración y firmados por la misma mano, la enorme suma de 590,297 pesos! Iil resultado fué de que la escuela se quedó sin bienes y sin jardín botánico.

\section{HACIENDA Y LLENOS.}

Ta extensión de los terrenos es la siguiente:

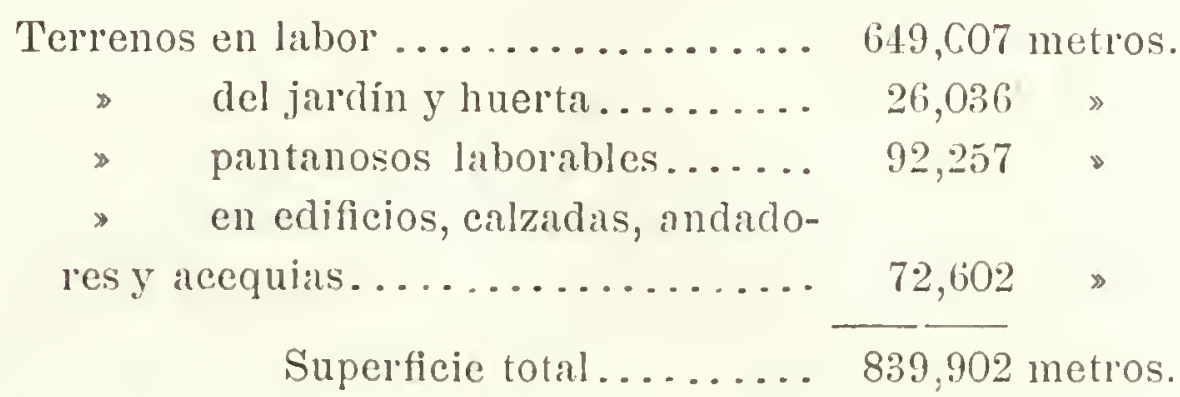

83 hectaras, 99 aras, 02 centiaras, ó cerca de dos caballerías.

Se ve que dista mucho de merecer el nombre de hacienda, que generalmente se le da. Si por las economías indispensables de la época en que se compró fué un triunfo y una ađquisición, hoy conriene darle mayor extensión, lo que no es difícil procurándose los terenos colindantes: los propios de la escuela están comprendidos mos bajo otros y una parte de ellos pantanosos; por fortuna, atravesados por dos ríos, se prestan á la mejora que debe procurarse. Ta magneyera, como esquilmo importante, requiere ma reposición.

En cuanto á los llenos, casi puede decirse que falta todo y algo más, puesto que el instituto exije, por su naturaleza, el conocimiento, cría y engorda de toda clase de ganados, el de todas las razas, y ser en fin, en cuanto diga relación con la parte rural, una finca modelo. Hoy se cuenta con un sólo establo, que no basta, y con un palomar; no hay un aprisco, ni zaurdas, ni gallineros, ni caballeriza; en fin, faltan los ganados y sus alojamientos. Faltan, igualmente, trojes, depósito para carretas, colección de instrumentos y máquinas, pues lo que se encuentra en cuanto á esto es linitado y generalmente malo. 
En vista de lo dicho ocurre naturalmente el preguntar, si conrendrá el que se continúe dando en San Jacinto la enseñanza agrícola y veterinaria, ó será preferible el trasladar la Escuela á otro lugar, supuesto el gasto que tiene que erogarse en aquel edificio. En sentir del que esto escribe, debe preferirse lo primero, por las razones siguientes: La de estar hecho un gasto, no despreciable, el que sería del todo perdido, con la traslación: la de hallarse situado convenientemente, tanto para que las familias puedan mandar á sus educandos, sin tropezar con las dificultades que aún se exageran entre los mexicanos, cuando los establecimientos están distantes, como para aprovechar la buena instrucción de los profesores y la puntual asistencia de los empleados, que faltaría sin duda en otra localidad: la de contar con todos los recursos de man Ciudad protectora, sin los inconvenientes de que los alumnos vivan dentro de ella. Bajo el punto relativo á la salubridad, la experiencia de más de nueve años tiene satisfactoriamente demostrado, que San Jacinto es, en cuanto á esto, uno de los lugares más apropiado para una casa de educación.

Verdad es que, respecto á la instrucción práctica, sería útil el contar con una extensa propiedad rinral de las que no faltan en la Nación, que tuviera á la vez terrenos de climas fríos, templados y calientes; pero siendo los de San Jacinto templados, los cultivos de los otros dos quedarán perfectamente conocidos, y amn estudiados, cuidando de que se realicen las excursiones agrícolas.

Además de las razones dichas, hay una muy relacionada con otra cuestión importante y de la cual pasamos é ocuparnos.

¿Bastará un sólo establecimiento agronómico de enseñanza para toda la Nación? Entretanto que el número de sus habitantes, el estado de las vías de comunicación y el de los fondos públicos se hallen como lo están hoy, basta uno sólo convenientemente atendido. Si todas las leyes deben ser la emanación reglamentada de las necesidades y de las conveniencias de los pueblos, en las de instrucción pública es preciso seguir este sistema con extricta escrupulosidad y más todavía con las naciones que, como México, se hallan en su infancia y obligadas por otros motivos á observar una pludente economía: no hay para qué pretender un desarrollo prematuro, que costará la vida, ni menos un lujo ruinoso, que lejos de dar crédito apenas merece compasión. Por esta y otras razones análogas, conviene que la enseñanza agrícola, la veterinaria y todas las que correspon- 
den á las carreras especiales, como son la minería, medicina, ingeniería, comercio, etc., queden limitadas por ahora á un solo establecimiento, aun cuando la grande extensión del territorio nacional pidiera bajo otras consideraciones la multiplicación de ellos. Día llegará en que el aumento notable de la peblación ponga de manifiesto la necesidad; entonces Guadalajara y San Tuis Potosí, reclamarán su Escuela de Minas, de Agricultura y de Medicina; mas por hoy no hay otra razón para solicitar su establecimiento que la de provincialismo y las alucinadoras que se derivan de él.

En esas cindades, así como en otras de las principales, Puebla, Morelia, Guanajuato, Kacatecas, etcétera, conviene por ahora, organizar únicamente los estudios preparatorios, para todas las carreras; mas las cátedras superiores que constituyen los ramos profesionales, así como la recepción á los exámenes generales y la expedición de títulos, deben limitarse á sólo la Capital. Durante el Gobierno Virreinal únicamente en México hubo colegio para mineros, no se conoció la enseñanza agrícola, y aun la médica, nada más contó con la que daban las Unirersidades de aquí y de Guadalajara. Después de la independencia, cada Estado se propuso imitar inconsideradamente cuanto reía en la Capital; pero, careciendo de personas y de medios materiales, adecuados á la buena enseñanza, el charlatanismo y la ignorancia fueron generalmente el pésimo fruto de esas aspiraciones, emanadas del espíritu de provincialismo. Si, pues, se desea que las ciencias progresen y que las profesiones no se prostituyan, debe limitarse el número de las Escuelas especiales á las extrictamente necesarias, organizar prudentemente la enseñanza preparatoria y multiplicar cuanto más se pueda los establecimientos de educación primaria, que es por hoy lo que más conviene.

Fundados en tales principios generales, emanados y apoyados en los hechos que han pasado, y en atención á lo dicho, respecto de la enseñanza agrícola en particular, podemos concluir con las siguientes proposiciones:

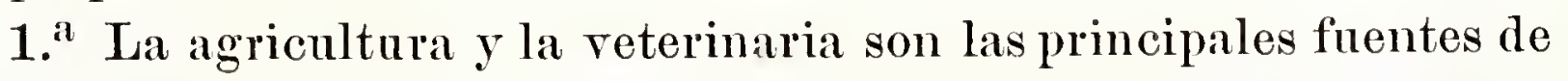
riqueza nacional y, por lo mismo, al Gobierno conviene fomentarlas por cuantos medios sean necesarios.

2. ${ }^{\text {a }}$ Uno de los principales consiste en la buena organización de la enseñanza y en la estabilidad del plan que se adopte.

3. ${ }^{a}$ Por hoy couviene montar debidamente un solo estableci- 
miento nacional para la enseñanza agrícola, agregando á él la de la historia natural y la de veterinaria, conforme al proyecto de ley preinserto.

4. ${ }^{\text {a }}$ Este establecimiento debe ser el que actualmente existe en San Jacinto, pero con las mejoras propuestas y las más que se juzguen necesarias.

5. ' No conviene sostener más que diez y seis alumnos de gracia, y aun estos deben ser escojidos entre los que hayan dado pruebas irrecusables de talento claro, moralidad, buena conducta y que, además, aseguren su permanencia en el Fstablecimiento por todo el tiempo necesario para concluir su carrera.

6. ${ }^{\text {a }}$ No debe continuar la autorización que se dió á la Escuela de Agricultura para examinar y expedir títulos á los agrimensores.

Noticia de los alumnos que ha tenido la Escuela de Agricultura en los años que se expresan á continuación:

\begin{tabular}{|c|c|c|c|c|c|c|c|c|}
\hline \multirow{2}{*}{\multicolumn{2}{|c|}{ A $\mathbb{N} O S$}} & \multicolumn{2}{|c|}{ INTERNOS } & \multirow{2}{*}{$\begin{array}{l}\text { Medios } \\
\text { pupilos } \\
\text { de paga }\end{array}$} & \multirow{2}{*}{$\begin{array}{l}\text { Externos } \\
\text { en clase } \\
\text { superior }\end{array}$} & \multirow{2}{*}{$\begin{array}{c}\text { Externos } \\
\text { cn 1 a.s } \\
\text { letras }\end{array}$} & \multirow{2}{*}{ TOTAL } & \multirow{2}{*}{$\begin{array}{c}\text { Deducilos } \\
\text { los exter- } \\
\text { nos de pri- } \\
\text { meras le- } \\
\text { tras quedar. }\end{array}$} \\
\hline & & de gracin & de paga & & & & & \\
\hline Noviembre & 1855 & 10 & 14 & & & 18 & 42 & 24 \\
\hline . , & 1856 & 13 & 35 & & 3 & 27 & 78 & 51 \\
\hline , & 1857 & 32 & 118 & 15 & 2 & 42 & 209 & 167 \\
\hline ", & 1858 & 36 & 94 & 9 & 9 & 41 & 189 & 148 \\
\hline , & $1859^{*}$ & 35 & 43 & 9 & 3 & 44 & 134 & 90 \\
\hline ," & 1860 & $\ddot{33}$ & 56 & 10 & 6 & 40 & 145 & 105 \\
\hline :" & 1861 & 34 & 18 & 10 & 4 & 13 & 79 & 66 \\
\hline$:$ & 1862 & 34 & 31 & 8 & 7 & 18 & 98 & 80 \\
\hline Mayo & 1863 & 5 & 2 & 4 & 6 & 26 & 43 & 17 \\
\hline Abril & 1864 & 20 & 6 & 7 & 3 & 48 & 34 & 36 \\
\hline
\end{tabular}

* En este año fueron vendidas las fincas y circuló con algún fundamento la noticia de haberse mandado cerrar el Establecimiento. 


\section{PERSONAL DE LA ESCUELA DE AGRICULTURA} al finalizar el año de 1855.

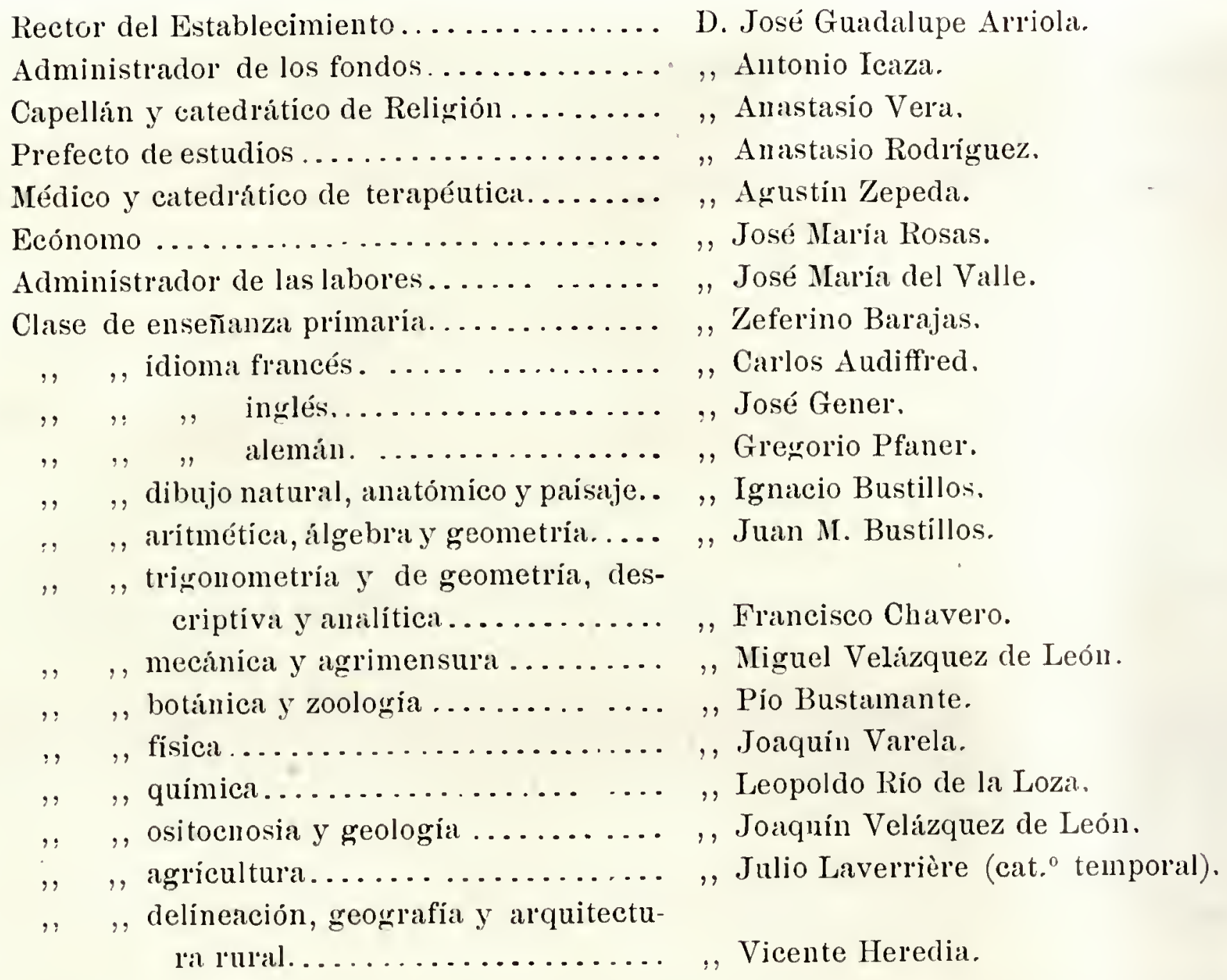

NOTAS.-Las cátedras de los Señores Bustillos, Velázquez de León, D. Joaquín; Velázquez de León, D. Miguel, y Audifred, fueron servidas por los sustitutos D. Isidoro Chavero, D. Francisen Hermosa, D. Joaquin de Mier y Teriu y D. José Gener.

Los sueldos correspondientes à este año, fueron satisfechos. 


\section{PERSONAL DE LA ESCUELA DE AGRICULTURA \\ al finalizar el año de 1856.}

JUNTA PROTECTOFA.

CARGOS Y CÁTEURAS.

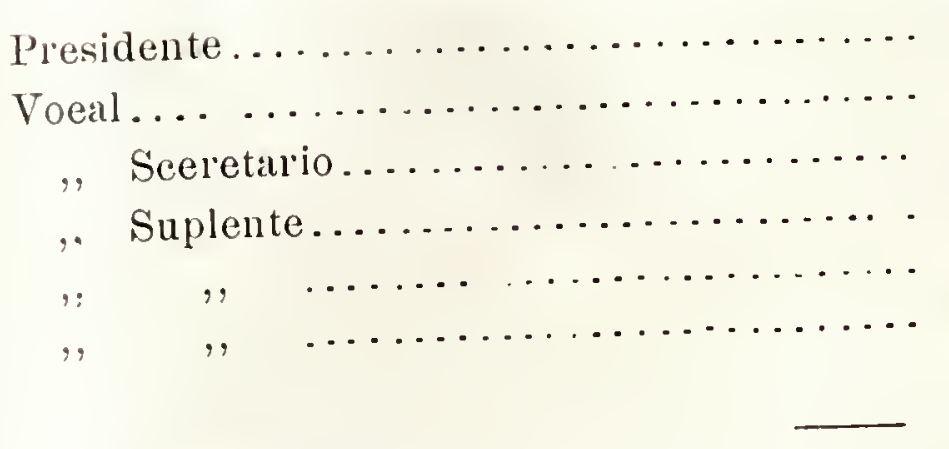

NONBRES.

Sr. Lic. D. José Urbano Fonseea.

,, ,. ,, Mariano Riva Palacio.

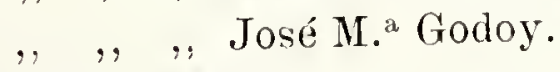

D. Luis Robalo.

, Joaquín G. Icazbalceta.

,, Manuel Campero.

P. Director y eatedrátieo de químiea.

Viee-Direetor y eatedrático temporal de

Capellán y catedrático de Religrión......., ,, Vicente Garcia.

Prefeeto y Secretario ............... , Ignacio Rivera.

Sub-Prefecto y preparador de quimiea.... ,, Amado Aguirre.

Administrador de los fondos.......... ,, Antonio Icaza.

Administrador de las labores......... ,, J Jaquín Guzmán.

Mayordomo.................. , José Dominguez.

P. Médico del Estableeimiento y eatedrático de veterinaria .............

Maestro de ejercicios gimnásticos........

,, de manejo de armas ...........

P. Dibujo natural, anatómico $y$ de paisaje...

P. Cátedra de primeras letras ..................

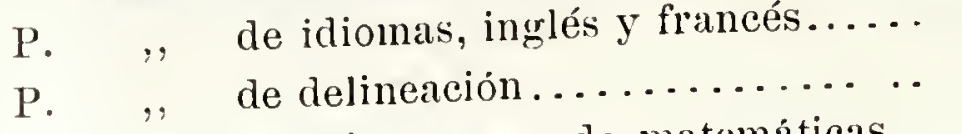

P. , , de primer curso de matemáticas..

P. $\quad$, de segundo ,, ,. $\quad$, , . , ,. Joaquín de Mier y 'lerán.

P. , de greografia y agrimensura......, , Francisco Chavero.

P. , de botánica y zoología........., Pio Bustamante.

P. $\quad, \quad$ de fisica................, Joaquín Varela.

NOTAS. - La clase de primer eurso de matemáticas fué servida por el Sr. D. Isidoro Chəvero como sustituto del Sr. Bustillos.

La P. indica que los profesores eran propietarios, $y$ los qne no la tienen, interinos.

Fn este año quedaron pagados todos los profesores y empleados. 


\title{
PERSONAL DE LA ESCUELA DE AGRICULTURA
}

\author{
al finalizar el año de $185 \%$.
}

El de la Junta protectora, Direetor, Administrador de los fondos, Capellán, Médico y Mayordomo, continuaron como en el año anterior y además los siguientes:

Prime: prefecto

Segundo prefecto

Subprefeeto y perparador de quínica....

Profesor de anatomia.... ...........

Jefes

Mayordomo

Eseribiente y sustituto de primeras letras.

Marstro de ejereicios gimmísticos.......

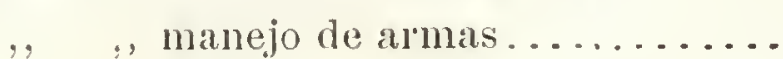

., . música

P. Cátedra de dibujo natural, anatómico y paisaje..................

P. , $\quad$ 1. de edueación prinnaria......

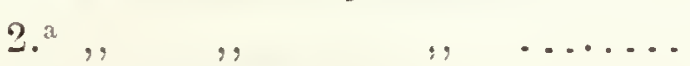

P. .. de idioma francés............

P. $,, \quad, \quad, \quad$ inglés...........

,,$\quad$.,$\quad$ alemán............

P. $\quad$ : , botánica y zoología.........

.. , anatomía y fisiología........

, . . anatomía y farmaeologia.....

. . delineación...............

P. .. . greometria y sus aplieaeiones..

. . primer año de matemáticas...

„. . segundo año de matemátieas..

., . meciniea y analitiea........

., , topografía, geología y astronomía .................

P. ., , construcciones propias del ingeniero...............

P. $\quad, . \quad$., física ...............

P. $\quad, \quad$, químiea.............

., , arricultura... . ..........

. . ., ecollomía y dereeho rural....
D. Imnaeio Rivera.

, José María Vergara.

, Juan Carmona.

, Felipe Zepeda.

, Luis Orozeo y D. Albino Magaña.

, José Dominguez.

, Pedro Miranda.

.. Feliciano Chavarria.

, Alitonio Martel.

,A Arustin Balderas.

, Ignacio Bustillos.

, Zeferino Barajas.

, José Ortiz Monasterio.

, José Gener.

José Gener.

, Oloardo Hassey.

„, Pio Bustamante.

, Irnaeio Alvarado.

, Eugrenio Bergeyre.

,, Luis G. Anzorena.

,Vieente Heredia.

„. Isidro Chavero.

,, Joaquín Mier y Terák.

, Juan Cardona.

„Franeiseo Chavero.

., Juan M. Bustillos.

, Joaquín Varela.

", Leopoldo Río de la Loza.

, Santiago Motte.

, Joaquín Guzmán.

NOTA. - Hor nada se debe por los sueldos correspondientes al año de 1857. 


\title{
PERSONAL DE LA ESCUELA DE AGRICULTURA
}

\author{
el 15 de Enero de 1861.
}

La Junta Protectora continuó, menos los Sres. Riva Palacio y Rovalo.

Director .......................

Vice-Director....................

Capellán y catedrático de Religión........

Prefecto......................

,, segundo y preparador de química

Tesorero adminisirador .............

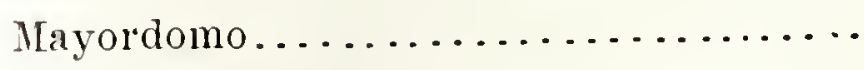

Preparador de física................

Prosector de anatomía ..............

P. Médico y catedrático de patología y farmacología ............................

Cátedra de ejercicios gimnásticos. ........

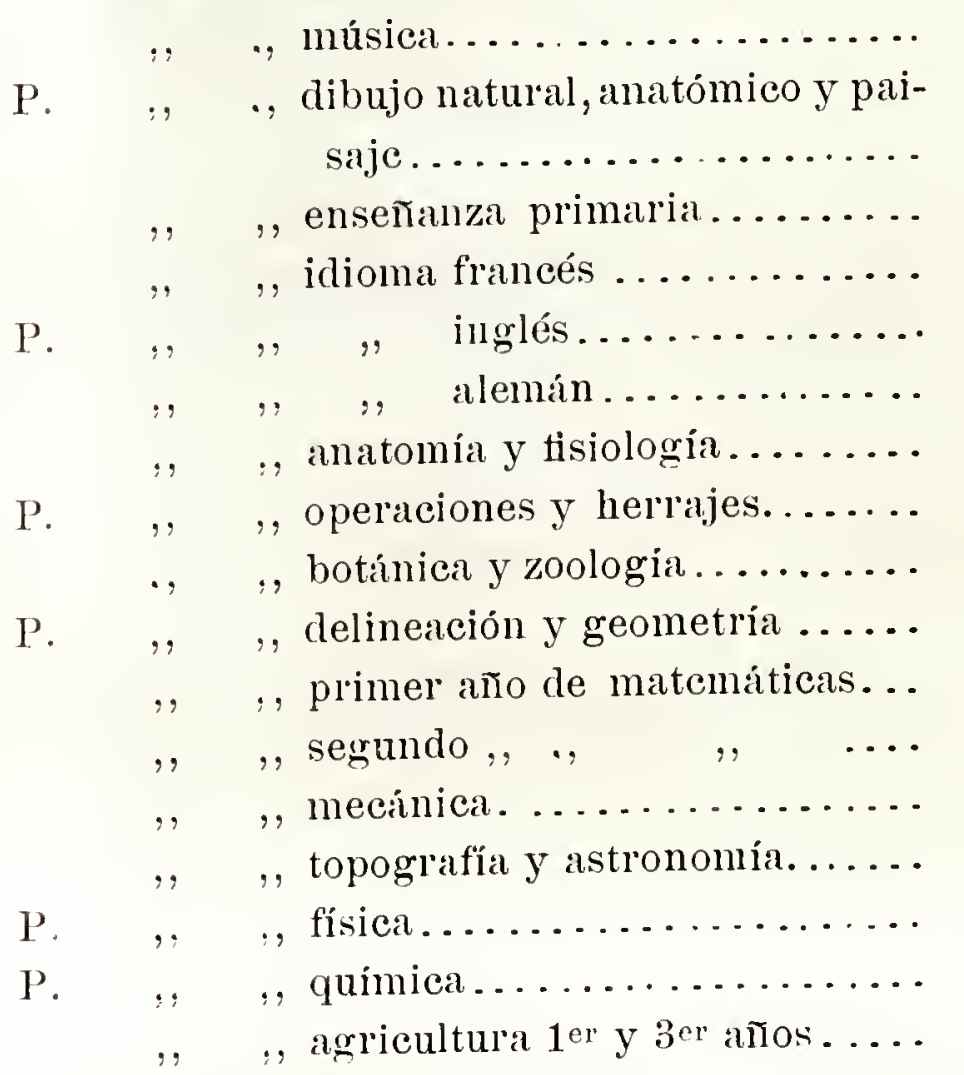

D. Leopoldo Río de la Loza.

, Joaquín Mier y Terán.

, José María Garay.

, Luis Orozco.

,, Sebastián Reyes.

,, Ramón Alcaraz.

, José Domíngruez.

, Miguel Parra.

, Felipe Zepeda.

, Agustin Zeperla.

, Joaquin Noreña.

", Agustín Balderas.

, Ignacio Bustillos.

, Crisófolo Magaña.

,, Antonio Balderas.

"José Gener.

,, Oloardo Hassey.

,, Ignacio Alvardo.

,, Eugrenio Bergeyrc.

, Lauro M. Jiménez.

, Vicente Heredia.

, Isidoro Chavero.

,, Joaquin Mier y Terán.

,, Juan Cardona.

, Franciseo Chavero.

,. Joaquín Varela.

,. Leopoldo Río de la Loza.

", Francisco Collantes.

NO'TA. - De los años de 1858 á 1861 se adeuda á los profesores una parte de sus sueldos, cuyas cantidades no figuran por no haberse podido ministrar los datos correspondientes. 


\section{PERSONAL DE LA ESCUELA DE AGRICULTURA}

en Mayo de 1863.

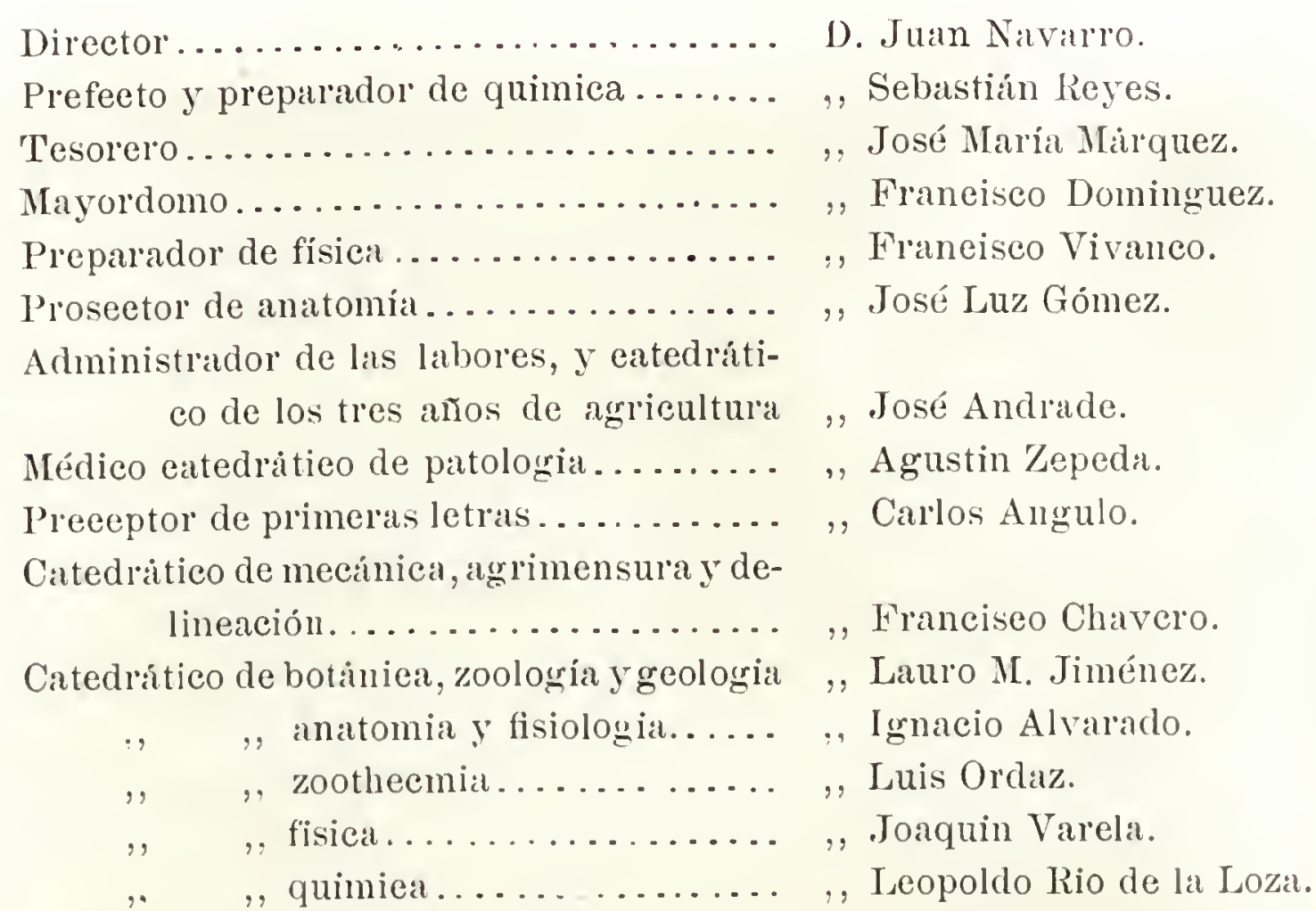

NOTA.-De 1861 i Mayo de 1863 se quedaron debiendo a los catedriticos parte de sus sueldos. 


\section{PERSONAL DE LA ESCUELA DE AGRIOULTURA}

\section{en 1864.}

Director y catedrático de física y química elementales................ D. Joaquin Varela.

Prefecto de estudios y Secretario ......... ,, Ignacio Vivanco. ,, y sustituto de cátedras.........., , Sebastián Reyes.

Rector, Capellán y Catedrático de Religión.. ,, Jesús Orsuño.

Ecónom y Secretario ............... ,, Efrén Sánchez.

Conserje y guarda ropa.............. ,, Tomás Becerra.

Admiuistrador de las labores............ ,, Lucio Becerra.

Preparador de física................ ,, Luz Gómez.

, $\quad$, química $\ldots \ldots \ldots \ldots \ldots \ldots \ldots$, , Antonio Rolón.

Maestro de ejercicios gimnásticos y natación. ,Joaquín Noreña.

Catcedrático de idioma francés..........., , José Gener.

$,, \quad, \quad, \quad$ inglés............, , Roberto Heaven.

, , , botánica y zoologia ........ ,, Lauro Jiménez.

$\begin{array}{lll}, & , \text { mecánica y agrimensura ..... , Juan Cardona. } \\ , & , \text { estudios preparatorios....... , Luis G. Ansorena. }\end{array}$

Preceptor de primeras letras..........., , Carlos Angulo.

El que suscribe ha estado encargado de formar esta reseña histórica. NOTA. - Todos los sueldos correspondientes a este año, han sido satisfechos con puntualidad. 
Es adjunta la reseña histórica de lo que ha sido la Agricultura en México, y con particularidad la enseñanza de esta ciencia, desde su establerimiento en la Escuela de San .Tacinto.

Aunque el trabajo quedó concluido desde el 28 del pasado, y pude por lo mismo haber cumplido exactamente con la disposición del Ministerio de Eomento, que fijó como plazo el día primero del actual, el tiempo empleado en que lo pusiesen en limpio, el cotejo y correcciones indispensables y la rectificación de los estados finales han demorado la entrega que alora hago; debiéndose tener presente que. como sabe esa Dirección, casi un mes transenrió del tientpo en que se me dió la connisión el 16 de Marzo en que recibí los documentos, que se jurgó necesario tener presentes.

No quedo satisfecho de que el adjunto escrito llene plenamente el objeto que todos debemos desear, pero sí lo estoy de haberlo procurado, á costa de mayor trabajo del que correspondería si sólo se juggara por los resultados. Esto se comprenderáal saber, que la maror parte del tiempo fué perdido en la rista de los expedientes, en procurarse las leyes, reglamentos y disposiciones que era conveniente tener á la vista, y, por último, en concretar la serie dilatada de acontecimientos y coordinarlos después. Me parece que únicamente falta como dato importante, mostado que dé á conocer el pasivo de la Escuela de Agricultura, cuyos comprobantes no he conseguido hasta la fecha. 


\section{TAIA DE BOSQUES}

\section{EXPORTACIÓN DE MADERAS}

Desde 30 de Septiembre de 1S54, presentó á esta Secretaría una exposición la Sociedad promovedora de mejoras materiales y morales, manifestando los males consiguientes á la enorme tala que han sufrido y sufren los bosques con que se surte esta Capital de maderas, leña y carbón, refiriendo el hecho de que los indígenas de los pueblos que tienen bosques propios, han cortado y cortan á su antojo los árboles, sin sujeción á la ordenanza antigua de bosques y sin observar siquiera el método que aconseja la razón en beneficio propio, y previendo la alza progresiva de precios en las maderas de construcción y la más trascendental al común de los consumidores, en las que sirren para combustible, supuesto que aquí se carece del carbón de piedra con que cuentan otros países.

También indicó que el sistema generalmente empleado por los indígenas en el corte de los encinos, es el de trozarlos por el tronco, y no por los brazos, dejando una banderilla, como vulgarmente se dice, ó de horca y pendón como previene la ordenanza, de que resulta que el árbol así destruido, nada puede producir en lo sucesivo, mientras que cortándole los brazos gruesos, á los cuatro años está más frondoso, y con brazos mayores que cuando se cortó.

Que en los cortes de ocote y oyanel es más considerable la tala y el desperdicio, porque nunca cortan un árbol grueso para sacar de él diversas piezas, según permite su diámetro, sino que buscan un árbol del grueso de la pieza que se proponen sacar; y si por ejem- 
plo, necesitan una vigueta ó morillo, no elijen la punta de un árbol grueso, cuya base produciría otras piezas grandes, pres talan un árbol tierno, que con el tiempo daría piezas de más tamaño y valor que la rigueta ó morillo que en lo pronto necesitan; cuando laciendo uso del método establecido para el corte de maderas, se aprovecha liasta la ńltima rama de un árbol, sin talar los tiernos que van á reemplazar á aquéllos, contribuyendo así á la conservación de los bosques.

Que en auxilio de estos medios destructores emplean otro de más trascendentales consecuencias, cual es el de las quemazones, que rulgarmente llaman chamusquinas, porque desde el mes de Enero incendian los pastos resecos con el hielo, bajo el pretexto de que nazcan mejor los nuevos; y como los aires dominantes en esta estación extienden el fuego á muchas leguas de distancia, resulta á veces que no sólo destruyen los retoños y árboles en sazón, sino también las leñas, maderas y carbón existentes en los puntos cilcunvecinos, sin castigarse á los incendiarios con la pena que prescriben la ordenanzą de bosques y las leyes commues.

Que habiendo, por otra parte, aumentado el consumo del combustible por las fábricas que usan rapor y por el mayor número de panaderías y baños que cada día ra exigiendo el crecimiento de la población, ha subido de punto la tala y desperdicio de los bosques, mayormente cuando en los que circundan el Valle de Mréxico, no se planta un sólo árbol, con lo cual llegará el caso de que no liaya bosques sino á grandes distancias; experimentándose los males que desde entonces se anunciaban, y se sienten más cada día de la escasez y carestia de maderas, leña y carbón, de insalubridad en la atmósfera por la falta de arboledas, y diminnción ó retardo de las lluvias.

La sociedad expuso también, que la frecuente renovación del personal de los Ayuntamientos, ha sido perjudicial al plantío de árboles en los caminos, calzadas, alamedas, y paseos públicos de sus respectivas demarcaciones, pues terminando en brere tiempo el período ordinario de estos cuerpos colegiados, cuando apenas empiezan á instruirse en los negocios de su municipio, hau tenido que dejarlos á sus sucesores; concluyendo con proponer un proyecto de ordenanzas de bosques y plantíos, porque habiéndose encargado detenidamente de examinar las leyes que sobre la materia rigen en 
otros países, encontró que ninguna era adoptable al nuestro, por ser enteramente diversas sus circunstancias.

Ese proyecto se pasó á informe del Agente general de Agricultura, quien lo evacuó extensamente en 31 de Enero de 1855, conriniencio en el hecho de que los montes arbolados sufren una tala considerable, especialmente los cercanos á las grandes poblaciones: que el mal viene de muy atrás pues ya se hacía sentir desde antes de la conquista, según el testimonio de los historiadores: que después de ella ocnrió su intensidad, como lo hizo notar el Barón de Humboldt: que ésta vá en anmento todos los días, por las cansas que asigna la Sociedad de mejoras y que á esta incuria en la conservación y renovación de los árboles, se deben los malos efectos y se deberán todavía otros mayores de los que indicó dicha corporación.

Aunque ese estado de cosas pedía urgente remedio, y amque la agencia convino en que tocaba ponerlo al Supremo Gobierno, porque en todas partes corresponde al poder público reprinnir los abusos de la propiedad particular, que ceden en perjuicio del bien común, no le parecieron apropósito en su totalidad, las medidas consultadas por la sociedad para el logro del laudable fin que se propnso; $y$ aduciendo sobre el particular las ilustradas doctrinas de Jorellanos y refutando el proyecto en la parte que lo calificó incongruente é irrealizable, concluyó proponiendo el que conceptuaba que podía entonces adoptarse.

No sólo las citadas Sociedad y Agencia fueron el orden por donde se trasmitía al Supremo Gobierno el clamor de $u n$ mal que se lamentaba hace tiempo y lacía profunda impresión en varias partes: la Sociedad de mejoras materiales de Acayucan, en 26 de Junio de 1853; el Ayuntamiento de México y el Gobierno de su Distrito, en 21 de Febrero de 1854; la Jefatura política del Territorio de Teluantepec, en 18 de Maryo del mismo año; el Interventor representante del Supremo Gobierno de la Compañía Sloo, del expresado Tehuantepec, en 28 de Novienbre del propio año; la Diputación territorial del Mineral del Monte, en 31 de Enero de 1857; el Agente en Jalapa por este Ministerio, en 5 de Mayo de 1857, y hasta en nuestros días, el minero del Chico, D. Tomás Mancera, en ocurso de 13 de Enero último, han representado enćrgica y rigorosanente acerca de esta materia, promoviendo se dicten las medidas cficaces para 
contener un mal que cada día va en aumonto, y exponiendo á su verz que continúa la tala de los bosqnes y la carestía del combustible; que del ameno y frondoso bosque del mineral ya sólo queda el nombre, cuando antes contaba con nunerosos y elevados encinos, lo cual es ya muy dificil reponer, pues necesitan el largo período de cien años para estar en su virilidad; que con notable perjuicio de la salubridad pública, la agua se ha desecado en sus veneros pol falta de los árboles; que el arbitrio más directo para impedir su total destrucción, sería hacel uso del carbón de piedra, tanto en las máquinas de vapor como en los lormos de las ferrerías, y en todas las otras operaciones en que fuese aplicable dicho fósil, que hay en gran abundancia en Zacnaltipán; y que mua patriótica apelación á los particulares, sería muy débil estímulo para salvar los intereses de la commuidad, ann cuando las antoridades quieran velar y se esfuereen en hacer eficaces las disposiciones relativas á arbolados y bosques, porque, ó no laallan la cooperación de los habitantes y labradoles, 6 á sus exhortaciones y providencias oponen la fatal fuerza de inercia, si no es que quedan nulificadas por las frecuentes excitaciones políticas, que nada útil y prorechoso dejan plantear en el país.

Es rerdad que en circular de 15 de Abril de 1557, dirigida á los Gobernadores de los Estados, se les excitó á que bajo su más estrecha responsabilidad procurasen la observancia de las disposiciones rigentes, orderiando que no se usare por leña sino las ramas de poda y los árboles riejos y deformes; que por cada uno que se cortare se plantaran cuatro nuevos; y que á los infractores de dichas disposiciones se les castigase con penas severas; pero esa circular ni fué bastante eficaz para remediar el mal en toda su extensión, ni los Gobernadores cuidaron de llevarla á efecto, ni tampoco fué acatada por los que debieron cumplirla, y sin embargo de que el 19 de Septiembre de 1853 expuso el Ministerio que se estaba formando un proyecto de ley que reglamentase el corte de maderas y la conserración de los bosques, no consta en esta Secretaría que hubiese llegado á expedirse.

Ta reseña histórica de esos hechos conduce á otras consideraciones análogas, porque por una precisa consecuencia de la continua agitación del país, por el desplestigio en que cayeron sus autoridades á causa de su fácil é incesante destitución, y porque en rez de ocuparse exclusiramente del bienestar y mejora del pueblo, nás bien 
cuidaban de conservarse en los puestos, estando siempre en atalaya contra sus enemigos, llegó á relajarse en sumo grado el eficaz resorte de la obediencia, tan necesario para que surtan efecto las disposiciones de los que mandan.

Además ha hecho conocer la experiencia, que no ha sido sólo la impericia en el corte de árboles la que ha dado margen á su derastación, sino también la necesidad, siempre creciente, de maderas y combustible para las habitaciones, las operaciones del laboreo de minas, las máquinas de rapor y el beneficio de plata por toneles, que requiere gran cantidad de leña para mantener el fuego noche $y$ día, no menos que el establecimiento de ferrerías $y$, recientemente, el de los ferrocarriles, que aún no emplean, como en Europa, el carbón de piedra:

A estas causas se agrega la del interés de los propietarios, de los madereros, de los leñadores y carboneros, en procurar á cualquier costo sacar las mayores ventajas posibles del consumo de esos artículos, al precio á que el público se ve obligado á pagarlos por necesidad, sin atender tales especuladores á que se derasten los bosques, ni cuidar tampoco de su reposición por medio del plantío de niteros vástagos, que repongan con el tiempo los árboles que destruyan.

Pues todaría se agrega á esto la insuperable dificultad de sobrerigilar que el corte se haga con sujeción á las reglas establecidas, porque la vasta extensión de las serranías, unicla á la diseminada y escasa población que hoy tiene nuestro extenso país, y la facilidad que los indígenas tienen de transitar esas serranías por veredas practicables ó enteramente desconocidas, y aun la posesión de hecho en que lam estado y aún permanecen de explotar á sn arbitrio este ramo de riqueza pública, lıan hecho nugatoria toda medida que tienda á civilizarlos en este punto y poner coto á práctica tan abusiva, siu ser bastante eficaz para conseguirlo, el establecimiento de guardabosques, porque, en el aislamiento á que tienen que estar reducidos en el ejercicio de sus funciones, corren grave peligro de sar víctimas de su celo, lo cual, naturalmente, retraerá á muchos de aceptar estos comprometidos cargos, aun cuando se les asignen regulares dotaciones, ó los orillará á colndirse con esa clase de industriales ó á disimular que sigan cono hasta aquí en el misno desorden que observan, por temor de no perder los destinos ó la vida: siendo testimonio de la expresada dificultad el hecho que refiere el Prefec- 
to Político de Pachuca, á consecuencia de la orden que se le dirigió para que impidiese la destrucción de los montes de Capula, de los cuales se estaban sacando, cada semana, hasta cuarenta mil arrobas de leña, pues ha manifestado que los naturales de aquellos montes se subleran con frecnencia; y que, por la escabrosidad de los lugares, no hay rigilancia que baste, ni de propietarios, ni de antoridades, á evitar dicho abuso, supuesto que á pesar de las disposiciones superiores y de la fuerza armada puesta para obserrarlas, roban constantemente los árboles y la leña.

A vista de estos hechos, difícil es resolver el problema de si será mejor aplazar la expedición de la ordenanza de bosques y plantíos para cuando acabe de pacificarse el país, y moralizándose sus latbitantes, se lallen en aptitud de acatar y obedecer las reglas que se establezcan, 6 si no obstante la actual situación y la tenaz rebeldía con que algunos se oponen á los positisos progresos y adelantos, que está reclamando la cultura del presente siglo, será conveniente dar desde hoy el paso de expedir esa ordenanza, consultando en ella las medidas oportunas para que no se quede sólo escrita y puedan llegar á lograrse sus interesantes objetos.

A la prudencia y sabiduría de V. M. toca resolver esta cuestión y á mí proponerle el proyecto de que se trata, como lo verifico despnés de 1 m maduro examen sobre tan delicada materia, adoptando en su mayor parte el que consultó la Agencia general de Agricultura, como también el reglamento que la Isegislatura de Jalapa expidió el 19 de Diciembre de 1845, y ampliando nno y otro con los artículos conducentes, además de losque me han parecido necesarios respecto á la explotación de maderas, mediante á que las preciosas y variadas que se extraen para el extranjero, apenas rinden una corta ntilidad al fértil suelo que las produce. 


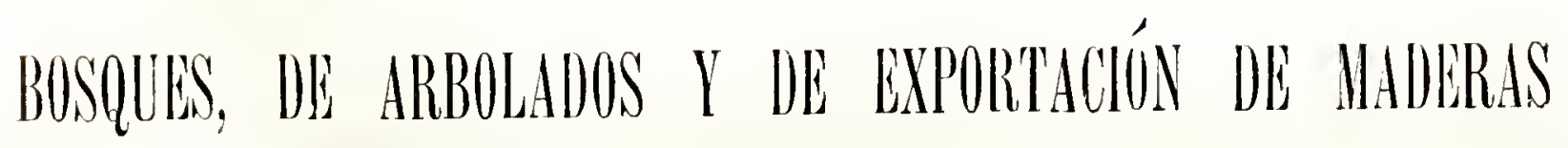

FORMADO POR EL SR. DR. DON LEOPOLDO RIO DE LA LOZA.

\section{CAPÍTULO I.}

De los plantios, su conservación y aumento.

Art. 19 'Todos los funcionarios municipales del Imperio y la Dirección de caminos, quedan obligados á multiplicar y conservar los árboles en los términos que expresa esta ley.

Art. 2o Igual obligación tienen los propietarios de predios rústicos, ó los arrendatarios por cuenta de los primeros.

Art. 39 Los propietarios de que habla el artículo anterior, plantarán cada año cinco árboles, cuando menos, por cada caballería de tierra de regadío, y uno, á lo menos, por cada una de las de temporal. Los que sólo tuvieren una caballería ó menos, plantarán el número proporcional hasta cubrir sus linderos.

Art. 40 Las Municipalidades y Comisarías pondrán, annalmente, cuando menos, á razón de un árbol por cada cien liabitantes. Los Prefectos, en vista de las circunstancias de cada población, podrán asignarles un número mayor de árboles.

Art. 5o La Dirección general de caminos pondrá cada año cinco árboles por cada legua de los caminos que están á su cargo. El mismo número plantarán los empresarios particulares de caminos y ferrocarriles. 
Art. 69 Las plantaciones encargadas á los funcionarios municipales, se harán en las plazas y en los lugares que designaren las respectivas Juntas protectoras de arbolados; las que lo están á la Dirección general de caminos yá los empresarios, en las calzadas de su cargo; y las de particulares, en los lugares de su propiedad que ellos mismos eligieren.

Art. 79 Los Ayuntamientos y Comisarios municipales formarán desde luego dos padrones, en los que conste: la extensión de los predios, tanto nacionales, como del común ó de propiedad particular, á fin de conocer y fijar el número de árboles que debe plantar, todos los años, cada uno de los respectivos responsables. Del 15 de Marzo al 15 de Abril procederán dichos funcionarios al examen cor'respondiente, para asegurarse de haberse ó no cumplido con las obligaciones contenidas en esta Ordenanza, dando cuenta á la Junta protectora, la que impondrá á los infractores, gubernatiramente, las penas en que hubieren incurrido.

Art. So La Dirección general de caminos remitirá, igualmente, cada año, en la primera quincena de Maỵo, al Ministerio de Fomento, un estado general, en el que conste el lugar, número y especie de árboles que hubiere puesto, así como los que corresponden á los empresaios de caminos y de ferrocarriles. Las Juntas protectoras de arbolados remitirán dicho estado á los Prefectos políticos.

\section{CAPÍTULO II.}

De la poda y del corte de maderas.

Art. 9o La poda de Ios árboles, se laará solamente en invierno y á la caída de las hojas, permitiéndose cortar únicamente las partes secas, y de las rivas, las que fueren indispensables para eritar la defornidad de los árboles, o para aumentar la copa en los de las calzadas. El corte total de un árbol, sea de la especie que fuere, en ningún caso se hará, sino lubiere llegado á su decrepitud, ó cuando menos á su perfecta ririlidad. Menos se permitirá el cortar mayor número del que corresponde, conforme á las disposiciones rigentes y á todas las reglas que ellas prescriben.

Art. $10{ }^{\circ}$ Todo el que esturiere autorizado para cortar maderas, quedará sujeto á las reglas siguientes: 
1. a Las estacas se cortarán de la ramazón; y en general, toda pieza chica, de las puntas de los árboles gruesos y sazones.

2." Los oyameles, ocotes, cedros y Ayacahuites, se cortarán á tres cuartos de rara de altura, sobre el nivel del suelo. Los encinos madroños y ahuehuetes, se cortarán de horca y pendón por las ramas, dejando la mayor y más delecha, para que sirra de guía. Sólo se cortarán por el tronco los árboles de estas tres últimas clases, cuando por riejos no puedan dar ya retoños vigorosos, y por cada uno de estos que se corte, se plantáán cuatro vástagos que los reemplazen.

3." Las cortezas de uso industrial, ó medicinal, serán cortadas únicamente de los árboles, que han llegado á su decrepitud, de los arrancados por los vientos, ó de los que hubieren muerto.

4. Ta extracción de la trementina $y$ demás principios, sean resinosos, gomosos etc., así como las colectaciones de fruta, ó de frutos, tales como los que dan la cera vegetal, las bellotas y demás, no podrán hacerse destruyendo el vegetal, sino cortando los frutos á mano, $y$ haciendo las incisiones á una altura tal del árbol que éste no muera hasta que haya dado su máximo producto. La extracción de la trementina sólo se hará de los árboles adultos.

\section{CAPÍTULO III.}

De la exportación de maderas.

Art. 119 Ningún buque nacional ó extranjero podrá exportar maderas de construcción ó de ebanistería, de los puertos habilitados para el comercio de altura ó cabotaje del Imperio, sin previo permiso de la Junta protectora del puerto respectivo.

Art. 12. ${ }^{\circ}$ Para obtener ese permiso deberá el consignatario ó Capitán del buque, presentar á dicha Junta su solicitud, acompañada de un certificado de la Aduana Marítima, en que conste haber concluido su descarga y no tener pendiente responsabilidad alguna con la Hacienda pública, conforme á las leyes.

Art $13 .^{\circ}$ Al expedir el permiso deberá el Capitán ó consignatario del buque, entregar en la caja de la Municipalidad respectira, dos pesos cincuenta centavos por cada ma de las toneladas que mida el mismo buque, según el certificado que presentará de la Capi- 
tanía del puerto, pagando, además, un peso por la salida de cada árbol, ó la madera equivalente.

Art. 14. ${ }^{\circ}$ Estos permisos no se concederán sino por las Juntas protectoras que residan en los puertos labilitados para el comercio de altura, de los cuales podrán pasar los buques al de cabotaje que hayan designado para tomar la madera, sujetándose previamente los buques extranjeros, á lo que previene la ordenanza marítima vigente.

Art. 15. Cuando los consignatarios ó Capitanes de buques extranjeros pretendan que éstos exporten maderas de las que expresa esta ley, de algún río ú otro punto de la costa del Imperio, no habilitado para el comercio de cabotaje, deberá solicitar el permiso corespondiente de la Secretaría de Fomento, por conducto de la Junta protectora del puerto más inmediato, á los habilitados para el comercio extranjero.

\section{CAPÍTULO IV.}

De los desmontes.

Art. $16 .^{\circ}$ No se podrá hacer desmonte total ni parcial de ningún bosque, sino eon licencia escrita de la respectiva Junta protectora de arbolados, y ésta, para concederla ó negarla, mandará instruir expediente sobre la necesidad del desmonte que se solicita.

\section{CAPÍtULO V.}

$$
\text { De los incendios. }
$$

Art. 17. Se prohibe todo incendio en los arbolados, ya sea cansado por simple daño, por mejorar los pastos, por la mala situación de las carboneras, ó por cualquier otro motivo.

Art. 1S. ${ }^{\circ}$ Todo el que aprehenda ó denuncie á un incendiario, quedará exento, durante un año, del sorteo para el ejército y de toda carga concejil. 


\section{CAPÍTULO VI.}

De las penas en que incurran los infractores de esta Ordenanza.

Art. 19. Los dueños de predios rústicos, los f̂uncionarios municipales, los directores $\mathrm{y}$ empresarios de caminos que no planten el número de árboles que les corresponden, según las prevenciones de esta ley, pagarán cinco pesos de multa por cada árbol que dejen de plantar, entendiéndose que la multa respecto de los funcionarios $y$ empleados es personal y no se ha de cubrir de los fondos nacionales.

Art. 20. ${ }^{\circ}$ Todo el que corte un encino, madroño ó fiesno, por el tronco, y no de horca y pendón, además de satisfacer al dueño el duplo ralor del árbol, pagará una multa de tres pesos, y si no tiene para cubrirla, sufrirá de uno á seis meses de obras públicas. En igual pena incurrirá el que no reponga los árboles cortados, conforme á lo dispuesto en la parte 13. ${ }^{\mathrm{a}}$ del art. 42.

Art. 21. 'Todo el que corte ó mande cortar cualquier árbol que no hubiere llegado á su mayor crecimiento, pagará una multa de dos á cien pesos, según los casos, ó sufrirá de uno á seis meses de obras públicas, á juicio de la Junta protectora.

Art. 22. ${ }^{\circ}$ Todo individuo que sin la correspondiente licencia dada por escrito, sea de la autoridad, ó en su caso del propietario del arbolado, extrajese maderas, leña, carbón, zacate, hojas secas, frutas silvestres ó cualquiera otro artícnlo de los que producen los montes, además de pagar al dueño el valor del efecto, pagará una multa de veinticinco centaros á cien pesos, ó de tres días á seis meses de obras públicas.

Art. 23. ${ }^{\circ}$ Todo incendiario de montes, además de pagar los perjuicios y costas de apagar el incendio, será puesto á disposición del Juez, quien le impodrá como pena de seis meses á cuatro años de obras públicas.

Art. 24. ${ }^{\circ}$ Por todo desmonte que se haga en bosques de pertenencia de los pueblos, sin la licencia que previene esta ordenanza, además de quedar el terreno desmontado, sin uso alguno hasta rolver á ser montuoso, pagarán los individuos de Ayuntamiento ó Comisario Municipal á cuya jurisdicción pertenezca dicho tereno, una 
multa de ciento á quinientos pesos, que el respectivo Prefecto político queda obligado á hacer efectiva gubernativamente. A los propietarios particulares se impondrá la misma pena.

Art. 25. ${ }^{\circ}$ Las penas establecidas en este capítulo se duplicarán en caso de reincidencia.

\section{CAPÍTULO VII.}

De los premios que se otorgan á los que se ocupen de la multiplicación de los árboles.

Art. 26. 'Todo agricultor que acreditare competentemente tener, en el curso de un año, mayor número de árboles prendidos, de aquel que le corresponde conforme á las disposiciones vigentes, ó el que presentare un almácigo bien logrado, con plantas arbóreas, sean commes ó de nueva industria, tiene derecho á solicitar los premios establecidos en esta Ordenanza.

Art. 27. ${ }^{\circ}$ Estos premios consisten: $10^{\circ}$, en una mención honorífica; 2. ${ }^{\circ}$, en el accésit al premio; $3 .^{\circ}$, en un premio primiero, y 4. ${ }^{\circ}$, en in premio extraordinario.

Art. 2S. ${ }^{\circ}$ La mención honorífica se hará constar por un certificado que dará la respectiva Junta Protectora, expresando que el interesado hamerecido bien del público, por la produceión en un año de un número de plantas arbóreas que no será menor de doscientas ni pasará de cuatrocientas, ya sean obtenidas por semilla ó bien por estaca ó planta.

Art. 29. ${ }^{\circ}$ El accésit consistirá en un diploma que dará el Ministerio de Fomento, con la medalla que para recompensar el mérito ciril estableció la ley de 14 de Octubre de 1863, pero de dos centímetros de diámetro. Este premio corresponde al que acredite haber logrado reproducir en un año, conforme á lo dispuesto en el artículo anterior, de quinientas á ochocientas plantas arbóreas.

Art. 30. Obtendrá el premio primero el que acreditare de la misma manera haber logrado en el año mil plantas. El premio será la medalla á que se refiere el artículo 29 , pero con el tamaño que fijó dicha ley, y el diploma correspondiente. 
Art. 31. El premio extraordinario se otorgará á todo el que contribuya á la multiplicación de los árboles, con tal que el número exceda al que designa el artículo anterior. Este premio consistirá en la medalla civil, con el diploma correspondiente, y además, en la dispensa de las cargas ó de las contribuciones personales, conforme á la importancia del mérito contraido, y por el tiempo que, á propuesta de la Junta Protectora, acordare el Ministerio de Fonento.

Art. 32. ${ }^{\circ}$ El agricultor que remiere dos certificados de mención honorífica, tiene el derecho de cambiarlos por la medalla y el diploma que acreditan el accésit; el que tuviere este diplona y un certificado, podrá cambiarlos por los comprobantes al prinner premio; el que reuniere dos primeros premios, tiene derecho al extraordillario.

Art. 33. ${ }^{\circ}$ Los agraciados con el accésit ó con el primer premio, podrán usar la medalla pendiente de ma cinta verde y puesta al costado izquierdo; los que lo fueren con el extraordinario, la usarán pendiente del cuello, con igual cinta rerde: una y otra de un centínietro de ancho.

\section{CAPÍTULO VIII.}

De los inspectores de los arbolados.

Art. 34. ${ }^{\circ}$ La primera autoridad política del partido, risitará en su demarcación, con el carácter de inspector, sea solo, ó asociado con algunos de los funcionarios municipales, todos los arbolados, inclusos aun los de propiedad particular, así como los de las calzadas, y vías de comunicación, cuando menos tres reces al año.

Art. 35. ${ }^{\circ}$ Son obligaciones de los inspectores:

1. Cuidar del cumplimiento de esta Ordenanza.

2." Imponer á los infractores las multas que determina esta ley, y cuidar que sean enteradas en la tesorería de la Junta Protectora.

3. ${ }^{a}$ Pedir á los Jueces y jefes de fuerza de policía, y á falta de ésta á los de cualquier otra armada, los auxilios que necesiten para el ejercicio de sus funciones.

4. Formar una memeria escrita que remitirán á las Juntas Protectoras de arbolados en los primeros quince días del mes de Abril 
de cada año, en la que aparecerán el número de árboles y las clases de los que han sido plantados en el curso del año anterior, las infracciones de Ordenanza que hayan castigado, el monto á que ascienden las multas impuestas, y las demás noticias y observaciones que reputen conducentes al objeto de que trata la memoria.

Art. 36. Dichas Juntas pasarán, en los segundos quince días del mes de Abril de cada año, las expresadas memorias á los Prefectos políticos de los Departamentos, agregando las observaciones que estimen oportunas.

Art. 37. ${ }^{\circ}$ Los Prefectos políticos remitirán al Ministerio de Fomento, dentro de los primeros quince días del unes de Mayo de cada año, la coleceión de memorias que hayan reeibido, añadiendo cuanto sobre ellas les ocurra.

Art. 38. ${ }^{\circ}$ La Dirección general de caninos, remitirá directamente al Ministerio de Fomento, en el mes de Mayo de cada año, relación pormenorizada de los plantíos que hayan hecho en el anterior, expresando el número de árboles plantados en cada calzada y ferrocarril.

\section{CAPÍTULO IX.}

De las Juntas protectoras de arbolados.

Art. 39. ${ }^{\circ}$ Se establecerá en cada partido una Junta protectora de arbolados y plantíos, compuesta del Prefecto, como Presidente; del cura pároco; del Aduninistrador de rentas, y de dos labradores propietarios y dos suplentes, probos é inteligentes, que nombrará la respectiva Prefectura.

Art. 40. ${ }^{\circ}$ La instalación de estas Juntas tendrá lugar á los ocho días de recibirse en cada partido esta ley, elegirá desde luego á plnralidad de rotos, un Secretario de entre sus individuos, que llere el libro de actas y correspondencia y el de registro de boletas para cortes de madera y permiso de su exportación, participando al Ministerio de Fomento su instalación, por medio de los órganos establecidos.

Art. 41. ${ }^{\circ}$ Las sesiones de las Juntas serán públicas, tendrán lugar dos cada mes, designando la fecha en que ha de celebrarse la 
ordinaria el mismo día de su instalación, sin perjuicio de tener las extraordinarias que juzguen oportunas. Además, para expeditar sus trabajos, formarán un reglamento interior, y darán cada tres meses parte de sus acuerdos al Prefecto político respectivo.

Art. 42. ${ }^{\circ}$ Son obligaciones de la Junta:

1. El más exacto y puntual cumplimiento de la presente Ordenanza, en la parte que le concierne.

2." Proponer al Gobierno las reformas, adiciones 6 variaciones que estime convenientes al objeto á que se dirige esta Ordenanza, fundando siempre el motivo de las modificaciones que consulte.

3. a Dictar las disposiciones que le competen y requerir á las demás autoridades para que tomen las providencias que correspondan al aumento y mejora de los bosques y arbolados.

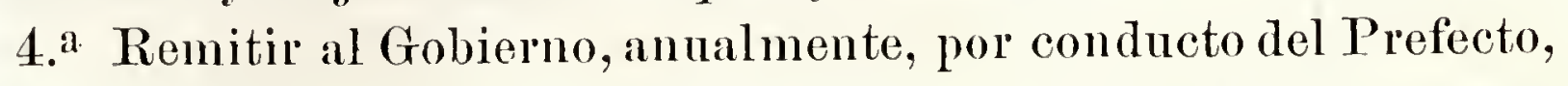
en la segunda quincena del mes de Abril, la memoria de que trata el artículo $16 .^{\circ}$ y un estado especificativo de los bosques existentes en el período de su comprehensión, detallando los que sean, por los nombres con que actualmente están conosidos y distinguiendo los antiguos de los que se hubieren formado de nuevo.

5. a Designar el sitio ó sitios más análogos para la formación de viveros ó almácigos y trasplante de árboles, las especies que de éstos han de propagarse en cada lugar, y el tiempo en que debe verificarse, así la propagación por granos ó estacas, como la plantación de árboles.

6. a Si en la adquisición de los sitios á propósito para los objetos expresados hubiere alguna dificultad, ocurrirán al Gobierno á fin de que la remueva; en la inteligencia de que siempre que se trate de terrenos de propiedad nacional ó de commidad se hará uso de ellos; pero si en el terreno que se designe hay alguno ó algunos que lo estén poseyendo con título legal, se les dará el tiempo necesario para que lo desocupen, indemnizándoles previannente, á juicio de peritos, los perjuicios que reciban.

7. ${ }^{a}$ Proporcionarse las semillas, plantas $y$ estacas que sean necesarias y que más convengan á la localidad respectiva.

8. ${ }^{2}$ Hacer que se vigilen los cortes de maderas, bajo las reglas que contiene esta Ordenanza, y cuidar de que se exijan y enteren las multas en que incurran los contrarentores, aplicándoles los castigos que merezcan. 
9." Sobrevigilar que los celadores de bosques y los risitadores estén por su cuenta armados.

10. Cuidar también de que residan en el punto de la demarcación que se les señale para vigilarla, sin que puedan ausentarse de ella ni mudar de residencia, á menos de que obtengan permiso de la Junta. Esta, en los terrenos de propiedad nacional, podrá designarles un pedazo de tierra para que lo labren y formen sus habitaciones.

11. Ponerse de acuerdo con los propietarios particulares de bosques, para que, en obsequio del bien común, del método y del orden, hagan que se ejecuten cumplidamente las prevonciones de esta Ordenanza, sin dar lugar á las penas que establece.

12." Cumplir en lo que les concierne con el artículo $7 .^{\circ}$, cuidando escrupulosamente se hagan efectivas las penas establecidas.

13." Vigilar con toda eficacia que por cada árbol viejo ó deforne que corte, se planten cuatro vástagos, conforme previene la parte $2 . "$ del artículo 10 .

Art. 43. ${ }^{\circ}$ Son atribuciones de las Juntas:

1." Nombrar y destituir á los celadores de bosques, conforme á las atribuciones que designará el reglamento.

2. ${ }^{a}$ Nombrar igualmente y destituir del mismo modo nuo ó más agentes que en los pueblos del partido de su comprehensión desempeñen las funciones que se les confieran, para la más puntual observancia de la presente Ordenanza, sin que puedan excusarse los nombrados, á menos de que tengan impedimento legal calificado bastante á juicio de la autoridad política. Dichos agentes tendrán el carácter de jefes y sobreriggilantes de los celadores, y además el de visitadores de los bosques, inclusos aún los de propietarios particulares, estando subordinados inmediatanente á los inspectores de bosques y plantíos.

3." Designar las dotaciones que han de disfrutar los celadores y los agentes, quienes serán pagados de las arcas de cada Municipalidad, siempre que el fondo de multas no baste en rirtud de tener que cubrir la atención preferente, que es la de plantaciones.

3. ${ }^{a}$ Designar también, en el interior de las poblaciones, las platzas, paseos ó calzadas y demás en que fuere conveniente formar arbolados, hacer los plantíos y cuidar de su conservación, bajo las reglas que fijarán.

$5 .^{a}$ Conceder ó negar permisos determinados para el corte de 
maderas, dando á los interesados la debida boleta, que será registra da en el libro correspondiente, exigiéndoles por el permiso la cuota que señalará la tarifa.

$6 .^{a}$ Expedir iguales boletas para el mismo corte, respecto de los terrenos comunales ó de comunidad de indígenas, cerciorándose previamente de la legalidad con que poseen esos terrenos. Las boletas se expedirán sin exigir cantidad alguna á los que acreditaren hallarse legalmente en posesión de este derecho.

7.a Procurar que conforme se vayan cumpliendo los términos de

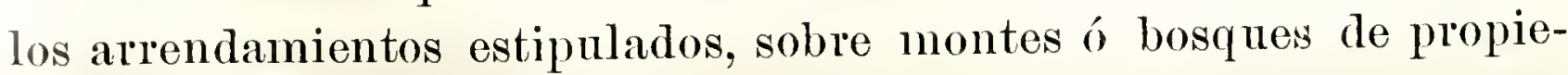
dad nacional, no se consientan otros sino con las garantías necesarias y utilidades convenientes, según las disposiciones del reglamento.

S." Hacer contratos de arrendamiento por tiempo limitado, sin que pase de cinco años, y previa aprobación del gobierno.

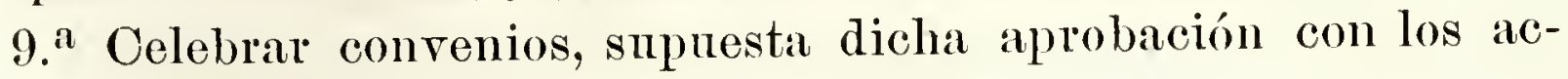
tuales empresarios de corte de maderas y con los que en lo sucesiro se dediquen á este ramo de industria, así respecto del número de árboles que deben reponer anualmente en el punto del corte, además de los designados en esta Ordenanza, como de la pensión que han de satisfacer por rirtud de su especulación, expidiéndoles el correspondiente permiso.

10. an caso de que no sea conveniente que se continúen ó se establezcan cortes de madera en algún sitio, suspenderán ó negarán la licencia mientras el Gobierno resuelve con vista del informe circunstanciado de la Junta y del Prefecto político, quienes cuidarán de extenderlos exacta y concienzudamente.

11. Aprobar ó desaprobar las lieencias supletorias que otorguen sus agentes para cortes pareiales de madera en caso de necesidad momentánea y urgente, que para ellos hubiere, estableciendo siempre el número de árboles que deben reponerse por cuenta de los interesados ó la cantidad que han de enterar al fondo para su reposición. Esta disposición y las dos anteriores, sólo se contrahen á los bosques y arbolados públicos; pero nunca á los de propiedad de particulares, á quienes las Juntas no pueden impedir los cortes, si bien informarán al Gobierno cuando observen 6 sepan asertivamente que aquellas no se hacen con sujeción á las reglas de esta Ordenanza, para que sufian las penas que establece.

12. ${ }^{a}$ Expedir permisos por escrito para la exportación de made- 
ras, cuidando de que se enteren en las arcas de la Municipalidad los derechos de que se hablará después.

13. ${ }^{a}$ Celar que los productos de estos derechos y los de boletas para el corte de maderas, como también los de las multas que se exijan, sean invertidos en los nuevos plantíos, acotándolos ó cerrándolos si fuere posible, $y$ en el pago de dotaciones de los celadores y agentes.

Art. 44. Las Juntas protectoras de los partidos de los Departamentos $y$ territorios en que se producen maderas preciosas, tendrán presente al ejercer la facultad 5." las cirenstancias peculiares de sus partidos y las cuotas que se han pagado hasta aquí por el cotte de esas maderas, para fijar las que en lo sucesivo deban satisfacerse según la asignación de la tarifa que será propuesta desde luego, procurando que se saquen para el país las mayores utilidades posibles.

\section{CAPÍTULO $\mathrm{x}$.}

Vigilancia de las autoridades y demás funcionarios públicos.

Art. 45. Los celadores y risitadores de bosques, quedan exentos del sorteo para el ejército, y de toda carga concejil durante el tiempo en que ejerzan sus cargos. y las autoridades les darán auxilio siempre que lo pidan. Dichos celadores y risitadores podrán arrestar y conducir ante el Juez más immediato, á todo individuo que sorprendan en delito infraganti, como contraventor á esta Ordenanza, para que sea juzgado y castigado sumaria y debidamente; dando aquéllos parte del hecho á los inspectores.

Art. 46. ${ }^{\circ}$ Toda autoridad, corporación civil, funcionarios y empleados públicos están obligados á celar la conservación de arbolados, en la parte que les corresponda ó en la que su celo les sugiera, dando ariso de las infracciones que adriertan de esta Ordenanza, ya sea al inspector respectivo, ya á la Junta protectora del partido, ó ya á la autoridad pública.

Art. 47ํ. Estos avisos serán preferentemente atendidos para dictar, en su caso, las providencias conducentes.

Art. 48 $8^{\circ}$ Uno de los deberes más estrechos de la policía rulal, será el de rigilar la observancia de esta Ordenanza, ar'restando á los 
infractores para que, puestos á disposición de la autoridad competente, sufran el castigo que hayan merecido.

Art. 499 Cualquier descuido ú omisión de parte de los funcionarios á quienes toque la vigilancia de este ramo, se castigará con una multa proporcionada que aplicarán en su caso los inspectores, la Junta protectora ó los Prefectos de los Departamentos.

Art. 50? Ias obligaciones impuestas á los propietarios las ejecutarán en su caso los arrendatarios.

Art. 519 En vista do los datos que remitirán las Juntas protectoras, formará el Ministerio de Fomento, los reglamentos á que aquéllos dieren lugar.

Art. 529 Quedan derogados: el decreto de 14 de Agosto de 1854, las circulares de 2 de Septiembre de 1858 y 2 de Noviembre de 1860, el reglamento de 18 de Abril de 1861, así como todas las leyes, reglamentos ú órdenes contrarias á ló dispuesto en esta Ordenanza. 


\section{DICTAMEN}

\section{ACERCA \\ DE LAS CANERÍAS DE PLOMO,}

APROBADO POR EL COLEGIO DE MEDICINA, EN 1840.

(Tomado del "Periodico de la la Academia de Medicina de México.")

Ha llamado la atención dél Exmo. Ayuntamiento la cuestión suscitada estos días, sobre si perjudican á la salud de los habitantes de México las aguas potables conducidas en caños de plomo. Sin embargo de que antes de poner estos tubos consultó aquella corporación con personas instruidas, y no se resolvió á quitar las de barro hasta que quedó satisfecha de que los nuevos acueductos no serán capaces de dar á la agua cualidades nocivas, ha querido ahora oir la opinión del Colegio de Medicina, tan justamente convencida de la innportancia del asunto, como celosa del bien común.

Con este objeto ha remitido el expediente que obra en su secretaría, y se reduce á cuatro cuadernos relativos al asunto, que contienen los informes y providencias tomadas desde 1718 hasta 1801. De ellos aparece, que la cuestión se ha ventilado más bien por lo relatiro á la comodidad y economía, que por lo que respecta á la salubridad pública. Ni es de extrañar que haya sucedido así en Mexico, en aquella época, pues ni la química poseía los nuevos descubrimientos que la han enriquecido posteriormente, ni era la ciencia más cultivada entre nosotros: por estas razones, muy poco ó ningún provecho se puede sacar para resolver la cuestión que se ha encargado al Colegio de Medicina, de los datos que suministran los referidos cua- 
dernos, cualquiera que sea por otra parte la celebridad de las autoridades y personas que han intervenido en el asunto.

A pesar de esto, se advierte que las cañerías de plomo, han tenido en todo tiempo á su favor la opinión de muchas personas; y las que han sido de distinto sentir, coino el proto-medicato de 1718, no dieron razones para apoyar su aserto; y sólo D. Fausto Elhuyar alegó en 1801 la fácil destrucción de este metal, y su conversión en óxido más ó menos soluble en el agua, y, por consiguiente, más ó menos nocivo á la salud.

La cuestión que se quiere resolver es práctica, y nada se hará atendiéndose á las teorías, sin observar los hechos y repetir los experimentos. Saber si las aguas potables son ó no puras; conocer en el segundo caso las substancias que hay en ellas; en qué cantidades, y estudiar la acción química que ejercen sobre el plomo de los caños que las conducen, he aquí los puntos principales para decidir con fundamento.

La comisión nombrada por la Dirección de ciencias médicas para ocuparse del asunto, estaba satisfecha por los trabajos particulares á que se habían dedicado dos de sus individuos, que no había datos para asegurar que las agurts de México, conducidas por tubos de plomo, perjudican visiblemente la salud. No obstante, resolvió hacer de ellas un nuevo reconocimiento, buscar, valiéndose de los reactivos más sensibles, el metal de los caños ó alguno de los compuestos que pueden formar uniéndose á otros cuerpos, para examinar la cuestión médica después de conocer la naturaleza y cantidad de las substancias contenidas.

Poco satisfecha de su saber, pretendió asociarse con otros profesores de juicio y de conocimientos, á fin de que nada dejara que desear su resolnción. Siente no haberlo conseguido, ápesar de sus esfuerzos, pero tiene la satisfacción de presentar el resultado de sus trabajos, apoyado en hechos que alejan de sí las conjeturas, y en la íntima convicción de cada uno de los individuos que forman la comisión.

La agua delgada es la más pura de las dos que se gastan, en México: los cuerpos gaseosos que contiene no son más que un poco de aire y muy corta cantidad de ácido carbónico. Las substancias fijas son: sulfato de cal, cloruro de sodio y poquísimo carbonato de magnesia, en la proporción de un cuatro mil avo de las tres sales.

En la gorda hay también gas carbónico, menor cantidad de aire, 
sulfato de cal, cloruro de sodio $y$ carbonato de cal y de magnesia, en la proporción de un mil avo de estos cuatro cuerpos.

Ninguna de las dos aguas en su estado natural cambia los colores azules regetales; pero reducidas por la evaporación á la rigésina parte de su peso, manifiestan ser alcalinas, á causa de los carbonatos que tienen en disolución. En mua y otra hay restos de materias orgánicas, y á éstas se debe atribuir el color amarillento que adquieren, cuando se eraporan, para reducirlas á menor volumen.

Ninguno de cuantos reactivos aconsejan los antores para descubrir el plomo, ha hecho, ni sospechar, que puedan contenerlo alguna de las aguas; siendo de notar que se laan tomado de las fuentes más distintas, que por lo mismo estuvieron más tiempo en contacto con el metal de los caños. Mas prescindiendo de estos hechos, está demostrado que las aguas de la ciudad no son absolutamente puras: se sabe cuáles son las substancias extrañas que contienen, y es unuy fácil conrencerse de que éstas no pueden obrar sobre el plomo en las circunstancias en que se hallan en contacto con él.

Supóngase que se forma un proto-óxido de plomo, como temió el Señor Elhurar, que no queda adherido en forma de cubierta á las paredes del tubo, sino que se desprende; pues en este caso se precipitaría, porque su peso específico es mayor que el del agua; y amn cuando fuera arrastrado por la corriente, quedaría depositado en los recodos de los caños, principalmente en los ángulos formados por la unión de los tubos horizontales con los ascendentes, ó en los depósitos y fuentes. Es rerdad que algunos autores creen que el óxido de plomo es en parte soluble en el agua, que los álcalis facilitan la oxidación del metal, y que los plombatos de potasa y de sosa sou solubles; pero ellos mismos aseguran que no sucede esto cuando los álcalis se hallan al estado de carbonato. Por otra parte, la sosa que hay en las aguas está combinada con el ácido hidro-clórico, que tiene mayor afinidad que el plomo, lablando segín la teoría más conocida, y pol lo mismo no puede revificarse la descomposición del hidro-clorato, y formarse el eloruro metálico.

El aire contenido en las aguạs es más abundante en oxígeno, polque su afinidad con ellas es mayor que la que tiene con el ázoe, según las observaciones del Barón Thenard quien asegura que puesta la agua á herrir, el último aile que se desprende está más cargado

* Tom. 1?, pág. 241, 6. a edición. 
de oxígeno que el primero; lo que prueba que la unión de estos dos cuerpos es suficiente para mantenerla en circunstancias commnes, é impedir, por lo mismo, la acción del sólido falto de poder para hacer que se efectúe el doble trabajo de descomposición y combinación.

Segín esto, es evidente que el oxígeno del aire contenido en las aguas, no obra activamente sobre el plomo de los caños, por el estado particular en que se encuentran los dos cuerpos; y que, aun cuando se verifique la combinación por motivos extraordinarios, como ninguno de los cuatro óxidos admitidos por Belzelius son solubles en las rguas de México, quedarían precipitados, y no cambiarían el estado de estos líquidos. Tampoco se puede formar sino el óxido menos oxigenado, que, como dice Lassaigne, «se obtiene cuando el metal está sumergido en agua aereada; pero es tan superficial la capa de óxido, que las partes que están debajo conservan su brillo y sus propiedades, á un pequeño espesor.» El mismo autor se expresa también en estos términos: «En razón de lo poco que se altera el plomo, se la destinado para conducir y distribuir las aguas potables.»

La comisión se abstiene de entrar en pormenores respecto del ázoe, porque el que esté más empeñado en persuadir que hoy las ağuas de la capital son dañosas, no se valdrá de este cuerpo para explicar la descomposición del plomo.

No sucederá lo mismo con relación al último gas de los que hemos dicho contienen las aguas. El ácido carbónico tibre es capaz de unirse al plomo y formar un compuesto insoluble en el agua, que llega á ser soluble cuando estú sobrecargado de gas carbónico; pero aun la agua gorda, que es la más impura de las dos que se gastan en la ciudad, no está sobrecargada del gas, y por lo mismo no forma el bicarbonato, como se demuestra claramente sirviéndose de los reactivos usados para descubrir el plomo, y viendo el trabajo que cuesta obtener esta sal aun en las fábricas de albayalde, en donde se encuentran los elementos necesarios para formarla. La temperatura y la presión atmosférica no favorecen la combinación, y cuando se ha verificado, es tan poco estable el nuevo compuesto, que en un suave calor, como dice el mismo Lassaigne, hace que pierda el ácido carbónico, y quede, por residno, proto-óxido de plomo.

Las opiniones de este químico sirven de respuesta á los que, sin haber meditado á Orfila, lan tomado sus expresiones para persuadir que las aguas de México se impregnan del plomo de las cañerías. 
Al hablar el autor, de este metal, en su tratado de medicina legal, ${ }^{1}$ dice: «Que la agua que ha pasado por acueductos de plomo, ó que ha caído en techos cubiertos por este metal, puecte tener en disolución gran cantidad de este veneno para determinar graves accidentes.» II prefesor Orfila cuidó bastante de no asegurar, que toda agua que se hallara en estas circunstancias determinaría precisamente accidentes graves; no sólo se sirvió de estas expresiones puede tener, sino que agregó en el mismo párrafo los caracteres que presenta un líquido cuando está impregnado de plomo. ¿Quién que haya tomado las aguas potables de esta capital dirá que tienen un subor Tigeramente asucurado y estíntico? La comisión ha risto, que los sulfatos, los hidro-sulfatos, los cromatos y los álcalis noobran sobre las aguas en cuestión como sobre la disolución de acetato de pilomo, propiedad que el mismo autor ${ }^{2}$ cree necesaria para sospechar que ma ağua es dañosa.

Ta comisión podría citar unchos autores que opinan en favor de las cañerías de plomo, pero haría fastidioso este escrito, y por tanto se conforma con remitir á los escrupulosos á los artículos respectivos del Diccionario 'Tecnológico, principalmente al que escribió Franceur, ${ }^{3}$ y con traducir el siguiente párrafo del Tratado de quínica de Giraudin, publicado en 1539. «Ta oxidación del plomo en el aile húmedo, dice el autor, ${ }^{4}$ es muy pronta, pero superficial. IS menos rípida bajo ta agua aerendu. Cuando.el agua se renuera, el óxido se cambia poco á poco en carbonato de proto-óxido de plomo, que es blanco. La agua facilita singularmente la formación de este carbonato. He aquí por qué se advierte siempre una costra blanca sobre las paredes de los receptáculos, meeiscmnnte un poeo mas allá de la superficie del agur. Por fortuna este carbonato es insoluble; de manera que no comunica al líquido ninguna propiedad danost.

El que observe con cuidado los tubos que han servido para conducir las aguas, notará que la superficie interior presenta el mismo aspecto, como lo ha risto la comisión, que ofiecen las láminas de plomo expnestas algún tiempo al contacto del aire.-Las paredes de

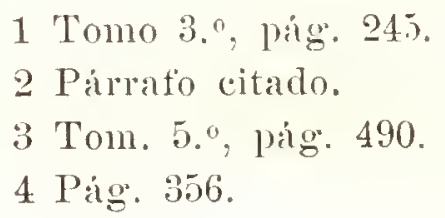


los cañones no disminuyen notublemente de espesor, ni hay en su cara interna las desigualdades que presentaría si hubiera reacciones químicas.

A más de estos datos, suficientes para decidirse en faror de läs cañerías de plomo, hay otros no menos importantes. Supóngase que el oxígeno del aire contenido en las aguas se une al metal $y$ forma un proto-óxido; que éste se combina con el ácido carbónico y la convierte en carbonato de plomo, ¿qué tiempo durarían en buen estado las cañerías? Basta calcular las proporciones de los dos gases contenidos en las aguas, y la que pasa de líquido en un tiempo dado, para convencerse que antes de un año se habrían convertido los cañones en albayalde, lo que es absolutamente falso.

La comisión ha descuidado de intento tomar en cuenta las substancias sólidas contenidas en las aguas, al ocuparse del gas carbónico, porque los argumentos tomados de la acción que ejerce sobre aquéllas, son en favor de su opinión. El ácido carbónico que contiene una agua, se mantiene en el líquido mientras no se aumenta la temperatura ó se disminuye la presión; pero faltando estas circunstancias, se desprende, aun cuando el agua tenga en suspensión $o$ en disolución algunos cuerpos que carezcan de una fuerza de atracción bastante poderosa para que se verifique la combinación; pero si en las substancias contenidas en ellas hay afinidad, el gas se divide y se desprende la mayor parte, uniéridose la otra al cuerpo, con quien se obliga á poner en contacto. He aquí por qué se emplean las máquinas de presión para preparar los carbonatos y bi-carbonatos, con el objeto de no perder el ácido, como sucedería sirriéndose de rasijas descubiertas. Según esto, zcómo suponer que el plomo, que no es de los cuerpos que tienen más afinidad que la cal y la magnesia, tome de preferencia el gas carbónico? Es verdad que los carbonatos alcalinos son capaces de ceder á este metal el gas con que se hallan unidos, pero es precisamente cuando el plonio está combinado con un ácido más fuerte que el carbónico para unirse á la base de la sal formada por éste; y también porque en tal caso se halla al estado de gas naciente, lo que no sucede en las aguas de que se trata.

Ya es tiempo de hablar de la acción que ejercen las substancias fijas contenidas en las aguas sobre el plomo de los tubos que las conducen.

Las bases que se encuentran en el agua son la cal, la sosa y la 
magnesia; pneden unirse al plomo y formar plombatos solubles, siempre que no estén en combinación con otros enerpos que tengan mayor afinidad. No se puede negar que los ácidos sulfúrico, hidroclórico y carbónico, se unen á aquellas bases de preferencia al plomo, aun suponiéndolo al estado de proto-óxido; tampoco cabe duda que el sulfato de plomo es insoluble en la agna, y que el óxido métalico no descompone al sulfato de cal, única combinación que existe en las aguas, formada por el ácido sulfúrico. La sal de sosa no es descompuesta por el plomo, y aun en la hipótesis de que se formara el cloruro y que hubiera igualmente el óxido de plomo en mayor cantidad, se obtendría el cloruro con exceso de base insoluble en la agua, $y$ por lo mismo incapaz de perjudicar á la salud.

Sólo resta estudiar la acción que ejereen por si las aguas potables de la ciudad, sobre el plomo. La comisión cree inútil detenerse minuciosamente en este punto, porque los autores de más nota están de acuerdo en que las aguas que contienen sales solubles no obran sobre el metal, aun cuando se halle en ellas alguna cantidad de aire. Por tanto se ocupará mejor en referir un hecho que por sí sólo no deja duda que las aguas de que se trata no contienen el metal, ni alguno de los compuestos que puede formar unido á otros cuerpos. Este hecho es la contraprueba más segura que destruye cuantas teorías se pudieran inventar para persuadir lo contrario; y él solo basta para sosegar á los tímidos que esperan por momentos ser atacados de los terribles síntomas del cólico de plomo. Se han tomado norecientas norenta y mere partes de agua, en la que se disolvió nua de acetato de plomo; se trató un poco de este líquido por el mismo ácido hidro-sulfúrico que sirrió para buscar en las aguas el plomo que se supone, y al momento se formo un precipitado negro, tan abundante, que ocupó la mitad del líquido que servía para la experiencia. Después se tomó una parte de las mil que contenían el plomo, y se mezcló con otras norecientas norenta y nueve de agua pura; el mismo reactivo demostró claramente la presencia de la sal metálica. Es decir, que el ácido hidro-sulfúrico de que se usó, puede descubrir una millonésina parte de plomo; pero como las aguas de la capital se habían reducido á una rigésima de su peso, se puede asegurar, sin temor de equirocarse, que no hay en éstas un veinte millonaro de plomo.

Acaso no faltará quien pretenda persuadir, que en alguna de las 
diversas épocas del año, y aun en las distintas horas del día, es cuando se forman los compuestos de plomo que se suponen; pero aun esta sospecha queda destruida, si se atiende á que la agua gorda no cambia de propiedades por la variación de las estaciones; que la delgada no contiene en tiempo de lluvias sibstancias que obren sobre el plomo, en las circunstancias en que éste se encuentra; que la naturaleza de los terrenos por donde pasan estas aguas, no puede cambiar la posición de éstas, $y$, en fin, que el estado eléctrico de la atmósfera no favorece la combinación de las substancias que contienen las aguas con el metal de las cañerías.

La comisión desea no dejar punto por tratar de cuantos puedan servir para ratificar su opinión; por lo mismo, aunque parezca inútil que se ocupe de la parte médica, quiere hacer notar una obser vación interesante, sacada de los hechos que ha referido.

Los reactivos descubren una millonésima de sales de plomo, pero no manifiestan una mil millonésima. Supóngase que las aguas de México contienen esta proporción; supóngase, también, que un habitante de esta ciudad tome diariamente cuatro cuartillos de agua, que, sin duda, no es el término medio, y de ambas suposiciones resulta, que en el espacio de un año habrá tomado mil cuatrocientos sesenta cuartillos de líquido, que no tienen más de trece granos, cuatrocientos cincuenta y cinco mil avos del compuesto de plomo, gratuitamente supuesto: dosis que no inquietaría la conciencia del mismo Hahnemann.

Por otra parte, la comisión, que justamente ha tenido presente la opinión respetable de los profesores del Colegio de Medicina, no puede dudar que las enfermedades reinantes en esta ciudad, desde que hay cañerías de plomo, nada tienen de común, con las que produce este metal; cuya opinión se ve confirmada en el estado de muertos y nacidos del año de 839, que acaba de publicar el Exmo. Ayuntamiento, pues en él consta que de 5,635 personas que fallecieron, sólo 27 han sucumbido al cólico, y no se expresa que haya sido saturnino.

Los raciocinios expuestos, y más que ellos los hechos consignados, conducen irremisiblemente á creer que madie dudará que las aguas potables de México no tienen una reinte millonésima de plomo; que no hay hecho alguno que demuestren contengan esta cantidad verdaderamente homeoputica, y que aun cuando se suponga gratuitamente su existencia, no es capaz de aíterar la salud de los habitan- 
tes de esta ciudad. Por lo mismo, en el humilde sentir de la comisión, sus trabajos deben producir un pleno convencimiento de que los acueductos de plomo no se oponen á la salubridad pública.

Mèxico, Abril 25 de 1840.

L. $\mathfrak{R}$ io de la $\mathfrak{L} a z a$.

Tanuel gRobredo.

$\mathfrak{L}$. de la $\mathfrak{L} a s c u a$. 
DIOTAMENT

Aprobado por la Sociedad de fisistoria Natural, en la sesión del 17 de Abril de 1873, y que tué presentado por la comisión nombrada para dilucidar

la cuestión suscitada con motivo del fraccionamiento

del aerolito de la "Descubridora."

(Tomado del periódico "La Naturaleza.")

Por acuerdo de Séptiembre de 1871, la Sociedad Mexicana de Geografía y Estadística mandó dividir en fragmentos el hermoso aerolito de que hizo donación D. Florencio Cabrera, de San Luis Potosí, á nombre de D. Vicente Irizar; aerolito llamado de la «Descubridora,» y que era uno de los ejemplares más notables por su magnitud entre los existentes en nuestra República.

Al saber esta resolución la Sociedad de Historia Natural, que se ha dignado nombrarnos en comisión para estudiar este asunto, creyó que debía manifestar su opinión, contraria á aquella determinación, que le parecía y le parece perjudicial á las investigaciones científicas y al buen nombre de México como pueblo civilizado.

Por esto mismo, sin pasión para juzgar, y mucho menos sin prerención respecto de la Sociedad Mexicana de Geografía y Estadística, á la que nos honramos en pertenecer algunos de los que subscribimos este escrito, hemos creído examinar esta cuestión para manifestar los fundamentos de nuestra opinión, que, por desgracia, no está conforme con la de los ilustrados vocales de aquella Sociedad que subscribieron el dictamen de 31 de Agosto de 1872, apoyando el acuerdo de que hemos hablado.

En toda esta cuestión, la Sociedad de Geografía y Estadística laa procedido con la vacilación propia de las resoluciones erradas, de las 
resoluciones que no pueden defenderse, porque han sido dictadas con precipitación y sin examen; y si no turiéramos pruebas tan concluyentes de este aserto, sería ma tan clara como terminante el dictamen ya citado de 31 de Agosto, el que, aunque escrito con fluidez y erudición histórica, no nos parece suficientemente fundado, pudiendo considerarse más bien como ma obra de imaginación, como nua obra literaria, que como un trabajo científico basado en principios ciertos é incontestables.

Que la corporación expresada ha procedido en este asunto con racilación y de una manera constantemente indecisa, lo explica la listoria de este mismo asunto, que ramos á referir á grandes rasgos. En la sesión del 5 de Agosto de 1871, se dió cuenta á la Sociedad de Geografía y Estadística de luaberse recibido el aerolito de que se trata, remitido de San Luis Potosí, y fueron nombrados en comisión para estudiarlo los socios D. Leopoldo Río de la Loza y D. Gumesindo Mendoza, á quienes se agregaron después D. Antonio del Castillo, y más tarde, D. José Joaquín Arriaga.

Los dos primeros señores dieron desde lnego principio á sus trabajos, rectificando el peso del aerolito y haciendo que en su presencia se acabara de separar, por el mecánico Sr. Rossemberger, ma parte que había empezado á desprenderse; habiéndose autorizado en la sesión del 19 de Agosto, al Tesorero de la Sociedad para hacer el gasto de ese trabajo. De la porción separada se hicieron tres partes, las que fueron distribuidas entre los tres primeros comisionados, á fin de que cada uno ejecutara sobre ellas los trabajos correspondientes, para compararlos entre sí, una vez terminados.

Entretanto, la Sociedad acordó ceder el aerolito al Museo Nacional, como lugar más propio para ser expuesto al público y conservarse. Mas desgraciadamente, este acuerdo fué derogado por la misma Sociedad en su sesión del 30 de Septiembre del mismo año, y en consecuencia de esa misma determinación l'esolvió colocar la masa neteórica en la sala de sus sesiones para que estuviera á la vista; siendo notorio que en Septiembre de 1871 derogó sus anteriores acuerdos, resolviendo el fraccionamiento del curioso meteorito, que al efecto fué entregado al Sr. Beaurang.

La simple exposición de los diversos y contradictorios acuerdos de la Sociedad Mexicana de Geografía y Estadística, que acabamos de referir, prueba eridentemente su indecisión y falta de seguridad 
para adoptar la fatal resolución que venimos combatiendo y en la cual no hay la franqueza de reconocer un error verdaderamente lamentable, puesto que ese error ha sido causa de un atentado científico, que la Sociedad de Historia Natural ha creído de su deber reprobar públicamente, sin que en nada hayan influido para cambiar su opinión á este respecto las observaciones contenidas en el dictamen ya citado de 31 de Agosto.

Antes de ahora, en la infancia de la civilización ó entre los pueblos poco adelantados, pudo sostenerse como conveniente el fraccionamiento de una gran urasa meteórica como la de que tratamos, ó pudo llevarse á cabo sin llamar la atención de nadie, y nosotros mismos podríamos citar en apoyo de este aserto, tan poco conforme con los preceptos y las necesidades de la ciencia, entre otros casos, el que refiere Dufrenoy, de la destrucción del meteórico de Tocavita en el pueblo de Santa Rosa, y que el gobierno de Colombia compró para hacer una espada al libertador Simón Bolívar. Pero hoy, fraccionar un aerolito de las dimensiones del de la «Descubridora,» es una rerdadera profanación que reprobarán todos los amantes á las ciencias, porque de esas masas hay tres elementos principales de estudio que destruye el fraccionamiento; elementos esenciales que constituyen su mayor mérito, á saber: el tamaño, el peso y la forma.

Antes de ahora también, en la infancia de la civilización, «hubo un tiempo en que los aerolitos fueron objeto de la adoración supersticiosa de los pueblos antiguos: en Galacia se adoraba á Cibeles en una piedra caída del cielo; en Emesia, en Siria, había una piedra semejante consagrada al culto del Sol, y la caída del célebre meteorito de Ágos Potamos impresionó vivamente á los'Tracios.»

Pero la ilustrada Sociedad de Geografía y Estadística no podrá suponer, ni por un momento, que la Sociedad de Historia Natural haya reprobado el fraccionamiento del aerolito de la «Descubridora,» movida por un sentimiento de superstición religiosa ó de fanática adoración por la piedra destrozada, porque tal suposición sería ajena de corporaciones serias que se ocupan de ciencias físicas y naturales, y no podría hacerse por ella un cargo á hombres cultos por hombres ilustrados en el siglo en que rivimos. Podría creerse que este recuerdo de otra edad, había sido evocado más bien para deslumbrar á los que no penetran en el fondo de las cuestiones, que para refutar un parecer que está çe acuerdo con la opinión de los hombres 
dedicados al estudio de las ciencias, en los cuales no ejercen la misma influencia que en los de imaginación, las raporosas creaciones de la fantasía, tanto más peliguosas cuanto mayor es el brillo con que suelen presentar'se.

Por lo mismo, la observación anterior sólo debe tomarse como una reminiscencia histócica de una época bien atrasada y que no puede tener aplicación alguna en nuestros días, ni aun para disculpar un error como el que tenemos la necesidad de combatir.

Tampoco nos parece fundada otra observación del dictamen de que tratamos, deducida de una reflexión del immortal autor del Cosnos, y que copiamos para examinarla.

Los autores del dictamen se expresan así:

«Los progresos en el estudio de los meteoros ígneos, dice el ilustre autor del Cosmos, serán tanto más rápidos, cuanto que absteniéndose de tomar el camino que lasta aquí se ha seguido, los observadores separen cuidadosamente los hechos de las hipótesis, sujeten á prueba cada fenómeno, sin que por eso deban decretar como falsas ó dudosas todas aquellas cosas de que no se tenga una explicación satisfactoria. Me parece sobre todo importante no confundir con las relaciones físicas las relaciones numóricas y geométricas, generalmente más fíciles de rerificar, cuales son: la altura, la velocidad, la unidad ó pluralidad de los puntos de que parecen partir los meteoros, el promedio de aerolitos, ya sean aislados ó periódicos, que caen en un tiempo dado; en fin, la magnitud y forma de las apariciones.»

«Por lo demás, agrega el Barón de Humboldt, con el transcurso del tiempo, el estudio de estas clases de circunstancias, quiero decir, de las relaciones físicas y numéricas, debe necesariamente conducirnos al mismo fin, á rerdaderas consideraciones sobre la generación y naturaleza de estos fenómenos.»

Dedúcese de lo que precede, agrega el dictamen, que el estudio de las propiedades de los cuerpos del género del que nos ocupa, no debe limitarse á calcular su peso, su densidad y volumen; no basta definir su color, describir su estructura molecular; necesario es también conocer los diferentes aspectos con que puede presentarse su fuerza, su flexibilidad, su maleabilidad, su grado de pulimento, etc.; ya pod los resultados de apreciación, bajo el punto de vista de la especulación científica, ya porque pudieran encontrar algunas aplicaciones útiles en la industria, toda rez que se logre producir artificialmente 
las amalgamas que, en su composición, nos presentan las masas meteóricas.»

Hasta aquí la parte del dictamen necesaria para nuestro objeto, y en la cual se encuentran datos abundantes y preciosos para apoyar nuestra opinión, como vamos á demostrarlo, viniendo ellos á producir, una vez bien examinados, consecuencias enteramente contrarias á las que creyeron deducir los autores del fraccionamiento.

El mismo Señor Barón de Humboldt, recomendaba, según acabamos de rer, como altamente útiles para el estudio de los meteoros ígneos, su magnitud y su forma, circunstancias esenciales, propiedades necesarias que desaparecen en gran parte, ó quizá del todo, bien considerada la cuestión con el fraccionamiento, el cual disminuye la magnitud y modifica radicalmente la forma.

Por lo mismo, nosotros no comprendemos cómo de esta opinión, que se ha citado como una autoridad, y que lo es en efecto, no comprendemos, decimos, cómo de esta opinión respetable, tan clara $y$ terminantemente manifestada, los Señores que suscriben el dictamen, hayan podido deducir que es útil y conveniente el fraccionamiento, que destruye sin necesidad y sin objeto digno de atenderse, dos circunstancias indispensables al estudio de los aerolitos según la misma opinión que se cita; subiendo de punto nuestra sorpresa al decirnos la comisión que el fraccionamiento es necesario también para conocer los diferentes aspectos con que puede presenturse su fuerzu de cohesión, (?) indagando su tenacidad, su dureza, su flexibilidad, su maleabilidad, etc; objetos que pueden conseguirse, como lo probaremos más adelante, sin esa deplorable circunstancia.

Asimismo encuentran muy importante el fiaccionamiento, los autores del dictamen, á fin de que los aerolitos no solamente se estudien en su superficie, sino que se examinen on el punto de vista de sus aplicaciones industriales, todu vez que se logre producir artificialmente las amalgamas que en su composición nos prescntan las masas meteóricus. Citamos textualmente estos conceptos del dictamen, después de haberlos examinado, de lraberlos meditados detenida é imparcialmente, pues ellos, ó nada dicen, ó dicen algo que nadie puede comprender. En efecto, ¿qué significa producir artificialmente las amalgamas que en su composición nos presentan las masas metéoricas?... Nadie podra explicarlo satisfactoriamente, porque los hierros meteóricos no son amalgamas sino ligas. Así lo comprueban 
los numerosos y concienzudos estudios hechos en Europa sobre estos cuerpos, por eminentes profesores. Ni en aquéllos, ni en las análisis que practicamos, ha podido encontrarse, como reremos después, el mercurio, que es el elemento distintivo de las amalgamas.

Los autores del dictamen dicen, en uno de los párrafos de su escrito, refiriéndose á la masa meteórica: «Su figura, aunque conservando restigios de una forma geométrica, es, sin embargo, tan irregular, que en el estado actual de la ciencia, no es posible deducir de ella alguna conclusión en apoyo de las diversas hipótesis que se han hecho acerca de los aerolitos, por una parte, y por la otra, sien la configuración externa de los cuerpos meteóricos se creyese encontrar algún dato para la resolución del problema que investiga su procedencia, nada más fácil que llenar los racíos que respecto de su forma pudiese dejar una simple descripeión ó un dibujo, modelando la masa sobre el natural.» $\mathrm{Y}$ en otro párrafo posterior, se agrega: «Es un hecho que todas las masas meteóricas poseen un carácter común, sean cuales fueren las diferencias de su constitución química interna: es un aspecto bien pronunciado de fragmento y á memudo una forma prismática ó piramidal truncada; caras anchas y un poco curvas, las avistas redondeadas» * y después: el aerolito de la "Descubridora,» tiene una forma muy marcada de prisma triangular de base ojival.»

El simple estudio de estos párrafos, da la medida más completa de su importancia y de lo que pueden influir en una apreciación racional y meditada para esclarecer una cuestión científica, digna de examinarse bajo las diferentes faces que se presentain.

En el primero de esos párrafos, dicen sus autores, de una manera absoluta, que los aerolitos, «sólo conservan vestigios de una forma geométrica;» en el segundo ya la admiten «á menudo» y como «un carácter común,» y, por fin, en el último, aseguran que el meteorito de la «Descubridora» «tiene una forma muy marcada de prisma triangalar,» lo cual una rez reconocido, era motivo suficiente para conservarlo, á fin de poder estudiar esa forma, examinándola y sometiéndola á todas las-obserraciones necesarias. ¿̇erá, acaso, despreciable é indigno del más prolijo estudio ese «carácter común» que, según el barón de Humboldt, subsiste, «sean cuales fuesen las diferencias de la constitución química interna» de ese género de masas? ¿No es de llamar la atención esa comunidad de forma, y no se-

* Cosmos, -tomo 1., pág. 133. 
ría suficiente este hecho para haber conservado intacto el aerolito, objeto de la cuestión, ó es de ninguna importancia al estudio comparativo? Esos «vestigios de una forma geométrica» de que hablan los autores del dictamen, ¿no merecían la atención de la ciencia? ¿Sería preciso que esa forma fuese perfecta, para ser digna de estudio? La ciencia sabe aprovechar circunstancias que por poca meditación se juzgan á veces como despreciables: lo que parece insignificante á una mirada investigadora, es tal rez inagotable tesoro para aquélla. Aun cuando nuestro meteorito no tuviese una forma geométrica muy marcada; aun cuando sólo tuviera vestigios de ella, esto bastaría para excitar el deseo de estudiarla. Precisamente debería haberse conservado, porque «no es posible que la ciencia en su estado actual deduzca de ella ninguna conclusión en apoyo de las diversas hipótesis que se han hecho acerca del origen de los aerolitos:» las observaciones de hoy, reunidas á las de mañana, llegarían á producir esa conclusión práctica.

No comprendemos, á la verdad, cómo pueden haber incurrido en tan notables contradicciones, los ilustrados micmbros de la Sociedad de Geografía y Estadística, que cabalmente destruyeron la forma del aerolito de la «Descubridora,» llevados de su ardiente entusiasmo por el progreso científico.

Para estudiar la masa, bajo el punto de vista de sus aplicaciones industriales, jera preciso aniquilar completamente su forma? $\dot{b}_{\text {Es }}$ tan poca la importancia que le dan los antores del dictamen? Por más que supongan oscura la ciencia sobre este punto, siempre es útil tal estudio: esa misma oscuridad debe estimular á la iuvestigación.

Debe tenerse presente, que en los aerolitos no sucede lo mismo que con muchos de los otros cuerpos que están sometidos al dominio de la Mineralogía, en los cuales se han apodido determinar con precisión sus caractéres físicos y su composición química, liasta el punto que cada uno de ellos tiene su historia completa y el conjunto de los caracteres constantes que los determinan perfectamente. En los aerolitos, por el contrario, la incertidumbre respecto de su origen, la diversidad de sus formas, la variedad de proporciones en sus elementos constitutivos, etc., hacen que cala ejemplar tenga un interés particular para el mineralogista que trata de encontrar el maror número de caracteres constantes con que formar la descripción precisa de esos cuerpos. En consecuencia, en esta clase de estudios 
descriptivos, al mismo tiempo que se estudian las propiedades químieas, debe tenerse el mayor euidado en estudiar las fisicas, combinando los proeedimientos de modo que, al investigar las unas, no se inutiticen los medios de determinar las otras; pues no debe olvidarse que cualquiera circnustancia interesante que pasase inadvertida, ó que no pudiera ya areciarse por la imperfección de los procedimientos empleados, sería una pérdida irreparable para la cieneia. Desgraciadamente tenemos que lamentar este triste resultado, respecto del aerolito de la «Descubridora» porque, como hemos visto, de una marera innecesaria fué unandado destruir sin que la comisión nombrada por la Sociedad de Geografía hubiese hecho el gran rúmero de observaciones que requería el interesante estudio de aquel ejemplar,y cuyo rosultado habría enriquecido en gran manera la colección de datos que se han determinado acerca de las analogías y diferencias que presentan esos cuerpos extra-terrestres, dándose un paso más en ese estudio descriptio en que la ciencia ha fijado tanto su atención.

Sabido es el interés que presentan en la Minepalogía los earcuteres exteriores de los euerpos de que se ocupa, para establecer su estudio comparative, y señalar aquellos que los doterminan más particularmente; y por tanto, tiene el mayor cuidado en conocer con exactitud la forma cristalina, el color, el lustre, etc.... y y con la reunión de estos caracteres, establece el diferencial y propio de cada substancia. Fijándonos de preferencia en el primero de los datos mencionados, bastará, para demostrar su importancia, el recordar que los progresos de la Mineralogía se han hecho palpables, desde que Romé de Tisle, Haïy y otros sabios, determinaron las leyes preciosas de la Cristalografía y establecieron sus grupos cristalinos, en los cuales se fueron colocando los diversos cuerpos que antes estaban perdidos en un sinnúmero de clasificaciones confusas. La forma cristalina de los aerolitos no está aún perfectamente determinada, y en el mayor número de los que se han estudiado, como lo confiesan los autores del dictamen, han podido observarse algunos elementos cristalográficos, más ó menos sensibles, y diversamente desarrollados en cada uno de ellos. El estudio comparativo de estos signos geométricos y el de las irregularidades que presentan, al mismo tiempo, que daría gran luz sobre la cuestión cristalográfica, ¿no podría revelar algunas de las circunstancias desconocidas en que se encuentran las masas meteóricas antes de llegar á nuestro planeta? 


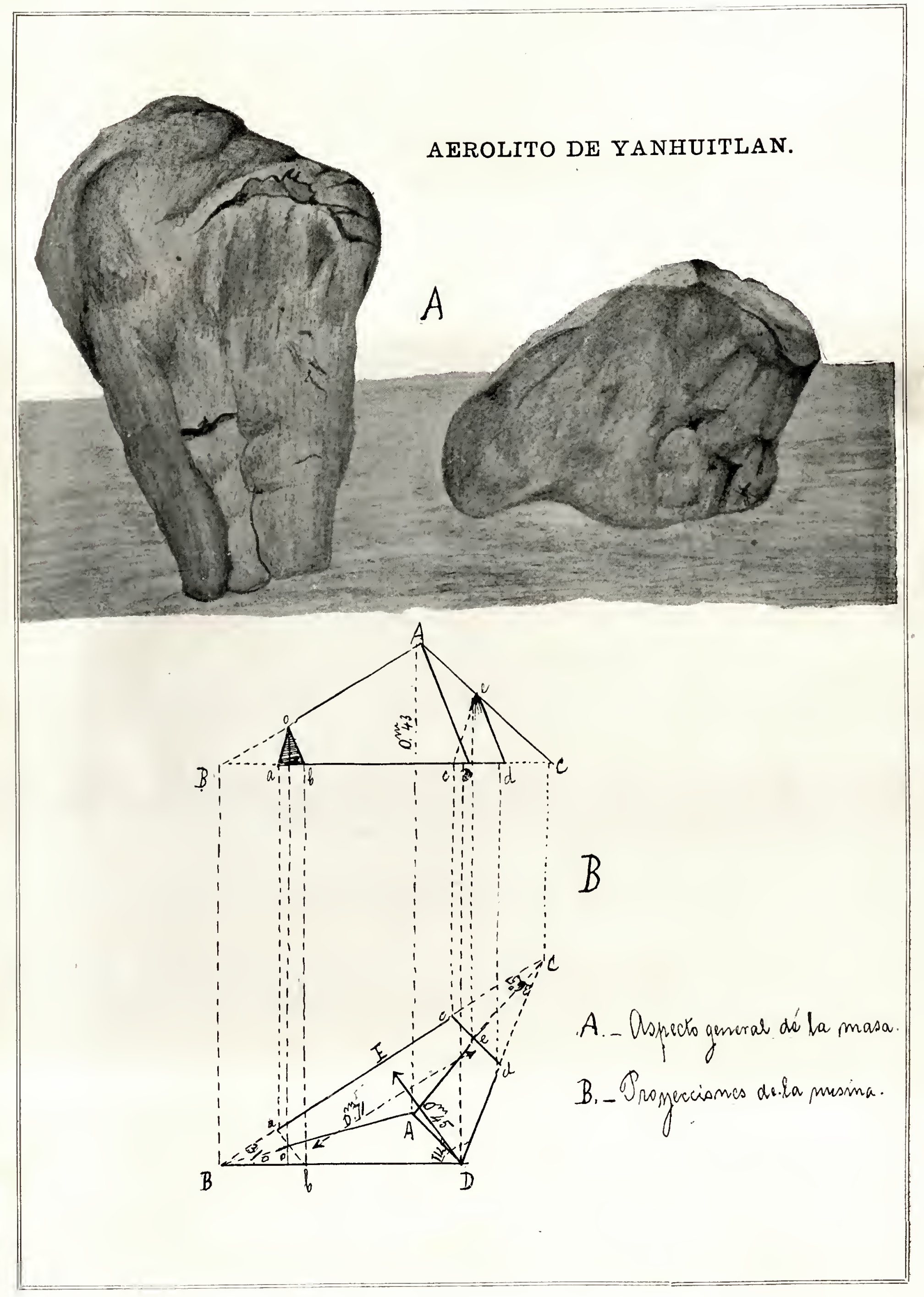


¿Estas irregularidades están sujetas de algún modo á la ley de simetría? ¿La dirección y clase de movimiento que trajeron en su curso, influyeron de alguna manera en la producción de esas anomalías? Como se ve, estas cuestiones están íntimamente ligadas con el estudio cristalográfico, y con las circunstancias desconocidas en que se encontraron aquellos cuerpos, para cuya averiguación niegan de una manera absoluta, la importancia de la forma, los antores del dictamen, «en el estado actual de la ciencia,» cnyo motivo debería precisamente impulsarnos á reunir todos los datos posibles en este sentido.

Muchos de los aerolitos que se han encontrado en nuestro país, presentan signos geométricos bastante sensibles aunque diversamente desarrollados. El ejemplar que fué remitido de Oaxaca, hace algunos años, llamado de Yanhuitlán, y que se encuentra ahora en. nuestro Museo Nacional, tiene una figura piramidal bastante notable; me parece provenir de un tetraedro, cuyo desarrollo fué interrumpido por causas poderosas. Al hacer la descripción de este ejemplar, en 1864, uno de los que subscriben manifestó la hipótesis de que: «Esa masa presentaba la figura de un tetraedro irregular ó de una pirámide oblicua de base triangular cuyos tres ángulos serían de $112^{\circ} 30^{\prime}, 36^{\circ} 30^{\prime}$ y $31^{\circ}$; siendo muy de notar, el truncamiento de los ángulos B. y C. de la proyección de la pirámide (lám. 1, Fig. B.) La altura de ésta, es decir, la del vértice A, deberá estimarse, con corta diferencia, igual á la mayor profundidad actual del fierro meteólico, puesto que las aristas A. B., A. C., A. D., se conservan aún lo bastante para determinar la figura, no pudiendo dudarse que las interrupciones, notoriamente artificiales, que se observan en la intersección de las caras laterales, proceden de las muestras que se han tomado en los puntos más accesibles al cincel, las cuales no deben confundirse con las alteraciones ó módificaciones que le son peculiares.

Entre los caracteres de cristalización que pudieran suponerse, sería acaso el más notable, el truncamiento indicado en A. B. y C. D. cuyas faces, sensiblemente paralelas entre sí, son perfectamente planas, como si en ellas no hubiera obrado la causa que desarregló muchas partes de la figura original redondeando las caras, y principalmente la interseción de la base de las faces laterales, así como el ángulo triedro D. El carácter de estos detrimentos es el mismo que 
habría resultado en un prisma semejante de piedra, rodado largo tiempo por un torrente impetuoso. También llama la atención una ranura perfectamente recta de cosa de $0 .{ }^{m} 003$ de profundidad, que se advierte en la base, á $0 .{ }^{\text {: }} 011$ del truncamiento A. B. y paralela á ella. Aunque por su apariencia pudiera juzgarse hecha artificialmente por medio de la sierra, repugna tal hipótesis, considerada la suma dureza del metal y rarios accidentes que indican ser otra la causa.

«Las medidas aproximadas de la masa metálica, son: $0 .{ }^{\mathrm{m}} 71$ de truncamiento á truncamiento; $0 .{ }^{\mathrm{n}} 45$ en su mayor latitud correspondiente al eje transversal D. E., y $0{ }^{m} 43$ de altura en el punto corespondiente á A.

"Acaso pudiera confirmarse la suposición antedicha, teniendo presente una propiedad particular del metal, y es, que al escofinarlo, y, más aún, al forjarlo, se nota esa separación laminar que no es comúm encontrar en los fierros del comercio, y sí, como se sabe, en los cuerpos cristalizados. Así es, que en el supuesto de que esa grande masa fuera un cristal modificado ó en parte destruido por accidentes especiales, acaso se tendría un camino para llegar á descubrir el origen de esos meteoritos. Aun sin ello, creo que debe fijarse la atención en un hecho que, por serlo, no hay en él de teoría. ¿Cual es? La existencia de los pequeños cristales que se descubren en algumas grietas. Cuestiones son estas que exigen todos los conocimientos de las personas dedicadas al estudio de los curiosos fenómenos meteorológicos: ellas apoyarán ó desecharán la idea que tne he decidido á indicar, fundada en resumen, en estos datos principales:

«Ia forma del sólido.

«La separación laminar, $y$

«La existencia de algunos pequeños cristales en las caridades ennegrecidas que presenta la masa.»

Para que pueda apreciarse debidamente la importancia de este ejemplar, presentamos una lámina que ayudará á la comprensión de los raciocinios anteriores.

El meteorito de Charcas, que fué enviado á Francia y se conserva con el mayor interés en el Museo de Historia Natural de París, tiene también la forma de un tronco de pirámide, según consta en la descripción que publicó de ese ejemplar el profesor de Geología Mr. Daubrée: en esta descripción remos una prueba de la necesidad que hay de establecer estudios comparativos entre estos cuerpos, 



\section{AEROLITO DE LA "DESCUBRIDORA."}
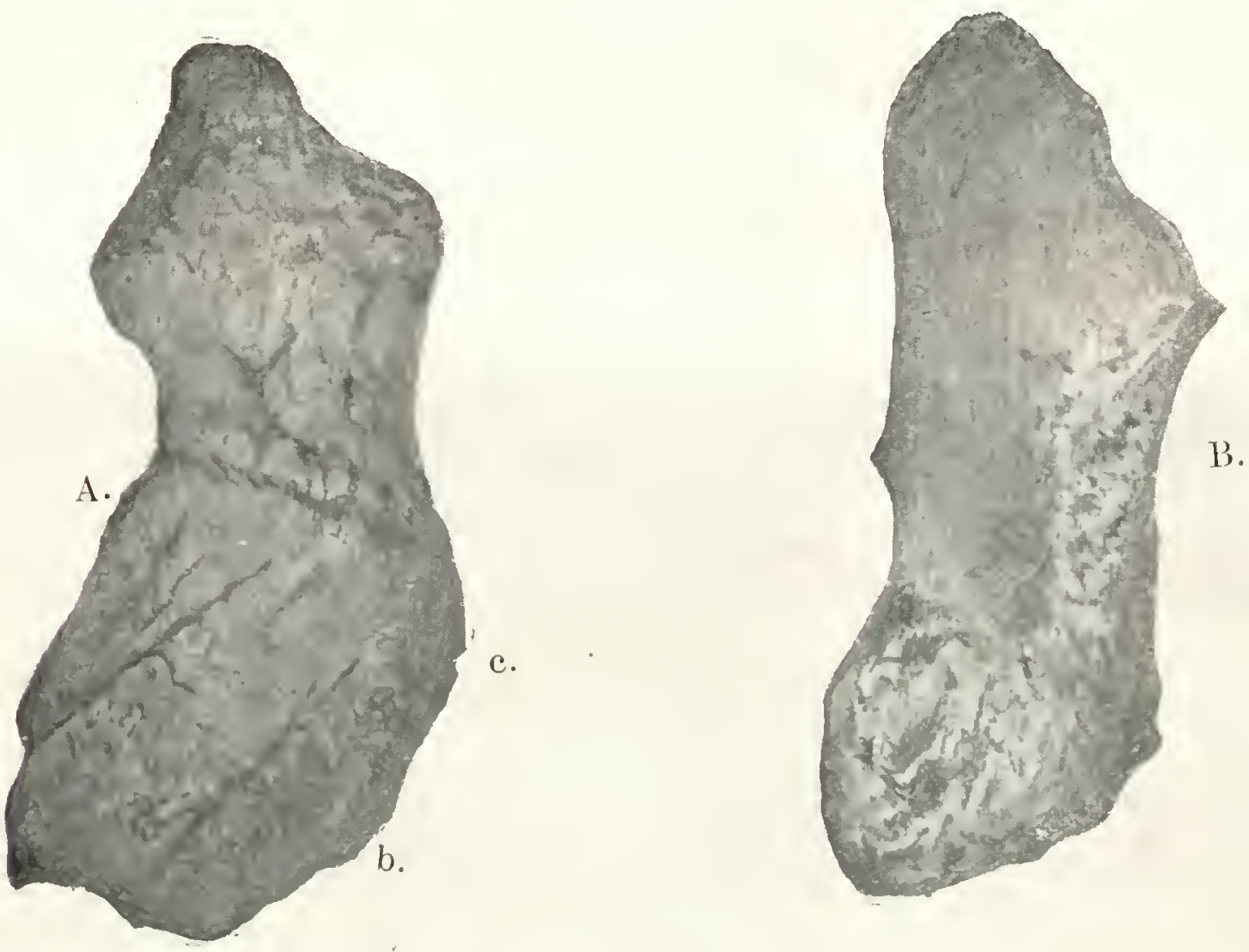

a.

A. B. C. - Vistas de tres caras de la masa.

D.-Figuras de Widmanstotten

C.
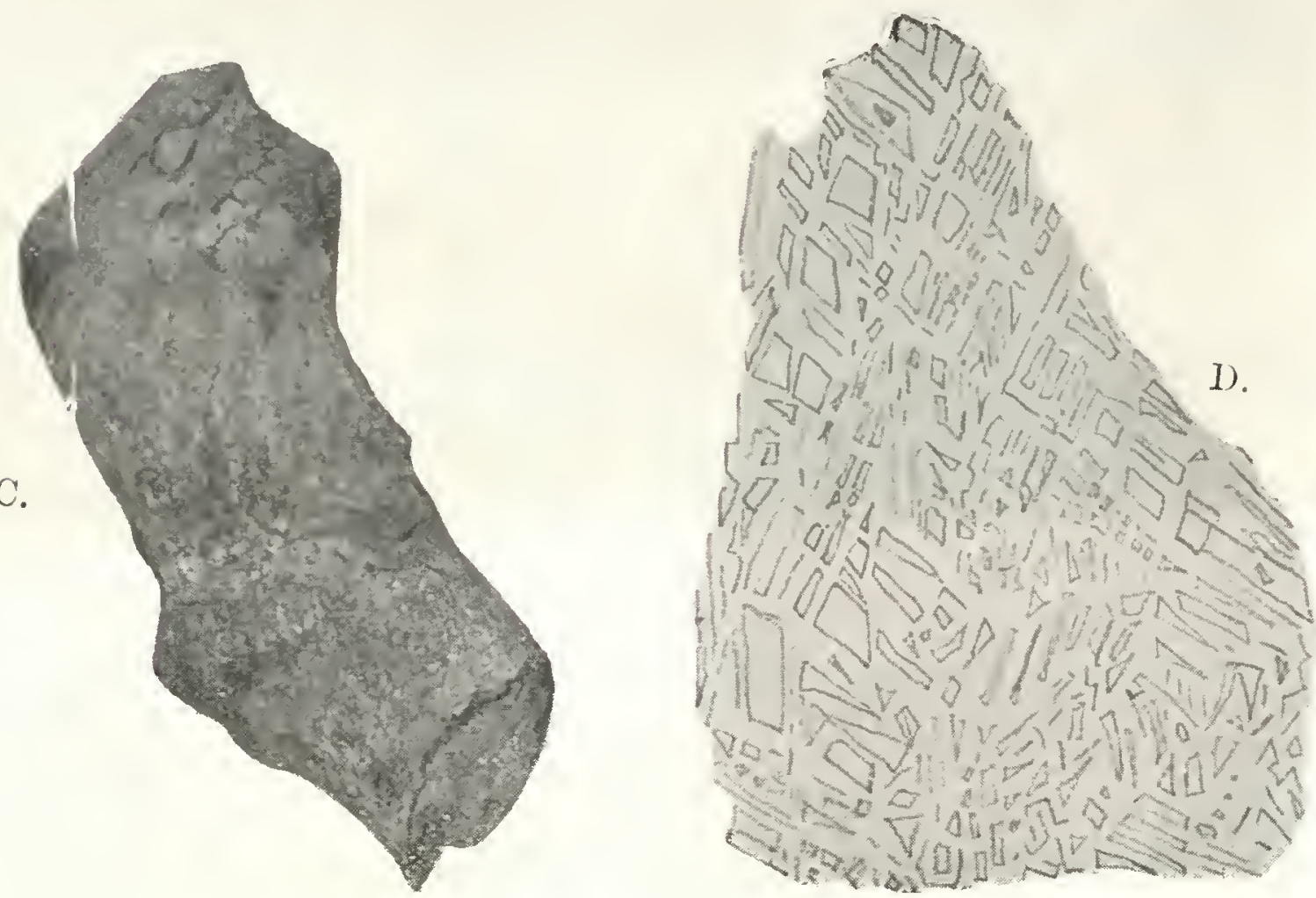
pues antes de emprenderla, refiere el ilustrado profesor, la que ya ha hecho del fierro meteórico de Caille, para tener así un término de comparación. En una pequeñísima superficie del meteorito, que mandó pulir para examinar las figuras de Windmanstaetten, encontró que las hojas de la Schreibersita, èstaban en parte dirigidas paralelamente á las caras del octaedro regular, y otras á las del docaedro romboidal.

En un pequeño aerolito de Xiquipilco, que posée nuestra Sociedad, se ha podido descubrir con facilidad una parte de un octaedro, siguiendo con un cincel la dirección de las láminas de la Schreibersita.

El aerolito de la «Descubridora» debió haber sido muy interesante con respecto á su forma. Cuando tuvimos noticia de su fraccionamiento, algunos de los que subscribimos, nos apresuramos á examinarlo, antes de que el cincel del mecánico acabase de destruir su forma general, para conservar siquiera una idea de sus caracteres geométricos; desgraciadamente llegamos tarde: la masa meteórica estaba ya dividida y no nos era posible apreciar su conjunto. Nuestra pena aumentó al observar que algunos fragmentos presentaban secciones triangulares pertenecientes tal vez á una pirámide, cuya regularidad no nos era ya dado estudiar. En la superficie de aquellos fragmèntos se notaban, sin ayuda del ácido, las láminas de la Schreibersitn, formando diversas figuras romboles, que parecían corresponder á cruceros octaédricos. La costra exterior esmaltada de esta masa, no tuvo seguramente el espesor necesario para preservarla de la oxiçación, y la intemperie puso de manifiesto las láminas de aquel fosfuro. En el pequeño fragmento que nos sirvió para los experimentos, $y$ de que hablamos antes, se mandí pulir una parte de su superficie, que, sometida á la acción del ácido azótico diluido, dejó ver con la mayor claridad las figuras de Windmanstaetten, principalmente dejando sumergida la placa en el ácido por algún tiempo, pues continuando la disolución del hierro, aparecen en relieve las láminas insolubles del fosfuro. Tenemos el honor de presentar una copia exacta de dicha placa (lám, 2, fig. D), la cual se dibujó colocando un papel sobre las figuras, y frotándolo con un fragmento de plombagina. Los mismos dibujos se obtuvieron paronando dos piezas, las cuales adquirieron el color pardo de tumbaga, á $1 .^{\circ}$ del pirómetro, y el azul violado á $2 .^{\circ} \mathrm{El}$ aspecto mismo de la placa da á conocer su importancia, 
pues en ella se re una serie de triángulos y cuadriláteros, en muchos de los cuales se encuentra, con bastante frecuencia, el ámgulo de $109^{\circ}$ que corresponde al crucero del octaedro. El agrupamiento de las figuras es irregular en algunas partes, pero en otras se reunen en series, cuyas direcciones forman entre sí el ángulo citado. La tendencia que tiene la Schreibersita, á colocarse èn estas direcciones, y aum el desorden que se le nota en algunos puntos, creemos explicarlo fácilmente, y de una manera que contribuye á la resolución del problema cristalográfico del hierro meteórico. Probablemente, durante la solidificación de la masa, los elementos necesarios se combinaron para formar la Schreibersitu, y ésta comenzó á cristalizar; pero cuando apenas labóan principiado á formarse sus láminas, llegó el momento de la cristalización del hierro según el sistema isométrico, y aquellas láminas fueron arrastradas en la dirección de los cruceros del ńltimo; mas la tendencia cristalina, propia de la Schreibersita, y tal rez la cooperación de agentes desconocidos que concurrieron á estos fenómenos, impidieron la regularidad perfecta en la distribución de las láminas del fosfuro. Si por la cooperación de esos agentes, la figura cristalina de los aerolitos no puede desarrollar'se perfectamente, y que por esta causa aparezca en muchos casos como forma fragmentaria, el estudio de la figura está íntimamente enlazado con el de su origen, para averignar si estos cuerpos nos presentan su forma propia, más ó menos alterada, ó son fragmentos de otros, de cuya fignra pudieran proporcionarnos algma idea. El estudio comparativo es, en estos casos, más interesante, pues sabido es que por el examen de los fragmentos, se ha intentado ya la restauración de ma masa mayor.

Atendida la ilustración de las personas que nos dispensan la honra de escucharnos, creemos que bastará lo dicho para demostrar la importancia del estudio de la forma de los aerolitos, por lo cual, pasamos á ocuparnos de otros puntos del dictamen de la Sociedad de Geografía.

Encnentran sus antores muy conreniente reemplazar las masas destruidas modelándolas sobre el natural. Así se hace, en efecto, con muchos de los objetos de historia natnral, principalmente cuando están sujetos á alterarse ó descomponerse, ó cuando su gran valor los pone fuera del alcance de ciertas fortumas, como sucede con las piezas anatómicas y con las piedras preciosas; pero se comprende fá- 
cilmente, que los modelos no pueden tener nunca el mérito de los originales que representan, y mucho menos, como en el caso que nos ocupa, pues: la más ligera contracción ú otvo accidente cuclquiera que se verificase en el modelo, ocasionaría una serie de errores muy notables en las apreciaciones geométricas.

«Cuando los Académicos del Cimento, de Florencia, hacían arder un diamante en el foco de un espejo ustorio; cuando Lavoisier y Guyton de Morveau y Sir Aumphry Dary, repetían el mismo experimento en el oxígeno, ilevantóse, por ventura contra ellos voz alguna porque sometían á la combustión uno de los cuerpos más apreciados por la humanidad? Esto preguntan los autores del dictamen, y después responden: "No; porque sus indagaciones, aunque costosas, iban á arrancar un secreto á la naturaleza; iban á ilustrar uno de los arcanos de la ciencia; iban, en fin, á poner de manifiesto, que entre el carbón que alimenta nuestros logares y esos hermosos brillantes que reflejan los colores del iris, no existía ninguna diferencia en su composición química, y que sólo la diversidad de su agrupamiento molecular era la causa que influía en su aspecto exterior.»

Hubieran podido agregar: que esos experimentos los continuaron Smithson, Thenard y otros químicos distinguidos, y en nuestros días, Dumas, Stas, y esa pléyade de sabios, honra de la civilización, gloria inmortal de la humanidad, dejándose arrebatar por las hermosas concepciones de una fantasía deslumbradora $y$ fecunda; pero ninguna de esas consideraciones es aplicable al caso de que se trata. Es imposible suponer que los académicos de Florencia, ó los otros sabios, cuyos trabajos admiramos reconocidos, lubieran sometido á sus experiencias, para destruirlos, como se ha destruido sin razón el meteorito de la «Descubridora,» los grandes diamantes históricos tan l'aros en su especie, como son: los llamados «El Regente,» «El Gran Mogol,» «La Estrella del Sur,» «El Diamante Amarillo ó Florentino,» «El Saucy,» Eldiamante Verde, ó «Green Vaultss,» etc. Fra imposible que los hubiesen destruido $y$, mucho menos, sin haber determinado antes su forma cristalina y otras de sus propiedades físicas, y sin saber si eran idénticos, ó tenían algunas diferencias que les diesen un interés particular, pues el haber procedido de otro modo, era invertir el orden racional de las inrestigaciones científicas. No podemos suponer tampoco, que para invertir ese orden, se hubiesen preocupado aquellos sabios con el deseo de conocer la composición 
de los ejemplares citados para areriguar si el arte con su constancia, tendría medios de imitarlos, ó si la industria, con los portentos que realiza diariamente, dirigida por la ciencia, podría aprovecharlos en alguna de sus múltiples aplicaciones.

Los académicos florentinos y los otros químicos que después han sometido al análisis el diamante, han operado sobre ejemplares cuya desaparición no importaba una pérdida irreparable, ó sobre los fragmentos desprendidos por la tabla cuando se labra la piedra.

Pocos profesores se habrán ocupado tanto del estudio de los aerolitos, como Mr. Daubrée, á quien turimos ya la homra de citar. Todos los meteoritos que existen en el Museo de Historia Natural de París, han sido escrupulosamente estudiados de distintas maneras, pol aquel distinguido geólogo; y sin embargo de estas multiplicadas y distinguidas pruebas á que ha sometido dichos cuerpos, se puede observar aún la forma general de cada uno, para establecer ńtiles y frecuentes comparaciones con los ejemplares que se encuentran en ambos continentes, y cuya descripción se conozca. Mr. Daubrée, ha examinado también los productos que resultan de la fusión de las substancias meteóricas, y despnés, por medio de la síntesis, ha logrado reproducirlas, con mucha aproximación, colocando rocas terrestres análogas á aquellos productos, en circunstancias propicias; pero en ninguno de sis interesantes experimentos, ha consumido en su totalidad ni ha desfignrado tampoco las masas cnyas propiedades se proponía estudiar.

Ojalá y la Sociedad Mexicana de Geografía y Estadística, en el estudio que se propuso hacer del aerolito de la «Descubridora,» hubiera también dispuesto los procedimientos, de tal manera, que sin alterar la forma, hubiese determinado todos los caracteres físicos y químicos, pues anm para comparar la composición química del interior con la de la superficie, como se proponía hacerlo, creemos que linbiera bastado un taladro, ú otro medio menos deplorable que el que puso en ejecnción.

Dicen en otro lugar los autores del dictamen que nos ocupa: «Sería ridículo que quisiésemos diridir todas las masas meteóricas que poseemos; pero están íntegras las que figuran en nuestros museos, y no habiendo sido analizadas sino superficialmente, parece muy razonable el que, para fucilitar los estudios y hacer mayor número de experimentos, fraccionemos el aerolito de la "Descubridora, por- 
que, á la verdad, las mismas razones que pudieran dársenos para suspender la operación que se practica, esas también podrían alegarse al botánico que mutila una planta para estudiarla, al zoólogo que para hacer sus investigaciones sobre los cuerpos animados, se ve en la necesidad de destrozarlos; al químico, que queriendo averiguar la composición de una sustancia en un hermoso ejemplar cristalizado, hace el sacrificio de su bella forma, pulverizándolo y disolviéndolo.» La contestación á estas palabras está comprendida en lo que hemos dicho sobre el interés particulur de cada meteorito. No es exacto que las razones que aleganos contra el fraccionamiento, sean las misunas con que pudiera combatirse al botánico, al químico, y al zoólogo, que, encontrando en abundancia ejemplares idénticos los destrozan para hacer sus estudios. Ninguno de estos investigadores destruiría, seguramente, ejemplares de interés particular, para hacer así observaciones incompletas, $y$ dejar una listoria también incompleta, de objetos que ya no existieran.

Acaso bastaría ya lo expuesto para decidir imparcial y equitatiramente en la cuestión que origina este escrito; pero vamos á añadir el estudio que hemos hecho del fragmento arrancado de la masa por los Sres. Río de la Tuza y Mendoza, á fin de demostrar que no labía necesidad de la destrucción total del meteorito para verificar las investigaciones que se proponía hacer la Sociedad de Geoglaafía y Estadística.

Segŕn manifestamos antes, no nos fué posible tomar siquiera una idea aproximada de la forma general de la masa, y por esto omitiuros su descripeión; pero á juzgar por la figura de las secciones y por lo que se leé en el dictamen que impugnamos, debemos suponer que aquélla era sensiblemente piranidal. Posteriormente al fiaccionamiento, hemos recibido unas fotografias que fueron tomadas de diclia masa enando estaba en San Iuis Potosí, las euales representan aisladamente tres de las caras del poliedro (Lám. 2, figs. A. B. C.). Se notan en los contornos algunas líneas rectas que, en su mayor parte, deben corresponder á la dirección de los cruceros, pues al prolongar las principales, se obtienen algunas figuras semejantes á las que puso de manifiesto el ácido azótico en la placa pulida que se mencionó, y entre los ángulos de las intersecciones se encuentra con bastante frecuencia el de $109^{\circ}$ que corresponde al crucero del octaedro. En la figura A se nota una hendedura que debe seguir la 
misma dirección, y presenta la particularidad de ser sensiblemente paralela á la linea a $b$ del contorno, así como á otra línea negruzca que se encuentra entre ambas: signiendo la traza de la hendedura, se ve que va á terminar en una línea angulosa que parte del punto $c$ en donde parece que había una notable prominencia. Al observar estos dibujos, hemos lamentado una vez más la falta de la figura original, y una vez más rechazamos, también, la opinión de sustituirla con modelos ó dibujos.

El color de la masa, en la parte que estaba expuesta á la atmósfera, es negro-parduzco, pero en algunos puntos aparece blanco de plata, debido á la presencia de la Schreibersita: en la superficie de ruptura, es de gris de acero blanquecino. La estructura de este fierro meteórico es notablemente cristalina; en general, es poco lustroso, de lustre metálico; la parte oxidada de la superficie es mate.

Su dureza es de 8 ; es dúctil y maleable.

Su peso específico es de 7.38 ; el peso absoluto, estimado en San Luis Potosí, era de $576,037 \mathrm{~kg}$.

Atrae notablemente á la aguja magnética por ambos extremos.

En el interior do la masa hay algunas cavidades irregulares ocupadas por una substancia cristalina, pulverulenta, de color amarillo de bronce que pasa á pardo de tumbaga, y de lustre metálico, que es la Froilita de Haidinger, ó sulfuro doble de fierro y níquel.

La composición química del hierro meteórico de la «Descubridora» es la signiente:

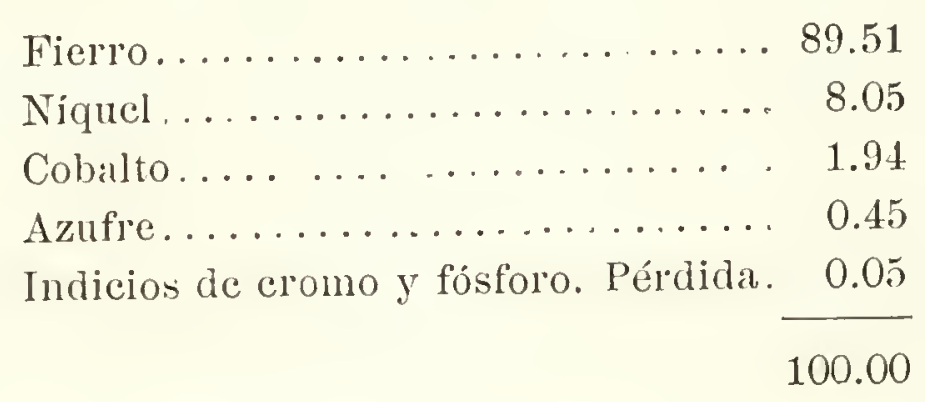

Esta análisis, así como la determinación del peso específico, fueron ejecutados por nuestro consocio el Sr. D. Patricio Murphy, tan rentajosamente conocido como químico inteligente y hombre de instrucción. En la apreciación de esos cuerpos simples, signió extricta y cuidadosamente el procedimiento indicado por Rivot para la análisis de los aerolitos.

En rista de los caracteres mencionados, creemos que dicha ma- 
sa correspondía á la sección de los Sideritos, y al grupo de los Holosideros de M. Danbrée.

Indicamos á continuación el resultado de alguno de los experimentos que hemos practicado, para conocer las propiedades físicas del hierro meteórico de la «Descubridora.»

Sn resistencia á la ruptura por compresión, es de 38 kg. por mílimetro cuadrado. Los dirersos ejemplares que fueron estudiados, afectaban la forma prismática ó cúbica; en todos se verificó la fractura de una manera semejante, y manifestaron una tendencia constante á dividirse, principalmente en dos partes casi iguales por un plano diagonal, comprendido entre dos aristas opuestas de las bases, que cortaba á dos de las caras laterales según dos líneas oblicuas. Paralelamente á dichas líneas, se iniciaron también algunas aberturas. En el fierro meteórico marcha la fractura de un modo mucho inás regular que en otras clases de fierro que se estudiaron simultáneamente con aquél, con especialidad el de la fábrica de la «Encarnación.» En ambos se anuncia el fenómeno bajo una presión próximamente igual, pero marcha desde este momento mucho más velozmente en el fierro meteórico, lo que, en nuestro concepto, es debido á la estructura cristalina de la masa, y á su heterogeneidad; pues probablemente la fuerza de cohesión en el fierro de la «Encarnación,» supera á la de adhesión entre los cristales del fierro meteórico.

La resistencia á la ruptura por extensión, es de $40 \mathrm{~kg}$. por milímetro cuadrado. Es verdaderamente increíble el alto grado de elasticidad del alambre del fierro meteórico, pnes repetidas veces durante cada experimento, se suspendía la acción de la potencia, para determinar los alargamientos, correspondientes á fuerzas dadas, $y$ frecuentemente sucedió, estando ya muy cercanos los alambres á su ruptura, recobraran con notable precisión su longitud primitiva. Pudo observarse que durante la operación los alargamientos se verificabau en la misma relación que el crecimiento de la fuerza empleada. En el momento de la ruptura, y en el punto en que ésta se rerificaba, se producía un estrechamiento de la sección transversal, que la reducía á 0.70 ó 0.75 de su magnitud primitiva, desarrollándose al mismo tiempo una cantidad de calor que hacía subir el termómetro centigrado, $0.50^{\circ}$ o $0.75^{\circ}$. El nódulo de elasticidad de tensión del alambre de fierro meteórico, es $7.436,17 \mathrm{~kg}$. por milímetro cuadrado. Parecía haber contradicción entre el valor del nódulo que es relati- 
vamente pequeño, y el alto grado de elasticidad de que antes se habló; mas atendiendo á lo que significa el nódulo, desaparece la duda; y es clara la razón, pues la experiencia demuestra que los alambres se alargan con muy poca fuerza, y recobran su longitud primitira con la misma facilidad con que la pierden. Con el fin de observar las modificaciones producidas por la ruptura, se sometió á la experiencia, cinco veces, uno de los alambres, y se rompió bajo la acción de fuerzas que crecieron en la relación de 1 á 1.13 á 1.22, á 1.32, á 1.42. Aumentaba la resistencia pero disminuía la elasticidad, pres se produjo un alargamiento permanente medio do 0.0002 , de la longitud primitira.

El nódulo de la elasticidad de flexión es $1.134,795527 \mathrm{~kg}$. por milínetro cuadrado.

El coeficiente de dilatación lineal entre 0 y 100 grados, es $0,00,002,336,783$.

El de la dilatación cúbica es 0,00007010349.

El fierro meteórico de la «Descubridor'a,» es notablemente maleable en frío, disminuyendo su espesor extriordinariamente sin romperse, y desarrollando á la vez una gran cantidad de calor que lo pavona de amarillo pajizo. En caliente se hojea muy fácilmente, lo cual es también ocasionado por la heterogeneidad de la masa, que se disgrega á causa de la elevación de temperatura, siendo en consecuencia muy dificil soldar dos piezas. Para ser forjado necesita un gran número de caldas, durante las cnales se forma una escoria que llega á reces hasta 0.30 del peso primitivo.

Al citar estas experiencias tenemos que cumplir con un deber de justicia manifestando, que en todas ellas nos ayudó con la mayor eficacia nuestro apreciable consocio el joren D. Miguel Pérez, á quien la Sociedad estima como á uno de sus miembros más laboriosos.

Antes de concluir, debemos de mencionar, que con posterioridad al dictamen que combatimos, se dijo por algunos rocales de la Sociedad de Geografía y Estadística, que entre los fragmentos del aereolito partido, se habían encontrado dirersas poreiones de tierra vegetal, presentando ese increíble descubrimiento como una ventaja inmensa producida por el fraccionamiento del meteorito de la «Descubridora.»

Deberíamos pasar por alto este punto, porque el grave error 
científico que envielve, fué rectificado; mas hemos visto en «El Americano,» una carta que de México le dirige á su redactor, el Sr. D. Andrés Clemente Vázquez, miembro de la Sociedad de Geografía, en la que, ocupándose de esta cuestión, dice....

«Y ya que le hablo de la Sociedad de Geografía y Estadística, roy á referirle un hecho que puede ser de mucha trascendencia para el mundo científico.

"A la Sociedad le fué regalado nn inmenso aereolito, que cayó en terrenos del Estado de San Luis. Hubo un socio que propuso la división del aerolito para hacer todo género de experimentos con la materia del mismo, y la moción fue aprobada.

«La Sociedad de Historia Natural, compuesta en su mayor parte, de hombres del antiguo régimen, protestó contra dicha determinación porque creyó ver en ella un atentado. La socicdad de Geografía no permaneció en silencio en su defensa: dió al público una magnífica Memoria, en la cual se evidenciaban magistralmente las ventajas del análisis y de la exploración, y los hechos han venido á darle la razón á tan respetable instituto. Sé que dentro del aerolito se ha encontrado una sustancia extraña que hasta ahora parece tierra.

«Usted calculará con su magnífico talento, todo el partido que de ese dato, de ese hecho irrecusable, habrán de sacar los defensores de la pluralidad de los mundos.»

Es sensible que en un periódico destimado á la defensa de la honra de América, aparezcan apreciaciones que, por ligeras, pudieran ceder en descrédito de la ilustración mexicana. El desprestigio que se procura arrojar sobre la Sociedad de Historia Natural, impone á nuestro honor el penoso deber de entrar en algunas explicaciones científicas.

En la mayor parte de los Sideritos hay cavidades más ó menos irregulares de diversas formas, entre las que predomina la cilíndrica. Estas cavidades están ocupadas por la Froilita, y por el protosulfuro de fierro, en los cuales se nota siempre, la tendencia á la cristalización, el color y el brillo metálico que los caracterizan. En el fierro meteórico de Caille, en el de Charcas $y$ en otros muchos, se había observado ya la presencia de estos sulfuros. Hace tiempo que Rammelsberg, al hablar de los Sideritos, decía: «Oasi siempre contienen partículas más ó menos grandes de sulfuro de fierro, que, sin embargo, no parecen ser de pirita común, ni de pirita magnética, si- 
no de protosulfuro de fierro» La Froilita cuya presencia habíamos señalado en el aerolito de la «Descubridora» desde que examinamos el fragmento que sirvió para las experiencias, fué la que dió lugar á aquella equirocación que pareció por un momento servir de arma poderosa para combatir nuestra franca protesta contra el fraccionamiento del meteorito. Cuando se dudó en la opinión pública de la exactitud de aquella clasificación, tuvinos noticia de que el Señor profesor de quínica de la Escrela de Ingenieros, demostró hasta por la análisis, la verdad de la opinión que nosotros habíamos formado. La sustancia que se había tomado por tierra vegetral, resultó ser una mezcla de Froilita y de sulfuro de fierro.

Deploramos que, sim expresar fundadamento alguno científico, se haya tomado un error, como pretexto plausible para herirnos. - La palabra tierra, en la acepción en que fué tomada, significaba que la materia en cuestión, estaba formada de una mezcla de compuestos minerales y orgánicos.

No creemos necesario demostrar la inposibilidad de que los últimos pudiesen subsistir á la alta temperatura á que llegan los cuelpos meteóricos á nuestro planeta, y menos aún, á la que tenían, cuando cristalizaron algunas de las substancias que los componen, y renunciando á este método sencillo de demostración, es evidente que para deshacer tan equivocada idea, bastará dar una ojeada sobre la naturaleza de los cuerpos que constituyen los Sideritos. Ta presencia del hierro nativo, la de los silicatos de base de protóxido, y la de los fosfuros, manifiesta que se ha efectuado en ellos una serie de reducciones que harían imposible la persistencia de los compuestos orgánicos. El ilustre geólogo que hemos citado, al hacer $u$ estudio comparativo entre las substancias más comunes de los aerolitos y las rocas terrestres, después de hacer mérito del menor grado de oxidación de las primeras, y de haberlas reproducido por la reducción de las segundas, al hablar de esas analogías y diferencias, concluye con las siguientes palabras:

«Sin insistir más sobre otros contrastes de la misma naturaleza, reconocemos que la diferencia esencial entre los meteoritos y las rocas terrestres análogas, consisten en que los primeros presentan en estado de reducción, lo que las segundas contienen en estado de oxidación. Todo hace creer que las masas, entre las cuales existe tal semejanza de composición, habrían sido idénticas, no obstante la inmen- 
sa distancia que las separa, si no hubiesen sufrido acciones diferentes.» Todas las roeas terrestros que presentan tan notoria semejanza con los aerolitos, pertenecen á las regiones profundas de la tierra. El ilustre Daubrée, prosiguiendo infatigable en sus observaciones comparativas sobre los meteoritos, ha llegado á restaurar teóricamente el planeta de que forman parte, y examinando cuidadosamente sus densidades, los considera como pertenecientes también á la masa interior de aquél. Así, pues, no formando parte de la corteza exterior, y más aún por las reducciones que han sufrido, no pueden contener en su masa la pretendida tierra vegetal. Por lo anterior se ve, que tal vez mejor partido se puede sacar para defender la pluralidad de los mundos, del precioso - estudio comparativo que venimos recomendando, para que es indispensable conservar á los meteoritos su forma, que de su fraccionamiento y de la equivocada creencia de que exista tiema vegetal en su interior.

El fraccionamiento del meteorito de la «Descubridora,» no ha producido ningún resultado que pudiera considerarse como nuevo,ó que equivaliese al interés que rerdaderamente tenía el estudio de la figura general de la masa. Cuando la ciencia nos ha enseñado con una precisión y con una lucidez admirables, las leyes de la composición atómica de los cuerpos; cuando sabemos los principios en que descansa la constitución molecular de los compuestos, no podemos comprender qué necesidad había del fraccionamiento de las grandes masas, ni del aniquilamiento de su forma cristalina para determinar su composicion ó para inrestigar propiedades nuevas y aplicaciones desconocidas; no pudiendo comprender tampoco, cómo no tuvieron presentes estos principios los ilustrados miembros de la Sociedad de Geografia al decretar su lastimoso acuerdo, y por esto insistimos en creer que fué la consecuencia de ma precipitación fatal.

$$
* * *
$$

Oumpliendo con los justos deseos de la Sociedad de Historia Natural, tenemos la honra de presentar el finto de nuestros estudios, después de algunos meses de madura reflexión y del frío examen, durante los cuales habrá calmado ya la excitación que en algunos 
ánimos produjo nuestra protesta. Impulsados desde el principio por el interés de la ciencia y de la patria, hemos estudiado, selenos y sin pasión. Eiste asunto era para nosotros, y para la Sociedad, cuestión de ciencia, $y$ nunca de odios, que ni existen ni deben existir entre los que llevan por fin único el adelanto científico, y por lema el bien de la humanidad.

Así lo hemos juzgado siempre; con tal convicción hemos trabajado; así lo juzgamos todavía, y esperamos que la Sociedad Mexicana de Geografía y Estadística, y quienquiera que de este punto se ocupe, lo considerará bajo el mismo punto de vista que nosotros. Ias investigaciones á que nos hemos entregado; el severo estudio que hemos hecho, $y$ los cuidadosos experimentos que hemos practicado, eran indispensables, pues nunca nos hubiéramos atrevido á presentar á la Sociedad apreciaciones vacías, en cuestión de tan alta importancia. Tranquilos esperamos, pues, su fallo; hemos procurado corresponder á su confianza é interpretar sus sentimientos.

Respetamos á la Sociedad Mexicana de Geografía y Estadística, cuanto corresponde á su ilustración y á su merecida fama; mas si comprendiéramos que el fraccionamiento era una necesidad inèludible, $y$ que sus resultados fuesen útiles y convenientes, no podría suponérsenos tan obcecados é injustos, que dejáramos de reconocerla y apreciarla. Pero si no tan sólo no encontramos tal necesidad, sino que vemos que la razón en que se funda ha sido causa de una medida inconducente y errada, ¿por qué no hemos de combatirla, como debe de combatirse todo error? Si tal razón ha dado origen á una resolución que de algún modo puede desconceptuar á nuestro país ante el mundo científico, como es posible que suceda en el presente caso, ¿por qué no esforzarnos para hacer patente que ese error no ha tenido en su apoyo la sanción de todos los hombres que en México se ocupan de las ciencias físicas y naturales? Quizá podría contestársenos que el error está de nuestra parte, que nuestra poca ilustración no nos hace apreciar convenientemente las condiciones $y$ circunstancias todas que concurren en esta cuestión importante, y que, por lo mismo, el acto que reprobamos es digno de cumplido elogio; pero como las razones que se han emitido para apoyarlo y defenderlo, no son fundadas ni concluyentes, por no estar de acuerdo con los principios de la cienciạ, según hemos procurado demostrar; como no solamente no dis- 
culpan este acto, sino más bien lo condenan al pretender presentarlo como necesario y conveniente, como puede deducirse de las reflexiones que ellas mismas nos han sugerido en el examen que acabamos de hacer, debemos creer que el error no viene de nosotros, y que el fraccionamiento del meteorito de la «Descubridora,» ha sido un hecho digno de reprobación científica.

México, Abril 10 de 1873.

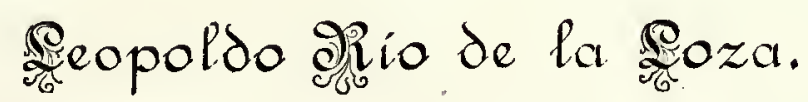




\section{DICTAMEN}

de la comisión formada por Don Leopoldo Rio de la Loza, Gabino Barreda, Alfonso Herrera y Gumesindo Mendoza, sobre un estudio heclio por el Doctor Desiderio Germán Rosado, de un insecto llamado "Botijón."

(Tomado del "Boletin de la Sociedad de Geogralia v Estadistica.")

Conforme al acuerdo de la Sociedad, hemos examinado el insecto conocido en Tabasco con el nombre rulgar de «Botijón,» y remitido por el Señor Doctor Don Desiderio Germán Rosado, el cual lo emplea en substitución de la cantárida, para formar con él emplastos y otras composiciones resicantes, por las propiedades de este género que dicho insecto posee.

Como era de suponerse, en virtud solo de las propiedades cáusticas del insecto, pertenece á la familia de los traquélidos, entre los coleópteros, hetereómeros y á la pequeña subfanilia de los resicantes, propiedad que hasta ahora no se ha hallado sino en los insectos comprendidos en la familia arriba mencionada.

Examinando cuidadosamente el insecto, y recomponiéndolo cuanto ha sido posible, por laber llegado en muy mal estado todos los individuos que se nos entregaron, hemos podido determinar no sólo el género, sino la especie, reconociendo que el insecto de que se trata es el Canthruris Lemmistr, de Lat.

Este insecto, como todos los de su género, tiene propiedades resicantes, cosa que se deja ya entrever por el olor particular que despide. Además, la experiencia clínica ha demostrado que posee en alto grado las propiedades de esta naturaleza, que los Señores León y Rosado le atribuyen con justicia, 
En 1861 se hieieron, efectivamente, en la clínica de la Escuela de Medicina varios experimentos con un emplasto preparado con el polvo de estos insectos, cuyos resultados, según el informe que entonces dió el Señor profesor del ramo, Don Mignel F. Jiménez, fueron que dicho emplasto era notablemente más activo que el que ordinariamente se empleaba en el hospital, el cual estaba preparado con el polvo de Cantharis Officinalis venido de Europa, pues constantemente se notó que el emplasto remitido de Tabasco, prodijo la ampolla én menor tiempo que el emplasto ordinario, liabiéndose visto en uno de los experimentos, que la epidermis estaba levantada y la serosidad acumulada debajo de ella, á las dos horas de aplicado aquél. Y aunque en otra ocasión se necesitaron veinticuatro horas para lograr el objeto deseado, siempre resultó que el emplasto preparado con la cantárida indígena, obró constantemente en menos tiempo que el que acostumbraba emplearse en el hospital, llegando á ser esta diferencia á la mitad y á veces á las dos terceras partes del tiempo que el otro necesitaba, y en uno de los casos el tiempo necesario para prodncir la vesicación con el primero, fué la cuarta parte del que se necesitó para obtenerla con el segundo. Cinco ó seis horas fué, por término medio, el tiempo necesario para que el emplasto produjese un efecto vesicante suficiente.

Ta comisión, sin embargo, cree necesario hacer presente que, amnque según dijo en aquella época el remitente, el emplasto que mandaba estaba preparado de la manera ordinaria y sólo substiturendo el insecto llamado Botijón en vez de la cantárida extranjera, 110 se conocen exactamente las proporciones en que el polvo de aquél entraba en la composición, lo cual hace que la acticidad respectiva en ambas no laya podido compararse con toda exactitud en las experiencias que hemos citado, pero siempre resulta que el insecto de Tabasco posee las propiedades epispáticas necesarias, para substituir, con ventaja, á la cantárida traída de Europa, en los países donde aquél se encuentra.

Mas como materia propia para el comercio, annque el Señor Rosado, dice en su impreso que los insectos son muy abundantes en los lugares propios para su multiplicación, las cuales que se les atribuyen de oculturse con montitud y desuparecer con vapides curchdo se les persigue, hacen ereer que su cosecha no será fácil cuando se quiera hacer un poco en grande $y$ que por lo mismo haya que sacar 
un costo que la haga poco propia para extenderse como efecto mercantil y para poder entrar en concurrencia con otros muchos insectos que se conocen en el país y cuyas propiedades resicantes no son menores que las del Botijón. En México, por ejemplo, abundan diversas especies resicantes, cuyo nso para la preparación de los emplastos epispáticos se va generalizando entre nuestros farmacéuticos, no sólo porque se obtienen á menos precio que la cantárida que viene de Europa, sino porque las indígenas son más activas en su acción.

El Cantharis Ensera, que vive sobre la calabaza, el chayote y el chayotillo, y que se conoce vulgarmente con el nombre de pipilu ciega ó fraile, es bastante abundante en el Valle de México y aun en el interior de la República; contiene los mismos principios que la cantárida oficinal, según las análises hechas por dos de nosotros (los Señores Herrera y Mendoza).

Habiendo ensayado en el Hospital de Jesús, su director el Señol Vértiz, el emplasto preparado conforme á la fórmula de la farmacopea mexicana, con este insecto, en rez de la cantárida extranjera, obturo muy buenos resultados, notándose que obra con más rapidez que el emplasto ordinario de cantáridas, necesitando por término medio de siete á ocho horas para obtener la resicación.

Ta cosecha de estos animales no ofrece gran dificultad, porque además de que son, como hemos dicho, bastante abundantes, son muy torpes para andar y no son capaces de rolar. Hoy, según los informes que hemos tomado, se cosechan más ó menos, anualmente, unas cuarenta libras de estos insectos, que los indios renden á doce reales libra, cuando están secos, y á menos precio cuando están fiescos. Si no se cosecha mayor cantidad, es acaso porque su uso no está bastante generalizado, ó porque la utilidad que pueden sacar de los insectos no ha llegado á conocimiento de los que cultivan las plantas en que se multiplican, pues hoy si los persiguen es más bien con la mira de eritar el perjuicio que les ocasionan, que por sacar de ellos algín provecho, á lo que hay que agregar la escasez de brazos.

Otros muchos insectos resicantes tenemos también en la República $y$ en el Valle de México, y entre ellos son muy notables los meloes, conocidos vulgarmente con el nombre de abadejos.

Un emplasto preparado con el insecto descrito por el Señor Ba- 
rranco, bajo el nombre de Meloe Tucia, ha dado en los experimentos que se han hecho los mejores resultados, siendo más activo que el preparado con el Cantharis Ensera, pues la vesicación se ha ob. tenido con aquél en el espacio de cinco horas por término medio. Un resultado casi igual se ha logrado también con otras especies del inismo género Meloe que existen en el Valle.

He aquí las principales especies vesicantes, conocidas entre nosotros y que pueden emplearse con ventajas como succedáneas de la cantárida: Cantharis Cardinales, $C$. Tunesta, C. Cinetipenis, $C$. Obesa, C. Maculata, O. Rufipenis, C. Octomaculata, C. Tuciolata, C. Cuchrinerveta, C. Erytrotoras, C. Nichiiy, la Eusera, de que hemos hablado ya. Además varias especies de abadejos ó de Meloes, cuya determinación no hemos tenido ocasión de hacer, pero que son muy abundantes, y como ya hemos dicho, muy activas, y sobre todo el Meloe Tucia del Señor Barranco.

Por lo mismo, la comisión cree que el insecto llamado en Tabasco «Botijón» es digno de llamar la atención y deben darse al Señor Rosado las debidas gracias: que dicho insecto teniendo, como se ha dicho, propiedades epispásticas, debe procurarse que su uso se vulgarice en todos los puntos donde su precio lo permita, y lo mismo debe procurarse con las otras especies indígenas mencionadas.

Marzo 28 de $1: 69$

Leopoldo Río de la $\mathfrak{L}$ ozà.

Gabino Sarreda. Elfonso ơlerrera.

Gumesindo Thendoza. 


\section{DIOTAIMEN}

que presentó la comisión de ciencias naturales formada por los Señores

Don Leopoldo Río de la Loza, Joaquín Velázquez de León

y Felipe Zaldivar, sobre la muestra de carbón

de piedra de la mina sifuada en el

Departamento de San Juan de los Llanos, del Estado de Puebla.

- (Tomado del "Boletin de la Sociedad de Ceografia y Estadistica.")

LEOPOLDO RÍO DE LA LOZA, RELATOR.

Ta comisión que subscribe, obsequiando los deseos de esta Sociedad, se reunió para examinar las muestras del combustible mineral que fueron remitidos á esta corporación por el Sr. D. Francisco Villanuera, de los minerales de S. Francisco Ixtactitlán de S. Juan de los Llanos, según se refiere en la comunicación pasada por la Secretaría de esta comisión; y conociendo la importancia que tendría en México la explotación del carbón fósil, el día que se encontrase situado á distancia conveniente de los lugares en que más útil sería su consumo, como los de minas, fundiciones y los más poblados, y donde más fábricas existen como sucede en esta capital, procedió con empeño al trabajo de sus indagaciones, teniendo la homra de presentar ahora el resultado de que pasa á dar cuenta á la Sociedad.

Habría deseado la comisión conocer el criadero de donde se extrajeron las muestras del carbón mineral que llegó á su poder, pues si es cierto que las muestras mismas ya indican los terrenos á que pertenece su formación, en ésta apreciaría un geólogo las ventajas que podrían sacarse aprorechando la parte más útil de esta producción. 
El carbón de piedra ú hornaguera, propiamente tal, se diferencía de la turba y de la lignita ó carbón pardo en su aspecto y una gran parte de sus propiedades, y tratándose del producto más útil, habríamos deseado que las muestras que examinábamos hubieran sido de la primera substancia. No ha sido así, pues en nuestro concepto es ma verdadera lignitu, la que se sujetó á nuestra investigación, siendo esta la especie que los geólogos y mineralogistas llaman carbón pardo lamoso ó pantunoso. Mas no siendo despreciable esta substancia por los principios que contiene, y que son de notoria utilidad á la industria, quisimos hacer un reconocimiento más prolijo, como pasamos á manifestar después de cerciorarnos de ser una lignitr, por el uso de la potasa cáustica.

Desde luego notamos en la muestra presentada, dos substancias carbonosas, una más impura que la otra, y colocadas juntas en rasos cerrados, y sujetándolas á la temperatura necesaria para su carbonización, nos dieron el carbón residuo ó especie de coke, que presentanos con este dictamen.

De 100 partes de lignita obtuvimos 62,5 de colie, y esta misma especie de coke, sobre 100 partes, produjo, 25 de ceniza, y de la lignita 15.

Ya se sabe que lo que se llama coke es el carbón de piedra despojado de la mayor parte de su hidrógeno, de su oxígeno, y demás materias volatiles por ma destilación previa, materia que en este estado se emplea con ventaja en la fundición de los minerales de fierro ý en el uso doméstico, en las chimeneas, etc., siendo de la mejor calidad el que procede de la especie de carbón que llaman canal (canaleoal), es decir, del carbón de piedla compacto.

Hablando geológicannente, hay entre el carbón de piedra propiamente tal y las lignitas, diferencias notables. Un geólogo buscando combustibles minerales se propondría hallar el mís imperfecto, es decir, la turba en los terrenos terciarios $y$ secundarios, y el carbón de piedra en los primarios, entre los terrenos peneo y devoniano, sin que por eso dejen de encontrarse dislocalas, digámoslo así, algunas de estas substancias; pero no son tan considerables estas diferencias de los combustibles minerales, en el orden químico, y rolviendo al reconocimiento analítico del que se nos encomendó, diremos que de 1000 partes resultaron: 
De agua y substancias volátiles..... 320 Desubstancias solubles en elácido cloro-

hidrico (carbonato de fierro y de cal). 320 Arcilla, Sílice y sulfato de cal........ 151 Carbón................... 466 Betún................... 35

Las operaciones dudosas se hicieron tres reces para fijar el promedio. Produjo en la destilación esta liguita una porción de gas hidrógeno que quemamos después; pero no habiéndolo recogido todo, no damos la cantidad en este reconocimiento. Nos parece por lo expuesto que siempre es digno de reconocerse el criadero de esta liguita, y que de su examen geológico resultarán otros datos más descisivos é importantes, relativos á la cantidad, mejor calidad y uso de estas substancias, sujetando siempre nuestra opinión á la de las personas más instruidas y respetables que componen esta Sociedad, á la que tenemos el honor de pertenecer. 


\section{EXTRACTO DEL EXPEDIENTE ANTIGUO}

\section{INSTRUIDO POR \\ EL SUBDELEGADO DE COLIMA,}

SOBbrE EL TERREMOTO QUE DESTRUYÓ PARTE DE AQUELGA CIUDAD

EL AÑO DE 1818.

(Publicado en el "Boletín de la Sociedad Mexicana de Geografía y Estadistica." 1' Ep. Tom. X. Pág. 39.)

He leído el expediente instruído por la subdelegación de Colima con motivo de los terremotos ocurridos de las dos á las tres de la mañana del día 31 de Mayo del año de 1818, y cumpliendo con el encargo de esta Sociedad, paso á formar un resumen de lo que hay de más importante en esos documentos oficiales.

Es sabido que el año de 1818, Colima figuraba en la categoría de las villas; la autoridad superior llevaba el nombre de subdelegado, quien estaba sujeto, tanto en el orden civil como en el nilitar, al gobernador é intendente de la provincia de Guadalajara. El primero de estos cargos estaba confiado en esa época á Don Juan Iinares, y el segundo al mny conocido General Don José de la Cruz. Al Señor Linares, anxiliado por el Ayuntamiento de la villa y por los alcaldes de barrio, tocó atender á la población en esa terrible catástrofe, y las providencias dictadas, los partes dirigidos á Guadalajara, y las representaciones hechas á la intendencia y al virreinato, forman el expediente que hoy posee la Sociedad. 
Este consta de ochenta fojas, y veinte de ellas corresponden al informe dado por el párroco de esa antigua villa, Don José Fugonio Bravo, eclesiástico de instrucción $y$, sobre todo, de imaginación tan viva, que si hubiera omitido mua parte de su narración, se supondría que el informe estaba escrito por algún joven vigoroso, activo y demasiado entusiasta; no sería fácil presumir que un anciano afligido por las fatales consecuencias generales que causaran los terrenotos; atormentado al ver la miseria de sus feligreses, sin habitación y abrigo, y sufriendo cuanto es de suponer por otra calamidad, cual fué la lluvia tenaz y prolongada, tuviera aliento para describir los sucesos, establecer sus teorías, proponer el remedio que suponía radical, y todo con una firmeza que desde lnego descubre sus íntinas convicciones. Ia Sociedad me permitirá que dé una idea aunque sucinta, de ese curioso escrito.

El Señor Bravo creyó de su deber, no limitar sus trabajos prestando á sus feligreses los auxilios que reclamaba la situación; era necesario, á su juicio, prevenir el mal y eritarlo en adelante. Para esto, quiso, no sólo tratar de las causas que en general determinan los terremotos, sino también las especiales de Colima, y más todavía, una rez encontrado el remedio, persuadía á la antoridad para que fuera adoptado. Para esto, sin duda, se decidió á dar á su informe nayor extensión, y comenzando por las teorias generales, reinantes en aquella época, ocuparse de la situación de la villa principalmente con relación al mar, concluyendo con su fin principal, que era demostrar la necesidad de que Ia población se estableciese en terrenos seguros como suponía que erán los de la hacienda de la Huerta. To es inposible, dice el Señor Braro, que en este lugar llegue á suceder lo que aquí ó annque la nueva población desaparezca como han desaparecido tantas y tantas ciudades; pero lo probable, lo más rorosímil, es, que no sea así, por estar hoy la villa en el centro de la línea que va del mar al volcán de S. á N. Y con ma distancia por el riento de sólo nueve á diez leguas.

Separados de esa línea los terrenos propnestos, para que se traslade á ellos la población, el peligro se aleja, supuesta la teolía que con tanta fe desarrolla, y es, en resumen, la siguiente:

Supone que el mar y el rolcán están casi comunicados, y que siendo dos enemigos poderosos, cada tino tiende á romper esa comnnicación; el fuego y el agua luchan para destruirse, el rolcán con 
su viro fuego eraporando las aguas del mar, y éste con su abundante líquido apagando los fuegos de su rival. Como de esta supuesta lucha, resulta una cantidad de rapores acuosos, hallándose comprimidos en el interior de la tierra, determinan esos terribles efectos á que ha estado y quedarí expuesta la población, si no varía de lugar.

No obstante esta teoría que el párroco desenvuelve, con varios pormenores y por la cual se decide en su extenso informe, indica no serle desconocidas otras, $y$ aun se llama partidario de la teoría eléctrica, mencionando la del enrarecimiento del aire, las fermentaciones, la ignieión de las naterias combustibles, etc. La del fuego central y la de las reaceiones químicas, eran, como debe suponerse, desconocidas para él.

En el cuerpo de su escrito manifiesta tal convicción en sus opiniones, que no teme aún pronosticar la proximidad y frecuencia de los terremotos en la línea de Norte á Sur, que no pierde de rista. Su raciocinio lo apoya en el estudio de los terremotos anteriores, comenzando por mencionar el de 1794, que destruyó igualmente á Zapotlán el Grande, Sayula y demás poblaciones de la líner. Cincuenta y siete años pasaron para sufrir otro movimiento fuerte, que tuvo lugar en 1806, siguiendo á éste otro aún más terrible en 1816, es decir, después de diez años, verificándose á los dos años, el de 31 de Mayo de 181S, que causó mayores males que los anteriores, anunciándose con esa frecuencia, dice, que se han de multiplicar los terremotos haciendo inhabitable la villa.

Es de notar que á pesar de los rarios partes dados por las autoridades y de otros muchos documentos que se hallan en el expediente, no pueda saberse exactamente cuál fué el número de muertos y el de los lastimados que hubo á consecuencia de ese último terremoto. El informe del Sr. Braro, que, como he dicho, merece más fe, sólo hace mención de ochenta y nueve muertos; mas como él mismo indica que son los que aparecen en los libros parroquiales, no debe concluirse que fueron los únicos muertos, pues muchos quedarían entre los escombros por falta de parientes ó personas que solicitaran fueran socorridos y que hicieran los gastos de parroquia, como es de presumir que se hacía para los ochenta y nuere á que se refiere. Menos se indica en dicho informe enál fué el número de los lastimados, é igual racío se advierte en cuanto al monto de las pérdidas pecuniarias: sólo se dice, en general, que fué considerable en alhajas, ropa, muebles y 
otros muchos efectos, pues todo se perdió, quedando el vecindario en la mayor miseria. Puede, no obstante, juzgarse de la riqueza de Colima por dos de los documentos que obran en el expediente: wno es el informe del síndico procnuador y otro el proyecto de una contribución municipal. En el primero consta que en el año de 1813 produjeron las alcabalas 131,542 pesos y las rentas decimales 72,283 pesos 4 reales. En el segundo se calcularía que produciría la pensión municipal 17,892 pesos 4 reales. Oreo que este último documento es igualmente interesante, porque da á conocer no sólo el consumo de los efectos, sino también los productos de Colima.

Como entre éstos figura el algodón y yo he creído y creo que no está lejos el día en que el cultiro de este precioso vegetal contribuya de una manera muy especial á la riqueza y aun á la paz de nuestra República, me parece conveniente llamar la atención de los agricultores y de los empresarios, á fin de que, aprovechando los primeros momentos favorables, dediquen unos su trabajo y otros sus capitales á una empresa rentajosa bajo mil títulos, no sólo en Colima sino en otros muchos lngares de la República. Y si es rerdad que hasta hoy ha habido que luchar con la inseguridad, con el mal estado de nuestros caminos y muy principalmente con la falta de brazos, es de esperar que con algún empeño, actividad y fe en los buenos resultados, se alejen los inconvenientes y no quedemos limitados á la exportación de la plata y del oro de nuestros gastados minerales.

México, Enero 29 de 1863.

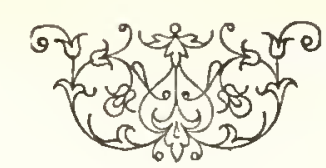




\section{EXPOSICION}

que hizo el Señor Secretario del Consejo Superior de Salubridad de México,

Doctor Don Leopoldo Río de la Loza, á nombre de dicha Coporación,

al E. Sr. Gohernador del departamento, pidiéndole

que destinara una parte de la

contribución personal

en la dotación de veinte plazas de Médicos de Distrito**

(Tomado del "Periódico de la Academia de Medicina de México")

México, Mayo 25 de 1841.

Excmo. señor:

El consejo supremo de salubridad, que está al alcance de las buenas disposiciones que ha manifestado V. E. por todo lo que se hace en beneficio de los pueblos de este departamento, que palpa el entusiasmo que le anima para proporcionar á sus habitantes médicos instruidos que minoren sus padecimientos y prolonguen su existencia, y en fin, que re con grata admiración los sacrificios que hace para perfeccionar la enseñanza y el ejercicio de las ciencias médicas, no ha dudado distraer un momento su atención, para pedirle á nombre de la humanidad, que sea el primero que proporcione los recursos de que carecen los pueblos que la ley ha confiado al cuidado de V. E.

Los individuos que forman el consejo están íntimamente convencidos de la justicia y necesidad de su pedido, y defendidos por una muralla impenetrable que hará enmudecer la crítica fatal de los que

\footnotetext{
* Annque no puede hoy tener efecto la parte de este proyecto, que trata de los recursos propuestos para datar las plazas de médicos de distrito, hemos creido útil el publicarlo tal como se remitió al gobierno del departamento.
} 
todo lo censuran; V. E. será venerado de los habitantes de la república si logra marchar á la rangnardia de este útil proyecto, y el consejo hará rer que no es el engrandecimiento de ese círculo de profésores, que sin más delito que su amor á la jurentud, se lıa hecho el blanco de genios inquietos, sino el del progreso, en cuanto tiene relación con los objetos que le están encomendados. Como al dirigir á V. E. esta exposición trata de no hacerle perder el tiempo, estampando cuanto puede inferir de un simple relato, se limitará á decir con claridad y sencillez lo que crea útil al objeto. Si consigue que se realice este proyecto, ó cuando menos que V. E. lo adopte, tendrá la satisfacción de haber arrimado una piedra al edificio social.

Los partes que se han recibido de varias prefecturas, manifiestan la escasez que hay en ellas de profesores del arte de curar. Sin eso, todo el que haya salido de la capital tiene que lamentarse del abandono á que están reducidos los infelices enfermos, y que admirarse al ver que la naturaleza lucha con las enfermedades y con los remedios de charlatanes y curanderos, en cuyas manos han de poner su vida los recinos de esos lugares.

No es éste el único mal que trae consigo la falta de hombres instruidos: careciendo de educación, faltos de moral y responsabilidad alguna, son asesinos impunes del género humano. A la clase menesterosa es á la que más destruyen, porque es la más ignorante, la más sufrida y la que más carece de recursos para ponerse en manos expertas. Los sangradores viciosos, los jugadores, los que sólo viren contentos con el ocio, he aquí por lo común quienes ejercen tan noble profesión. En muchos pueblos del departamento, se lia pensado reunir una cantidad por los recinos de proporciones para sostener un facultatiro; pero el ningún conocimiento que tienen de los profesores y las pocas garantías que dan los contratos particulares, dejan muchas reces sin efecto tan útiles proyectos. En prueba de lo dicho puede presentarse el oficio del señor prefecto de Temascaltepec, que, entre otras cosas, dice: «En Zacnalpan nada existe, y sus autoridades y principales recinos se han dirigido á mí, suplicando les proporcione un facultativo que se quiera establecer en aquella población, asegurándole una regular iguala. Todos mis esfuerzos lian sido hasta hoy inútiles, y deseara que la junta superior de salubridad realizara los míos en obsequio de aquella población, que hoy llama la aten“ión por su riqueza.» 
Las ciudades como México, Toluca, etc., proporcionan á los infelices el recurso utilísimo de los hospitales; pero los vecinos de pueblos no pueden disfrutar de este alivio, por la distancia de los lugares, ó porque son tan escasos sus recursos y tan limitadas sus relaciones, que ni les basta para gastar en la conducción, aun cuando la enfermedad lo permita, ni pueden estar seguros de encontrar un lecho para descansar por la última rez. ¿Q qué privilegio tiene la plebe de las grandes ciudades que no deba disfrutar la que habita las chozas aisladas? Esta es el yunque de las naciones; aquélla, en su mayor parte, la plaga y deshonra de las sociedades; en una se hallan vicios y virtudes, docilidad é inocencia; en la otra hay más vicios, malicia y corrupción; ésta vende caro su trabajo; aquélla se sacrifica para vivir con escasez; una y otra pertenecen á la especie humana, $y$ una $y$ otra deben ser atendidas.

En las circunstancias en que nos hallamos sería absurdo solicitar que se repartiesen algunos hospitales en el departamento; pero no lo es ciertamente pedir que se establezcan médicos de distrito en los lngares adonde se carece de este recurso. Es inútil referir la práctica que observan en este punto las naciones civilizadas, $y$ las grandes sumas que invierten los gobiernos para socorrer á los súbditos menesterosos, en las muchas casas de beneficencia destinadas á recibir enfermos crónicos, convalecientes, decrépitos, niños, mujeres de parto, etc , á más de los médicos de cantón, que no se encuentran entre nosotros; más inútil es ocuparse en probar las rentajas que sacan las naciones que cuidan de la salud y la vida de nu habitante: V. E. está al alcance de ellas, $y$ hará la aplicación conveniente, permitiendo al Consejo que pase á tratar otro de los puntos que se propuso ventilar.

Está en los intereses de los enfermos crónicon, del Consejo, del público y de los profesores, que haya en los pueblos hombres instruidos encargados de la salud y la vida de sus semejautes. Las primeras deben cuidar del cumplimiento do las leyes, $y$ entre las antiguas y modernas hay muchos que le imponen la obligación de no permitir que ejerzan ramo alguno de las ciencias médicas sino los profesores recibidos legalmente. Las autoridades y el Consejo ven á su pesar que mientras no tengan los pueblos esos profesores, no se les puede quitar el único $y$ aparente recurso de los que les proporcionan remedios, carezcan ó no de los conocimientos indispensables. ¿Cómo, pues, se podrá exigir á aquéllas ni á éste el cumplimiento de 
sus deberes? ¿Un juez no tiene en su demarcación facultativos que curen los heridos, que inspeccionen los cadáreres, que digan si hubo envenenamiento, muerte aparente, etc., en los casos que se presentan? ¿Qué hace? la práctica demuestra diariamente que un mal barbero, una partera ignolante, ó un presumido charlatán, son autorizados jurídicamente para desempeñar estas funciones comprometidas, que son de responsabilidad para los profesores. La smerte y aun la rida del presunto reo y de la población, queda al arbitrio de esa gente venal capaz de venderse á poco precio y de sacrificar por menos, cuantas víctimas pueda. ¿ $\mathbf{Y}$ cómo ese juez ha de prohibir que cure una fiebre el mismo á quien autorizó para que diere su opinión en un caso más comprometido? El Consejo, por otra parte, no puede pretender de V. E. que los jueces sólo ocupen á profesores, cuando está conrencido que no los hay en la mayor parte de los pueblos del departamento. Tampoco puede distribuir los Consejos subalternos ni cumplir con otras de las atribuciones que le están encomendadas por el ordenamiento.

Poco se necesita para demostrar que el público, compuesto de jueces, de enfermos, de ofensores y ofendidos, sacará grandes ventajas del arreglo que solicita. La ínfima clase, que carece de recursos, tendrá quien la rea en sus enfermedades, la media y la suprema hallará lo que le falta, aun cuando abunde en proporciones; el juez sentenciará descansando en el voto del saber; el delito no quedará impune y la inocencia será respetada. El soldado mismo que no está atendido, porque es notorio el mal estado del cuerpo llamado de salud, no quedará abandonado á su suerte, como sucede hoy cuando el cumplimiento de sus deberes le llama á esos lugares en donde no tiene recursos.

Lo dicho bastaría, para decidir á favor de la medida propuesta, porque los objetos que se han tocado son del mayor interés. Mas quedan otros que no earecen de fuerza y es preciso indicar. El colegio de medicina tiene un número de alumnos, que reunen á su instrueción la solidez de sus juicios y el reposo de la edad madura. Ia mayor parte del terreno de México no ha sido visitada por el filósofo ni el naturalista; se encuentra virgen en su mayor parte, y es el depósito de objetos preciosísimos que vendrán á sacar á luz los amantes de la naturaleza, avergonzándonos entonces de nuestra inercia y apatía. La materia nédica mexicana ha comenzado á formar- 
se á muchas millas de la república; nuestras plantas tienen que ir más allá de los mares á que les pongan un nombre que hemos de estudiar después en libros eseritos en otro idioma; el comercio de la droguería nos toma los simples para reducirlos á la menor expresión, y pedirnos por un pomo, adornado con atavíos insustanciales, enatro veces su valor real; los agentes terapéuticos más enérgicos se hayan diseminados en el departamento, entretanto que esperamos con ansia que nos vengan de Europa para ensayar su efecto; las artes tienen también que lamentar este mal, é indirectamente recibirán algún impulso si se realiza el proyecto; mas no siendo este objeto del Consejo, concluirá esta parte con asegurar que esos alumnos de que se ha hecho mérito, que han de recibirse muy pronto, que no han de tener inmediatamente en la capital bastante clientela para subsistir, que se han acostumbrado al estudio y le han cobrado amor á las ciencias naturales, sacarían de ellas el provecho que se desea, y contribuirán de varios modos al engrandecimiento de su patria.

Las corporaciones encargadas de la policía médica, necesitan tener representantes facultativos en los lugares que se confien á su cuidado. Ninguno mejor que los médicos de distrito pueden desempeñar esta comisión. Las autoridades políticas que no están obligadas á ponerlos ni tienen los conocimientos indispensables, se ren en el caso de decidir con peligro de error, ó de consultar á los superiores, cuyo paso, moroso por precisión, es un obstáculo al buen servicio, é impide la marcha de los asuntos.

Como el Consejo, al dirigir á V. E. esta sencilla exposición, no tiene más objeto que el de cumplir con las atribuciones que le señala el ordenamiento, quiere presentar el pro y la contra, con la franqueza que inspira la verdad.

Los recinos del departamento, como los más de los pueblos de la república, están acostumbrados á que los asistan en sus enfermedades curanderos é ignorantes que aplican remedios ridículos, que tienen el mayor cuilado en hacer misterio de todo, y aún conselvan los más perniciosos de los sacerdotes del arte. Un hombre racional que no erea en sus hechizos y amuletos, que no ponga en práctica las curaciones bárbaras á que están habituados y que no satisfaga sus caprichos, será á sus ojos un tirano en quien no tendrán confianza y acaso verán con horror. Pero este mal es preciso en una época de transición: la ignorancia de esa parte del pueblo ha de tener fin, 
y debe contribuirse á su felicidad, mejorando esa parte de su educación. La experiencia y la necesidad acabarán con preocupaciones tan perniciosas, $y$ llegará un tiempo en que bendigan al gobierno los mismos que al principio recibieran mal sus providencias.

Ya es tiempo de ocuparse del último punto, y acaso el de más interés; pero afortunadamente el que presenta hoy menos dificultades. Es muy justo que los que viven en sociedad contribuyan proporcionalmente á cubrir los gastos que tienen que erogarse, supuesto que las rentajas de ese orden social son comunes á los contribuyentes; mas como las fortunas no están ni pueden estar repartidas con igualdad, hay una clase que trabaja más, paga menos y en la que tiene el estado que invertir mayores sumas. A esta clase desgraciada es á la que la tenido á la vista el Consejo al emprender este pequeño trabajo y por ella ha quitado á V. E. un momento de sus complicadas atenciones.

La ley que se acaba de publicar en la capital, el doce del actual, establece una contribución personal, que han de pagar todos los habitantes de la república, varones, desde diez y ocho años cumplidos, que tengan bienes ó se hallen capaces de trabajar: según el artículo $2 .^{\circ}$ de dicha ley se destina la mitad del producto de esta contribución á cubrir el deficiente del presupuesto de gastos de cada departamento, y según el tercero pueden las juntas departamentales dictar y poner en ejecnción las proridencias de que habla la quinta atribución constitucional, entre las que se halla de mejorar los establecimientos de instrucción y beneficencia pública. Nada más nutil ni más necesario que inrertir una pequeña parte de esta contribución, en provecho de los contribuyentes. Futre los objetos de beneficencia pública, este es uno de los que más llama la atención y debe atenderse de toda preferencia. La E. Junta departanental, de acuerdo con V. E., ha dispuesto en el artículo 41 del ordenamiento, que entretanto se dotan cuatro plazas de médicos para pobres, se turnen para asistir á los de México los once catedráticos y el preceptor del establecimiento. V. E. y la E. Junta conocieron desde entonces la necesidad de esas plazas, anu en donde se tienen otros anxilios que faltan en los pueblos. La ley antes citada pone en manos de la E. Junta y de V. E. los recursos más á propósito para subvenir á esta necesidad, y el Consejo no duda que se pondrá el remedio, penetrado como está de la filantropía del gobierno departanental. 
Como por fortuna no todos los pueblos del departamento carecen de faeultativos, no en todos deben ponerse médicos de distrito. Por las notas que han dirigido los profesores y las noticias que tiene el Consejo, cree que por alıora pueden dotarse reinte facultativos, que distribuirá en rista de los datos que ha reunido y de los que faltan y espera recibir. Si esta corporación pretendiera una recompensa digna del trabajo y responsabilidad de los médicos de distrito, acaso no podría cubrir los gastos, la parte de contribución destinada al departamento; pero considerando la eseasez de recursos, que los profesores quedan en libertad para asistir á los recinos de proporciones que les han de pagar, y, sobre todo, fiado en la filantropía de los facultativos, quiere solamente señalar una gratificación con que puedan contar y decidirse á fijar su residencia en el punto que se les designe, cuidando de propagar la vacuna, de asistir á los pobres de valde, de curar á los heridos, inspeccionar los cadáveres y desempeñar los encargos que crea el Consejo pueda confiarles.

Como no todos los pueblos del departamento presentan iguales recursos, la dotación no puede ser general, y se debe aplicar en proporción á cada lugar. Tampoco puede dejarse de formar un cálculo para demostrar el poco costo con relación á las ventajas que resultaría al gobierno. Parece que los individuos que obtengan estas plazas, quienes han de ser precisamente médicos y cirujanos, no deben disfrutar menor gratificación que la de veinticinco pesos mensuales, ni á los que tengan más se dará una cantidad que pase de cuarenta. Supóngase que doce profesores disfruten reinticinco pesos, que cuatro tengan treinta, y cuatro cuarenta, resultarán los gastos de quinientos ochenta pesos cada mes; á él se agrega otro de doscientos veinte pesos en medicinas y barbero, siendo el total de ochocientos pesos, con cuya cantidad se tendrán socorridos más de cuarenta pueblos del departamento.

Como aúu no se han reunido todos los datos, no puede presentarse la exacta distribución en cada uno de los lugares que han de ser beneficiados: mas lo expuesto es suficiente para probar, que la contribución personal debe destinarse á un objeto tan útil y necesario; que es bastante para dejar mna pequeña parte al socorro de los contribuyentes, y que las utilidades que han de resultar al gobierno y al público son inmensas.

Si V. E. adopta este proyecto, tendrá el Consejo la satisfacción 
de formar el presupuesto con la especificación que exige el asunto. Entretanto, cree haber desenruelto los puntos que se propuso tratar, con la consición propia de estos escritos. Si no hay en él la claridad necesaria, si carece de frases poéticas que lo hagan ameno é interesante, $y$ si por último, le falta un estilo sublime que hable al entendimiento y decida al corazón, la prudencia de V. E. suplirá estos racíos, y el Consejo quedará satisfecho con haber procurado ol bien á la clase más necesitada del departamento. 


\section{EL FIERRO METÉÓRICO DE YANHUI'LAN.}

Sabido es que la voz Aerolitho se deriva del griego, y equivale en nuestro idioma á - piedra del aire- no obstante que el Diccionario la define diciendo -que es piedra que cae de las nubes. Pocos objetos pueden competir en cuanto á la sinonimia con estas misteriosas producciones; generalmente están confundidas, cualquiera que sea su composición, bajo las denominaciones de piedras del cielo ó del rayo, globos de fuego, fierro meteórico, nativo y volcánico, uranolitos, ceramnitos, acero nativo, bólidos, meteoritos, meteorolitos, etc., etc.; pero rigurosamente hablando, la voz aerolito es la menos propia, refiriéndose á las masas ferruginosas que, como la que me ocupa, difieren de las piedras meteóricas, por su tamaño, testura, composición, etc., etc. Así las han distinguido los mineralogistas y los geólogos, debiendo, por tanto, usar en lo que paso á decir, del nombre más propio y significativo, como lo es el de fierro meteórico.

Pero antes no estará de más, ya que se trata este punto, el llamar la atención sobre la propiedad de aquella voz, supuesta la conveniencia de uniformar el idioma. Suele decirse, aun por personas ilustradas, aerolita por aerólito, equivocando así el género y la acentuación; mas como se ha generalizado tanto el decir aerolito, $y$ por otra parte la pronunciación es más fácil, no veo gran inconveniente en adoptarla, mas sí lo hallo en hacer el nombre femenino.

El origen de estos cuerpos, así como el del fierro meteórico, no está aún satisfactoriamente decidido; pero sí el de su caída á la superficie de la tierra, de lo cual no se dudó aun doce ó catorce siglos antes de la era cristiana, según dice Beudant. $Y$ aunque más tarde 
no se dió fe al testimonio de los que presenciaron el 7 de Noriembre de 1492, en Ensisheim, la caída de las piedras meteóricas, casi á la vista del Emperador Maximiliano, ni las de otras muchas en diversas localidades y en años posteriores, cuyar marlación fué más tarde objeto de risa y burla. al fin. no pudiendo dudare más de heclos auténticos. connenzaron á racilar los sabios en 1795. y la convicción fué unirersal después de la cáda de piedras en Bengala, y del fenómeno del Aguila en Normandía. Desde entonces hasta hoy no se duda del fenóneno, ni menos en México, donde se ven caer con frecuencia todos los años, precismmente en esta époea.

Dos cuestiones preocupan á las personas inclinadas á la observación de los fenómenos y de las producciones naturales: la primera consiste en dudar, si dada una masa de fierro, es ó no meteórico; la segunda se refiere al descubrimiento del origen ó procedencia de esos trozes metálicos.

In cuanto á la primera, es preciso convenir en que, los que niegan y los que dudan, no carecen enteramente de razón, porque muchas reces se ha reputado como fierros meteóricos los que no lo son. Aquí mismo se turo como tal, durante algún tiempo, el fierpo procedente de ma alnadaneta. Por fortuna la existencia ó no del níquel es un buen medio para resolrel tales cuestiones. Varios de los que han risto el meteorito de Yanhuitlán, niegan que sea de origen meteórico; pero, en primer lugar, lo que se sabe con relación á su historia, aleja toda duda, y en segundo, la composición, confirma este origen.

En cuanto á la segunda cuestión, que es la relativa á la procedencia de estos cuerpos, se han formado las siguientes suposiciones, y otras que no es necesario mencionar.

Primera.-Que hallándose en la atmósfera las moléculas metálicas en estado de rapor, se condensan por el enfriamiento, y formando masas de dirersos tamaños, descienden en rirtud de la propiedad que es común á todos los cuerpos.

SEgUNDA.-Que esos trozos, así como los aerolitos propiamente dichos, son arrojados por los volcanes lunares.

Tercera.-Que son desprendidos de los planetas conocidos.

Cuarta.-Que en sí son planetas indispensables inapreciables por su tamaño, y que recorriendo su órbita, llegan á tocar un punto en el cual, siendo superior la fuerza de la atracción terrestre, rence 
ésta á la que les era propia y normal, lanzándose en consecuencia sobre nuestro globo.

Este último supnesto es el que generalmente se admite annque sin plena convicción, no obstante el apoyo que se pretende darle por la analogía con las estrellas errantes.

Como quiera que sea, el hecho es que en México abunda el fierro meteórico. En Jiquipilco, dice el Sr. del Río, fué la lluria menuda como lo indica la pequeñez de los pedazos que se hallan en los ter'renos de labor; habiendo caído en grandes masas en la hacienda de Potosí, Durango, Zacatecas, etc., ets. El Baron de Humboldt dice haber hallado en las inmediaciones de Toluca, y diseminadas en los campos, varias masas semejantes á las de San Yago, descubiertas por el Sr. Rubín de Celis. Se sabe, además, que en estos y otros lugares del territorio mexicano, hace algunos años que á veces se han servido los herreros del fierro meteórico, y que aun en ciertos casos lo estiman y prefieren por su buena calidad, lo cual se debe, entre otras cosas, á que está ligado con el níquel.

Las análisis hechas hasta aquí, manifiestan, que por lo común el fierro meteórico más puro contiene níquel, como el del Niágara, según Rochwel: se dice que John encontró solamente fierro y cobalto en un ejemplar de México; en varios existen ambos metales, y tanbién se han hallado, como más comunes, el cromo, manganeso, cobre, calcio, estaño, magnesio, etc., etc.; é igualmente otros elementos, ó sean mineralizadores, según llaman alginos, y son el azufre, silicio, arsénico, carbono, y aun en sentir de Berselius, una substancia particular que presume pudiera ser un nuevo cuerpo simple. ¿Pertenecerá éste á algunos de los nuevamente descubiertos, antes ó después de la preciosa invención del espectroscopio? * Tal vez; más por ahora nada puedo asegurar, en cuanto al de Yanhuitlán, del cual paso á ocuparme:

Procedencra.-El Sr. D. Ramón Larrainzar, en cuya casa he visto la masa meteórica, ha tenido la bondad de proporcionarme algunos informes, que coinciden con las noticias puestas por el Sr. D. Manuel Orozco en el Suplemento al Diccionario de Geografía y que substancialmente dice así, al tratar de esa producción meteórica:

* Diré de paso, que prefiero esta voz á la más usada de espectrómetro, porque me parece que asi lo exige la propiedad, supuesto que el instrumento no tiene por objeto medir el espectro, y sí ver en el espectro ó por medio de él. 
«Se cree que cayó en la Mixteca alta, al pie de un cerro conocido bajo el nombre de Deque-Yucunino, á siete mil pies ingleses de elevación, como á los $17^{\circ} 29^{\prime}$ de latitud boreal, y á $1047^{\prime}$ de longitud oriental de México, en un pueblo llamado Santo Domingo Yanlnuitlán, cabecera del partido de su nombre, Distrito de Teposcolula, del cual dista cuatro leguas, y veinticinco de la Ciudad de Oaxaca, que es la Capital del Departamento á que pertenece el pueblo.» Nada se dice, ni creo que se sabe, en cuanto á la fecha y año en que cayó; pero sí se agrega que fué reconocido el meteorito por Mr. Austides Franklin Mormey, habiéndole encontrado fierro, níquel y sílice, sin mencionar las proporciones.

Peso de ra masa meteórica.-El mismo Sr. Larrainzar me aseguró haberla pesado, hallando que tenía novecientas diez y seis libras, ó sean cuatrocientos veintiún kilogramos, quinientos ochenta y cinco gramos, cuyo peso indudablemente no es el primitivo, pues luego se nota habérsele quitado una buena parte.

Aspecto.-Como se adrierte en los adjuntos dibujos marcados con los números 1 y 1 (bis), á primera vista es el de una matatena irregularmente piramidal, y cuyos extremos correspondientes al eje mayor, aparecen deprimidos, formando dos caras casi planas, una mayor que la otra; las superficies correspondientes á los ejes menores, son en su mayor parte unidas y compactas, dando en general un sonido fino $y$ claro, como el de un yunque; sólo en las pocas superficies ásperas, se percibe éste algo mate ó apagado. Casi puede decirse que no hay oxidación superficial, pues la que se advierte debe reputarse como insignificante, y más, teniendo presente, que la masa ha estado en condiciones farorables para cubrirse de orín, lo cual confirma la observación de algunos antores, quienes atribuyen esta propiedad á nua especie de barniz que libra al metal de las influencias oxidantes.

La masa presenta tal dureza, que fueron rotos dos cinceles al tomar una parte, costando no poco trabajo el obtener alguna limadura. Las superficies descubiertas presentan el gris de acero característico del fierro meteórico, aproximándose al blanco de plata; la parte visible del interior de las grietas, de que trataré adelante, se encuentra en parte ennegrecida, $y$ se perciben algunos cristales rudinentarios correspondientes al primer sistema. Por último, haré notar que en varios puntos se descubren los efectos del instrumento 
empleado para tomar ejemplares, debiéndose inferir, como dije, que el peso actual es seguramente menor que el primitivo.

Mas volviendo á la forma, agregaré: que al tomar las medidas de la masa meteórica, en unión de mi apreciable amigo el Sr. Don Luis Varela, le ocurrió la idea de ver en ella un grande cristal cuyas formas regulares, aunque alteradas por causas tan desconocidas como su origen, pudieran determinarse muy aproximadamente, por la integración á que conducen las partes menos alteradas. En efecto, pudiera ocurrir como hipótesis, el representarse un tetraedro irregular, ó una pirámide algo inclinada de base triangular, cuyos tres ángulos serían de $112 \circ 5,36^{\circ} 5$ y $31^{\circ}$, siendo muy de notar el truncamiento de los dos ángulos triedros agudos, B, C. (figura 2. ${ }^{a}$ ) de la proyección horizontal de la pirámicie. La altura de ésta, es decir, la del vértice $A$, deberá estimarse, con corta diferencia, igual á la mayor profundidad actual del fierro meteórico, puesto que las aristas $A$. B., A. O., A. D., se conservan aún lo bastante para determinar la figura, no pudiendo dudarse que las interrupciones notoriamente artificiales que se observan en la intersección de las caras laterales, proceden de las muestras que se han tomado en los puntos más accesibles al cincel, que no deben confundirse con las alteraciones ó modificaciones que le son peculiares.

Entre los caracteres de cristalización que pudieran suponerse, sería acaso el más notable el truncamiento indicado en A. B. y C. D., cuyas fases sensiblemente paralelas entre sí, son perfectamente planas, como si en ellas no hubiera obrado la causa que desarregló muchas partes de la figura original, redondeando las caras y principalmente la intersección de la base con las fases laterales, así como el ángulo triedro D. El carácter de estos detrimentos es el mismo que habría resultado en un prisma semejante de piedra, rodado largo tiempo por las aguas de un torrente impetuoso.

También llama la atención una ranura perfectamente recta de cosa de tres milímetros de profundidad, que se advierte en la base, á once milímetios de truncamiento A. B. y paralela á ella. Aunque por su apariencia pudiera juzgarse hecha artificialmente por medio de la sierra, repugna tal hipótesis, considerada la suma dureza del metal y varios accidentes que indican ser otra la causa.

Las medidas aproximadas de la masa metálica, son: 71 centímetros de truncamiento á truncamiento, 45 centímetros en su mayor 
latitud, correspondiente al eje transrersal D. E., y 43 centímetros de altura, en el punto correspondiente á A.

Acaso pudiera confirmarse la suposición antedicha, teniendo presente una propiedad particular del metal, y es, que al escofinarlo, y, más aún, al forjarlo, se nota esa separación laminar, que no es común encontrar en los fierros del comercio, y sí, como se sabe, en los cuerpos cristalizados. Así es que, en el supuesto de que esa grande masa fuera nu cristal modificado ó en parte destruido por accidentes especiales, acaso se tendría un camino para llegar á conocer el origen de esos meteoros. Aun sin ello, creo que debe fijarse la atención en un hecho, que por serlo, nada hay en él de teoría, cual es la existencia de los pequeños cristales que se descubren en algunas grietas. Cuestiones son estas que exigen todos los conocimientos de las personas dedicadas al estudio de los curiosos fenómenos meteorológicos, ellas apoyarán ó desecharán la idea que me he decidido á indicar, fundado en resumen en estos datos principales: la forma del sólido, la separación laminar y la existencia de algunos pequeños cristales, en las caridades ennegrecidas que presenta la masa.

Veamos las indicaciones relativas al peso específico y á la composición.

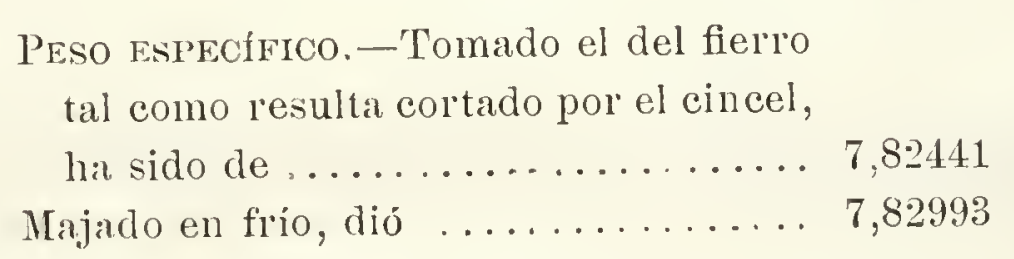

Este peso está tomado en una balanza de precisión sensible á mn diezmiligramo, con mo masa de poco más de doce gramos, y reducida la temperatura del agua á $+4^{\circ} \mathrm{c}$.

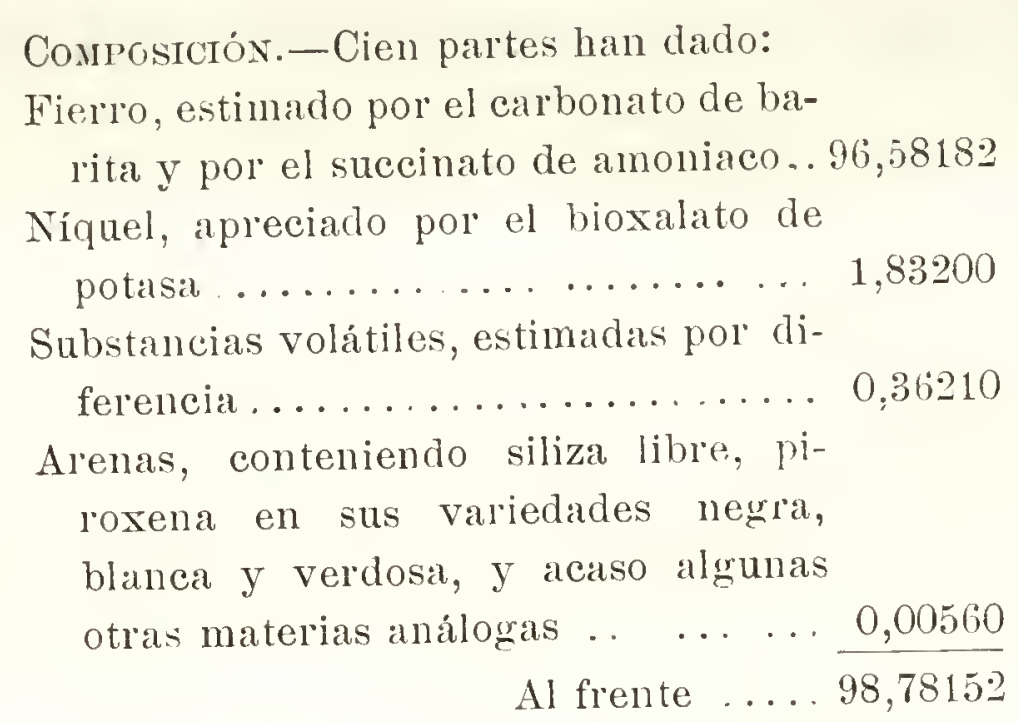


Del frente.... 98,78152

Carbono, estimado por el bióxido de mercurio................ 0,00018

Cal, separada por el sulfidrato y por el oxalato de amoniaco........... 0,60815

Alúmina y pérdida............. 0,61015

$$
=\underline{100,00000}
$$

\section{ADVERTENCIAS Y OBSERVACIONES.}

Se ha fijado la proporción del fierro sin considerar la que se obturo por el permanganato, atendiendo á la mayor exactitud en los métodos de pesadas, á la baja indicación que dió este reactivo, y á la coincidencia entre los dos mencionados antes. Oomo la cantidad limitada de metal de que podía disponer, no permitió repetir la operación, para estudiar el carbono, y como además está calculado por el volumen de ácido producido y no por el peso, no confío en el resultado, y sí presumo que la proporción ha de ser mayor, puesto que las substancias volátiles parecen ser carbonadas, Io que por igual motivo no he podido estudiar. La sílice y demás que constituyen las arenas, han sido apreciadas por el aspecto.

Me parece que podrá ser útil el anunciar, que en las varias reacciones propias á estos trabajos, se han presentado algunos fenómenos no cumunes, que pudieran conducir á la presunción de ser debidas á la existencia de algún cuerpo ó combinación desconocida.

No debo concluir sin llamar igualmente la atención sobre algunos puntos que juzgo de interés, ya con relación á la procedencia de estos meteoros, y más aún á la necesidad de rectificar las análisis de los que fueron examinados hace algunos años, así como las de los que no han sido analizados. En cuanto á lo primero, me fundo en los adelantos de la ciencia, en la mayor exactitud de los medios con que hoy puede contarse y en que habiendo, como hay en general, diferencias en los resultados analíticos, la repetición de éstos conducirá á la exactitud. Con relación á lo segundo, es decir, á las producciones meteóricas aún no examinadas, es fácil conocer la razón que hay para ello: además, casi pudiera decirse que hasta una época ree- 
ciente se ha señalado la existencia de compuestos ó de elementos que hicieran presumir en la de algunos cuerpos orgánicos fuera del globo terrestre. Esos nueros cuerpos simples que sospechó $\mathrm{Mr}$. Berzelins que existiŕan en estos productos meteóricos; ese barniz á cuya presencia atribuyen otros la no oxidación de las masas ferruginosas; y por último, lo que se anuncia respecto al curioso fenómeno meteórico observado en Mayo de 1863 en Montauban y rarios lugares de Francia, así como el análisis de esas producciones, todo tiende á apoyar la hipótesis relativa á la existencia de substancias orgánicas en esas curiosas producciones, demostrando más y más la importancia en la indagación del origen ó procedencia de unas y otras. Y ya que en el teritorio mexicano abundan, tanto el fierro meteórico como los aerolitos, no será tiempo perdido el que haya de emplearse en examinarlos, y en el estudio propio para la resolución de las cuestiones que están por resolver. 


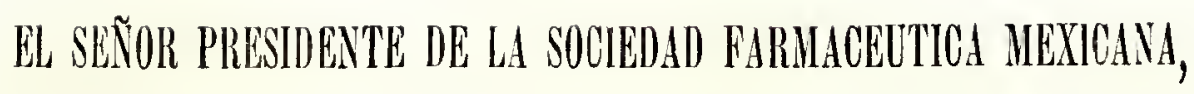

\author{
DOCTOR DON \\ LEOPOLDO RIO DE LA LOZA, \\ PIDe al sex̃or Presidente de la República, \\ por cunduC'o jel señor Ministro de Gobernación, \\ LA PROPIEDAD LI'TERARIA DE LA FARMACOPEA \\ Y SU OBSERVANCIA EN LAS OFICINAS \\ DE FARMACIA.
}

(Tomado de la "Gaceta Médica," Periódico de la Academia de Medicina de México).

La Sociedad Farmacéutica de México tiene la satisfacción de poner en conocimiento del ciudadano Presidente de la República, por conducto del Ministerio del digno cargo de Ud., que está concluida la impresión de la «Tarmacopea Mexicana,» y sólo pendiente de la encuadernación, porque para mandarla hacer necesita conseguir la resolución del Supremo Gobierno, relativa á dos puntos importantes.

Es el primero la declaración de la propiedad literaria, á la cual tiene derecho la Sociedad, conforme á la ley. Dicha declaración ya se pide hoy por conducto del Ministerio de Justicia.

El segundo, y que motiva estacomunicación, es relativo á pedir al ciudadano Presidente, que si revisada la obra, de la cual remito á Ud. dos ejemplares, se juzgare que puede substituir con algunas ventajas á la antigua «Farmacopea,» publicada en 1846, y cuya edición está agotada, tenga la bondad de disponer que las boticas del Distrito Federal y las de la Baja California, se arreglen á las prescripciones de la «Nueva Farmacopea» en lo relativo á las preparaciones oficinales, pues en cuanto á las magistrales, claro es que tienen los profesores médicos la libertad necesaria para prescribir las que les convinieren ó juzgaren preferibles. 
Como la Sociedad juzga conveniente poner cuanto antes á disposición del público la obra mencionada, ruega á Ud. que tenga la bondad de interesarse en el despacho de este asunto.

Independencia y Libertad. México, Agosto 10 de 1874.-Leopoldo Río de la Lowa, presidente.-C. Lic. Cayetano Gómez y Pérez, encargado del Ministerio de Gobernación.-Presente. 


\section{REFUTACIÓN A LA LEY DE 30 DE ENERO DE 1857.}

(Tomado de "La Unión Médica de "México."

La primera lectura de esa ley nos hizo conocer las dificultades que presentaría su ejecución en unas partes, y que on caso de llerarse en otras á efecte daría resultados contrarios al espíritu con que sin duda fué dictada. Desde luego nos propusimos llamar la atención de la autoridad en solicitud de un remedio, tanto más conreniente y necesario cuanto que todo el que vea la ley aun pudiera inferir que las ciencias médicas se hallan en México, en un atraso que á la verdad no tienen. Sin tiempo para realizar oportumamente ese propósito, hemos tenido el gusto de ver publicados dos artículos en el Boletín del Cuerpo Médico Militar, en los que se tocan los puntos principales. No obstante, como el autor del artículo se ocupó someramente del décimocuarto de la citada ley, y no estemos enteramente conformes con todas sus observaciones, haremos algunas que acaso puedan apoyar las que esencialmente comprenden los artículos del Sr. Vander-Linden.

El cloruro de zinc es acaso el compuesto menos adecuado para inyectar los cadáveres que se pretenden conservar: desde luego tiene el inconveniente de ser más untuoso al tacto que otros cloruros; de que la preparación no es de uso común y sí de precio más subido; pues aún cuando esta consideración no se juzgue de grande importancia, no por eso debe despreciarse: los instrunentos son atacados más fácilmente, y sobre todo, y es la razón principal, lejos de conservar la coloración natural de la piel es común que tome un aspecto bronceado ó moreno, más ó menos subido, según el método y 
cuidado que se tiene en la preparación del cloruro. Resulta que, lejos de ser el del zinc el mejor comservador y el más económico, es por el contrario una de las substancias cuyo uso debe proscribirse en tales casos.

Quiero, sin embargo, suponer que hay en esto equivocación, y que al contrario es hoy el mejor de los conservadores: ¿ge inferirá, como dice el Sr. Vander-Linden, que lo ha de ser siempre? ¿Será protdente que una ley marque el hasta aquí de las investigaciones? A la verdad, que apenas pueda concebirse cómo al profesor ó profesores que intervinieron en la formación del art. 14 de la ley, se ocultaron estas y otras muchas reflexiones que es excusado presentar: y digo que intervino algún facultatiro, porque no es de creer fuera puesto por personas extrañas: acaso se quiso dar una prueba de erudición con perjuicio de la ciencia médica. Sea como fuere, pretendemos con el articulista, que se revise la ley y se medite, consultando con personas capaces de juzgar sobre cada uno de los puntos facultatiros que comprende: el roto de un hombre instruido será bueno; pero pnede alguna rez ser parcial ó inadecuado; puede no ser meditado; y ya que el legislader carece de los ronocimientos necesarios para juzgar rectamente, debe asesorarse como lo hace en casos análogos. Entretanto se revisa la ley, sería conveniente suspender sus efectos. 


\section{CONSERVaGí́N dL LOS CADÁVERRS.}

(Tomado del "Periódico de la Sociedad Fiioiátrica de México,"

La conservación de los cadáveres por las sales de alúmina ó sus compuestos binarios, no debe tenerse como seguro, sino tomando otras precauciones á más de las indicadas en la memoria relativa á su preparación, leída por el Sr. Varela en la sesión del mes de Enero. Creo será de alguna utilidad dar á conocer algunas de las observaciones que he podido hacer sobre esto en los casos que se me han presentado, y cuyos resultados son conocidos de algunos de los socios que me escuchan.

Advertiré, en primer lugar, que no hay inconveniente en que las soluciones de acetato y de cloruro recomendadas, se usen á más de los diez y siete grados que se aconseja generalmente; por el contralio, mientras más concentradas están es más seguro el efecto, y bien puede usarse una mezcla de las dos que marca $20^{\circ}$ sin temor de que cristalice, lo que sería sin duda un inconveniente. A ese grado estaba la que sirvió para la Señora Cortina, y la inyección se hizo con la misma facilidad que si se hubiera empleado la que generalmente se recomienda, y no obstante que el líquido abandonado al aire en corta cantidad, cristalizaba en muy poco tiempo. Es verdad que la mayor concentración aumenta el valor del líquido; mas debe tenerse presente, que el aumento consiste en nua mitad más, que nada importa supuesto el gasto principal de la operación. Y aunque en los casos comunes el líquido á $10^{\circ}$ asegura por sí el resultado, hay otros en que es indispensable asociarlo con algunas substancias que 
favorezcan su acción. La infiltración parcial ó total y el derrame en alguna de las cavidades, hacen ineficaz este medio de conservación, notándose tres efectos que se oponen al que desea, y son: la descomposición de las sales de alúmina por la serosidad; si mayor dilatación en el agua, y por último, que la cantidad de líquido inyectado disminnye en razón directa de la serosidad infiltrada.

Como toda la alúmina precipitada por la serosidad deja de ser higroscópica, y la rirtud de sus sales depende de esa propiedad, cuanta mayor sea la cantidad de óxido precipitado, hay mayor facilidad de que se verifique la descomposición cadavérica. El líquido inyectado y la serosidad derramada, se mezclan en parte después de algún tiempo, y lejos de impedir la desconposición la farorecen, porque sobrando agna para disolver las sales, queda más de la necesaria para la descomposición, supuesto que la serosidad privada de bases y la alúmina precipitada, dejan libre la agua correspondiente.

Aunque no tengo un número suficiente de datos para demostrar que las infiltraciones no permiten la inyección de toda la cantidad de líquido que sin ellas adnitirían los rasos sanguíneos, me bastará decir que así lo he observado en dos casos, y que el raciocinio no se opone á estos hechos.

Cuando lay ascitis ó hidro tórax, es fácil remediar los inconvenientes indicados haciendo previamente la punción, para dar salida al líquido derramado en las caridades y hacer después la inyección; mas no sucede lo mismo en los casos dé edema, ni yo sé si el método que he adoptado es el más conveniente. Largas incisiones que interesen la piel y el tejido celular, un vendaje que comprima fuertemente y con igualdad, abandonar el cadáver por doce ó más horas para poner después nuevas vendas, si no fueren suficientes las primeras y dejar el cadáver en el baño conservador; he aquí lo principal del método que he seguido hasta ahora y ha dado buenos resultados.

Aunque antes preparaba el agua del baño con el mismo líquido albuminoso empleado en la inyección, me persuadí bien pronto que no era suficiente, y preferí nsar una solución de bichoruro de mercurio hecha en alcohol aromático y proporcionada al estado y al tamaño del cadáver. Para esto me sirvo de una tina ó cajón hecho al intento para que el cadáver quede sumergido en el líquido sin que sea necesaria mucha cantidan de agua como se tiene que emplear, 
sirriéndose de las tinas commnes. Dos libras de bicloruro disuelto en seis de alcohol de cidras eompnesto, es suficiente para un cadáver de adulto, siempre que no haya comenzado la descomposición, ni lubiere infiltraciones, ni muerto de alguna de esas enfermedades en que hay descomposieión de la sangre, como sucede en el escorbuto, fiebre $\mathrm{y}$ escarlatina tifoideas: en estos casos es preciso poner una libra más de bicloruro $y$ tres más de alcohol aromático.

El resultado es más seguro cuanto más permanecen los cadáreres en el baño; pero debe éste interrumpirse de tiempo en tiempo para que por su exposición al aire se erapore el agua de la periferia, faroreciendo así la descomposición del bicloruro, con el objeto de que el proto, que resulte forma una capa más gruesa, que se oponga á la acción del aire y asegure el resultado.

Acaso pudiera creerse, que supuesta la preferencia que doy al compuesto de mereurio para el líquido del baño, también debería usarlo para la inyección, abandonando enteramente las sales de alúmina; mas tengo entre otras razones, dos que considero de gran peso: 1. "Las sales de alúmina inyectadas, reobran sobre el bicloruro y los productos que resultan, impiden la descomposición orgánica. 2. La solución mereurial ataca los instrnmentos y los destruye con facilidad.

Debo también notar, que el método propuesto no tiene el gran inconveniente de ennegrecer los cadáveres como se laan risto en México algunos, aunque probablemente ha consistido en la mala preparación de las soluciones que generalmente se han hecho por doble descomposición. Pudiera sospecharse que el uso del mercurio en el líquido del baño determinará el mismo efecto, pero no srcede así según ha demostrado la experiencia.

Para dar á conocer mejor el buen efecto de las sales de alúmina empleadas en las inyecciones, referiré un hecho que últimamente notaron conmigo los Seños Durán, Galenxowski y Martínez del Río. El cadárer de la Señora Cortina había sufrido tal descomposición á las reinticuatro horas después de la muerte, que se hacía notable hasta en el cuello y orejas: quince horas después de la inyección y al primer baño había desaparecido enteramente, aun en mucha parte de la espalda.

Es inútil ocuparse en manifestar que, no obstante las preparaciones indicadas, hay cadíreres que no pueden conservarse por la 
inyección, sea cual fuere el método que se adopte y el líquido que haya de emplearse: el embalsamiento es en tales casos el mejor recurso, y el barniz de albuminato de cal puesto antes del primer vendaje, contribuye mucho al buen resultado.

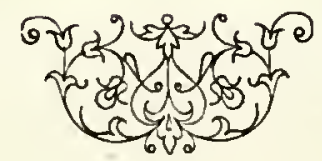




\section{TERAPÉUTICA}

APUNTES SOBRE LOS EFECTOS DE LA TARÁNTULA,

ADMINISTRADA AL INTERIOR.

(Tomado del "Periódico de la Sociedad Filoiátrica de México.")

Aunque teníamos pensado no publicar nuestras observaciones sobre el uso de la tarántula hasta que fueran suficientes para poder formar una historia completa de la acción de este nuevo agente terapéutico, nos hemos resuelto, sin embargo, á dar ahora estos apun. tes por no privar á los que quieran emplear pronto este producto animal, de los pocos datos recogidos hasta ahora $y$ de cuya exactitud salimos garantes, y nos hemos afirmado cada vez más en esta resolución al réflexionar, en que, el que quiera administrar esta subs. tancia, no sólo se encuentra en una ignorancia casi completa de su acción sobre la economía animal, sino aun de las preparaciones $y$ dósis en que debe emplearse, pues lo único que se sabe es que es un sudorífico bastante enérgico. En vista de esto hemos creído que estas observaciones, aunque cortas en número é incompletas en algunos puntos, pueden ser útiles á los médicos que quieran usar de ma medicina que, en nuestro juicio, ha de ser con el tiempo de una aplicación frecuente y provechosa. No por esto dejaremos de continuar haciendo observaciones que, reunidas á las que publiquen otros profesores, nos den nuevos datos que nos pongan en estado de describir la acción fisiológica y terapéntica de la tarántula con más extensión y exactitud. 
Ahora comenzaremos estos apuntes con la descripción zoológica del auimal, para que puedan tenerla á la vista los sujetos que deseen emplearlo.

\section{DESCRIPCION .}

La tarántula pertenece á los animales articulados, clase 3. ", aracnides, tribu de las vagabundas, priner subgénero Licosu taréntulu.

Tiene ocho ojos planos, de los cuales dos son mayores. Las mandíbulas en ganchos, cuerpo sin escamas, cuatro pares de patas lobustas y cada una con siete articulaciones, dos pedipalpos poco más pequeños y sin zarpa, dos manclnones carnosos en la extremidad abdominal. Las tarántulas habitan en excavaciones heclas en la tierra y entapizadas de filamentos que impiden se desplomen las paredes. En invierno cierran por lo común la entrada de estas habitaciones ó permanecen en ellas acechando la presa si carecen de provisión. Ia hembra lleva consigo sus crías por algún tiempo en la parte externa del abdomen, asegurándolas por medio de hilos; cntonces el animal tiene el aspecto más horrible.

Tas tarántulas de que hemos liecho uso, han sido traídas de las tierras calientes situadas al Sur de México, en cuyos lugares se encuentran en abundancia.

\section{Preparación farmacéutica de tarántulas, $y$ dosis en que se han empleado.}

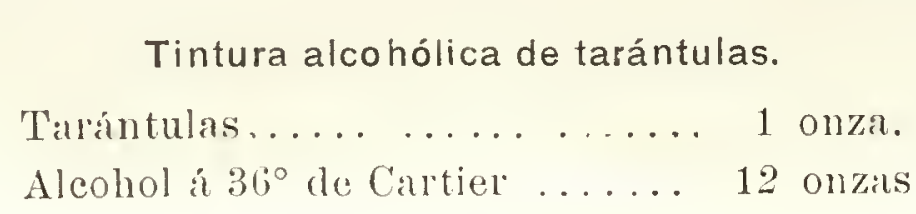

Se lavan las tarántulas con alcohol á $22^{\circ}$, se machacan, se dejan en maceración en el de $36^{\circ}$, por quince días, se cuela el líquido con expresión y se filtra por papel.

Del mismo modo se prepara la tintura etérea, empleando el étel sulfúrico medicinal en lugar del alcohol á $36^{\circ} y$ las alcohólicas de $22^{\circ}$ y $32^{\circ}$ empleando el alcohol á cstos grados. 
El cocimiento se ha hecho poniendo á hervir durante dos minutos un escrúpulo de tarántulas en una libra de agua común, y colando el líquido. Debe prepararse diariamente porque se altera con facilidad.

El cerato se ha preparado reduciendo por trituración á una masa suave dos onzas de tarántulas, y mezclándola á una libra de cerato de Galeno: también se ha preparado mezclándolo con la tintura al cohólica de $32 .^{\circ}$

Al interior se han usado el cocimiento acuoso, las tinturas alcohólicas á $22^{\circ}$, á $32^{\circ}$ y á $36^{\circ}$, y la etérea, al exterior, las tinturas alcohólicas y el cerato.

El cocimiento se ha dado hasta la dosis de 10 onzas en veinticuatro horas, en una ó en dos tomas, comenzando por una onza.

Las tinturas alcohólicas hasta la dosis de doscientas gotas en nua ó dos tomas, comenzando por cuatro. *

El éter, hasta veinte gotas en las veinticuatro horas comenzando también por cuatro.

De las tres preparaciones, acuosa, etérea y alcohólica dadas varias veces á los unismos individuos, calculando las proporciones de manera que tomaran la misma cantidad de producto animal, es decir, cantidad de líquido en que se hubiera empleado la misma porción de tarántula, ha resultado menos activa la acuosa, más la etérea y mucho más la alcohólica. Para mayor claridad se prepararon las tres con la misma cantidad de animal á razón de una onza por libra, $y$ se obtuvo siempre el mismo resultado.

La causa de que no se usara habitualmente del cocimiento acuoso preparado á razón de onza por libra, era la rapidez con que entraba en putrefacción, tanto mayor, cuanto era la cantidad del animal con relación á la del agua.

Respecto de las tres tinturas alcohólicas so ha notado que la de $36^{\circ}$ es la más enérgica; esto hace creer que la de 40 lo será más, pero todaría no la hemos usado.

* Es digno de atención el que aun con esta dósis de cuatro gotas, los enfermos suden muchas veces con abundancia, sobre todo si se atiende a lo my pequeña que debe ser la cantidad de principio activo que contengan cuatro gotas de alcohol, cuando la tintura tiene la duodecima parte de tarántula y todavia queda del animal un gran residuo por las partes que no son solubles. Este es un fuerte argumento contra algunos autores de terapéutica que no admiten sudoríficos propiamente dichos y dicen que cuando un liquido hace sudar, es por la mueha cantidad y alta temperatura á que se le administra. 
Al exterior hemos hecho uso del cerato y la tintura alcohólica: el primero en las úlceras, la segunda en las manchas dolorosas de los lazarinos; pero no teniendo hoy sino muy pocos datos, hablaremos de esto cuando nos ocupemos de la parte terapéntica.

\section{ACCION SOBRE LA ECONOMIA.}

Sobre 13 enfermos, 10 lazarinos, 2 elefancíacos y 1 atacado de ambos males, á quienes se han dado las preparaciones de tarántulas, se ha notado que han obrado como sudoríficas, aumentando notablemente la transpiración cutánea; el tiempo que ha pasado entre el acto de tomar la substancia y la aparición del sudor ha variado mucho, siendo en algunos de unos cuantos minutos, y en otros hasta de muchas horas; parece que esto depende de algunas circunstancias concomitantes, como la quietud, el abrigo, etc.; $y$ sucede á reces que aun en medio del sudor, si el enfermo se descubre ó hace algunos movimientos, el sudor se suspende, volviendo á reaparecer por el abrigo y la quietud, aunque no tome nueva cantidad de substancia. A dos enfermos que estaban tomando hacía algunos días la tintura, y en quienes se suspendió su uso por haber sido atacados el uno de erisipela, $y$ el otro de congestión sanguínea cerebral, se han visto continuar sudando hasta tres días después de haber cesado de tomarla; esto hace creer que la substancia predispone á la economía para que las cansas que farorecen la traspiración cutánea, la produzcan en cantidad muy considerable, aun cuando ellas por sí solas en el estado habitual sean suficientes para producir este efecto, $y$ es de creerse también por lo antes diclıo, que esta predisposición no es pasajera, aunque los datos que poseemos no sean bastantes para apreciar su duración con todo rigor. Algunos enfermos antes de presentarse el sudor dicen que sienten calor, principalmente en la cabeza; varios se quejan después de tomar la substancia de un ligero dolor en el estómago, que se disipa pronto.

El sudor comienza por el pecho y, á proporción que va siendo más fuerte porque se aumenta la dosis de la medicina y el tiempo que lleva de usarse, se extiende gradualmente al resto del tronco, cabeza, parte interna de los muslos, brazos, manos, piernas y pies; de 
estos últimos, de los pies, pocos enfermos lan sudado y esto pasado algún tiempo de tomar las preparaciones; pero sí se nota que aun las partes que no sudan al aumentarse la traspiración, en las otras, se ponen calientes; la cantidad de sudor debe ser considerable, supuesto que la ropa á veces se empapa completamente: una rez se pesó la camisa de un enfermo que acababa de sudar, y se notó un aumento de dos onzas, pero hay que notar lo mucho que el líquido se evapora, y que no sólo la camisa sino también la demás ropa estaba mojada.

El pulso no ofrece grandes cambios á consecuencia de la administración de la substancia, se le advierte algo más frecuente antes de presentarse el sudor y durante él.

La digestión parece que no sufre alteración ninguna: en algunos enfermos se advierte aumento en la gana de comer; ningún enfermo la tenido sed. La orina no ha presentado diminnción en su cantidad más que en un solo enfermo, y eso por sólo dos ó tres días, lo que se hace muy notable atendida la falta de sed y el aumento de la transpiración cutánea. Esto no sólo se ha observado en los enfermos del hospital de San Lázaro; el señor Martínez Villar nos ha comunicado nua observación de un sifilítieo á quien administró la tintura alcohólica de tarántula á $32^{\circ}$ hasta la dósis de 15 gotas por día y en el que nunca advirtió diminución en la orina, aun en el día en que los sudores fueron más abundantes; se expresa así en su observación: «El sudor ha sido abundantísimo, no ha habido sed, ni aumento ni diminución en la cantidad de la orina, ni tampoco cambio el sus cualidades; el pulso está á 100, etc.»

En fin, concluiremos con manifestar que, de los 13 enfermos citados, tres estaban atacados de diarrea y en ellos la acción sudorífica de las preparaciones ha sido en algunos días perceptible aunque débil $y$ en todos los demás enteramente nula.

Finalmente, prometemos, como ya hemos dicho, publicar los datos que rayamos adquiriendo, principalmente los relativos á la acción terapéntica y creemos poder cumplir nuestra promesa en atención á que la principal dificultad que consiste en la adquisición de un número sufieiente de animales, no existe hoy para nosotros, pues la Comisión del Excmo. Ayuntamiento encargada del hospital de Sau Lázaro sabedora de que por este producto animal se habían obtenido si no curaciones, á lo menos alivios notables en algunos enfermos, ha promovido con el mayor celo y eficacia la adquisición de las ta- 
rántulas, deseosa de mejorar la situación de los infelices atacados de esta enfermedad tan temible, particularmente en nuestro país.

México, Septiembre 30 de 1844.
L. $\mathfrak{i}$ ío de la $\mathfrak{L}$ oza.
OR. $\mathfrak{Q}$ ucio. 


\section{HIGIENE PÚBLICA}

(Tomado del "Periódico de la Sociedad Filoiátrica de México.")

Publicamos á continuación el luminoso é importante trabajo presentado y aprobado por el Superior Consejo de Salubridad, sobre la situación y demás condiciones higriénicas de los tiraderos y sumideros diurnos y nocturnos. Creemos que nuestros lectores verán con interés un documento en que se resuelve con solidez y cordura una de las más urı́rentes cuestiones de higiéne publica.

\section{Secretaría del Consejo de Salubridad de México.}

En sesión de 19 del corriente aprobó el Consejo el siguiente dictamen:

«La comisión encargada de abrir dictamen sobre la comunicación que el Sr. Alcalde primero del Exmo. Ayuntamiento, dirigió con fecha 30 del próximo pasado Marzo á este Consejo, consultando varios puntos de salubridad, sobre el importante ramo de limpias, se encuentra embarazada, pues si la gravedad del negocio, exije tiempo y meditación, su urgente premura le obliga á no detenerse en sus trabajos más que lo muy necesario para emitir su opinión. Afortunadamente haciendo la Comisión un análisis de las diversas cuestiones cuya resolución se busca, se ha convencido de que hay unas de ejecutivo despacho para los fines que ahora se propone al Exmo. Ayuntamiento, y otras que, aunque de mucha importancia, bien pueden diferirse un poco de tiempo para tener el de meditarlas mejor: desde luego parece que el Consejo de Salubridad debe ocuparse de las primeras y reservar las segundas para reflexionar sobre ellas con atención y resolverlas con oportunidad. 
La comisión opina que entre los problemas propuestos en la expresada comunicación, son del momento los siguientes:

19. Buscar el medio más apropósito y económico para destruir los muladares, y qué nso útil puede darseá los residuos.

29. En qué puntos y con qué precauciones convendrá establecer los tiraderos y sumideros generales diurnos y nocturnos. Consecuente á su opinión, pasa la comisión á encargarse de estos puntos, y aunque le inspiran demasiada confianza las luces del Consejo para no temer queden incorrectas las equivocaciones quo ella padeciere, sin embargo, sabe muy bien que la topografía médica respectiva, es indispensable para resolver satisfactoriamente las cuestiones prácticas de higiene pública, y que es muy aventurado ocuparse de éstas sin los datos que aquélla suministra, como desgraciadamente sucede hoy en México.

Entrando hoy en materia: la comisión no encuentra hoy otros medios más económicos y adecuados para destruir los muladares de la cindad, que la combustión 6 el acarreo: y desde luego se decide por la primera por las sencillas razones de ser evidentemente el menos costoso, el más violento y el que evita la conducción de materias orgánicas en putrefacción: á fin de que la combustión llegue á convertir los muladares en un corto residuo de fácil trasporte es necesario que después de habel quemado la superficie de estos asquerosos montones, se remuevan cuantas reces fuese necesario para destruir todas las materias orgánicas. Ia combustión presenta además la rentaja de hacer que desaparezcin algunas substancias nocivas y de contribuir con la elevación de temperatura, á purificar la atmósfera que por lo común se encnentra en esos lugares cargada con las emanaciones de los pantanos. Sus únicos inconvenientes, que son los de un incendio, se pueden prevenil facilmente, tomando en los sitios en que hubiere este peligro las precauciones necesarias i $Y$ los productos de esta incineración á qué uso útil podrán destinarse? Esta segunda parte de la cuestión es de resolnción más obria quela primera: no son á propósito para engrasar los terrenos incultos, estando llenos de escombros, fragmentos de vidrio, etc; ni pueden dar por'las sales delicuecentes qne contienen, la consistencia que se bus ca en los pisos de los cimientos de las calles y plazas mu frecuentadas. Resta, pues, sólo emplearlos en la nivelación de aquellos parajes en que no fuere necesaria mucho solidez: y de todos modos se 
puede asegurar, que siendo ya incapaces de entrar en putrefaceión, no pueden ser nociros á la salubridad.

La comisión se vé obligada á extenderse un poco más, al exponer sus ideas sobre la segunda de las cnestiones que se ha propuesto ventilar, porque ésta es complexa y abraza otras muchas del mayor interés. Después de un maduro examen se ha convencido de que los tiraderos generales deben hallarse á la distancia de doseientas varas, lo menos, de la última labitación de la ciudad; si estuvieran más próximos comprometerían su salubridad, y si más lejanos, se opondrían á la economía. Los diurnos pueden situarse en todos los rumbos, en los parajes que al Exmo. Ayuntamiento parezcan más apropósito, con tal de que se tenga cuidado de vaciarlos con alguna frecuencia para que no con el transeurso de los años se lleguen á formar esas montañas de inmundicias, que en vano se han fatigado pol hacer desaparecer algunas ciudades de la Europa. Estos sitios deben tener la extensión conveniente, á fin de que, presentando mayol' superficie, se facilite la combustión de las basuras, que debe ser en ellos constante; pero antes de entregar al fuego los desechos de la ciudad no hay obstáeulo en permitir la rebusca con las reglas que se crean oportunas, á los infelices que viven de este miserable recurso, tanto por que no se debe destruir lo que todavía es útil, como por no quitar esta ocupación á los que no tienen otra. Será, pues, conveniente fijar el tiempo en que los carros pueden vaciarse en tales sitios, las reglas que se deben seguir al permitir la rebusca, las épocas de la variación de estos tiraderos, $y$, finalmente, el modo con que se debe practicar la combustión para su exterminio.

Respecto á los sumideros nocturnos, la comisión opina que se deben situar precisamente entre S. E. y S. O. de esta ciudad, por que sus vientos dominantes son los del $\mathrm{N}$. y los del S. y porque atraviesan la parte de nuestros horizontes más cubierta de vegetales. También la extensión de los ejidos que se encuentran en aquellos rumbos, proporciona mayor facilidad para cambiar con frecuencia dichos sumideros. Estos deben ser excavaciones, cuya profundidad sea proporeionada á la sequedad del terreno y cuya extensión sea relativa á su número y á la cantidad de materias que haya de depositarse. Con la tierra de estas excavaciones será conveniente formar los bordos y levantar tapias de adobe de seis varas de altura en la parte que ve á la ciudad, porque es útil impedir que los gases 
que se desprenden de estos focos pestíferos sean aventados á la población cuando sople el viento Sur. Con este mismo objeto y para oxigenar más la atmósfera de aquellos sitios, será igualuente oportnno plantar una arboleda del lado de las tapias que mira al Norte para que con el tiempo exceda la altura de éstos y asegure más el efecto que se busca. Antes de que los sumideros construidos del modo que se ha descrito, se llenen completamente deben cubrirse con la misma tierra que sirvió para los bordos, cuidando de mezclar bien con ella las materias immundas, á fin de que se forme un excelente abono para beneficio de los terrenos pobres.

Bien conoce la comisión ser insuficientes los medios que propone para establecer en esta populosa cindad, la policía de limpieza y salubridad tan necesaria al bienestar de sus moradores y al crédito de sus autoridades; pero este Consejo que ha manifestado en todas ocasiones $n$ positivo entusiasmo por corresponder dignamente á los objetos de su institución, no dejará perder la bella oportunidad que le presenta el ilustrado celo de los Sres capitulares que actualmente forman el Exmo. Arruntamiento, para lealizar sus deseos no sólo en uso de la atribución vigésima del ordenamiento, sino en obsequio de la ciencia médica, del honor mexicano y de la hnunanidad doliente. Más adelante podrá, sin tanta premura, ocuparse de proponer ideas sobre la limpia de calles, albañales de cuarteles y de casas de comunidad, construcción de letrinas públicas y particnlares, reforma de hospitales y demás ramos á que pnede referirse la commicación que lat motivado este dictamen».

Y cmmpliendo lo acordado por el mismo Consejo, tengo el honor de transcribirle á V. S. protestándole mi debida consideración.

Dios y Libertad, México, Abril 19 de 1843.-Leopoldo Río de la Loza.-Sr. Alcalde de primera elección del Exmo. Ay nntamiento.

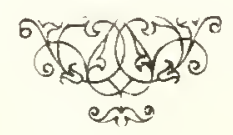




\section{TRATAMIENTO DE LA EPILEPSIA}

«La niña G. M., de seis años de edad y de buena salnd, dormía tranquilamente una noche en la que un accidente desagradable $y$ aterrador la despertó repentinamente: al siguiente día se adrirtió que estaba fuera de sí, en un éxtasis que sólo duró algunos minutos, lo cual llamó poco la atención de su familia, juzgándose que sería un mal pasajero. Mas pocos días después se repitió el ataque, siguiendo otro y otros con más ó menos frecuencia y durando más ó menos tiempo el estado de privación ó insensibilidad. Fué entonces preciso ocurrir á los auxilios médicos, pero en vano se pusieron en práctica todos los que aconseja la ciencia y ann todos aquellos usados por el rulgo: el mal se desarrolló con todos los síntomas característicos de la epilepsia, $y$, por fin, en vista de la ineficacia de los medicamentos se omitió todo tratamiento aguardando la aparición del período menstrual, como la única esperanza de curación. Esperanza desvanecida, porque el mal ammentó lejos de quitarse, observándose de tiempo en tiempo, ya un estado cataléptico terminado con profundos suspiros, ya comatoso, tetánico, etc., etc., que condujeron á la enferma á un idiotismo no permanente, pero sí repetido con frecuencia.

Así transcurrieron catorce años sin conseguir más que cortos alivios y en períodos limitados, hasta que á la edad de reinte años, y sin causa conocida, los ataques fueron tan frecuentes que apenas se 
suspendían tres, cuatro y á lo más cinco minutos para volver con mayor ó menor intensidad, de manera, que la fatiga del mal duraba más que el descanso aparente de la enferma. Preciso era aguardar que la muerte pusiera término muy pronto á tan penosos sufrimientos; la enferma, no obstante, siguió así y casi sin alimento alguno durante diez y ocho días, con admiración de cuantos lo vieron. No era posible ser indiferente á tal situación, ni limitarse sólo al tratamiento paliativo; yo me resolví á proponer á la fanilia la administración de una substancia, que si bien por sí ó por incidencia pudiera ocasionar la muerte, era en mi opinión la única esperanza. Una rez obtenido el consentimiento de los interesados, comencé á administrar á la enferma la yerba de la Puebla (senecio canicida), de la manera siguiente:

Mandé escojer la planta más reciente y reducirla á polvo, de manera que conturiera todas sus partes, es decir, raíz, tallo y hojas: dos dracmas del polvo fueron divididas en doce papeles, de los cuales administré uno; pasaron dos horas sin modificación alguna en los síntomas y dí un segundo papel; á las dos horas siguientes se notó alguna rariación, sobre todo en los movimientos convulsivos, lo cual me decidió á esperar más tiempo para dar ó no otra toma, que al fin dispuse se administrara otra, pasadas otras dos horas; después de esta toma no me quedó duda de que la medicina ejercía su acción, los morimientos convulsiros eran más fuertes, pero los accesos menos frecuentes y el semblante de la enferma recobró alguna aninación; se le dió un alimento ligero y se dejaron pasar cuatro horas sin darle otra cantidad del polro. La cuarta toma produjo efectos más marcados: el cuadro era el de un acceso epiléptico en el cual el paciente conservaba su conocimiento; el estado letárgico se alejó más y más, la enferma pudo dormir aunque con las interrupciones consiguientes á los ataques cada rez más distantes.

Creí entonces disminuir la dosis del polvo reduciéndola á la mitad en cala toma, dar una cada cuatro horas y sostener su administración. Seis días después de haber comenzado el tratamiento con el polvo de la yerba, me recibió la enferma en el corredor de la casa, alegre y en completo bienestar.

Ocho meses se pasaron sin acceso ni aun amago alguno, disfrutando la paciente de completa salnd, robustez, inteligencia, buena locilidad y obediencia que antes no había; apetito y sueño buenos, 
laboriosidad, todo, en fin, anunciaba el completo restablecimiento y por tanto la desaparición del mal.

Desgraciadamente no fué así; un día, cuando menos se esperaba, vino una indigestión que se atribuyó á que la enferma había tomado chirimoya, y pocas horas después un nnevo acceso anunció que la enfermedad no había desaparecido.

Los ataques vinieron con más ó menos retardo, y al fin, pasado algún tiempo, todo volvió á su estado primitivo.

Fueron administradas nuevamente algunas tomas del polvo, mas lıabiéndose creído que las convulsiones aumentaban, se suspendió la administración sin que hasta hoy se haya tenido la constancia necesaria para observar los efectos que produjera.

¿Esa larga interrupción del mal indicará que no hay en el caso que me ocupa lesión orgánica alguna y que se debe, por lo mismo, insistir en la administración del senecio?

Yo creo que debe administrarse.

Agosto 14 de 1866. 


\section{ORAOIOI}

\section{PRONUNCIADA POR EL SEÑOR \\ D. LEOPOLDO RIO DE LA LOZA,}

EN LA UNIVERSIOAD PONTIFICIA, AL RECIBH ET, GRADO DE

DOC'NOR EN TEOLOGIA.

Onni quidem tempore praclarisimum munus quo hodiernadie me decorari roluistis, reluti eximia gratia ab hominibus literarum cultu maxime perpolitis existimatum est, quanquam ad tanti homoris consecutionem, omnibus statutibus huyus alme Academis doctorum inaugoratine asiguatis, se liberter snbjicerunt.

¿Quid ergo dicam de magditudine gratis quam mitri omni merito destituto, duntaxat maxima, miraque largitate restra solemniter nune confederam decreristis? Vos, forsitan, nticredo publica roce nitentis, in me tali modo omandum adncti fuistis; vermmtanen in hac re, valde benigne judicatis: si quid de me benedicitur mitri omnio immeritum est, ideoque magis, atque magis a rolvis in me collata gratia angetur. Quanobrem, Doctores amplisimi, mentem meam sentio angoribus affectari, ex alia enim parte, totam apud me gratuiti beneficii restri, cuyus debitorem me falteor intensionem considerabo; ex altera autem me ad ejus saltem minimam retributionem impotentis attendo, et magno, moerore officio. ¿Quid enim dulcis? Quid jucamdius, quam graticordis veras intimas que affecciones, in lucem profene frosse? Si fuerit mitri datrm nilil desiderabo. Attámen in anxietate mea hoc effugium liceat refrerire: ut ros metipsi qui hunc mitri tantum honorem contulistis inertia 
verba á trementibus labiis probata indulgentissimo adimo accipiatis; unicuique restrum, caterisque dignissimus sodalibus qui hujus illustris, nationalis adque pontifica Academis ornamentum constitunt, ex meo toto corde sincere gratificor. Cara mitri semper evit, tanti beneficii recordatio, quia benevolemtian erga me restram commemorare possum, rependere numquam.

Dixi. 


\section{A CION}

PRONUNCIAOA POR EL SEÑOR

\section{LEOPOLDO RTO DE LA LOZA,}

FN I,A UNIVERSIDAD PON'IIFICIA, AL RECIBIR EL GRADO DE

DOC'TOR EN TEOLOGIA.

(Traducción literal).

Ciertamente en todo tiempo se ha estimado el ilustre obsequio con que hoy habéis querido condecorarme, como una gran gracia de los hombres que se consagran al cultivo de las letras, aunque para conseguir tanto honor se han sugetado de buena roluntad á todos los Estatutos de esta Academia Madre de Doctores desde su fundación.

¿Qué diré, pues, de la magnitud de la gracia que ahora habéis dispuesto decorarme solemnemente á mí, destituido de todo mérito, tan sólo por ruestra grande y admirable largueza? Vosotros, quizá, como lo creo, fiandoos en la roz pública hacia mí, de tal modo habéis sido impelidos á decorarme; sin embargo, sobre ésto habéis juzgado muy benignamente: si algo bueno se dice de mí es inmerecido totalmente, por lo mismo se aumenta más y más el faror que se me ha conferido por rosotros.

Por todo esto, ilustres Doctores, siento que mi alma se afecta con sobresalto, pues por una parte me confesaré deudor de vuestro beneficio tan gratuito para mí, por otra parte me veo impotente para recompensarlo aunque sea poco y me afecto con gran pena. ¿Qué hay más dulce, qué más grato como poder manifestar públicamente 
las sinceras é íntimas afecciones de un corazón agradecido? Si me fuera dado, ninguna otra cosa deseara. También en mi perplegidad séame permitido hallar este recurso: que vosotros mismos que me habéis conferido este tan gran honor, que mis insulsas palabras escapadas de mis trémulos labios las reciban con indulgentísimo sentimiento: á cada uno de vosotros y á los demás distinguidísimos compañeros que forman el ornamento de esta ilustre Nacional y Pontificia Academia, con todo mi corazón lo agradezco sinceramente. Siempre será grata para mí la memoria de semejante beneficio, porque vuestra benevolencia conmigo la podré recordar y nunca corresponderla. 


\title{
DR. D. LEOPOLDO RIO DE LA LOZA,
}

\author{
P'RONUNCIADO \\ EN LA INAUguración De DHCHA SOcHedad.
}

\section{(Tomado de "El Observador Médico.")}

\section{SENTORLS:}

Tengo la más grata complacencia al concurrir á la erección de la duodécima sociedad médica que se establece en la capital de la República, desde nuestra independencia hasta la fecha. *a Lango, porque anlielo por los adelantamientos científicos de todo género, y la experiencia me ha enseñado que á las asociaciones, como á la que alora se instala, deben en México las ciencias médicas sus notorios progresos. La tengo, porque al otorgarme el lugar distinguido que ocnpo, recibo el expontáneo testimonio de amistad y de gratitud

* Yo estará por demás dar á connecer los nombres de esas asociaciones: Academia de Mredicina pricticar.

Sociedad Médica del Distrito.

Academia do Medicina de Mexien.

Confratemidad Médica.

Academia farmacéutica de Méxien.

Sociedad Médicar de emulación.

Sociedad Filniátrica.

Sociedad de entusiastas.

Sociedad Médiea de Benetienein.

Academia de Medicina la actual.

Sociedad Fraternal Medica.

Asociación Médica, Pedro Escobedo. 
de mis apreciables comprofesores y de mis no olvidados discípulos. Ta tengo, en fin, porque esta naciente remión, llena de rida y de esperanza, ha comenzado por un acto de justicia al conservar el nombre respetable del inteligente catedrático que, desde 1822 , sacó á la cirugía de la práctica rutinera en que se hallaba, y del menosprecio con que, no sin razón, era vista por muchos. Yo, en particular, secundando las nobles miras de esta Asociación, aprovecho la oportunidad para dejar consignado en el acta de esta solemnidad, mn testimonio de mi reconociuniento á mi filantrópico maestro y muy excelente amigo, el Sr D. Pedro Escobedo.

Cumplido este grato deber, espero me será permitido el ocupar un corto tiempo la atención de las personas que turieren la bondad de escucharme.

Fs común en las solemnidades, como la presente, el tomar por tema de los discursos algún punto relacionado con la historia, con los progresos ó las rentajas de las asociaciones; hablar sobre la marcha que se propone seguir en sus trabajos la que nuevamente se ins. tala, ó bien presentar la biografia de algńn personaje, notable ya por sus escritos, per su saber ó por los bnenos servicios prestados en beneficio del género humano. Mas yo, Señores, propongo desriarme de esa costumbre, y pretendo tratar, aunque sea breremente, de un pminto médico que juzgo de utilidad práctica y, que aun me atrevo á decir, que establece principios que hoy ya tienen ma aplicación general en el orden farmacológico.

¿Quién no sabe cuán antigno es el uso quo se ha hecho en medicina de los compuestos calcáreos, y cuán variadas han sido también las formas, las preparaciones y el origen ó procedencia de ellas? Han pasado los años y los siglos, se han modificado y cambiado los sistemas médicos, se han perfeccionado más ó menos los artes auxiliares del ramo de curar, y esos compuestos no han caído en el olvido absoluto, ni menos en ese descuido á que los prácticos inteligentes tienen que condenar con frecuencia los mil y mil remedios recomendados pomposamente por araros especuladores, por fanáticos ignorantes y aun por médicos inteligentes, quienes apoyados en los principios generales de la ciencia y animados por el buen deseo de anmentar el número de los agentes farmacológicos, se han resuelto, no pocas veces, á observar á la cabecera de los enfermos, los efectos terapéuticos de las preparaciones nnevamente recomendadadas. $Y$ dá que 
atribuir esta estabilidad en el uso de los compuestos calcáreos? ¿Cómo es que en todos los diversos países, en todas las escuelas y todos los prácticos los lıan prescrito con más ó menos constancia, ya solos, ó bien con otros coadyuvantes más ó menos eficaces? ¿Habrán sido y aun serán estimados como sencillos é inactivos excipientes?

Basta recor'rer algunas obras de Materia Médica, para notar que en innumerables preparaciones constituyen la base de ellas, con exclusión de toda otra substancia activa, para persuadirse que los médicos de todos los tiempos los han considerado como medicamentos eficaces, dotados de propiedades particulares, y cuya administración es frecuentemente seguida del mejor éxito. Verdad es que la cal y sus compuestos no pertenecen á la categoría de esos agentes medicinales tan activos que, como los de mercurio y de antimonio, de fierro y de yodo, de belladona, de quina, de opio y otros, ejercen una acción especial, constante y earacterística, sobre la economía animal, y la ejercen con tal regularidad, que puede el médico calcular casi matemáticamente, no sólo las dosis que conviene administrar y los efectos que han de produeir, sino también el tiempo en que han de presentarse tales efectos, su duración y sus resultados. No obstante, si los que determinan los compuestos calcáreos no siempre son tan marcados y precisos, no por ello dejan de ser evidentes y en muchos casos de éxito seguro. Para que éste lo sea aún más, conviene que tales preparaciones se usen mejoradas conforme á las nuevas doctrinas, tanto químicas como fisiológicas y terapéuticas, supuesto que antes no pudieron alcanzar esos medicamentos los grados de perfeceión de que son hoy susceptibles.

No es mi ánimo ocmparme en este escrito de la cal y de todos sus compuestos: me limitaré á tratar de sólo dos de los más usados y que por lo mismo exigen toda la atención del práctico. Estos son los carbonatados y los fosfatados.

Sabido es que en los primitivos tiempos en que tuvo su origen el arte de curar, comenzaron á emplearse innumerables productos de ese género, cuya verdadera naturaleza era desconocida, pero que más tarde vino á demostrar la química que en su mayor parte tienen una misma composición, á reselva de algunos más ó menos silícicos, ó aluminosos, á los cuales la ignorancia de aquellos tiempos había supuesto la misma composición y las mismas propiedades medicinales que aquéllos. Fáeil es conocer cuánto debió influir en tal supuesto el fana- 
tismo y la superstición: el hecho es que figuraban al lado de los carbonatos y de los fosfatos calcáreos, las amatistas y las perlas, las conchas de que éstas se extraen y los rubíes orientales: en fin, basta recordar la fama que por muchotiempo tuvieron los cinco fragmentos preciosos, llamados así por los antiguos, y compuestos de las esmeraldas, los granatas, los rubíes, las sardónicas y los jacintos. Varias de las personas que me oyen saben que, aún hace pocos años, figuraban entre las preparaciones oficinales de uso común, las célebres conservillas de alquermes y de jacintes, compuestas, entre otras substancias, de esas piedras preciosas, de las perlas, los corales y la lazulita. ¡Cuán caros costaban entonces á los pobres pacientes todos estos y tantos otros inútiles y aun perjudiciales remedios que salían de los amuletos!

Mas por fortuna las investigaciones científicas, hechas á la rez en el orden químico y en el médico, han llegado á demostrar por una parte que muchos de esos productos naturales tienen una misma composición y unas inismas propiedades medicinales, y por la otra que difiriendo enteramente varios de ellos en cuanto á su composición, también difieren en cuanto á la acción fisiológica y terapéutica. Nada liay, en efecto, de común entre la que ejercen los compuestos calcáleos y los magnesianos, comparada con la que producen los silícicos y los aluminosos; á la vez que son commines la que determinan, por ejemplo, las partes huesosas de los diferentes animales, recomendadas por los antiguos como remedios especiales para determinados casos. El nso de las preparaciones calcáreas carbouatadas $\mathrm{y}$ fosfatadas ha continuado hasta hoy $\mathrm{y}$ seguirá en adelante; en tanto que esas piedras preciosas laan sido condenadas al olvido, por el unánime asentimiento de los prácticos instruidos.

Mas no por esto la exclusión es tan absoluta cual conviene á los intereses clínicos. Esos compuestos calcáreos de que he hecho mención, y también los magnesianos, contienen en más ó en menos los aluminosos y aún los silícicos, que alterando la pureza de aquéllos, modifican cuando menos sus efectos. He aquí el punto sobre el cual pretendo llamar la atención de los prácticos que me escuchan, apoyado en alguno de los principios médicos, que, no obstante serles bien conocidos, no estará de más el indicarlos, aunque sólo sea como un simple recuerdo.

Es de grande interés práctico, generalmente lablando, que los 
agentes terapéuticos remun las siguientes cualidades: ser puros, de composición constante, hallarse á un mismo grado de hidratación y lo más diridido que fuere posible; cualidades que son más necesarias respecto de las substancias destinadas al nso interno. Pero tanto el fosfato y más principalmente el carbonato de cal, distan mucho de todas esas recomendaciones, y, por lo mismo, los efectos que determinan difieren en muchos casos.

Se sabe que el carbonato de cal, empleado por los antiguos prácticos, fué el producto natural conocido con nombre de creta, variedad terrosa de las calcáreas carbonatadas. Este compuesto, tan abundante por todas partes, como variable en cuanto á las materias extrañas que contiene, es de uso muy general, y útil, sí, para las artes y diversas industrias; mas no podrá dudarse que es también el menos adecuado para los medios medicinales. No es de hoy el conocimiento de esta rerdad, pues ya remos en los buenos tratados de farmacia, que no se mencionan los antiguos procedimientos de preparación, y sí están recomendados los de precipitación. En efecto, por este medio se obtiene un producto que reme todas las condiciones que antes he mencionado, y satisface por tanto todas las exigencias terapénticas. Blancura perfecta, poca densidad, pureza, división extrema, hidratación, composición constante, nada desagradable al paladar, y fácil disolución aun en los ácidos débiles; he aquí el eonjunto de propiedades que hacen muy preferible este medicamento, totalmente artificial, estando bien preparado, á esa rariedad tan numerosa de los naturales, aun cuando hayan sido sometidos á la decantación y lavación recomendadas.

Dos objeciones pudieran hacerse en contra de las ideas emitidas: una con relación á las propiedades medicinales de alguno de los - cuerpos extraños contenidos en la creta natural, y otra que llamaré con su rerdadero nombre, diciendo que es de interés comercial.

Si las substancias extrañas contenidas en las cretas naturales fueran ímicamente las calcáreas fosfatadas, no ofrecería la administración de ellas, en cuanto á esto, inconveniente alguno; mas, lejos de esto, se encuentran otras que en rez de ser coadyurantes del carbonato de cal, determinan efectos contrarios, y aun algunas pueden dar lugar á otros padecimientos que agraven el que se pretende combatir.

Fácil es persuadirse de esta rerdad, al recordar que entre dos 
calizas naturales es común hallar, en proporciones variables, compuestos silícicos, aluminosos, ferruginosos y magnesianos, con más restigios manganesíferos, y ann más materias orgánicas de diversa naturaleza con las betuminosas, de las que Bendant enumera siete variedades, entre las que se hallan las de olor de hidrógeno sulfurado, de sulfuro de carbono $y$ de hidrógeno arsenical. Fn rirtud de estos datos y de otros rarios, que omito en ahorro de tiempo, ¿quién podrá dudar de las grandes rentajas que resultarán al dar la preferencia, para los usos medicinales, al carbonato de cal artificial? Digo artificial, y no precisamente obtenido por precipitación, porque entre los rarios procerlimientos que he usado, me ha dado buen resultado el directo, con intermedio.

En cuanto á la seguna dobjeción, que es la de economía, aún parecerá á algunos ridículo el que me ocupe de ella: mas como estoy persuadido por lo que se vé día á día que, generalmente hablando, hoỵ se atiende más á los intereses pecnniarios que á la salud y la rida del hombre, preciso es tener en cuenta esa avarienta propensión del género humano. Es un hecho, que cuando se ofrece á los droguistas una cantidad de lo que se conoce en el comercio bajo el nombre de Blanco de España, al ínfimo precio de cinco ó seis pesos quintal, y en algunos casos hasta dos y tres, lo compran para revenderlos en las tapalerías con ese mismo nombre, y á las boticas con el dé Creta preparada; mas á éstas, á precio mayor que á las primeras. Nó creo que todos harán tal cosa; pero sí creo que es preciso desconfiar de todos y siempre dar la preferencia al producto artificial, y al que llamaré creta merlicinal artificial, para distinguirla de la que es conocida con los nombres de creta meparada ó carbonato de cal.

A lo expuesto con referencia á este compuesto, poco tengo que añadir, respecto del subfosfato de los huesos, que, conto he indicado es el único fosfatado con el que de hecho se substituyen desde hace algún tiempo todos esos variados productos tan usados aun sólo hará cuarenta años. Hay desde luego una diferencia que considerar entre ambas preparaciones: la de la creta se reduce á la loción, decantación y desecación de la calcárea natural; en tanto que la de los huesos exije previamente la calcinación y después la pulrerización, levigación, lavación, etc., en el caso de seguir el procedimiento común; mas como he dicho que debe preferirse, sea el de doble descomposición, ó bien el de disolución y precipitación, en 
uno y otro caso los trabajos son más complicados y mucho mayores los gastos. Pero iqué importa esto cuando se trata de las substancias medicinales? ¿Que significa el doble ó triple valor de esos preparados al lado de la salud, ó cuando menos del alivio que por su medio se puede alcanzar? Y esto es tanto más que notarse, cuanto que las diferencias son rerdaderamente insignificantes; si esas substancias inadecuadas como agentes farmacológicos, cuestan hoy, por ejemplo, de seis á reinticinco centavos libra y las preparadas debidamente han de costar de veinticinco á cincuenta, ó aún más; no hay duda que el aumento en el precio es inapreciable para el paciente y poco gravoso para el negociante. Mas aun cuando lo fuera, el deber profesional, el de humanidad $y$ el de conciencia, exigen que se adopten los procedimientos preparatorios más conformes con los principios cientificos, y con las indicaciones terapénticas, supuesto que la misma escrupulosidad es una condicion esencial, tratándose de la práctica médica y de la farmacéutica; mas ellas no serán fructuosas si se toman en cuenta, si se hermanan las doctrinas y buenos principios de los rarios ramos que constituyen el arte de curar. El asunto de que me he ocupado exije la cooperación de las doctrinas químicas, de las fisiológicas, de las farmacológicas, y por último, de las observaciones clínicas. Sobre los resultados de éstas, llamo la atención de los prácticos, y abrigo la esperanza de que ellas vendrán á confirmar mis observaciones particulares. La tengo, igualmente, de que los farmacéuticos, fijando más su atención respecto á los compuestos calcáreos de que he hecho mérito, proscribirán los productos naturaies usados hasta hoy, substituyéndolos con las preparaciones hechas conforme á las últimas doctrinas recomendadas en los libros.

Concluyo, Señores, pidiendo me disimulen, si juzgaren que el punto de que me he ocupado es impropio de esta solemnidad. Al darle la preferencia sobre todos los de el orden común, he querido presentar á la Asociación Médica Pedro Escobedo, un pequeño trabajo del género que conforme al Reglamento se propone seguir en sus labores; así como el darie, por este medio, un testimonio de agra decimiento por el honor que ha querido dispensarme. 


\title{
DISCURSO
}

PRONUTCIADO

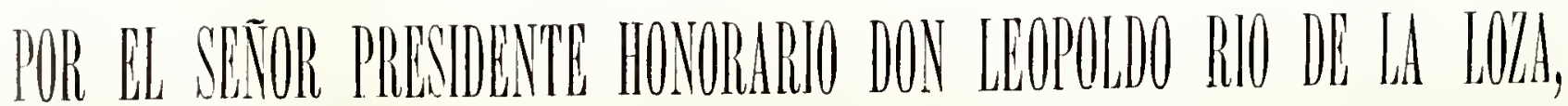

\author{
EN LA SESIÓN DEL Dí 4 DE JULIO DE 1869 ,

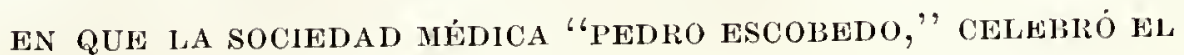 \\ PRIMER ANIVERSARIO di SU INSTALACión. \\ (Tomado de "El Observador Médico.")
}

Señores:

Un año hace que tuve el honor de concurrir á la instalación de esta Sociedad científica y á la vez médica de beneficencia, y en esa solemnidad expuse algunas ideas relativas á los compuestos calcáreos, considerados como agentes ó medios farmacológicos: hoy me propongo llamar la atención de la misma Sociedad, y de todos los profesores, presentando algunas indicaciones generales comprendidas igualmente en el extenso y aún vacilante círculo de la medicación. Ella es sin duda la parte más valiosa del arte de curar; es á la que el práctico consagra definitivamente sus afanosas indagaciones; es la que pone de manifiesto, con hechos irrecusables, los interesantes servicios que la ciencia presta á la humanidad, $y$, sin embargo, es á su vez la más difícil de ser dominada, y en varios casos la más insegura en sus resultados.

En efecto: si se considera la medicación como la parte de la terapéutica que se ocupa especialmente de las modificaciones orgánicas determinadas por los agentes farmacológicos, ó sea la parte á 
que algunos autores han dado el nombre de Farmacotecnia, se conrendrá en que, no obstante ese considerable aumento de medios $y$ de métodos curativos, la terapéntica es, como dice Darembergy y otros, la parte de las ciencias médicas que proporcionalmente la adelantado menos.

Esto proviene, sin duda, entre otras causas, de lo dificultoso que es el valorizar debidamente los resultados terapéuticos y de conocer cuál sería la marcha de la enfermedad, sin la intervención de esos agentes. Pero á mi juicio esas dificultades han aumentado en la actualidad, y no son por tanto los únicos obstáculos que se presentan á la cabecera del enfermo. Hoy tiene que luchar el médico con las preocupaciones, ya sean de buen origen, como las que proceden del simple deseo de recobrar la salud, ó ya del especulativo, bien pecuniario, noredoso y fundado unicamente en simples teorías, más ó menos nacionales.

¿Quién que haya fijado un tanto su atención no observa que los medicamentos y los remedios han llegado á confundirse por el considerable y diario aumento de los segundos, por las modificaciones que la novedad ó la avaricia introduce en los primeros, $y$, lo que es aún peor, por la exagerada aplicación de los principios y doctrinas tomadas de las ciencias auxiliares del arte de curar?

Tomemos en confirmación de esta rerdad algunos de los muchos ejemplos que día á día se nos presentan; comenzando por mencionar una de las preparaciones que, no sin fundamento, ha sido en todos tiempos y aún es considerada como verdadero medicamento y medicamento de efectos palpables, de aplicaciones frecuentes para satisfacer varias indicaciones y sin duda de notoria utilidad. Quiero liablar del acetato de amoníaco de los modernos y establecer una comparación con los espiritus de Minderevo de los antiguos.

Introducida la reforma de esta preparación oficinal, á principios del siglo actual; acogida en varios países más ó menos ilustrados, y apoyada en el principio general que establece la preferencia que conviene dar á las substancias puras y de composición menos inconstante, parece que tal reforma quedaría sancionada por el tiempo y confirmadas por la doctrina. No obstante esto, yo me atrero á presentar á la consideración de los médicos algunas ideas en contrario, y en solicitud de que, haciendo un examen eomparativo y práctico, sobre los efectos terapéuticos de una y otra preparación, deci- 
dan sin preocuparse á cuál se deba dar la preferencia. Quiero más: deseo que se observen especialnente esos efectos en el tratamiento de las fiebres llamadas esenciales, y aun en las otras enfermedades febriles, en las que estan recomendadas las preparaciones de que me ocupo. Bien sé que el que se opone á las costumbres ó á los liechos que aparecen como sancionados, se expone á no ser escuchado y aun acaso á la crítica, más ó menos fundada: sé que declarándome aliora partidario de la antigua preparación, combato las ideas que lace años tenía acerca de los acetatos amoníacales; mas no obstante, una vez que los hechos y los últimos descubrimientos relatiros á la naturaleza de los productos pirogenados me han hecho cambiar de ideas, creo que debo exponerlas con la franqueza que exigen la rerdad y la ciencia. A esto se agrega que cuando el profesor Gay acepta la opinión de Claussier, relativa á la mayor actividad de los medicamentos pirogenados entre los cuales se numera el espíritu de Minderero, y cuando antes del empleo de la nueva pleparación disfrutó aquella de tan general aceptación, que á la del uso actual no se concede en tan alto grado; parece prudente el emprender nuevas pruebas comparativas, que fijen el verdadero valor de esos agentes farmacológicos, cuya acceión sobre la economía nadie pone en duda.

Yo no me ocuparé para apoyar estas breves indicaciones en la enumeración de esos diversos principios inmediatos, separados loy de los productos pirogenados. ¿Quión no conoce su importancia, su utilidad, su acción sobre el organismo y la variedad de los compuestos característicos que forman? Basta anunciar que la química cuenta loy aún con medios sintéticos para obtener esos variados hidrocarburos entre los cuales figuran algunos más 6 menos actiros, cuyos efectos fisiológicos y terapéuticos los oleva á la categoría de medicamentos heróicos, como son por lo común innumerables substancias renenosas.

La simple condensación molecular de varios de los productos pirogenados y la eliminación, como dice Berthelot, de algunos equivalentes de hidrógeno, son suficientes para lograr esas curiosas transformaciones, fuera del organismo, pero que pueden tener lugar $y$ aun ser favorecidas por su inflencia, tratándose de las preparaciones pirogenadas y además amoníacales. Tampoco entraré en los pormenores lelativos á la acción fisiológica y terapéutica del acetato de amoníaco; sólo notaré que para estimarlas debidamente, y so- 
bre todo tratándose del examen comparativo, es indispensable que la administración de ambos preparados sea franca $y$ en dosis relativamente elevadas y proporcionales á los casos á que sean aplicados, pues es bien sabido que en general los efectos son mareados en las enfermedades febriles, pero empleando dosis proporcionales á la tolerancia del paciente.

Se acusa sin razón al acetato pirogenado, de ser una preparación inconstante, pero sin atender á que las mismas reglas que se observan para preparar y conservar el acetato común son aplicables á aquél y queda salvado el inconveniente. Fácil es conocer que al tratarse de modificar el antiguo medicamento, se obró con esa festinación que commmente produce el entusiasmo, con especialidad cuando ma reforma se presenta adornada con el ropaje sobrepuesto, pero seductor, de mua verdad reconocida ó de un principio establecido. ¡Cuántos casos análogos se presentan cada día, desde que la salud y la rida están bajo el dominio de la punible especulación! Mas rolviendo á la cuestión principal diré: que si los novadores de la antigua práctica se lubieran limitado á recomendar y aun á fijar los grados areométricos de los espíritus de Minderero, habrían logrado satisfacer mejor las exigencias terapénticas con la grande rentaja de no alterar, como indudablemente quedó alterado en su esencia, el útil agente empleado por los antiguos con tan felices resultados. Si hoy se hace preparar esta solución salina cuidando que marque los mismos cinco grados que se exige para el de uso común, y además que el líquido amoníacal sea rectificado previamente, desaparecerá esa inconstancia que 110 sin motivo se quiere eritar.

Otro de los motiros ó defectos atribuidos á la antigua preparación, es la de tener un color, olor y sabor más repugnantes que la que hoy se administra. No debo ocuparme en combativ tal especie, porque los prácticos de buen juicio estimarán mejor que yo, el poco ralor que en sí tienen esos inconvenientes.

Acaso yo esté preocupado, y acaso también no falten quienes , rean en estas breves indicaciones la opinión de uno de tantos partidarios de las prácticas antiguas; mas lejos de ello, he dado algunas pruebas públicas de que soy anante de las reformas sociales; de que estoy persuadido, quẹ las cuestiones del género de la que me ocupa, se deciden por los resultados prácticos y no simplenente por la fe 
médica: una serie de observaciones seguidas con inteligencia, juicio recto y la debida imparcialidad, son las únicas á que debemos dar crédito. Si alguno de los profesores que me escuchan, y particularmente los empleados en los hospitales, quisieren encargarse del examen comparativo que he indicado, me atrevo á esperar que lleguen á reconocer más tarde que, el acetato de amoníaco pirogenado y preprorado debidtumente, es preferible al que hoy está en uso.

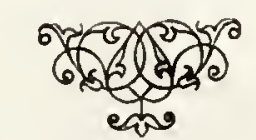




\section{DISOURSO}

pronunciado por el señor

\section{LEOPOLDO RTO DE LA LOZA}

EN EL ACTO DE Quimica de la EsUUela De Medicina,

EL DÍA 7 DE DICIEMBRE DE 1845 .

(Tomado del "Periódico de la Sociedad Filoiátrica de México."

Excmo. Señor:

Aunque la Escuela de Medicina ha dado repetidas pruebas del interés que toma por los adelantos de la jurentud estudiosa, y son bien conocidos los sacrificios de todo género que en el período de doce años que tiene de establecida ha hecho en bien de la ciencia, cuenta entre sus primeras obligaciones la de manifestar al público, anualmente, el estado de la enseñanza médica. Para llenar este deber, hubiera apreciado que cada una de las trece cátedras establecidas por la ley, diera los actos públicos, que bien pueden sustentar los alummos, examinados con la sereridad que exige la noble profesión á que se han dedicado; mas ya que no ha podido realizar enteramente sus nobles deseos, se limita á presentar uno solo de la cátedra de estudios preparatorios por ser de las dos que estableció el nuevo plan de estudios publicado en Agosto de 1S43, sin embargo de que el corto tiempo que la han cursado los alumnos, no permite esperar los adelantos consiguientes á un curso completo y al orden y regularidad que es de suponerse no faltará en lo sucesivo. Esta con- 
ducta franca, y hasta cierto punto atrevida, dará á conocer al público y á V. E. que lejos de ocultar los defectos del establecimiento tras el brillo alucinador de una función literaria, quiere que se juzgue del servicio de las cátedras por aquella en que menos se ha debido aprovechar.

Pendiente de la resolución del Supremo Gobierno, no pudo comenzar la de química hasta el mes de Mayo último, conclnyendo en Octubre; las lecciones no fueron diarias, porque no es conveniente que lo sean las de las cátedras experimentales; las festividades religiosas y políticas, así como otros motivos, disminuyeron el número de lecciones hasta tal punto, que sólo se dieron sesenta y seis en todo el año escolar: si á esto se agrega que las notorias escaseces de la escnela no permitieron erogar los gastos indispensables en cada lección para el aprovechamiento de los alumnos; no se culpará á éstos ni á aquélla de las faltas que sólo han dependido de las circunstancias particulares en que se ha encontrado.

Despnés de esta sencilla manifestación, toca al público juzgar de los resultados; pero antes séame permitido recordar en pocas palabras los interesantes servicios que, sin interrupción, presta la química á varios ramos de la ciencia del hombre.

Desde que el ilustre médico del hospital de Bagdad, turo en el décimo siglo, la feliz ocurrencia de emplear las preparaciones químicas para la curación de las enfermedades, que afligen á la especie humana, no ha faltado quien le siga en sus benéficas investigaciones ampliando más y más el inmenso campo que pudo vislumbrar el insigne Rhasis. Mas estaba reservada al inmortal Lavoissier la gloria de abrir el nuevo camino que debía conducir á la ciencia casi á su perfección y con una velocidad sorprendente. Treinta años fueron suficientes para exceder en mucho á los trabajos de sus antepasados, y para dar nueva vida á la agricultura y á las artes, al comercio y á la medicina. Entonces los pueblos tributarios, montando sus fábricas, levantando sus talleres, regularizando su comercio, perfeccionando sus establecimientos de educación y mejorando la policía de salubridad y ornato, dieron de mano á la miseria, proporcionaron ocupaciones lucrativas, aumentaron los ingresos nacionales, atendieron á la salubridad de las poblaciones, hallaron medios de satisfacer las comodidades sociales, de defenderse, de ser considerados, y lo que es más, aseguraron su rerdadera independencia, se hicieron rigorosos y pu- 
dieron sin auxilios extraños atender á sus necesidades. Pero no siendo mi ánimo trazar el cuadro halagiieño que tan bien dibujado se encuentra en la historia de la ciencia y de las naciones civilizadas, vuelvo al punto de que me había desviado, examinando las mejoras notables que la química ha introducido en cada uno de los ramos de la medicina.

La anatomía, fundamento principal de esa ciencia, que con exquisita escrupulosidad y tacto fino, descubre en el cadáver los resortes más pequeños del morimiento y las cualidades aparentes de los seres organizados, que patentiza las alteraciones ocultas de los tejidos de. los órganos y de los aparatos, que da á conocer desde la simple textura de los acotiledones y de los zoófitos, hasta la sorprendente máquina de los árboles y de los hombres; la anatomía, repito, no debe menos sus progresos al horno investigador del químico, que al afilado escalpelo del prosector.

No hay ya que temer el repugnante desprendimiento de gases pestilentes, producidos por las reacciones cadavéricas: los compuestos oxigenados del arsénico, el bicloṕuro de mercurio, uno de los carburos de hidrógeno y las sales de alúmina, evitan las descomposisiones á que, sin esos medios, llegan necesariamente los seres más complicados de la creación. Desaparecieron para siempre ciertos amuletos ridículos que, enmascarando con su grato aroma las emanaciones nociras, inspiran alguna confianza á los anatómicos y á los químicos de la edad media. El descubrimiento del cloro, el estudio de sus propiedades y el de la naturaleza y proporciones de sus compuestos, ofrecen un medio fácil y seguro de purificación, convirtiendo en productos inocentes las combinaciones venenosas más activas.

Hoy no se duda cuál sea la naturaleza de los líquidos orgánicos, como no se duda tampoco de la de los tejidos vegetales y animales. La anatomía patológica, fuente inagotable de descubrimientos útiles, nos ofrece también á cada paso alteraciones curiosas, que conservadas por los procedimientos químicos más simples, forman gabinetes preciosos, considerados con razón como otros tantos libros prácticos de mayor interés para el diagnóstico. Ya se re que á tan útiles adelantos no ha sido extraña la química y que hoy con más razón debe preceder al estudio de la ciencia que da á conocer la estructura de los seres vivos y las alteraciones que resultan del estado patológico. 
Todo lo que pudiera decir en este momento de la fisiología, sería poco y aun parecería exagerado: tantos y tan importantes laan sido los servicios prestados por la química á este ramo de las ciencias naturales. Si la marcha del espíritu en los estudios fisiológicos (ha dicho un célebre profesor contemporáneo) hubiera sido guiada por la razón, se habrían fijado desde luego de una manera exacta las propiedades físicas y químicas de los diver'sos tejidos y líquidos del cuerpo, y se habrían estudiado las que la vida añade ó quita á sus elementos; mas no ha sido esta la marcha que se ha seguido, y los perjuicios á la ciencia dependieron sin duda de que los fisiologistas fueron extraños á los conocimientos físicos y químicos. Basta notar, dice Magendie, la semejanza de los órganos digestivos con un aparato químico dispuesto para obtener determinados productos; la del respiratorio con otro de combustión que, como rn verdadero horno de muy seneillo artificio, quema con regularidad el combustible, produciendo un calor constante $y$ uniforme; basta, por último, ver tantos otros formando agua, gas carbónico, cloruros, etc., y separando esos mismos compuestos con sorprendente exactitud, para inferir que la fisiología se ha elevado al lango de la ciencia, apoyándose en las físicas y haciendo aplicaciones útiles de sus descubrimientos.

Mas sea que se considere á la anatomía y á la fisiología íntimamente ligadas á la patología, ó que las inspecciones cadavéricas y los métodos de exploración layan contribuido igualmente á sus progresos, el hecho es, que ha llegado á ser hoy ma de tantas pruebas que no dejan dudar de los adelantos de la medicina. Véamos, si no, qué enfermedades pueden clasificarse por medio de datos tan positivos y seguros como los que ministra la ciencia que se ocmpa de las reacciones moleculares de los cuerpos, y cuán importante es descubrir las prineipales alteraciones de los líquidos del cuerpo limmano.

Por mucho tiempo fué desconocida la naturaleza de tres flúidos á cual más necesario en los fenómenos de la nutrición; el quilo, la linfa y la sangre: con el auxilio de la química se ha llegado á demostrar su analagía de conposición, probándose con ella, como dice l'Heritier, que la modificación del nno, determina necesariamente la de los otros dos. Partiendo de datos tan seguros se han examinado mejor las alteraciones de ese sistema de vasos que constituye el aparato circulatorio $y$ se han facilitado los medios de hacer obrar en la economía las substancias medicinales, sabiendo que la absorción es 
tanto más activa cuanto la digestión es menos reparadora. Mas pasemos á otras pruebas.

Ya no se confunde el pus encontralo en los rasos linfáticos de algunos enfermos atacados de phlegmatíc clba dolens, de úlceras y de cáncer con los otros líquidos naturales ó alterados; tampoco se duda de la presencia de sales calcáreas en los casos de espina rentosa, ni que penetran hasta las entrañas las substancias venenosas aplicadas exteriormente, aun cuando sean insolubles.

Además, el sentido físico-químico de la sangre, de ese líquido eminentemente reparador, fuente de vida y que, del nacimiento á la unerte, recorre un doble círculo, solidificándose en su curso, dejando una parte de sus principios inmediatos, quitando el carbono á los tejidos para transformarlo en ácido, ganando ó perdiendo oxígeno; origen principal del calor animal, de la acción nerviosa y del equilibrio eléctrico que resulta de la diferente cohesión del líquido arterial y venoso; la sangre repito, da á conocer por las alteraciones químicas apreciables, muchas de las orgánicas, proporcionando también, algunas veces, los medios de corregirlas. Al principio de las fiebres aumenta la cantidad de agua $y$ disminuye la de fibrina $y$ materia colorante, la de albúmina y de sales, mientras que al fin de estas enfermedades no se limita la alteración á sólo las proporciones, sino que varían sus elementos hasta tal punto que no es extraño se dudara en una época si era sangre el líquido vomitado en la fiebre amarilla, y si lo era el de las hemorragias en el período adinámico de la tifoidea.

No la muclio se atribuyó á la bilis la coloración ictérica de la piel $y$ de la conjuntiva, suponiéndose que enteramente formada eircula con la sangre, sale con la orina y con el líquido de la transpiración, hasta que los trabajos de Chevreul, Andral y Lecanu dieron á conocer que la sangre de los ictéricos sólo contiene los principios colorantes de ese producto de la secreción. ¿La presencia de la urea en la misma sangre y de la albúmina en el líquido secretado por los riñones, no son un signo precioso de la enfermedad conocida con el nombre de mal de Bright? ¿La de la azúcar en este último no es patognomónico de la diabetes? ¿No se sabe, además, por los trabajos de los químicos modernos, que aquellas glándulas sólo separan la azúcar sin intervenir en su formación? Nuestros mineros de Guanajuato sucumben con frecuencia á una enfermedad que depende, sin duda, 
de la alteración de la sangre, y que reclama, por lo mismo, los trabajos de la química, la que no será extraño descubra algunos medios de librarlos de una muerte cierta, dando á conocer el asiento, naturaleza y método curativo del mal.

Las interesantes experiencias de Magendie y Bonillard sobre la clorosis, así como las microscópicas de Donné, han adelantado mucho la historia y tratamiento de esta enfermedad. El estado de la sangre de los escorbúticos, de los coléricos, de los gotosos, elefancíaticos, etc.; el de la orina en esas mismas enfermedades y en las fiebres eruptiras, hepatitis, metritis y cáncer, aseguran en muchos casos el diagnóstico y facilitan remedios útiles para el tratamiento. Debe, por lo mismo, el médico iniciarse en los misterios de la química para penetrar en los de la patología.

Preciso es, para no difundirse más, tocar sólo de paso los otros dos ramos que lacen parte de la ciencia del hombre: la farmacología y la medicina legal.

La historia natural médica, la farmacia y la materia médica, han sufrido tales reformas en el presente siglo, que sería indispensable dar un extenso tratado para poderlas enumerar. Basta decir que, antes de esa época, eran desconocidas las bases salificables y muchos ácidos y productos orgánicos; que se ignoraban los medios seguros de purificación; que se administraban con timidez agentes preciosísimos, cuyas propiedades son relativas á las dosis; que los códigos farmacéuticos eran más bien un indigesto catálogo de fórmulas empíricas; que no se había fijado la atención en la incompatibilidad de las substancias medicinales, ni en la acción que ejercen sobre ellas el calórico, la luz y la electricidad; que los aparatos eran tan limitados como inperfectos y escasos los auxilios que podía prestar la historia natural; basta mencionar, en fin, que no se conocían los radicales compuestos, ni la presencia constante y proporcional de los elementos del agua y del gas carbónico entre los de los seres organizados. No obstante esto, es preciso confesar que no han llegado á su perfección la terapéutica ni el arte de formular; pero sí puede asegurarse que, dejando el empirismo y la fatal polifarmacia, adelantan cada día lıaciendo más palpables sus ventajas y utilidad.

Desde la primera época del mundo, debió notarse que la mordedura ó piquete de algumos animales causa accidentes funestos, y aun suele ocasionar la muerte; que iguales efectos produce el uso de al- 
gunos regetales y de muchos cuerpos anorgánicos; desde entonces se cometieron grandes crímenes, que los delincuentes procuran ocultar más que las autoridades se empeñan en descubrir; se dieron leyes penales, se atendió á la salubridad de las poblaciones, se cuidó de la de las familias y de los individuos, y con tales elementos se organizó más tarde la toxicología, la higiene pública y privada, la jurisprudencia médica, la medicina legal, en fin, que, como dice Anglada, debió comenzar con la raza humana. No fué, sin duda, este ramo al principio más que un cúmulo de observaciones empíricas comunicadas por tradición; pero la llegado al grado de verdadera ciencia, necesaria á los gobiernos, útil á los magistrados, benéfica á los inocentes, azote de los criminales y eminentemente protectora de la especie humana. Si alguna rez se han hecho falsas aplicaciones de sus principios, si se han exagerado sus servicios, si no se ha comprendido su importancia ó si se ha abusado de sus doctrinas, culpables son los hombres y no la medicina legal, que debe su utilidad incuestionable á los verdaderos progresos de la química.

He llegado al término que me propuse, manifestando los servicios que presta cada día la química á los diversos ranos de la ciencia del hombre.

Taa escuela de medicina, que desde su fundación se penetró de esta verdad, ha trabajado con empeñoso afán hasta ver realizados sus filantrópicos deseos. Contando con el firme apoyo de un ministro, que aumque extraño á la medicina, no lo fué al adelantamiento de las ciencias, consiguió en 1843, no sólo que se establecieran las cátedras de física y química, sino que ellas tuviesen los instrumentos y aparatos necesarios para hacer efectiva la enseñanza; y si por circunstancias que son bien conocidas no ha logrado completar el gabinete y montar el laboratorio cual corresponde, tiene fundadas esperanzas de conseguirlo, fiada en la decidida protección del Supremo Gobierno, no menos que en la cooperación de otras personas que tan importantes servicios le han prestado. Sus nombres serán de gratos recuerdos para los amigos de la humanidad, como lo son ya para esta jurentud entusiasta y para los actuales profesores de la escuela, quienes tampoce olridan los interesantes serricios y mérito distinguido del sabio profesor D. Isidro Otvera, cuya muerte deploran. 


\title{
DISCURSO
}

PronUNCIAdO POR EL SEÑor DOCtor

\section{LEOPOLDO RIO DE LA LOZA,}

\author{
PRESIDENTE DE IA SOCIEDAD MEXICANA DE IIISTORIA NATURAL, \\ EN LA SESION GENERAL
}

CELEBRADA EL 12 DE ENERO DE 1871.

\section{SEÑORES:}

Obligado por nuestro Reglamento á dirigiros la palabra en esta sesión, y agotados con el informe que acaba de leer el señor Secretario los puntos de que para ello pudiera servirme, me limitaré á presentar á la Sociedad algunas indicaciones que, desarrolladas por ella, acaso contribuyan á la consecución de las nobles miras á que se dirigen sus tareas. Mas antes me ocuparé en consignar brevemente algunos hechos, que aunque sabidos hoy por muchos, pudieran ser más tarde adulterados ó desconocidos.

No hace reintiocho meses que fué instalada la Sociedad de Historia Natural por un corto múmero de profesores laboriosos, instruidos y emprendedores, quienes, amigos entre sí, lo son también de las ciencias, de la prosperidad $y$ del buen nombre de nuestra patria. En tan corto período, los resultados de sus laudables afanes han excedido á sus esperanzas, como lo demuestra la reseña cuya lectura acabamos de oir, y las buenas y útiles relaciones establecidas en la mayor parte de los Estados de la República y aun fuera de ella. Hoy debemos felicitarnos por ello, así como al observar que el estudio de las ciencias naturales ha salido de los estrechos y muy forzados lími- 
tes á que se hallaba reducido hasta hace pocos años. Los médicos y los farmacéuticos fueron los únicos que, obligados por las leyes, concurrían poco más de una hora por unos cuantos días, á la mal organizada clase elemental de botánica, y eso sin fe en la utilidad de tal estudio, y por lo mismo, sin la dedicación indispensable, siquiera para conocer los prineipios fundamentales del ramo. En cuanto al de zoología, bastará recordar que, en general, apenas era conocida de 111 y pocas personas.

Y no se crea que tal estado de cosas perteneció solamente á la época virreinal, uo; doce años después de nuestra independencia siguieron las cosas en el mismo estado; y, preciso es decirlo, á la ilustración, á la cultura, á los afanes de la clase médica, anxiliada más tarde por algunas personas ilustradas y después por los ingenieros de minas, se debe la marcha progresiva y aun el entusiasmo que hoy se advierte por el estudio de las ciencias naturales. Cuántos años han transcurrido para conquistar esta mejora; cuántos esfuerzos ha sido preciso reunir y cuántas preocupaciones que vencer, son hechos bien conocidos de las personas que me escuchan.

Y si bien desde 1833 fueron organizados por la ley como lo están actualmente los establecinientos especiales de enseñanza, en cuyo prograna figuró la de la historia natural, la violenta derogación de tales disposiciones nulificó la mejora intentada por los ilustrados antores del primer plan de estudios más adecuado á las necesidades de México.

Increíble parecerá que cuando en los países civilizados del mundo, no se dudaba del enlace de las ciencias naturales con las principales carreras profesionales y su estudio era obligatorio, se pretendiera, en la capital de la República, sostener la inutilidad de tales conocimientos para los ingenieros y aun para los agricultores. Recuerdo con asombro que en la visita que un personaje de influencia hizo á la Escuela de Agricultura en 1856, calificó de inútil y gravoso al Gobierno ese establecimiento, fundándose en que en nuestro país, cuya fertilidad era notoria, bastaba la máctica, decía, para labrar la tierra y para conocer las yerbas.

Después, y ann hoy mismo, dno juzgan rarias personas como nna extraña exigencia las disposiciones relatiras del plan de enseñanza vigente, con especialidad en lo relatiróá estudios preparatorios? ¿No hemos oído las severas críticas que se hacen con frecuencia sobre este 
punto? Las persomas dominadas por las primeras impresiones, las que repiten lo que oyen sin examen alguno, las que preocupadas por el deseo de que sus hijos concluyan su carrera en el menor tiempo posible, y las que sólo se ocupan en criticarlo todo, son otros tantos enemigos de lo bueno y de lo útil.

Ellas no reflexionan que aun la simple educación social no debe limitarse al estudio de las primeras letras: que los adelantamientos y perfección en las carreras profesionales exigen una base sólida de instrucción, un conjunto de nociones indispensables, sin las cuales aun la tecnología científica se dificulta. Ellos, y por desgracia otros varios, ignoran que la riqueza de nuestro país no debe limitarse á la explotación de unos cuantos minerales, no ciertamente; el reino orgánico es tan abundante, tan variado, y es llamado á ser tan útil y productivo, como el anorgánico. Y siendo esto así, ¿̇por qué no aprovechar esa fuente inagotable con que nos brinda la naturaleza? ¿Por qué no fomentar cual conviene el estudio de la botánica y de la zoología, procurando á la rez, con las exploraciones, aprovechar tantas $\mathrm{y}$ tan variadas producciones, limitadas hoy en su explotación y abandonadas en su mayor parte?

Por fortuna se ha dado un paso adelante en estos últimos años, cuyos benéficos resultados han correspondido, como ya dije, á las nobles miras de las personas estudiosas y decididas á consagrar su tiempo y su trabajo á la consecución de una importante mejora.

La instalación de la Sociedad de Historia Natural, la publicación de su periódico, y la reorganización del Museo Nacional, han contribuido á esa mejora de mna manera eficaz; y no hay exageración al decir que la unión, la buena armonía y los mutuos auxilios de ambos establecimientos, los han colocado en condiciones favorables para que las ciencias naturales lleguen en nuestro país al grado de cultura á que se encuentran en las naciones civilizadas.

De esperar es que esa unión y buena armonía, que tan felices resultados han dado en el corto período transcurrido, se sostengan y aumenten en el año actual, á cuyo fin me será permitido el proponer á la Sociedad una idea, que si fuere acogida benignamente, sabrá realizarla de la manera posible y conveniente.

He dicho, $y$ es bien sabido, que las exploraciones en lo relativo á las ciencias naturales son tan necesarias, que sin ellas no pueden adelantar. Por otra parte, no habrá quien dude, que si nuestro Musco 
ha de ser verdaderamente nacional, deben encontrarse en él todas las producciones notables de la República, para lo cual es indispensable la recolección, hecha con la inteligencia necesaria; y como en nuestro país no es un ramo á que se hayan dedicado personas á quienes poder confiar ese trabajo, resulta la mayor necesidad de organizar las comisiones exploradoras.

Por desgracia el estado del Erario acaso no permita hacer todos los gastos que requiere una comisión bien montada; mas podría reducirse por hoy á determinadas localidades $\mathrm{y}$ al personal indispensable para lograr el fin propuesto.

También sería conveniente, á la vez, el excitar á los gobiernos de los Estados á que nombrara sus comisiones exploradoras, pues si no todos, varios hay que cuentan con algunos recursos para erogar los gastos: y aquéllos que no los tienen podrían arbitrar medios para cubrirlos. Verdad es que los resultados de ese sistema de trabajos es, por su naturaleza, lento; mas conviene tener en cuenta que las empresas de este género llegan más tarte á sostenerse por sí; y una vez organizadas, aun á ser productivas.

El Gobierno puede contar, por otra parte, con la cooperación de la Sociedad de Historia Natural, y ésta, á su vez, con la adquisición de algunos ejemplares, ya para enriquecer la colección, ó bien para fomentar el cambio con las asociaciones relacionadas con ella.

Sea lo que fuere, yo suplico á las Sociedades que examinen esta cuestión, sea acogiéndola y haciendo las modificaciones que juzgue necesarias, ó bien desechandola si la cree irrealizable. Antes de terminar, cumpliré con un deber de justicia y de reconocimiento, manifestando en esta sesión solemne el que tiene la Sociedad de Historia Natural, al Soberano Congreso, al Supremo Poder Ejecutivo y al ciudadano Director del Museo Nacional, por la protección que le han dispensado y que espera continuarán dispensándole en atención á los felices resultados obtenidos hasta ahora. La corporación ha procurado secundar con sus trabajos las nobles miras del Supremo Gobierno, fomentando los adelantos y mejoras en cuanto se relaciona con la Historia Natural, los medios indicados, y cuanto más se relaciona en adelanto, los pondrá en acción con el mismo fin, y los dará á conocer con la debida oportunidad.

Concluyo, Señores, haciendo votos por los progresos de la Sociedad y por el bienestar de sus dignos miembros. 


\section{DISOURSO}

PRONUNCIADO WN LA ESCUELA DE AGRICULTURA,

POR EL SEÑOR DOCTOR

\section{LEOPOLDO RIO DE LA LOZA}

\section{SEÑORES:}

Si la prosperidad de las naciones dependiera principal ó exclusivamente de la instrucción de los ciudadanos en los ramos profesionales y literarios, que hasta principios de este siglo continúan la carrera pública de las letras, México sólo debería protejer en los Colegios establecidos antes de ahora, las cátedras necesarias al eclesiástico y al minero, al jurisconsulto y al médico; pero tal sistema, aumentando notablemente las clases consumidoras, disminuiría, como ha disminuido los recursos de todo género, y, manteniendo en el abandono los abundantes elementos diseminados en el vasto territorio de la República, contribuiría de un modo eficaz á nuestro aniquilamiento gradual. ¿ $\mathrm{Ni}$ cómo podría satisfacer las necesidades de todas las clases, los escasos recursos de la agricultura rutinera, ó las del mezquino y tímido comercio que hasta aquí hemos tenido? Nuestras minas, aunque ricas y numerosas, empobrecidas unas por el tiempo y las labores, otras inutilizadas por el abandono en la época llamada de la insurrección, apenas bastarían para reparar las pérdidas del comerciante, consumiéndose sus frutos, sobre todo en las frecuentes exportaciones, y en alimentar al jurista, al medico y al empleado; al político y al militar, desgraciadamente empeñados en dirigir á la nación, víctima inocente, cuando no de las ambiciones, de las engañosas esperanza y de los funestos resultados de las inexperiencias. 
Si la felicidad social está íntimamente relacionada con la inteligencia y el vigor, y si tales dotes se adquieren con la metódica y esmerada aducación, explotando los recursos naturales y dando la preferencia á los ramos productiros; inútil y aun perniciosa sería toda disposición que descuidando los positiros y locales, atendieran más bien á los extraños y especulatiros. Haber procedido de este modo es la causa de los males que se han sucedido sin interrupción: nuestra pobreza y debilidad no reconoce otro origen. Persuadido de estas verdades, ture el honor, hace tres años, de presentar al público 11 plan de enseñanza, 6 más bien ma modificación al establecido en nnestros colegios, cuya base consistía on el fomento de ramos nuevos y positiros, que sirvieran para explotar con mano inteligente el extenso y rico territorio, que aún nos dejara la codicia del recino. Dos de esos establecimientos adoptaron con entusiasmo la modificación propuesta; pero al de San Gregorio cupo la gloria de no retroceder á las dificultades, y de dar á México una carrera completa, nueva y necesaria, proporeionándome el honor de establecer la clase de Quínica aplicada á la agricultura, y de dirigir la palabra en este momento á la respetable concurrencia que me escucha. Sin abusar de su tolerancia, séame permitido en este acto solemne, que llame la atención hacia tres puntos, como principales de mi breve ỏiscurso.

Recordaré en primer lugar la utilidad de la carrera agrícola, ó más propiamente, de la agronomía; en segundo, la del estudio de la Química inaugurado en el presente año; y el tercero la franca exposición de los obstículos que han impedido á los alumnos el adquirio todos los conocimientos que ellos mismos deseaban.

Si no hay filósofo que, al contemplar el universo, vea con fría indiferencia ese armonioso conjunto que presenta la obra admirable de la suprema inteligencia, tampoco hay quien desconozca la utilidad de la labranza y la necesidad de sostener y mejorar por su medio la buana marcha de los sucesos, y con ella la prosperidad y riqueza de las naciones.

El cultivo de los campos, como todo lo que está subordinado al entendimiento humano, se perfecciona con la observación y con el estudio, y desde la brillante historia que hace conocer su origen que fué sin duda el de las sociedades, y su marcha en la época de José, en el Egipto, hasta la edad presente, que lo es de los descubrimientos científicos, todo es interesante, todo nitil, y másó menos encade- 
nados con los importantes ramos que forman las delieias del hombre. «Qué hay dice, un escritor contemporáneo, más noble y grandioso que la agrieultura? Ella hace la opulencia de los imperios y es la felieidad del génelo humano.»

El cultivo de los campos es, en efecto, la fuente de donde nacen los goces sociales: en él encuentra el hombre el más bello paisaje que lo divierte, el aire purísimo que lo vivifica, el variado alimento que lo sustenta y da pasto á sus ganados, el fruto jugoso que lo refresca, la embriagante bebida que lo ontona y hasta el eficaz remedio que alivia sus dolencias y que más de nua vez lo libra del sepulcro. Ias abundantes cosechas le proporcionan, además, el medio de relacionarse con todos los países del globo; de interesarse en la mejora de las rías de comunicación; de cuidar de la seguridad de los caminos; de procurar un buen sistema tributario; de tomar parte en la defensa del Estado; en la paz pública, en la obediencia á las autoridades, en la conservación de las instituciones y en ser, en fin, útil á su patria, cuyo engrandecimiento asegura las propiedades adquiridas con el sudor de su rostro y con la dulce tranquilidad que deja en pos de sí la ocupación más noble y necesaria que le señalara el Onnipotente. Paréceme ver que en este instante no falta quien me juzgue animado del exagerativo entusiasino; pero desaparecerá tal concepto con el examen imparcial y juicioso que cada cual haga al meditar las proposiciones enunciadas, rerdaderas en sí mismas, con indèpendencia de toda ilusión. Sin embargo, creo muy conveniente concluir esta primera parte con la garantía de dos nombres iinstres:

«No seguiremos ocupándonos, dice Parmantier y Bose, del origen, marcha y progreso de la agricultura, porque no puede dudarse que este arte precioso es la base de la fuerza, de la riqueza y de la prosperidad pública y particular; que la fertilidad ó la esterilidad han dominado á su vez en un mismo país según que ha sido protegida ó desdeñada, honrada ó despreciada: pero siempre que las maciones lıan tomado empeño en que floresca, han adquirido tal grado de poder, que nadie se ha atrevido á medir con ella sus fuerzas.»

Demostrada la utilidad de la industria agrícola será fáeil dar á conocer la necesidad de la instrucción científica, y también que la química es uno de los ramos, indispensables á esa carrera, conside- 
rada por el Sr. Lamberto como la única propia para hallar la felicidad temporal.

Seré breve al ocuparme de este segundo punto.

Los agricultores de la República no han tenido hasta el presente otras reglas, que las muy equívocas, tomadas de la rutina; pudiendo asegurarse que se encuentraactualmente como muchos da los ramos de instrucción que se extraviaron en su origen; es decir, apoyados en la desordenada y pernieiosa tradición, y en las nuy escasas é incompletas observaciones particulares, ocultas muchas de ellas total ó parcialmente con el velo misterioso de la avaricia. Perocuando se conoce la relación de la ciencia agrícola con tantos y tan variados objetos, como presenta la naturaleza, forzoso es convenir en que la ha de tener con todas las ciencias exactas para que sea fiuctuosa y reereativa, y que si México aspila á su folicidad, debe marchar con los progresos de la época.

Nada es el agricultor sin la botánica, dice Giraldin, que le da á conocer las plaritas y las nociones que lo han de dirigir en la preferencia relativa de las especies que debe cultivar. Sin la zoología que le indica los animales útiles y los dañosos, así como la manelaa de edncarlos y el nso que puede hacerse de ellos. Sin la mecánica que lo proree de uráquinas, instrumentos y utensilios para facilitar sus labores, con mayor perfección, prontitud y economía. Sin la física que le enseña la influencia respectiva de los agentes naturales. Sin la química, por cuyo medio descubre la naturaleza de los terrenos de labor, la manera de mejorarlos, las ventajas de los diversos abonos, los riegos, el ralor comparatiro de los productos alimenticios, los medios de satisfacer sus necesidodes, con los varios productos alimenticios, de la industria, y tantos otros cuya enumeración juzgo excusada. La agronomía propiamente llamada así, $́$ sea el conjunto de los principios científicos tomados de la historia natural, de la física, de la mecánica y de la química, aplicadas al cultivo; ha nacido de los progresos de estas eiencias; y el siglo actual, rico para ellas en desenbrimientos y en aplicaciones, la ha elerado á un punto en que distaba mucho en el pasado. El estudio de las ciencias exactas, en el que está comprendido el de la química, es de consiguiente útil á los agricultores, y muy más necesario á los de la República, por lo mismo que en ésta no abundan los hombres científicos. 
Debo pasar á la tercera parte aprovechando el tiempo de que puedo disponer.

Penoso sería, á la rerdad, el tener que descubrir los propios defectos, si no estuviera persuadido de que la verdad siempre triunfa, y de que en todos los casos debe preferirse al engaño. Si las carreras teniricas de nueva creación encuentran obstáculos que sólo el tiempo y la constancia hacen desaparecer, mayores deben ser para las prácticas, y sobre todo, si se carece de los recursos nesesarios. La agronónica instinida en este Colegio, ha tenido que luchar con esos inconrenientes, y hasta con las preocupaciones anexas á la falta de educación y á los malos habitos: la cátedra de quínica no podía librarse de este mal, y de otro que por fortuna ha desaparecido con el sólo hecho de haber terminado el año escolar.

Sin local adeenado para las leceiones; sin más substancias, instrumentos y aparatos propios, que los que pudo adquirir con la donación, que le hiciera la Junta de industria, por el afanoso empeño de uno de sus dignos vecales de la Directiva de este Colegio, la clase de quínica no ha contado con los medios suficientes para que el finto correspondiese á los afanes tan satisfactoriannente como era de desear.

Si á esto se agrega que los cuatro cursantes de la misma clase carecían del estudio de la física, y que tuvieron que hacer conjuntainente el de los dos ramos, crya extensión es conocida, no se extranará que apenas adquieran en siete meses de lecciones alternadas los conocimientos que manifestará en esta función el alummo que presenta el Colegio á la calificación del público. Yo eonfó, por lo mismo, en el buen juicio y en la rectitnd de los que puedan juzgar, esperando, además, dirijan su consideración á las mayores dificultades, algunas de ellas invencibles, para dar una función de este género en tiempo muy limitado, en un establecimiento sin laboratorio, y, lo que es peor, teniendo que colectar y conducir de varios puntos cnanto se ha creído necesario disponer.

Pero sea cual fuere la estimación que haya de hacerse de ésta y de las funciones orgánicas de los días precedentes, ella nnnca podrá rebajar el mérito de la intitución. Esta es necesaria en la Repríblica; - es conveniente y útil á los alumnos de este Colegio, y ha de ser el eslabón que una á las carreras literarias y consumidoras, con las literarias y productoras, así como con las industrias artística y fabril. 
Yo me congratulo con mi desgraciada patria, polque ha dado mu paso de positivo adelanto para su futura prosperidad con la administración que, desciándose del orden común, no puso obstáculo alguno á la ejecución del plan que le propusiera la Junta Directiva de este seminario, con la misma Junta que, dando ma prueba inequíroca de que no limita su atención al recinto del Establecimiento que le está encomendado, realizó un pensamiento cuyos resultados son de interés general: me congratulo, en fin, con los Señores Réplicas y demís personas que han tenido la bondad de homrar con su presencia el acto público de química agrícola que por primera vez se da en la República.

I rosotros, jóvenes apreciables á quienes les tocará la gloria de ser los primeros agrónomos que vea México, educados en las aulas de uno de sus Colegios, segnid eonstantes el camino que habéis tomado: despreciando. como hasta aquí, los obstáculos y haciendo un esfuerzo para perfeccionar los conocimientos adquiridos. Ia Nación colocará vuestros nombres entre los de sus mejores cindadanos; el Colegio de San Gregorio, entre los de sus hijos predilectos, y yo, entre los de mis aprovechados disépulos y apreciables amigos. ¡Jurentud mexicana! si queréis hallar alguna felicidad on la rida, procuraos llenar vuestros deberes civiles y religiosos, y alcanzar eon el estudio un laurel que adorne ruestras sienes.

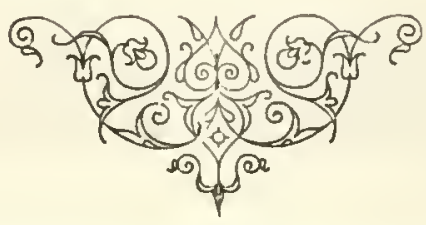




\section{N D I C E}

$$
\text { PíGs. }
$$

Acuerdo por el que se resolvió la publicación de esta obra....... viI

Prólog̣o

Introducción al Estudio de la Química. Advertencia de la primera edición.

Advertencia para la segunda edición..................

Introducción al estudio de la Química. Primera parte..........

Segunda parte ...............

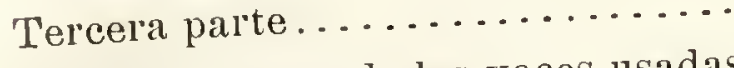

Lista de alırunas de las voces usadas impropiamente, $y$ otras cuya equivalencia es necesario fijar .. Apéndice que servirá, concluido que sea el estudio de la química olgánica ................

Lista alfabética de los cuerpos simples, de los signos que los representan, de sus equivalentes $y$ de los compuestos que forman con el oxigeno................

Tabla de signos y equivalentes químicos.................. Lenguaje cientítico. Propiedad de las palabras equivalentes....... 89

Opinión del Sr. Dr. D. Lcopoldo Río de la Isoza, sobre la química elemental de Guerin-Varry ..... 92

Discurso pronunciado por el Catedrático de Química Médica en la Escuela de Medicina, en el acto público del ramo, el día 23 de Noviembre de $1852 \ldots . . \ldots . .94$

La goma archipín ............ 101

3 El origen del Tequesquite en el lago

47 de Texcoco .............. 107

Azufre y Salitre............. 111

Cistina .................. 114

61 Método fácil para preparar el valerianato de zine .......... 118

Química. Nuevo papel reactivo .... 120

7 Almejas................... 122

Drogas medicinales........... 124

Ajenjo................... 128

¿Debe preferirse como purgante el proto-cloruro de mercurio al vapor? ................... 130

Nuevo procedimien to para obtener el

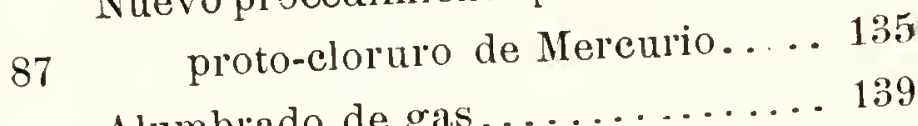

Alumbrado de gas............ 139 
Azoturo de hidrómeno... . . . . . 142

Remedios inconstantes.......... 147

Liparolado de estramonio . . . . . . 15

Algunas preparaciones farmacéuticas. Emulsión de cera....... 157

Sobre vejigatorios ............ 166

Variedades. Falsificacióll del chocolate ............... 171

Examen de un liquido arrojado por vómito ............... 17

¿Deben proscribirse las medidas de capacidad en las ofieinas de fallmacia? ............... 176

Un vistazo al layo de Texcoco . . . . 180

Aguas potables de México........ 193

Opúseulo sobre los pozos artesianos y las aguas naturales de más uso en la ciudad de México, con algunas noticias relativas al corte geológico del Valle, y una lista de las plantas que vegetan en las inmediaciones del Desierto Vicjo. 205

Tabla analitica de las aguas más usadas en la ciudad de México.... 220

Apuntes relativos á las fuentes brotantes ó pozos artesianos..... 222

Tabla analítica de las nueve fuentes brotantes abiertas por D. Sebalstiản Pane en la Ciudad de México el año de $1863 \ldots . . .232$ y 233

Quimica. Atrua potable de Teotiluacán . . . . . . . . . . . 234

Algunas observaciones sobre la utilidad de las aruas minerales... 236

El liquen tintóreo de la Baja Califor11ia .................. 243

Apuntes sobre algunos productos del maxuey ............... 255

El animal planta..........271 y 276

El Cactus Ophioides ........... 281

La Amricultura y la Veterinaria en la Nación Mexicana........... 283
Noticia de los alumnos que ha tenido la Escuela de Agricultura .... 321

Personal de la Escuela de Agricultura al finalizar el año de 1855 . . . 322

Personal de la Escucla de Agriculiura al tinalizar el ano de $1856 \ldots 323$

Personal de la Escuela de Agricultura al finalizar el año de $1857 \ldots$. . 24

Personal de la Escuela de Agricultura el 15 de Enero de 1861 ... . 325

Personal de la Escuela de Agricultura en Mayo de $1863 \ldots . . . . .326$

Personal de la Escuelia de Agricultulæa en $1864 \ldots . . . . . . . . . .327$

Tala de bosques y exportación de maderas............... 329

Proyecto de ordenanzas de bosques, de arbolados y de exportación de maderas.............. 335

Dictamen acerca de las cañerias de plomo................ 348

Dictamen aprobado por la Sociedad de Historia Natural, en lar sesion del 17 de Abrịl de 1873, y que fué presentado por la comision nombrada para dilucidar la cuestión suscitada con motivo del fraccionamiento del aerolito de la "Descubridora" ......... 357

Dictamen de la comision formada por Don Leopoldo Rio de la Loza, Gabino Barreda, Alfonso Herrera y Gumesindo Mendoza, sobre un estudio hecho por el Doctor Desiderio Germán Rosado, de un insecto llamado "Botijón". .... 380

Dictamen que presentó la comisión de ciencias naturales formada por los Señores Don Leopoldo Río de la Loza, Joaquin Velázquez de León y Felipe Zaldívar, sobre la muestra de carbón de 
piedra de la mina situada en el Departamento de San Juan de los Llanos, del Estado de Puebla

Extracto del expediente antiguo instruido por el subdelegado de Co. lima, sobre el terremoto que destruyó parte de aquella ciudad el año de 1818 .

Exposición que hizo el Señor Secretario del Consejo Superior de Salubridad de México, Dr. D. Leopoldo Río de la Loza, al E. Sr. Gobernador del departamento, pidiéndole que destinara una parte de la contribución perso nal en la dotación de veinte plazas de Médicos de Distrito.... 391

El fierro meteórico de Yanhuitlál . 399

El Señor Presidente de la Sociedad Farmacéutica Mexicana, Doctor Don Leopoldo Río de la Loza, pide al Señor Presidente de la República, la propiedad literaria de la farmacopea........ 407

Refutación á la ley de 30 de Enero de 1857 ............... 409

Conservación de los cadáveres . ... 411

Terapéutica. Apuntes sobre los efecde la tarántula, administrada al interior .............. 415

Higiene pública............. 421

Del senecio en el tratamiento de la epilepsia ............. 425

Oración pronunciada por el Señor Dr. D. Leopoldo Río de la Lozá, en la Universidad Pontificia, al recibir el grado de Doctor en Teología (en latín)......... 428 384 Oración pronunciada por el Señor Dr. D. Leopoldo Río de la Loza, en la Universidad Pontificia, al recibir el grado de Doctor en Teología (traducción literal)...430

387 Discurso del Señor Presidente Honorario de la Sociedad Médica "Pedro Escobedo," Dr. D. Leopoldo Río de la Loza, pronunciado en la inaưuración de dicha Sociedad .................. 432

Discurso pronunciado por el Señor Presidente Honorario Dr. Leopoldo Río de la Loza, en la sesión del día 4 de Julio de 1869 , en que la Sociedad Médica "Pedro Escobedo," celebró el primer aniversario de su instalación ... . . . . . . . . . . . 439

Dircurso pronunciado por el Señor Dr. D. Leopoldo Río de la Loza en el acto de Química en la Escuela de Medicina, el dia 7 de Diciembre de 1845 . . . . . . . . 444

Discurso pronunciado por el Señor Dr. D. Leopoldo Río de la Loza, Presidente de la Scciedad Mexicana de Historia Natural, en la sesión general celebrada el 12 de Enero de $1871 \ldots . . . . . .451$

Discurso pronunciado en la Escuela de Agricultura, por el Señor Dr. D. Leopoldo Río de la Loza.... 455

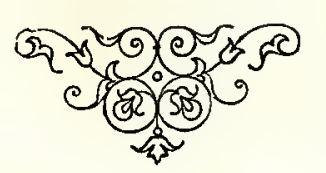






\section{UNAM}

FECHA DE DEVOLUCIÓN El lector se obliga a devolver este libro antes del vencimiento de préstamo señalado por el último sello

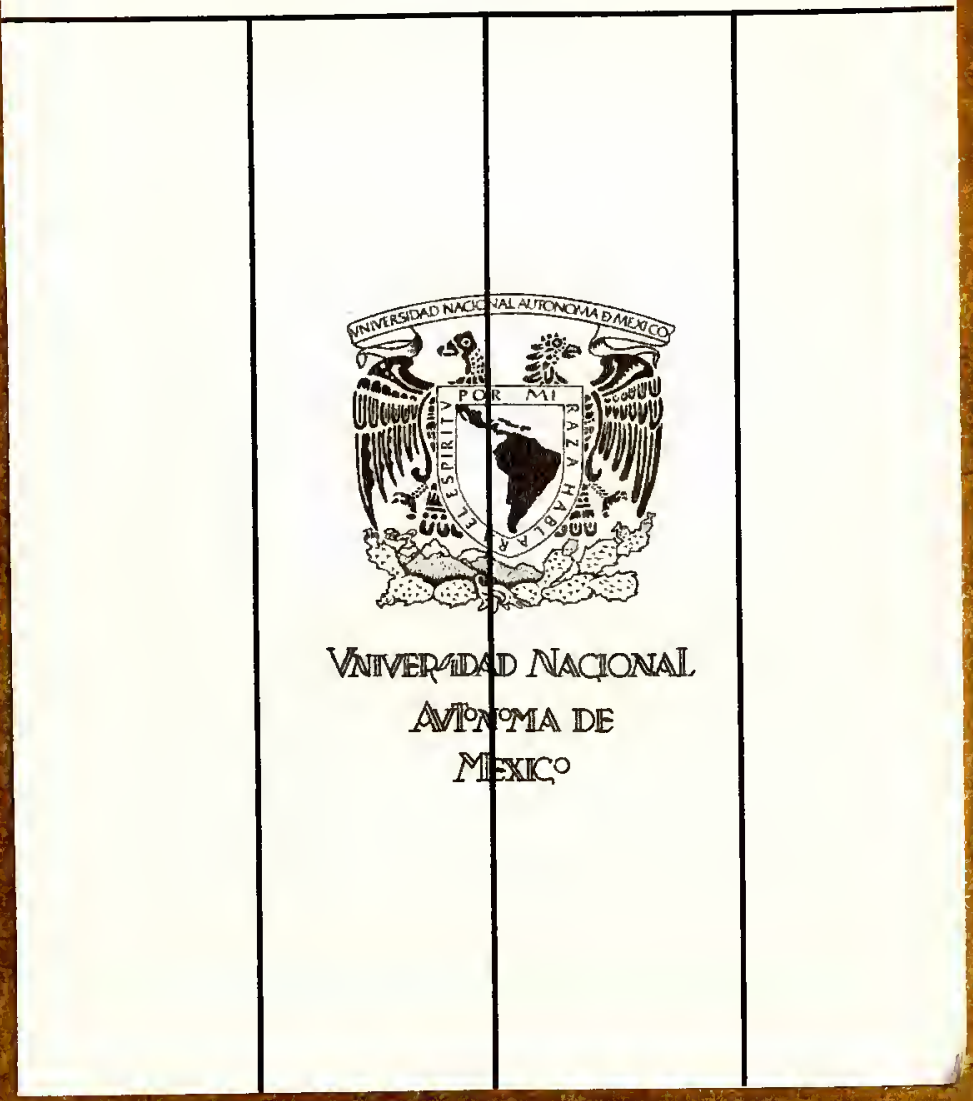




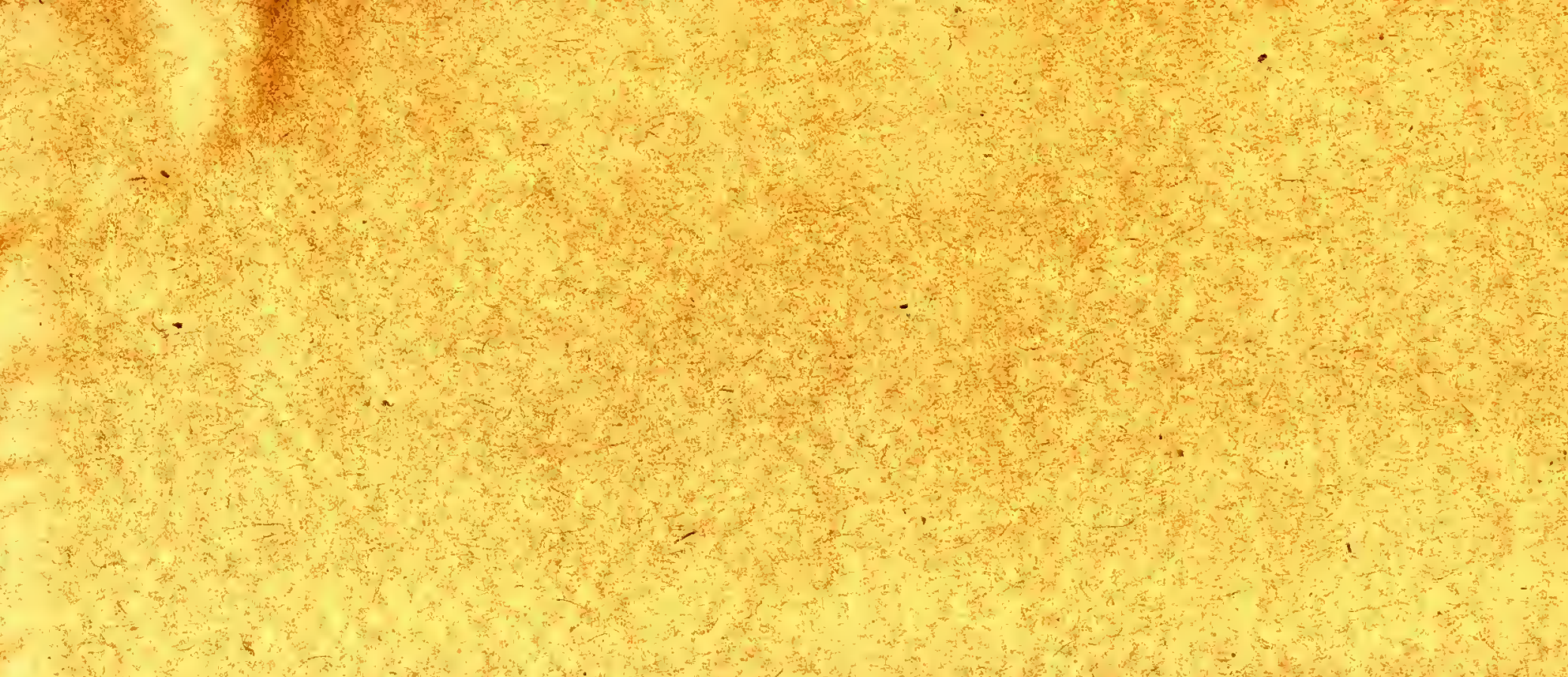

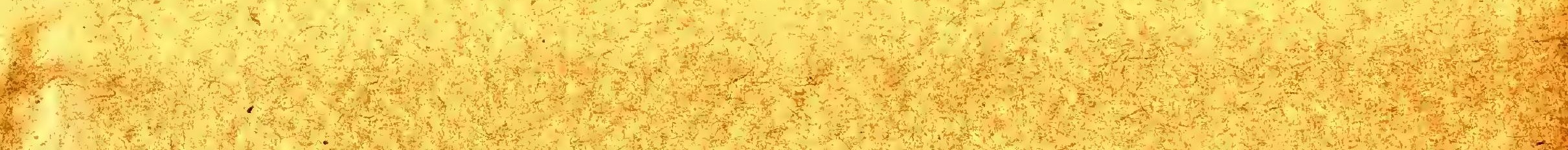
3
3 34
3

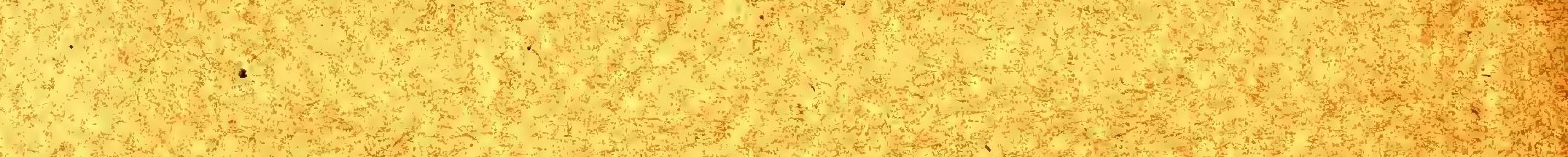

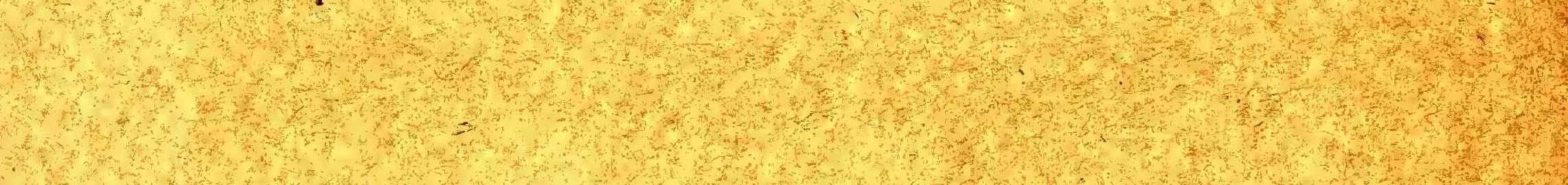

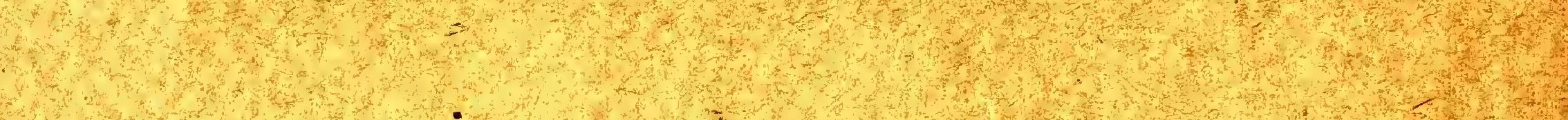

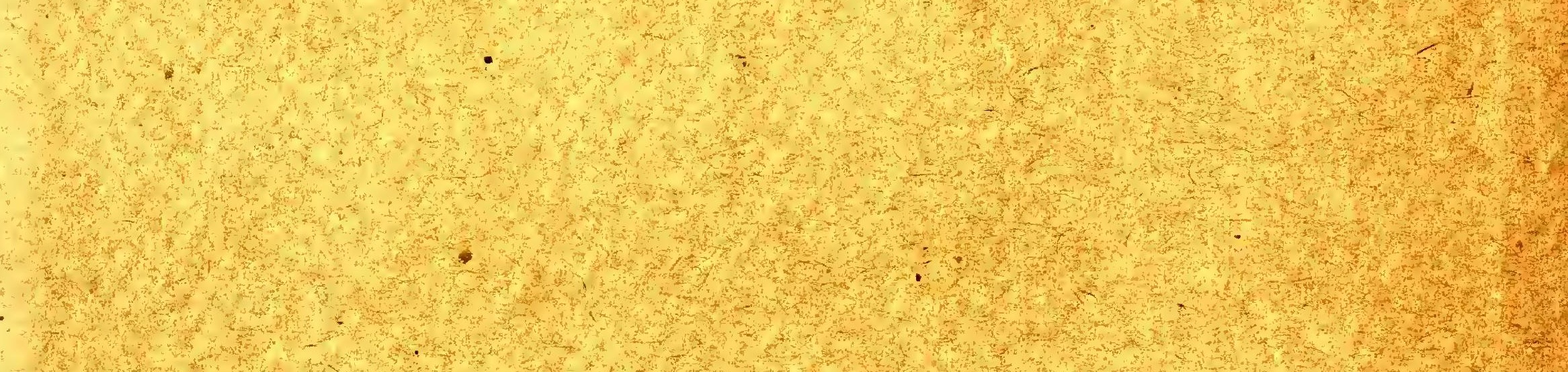

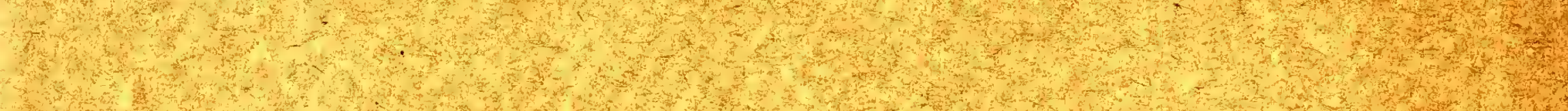

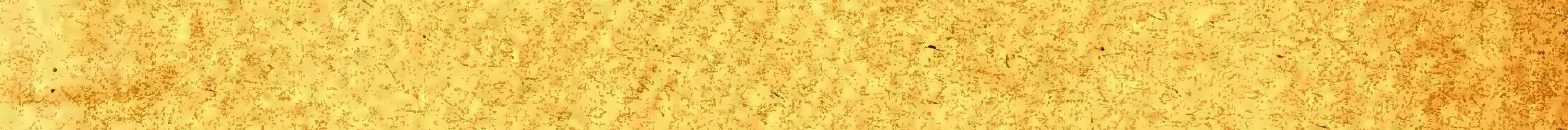

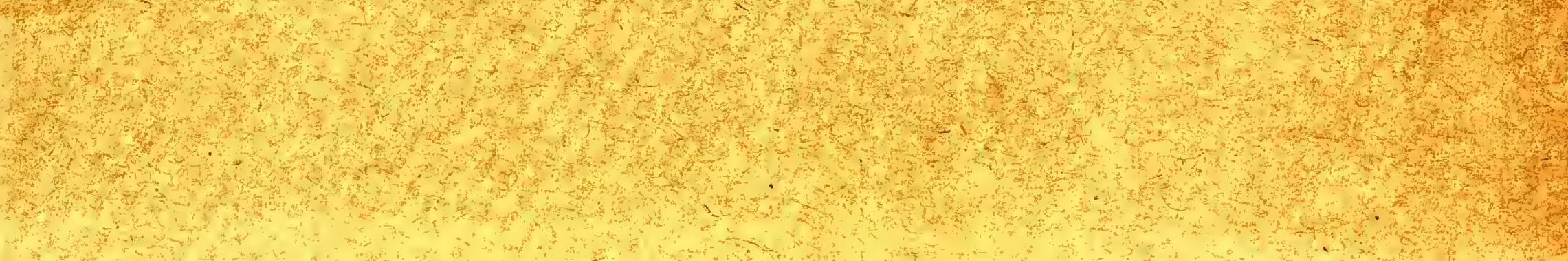


